ANTJE LANGER

\title{
Disziplinieren und entspannen
}

Körper in der Schule -

eine diskursanalytische

Ethnographie

[transcript] 
Antje Langer

Disziplinieren und entspannen 
Antje Langer (Dr. phil.) lehrt am Fachbereich Erziehungswissenschaften an der Universität Frankfurt/Main. Ihre Forschungsschwerpunkte sind Diskursund Institutionenanalyse, Körpersoziologie sowie Geschlechterforschung. 
AYTJE LASGER

\section{Disziplinieren und entspannen}

Körper in der Schule - eine diskursanalytische Ethnographie 
Diese Arbeit wurde 2007 unter dem Titel »Disziplinieren und entspannen. Diskursanalytisch orientierte Ethnographie zum Einsatz des Körpers in der Schule« an der Universität Frankfurt, Fachbereich Erziehungswissenschaften, als Dissertation eingereicht.

\section{Bibliografische Information der Deutschen Nationalbibliothek}

Die Deutsche Nationalbibliothek verzeichnet diese Publikation in der Deutschen Nationalbibliografie; detaillierte bibliografische Daten sind im Internet über http://dnb.d-nb.de abrufbar.

\section{(C) 2008 transcript Verlag, Bielefeld}

\section{(). (1) @ (9)}

This work is licensed under a Creative Commons Attribution-NonCommercial-NoDerivatives 3.0 License.

Umschlaggestaltung: Kordula Röckenhaus, Bielefeld Lektorat \& Satz: Antje Langer Druck: Majuskel Medienproduktion GmbH, Wetzlar ISBN 978-3-89942-932-9

Gedruckt auf alterungsbeständigem Papier mit chlorfrei gebleichtem Zellstoff. Besuchen Sie uns im Internet: $h t t p: / / w w w$ transcript-verlag.de

Bitte fordern Sie unser Gesamtverzeichnis und andere Broschüren an unter: info@transcript-verlag.de 


\section{Inhalt}

$\begin{array}{ll}\text { Einleitung } & 9\end{array}$

Historische und gegenwärtige Blicke auf Körper und Schule 19

Historische Prozesse der Körperdisziplinierung 19

Körper, Schule und Geschlecht - aktuelle ethnographische Studien 26

Körper, Macht und diskursive Praktiken 33

Disziplin, Macht und Selbstsorge $\quad 34$

Disziplinierte Körper - zum Begriff der Disziplin 36

Eine Analytik der Macht 38

Selbstverhältnisse - Technologien des Selbst $\quad 39$

Diskursive Körper? $\quad 42$

Körper in Interaktionen $\quad 48$

Diskursive Praktiken $\quad 51$

Diskurstheoretische Annahmen $\quad 53$

Zum Stand der Diskursforschung $\quad 56$

Subjekt, Macht und Diskurse -

zur Performativität diskursiver Praktiken $\quad 58$

Der Begriff der Problematisierung $\quad 64$

Grenzen der Diskurse $\quad 65$

Analytische Ebenen der Untersuchung diskursiver Praktiken $\quad 67$

Diskursanalytische Ethnographie -

$\begin{array}{lr}\text { Forschungsprozess und Methoden } & 69\end{array}$

Körperpraktiken in schulischen Interaktionen $\begin{array}{ll}\text { zum Prozess der ethnographischen Feldforschung } & 70\end{array}$

»Es riecht nach Schule« - erste Eindrücke im Forschungsfeld 72

$\begin{array}{ll}\text { Forschungsbeziehungen } & 74\end{array}$

Den >Körper in der Institution Schule erforschen 76 
Die Erweiterung des Materialkorpus $\quad 78$

$\begin{array}{ll}\text { Zur Auswahl der Medien } & 79\end{array}$

Alles Körper oder was? Von der ersten Sichtung des Materials zu einer thematischen Gliederung $\quad 83$

Forschungspraxis einer interpretativen Analytik 86

Theoretical sampling $\quad 86$

Auswertungsmethoden für die Text- und Bildinterpretation $\quad 89$

$\begin{array}{ll}\text { Reflexion des Forschungsprozesses } & 92\end{array}$

Lernende und gelehrige Körper 95

Raumordnung als Sitzordnung $\quad 96$

Geschlechter-Räume $\quad 99$

Auf die Plätze - fertig - los? Die Regel von der Ausnahme der Regel 104

UmOrdnungen $\quad 106$

Den Schultag begleiten und bekleiden 108

$\begin{array}{ll}\text { Zeitzeichen } & 109\end{array}$

Kappen ab und Jacken aus! 111

»Körperportrait« eines Schülers 116

Spiel(räume) der Bewegungen $\quad 119$

Bühnenwechsel 121

Übung zwischen Spiel und Zwang 124

Körper(bewusstseins)schulung in pädagogischen Texten 127

Körper als Problem: Körperkonzepte zwischen Natur und Kultur 128

Körper als Ziel: Körperbewusstes Lernen und Lehren 133

Gelehrige und entspannte Körper:

Übungen zur Geschlechtsidentität $\quad 137$

SchülerInnen-Körper 143

Körper, Sanktion und Disziplin(-ierung?) 145

Phänomene schulischer Sanktion $\quad 146$

Ausschluss und Einschreibung aus der Perspektive der Lehrerinnen 153

Zur Tabuisierung von Disziplinieren und Strafen 158

Strafe(n) im Spannungsfeld von Legitimation und Tabu $\quad 159$

Das Problem mit der Disziplin: Autorität und Störung 163

Disziplin und Disziplinierung:

Prävention, Normalisierung, Sanktion $\quad 168$

Rituale als präventive didaktische Praktiken $\quad 175$

$\begin{array}{ll}\text { Disziplin und Strafe } & 182\end{array}$ 
Spiel mit den Grenzen - spiegelnde Inszenierungen 184

Über den eigenen Körper sprechen 188

Kleider machen Leute $\quad 189$

Autorität verkörpern $\quad 193$

Körperpraktiken von LehrerInnen 196

Der Lehrkörper als Medium pädagogischer Praxis 199

$\begin{array}{lr}\text { Unterrichtseinstiege } & 199\end{array}$

Effektivierungen 201

Lehrkörper im Einsatz 207

Der Lehrkörper als Lernziel und Übungsobjekt 208

Anrufungen durch ExpertInnen $\quad 209$

Zur Herstellung eines Lehrkörpers $\quad 210$

Lexikon einer (natürlichen) Körpersprache $\quad 216$

Der kranke Körper als Problem:

Selbstsorge und Prävention, Heilung und Vorbild 219

Körperpolitiken zwischen Professionalität und Selbst 226

\section{Körperliche Bezugnahme als Aspekt}

pädagogischer Beziehungsarbeit 231

Körperkontakte im Unterricht: Beobachtungen 231

Körperkontakt als pädagogisches Mittel und die Figur des Hauptschülers 234

Grenzen und Grenzziehungen im Rahmen von

Moral, Professionalität und Geschlecht 240

Geschlechterdifferenzen 244

Grenzgänge, institutionelle Rahmung und Machtverhältnisse $\quad 249$

Körperkontakt - eine Leerstelle im Diskurs? 255

Körperlicher Bezug als Teil pädagogischer Beziehungsarbeit 265

Einsatz- und Gebrauchsweisen des Körpers in der Schule 267

$\begin{array}{ll}\text { Dank } & 277\end{array}$

$\begin{array}{ll}\text { Literatur } & 279\end{array}$

Zitierte Artikel aus dem Materialkorpus 301

$\begin{array}{ll}\text { Abbildungsverzeichnis } & 309\end{array}$ 



\section{Einleitung}

"Ein beherrschter und funktionsgehorsamer, kalkulierbarer Körper, wer kann bezweifeln, daß auch er ein mehr oder weniger heimliches Lernziel der alltäglichen Schule ist?« (Rumpf 1996a: 8)

Erziehung setzt unter anderem am »Körper« an. Dieser ist zugleich Mittel und Ziel von Lern- und Erziehungsprozessen. Nicht zu vergessen dabei ist, dass auch die Lehrenden und Erziehenden selbst mit ihrem Körper in Erscheinung treten. Wie sehr der Körper und Körperlichkeit im Mittelpunkt stehen, wird zum Beispiel bei der Klein(st)kindererziehung offensichtlich. Doch ist darüber hinaus Körper(lichkeit) in institutionalisierten pädagogischen Prozessen ein eigenständiges Thema der Pädagogik?

In den letzten zwanzig Jahren steht »der Körper « in vielen verschiedenen wissenschaftlichen Disziplinen und in der (medialen) Öffentlichkeit durchaus hoch im Kurs. Selten wird ein Gegenstand von derart vielen verschiedenen Wissenschaften gleichzeitig erfasst. Aus den vielfach interdisziplinären Debatten resultieren disziplinspezifische, vergleichbare, sich ausschließende oder sich gegenseitig ergänzende Auffassungen vom Körper. Ein gemeinsamer Zugang zum Körper liegt in besonderem Maße in der Kategorie Geschlecht, da die Frauen- und Geschlechterforschung traditionell an das Nachdenken über den biologischen Körper als materielle Grundlage und Politikum, Differenzkategorie oder Einschreibefläche anschließen kann. So finden sich in diesem Bereich wohl auch die meisten Publikationen, denn »die Geschichte der Geschlechter-Forschung ist zugleich eine von spezifischen Sichtweisen des Körpers« (Frei Gerlach 2003: 9). Ein anderer nicht nur im Bereich der historischen Forschung angesiedelter Zugang ist die Formulierung einer »Körpergeschichte $\ll^{1}$, in der es sowohl um einen Begriff und die jeweiligen Bilder und

1 Einen systematischen Überblick liefert dazu Maren Lorenz (2000). 
Konzepte vom (geschlechtlichen) Körper, deren gesellschaftliche Kontexte sowie um eine Sozialgeschichte des Körpers geht (vgl. z. B. König 1989; Hersey 1998; Wischermann/Haas 2000). Entscheidend dabei ist (auch für nicht historisch arbeitende Studien), dass der menschliche Körper als ein historisch "gewordener" betrachtet wird. Gerade auch die Wissenschaften bzw. verschiedene wissenschaftliche Disziplinen sind in diese Körpergeschichte verwoben, wie insbesondere Michel Foucault (1998/1975), Barbara Duden (1987) oder Elisabeth Mixa (1996) herausgearbeitet haben. Sich mit historischen Körperkonzepten zu befassen, ist deshalb so wichtig, weil anhand solcher Studien deutlich wird, dass die Gegebenheiten ihre Natürlichkeit erst erlangen. Die Prozesse ihrer Naturalisierung werden offen gelegt.

Mit zunehmender Einbindung des Themas »Körper« in wissenschaftliche Debatten und Theorien gehen Versuche einher, den Körper bzw. körperlichen Leib als maßgeblich gesellschaftlich geprägten auf einen Begriff zu bringen. Dabei zeigt sich, wie schwierig »der Körper« zu fassen ist. Begriffliche Unschärfen zu beseitigen oder zu minimieren, ist neben der verstärkten Thematisierung des Körpers in Bezug auf gesellschaftliche Prozesse Ziel einer sich in den letzten Jahren entwickelnden und etablierenden Körpersoziologie. ${ }^{2}$ Neben dem Verhältnis von Körper, Leib und Identităt (Alheit 1999; Rohr 2004; Stockmeyer 2004) werden zunehmend Fragen der Ästhetik und Ästhetisierung, der Symbolisierung, Inszenierung und Theatralität diskutiert (Willems/ Jurga 1998; Fischer-Lichte 2000; Koppetsch 2000; Hahn/Meuser 2002; Gaugele/Reiss 2003). Dabei ist es häufig der »exotische« Körper, der interessiert, weil er tanzt, gepierct oder tätowiert ist bzw. im Rahmen des steten »Fitnessbooms« gestählt wird.

Ausgangspunkt, um die Bedeutung des Themas sowie dessen Konjunktur festzustellen, sind für die meisten AutorInnen ${ }^{3}$ Diagnosen über gesellschaftli-

2 Diese wird derzeit gewissermaßen als Teildisziplin von einigen WissenschaftlerInnen vorangetrieben - einmal in Reaktion auf den »Körperboom«, aber auch, um daran wesentlich beteiligt zu sein. Die einschlägige Wirkung des Themas »Körper « und die Herausbildung einer Subdisziplin lassen sich bei dieser Entwicklung gut beobachten. Wichtige Ereignisse waren dabei 1995 das Erscheinen der Zeitschrift »Body \& Society« im englischsprachigen Raum (vgl. die thematische Übersicht dazu bei Jäger 2004: 39) wie auch 1998 die Bildung einer Adhoc-Gruppe »Körper« der Deutschen Gesellschaft für Soziologie (DGS) (ebd., 12). Zudem ist mittlerweile die erste deutschsprachige Einführung in die »Soziologie des Körpers« (Gugutzer 2004) erschienen, in der verschiedene soziologische Zugänge zum Körper als für die Disziplin relevante vorgestellt werden.

3 Aufgrund der besseren Lesbarkeit verwende ich in der Arbeit bei der gemeinsamen Nennung weiblicher und männlicher Personengruppen die Schreibweise mit Binnenmajuskel. Das Binnen-I ist zwar nicht gerade elegant, stört jedoch den Lesefluss weniger als eingefügte Schräg- und Bindestriche oder die Nennung beider Formen. 
che Veränderungen. Durch postfordistische Arbeitsbedingungen werden die Anforderungen transformiert, die an den menschlichen Körper gestellt werden. Es komme zur »Erosion der körperlichen Prägekraft der Arbeitstätigkeiten« (Alkemeyer 2003: 7): Der Körper werde in seiner Gesamtheit weniger beschäftigt und so gewissermaßen »freigesetzt«, was beispielsweise im Fitnessboom kompensiert würde. Eine solche Perspektive bezieht zwar ein, dass es bestimmte gesellschaftliche und kulturelle Bedingungen sind, die den Körper »formen «, ausgeblendet wird jedoch dabei, dass die vermeintliche Freisetzung (und nicht nur das Training am Fitnessgerät) ebenso eine bestimmte Form der Körperbearbeitung darstellt. Denn wird die körperliche Arbeitskraft des Industriearbeiters nicht mehr gebraucht, so ist es doch ein anderer »Arbeitskörper« (Rumpf 1981: 44) - der eben andere Körpertechniken verlangt. Vor dem Computer zu sitzen beispielsweise schaltet den Körper nicht aus, sondern beansprucht ihn auf bestimmte Weise - eine Weise, auf die schulische Körperpraktiken bestens vorbereiten, wie schon das Eingangszitat von Rumpf hervorhebt. Insbesondere Schule trennt deutlich zwischen Phasen, in denen SchülerInnen still sitzen oder sich bewegen sollen. Ulrike Pilarczyk und Ulrike Mietzner resümieren in ihren fotoanalytischen Arbeiten zum körperlichen Habitus in der Schule: »Vermutlich erwerben [die Heranwachsenden, A. L.] hier die >Antennen für institutionsadäquates Verhalten, das später auch andere Institutionen von ihnen erwarten. Das Medium, das ihnen dieses Körperlernen ermöglicht, ist der Körper, ist die Person des Lehrers bzw. der Lehrerin, die das, was von ihnen in der Institution erwartet wird, vorführt. Noch im gescheiterten Erziehungsversuch lässt sich dieser Zusammenhang auf der Körperebene beobachten. « (Pilarczyk/Mietzner 2005: 185)

Auch in den Erziehungswissenschaften wird vorwiegend der sichtbar inszenierte Körper betont, der als Identitätssressource genutzt und betrachtet wird. Diese Thematisierung gehe an der Schule nicht vorbei, wie Johannes Bilstein und Gabriele Klein in einer Ausgabe der Jahresschrift »Schüler« zum Thema Körper konstatieren (Bilstein/Klein 2002: 4). Das demonstriert die Zeitschrift selbst: Körperpraktiken und -vorstellungen von Kindern und Jugendlichen rücken - jenseits von Schule - verstärkt in den erziehungswissen- 
schaftlichen Fokus (z. B. Friedrich 2002; Rose 2002; Wohne 2002). ${ }^{4}$ Dabei ist das pädagogische Interesse am Körper der SchülerInnen kein neues. Das zeigt der Blick auf den historischen Prozess der Schulentwicklung. Denn die Institution Schule, so Bilstein und Klein weiter, sei nicht nur eine staatliche Lehranstalt, sondern »auch eine Veranstaltung der Körper. Als körperliches Ereignis erfülte Schule schon immer eine Vielzahl von Disziplinierungs- und Konventionalisierungsanforderungen « (Bilstein/Klein 2002: 5). Eine Aufgabe der Schule sei es, den SchülerInnen beizubringen, ihre eigene Körperlichkeit zu regulieren, auch weil körperliche Zustände und Umstände einen direkten Einfluss auf Arbeit, Leistung und das Miteinander in der Schule haben. Eckart Liebau spricht von einer indirekten Einwirkung der Lehrenden auf die Entwicklung der Bewegung und damit auf den Körper der SchülerInnen. LehrerInnen könnten allerdings nur »unterstützen, behüten und entgegenwirken« (Liebau 2002: 34), denn die entscheidende Aktivität liege bei den Lernenden selbst.

Damit stellt sich die Frage, was mit dem Körper ist, der als selbstverständlich vorhandener immer schon funktionieren muss und gesellschaftsfähig sein bzw. werden soll. Mich interessiert, wie dieses Thema in pädagogischen und erziehungswissenschaftlichen Kontexten mit dem Bezug auf die Institution Schule verhandelt wird. Dies untersuche ich ausgehend von Beobachtungen des Schulalltags einer 7. Klasse und der Beschäftigung mit der unübersichtlich erratischen Körper-Lektüre. Auf den ersten Blick wird die Konjunktur des Themas dort zwar stets proklamiert, tatsächlich wird es aber wenig aufgegriffen, wenngleich Einigkeit besteht, dass schulische Sozialisation und Wissensvermittlung immer auch am Körper ansetzt. Doch auf welche Weise geschieht dies, mit welchen Körperpraktiken von SchülerInnen und LehrerInnen und innerhalb welcher Diskurse? Inwieweit wird es expliziert oder innerhalb anderer Themenbereiche impliziert? In diesem Zusammenhang ist zu fragen: Wie stellt sich überhaupt das Verhältnis von Körper(lichkeit) und Schule sowie die diskursive Vermittlung dieses Verhältnisses dar? Diesen Fragen gehe ich mit der vorliegenden Untersuchung nach. Sie umfassend zu beantworten ist allerdings kaum möglich, denn Menschen und ihre Situationen bzw. Inter-

4 Darüber hinaus haben Heinz Hengst und Helga Kelle (2003) das Thema erstmals in der Kindheitsforschung aufgegriffen. In ihrem Band wird den gesellschaftlichen Veränderungen und den Anforderungen an Kinder-Körper sowohl theoretisch als auch empirisch nachgegangen. Bereits in den 1990er Jahren betrachtet Cornelia Helfferich (1994) in ihren Arbeiten Jugend, Körper und Geschlecht hinsichtlich vielfach geschlechtsspezifischer und durch soziale Herkunft bedingte Praktiken bzw. Bearbeitungsstrategien. Auch Karin Flaake und Vera King beschäftigen sich aus psychoanalytischer Perspektive mit Körperlichkeit im Rahmen weiblicher und männlicher Adoleszenz (Flaake 2001; King/ Flaake 2005). 
aktionen sind ohne ihre Körper nicht zu denken, Leiblichkeit ist eine zwangsläufige Bedingung des menschlichen Daseins. Diese Aussage erscheint fast paradox vor dem Hintergrund, dass die Sozialwissenschaften sehr lange ohne die Thematisierung des Körpers ausgekommen sind (vgl. Burkhart 2003: 173; Frömmer et al. 2003: 6; Hengst/Kelle 2003). Beginnt man sich jedoch mit Körper und Leiblichkeit zu beschäftigen, scheint es keinen Bereich zu geben, wo sie keine Rolle spielen - auch innerhalb schulischer Praktiken. Der Körper ist überall zugegen und das Thema wird grenzenlos. Dieses Problem, das mich während der gesamten Arbeit begleitete, galt es zu bearbeiten. Zur Eingrenzung werden es daher verschiedene als wichtig identifizierte Bereiche sein, in denen Körper(lichkeit), pädagogische Beziehung und die Institution Schule aufeinander treffen. Dabei werden Zumutungen und Möglichkeitsbedingungen relevant, unter denen SchülerInnen und LehrerInnen agieren, sowie die Bezüge, die zu ihrer Körperlichkeit sowohl in Körperpraktiken selbst als auch im Reden darüber hergestellt werden.

Um eine differenzierte und detaillierte Analyse der Körperpraktiken und der damit verknüpften Problematisierungen sowie pädagogischer Steuerungspraktiken vorzunehmen, wählte ich folgende Zugänge: Zum einen nutzte ich Materialien eines ethnographischen Forschungsprojektes, in dem Körperinszenierungen heranwachsender SchülerInnen untersucht wurden. ${ }^{5}$ Gemeinsam mit der Forschungsgruppe habe ich in einer 7. Klasse einer großstädtischen Hauptschule teilnehmend beobachtet und Interviews mit SchülerInnen und LehrerInnen geführt. Kontrastierend analysierte ich zudem schulpädagogische Fachzeitschriften.

Auch in der Feldforschung ging es zunächst um die oben geschilderte sichtbare Inszenierung hinsichtlich der Frage, wie Heranwachsende ihre Jugendlichkeit in Szene setzen, dabei ihr Frau- oder Mann-Werden hervorheben und es somit fortlaufend produzieren, sowie letztlich, wie dies durch LehrerInnen pädagogisch begleitet wird. Die Altersklasse der 12- bis 14-Jährigen als AkteurInnen in pädagogischen Situationen bot sich an, da angenommen werden kann, dass sie sich nicht nur aktiv, sondern auch zunehmend reflexiv mit den eigenen körperlichen Veränderungen, aber auch den diesbezüglichen gesellschaftlichen Anforderungen auseinandersetzen. Im Forschungsfeld Schule zeigte sich nun, wie maßgeblich die institutionellen Strukturen die Praktiken der beteiligten Akteure rahmen und unmittelbar beeinflussen. Denn lediglich von pädagogischer Begleitung eines ansonsten natürlich ablaufenden

5 Das Projekt »Körperinszenierungen im Jugendalter - jugendliche und pädagogische Perspektiven« wurde im Zeitraum von 2002 bis 2005 von einer Projektgruppe unter der Leitung von Prof. Dr. Barbara Friebertshäuser und mir durchgeführt und vom Hessischen Ministerium für Wissenschaft und Kunst gefördert. 
Prozesses konnte nicht die Rede sein. Beobachten ließ sich immer wieder, dass es zwischen den Vorstellungen der LehrerInnen, was angemessene Körperpraktiken seien, und den Verhaltensweisen der Heranwachsenden ein Spannungsverhältnis gab, das vielen Konflikten rund um den Unterricht zugrunde lag und somit indirekt auf die schulische Situation einwirkte. Deutlich wurden zudem die Notwendigkeit und Selbstverständlichkeit, den eigenen Körper zu beherrschen und sich angemessen zu verhalten.

Da sich solche Auseinandersetzungen kaum losgelöst von diskursiven Verweisungszusammenhängen ereignen, interessierte mich weiterhin, von welchen pädagogischen Diskursen das Beobachtete gerahmt und durchzogen wird. Um herauszuarbeiten, wie Körper und Körperlichkeit bezogen auf Erziehungsund Bildungsprozesse sowie ihr Verhältnis zur Institution Schule problematisiert werden, untersuchte ich hierzu praxisnah konzipierte schulpädagogische Fachzeitschriften der Jahre 1995 bis 2005. Mit dem so konzipierten Forschungsdesign liegen verschiedene Materialien und Textgenres vor: wissenschaftliche Texte, didaktische Konzepte sowie Erfahrungsberichte, die eine Art »best practice « illustrieren; daneben Bilder, Interviewtranskripte und Beobachtungsprotokolle. Mit den beiden Zugängen, der ethnographischen Feldforschung und dem diskursanalytisch aufbereiteten Zeitschriftenkorpus, soll nicht der Eindruck erweckt werden, als gingen die Beobachtungen der Feldforschung in den diskursiven Praktiken in den Texten der Fachzeitschriften auf oder als ließen sich bestimmte Denkweisen kausal auf spezifische Beobachtungen oder Äußerungen von Lehrenden beziehen. Die Analyse zeichnet sich stattdessen als ein wechselseitiger Prozess aus, in dem die Materialien einander gegenüber gestellt und kontrastiert werden, wobei sich Verknüpfungen, Irritationen, Spannungen, Brüche und Widersprüche ebenso zeigen wie bestimmte Leerstellen im Reden über Körperlichkeit an der Institution Schule über die Hauptschule im Speziellen hinaus.

Für die Feldforschung haben wir unter anderem deshalb die Schulform Hauptschule ausgewählt, weil sie in der empirischen Forschung bislang vernachlässigt wurde. Zudem vermittelte eine pädagogische Mitarbeiterin den Zugang und sowohl die Lehrerinnen der Klasse als auch der Schulleiter ließen sich interessiert auf unsere Forschung ein. Eine weitere Besonderheit ist, dass in der Schulklasse auch integrativer Unterricht stattfand, so dass zum Teil zwei Lehrerinnen gemeinsam im sog. Teamteaching unterrichten - eine Situation, die wohl die wenigsten LehrerInnen und SchülerInnen in ihrem Schulalltag kennen. Die verhältnismäßig jungen Lehrerinnen, neben den beiden noch eine weitere Fachlehrerin, unterrichten die Schulklasse bereits seit zwei Jahren und kennen »ihre« SchülerInnen gut. Zwar ist diese Konstellation als solche nicht verallgemeinerbar, die jeweils geschilderten ethnographischen Be- 
schreibungen in der empirischen Analyse stellen aber dennoch »typische« Situationen im Schulalltag dar. Welche Rolle dabei die Hauptschule als spezifische Institution spielt, ergibt sich jeweils in konkreten Situationen am Material, sie selbst steht nicht in erster Linie im Fokus. Die Beobachtungen und Interviews stellen Ausgangspunkte für begründete Fragen und Suchbewegungen in den Zeitschriftenartikeln dar, welche sich an Lehrende mit dem Ziel professioneller Praxis richten. In den Zeitschriften werden bestimmte (pädagogische) Körper-Politiken vertreten, insofern Konzepte von Körperpraktiken und körperlicher Beschaffenheit von SchülerInnen und LehrerInnen entworfen werden, die beim Unterrichten bzw. im schulischen Alltag zur »Anwendung« kommen (sollen und können).

Insofern frage ich nach den Einsätzen des Körpers. In der Online-Enzyklopädie Wikipedia ist unter dem Begriff >Einsatz die »Warnung « zu lesen: »Der Titel dieses Artikels ist mehrdeutig.« Wird das Wort zumeist im Zusammenhang mit ordnenden und kämpfenden Einsatzkräften verwendet, die entweder retten oder verhindern, kann er ebenso gut als ein Wert fungieren, der in einem Spiel investiert wird, etwa beim Pokern. Verbunden ist damit immer auch ein gewisses Risiko. Wenn etwas eingesetzt wird, kann dies im technischen Bereich Teil eines anderen, und somit situiert werden oder zur Anwendung kommen. Ferner kann unter Einsatz Engagement oder eine besondere Leistung verstanden werden oder noch einmal anders: ein bestimmter Zeitpunkt, wenn beispielsweise Musikinstrumente in einem Orchester mit dem Spiel beginnen. Durch diese Mehrdeutigkeit ist der Begriff als Metapher für diese Arbeit besonders brauchbar: Es finden sich die ein oder andere Spielart ebenso wie Überlagerungen. So unterschiedlich diese Konnotationen sein mögen, gemeinsam haben sie, dass sie jeweils eine bestimmte Funktion haben und in der Relation zu etwas stehen, vielfach zu einem anvisierten Ziel mit mehr oder weniger ungewissem Ausgang.

Die genaue Betrachtung mittels der Metapher des Einsatzes vor dem Hintergrund diskurstheoretischer und interaktionistischer Theorien ermöglicht, die Blackbox des selbstverständlichen, »impliziten«, gesellschaftsfähigen Körpers zu erhellen und das Verhältnis zwischen Körper und schulpädagogischen Konzepten bzw. Schulalltag zu reflektieren. »Lehr- und Lernkörper« sind zwar immer »irgendwie« da, es wird etwas mit ihnen »gemacht«, aber eigens problematisiert und damit reflexiv wird dies in der Regel nicht. Die Studie steckt daher ein Beobachtungsfeld ab, das zwar für (schul-)pädagogische Interaktionen zentral ist, aber wenig Beachtung erfährt, obwohl allerorten auf den menschlichen Körper geschaut bzw. gerade weil geklagt wird, dass dies zu wenig geschähe. Zugleich hat die Fokussierung auf den Körper von SchülerInnen und LehrerInnen bzw. Lern- und Lehrkörper einen Perspektiven- 
wechsel auf gängige und zugleich spezifische soziale Praktiken in der Schule zur Folge.

Zum Aufbau der Arbeit: Zunächst gehe ich noch einmal auf den gegenwärtigen erziehungswissenschaftlichen Diskussions- und Forschungsstand ein und skizziere weitere Ausgangspunkte der Arbeit. Zum einen beziehe ich mich auf Arbeiten, die die historische Entwicklung von Schule nachzeichnen und sich innerhalb der Schulgeschichte mit dem Verhältnis von Körper und Schule kritisch auseinandersetzen. Zum anderen schließe ich an ethnographische Studien im Zusammenhang mit Schule an, insofern sie methodologische Gemeinsamkeiten und je nach Forschungsgegenstand thematische Verknüpfungen aufweisen.

Im Kapitel >Körper, Macht und diskursive Praktiken zeige ich die theoretischen Perspektiven auf, die den Hintergrund der Untersuchung bilden. Zentral sind dabei zwei Schwerpunkte, die miteinander verwoben sind: der zugrundegelegte Körperbegriff sowie das Verständnis diskursiver Praktiken, die ich bei der Problematisierung von Körper(lichkeit) und Schule bzw. darüber hinaus analysiere. Diskurs- und körpertheoretisch schließe ich insbesondere an Begriffe und Analysen von Michel Foucault sowie Judith Butler und deren Rezeptionen an. Damit stehen komplexe Verflechtungen von Machtpraktiken und -verhältnissen, Wissensformen und Subjektivitätstypen zur Debatte, die pädagogische Handlungsfelder charakterisieren. Um Diskursivität auch situativ zu verorten und beobachtbare Körperpraktiken im Unterricht einzubeziehen, sind zudem die Interaktionskonzepte Erving Goffmans von besonderem Wert. Außerdem gebe ich einen Überblick über den Stand der derzeitigen Diskursforschung.

Das Kapitel 'Diskursanalytische Ethnographier führt in den Forschungsprozess ein. Ethnographie und Diskursanalyse derart miteinander zu verknüpfen ist ein Novum, weshalb ich mein Vorgehen ausführlich darstelle. Die Forschungsbeziehungen zu den SchülerInnen und LehrerInnen im Feld der Schule und die Datenerhebung vor Ort werden ebenso reflektiert wie die Erstellung des Zeitschriftenkorpus, die Auswahlkriterien für die Texte sowie die Auswertung der verschiedenen Materialsorten.

Den Hauptteil der Arbeit nimmt die empirische Analyse ein. Sie ist in vier Kapitel untergliedert, die sich mit verschiedenen Themenkomplexen beschäftigen, welche mit dem Thema Körper(lichkeit) verknüpft sind. Dabei wird der Körper der SchülerInnen und der »Lernkörper« sowie der Körper der Lehre- 
rInnen und der »Lehrkörper ${ }^{6}{ }^{6}$ unterschiedlich stark fokussiert. Es lässt sich ein Feld zwischen »Disziplinieren « und »Entspannen « rekonstruieren, das die gesamte Arbeit durchzieht. Entspannen erscheint zunächst als ein Gegensatz zur Disziplinierung. Letztlich sind beide aber vielfach verwoben: in Entspannungspraktiken innerhalb der geschlechtsspezifischen Arbeit, in Ruheritualen im Unterricht, in der Beseitigung von Störungen, in Entspannungstechniken für LehrerInnen, die ihrer Gesundheit und der Steigerung ihrer Leistungsfähigkeit und damit ihrer Selbstdisziplinierung dienen. Während zunächst der gelehrige aber auch widerständige Körper der SchülerInnen innerhalb beobachteter institutioneller Raum-Zeit-Arrangements im Unterricht ins Blickfeld rückt, zeigt sich, dass ein solcher Blick auf die SchülerInnen für die Texte im Zeitschriftenkorpus ungewöhnlich ist. Die zunächst eher allgemeinen Betrachtungen des Körpers, die das Kapitel ,Lernende und gelehrige Körper beenden, scheinen mit den Beobachtungen nicht viel gemein zu haben und verursachen beim Lesen vielleicht Irritation.

Das Kapitel `Körper, Sanktion und Disziplin(-ierung) ‘ nimmt eine Irritation während der Feldbeobachtung zum Ausgangspunkt: vom Unterricht ausschließende Strafpraktiken sowie besondere Formen von Strafarbeiten. Die Beobachtungen führen zur Frage, wie es eigentlich um das Verhältnis von Körper und Strafe und im Weiteren um Körper und Unterrichtsstörungen, Disziplin und Disziplinierung steht. Dabei zeigt sich eine Tabuisierung von Strafe(n) und Disziplinierung, welche Lehrende vor das Problem stellt, wie ohne Disziplinierung zu Disziplin gelangt werden könne. Im pädagogischen Diskurs rücken an diese Stelle rituelle Praktiken der Unterrichtsführung.

Relevant wird hier zudem der Körper der Lehrenden. Er steht im Mittelpunkt des Kapitels ,Lehrende und gelehrige Körper. Als »Lehrkörper« eingesetzt bekommt der Körper der Lehrenden eine wichtige Rolle innerhalb professionellen Arbeitens zugeschrieben. Denn Lehrende gelten als Vorbilder und ihre Führung der Schulklasse soll die einzelnen SchülerInnen zur Selbstführung anhalten. Da der Beruf des/der LehrerIn vielfach mit Krankheit und Burnout verbunden ist, wird zudem der kranke Körper problematisiert.

Wiederum anschließend an den geschilderten Einsatz des Lehrkörpers rücke ich in Kapitel ‘Körperliche Bezugnahme als Aspekt pädagogischer Beziehungsarbeit ‘ die Interaktionsprozesse zwischen Lehrerinnen und SchülerInnen in der beobachteten Schulklasse ins Blickfeld. Es zeigen sich Faktoren dieser Einflussnahme und Legitimierungen im Spannungsfeld zwischen Pro-

6 Mit dem Begriff »Lehrkörper «, den ich im Folgenden verwende, ist nicht die gesamte Lehrerschaft einer Schule gemeint, sondern ein spezifischer professioneller Einsatz des Körpers der lehrenden Person (vgl. Kap. )Lehrende und gelehrige Körpers). 
fessionalität, Sexualität, Gender und gesellschaftlicher Klasse. Die Gratwanderung beim Einsatz von Körperkontakten spiegelt sich in einer weitgehenden Tabuisierung in den Fachzeitschriften wider.

Diese vier Komplexe schließen andere Themen aus, die ebenso im $\mathrm{Zu}$ sammenhang mit Körper und Schule relevant sein könnten: spezifische Unterrichtskonzepte, Gewalt, Gesundheits- und Drogenprävention für SchülerInnen oder - auf einer anderen Ebene - Unterrichtsmaterialien, die den menschlichen Körper thematisieren. Sie bilden keinen abschließenden oder gar einheitlichen »pädagogischen Körper-Diskurs« ab. Vielmehr eröffnen sich im Feld von »Disziplinieren« und »Entspannen« widerstreitende, sich ergänzende oder überlagernde Praktiken, aber auch »diskursive Leerstellen«, die auf Tabuisierungen und die Grenzen des Sagbaren verweisen. Diese Relationen resümiere ich im letzten Kapitel noch einmal.

Abschließend ein Lesehinweis: Die Materialien der Feldforschung und der Zeitschriftenanalyse habe ich in den Kapiteln getrennt analysiert. Sie nehmen dort jeweils thematisch bedingt unterschiedliche Plätze ein. In allen Kapiteln beginne ich der Übersichtlichkeit halber mit den ethnographischen Beschreibungen und gehe daran anknüpfend zur Analyse der Zeitschriftenartikel über. Lediglich im Kapitel 'Körper, Sanktion und Disziplin(-ierung)< changiere ich zwischen den Materialsorten und den zugehörigen Analysen aufgrund des Gegenstands bzw. meiner Argumentation. Bevor ich jedoch zum facettenreichen Einsatz des Körpers in der Schule und seinen Gebrauchsweisen komme, werfe ich im Folgenden einen Blick in die zurückliegende Schul- und Körpergeschichte. 


\section{Historische und gegenwärtige Blicke auf Körper und Schule}

In erziehungswissenschaftlichen Debatten zum Thema Körper werden Zusammenhänge, Perspektiven und theoretische Bezüge zu Körper und Leib, Identität, Inszenierung sowie Geschlecht eröffnet, die vergleichbar sind mit der Art, wie diese interdisziplinär verhandelt werden. Insgesamt zeigt sich, dass Schule und ihr Verhältnis zu den in ihr agierenden Körpern, welche sie zugleich mitgestaltet, kaum wahrgenommen und diskutiert werden. Diese Beobachtung trifft auch für andere pädagogische Institutionen zu. Das Verhältnis von Körper und (sozialem) Raum wird dabei fast ebenso wenig thematisiert, wie das von Körper und Kultur oder Migration. Körper werden in der Regel als individuelle gedacht und so gesellschaftlichen - vor allem aber institutionellen Zusammenhängen entzogen. Für meine Studie sind daher solche Arbeiten relevant, die das Verhältnis von Körper(lichkeit) und der Institution Schule im Speziellen in den Blick nehmen und über eine individuelle oder von Schule losgelöste Thematisierung hinausgehen.

\section{Historische Prozesse der Körperdisziplinierung}

Die Geschichte der Institution Schule lässt sich maßgeblich auch als Körpergeschichte begreifen. Das zeigen besonders die Erziehungswissenschaftler Ludwig A. Pongratz und Horst Rumpf, die die Vergangenheit dieser Institution reflektieren und sie anhand von verschiedenen Quellen untersuchen. Ihre Studien stammen aus den 1980er Jahren und damit aus einer Zeit, in der insbesondere Michel Foucaults Machtanalysen in »Überwachen und Strafen« (1998/1975) einige Auseinandersetzungen mit den schulischen Techniken der Disziplinierung zur Folge hatten (vgl. Caruso 2003: 26f.; Balzer 2004: 
17ff.). So beziehen sich auch die Ausführungen der beiden angeführten Autoren u. a. darauf.

Ludwig A. Pongratz betrachtet die historische Entwicklung der Schule im Prozess gesellschaftlicher Rationalisierung und Disziplinierung (1989, 1990, 1995, 2004) ${ }^{1}$. Er rekonstruiert den Prozess der Entwicklung von Unterricht und Schulsystem, indem er auf spezifische gesellschaftliche Machtformationen Bezug nimmt, die Foucault in seinen Analysen herausarbeitet hat. Zwangsläufig rücken damit institutionelle Umgangsweisen und Zurichtungen des Körpers in den Blick. Hier seien die Punkte herausgegriffen, bei denen Pongratz den Körper von LehrerInnen und SchülerInnen einbezieht und das Verhältnis von Körper und Schule thematisiert.

Grundlegend in Pongratz Texten ist die Aufteilung in drei historisch unterscheidbare, aber nicht gänzlich in sich geschlossene Machtformationen, wie sie Foucault beschreibt: ${ }^{2}$ zunächst im Mittelalter die Repressionsmacht ausgehend von einem Souverän als repräsentativer Figur. Sie operierte bei Abweichungen vor allem mit Mechanismen der Ausschließung, aber auch strafende Martern wurden zum Zeremoniell der Souveränität. Mit der Aufklärung bildete sich im 18. Jahrhundert eine normierende Integrationsmacht heraus, die nun vielfach mit Einschließungsmechanismen arbeitete. Ab dem 19. Jahrhundert waren immer größere Bevölkerungsmassen ins Gesellschaftssystem zu integrieren und unter Kontrolle zu bringen. Es entwickelte sich die produktive und Kräfte steigernde, sich in die Körper einschreibende Disziplinarmacht, die sich weniger auf Vernichtung als auf Leben ausrichtete (vgl. ausführlich Kap. `Disziplin, Macht und Selbstsorge $`$ ). Für diese unterschiedlichen historischen Macht-Konstellationen arbeitet Pongratz die jeweiligen Wissensordnungen, Lehrpraktiken und -diskurse sowie ihre Brüche, Abgrenzungen und Effekte innerhalb der Pädagogik heraus bzw. das, was Schule dabei jeweils bedeutete.

Bezogen auf den Umgang und die Zurichtung des Körpers stand im feudalistischen »Zeitalter« der Repressionsmacht für einen verschwindend geringen Teil der Bevölkerung vor allem »der Aufbau eines souveränen körperlichen Habitus « (Pongratz 1989: 153) im Vordergrund. Macht war an körperliche Gewalt gebunden. »Als Kontrapunkt zur Machtwirkung, die sich am Körper des Unterlegenen ausließ und ihn verunstaltete, zielte die Ausbildung des Ritters auf körperliche Gestaltung.« (ebd.) Diese Orientierung an der äußeren

1 Der grundlegende Text ist die 1989 unter dem Titel »Pädagogik im Prozess der Moderne« erschienene Studie zur Sozial- und Theoriegeschichte der Schule. Ich beziehe mich im Wesentlichen darauf, es sei denn ein Gedanke wird in späteren Texten weitergeführt.

$2 \mathrm{Zu}$ den verschiedenartigen Unterscheidungen der Machtformationen innerhalb der Foucault-Rezeption vgl. Cornelis Horlacher (2005: 72). 
körperlichen Präsentation sei spätestens mit Comenius in der Zeit der Aufklärung verschwunden. Zunehmend zielten pädagogische Interventionen auf einen Innenraum, »hieße er nun Seele, Ingenium, Einbildungskraft, Bewusstsein oder Vernunft« (ebd.: 163). Dieser Innenraum wurde durch seine Konzeptualisierung und mittels pädagogischer Praktiken überhaupt erst hervorgebracht und konturiert. Als Kontrollformen, mit denen der Innenraum des Subjekts besetzt und die Kontrolle verinnerlicht wurde, und wie sie beispielsweise im Philanthropismus zu finden sind, nennt Pongratz: »Durchstrukturieren des Feldes der inneren Anschauung, um die Aufmerksamkeit zu richten und unerwünschte Vorstellungen zu unterdrücken; Vorgabe von positiv sanktionierten Wunschprojektionen, die als Ideale der Sittlichkeit beständig vor dem inneren Auge stehen sollten; und schließlich - von den Philanthrophen nur als Ausnahme akzeptiert - die Brechung des Willens durch körperliche Zucht.« (ebd.: 173)

Eine weitere Transformation konstatiert Pongratz in der ersten Hälfte des 19. Jahrhunderts. Unter anderem an Johann Heinrich Pestalozzis Elementarmethode zeigt er, wie die darin enthaltenen Techniken der Zerlegung, des Arrangements und der produktiven Reorganisation mit denen der Disziplinarmacht verwandt sind (1989: $180 \mathrm{ff}$; zusammenfassend 1990: 298ff.). Die Techniken der Elementarisierung des Unterrichts griffen mit architektonischen und schulorganisatorischen Arrangements, wie einer bestimmten Ordnung des Schulraums, der Einführung geschlechtsspezifischer Codes oder der präzisen Handhabe und permanenten Kontrolle des Körpers beim Sitzen, Melden, Schreiben etc. ineinander und brachten einen Normierungs- wie auch Normalisierungseffekt (ebd. 1989: 204) nach Maßgabe eines »fiktiven Normschülers« (ebd.: 185) ${ }^{3}$ hervor. Strafen sollten vor allem die Abweichung von dieser Norm reduzieren. Zielpunkt der Macht wurde demnach - und dies wird bei den Straftechniken besonders deutlich (Pongratz 1995) - »nicht mehr der Körper als Leidenssubjekt, sondern als Vorstellungsobjekt (Pongratz 1989: 144). « Fixpunkt der Orientierung war der »gelehrige Körper«, der mit minimalem Aufwand und maximalem Effekt zergliedert, resynthetisiert und durchdrungen werden sollte. Eindrucksvoll nachzuvollziehen ist das an der sog. Schulbank-Debatte im 19. Jahrhundert. Sonja Hnilica (2003) hat die Diskussionen und ihre materiellen Umsetzungen aus architekturtheoretischer Perspektive rekonstruiert und kommt zusammenfassend zu folgendem Ergebnis: »Die Schulbank ist das materielle Gegenstück einer Ideologie des unbeweglichen Schülerkörpers. Diese Überzeugungen entstanden aus einer Überlagerung von einer Reihe von Diskursen und Praktiken: der Einigung der Nationalstaaten, dem Wechsel von spektakulärer Macht von Souveränen zu panop-

3 Bei dieser Formulierung bezieht sich Pongratz auf Franz Kost (1985). 
tischer Disziplinarmacht, dem Aufkommen massenproduzierter Schulmöbel, der medizinischen Diskussion des sexuellen Verhaltens, dem Gedanken der Norm in der Psychiatrie, Medizin, Industrie etc.« (ebd.: 143) Damit treffen hier pädagogische Ideale, strategisch-militärische und industrielle Interessen sowie bürgerliche Sexualmoral aufeinander.

Mit der festen und allseits stattfinden Implementierung von Techniken der Disziplin in der Schule Ende des 19. Jahrhunderts zeigen sich erneut Brüche und Veränderungen, die Pongratz mit »Sanfte Wende und Panoptismus « (Pongratz 1990: 304) betitelt. Gemeint ist das Erstarken der reformpädagogischen Bewegung, mit der die heftig geführte jahrzehntelange Schulbank-Debatte mitsamt ihrer Pädagogik obsolet geworden zu sein scheint (vgl. auch Kost 1985). Maria Montessori beispielsweise prangerte 1909 an, dass die Schulbänke zwar nach neusten wissenschaftlichen Erkenntnissen die Gesundheit der Kinder verbessern solle, statt dessen fabrizierten sie aber Krankheit und Unterwürfigkeit (vgl. Hnilica 2003: 7). Um den »Bewegungstrieb« des Kindes nicht länger zu unterdrücken, sollten dagegen neue Steuerungsmechanismen gefunden werden, die darauf zielten, "möglichst früh die Fremd- in die Selbstregulierung zu überführen « (Pongratz 1989: 216f.). Relevant wurden somit weniger die äußeren als die inneren Arrangements, wie Motivationsstrukturen, psychische Dispositionen, die Schulgemeinschaft usw. An dem von Pongratz in allen hier angeführten Texten gern verwendeten Beispiel zum Verhältnis des Lehrers zur Hosentasche seines Schülers ${ }^{4}$ lässt sich dieser Wandel und die panoptische Kontrolle besonders illustrieren: "Kontrolliert die salte Pädagogik die Hosentasche daraufhin, ob sie ein sauberes Taschentuch aufwiese, so läßt die sneue` Pädagogik gerade umgekehrt das darin befindliche Sammelsurium auf den Tisch kehren, um Einblicke in das Schülerleben zu gewinnen und sich die jugendliche Sammelleidenschaft pädagogisch nutzbar zu machen.« (ebd.: 217f.) Subjektives Interesse an den SchülerInnen und objektives Interesse am Schulsystem werden scheinbar offen aber doch unmerklich gekoppelt. Die Individuen können sich so zugleich als Subjekte dieser Prozesse erfahren und ihnen dennoch vollständig ausgeliefert bleiben. Diese Doppelstruktur, so Pongratz, stabilisiere die Fiktion von Autonomie (ebd.: 219). Die höchste Strafe in diesem Arrangement sei deshalb der Ausschluss aus der Schulgemeinschaft selbst (Pongratz 1995: 192).

Nicht ganz soweit zurück in die Vergangenheit geht Rumpf (1981, 1996a/b, 1999) $)^{5}$ in seiner Auseinandersetzung mit dem Verhältnis von Körper

4 Dieses Beispiel ist dem Text von Kost (1985: 190f.) entnommen.

5 Auch hier beziehe ich mich im Wesentlichen auf das Hauptwerk von Rumpf zu diesem Thema, welches 1981 erschienen ist und den Titel »Die übergangene Sinnlichkeit. Drei Kapitel über Schule« trägt. 
und Schule. An Beispielen aus 150 Jahren Schulgeschichte vollzieht er nach, wie der von Norbert Elias beschriebene Zivilisationsprozess innerhalb der Schule vonstatten geht. Neben Elias bezieht er sich ebenfalls auf die Ausführungen zur Disziplinarmacht von Foucault. Rumpf geht davon aus und zeigt, dass die Institution Schule wesentlich an den von den beiden Autoren beschriebenen Prozessen beteiligt ist. ${ }^{6}$ Dafür untersucht er verschiedene als zentral identifizierte Praktiken: Programmatische Empfehlungen bzw. Vorgaben für das Lehrpersonal, Schul- und Tagebücher, Begriffe, Alltagsbeobachtungen, Schulaufgaben, Sportunterricht, Methoden der Wissensvermittlung, Lehrerfragen. Bei der Analyse der Materialien zeigt sich, wie Affekte und körperliche Wahrnehmungen systematisch unterdrückt werden bzw. kontrolliert werden müssen - egal, ob in der Art, als Lehrende Fragen zu stellen, um die »richtige « Antwort bei SchülerInnen zu implementieren und so »Wissensbestände « abfragen und vergleichen zu können, oder in konkreten Körperpraxen der SchülerInnen, wie z. B. dem geometrisch geordneten Sitzen. Beim Lernen in der Schule müssten sich die Beteiligten von den Inhalten, die sie lehren und lernen distanzieren. Sie dürften nicht »angetan « sein, sondern es ginge um abstrakte Welterklärungen. So werde nicht nur der Körper auf bestimmte Weisen »geformt«, sondern vor allem auch der Ausschnitt und die Art der Wahrnehmung des zu vermittelnden und sich anzueignenden Wissens. Rumpf kommt zu dem Schluss: »Die Körperlichkeit ist der verhandelten Sache nicht äußerlich; sie zeigt die Art der Teilnahme am Lernstoff an. [...] Der Lehrstoff, jeder Lehrstoff offenbar, fordert strengste körperliche Selbstzucht. « (Rumpf 1981: 49, Herv. i. O.)

Die Form der geforderten Körperbeherrschung geht einher mit einer technisch-administrativen Entwicklung, der »Lern-Körper« entspricht einem bestimmten zeitgemäßen »Arbeits- oder Konsumkörper« (ebd.: 43f.) bzw. »Verkehrskörper« (ders. 1999: 23). Unterrichtsabläufe und -methoden kommen der bürokratischen Organisations- und Verwaltungsform entgegen. So stellt Rumpf auch Mitte der 1990er Jahre noch fest, dass die Körperlichkeit der Schule bemerkenswert gut zu den Anforderungen von Verkehr und Arbeitswelt passe. Körpermodellierungen und -erfahrungen hätten hohe gesellschaftspolitische Relevanz, welche unterschätzt würde, wenn z. B. allerorten nur von Bewegungsarmut gesprochen werde (vgl. Rumpf 1996a: 9). Die Körperdisziplinierung orientiert sich am »Normalen« und stellt durch die Verkörperung von Werten in einem bestimmten Raum zugleich Normalität her. Abweichenden droht damit - wie Pongratz es ebenfalls formuliert - als mögliche Sanktion der soziale Ausschluss. »Denn vor allem Einzelwissen und Einzelkönnen -

6 Zu den unterschiedlichen Perspektiven und Fragestellungen von Elias und Foucault vgl. Kap. `Disziplin, Macht und Selbstsorge‘. 
wenn Menschen nicht über den Normalkörper in einer Gesellschaft, einer Kultur verfügen, dann sind sie out. Es ist ein Curriculum, das nirgends aufgeschrieben ist - das aber mitläuft bei allen Belehrungen und Einflußnahmen.« (Rumpf 1999: 24)

Mit dieser Untersuchung deckt Rumpf auf, was diese Art räumlich festgelegte und Zeit zergliedernde Wissensvermittlung impliziert und nach sich zieht: die Schärfung von Einzelsinnen beispielsweise, um zu messen, zu vergleichen, zu verbessern und zu steigern. Dies bringe eine Engführung sozialer Erfahrung mit sich. Denn nur wenn die Lehrpraktiken die Inhalte auf Distanz hielten, seien Lernvorgänge bei Schülern identifizierbar und steuerbar. »Die Sinnes-Disziplin schafft die isolierbare, kontrollierbare, durch Übung immer weiter zu vervollkommnende Seh-, Hör- Tastfertigkeit, welche sich befreit von der Bindung an Praxis, an Lebensgeschichte, an Sinn- und Machtzusammenhänge.« (Rumpf 1981: 72) In diese »Sinnes-Disziplin« seien sowohl SchülerInnen als auch LehrerInnen einbezogen, wie gerade die historischen Quellen, z. B. Vorschriften für das Lehrerverhalten, zeigen. Die Lerngruppe mit ungeordneten Körpern muss geordnet werden, denn die Körper bestimmen auch die Qualitäten der Inhalte und Tätigkeiten. Was gelernt werden kann und was nicht, konstituiert die Art des Bezugs auf die Lehrgegenstände mit.

Zur Aktualität dieser »neuralgischen Punkte« (ebd.: 68), wie Rumpf die von ihm ausgewählten Beispiele bezeichnet, bemerkt er, dass es zwar den Anschein haben könne, hier lediglich das Ausgefallene, längst Vergangene wieder hervorgeholt zu haben - die Starrheit der Schule habe sich doch längst gelockert -, die Tiefenstrukturen des Schullernens hätten sich jedoch gehalten bzw. perfektioniert. Gerade die Lockerung äußerer Kontrollen forciere die Intensivierung innerer Kontrollen, wie es auch Pongratz zeigt. Aktuelle Schulprobleme, so Rumpf, rührten auch aus der Annullierung des Körpers und der damit einhergehenden Überlastung der Sinne. »Die übergangene Sinnlichkeit« ist Gegenstand seiner Analysen und zugleich die Botschaft: das Leiblich-Sinnliche wieder einzubeziehen, und zwar nicht im Sinne einer »Domestikation« (ebd.: 227) als das zu bearbeitende, welches lediglich Randbedingung sei oder störe, sondern um überhaupt zu ermöglichen, die Aufmerksamkeit darauf zu richten.

$\mathrm{Zu}$ fragen bleibt, was es heißt, wenn Sinnlichkeit unterdrückt wird, und was sich ändern würde, wenn mehr Sinnlichkeit geweckt, zugelassen, gefordert werden würde. Welche Konsequenzen hat das und in wessen Interesse geschähe dies? In einem späteren Text, der Teil des Zeitschriftenkorpus ist, beschreibt Rumpf als eine Konsequenz den Verlust der Fähigkeit, sich auf Fremdes einzulassen. Es fehle die Übung, mit Gebärden und Gefühlen umzu- 
gehen, die Befremden wecken (vgl. Rumpf 1996a: 9). Zudem sei die Sprachfähigkeit nicht isoliert von der Fähigkeit zu betrachten, sich leiblich in der Welt zu bewegen (Rumpf 1999: 29). Mit Blick auf reformpädagogische und »subjektfreundliche Initiativen« (Rumpf 1981: 204) warnt der Autor aber auch davor, unvermittelte Regungen nun stattdessen unbesehen als authentische Erfahrung zu werten. Offen bleibt dabei allerdings, was dann an dieser Stelle stehen soll. Ebenso wenig wie die Zivilisierung oder Disziplinierung als quasinatürliche Prozesse angesehen werden dürfen (ebd.: 61) - womit sie gewissermaßen in den Praktiken getarnt und zugleich selbstverständlich gemacht werden - kann nun meines Erachtens ein anderer - sinnlicherer - Zustand nicht einfach als der natürliche angesehen werden.

Die Studien von Pongratz und Rumpf betrachten den Körper in der Institution Schule und im Prozess pädagogischer Praktiken aus einer historischen und teilweise ähnlichen wissenschaftstheoretischen Perspektive. Dabei erscheinen dieselben pädagogischen Praktiken auf der Oberfläche; der Körper wird aber jeweils unterschiedlich betrachtet, je nachdem ob der Fokus auf einer wieder herzustellenden Sinnlichkeit oder auf machtvollen Steuerungspraxen und einer Machtkritik (die bei Rumpf impliziert sind) liegen. In einer neueren Untersuchung mit dem Titel »Biopolitik im Klassenzimmer (2003) kritisiert Marcelo Caruso - ebenfalls die Analysen Foucaults aufnehmend die Ausführungen von Pongratz dahingehend, dass er im Anschluss an Foucaults »Überwachen und Strafen« zu sehr die Mechanismen der Disziplin in den Vordergrund rücke (ähnlich die Kritik Balzers 2004). Dies seien aber nicht die einzigen Techniken, die »disziplinarisch« wirken. Auf der Grundlage einer breiten Rezeption Foucaults in den letzten Jahren, insbesondere seiner späteren Werke, ergänzt und relativiert Caruso Pongratz wie auch weitere Autoren, die sich in den 1980er Jahren mit der Schule als Disziplinarinstitution beschäftigt haben (vgl. Caruso 2003: 33). Er begreift Unterricht als eine »Regierungssituation«, die spezifische pädagogische Formen annimmt (Caruso 2003: 15, 18). Unterricht stellt für ihn »eine operative Instanz der Erziehung dar, die durch codierte Techniken, wiederholende Verfahren und die Regierung kleinster Prozeduren den besonderen Charakter der intendierten Regelmäßigkeit des Kleinen aufweist« (ebd.: 25f.). In der Schule wird demnach nicht nur eine bestimmte institutionelle Ordnung hergestellt, sondern es mussten und müssen - historisch mit der Etablierung der Volksschule als Masseninstitution - die Wachstumsprozesse junger Menschen innerhalb von »Kollektiven« »geführt«, gefördert und geleitet werden. Caruso spricht hier von pädagogischer Regulierung (ebd.: 47). Er stellt sie als einen neuen Ansatz dar, der sich im Laufe des 19. Jahrhunderts entwickelte. Die Heranwachsenden selbst sollten in diese Regulierung aktiv eingebunden werden. Damit einher- 
gehend seien unter evolutionstheoretischen Einflüssen Ende des 19. Jahrhunderts mentale Wachstumsprozesse zu unhinterfragbaren Prämissen bei der Gestaltung von Unterricht geworden. Eine zentrale Rolle sei in diesem Prozess der Reformpädagogik zuzurechnen: »Unter Umständen bildete die sog. Reformpädagogik die Vollendung bzw. Überspitzung dieses regulierenden Ansatzes.« (ebd.: 51)

Die auf den Körper einwirkenden Disziplinen können als methodische Basis des Durchbruchs der Volksschule als Massenschule angesehen werden. Wie sich zeigen wird, ist diese Grundlegung aktuell immer noch von Bedeutung. Hier kann es nicht um die detaillierte Darstellung der historischen Prozesse innerhalb der Pädagogik in Bezug auf den Einsatz des Körpers innerhalb ihrer spezifisch machtförmigen Praktiken gehen. Deutlich sollte jedoch die Verbindung der Geschichte der Pädagogik bzw. des Schulsystems mit der des Körpers geworden sein, also die Tatsache, dass pädagogische Praktiken vielfach Körperpraktiken sind und somit spezifische Körper hervorbringen. Trotz der Erweiterungen, die Caruso dieser Schulgeschichte hinzufügt, habe ich die Studien von Pongratz und Rumpf ausführlich dargestellt, da sie in Bezug auf das historisch entstandene Verhältnis von Schule und Körper nach wie vor relevant sind und dieses Verhältnis sonst nicht in das Zentrum der Aufmerksamkeit gerückt wird. Nach wie vor ist, wie Walter Herzog in einem Aufsatz zum »Körper als Thema der Pädagogik« konstatiert, »die Reflexion der Pädagogik auf diese ihre Vergangenheit [...] eigenartig bescheiden« (Herzog 1985: 281).

\section{Körper, Schule und Geschlecht - aktuelle ethnographische Studien}

Mit diesem Resümee stellt sich die Frage, welche Forschungsarbeiten gegenwärtig zum Verhältnis von Körper und Schule aktuell sind, was zugleich einen weiteren zentralen Ausgangspunkt meiner Untersuchung markiert. In der letzten Dekade wurden im deutschsprachigen Raum einige für das infrage stehende Thema aufschlussreich erscheinende empirische Studien im Schnittpunkt von Schul- und Geschlechterforschung publiziert (Breidenstein/Kelle 1998; Faulstich-Wieland/Weber/Willems 2004; Güting 2004; Tervooren 2006). An sie knüpfe ich gleich auf mehreren Ebenen an: in Bezug auf den Forschungsgegenstand, hinsichtlich methodologischer Prämissen sowie bei der Frage möglicher methodischer Herangehensweisen.

Der Körper gerät in den Untersuchungen in zweierlei Hinsicht in den Fokus: zum einen, indem die Studien in der Regel Interaktionen innerhalb der Schule betrachten und dazu ethnomethodologische bzw. symbolisch-interak- 
tionistische Theoriekonzepte zugrunde legen. An interaktiven Vorgängen ist der Körper unmittelbar beteiligt, sie finden unter anderem mittels des Körpers statt, so dass ihre Beschreibung vielfach Körperpraktiken einschließt. Zum anderen haben sie Prozesse der Geschlechterkonstitution zum Gegenstand, für die, wie bereits erwähnt, der Körper unweigerlich eine Referenz bildet. Wurden bis Anfang der 1990er Jahre empirische Untersuchungen häufig im Rahmen des Konzepts geschlechtsspezifischer Sozialisation sowie der Debatte um Koedukation durchgeführt und so die mehr oder weniger passiven Einschreibungen und Differenzen zwischen Jungen und Mädchen betont, wendet sich die seit dieser Zeit neu konstituierende Kindheits- ebenso wie die Jugendforschung gegen die vorherrschenden Sozialisationstheorien (vgl. Tervooren 2006: 10ff.). Die Forschungsbereiche heben stattdessen die Eigenaktivität der Heranwachsenden hervor. Ein solcher Perspektivenwechsel vollzieht sich zeitgleich auch in der Geschlechterforschung. Fortan stehen mit dem Konzept des »Doing Gender« alltägliche Praxen der Herstellung von Geschlecht im Mittelpunkt. Mit dem so formulierten Konzept begreifen Candace West und Don H. Zimmermann (1991) Geschlecht als etwas, was jemand tut, und nicht als etwas, was jemand besitzt oder als Eigenschaft von Personengruppen zu begreifen wäre. Die beobachtete Realität gilt also nicht als gegeben, sondern als »gemacht «. In der Konstitutionsperspektive des »Doing ...«, welche von verschiedenen Autorinnen auch auf andere Prozesse hinsichtlich zentraler sozialer Kategorien übertragen wird, wie »Doing Adult« (Faulstich-Wieland/ Weber/Willems 2004: 182) oder »Doing Adolescence« (Breitenbach 2005: 81), interessiert die jeweilige Praxis der Erzeugung von Bedeutung. Damit werden interaktive Herstellungsprozesse und der darin eingebundene Körper relevant. Dies schlägt sich auch in den ethnographischen Studien zur Geschlechterkonstitution in der Schule nieder, auf die ich kurz im Einzelnen verweisen möchte, wobei ich sie hinsichtlich ihrer Thematisierung des Körpers betrachte.

Die Studie »Geschlechteralltag in der Schulklasse« von Georg Breidenstein und Helga Kelle (1998) führt in die Laborschule Bielefeld. Dort beobachteten die beiden Forschenden SchülerInnen vom vierten bis zum sechsten Schuljahr. Sie behandeln die Bedeutsamkeit der Geschlechterunterscheidung als empirische Frage und rekonstruieren die Situationen und Praktiken, in der die Differenzierung in Jungen und Mädchen relevant wird (Breidenstein/Kelle 1998: 15f.). Indem sie den situativ eingebundenen Gebrauch analysieren, mit dem die Kategorie Geschlecht innerhalb der »Sortierung « von Kindern oder in pädagogischen Praxen ins Spiel gebracht oder auch abgeschwächt wird, beziehen sie je nach Bedeutsamkeit bestimmte Körperpraktiken ein. So beispielsweise wenn SchülerInnen bereits allein durch ihre körperliche Anwesen- 
heit und ihr "Nichts-Tun« andere behindern, womit deutlich wird, dass es unmöglich ist, sich als SchülerIn während des Unterrichts der Klasse und dem Raum physisch zu entziehen (ebd.: 79). Auf andere Situationen werden die Forschenden aufmerksam, indem sie z. B. im Prozess der Geheimnisproduktion innerhalb kleiner Gruppen von SchülerInnen selbst - körperlich - ausgeschlossen werden. Die Körper der Kinder bilden untereinander eine geschlossene Formation, womit Außenstehende draußen gehalten werden (ebd.: 111). Im Rahmen von Beziehungsgefügen und Freundschaften spielen in der ethnographischen Beschreibung zudem die Körperkontakte unter den SchülerInnen eine wichtige Rolle (ebd.: 123).

Körperliche Berührungen betrachten auch Lothar Krappmann und Hans Oswald in ihrer bereits in Mitte der 1980er Jahre durchgeführten Studie »Alltag der Schulkinder « (1995) als Teil des Mit- und Gegeneinanders von Jungen und Mädchen. Ihre Beobachtungen führten sie in ersten, vierten und sechsten Jahrgängen von Berliner Grundschulen durch. Dabei ging es ihnen primär um die Interaktionen unter Gleichaltrigen und deren Aushandlung von Problemen (Krappmann/Oswald 1995: 18). Hinsichtlich körperlicher Kontakte kommen sie zu dem Ergebnis, dass es im Gegensatz zum Umgang unter Erwachsenen eine Vielzahl von unterschiedlichen Berührungssituationen und -szenarien gibt. Sie interpretieren dies als eine Form des Lernens, in der Sensibilität für Zärtlichkeit wie auch unerwünschte Nähe und körperliche Integrität entwickelt werden (ebd.: 198). Zugleich schildern sie ein mit zunehmendem Alter wachsendes körperliches Interesse am jeweils anderen Geschlecht, das sie aus den über die Beobachtungszeit hinweg häufiger werdenden Berührungen ableiten. Interessant ist diese Beobachtung, da die Körperkontakte sich häufig durch Ambivalenzen auszeichneten. Eindeutig positive Berührungen gab es wohl kaum, so dass meines Erachtens zu fragen ist, ob und inwiefern es den SchülerInnen notwendig erscheint, mehrdeutige Botschaften zu erzeugen und damit Situationen vieldeutig und offen zu halten.

Während diese beiden Studien jeweils Grundschulklassen in den Blick nehmen, positionieren Hannelore Faulstich-Wieland, Martina Weber und Katharina Willems (2004) sowie Damaris Güting (2004) ihre Forschung in den Unterricht eines Gymnasiums, um herauszufinden, welche sozialen Prozesse zwischen Lehrkräften und SchülerInnen erfolgen, die Aufschluss über die Bedeutung der Kategorie Geschlecht im Schulalltag geben. Ausgangspunkt ihres Kooperationsprojektes ist, dass die Adoleszenz Geschlechterverhältnisse in der Schule neu definiere, wobei unklar sei, wie die dort stattfindenden Interaktionen dazu beitragen (Faulstich-Wieland/Weber/Willems 2004: 21f.). Mit dieser Perspektive betrachten sie Genderkonstitutionen bei 13- bis 15-Jährigen. Da Geschlechterdifferenzen vielfach am Körper festgemacht werden, ste- 
hen unter anderem körperbezogene symbolische Inszenierungspraktiken im Fokus der Untersuchung, wie beispielsweise optische Präsentationsstrategien, die am Körper durch Kleidung offenbar werden. Als besonders bedeutsam stellen Faulstich-Wieland et al. den Zusammenhang zwischen den Inszenierungen des Erwachsenwerdens mit denen des Geschlechts heraus (ebd: : 222). Güting betont die institutionelle Geschlechtszugehörigkeit sowie die bereits erwähnten optischen Vergegenwärtigungen, auf denen die Faktizităt individueller Geschlechtszugehörigkeit gründe (Güting 2004: 219f.).

Die ausgehende Kindheit ist auch Gegenstand in Anja Tervoorens Studie »Im Spielraum von Geschlecht und Begehren« (2006). Sie untersucht den Übergang zur Jugend als kulturelles Projekt der Verkörperung, an dem die Kinder selbst aktiv mitarbeiten und das sich in fortwährend wiederholenden und sich ständig verändernden Prozessen des Einübens von Geschlecht und Begehren vollzieht. Die Studie wurde an einer sechsstufigen Grundschule durchgeführt. Neben Schulhof-Beobachtungen wertet Tervooren Videoaufnahmen einer Mädchen- und einer Jungen-Clique aus. In der Peergroup werden Geschlechterinszenierungen erprobt, vorgeführt, angenommen, wieder verworfen und neu inszeniert. Die Ethnographin fokussiert vor allem die Körperpraktiken der Kinder und beschreibt diese als Einübung von bezeichnenden Körperstilen (Tervooren 2006: 35). Diesen Stilisierungen sei regelrecht die »Arbeit« anzusehen, die Kinder in das Verkörpern von Erwachsenwerden »investieren«. Sie seien nicht unbedingt auf körperliche Veränderungen im Zuge der Pubertät zurückzuführen, sondern vielfach werde ein noch fiktionaler Körper evoziert, der in der Übertreibung einen Überschuss an Bedeutung produziere (ebd.: 227). Die Körperstile bezeichnet die Autorin zwar als männliche oder weibliche, jedoch nehmen vor allem die Mädchen ein Kontinuum zwischen diesen »Polen « war. Das Changieren kann auch deshalb aufgezeigt werden, weil Tervooren die beobachteten Rituale nicht unmittelbar vor dem Hintergrund gegebener Zweigeschlechtigkeit interpretiert. Sie bezieht nämlich sowohl die Körperpraktiken, sie durchziehende Diskurse wie auch Aspekte der Macht unter Kindern in die Interpretationen mit ein.

In dieser Reihe von Studien thematisiert die von Tervooren die Einsatzweisen des Körpers empirisch und theoretisch am stärksten. Der Schulalltag, der in den anderen Untersuchungen im Vordergrund steht, tritt dafür ein wenig zurück, zumal die Beobachtungen außerhalb des Unterrichts stattfanden. ${ }^{7}$

7 Innerhalb des DFG-Sonderforschungsbereiches »Kulturen des Performativen « gibt es allerdings ein weiteres Forschungsprojekt, das das Augenmerk auch auf Unterricht bzw. insbesondere Übergänge von Unterricht und Pause lenkt (Göhlich/Wagner-Willi 2001). In drei Schulklassen in den Jahrgängen 4-6 wurden Mikrorituale, wie z. B. Übergangsrituale, im Schulalltag sowie außeralltägliche Makrorituale, z. B. Feste, erfasst und somit Typen von Ritualisierungen gene- 
Von Unterrichtsbeobachtungen geht dagegen Georg Breidenstein in einer weiteren Forschung aus, deren Publikation mit dem Titel »Teilnahme am Unterricht. Ethnographische Studien zum Schülerjob« (2006) überschrieben ist. Hier stehen nicht genderspezifische Sichtweisen bzw. die Frage nach der Konstruktion von Geschlecht im Vordergrund, sondern die Frage, was SchülerInnen eigentlich im Unterricht tun und wie sie es tun (Breidenstein 2006: 9). Ausgangspunkt ist, dass Unterrichtssituationen weitaus komplexer sind, als allein unter dem Aspekt der Wissensvermittlung zu fassen ist. Zeitgleich vollziehen sich vielfältige Aktivitäten: In unterschiedlichen »Räumen« innerhalb des Schulraums finden ganz verschiedene, mehr oder weniger auf den Unterricht bezogene Handlungen statt, die sich häufig anhand von körperlicher Gesten beobachten lassen, beispielsweise beim Melden (ebd.: 99) oder im Gegenzug beim Versuch zu vermeiden »drangenommen« zu werden (ebd.: 102). $\mathrm{Zu}$ fragen sei nach den interaktiven Funktionen dieser Praktiken, die letztlich auch auf die des »Lehrerjobs « bezogen werden müssten, um eine sozialwissenschaftliche Theorie des Unterrichts formulieren zu können (ebd.: 264).

Die vorgestellten Studien unterscheiden sich in ihren Schwerpunkten, ihren Fragestellungen und teilweise auch in ihren theoretischen Bezügen. Sie haben jedoch eine Gemeinsamkeit: Es handelt sich um Schul-Ethnographien. Ethnographische Forschung betrachtet die jeweils untersuchte Kultur in ihrem alltagsweltlichen Vollzug. Tendenziell rücken die EthnographInnen in den Studien die SchülerInnen und deren Interaktionen ins Zentrum bzw. interpretieren (soweit möglich) jeweils aus der Sicht der beteiligten SchülerInnen bzw. LehrerInnen. Während die zuvor dargestellte historische Forschung notwendigerweise auf dem Studium von Quellen anhand verschiedener Text- und Bildmaterialien beruht, findet hier die Datenerhebung unmittelbar vor Ort statt. So ist der Titel von Breidensteins Studie auch in diesem Sinne zu verstehen: Nicht nur die SchülerInnen, sondern auch die Forschenden nehmen am Unterricht teil (Breidenstein 2006: 9). Teilnehmende Beobachtung wird dabei meist mit weiteren Verfahren qualitativer Forschung verknüpft, so dass vielfältige, sich ergänzende und kontrastierende Materialien vorliegen (Friebertshäuser 1997; Lüders 2000). Die Diskussion der methodologischen Prämissen sowie des methodischen Vorgehens in den einzelnen Untersuchungen, die konkreten Möglichkeiten, Probleme und Grenzen der Datenerhebung und des ethnographischen Schreibens lassen sich durch den gemeinsamen ähnlich strukturierten Feldbezug für die eigene Reflexion nutzen (vgl. Kap. sDiskurs-

riert. Rituale, verstanden als symbolisch kodierte Körperprozesse, stellen soziale Realität her, sie schreiben über die Erzeugung von Emotionen gemeinsame Werte und Normen einer Gruppe oder Institution in die Körper ein (Wulf 2001a: 91). 
analytische Ethnographie $<$ ). Darüber hinaus kontrastieren die Ergebnisse der Studien eigene Beobachtungen, bestätigen oder hinterfragen sie, so dass sie zur Validierung beitragen. In diesem Sinne werde ich mich im empirischen Teil an einigen Stellen auf diese Forschungen beziehen.

Tervooren kritisiert, dass in derart angelegten Untersuchungen und mit der sozialkonstruktivistischen Fokussierung auf die Interaktion der Subjekte strukturellen Aspekten und gesellschaftlichen Normen nur ungenügend Rechnung getragen werde. »Die Frage jedoch, woher die symbolischen und materiellen Ressourcen für diese Konstruktion stammen, gerät aus dem Blick und damit auch die Chance, den Bezug auf Normen und Traditionen einzubeziehen. « (Tervooren 2006: 16) Methodisch bearbeitet Tervooren dieses Problem, indem sie Beobachtungen und Befragungen, insbesondere Gruppeninterviews kombiniert, wodurch Netze von Argumentationen für die beobachteten Praktiken sichtbar werden, die auf solche »Traditionen« verweisen. Auch Kelle und Breidenstein rekonstruieren Konzepte der Kinder, mit denen diese sich ein Bild von Entwicklung, Geschlecht und Sexualität machen. Sie fragen nach den Sexualitätsdiskursen, die sie beispielsweise in Kommentierungen des Handelns anderer führen (Breidenstein/Kelle 1998: 165f.), oder danach, wie sie über die Altersangemessenheit von bestimmten Praktiken denken (ebd.: 255ff.). Damit werden Diskurse angeschnitten, die Situationen präfigurieren und vorab einen Rahmen für Be-Deutungen schaffen. Diese vorgenommenen Deutungen wiederum werden in konkreten Situationen aktualisiert, festgeschrieben aber auch verändert. Solche diskursiven Strategien rekonstruiert ebenfalls als Teil einer ethnographischen Arbeit Cordula Weißköppel (2001), in der sie zeigt, wie SchülerInnen in Alltagssituationen ethnische Differenzen produzieren. Bezogen auf einen Fall der Verweigerung zweier Schüler, am Sexualkundeunterricht teilzunehmen, untersucht sie argumentative Figuren im Gespräch mit dem Klassenlehrer, die die verschiedenen Sinnkonstruktionen und die Funktionen unterschiedlicher diskursiver Praktiken und so die Dimensionen des Falls aufzeigen (Weißköppel 2001: 216ff.).

All diese Bestrebungen, die beobachtbaren Interaktionen und individuellen Sinnzuschreibungen in ihrer Wechselseitigkeit mit gesellschaftlichen Strukturen und Diskursen zu beschreiben, bieten Anhaltspunkte für meine Arbeit, in der ich frage, wie und innerhalb welcher Diskurse sich das Verhältnis von Körper und Schule gestaltet und wie in unterschiedlichen Kontexten der Körper zum Einsatz kommt. In den drei letztgenannten Studien werden unterschiedliche Dimensionen aufeinander bezogen, die für mein Vorhaben, ethnographisches und diskursanalytisches Vorgehen sowie damit verbundene Theoriekontexte zu verknüpfen, interessant sind. Um dies weiter zu konkretisieren, 
werde ich im nächsten Schritt in die theoretischen Bezüge meiner Arbeit einführen und zugrunde gelegte Begriffe klären, um dann anschließend das Forschungsfeld dieser Untersuchung zu betreten und das Vorgehen vorzustellen. 


\section{Körper, Macht und diskursive Praktiken}

Aufgrund der vielfachen Thematisierung von >Körper< in den letzten zwei Jahrzehnten habe ich die Frage gestellt, inwiefern dies auch innerhalb der Pädagogik geschieht. Mit der These, dass Erziehungs- und Bildungsprozesse am Körper ansetzen und der Körper dabei auf bestimmte (historisch, geschlechtsspezifisch, sozial und kulturell geprägte) Weisen zum Einsatz kommt, rückten pädagogische Institutionen in den Blick. Bei der eigenen ethnographischen Forschung in der Schulklasse wurde deutlich, wie sehr die Inszenierungen von Jugendlichkeit durch die SchülerInnen dort vom schulischen Kontext geprägt wurden. So richtete sich der Fokus auf die Institution Schule und ihr Verhältnis zu Körperlichkeit bzw. den Körpern von SchülerInnen und LehrerInnen. Mich interessiert nun, wie mit diesen Körper(lichkeiten) umgegangen wird und wie sie problematisiert werden, kurz: welche Praktiken das Verhältnis von Körper und Institution Schule auszeichnen und mittels welcher Praktiken in der Schule gesellschaftsfähige Körper herstellt werden (sollen).

Dabei gehe ich von einer weiteren Annahme aus: >Umgangsweisen und >Problematisierungsweisen s sind nicht, als seien sie voneinander unabhängig, einfach einander gegenüberzustellen. Das heißt nicht: Hier wird über den Körper gesprochen, hier gibt es bestimmte Programmatiken, die entwerfen, wie z. B. der Lehr-Körper als Professioneller sein solle, und dort gibt es das wirkliche Handeln, wie Lehrende mitsamt ihrem Körper vor der Schulklasse erscheinen, sich bewegen, interagieren. Es heißt, dass es sich um jeweils spezifische Praktiken handelt, die aufeinander bezogen sind, die ineinander greifen, aneinander anknüpfen, andere ausschließen oder sich widersprechen. Wie lassen sich nun diese verschiedenen Praktiken untersuchen? Was haben sie inwiefern miteinander zu tun? Wie kommt man ihren Relationen auf die Spur? Eine entscheidende Perspektive ist dabei die der Analyse diskursiver Bezie- 
hungen, womit ich an diskurstheoretische Annahmen Michel Foucaults sowie ihre Rezeption in der Diskursforschung anschließe.

Um diese Fragen nach und nach zu beantworten, unternehme ich folgende Schritte: Zunächst greife ich die Arbeiten von Rumpf und Pongratz nochmals gezielt auf, um genauer nach ihrer theoretischen Referenz zu fragen. Auch für diese Autoren sind die Analysen von Foucault ein Ausgangspunkt. In dessen Arbeiten zeichnet sich ein spezifisches Körperverständnis ab, welches ich nochmals erweitere, um es als Grundlage für meine Untersuchung zu nutzen: zum einen auf einer körpertheoretischen Ebene - hier hat es in den letzten Jahren einige Versuche gegeben, soziologische Körperbegriffe zu formulieren, die Körper und Leib jenseits eines naturalistischen Verständnisses einbeziehen - und zum anderen auf der Ebene der Analyse von Interaktionsprozessen, in denen der Körper eine zentrale Rolle spielt. Dafür wiederum bieten sich die Konzepte und Modelle von Erving Goffman an, mit denen Interaktionen aus unterschiedlichen Perspektiven betrachtet werden können. Im letzten Schritt stelle ich die sich derzeit breit etablierende Diskursforschung vor und diskutiere in diesem Rahmen die oben genannten Fragen. Damit entwerfe ich ein theoretisches und methodologisches Konzept, das zugleich im Hinblick auf seine Eignung zur Analyse der praktischen Gestaltung des Verhältnisses von Körper und Schule geprüft wird. Als solches lag es im Vorfeld der Zusammenstellung und Analyse des Materials noch nicht vor, sondern wurde im Laufe des Forschungsprozesses in Auseinandersetzung mit dem Material entwickelt, orientiert am Auswertungsprozess und der damit korrespondierenden Literatur. Die gewählte Darstellung, so als existierte dieser Zugang bereits vor der Bearbeitung und Interpretation der Daten, ist der Anschaulichkeit und Verständlichkeit geschuldet; sie spiegelt nicht den vollzogenen Arbeitsprozess wider.

\section{Disziplin, Macht und Selbstsorge}

Ich habe im vorangegangenen Kapitel zwei Studien vorgestellt, die nach dem Körper in der Institution Schule und im Prozess pädagogischer Praktiken aus einer historischen und zumindest zum Teil ähnlichen wissenschaftstheoretischen Perspektive fragen. Dabei handelt es sich oberflächlich gesehen um dieselben pädagogischen Praktiken. Der Körper wird aber jeweils unterschiedlich betrachtet, je nachdem ob der Fokus auf einer wieder herzustellenden Sinnlichkeit oder auf machtvollen Steuerungspraxen und einer Machtkritik liegt. Während sich Pongratz an die Analyse der Disziplinarmacht bei Foucault anlehnt, verweist Rumpf zwar ebenfalls an einigen Stellen auf »Überwachen und Strafen« (Foucault 1998/1975), bezieht sich aber letztlich vor allem 
auf Elias' »Prozess der Zivilisation“ (Elias 1997/1939). Daraus folgen unterschiedliche Betrachtungsweisen des menschlichen Körpers, die ich kurz darstellen möchte, um zu begründen, weshalb ich mich im Weiteren vor allem (aber nicht ausschließlich) auf Foucault beziehen werde. Der Vergleich von Elias und Foucault ist auch deshalb bedeutsam, weil die Arbeiten beider Autoren zu den einflussreichsten innerhalb der sich derzeit ausdifferenzierenden Körpersoziologie gehören (Gugutzer 2004: 50).

Elias beschreibt in seiner Analyse der höfischen Gesellschaft das Wechselspiel von Sozio- und Psychogenese und zeigt implizit, wie der europäische Zivilisationsprozess seine Spuren am Körper der Menschen hinterlassen hat. Er rekonstruiert einen Modellierungsprozess der Triebe, Affekte und Emotionen, dem die Menschen insbesondere im 13. bis 18. Jahrhundert ausgesetzt waren. Um den Wandel körperlicher Einstellungen und Verhaltensweisen nachzuzeichnen, untersucht er vor allem Anstands- und Benimmliteratur ebenso wie Dichtung und Bilder. Als Gründe für die Veränderungen führt er die zunehmende Bevölkerungsdichte und daraus resultierend eine Zentralisierung staatlicher Macht sowie eine funktionale Differenzierung gesellschaftlicher Handlungsbereiche an (Elias 1997b: 330ff.). Seine zentrale These ist, dass wachsende "Interdependenzketten «, in die immer mehr Menschen einbezogen wurden, und damit verbunden ein Anwachsen gegenseitiger Abhängigkeiten eine zunehmende Affekt- bzw. Selbstkontrolle erzwungen habe. Elias macht diesen "Zivilisationsprozess « in allen arbeitsteiligen Gesellschaften aus. Er sei allerdings nicht als linear oder kontinuierlich, als mit einem Anfang und mit einem Ende versehen, zu verstehen. Und - dies ist vor allem für PädagogInnen von Interesse - er vollziehe sich mit der Sozialisation eines Menschen jeweils aufs Neue, indem Kinder in relativer kurzer Zeit ihre Bedürfnisse kontrollieren lernen müssten. "Nach einer Art ssoziogenetischem Grundgesetzく durchläuft das Individuum während seiner kleinen Geschichte noch einmal etwas von den Prozessen, die seine Gesellschaft während ihrer großen Geschichte durchlaufen hat.« (Elias 1997a: 78f.) Die individuelle Entwicklung könne dann als geglückt angesehen werden, wenn sich schließlich nach diesem durchaus konflikthaften Prozess gesellschaftlich gut angepaßte Verhaltensweisen und adäquat funktionierende Gewohnheitsapparaturen herausbildeten. Einher gehe diese Bewegung mit einer erhöhten »als selbständiger Automatismus eingebauten Selbstkontrolle« (Elias 1997a: 64). Dies wird als Übergang vom Fremd- zum Selbstzwang beschrieben.

Foucaults Blick auf den Körper unterscheidet sich in vielfacher Weise von der hier nur kurz umrissenen Perspektive von Elias. Während Elias den Körper als Ort von Bedürfnissen, Affekten und Trieben ausmacht und die lebensweltlichen Zwänge sowie ihre innerpsychischen Auswirkungen betrachtet, 
sind es bei Foucault vor allem die politischen-administrativen Techniken, wie auch die Wissenschaften, die auf die Körper einwirken und sie mittels spezifischer Praktiken »disziplinieren« und normieren. Eingebettet sind diese Analysen in eine umfassende Auseinandersetzung mit der »Bio-Macht«, welche sich vor allem auf den Zeitraum des 18. und 19. Jahrhunderts bezieht. ${ }^{1}$ Bei Elias stehen die Folgen dieser Körperbearbeitung für die Psyche im Mittelpunkt, während Foucaults ebenso wie mein Interesse auf die Praktiken der Machtausübung gerichtet ist. Gleichwohl - und das ist nicht nur ein wesentlicher Unterschied zu Elias, sondern relevant für diese Arbeit - ist die (Körper-)Disziplin im Sinne des Foucaultschen Verständnisses von Macht nicht lediglich Mechanismus einer Körperunterdrückung, sondern funktioniert mittels produktiver Effekte.

Darauf werde ich ausführlicher eingehen, da ich in der kommenden Analyse nicht nur im Anschluss an Foucaults Diskurstheorie arbeiten werde, für welche eben jener Machtbegriff zentral ist, sondern mich zudem an einigen Stellen der Interpretation auf weitere Begriffe Foucaults beziehe, sie dort aber nicht jeweils erneut erkläre. Im Folgenden beziehe ich mich vor allem auf das 1975 erstmals erschienene Buch »Überwachen und Strafen. Die Geburt des Gefängnisses«. Über die Thematisierung von Körpern, welche zunächst Anhaltspunkt für meine Wahl dieser Schriften ist, hinausgehend, sind es also vor allem die Machtanalytik und der Begriff der Disziplin, die für die weitere Arbeit und die Analyse der Institution Schule (nach wie vor) relevant sind (vgl. Pongratz 2004). Darüber hinaus beziehe ich mich auf Foucaults Geschichte der Sexualität (Foucault 1985, 1989) und werde die Begriffe »Regierung « und »Selbstsorge« aus seinen späteren Arbeiten einführen.

\section{Disziplinierte Körper - zum Begriff der Disziplin}

"Der historische Augenblick der Disziplinen ist der Augenblick, in dem eine Kunst des menschlichen Körpers das Licht der Welt erblickt, die nicht nur die Vermehrung seiner Fähigkeiten und auch nicht bloß die Vertiefung seiner Unterwerfung im Auge hat, sondern die Schaffung eines Verhältnisses, das in einem einzigen Mechanismus den Körper um so gefügiger macht, je nützlicher er ist, und umgekehrt.« (Foucault 1998: 176)

1 Mit der Entstehung liberaler Regierungsformen, die Foucault auf das Ende des 18. Jahrhunderts datiert, entwickelt sich ein neuer Typus von Machtpraktiken, die er Kontrolltechniken nennt. Gerichtet sind diese weniger auf das Individuum, sondern auf die Bevölkerung als Ganzes (Foucault 2004a: 161). Regieren bedeutet dann, das Leben der Vielen aufzuwerten und den Wohlstand zu mehren. So nennt Foucault diese Form der Macht Biomacht (Foucault 1999: 283ff.). 
Diesen Prozess, der nicht eine "plötzliche Erfindung« darstellt, macht Foucault in verschiedenen Institutionen aus: dem Gefängnis, dem Spital, der Schule, dem Militär usw. Er untersucht an Beispielen wesentliche Techniken, die er für verallgemeinerbar hält (Foucault 1998: 178). ${ }^{2}$ Derartige Techniken beziehen sich zum einen auf die Verteilung der Individuen (bzw. Körper) im Raum, d. h. eine spezifische Weise der Parzellierung und Funktionszuweisung sowie Klassifizierung unter anderem mittels der Architektur; und zum anderen auf möglichst effektive Nutzung der Zeit durch Rhythmisierung und Zerlegung in Abschnitte sowie die Zusammenschaltung von bestimmten Gesten und der Gesamthaltung des Körpers wie auch des Körpers mit Objekten. Zentrale Elemente sind die Instrumente der Überwachung - des »zwingenden Blicks« (Foucault 1998: 221) -, der sanktionierenden Kontrolle sowie der Prüfung als Techniken, die moderne Gesellschaften und eben jene disziplinierende Macht auszeichnen. "Zusammenfassend kann man sagen, daß die Disziplin mit ihrer Körperkontrolle vier Typen von Individualität oder vielmehr eine Individualität mit vier Merkmalen produziert: diese Individualität ist zellenförmig (aufgrund der räumlichen Parzellierung); sie ist organisch (dank der Codierung der Tätigkeiten); sie ist evolutiv (aufgrund der Zeithäufung); sie ist kombinatorisch (durch Zusammensetzung der Kräfte). Um das zu erreichen setzt die Disziplin vier große Techniken ein: sie konstruiert Tableaus; sie schreibt Mannöver vor; sie setzt Übungen an; und um das Zusammenspiel zu gewährleisten, ordnet sie >Taktiken` an.« (Foucault 1998: 216)

Techniken der Körperdisziplinierung finden sich zwar auch schon zu früheren Zeiten (beispielsweise die religiöse Askese oder die Sklaverei), doch unterschieden sie sich in ihren Mitteln und Wirkungsweisen (vgl. auch Treiber/Steinert 2005). Mit dem Anwachsen der Bevölkerung und der Herausbildung kapitalistischer Industriegesellschaften etablierte sich die Disziplinarmacht, in deren Zentrum weniger bloße Unterwerfungsmechanismen stehen, sondern Gefügigkeit und Nützlichkeit miteinander einhergehen. Gefragt sind damit »gelehrige Körper«. Heinz Steinert bringt dies folgendermaßen auf den Punkt: »Der zentrale Punkt ist hier, daß Disziplinarzwang kein einfach unterdrückender Zwang ist, sondern einer, in dem die Subjekte des Zwangs nützlich gemacht werden. Die Disziplin ist nicht in erster Linie darauf gerichtet, bestimmte Aktivitäten zu verhindern und zu unterdrücken, sondern sie führt

2 Hubert Treiber und Heinz Steinert kritisieren daran, dass dies insofern irreführend sei, als Foucaults Analysen vor allem die Verwaltungsperspektive in den Blick nehme, womit Foucault »ahistorischen Idealismus« (2005: 90) produziere. Ihre Kritik basiert auf einem Diskursverständnis, welches Diskurse als einheitliche Ereignisse begreift, die nicht differenziert und unterschiedlich folgenreich gedacht würden und letztlich auch Herrschaft nicht einbeziehen würden (ebd.: 89; Steinert 1993: 245). 
dazu, daß bestimmte Aktivitäten hervorgebracht werden.« (Steinert 1993: 241; Herv. i. O.) Die Produktivität der Disziplinartechniken hat entscheidend damit zu tun, dass sich die machtvollen Praktiken bis in die kleinsten Bereiche des Körpers erstrecken. Foucault spricht daher von einer »politische[n] Anatomie des Details« (Foucault 1998: 178).

\section{Eine Analytik der Macht}

Michel Foucault entwickelt die Konzeption der produktiven Macht als Analyseperspektive, die es erlaubt, diskontinuierliche Prozesse historischer (und gegenwärtiger) Machtpraktiken sowie -verhältnisse in den Blick zu nehmen. Somit geht es ihm weniger um die Frage, was Macht ist, als um die Frage, wie sie ausgeübt wird und wirkt (Foucault 1987: 243). Foucault macht eine Transformation der Machtpraktiken seit dem 17. Jahrhundert aus: vom Souverän zu den Disziplinartechnologien mit ihren spezifischen oben angesprochenen Macht-Wissen-Komplexen, deren Angriffspunkt vor allem der Körper als unterworfener und produktiver ist (Foucault 2000). Er schlägt einen strategischen Machtbegriff vor, der von einem komplexen Geflecht von Machtbeziehungen und Kämpfen ausgeht und nicht in Personen oder Institutionen seinen Ausgangspunkt hat: »Diese Macht ist nicht so sehr etwas, was jemand besitzt, sondern vielmehr etwas, was sich entfaltet; nicht so sehr das erworbene oder bewahrte >Privileg $<$ der herrschenden Klasse, sondern vielmehr die Gesamtwirkung ihrer strategischen Positionen - eine Wirkung, welche durch die Positionierung der Beherrschten offenbart und gelegentlich erneuert wird.« (Foucault 1998: 38) Ihre Produktivität und zugleich individualisierenden wie homogenisierenden Effekte erlangt »die« Macht weniger durch Repression und Verbote als durch das Prinzip der Normierung (vgl. auch Seier 2001: 100). Als Beispiel sei das Modell des Panopticon genannt (Foucault 1998: 251ff.): ein architektonisch ausgeklügeltes System, welches die Individuen zur Selbstbeobachtung anhält, da die Gefangenen in ihren ringförmig um den zentralen Beobachtungsturm angeordneten Zellen potenziell jeden Moment überwacht werden könnten, selbst jedoch nicht sehen, ob dies gerade geschieht. Sie müssen jederzeit damit rechnen, dass sie beobachtet werden könnten, was zu einem spezifischen Selbstverhältnis des potenziell beobachteten Individuums führt. In diesem Sinne ist die Anlage ein Modell für moderne Gesellschaften und Sicherheitstechnologien.

Über den Typus der Disziplinarmacht hinaus, der hier vor allem aufgrund seiner Ausrichtung auf den Körper relevant ist und gerade in der Institution Schule nach wie vor seine Spuren hinterlässt (vgl. Rumpf 1981: 69), zeichnet sich Macht insbesondere innerhalb der liberalen Regierungsform durch ein 
neues Verständnis von Freiheit aus. Es geht nicht darum, das Disziplinarindividuum vollständig zu unterwerfen (vgl. Rieger-Ladich 2004: 209), wie Foucault häufig gelesen wird, vielmehr ist >Freiheit` als konstitutives Element von Machtverhältnissen zu begreifen. Allerdings »nicht als Zustand, sondern als Praktik«, wie Julia Franz (2005: 28) schreibt. Foucault begreift Machtpraktiken als Handlungen auf Handlungen. Sie wirken also nicht unmittelbar und direkt auf andere Subjekte, sondern auf deren gegenwärtiges und künftiges bzw. mögliches Handeln. Macht sei »ein Ensemble von Handlungen in Hinsicht auf mögliche Handlungen; sie operiert auf dem Möglichkeitsfeld, in das sich das Verhalten der handelnden Subjekte eingeschrieben hat: sie stachelt an, gibt ein, lenkt ab, erleichtert oder erschwert, erweitert oder begrenzt, macht mehr oder weniger wahrscheinlich; im Grenzfall nötigt oder verhindert sie vollständig; aber stets handelt es sich um eine Weise des Einwirkens auf ein oder mehrere handelnde Subjekte, und dies, sofern sie handeln oder zum Handeln fähig sind. Ein Handeln auf Handlungen« (Foucault 1987: 255). In Abgrenzung zu einem Gewaltverhältnis (z. B. der Sklaverei) bleibt in Machtverhältnissen der andere als Subjekt des Handelns anerkannt und es gibt ein Feld möglicher Wirkungen und Reaktionen. So verstanden entsteht ein Moment von Freiheit, indem Macht auch gegen sich selbst gewendet werden kann, was sich mit der Einführung des Begriffs der Selbstsorge bzw. der Selbsttechnologien im Folgenden noch einmal präzisiert.

\section{Selbstverhältnisse - Technologien des Selbst}

Foucault formuliert als ein Ziel seiner Arbeiten, »eine Geschichte der Wege zu skizzieren, auf denen Menschen in unserer Kultur Wissen über sich selbst erwerben« (Foucault 1993: 26). Ihm geht es nicht um den Wahrheitsgehalt dieses Wissens, sondern um darüber stattfindende »Wahrheitsspiele« (ebd.; Foucault 1989: 13), um Techniken dieses Verstehens seiner selbst. Einen Typ solcher Praktiken nennt er »Technologien des Selbst«. Sie stehen in Beziehung zu weiteren Technologien: der Produktion von Dingen, des Umgangs mit Zeichen und Symbolen sowie der Macht. Die Entwicklung solcher Selbsttechniken untersucht er in der Kultur der Antike. Zwei Maximen stehen dabei in einem sich über mehrere Jahrhunderte transformierenden Verhältnis zueinander: die Vorschrift, auf sich selbst zu achten, sich um sich selbst zu kümmern und zu sorgen sowie das Gebot, sich selbst zu erkennen (Foucault 1993: 28). Diese Grundsätze waren keine abstrakten Prinzipien einer Lebensführung, sondern umfassten Praktiken der Selbstbeobachtung, der Meditation, der Exzerzitien sowie asketischer Übungen, mit denen man sich selbst ausführt und modifiziert. Das Delphische Orakel »Erkenne dich selbst« war, so Foucault, in der antiken griechi- 
schen Kultur zunächst untergeordnet und nur ein Moment umfassender Sorge um sich. In der sich herausbildenden christlichen Moraltradition trat der erkennende Moment in den Vordergrund: als Weg zur Selbstlosigkeit. Die unterschiedlichen Formen der Sorge haben demnach verschiedene Formen des Selbst zur Folge (ebd.: 31).

Foucault begreift die Technologien des Selbst als Praktiken, »die es dem Einzelnen ermöglichen, aus eigener Kraft oder mit Hilfe anderer eine Reihe von Optionen an seinem Körper oder seiner Seele, seinem Denken, seinem Verhalten und seiner Existenzweise vorzunehmen, mit dem Ziel, sich so zu verändern, daß er einen gewissen Zustand des Glücks, der Reinheit, der Weisheit, der Vollkommenheit oder der Unsterblichkeit erlangt« (Foucault 1993: 26). Die antiken Selbstpraktiken beziehen sich auf ein gelungenes Leben. Einher gehen damit Fragen zum politischen Handeln und zur Erziehung (vgl. Foucault 1996a: 93), denn zu einer solchen Selbstführung muss $\operatorname{man}^{3}$ durch Lehrer und Meister, die ebenfalls fähig sind, sich selbst zu führen, befähigt werden. Selbst- und Herrschaftspraktiken sind miteinander verknüpft. Diese Beziehungen zwischen Technologien, andere zu beherrschen bzw. zu führen, und Formen, in denen das Individuum auf sich selbst einwirkt, sind für Foucault von zentraler Bedeutung (Foucault 1993: 27). Dessen Hinwendung zu antiken Selbstpraktiken und den daraus resultierenden Verhältnissen zu sich selbst ist so nicht als Revision seiner Subjektkritik, wie sein Spätwerk vielfach rezipiert wurde (vgl. Horn 2001: 138), sondern innerhalb einer Analytik der Macht bzw. der Gouvernementalität ${ }^{4}$

3 Dass dieses »man(n)« nicht die Allgemeinheit betraf, wird bereits in der Aufführung der Dimensionen im dritten Band von »Sexualität und Wahrheit« mit dem Titel »Sorge um sich" deutlich. Die antike Moral der Selbstbeherrschung bezog sich als Problem einer kleinen gesellschaftlichen Elite »ausschließlich auf das Individuum, das Herr seiner selber und Herr des anderen sein muß, aber nicht auf jenes, das anderen gehorchen muß (Foucault 1985: 160).

4 In (etwas gewagter) Kürze ließe sich Gouvernementalité mit »Regierungsmentalität« übersetzen. Eine kritische Auseinandersetzung mit dem Begriff und seiner Rezeption findet sich bei Cornelis Horlacher (2005, 2007). Zu erwähnen sind in diesem Zusammenhang die sog. Governmentality Studies, die seit den 1990er Jahren an Foucaults Konzept der Gouvernementalität anschließen, wobei zunächst im englischen und französischen Sprachraum Formen des Regierens untersucht wurden. In den letzten Jahren wurde der interdisziplinäre Ansatz auch in Deutschland aufgegriffen. Ein Überblick über diese Entwicklung findet sich bei Ramón Reichert (2004: 11ff.). Meist werden Regierungsprogrammatiken in bestimmten gesellschaftlichen Bereichen untersucht. Den Arbeiten, die im Anschluss an Foucault entstanden sind, ist die Präferenz für Gegenwartsanalysen gemeinsam. Das unterscheidet sie vom Foucaultschen Fokus auf historische Analysen. Zwar ist sein genealogisches Verfahren im Herausarbeiten von Bedingungsund Möglichkeitsstrukturen gesellschaftlichen Handelns sehr produktiv, aber es birgt das Risiko, die historisch etablierten Machtpraktiken und Herrschaftsverhältnisse eines bestimmten Zeitraums mit gegenwärtigen vorschnell gleichzusetzen. 
zu verstehen. Nikolas Rose formuliert treffend: »Macht arbeitet durch, nicht gegen Subjektivität« (Rose 2000: 9).

Im Fokus steht das komplexe Zusammenspiel von Wissensformen, Machtstrategien und Praktiken der Selbstformierung. Zentral ist hier der Begriff der Regierung. Diesen fasst Foucault folgendermaßen: »Unter Regierung verstehe ich die Gesamtheit der Institutionen und Praktiken, mittels derer man die Menschen lenkt, von der Verwaltung bis zur Erziehung« (Foucault 1996b: 118). ${ }^{5}$ D. h. es geht um eine Analytik der Entwicklung von Technologien der Einflussnahme, der Produktion von Wissen, der Disziplinierung von Individuen und der Konstitution von Subjektivitäten, welche Grundlage und Mittel der Machtverhältnisse moderner Gesellschaften bilden. Der Modus der Regierung zielt nicht nur auf die direkte Steuerung von Handlungen individueller oder kollektiver Akteure, sondern ebenso auf die Art und Weise, wie diese ihr Verhalten selbst regieren. Er umfasst Formen der Selbst- sowie der Fremdführung, also des Führens von Führungen (Foucault 1987: 256; Lemke 2004a: 63). Pädagogische Prozesse und Vorstellungen von pädagogischen Prozessen zeichnen sich durch jeweils spezifische Verhältnisse von Fremd- und Selbstführung aus, wie sich auch in der Analyse (pädagogischer) Körperpraktiken und der Problematisierung von Körper(lichkeit) in Bezug auf Schule und pädagogisches Arbeiten zeigen wird. Käte Meyer-Drawe (1996) plädiert dafür, dass gerade die Erziehungswissenschaft die Transformationen der Macht kenntlich machen sollte. Es ginge »um die >Wahrheitsspiele auf der Grundlage spezieller Techniken spielen, um sich selbst zu verstehen, also um die Verbindung der >Technologien der Herrschaft $<$ mit den Kontrollpraktiken des Selbst« (Meyer-Drawe 1996: 662).

Foucaults Beschäftigung mit diesem Typus von Praktiken hat verallgemeinerbare Dimensionen, auch wenn er einen historisch sehr weit zurückliegenden Zeitraum in den Blick nimmt. Sie implizieren eine Beschäftigung mit sich selbst und zielen auf eine Transformation des Selbst. Als reflexive Praktiken umfassen sie eine Haltung sowie Handlungsweisen sich selbst und der Welt gegenüber, die über die Erkenntnis seiner selbst hinausgehen. Diese sind institutionalisiert und vielfach als pädagogische Beziehungen konstituiert. Auch wenn sich diese Praktiken auf sich selbst beziehen, sind sie doch nicht

5 Foucault entwickelte den Begriff zunächst im Kontext von Untersuchungen in der Renaissance und der frühen Aufklärung, wo er eine Vervielfältigung von Regierungskünsten beobachtete. Die uneinheitliche Verwendung des Begriffs sowie die mangelnde historische und analytische Abgrenzung verschiedener Regierungsmechanismen kritisiert Thomas Lemke (2000: 33a). Agnieszka Dzierzbicka (2006: 48) weist auf die Differenzierung der beiden Begriffe hin: Während Gouvernementalität das strategische Feld sich stets in Bewegung befindender Machtverhältnisse definiert, werde Regierung durch dieses Feld bestimmt. 
individuell, sondern als soziale Praktiken im Rahmen gesellschaftlicher Formationen und Machtverhältnisse zu verstehen (vgl. Wrana 2006: 30).

\section{Diskursive Körper?}

Die Reihe der Begriffsbestimmungen möchte ich abschließen, indem ich nun noch einmal nach Foucaults Körperverständnis frage und Konzepte vorstelle, die dies einerseits hinterfragen und andererseits um eine leibliche Dimension erweitern. In »Überwachen und Strafen« zeigt Foucault, dass der zentrale Ansatzpunkt für bestimmte (historische bzw. zu historisierende) Machttechniken, nämlich die der Disziplin, der Körper ist. Der gesellschaftliche Stellenwert des Körpers ändert sich, wie Foucault anhand der Strafpraktiken zeigt: Während im französischen Absolutismus grausame Martern öffentlich die Macht des Souveräns demonstrierten, ziel(t)en humanistische Formen der Bestrafung, insbesondere das Einsperren in Gefängnisse, und damit verbundene Wissenschaften - über den Körper - auf die Seele des Delinquenten (Foucault 1989: 41). Diese Idee, wie Körper und »Seele « zusammenwirken ${ }^{6}$, ist eine Ebene des mit der Disziplin verknüpften und damit historisierten Körperkonzepts. Eine weitere ist die der Nützlichkeit: Die beschriebenen Technologien setzen an einem produktiven, effektiven und nützlichen Körper an, sie normieren und individualisieren ihn gleichzeitig. Diese Vorstellungen vom Körper ergeben sich aus der Analyse, und zwar aus einer spezifischen Weise der Analyse und Methodologie: die Analyse der diskursiven Praktiken und ihre Einbindung in bzw. Durchzogenheit von Institutionen. Sie geht von einem »diskursiven Körper« aus, insofern der Körper als materialisierter, die Vorstellungen von ihm, der Umgang mit ihm, Produkt dieser Praktiken ist. Von Macht durchzogene ebenso wie Macht produzierende diskursive Praktiken »bringen wahre Körper, authentische Selbste erst hervor« (Lorey 1999: 95).

Eine solche Sicht auf den Körper stößt immer wieder auf Kritik. Eine Frage, die die Debatte zu den Begriffen »Körper« und »Leib« unter anderem ausmacht, ist die nach jener Materialisierung. Wenn denn Körper sozial konstruiert sind, von Diskursen durchzogen, was ist dann mit dem, was da zu spüren und zu berühren ist? Was für Effekte haben Diskurse bzw. diskursive Prakti-

6 »Eine Seele` wohnt in ihm [dem Menschen, A. L.] und schafft ihm eine Existenz, die selber ein Stück der Herrschaft ist, welche die Macht über den Körper ausübt. Die Seele: Effekt und Instrument einer politischen Anatomie. Die Seele: Gefängnis des Körpers. « (Foucault 1998: 42) Zum Verhältnis von Körper und Seele siehe auch Butler (1991: 198f.), zum Begriff in der im weitesten Sinne pädagogischen Tradition Höhne (2003b: 245-249) sowie die kritische Diskussion zu Foucaults Verständnis von Seele bei Schäfer (2004). 
ken, wie stehen sie zur Materialität des Leibes? Eine Kritik von Robert Gugutzer veranschaulicht das Problem:

»Was Foucault analysiert, ist ausschließlich das Reden über Körper, das Wissen vom Körper, nicht aber der Körper als Materialität oder eigenleibliche Erfahrung. Foucault untersucht nicht den Körper, sondern Diskurse über Körper.« (Gugutzer 2004: 81) Und weiter: »Foucaultianer würden dem entgegenhalten, es gibt keine vordiskursive Materialität und Erfahrung, weshalb es angemessen sei, die Diskurse zu untersuchen, die den materiellen und phänomenalen Körper hervorbringen. Dieser Diskursdeterminismus ist jedoch kritisch zu hinterfragen." Empfindungen seien nicht einfach in Diskurse auflösbar. Das sind sie auch nicht. Doch warum sollten sie es sein? »Körper und Leib sind nicht allein diskursive Konstruktionen, sondern besitzen ein Handlungspotenzial, das auf Diskurse rückwirken, sie initiieren und Strukturen verändern kann.« (ebd.) Auf einer solchen abstrakten Ebene formuliert, ist der Kritik nur zuzustimmen, aber auch der möglichen Entgegenhaltung. Diese doppelt mögliche Zustimmung ist Effekt einer Praxis der Unterscheidung diskursiver und nicht-diskursiver Praktiken, die auf eine Gegenüberstellung von Sprechen und Handeln rekurriert. Indem Sprechen und Handeln gegenübergestellt werden, setzt sich auch der Dualismus von Geist und Körper fort. Körper besitzen durchaus ein Handlungspotential, wie Gugutzer es proklamiert, doch über das Individuum hinaus wirksam wird es dann, wenn es in diskursive Praktiken eingeht.

In den letzten Jahren sind einige Arbeiten erschienen, in denen ein Körperbegriff erarbeitet wird, der die Dimension des leiblichen Erlebens stärker einbindet, in denen der Körper aber dennoch als sozial konstruierte Einheit begriffen wird (Gugutzer 2002; Jäger 2004; Ludewig 2002; Macha 2003; Schaufler 2002). Während das Wissen vom vergesellschafteten Körper offenbar eine wachsende Anerkennung genießt, wird nun gefragt, inwiefern man bei leiblichen Empfindungen und Erfahrungen davon sprechen kann, dass sie sozial erzeugt sind. Damit geht die Frage einher, wie der historisch gewordene und gesellschaftlich geprägte Körper eben als leiblicher und materieller theoretisch gedacht werden kann, ohne ihn damit zugleich wieder zu naturalisieren. Insbesondere bei Karin Ludewig (2002) und Hildegard Macha (2003) wird dabei deutlich, wie schwierig ein solches Vorhaben ist, solange die Dualismen dieses Denkens (Körper - Geist, Natur - Kultur etc.) bestehen bleiben $^{7}$, da innerhalb derer eine naturgebundene Leiblichkeit immer der Kultur

7 Wenn auch die Autorinnen durchaus erwägen, die Dualismen aufzugeben (vgl. Macha/Fahrenwald 2003: 36). Das Dilemma, in diesen Dichotomien (Natur/ Körper/Materie vs. Kultur/Geist/Bewusstsein) »gefangen« zu sein bzw. die ständige Gefahr des »Kippens«, die sich daraus ergibt, und die somit prekäre Gratwanderung stellt Andrea Maihofer (1995: 74ff.) gut nachvollziehbar dar. 
gegenüber gestellt wird. Auch mit dem Versuch, Natur neu zu definieren »als materielle körperliche Basis des Sozialen und der Erkenntnis, [...] beides [...] stets geschlechtstypisch gefärbt« (Macha 2003: 189), bleibt genau jene natürliche Vorgängigkeit (von Körper und Geschlecht) bestehen. Das dichotome Denken setzt sich dann in der Gegenüberstellung von voneinander unabhängig erscheinenden Diskursen und Erleben fort:

"Leibgebundene Erfahrungs- und Erlebnisweisen sind stets durch kulturelle Inszenierungen von Geschlecht beeinflusst, aber gleichzeitig nicht nur diskursiv, sondern ganz individuell körperlich erlebt und konstruiert. Körpererfahrung geht weit über diskursive Praktiken von Geschlechtsidentität hinaus. Zwischen Naturalisierung des Geschlechts und Diskursivität der Körper gibt es noch das unmittelbare körperlichsinnliche Erleben aus dem Körper, das erst in der Diskursivität und Begrifflichkeit zur Inkarnation kulturell geformter Geschlechterbilder wird.« (ebd.)

Es spricht nichts dagegen, letzteres gerade auch wegen der langen De-Thematisierung hervorzuheben. Aber wird mit solch einer Abstufung nicht eine bestimmte Beschaffenheit des Körpers, die an sich selbst schon historisch geworden ist, als natürlich unterstellt (vgl. Wulf 2003: 207)? Gesellschaftliche Diskurse und damit verknüpfte Normen materialisieren sich im Körper fühlbar. So verändert die »Dominanz des Auges« (Herzog 1985: 278) - also die Priorität des Visuellen, welche nicht schon immer besteht, sondern sich historisch entwickelte - auch die Wahrnehmungsweisen hin zu einer vornehmlich visuell ausgeprägten Sinnlichkeit. Oder die derzeit (unter anderem gerade deshalb) viel diskutierten Gentechnologien transformieren sowohl das Körperverständnis als auch den Körper selbst (vgl. Lemke 2006). In historischen Studien wird deutlich, wie durch das Aufkommen naturwissenschaftlicher Begriffe das Empfinden und Spüren der bezeichneten Körperstellen erst möglich wurde (vgl. Duden 1987; Laqueur 1992). Was jeweils als »Natur« konstituiert wurde, ist dabei Ergebnis geschichtlicher Prozesse und Kämpfe.

In der deutschen Sprache kann zwischen Körper und Leib unterschieden werden. Sprachgeschichtlich lässt sich das Wort Leib auf lib (althochdeutsch: Leben, Lebensweisen bzw. seit dem 11. Jh. lip: bleiben, leben) zurückführen. Das Wort Körper geht auf corpus (lat.) in der Bedeutung von Leib, Gestalt sowie Fleisch zurück und ist in vielen Sprachen als einzige Form erhalten geblieben (vgl. ausführlicher Lorenz 2000: 33f.). Insbesondere in der phänomenologischen Tradition wird die Unterscheidung von Körper und Leib genutzt und diskutiert. Die Grundannahme dabei ist, dass der Körper durch eine doppelte Gegebenheit charakterisiert sei: einmal im Sinne eines Objekts und einmal als der eigene gelebte Körper. Diese Unterscheidung ermöglicht einerseits den Blick auf verschiedene den »Körper« betreffende Phänomene, sie legt 
aber andererseits auch die von mir kritisierte dichotome Setzung nahe. Und zwar deshalb, weil damit zwar (zumindest in der Auseinandersetzung mit den verschiedenen Leib-TheoretikerInnen) oft eine Einheit zwischen beiden hergestellt wird, diese aber als Komplementarität - Körper und Leib als zwei Seiten einer Medaille - gedacht wird (vgl. Gutzter 2004: 146) ${ }^{8}$. Die Betonung des Leiblichen ermöglicht auch eine Betonung der Materialität und der Prozesse, die sich eben auf der Ebene des Spürens abspielen. Denn das Besondere des Leibes ist seine Unmittelbarkeit und, so Pierre Bourdieu, »was der Leib gelernt hat, das besitzt man nicht, wie ein wiederbetrachtbares Wissen, sondern das ist man (Bourdieu 1987: 135; Herv. A. L.). Diese Setzung ist dem Subjekt nicht unmittelbar transparent, sondern bestenfalls in Praktiken reflexiv. Der Körper (und damit auch das Geschlecht) wird, wie Maihofer es nennt, zur »Existenzweise « (Maihofer 1995), das kulturell, sozial und historisch Entstandene als »individuell affektive Wirklichkeit« (Tuider 2003: 57) empfunden.

Ein theoretisches Konzept, welches Foucaults Analysen aufnimmt und in Kritik und Erweiterung eine Verschränkung von Körperwissen und Leiberfahrung vornimmt, stammt von Ulle Jäger (2004). Sie schließt an das HabitusKonzept von Bourdieu an und verknüpft es sowohl mit den Körperkonzepten von Butler und Foucault als auch mit anthropologischen Leib-Theorien von Schmitz und Plessner. Hier vollzieht sie einen Schritt, den Ludewig (2002) ebenfalls im Anschluss an eine Kritik an Butler und Foucault zwar auch unternimmt, aber theoretisch nicht derart untermauert. Ziel ist, Emotionen, Empfindungen und leibliche Regungen in sozialwissenschaftliche Untersuchungen zum Körper einzubeziehen, ohne jedoch einen natürlichen Leib vorauszusetzen. Jäger begründet die Hereinnahme der Leibperspektive machttheoretisch: Wenn Macht-Wissens-Verhältnisse auf den Körper einwirken, stellt sich die Frage, wie es auf körperlicher Ebene zu Verfestigungen und unhintergehbaren Körperwahrnehmungen kommt, wie Macht gerade auf der Ebene des Leibes wirksam wird (ebd.: 17). Damit geht sie jene Kritik an, die Gugutzer vorgebracht hat. Sie begreift den Körper als verobjektivierten, als ein Körperwissen, während der Begriff Leib für den (eigenen) gelebten Körper steht und das Selbst umfasst (Jäger 2004: 49). Mit der Veränderung von Diskursen bzw. diskursiven Praktiken verändert sich auch der Gegenstand Körper. Zu überprüfen sei mit Blick auf Foucault und Butler, inwiefern das Räumliche (und damit Leibliche) der Materialität bei der Vorstellung diskursiver Materialisierung ausgenommen wird bzw. mitgedacht werden kann (Jäger 2004: 13). Dazu ist es notwendig, sich mit dem Begriff der Materialităt als Materialisie-

8 Die wichtigsten Unterscheidungsmerkmale der Begriffe Leib und Körper hat Gugutzer (2004: 152ff.) aufgeführt. 
rung bei Judith Butler vertraut zu machen, auf den Jäger sich bezieht und der für mein Verständnis von Körper und diskursiven Praktiken bedeutsam ist.

Butler stellt eine vorgängige Materialität des Körpers radikal in Frage. Sie erscheine zwar als natürliche, dies sei aber ein Machteffekt. Dementsprechend kritisiert sie auch die Unterscheidung von sex und gender. An die Stelle einer Materie als materiellen Substanz, Ort oder Oberfläche setzt Butler den Begriff der »Materialisierung«. Materialisierung heißt, die Materialität des Körpers wird gewissermaßen im Einüben und in den wahrnehmenden Reaktionen anderer hergestellt und so zu einem Effekt diskursiver Praktiken. Sie beschreibt dies als »Prozeß der Materialisierung, der im Laufe der Zeit stabil wird, so dass sich die Wirkung von Begrenzung, von Festigkeit und Oberfläche herstellt, den wir als Materie nennen« (Butler 1995: 32). Materialisierung verweist auf die unauflösbare Verschränkung von Diskurs und Materie, d. h. es gibt keine von Diskursen unberührte Materialität. Hannelore Bublitz schreibt in ihrer Einführung in Butlers Werk: »Die Annahme, dass Körper durch Diskurse und performative Sprechakte erzeugt werden, bedeutet jedoch nicht, dass Körper als materielle Realität vollständig auf Diskurse zurückzuführen sind; lediglich, dass es keine von der symbolischen Ordnung unberührte körperliche Materialität gibt. Diskursive Praktiken und körperliche Materialität verbinden sich als unauflösliche Einheit, deren Voraussetzung Diskurse als Apriori körperlicher Materialität bilden.« (Bublitz 2002: 40f.) Butler wird immer wieder (nicht nur, aber insbesondere von ihren KritikerInnen) so gelesen, als gäbe es keine materiellen Körper, als löse sie diese prinzipiell auf (z. B. Duden 1993; Lorey 1995; Maihofer 1995), ebenso wie sie es eben auch nicht außerhalb von Diskursen gäbe (Gugutzer 2004: 178). Auch wenn sich einige Stellen so interpretieren lassen, geht es Butler doch vor allem darum, dass die Materie des Körpers nicht von regulierenden Normen bzw. diskursiven Praktiken zu trennen sei. ${ }^{9}$

Ulle Jägers Kritik ist nun, dass einerseits die Räumlichkeit (Jäger 2004: 70f.) sowie der Leib als wahrnehmender (ebd.: 75) von Butler nicht bedacht werde. Phänomenologische Leibtheorien seien jedoch anschlussfähig, da sich einige Stellen bei Butler fänden, an denen der Begriff des Leibes über einen diskursiv erzeugten hinausgehe, indem sie mit Bezug auf Simone de Beauvoir den Leib als Situation denke, der nicht dasselbe sei wie der Kontext, in dem er steht, der Kontext aber auch nicht dem gelebtem Körper äußerlich sei (vgl. Jäger: 2004: 73f.). Der Begriff des Leibes, welcher auf einen Eigensinn verwei-

9 Entscheidend ist meines Erachtens der Hinweis von Butler: »Den Körper als konstruierten Körper zu denken verlangt, die Bedeutung von Konstruktionen selbst neu zu denken. « (Butler 1995: 16) Was dies heißen kann, erörtere ich in den Abschnitten zur Diskurstheorie (besonders Kap. >Diskurstheoretische Annahmen(). 
se, so Jäger, mache erst plausibel, wie eben jene diskursiven Effekte möglich sind und Macht wirksam wird, aber auch, dass der Leib selbst »Ort des Widerstands« sein kann (ebd.: 81). »Die Perspektive des Leibes wäre in diesem Sinne als ein weiterer Diskurs zu betrachten, nicht als Eigentlichkeit, Grundlage, vorgängiges Etwas, sondern als besondere Form von Materialität, die sich auch durch räumliche Ausdehnung auszeichnet, die für das Selbst erfahrund spürbar ist.« (ebd.) Jäger prägt den Begriff »körperlicher Leib«, um die Trennung zwischen Körper und Leib begrifflich zu überwinden und die Einheit bzw. Verschränktheit sowie die gesellschaftliche Konstituiertheit deutlich zu machen. ${ }^{10}$

Das verschränkte Verhältnis von Körper und Leib kann auf einer abstrakten philosophischen bzw. soziologischen Ebene durchaus so gedacht werden. Gugutzer weist in seiner Einführung zur »Soziologie des Körpers« (2004) zurecht darauf hin, dass die analytische Trennung, die sich auf die "Zweiheit des Körpers als Einheit von spürbarem Leibsein und gegenständlichem Körperhaben« (ebd., 152; Herv. i. O.) bezieht, eine zu heuristischen Zwecken sei und keine ontologische (sein dürfe). ${ }^{11}$ In der empirischen Forschung, so Christoph Wulf (2003: 214), könne man sich dem Körper allerdings immer nur annähern und jeweils nur bestimmte Aspekte untersuchen. Das zeigt sich im Weiteren auch daran, dass Körper und Leib zwar an Erziehungs-, Bildungsund Subjektivierungsprozessen permanent beteiligt sind, sich aber nicht von ihnen isolieren lassen. D. h. man kann das, was Körper jeweils ist, nicht jenseits gesellschaftlicher Körper-Praktiken begreifen. Letztendlich ist es auch vom Forschungsgegenstand abhängig, inwiefern eine Unterscheidung von Körper und Leib als analytische wichtig ist, um bestimmte Fragen und Ebe-

10 Auch Birgit Schaufler (2002) nimmt eine solche Neuschöpfung vor, indem sie vom »Leib-Körper « spricht, allerdings mit anderer Betonung. Dies auch deshalb, weil sie von anthropologischen Traditionen ausgeht, die sie mit psychoanalytischen sowie kognitionspsychologischen Theorien und knapp mit Elias und Foucault ergänzt, um dann zentrale Dimensionen von Leib-Erfahrungen auf somatogener, soziogener und psychogener Ebene zu formulieren (vgl. Schaufler 2002: 73ff.) und leib-körperliche Existenz zu beschreiben. Die gemeinsame Verwendung der beiden Wörter, um die Verschränkung von Körper und Leib darzustellen, hat Helmuth Plessner bereits 1928 vorgeschlagen (Plessner 1975). Die Zusammenführung kann aber sehr unterschiedlich akzentuiert sein, wie sich zeigt. Systematisierende Übersichten über diese Debatte finden sich bei Macha/ Fahrenwald (2003) oder Gugutzer (2004).

11 Analog dem »Werdegang« der feministischen Geschlechterforschung und der jeweils in bestimmten Phasen stattfindenden Betonung von Differenz bzw. Gleichheit, die sich als Teil eines politischen und damit auch strategischen Einsatzes verstehen lässt, muss bezogen auf die Thematisierung des Körpers zunächst eine besondere Problematisierung erfolgen, die den Leib gegenüber dem Geist stark macht, soll es nicht nur um eine esoterische, mit allerlei Assoziationen anfüllbare Ganzheitlichkeit gehen. 
nen überhaupt untersuchen zu können. In meiner Arbeit ist sie für die Anlage der Untersuchung nicht relevant, weil ich nach der Ebene individueller leiblicher Wahrnehmung nicht frage und sie als analytische Kategorie nicht zu meinem Instrumentarium gehört. Relevant wird sie jedoch dann, wenn in einigen Texten mit beiden Begriffen bzw. ihrer Unterscheidung operiert wird, sie für verschiedene Zwecke genutzt und funktionalisiert werden. An diesen Stellen wird die Differenz selbst zum Untersuchungsgegenstand.

Die vorangegangenen Ausführungen durchzieht ein Spannungsfeld zwischen Leib/Körper und Natur/Kultur, welches als solches nicht gänzlich aufzulösen ist, weiterhin für Diskussionen sorgen wird, in dieser Arbeit aber nicht im Zentrum stehen soll. Ich habe meine Arbeit aus diskursanalytischer Perspektive konzipiert, was impliziert, von diskursiven Körpern zu sprechen, mit denen spezifische Körperpraktiken einhergehen. »Wenn man dem performativen Charakter der körperlichen Identität folgt, könnte man den Körper mehr in Richtung einer stabilen und zugleich instabilen Körperpraxis verstehen. Eine Praxis, die nicht individuell ist, aber individuell gelebt wird.« (Müller 2000: 101). Im Folgenden wird weiter zu klären sein, was es bedeutet, von >diskursiven Körpern zu sprechen und welche theoretischen Konzepte dem zugrunde liegen. Ich steuere dabei vor allem jene Begriffe an, die für die nachfolgende Analyse der Problematisierung des Körpers und des Umgangs mit dem Körper innerhalb von Schule relevant sind. Dabei wird vielleicht auch Butlers Verständnis von Materialisierung noch einmal nachvollziehbarer. Zunächst möchte ich aber die Perspektive auf den Körper um einen weiteren theoretischen bzw. analytischen Zugang erweitern, der in der bisherigen Debatte über einen angemessenen Begriff außen vor blieb und besonders für den ethnographisch-feldforschenden Teil der Untersuchung relevant ist: der Körper in Interaktionsprozessen.

\section{Körper in Interaktion}

Eine weitere theoretische Perspektive ist für bestimmte (mikrosoziologische) Ausschnitte der Analyse von Körperpraktiken von großem Wert: die »Interaktionsordnung « von Erving Goffman. »Interaktionsordnung « hört sich nach einem starren Begriff an - Goffman umfasst damit so etwas wie ein Programm, dem er mit seinen Forschungen und theoretischen Konzepten nachgeht, um soziale Interaktionen als eigenständigen Gegenstand soziologischer Forschung zu etablieren (Goffman 1994: 55; vgl. auch Lenz 1991: 27-48; Knoblauch 1994: 7ff.; Willems 1997: 27ff.). Interaktion meint »Face-to-face-Interaktion«: die unmittelbare Interaktion, wenn Menschen es von Angesicht zu Angesicht miteinander zu tun haben, aufeinander treffen (Goffman 1994: 55). 
Goffman geht es dabei weniger um die sprachliche Kommunikation, wie sie die Konversationsanalyse in Augenschein nimmt, als vielmehr um vielfältige kontextabhängige Praktiken, bei denen Körper entscheidende Partizipanden sind. ${ }^{12}$ Er entwickelt keine explizite Körpertheorie, allerdings zeigt sich in seinen Analysen und anhand seiner Modelle, welche Bedeutung körperlicher Präsenz als integraler Bestandteil sozialen Handelns zukommt. Denn wesentlich sei, dass die Handelnden »deutlich das Gefühl haben, dass sie einander nahe genug sind, um sich gegenseitig wahrzunehmen bei allem, was sie tun, einschließlich ihrer Erfahrung der anderen, und nahe genug auch, um wahrgenommen zu werden als solche, die fühlen, dass sie wahrgenommen werden« (Goffman 1971: 28).

In der Begegnung treffen zuallererst zwei (oder mehrere) Körper aufeinander. Relevant wird dabei ein - explizites wie implizites - Wissen über die Situationen und »ihre Körper ${ }^{13}{ }^{3}$, auf das Goffman zurückkommt, wenn er in der »Rahmen-Analyse $(1996 \mathrm{~b})$ die »Organisation von Alltagserfahrungen« in den Blick nimmt und ein theoretisches Konzept der grundlegenden Rahmen direkter Interaktionen entwirft. Interaktionsprozesse (und damit auch das, was wir Körpersprache nennen) sind eine hoch konventionalisierte und normative Angelegenheit. Die an der Interaktion Beteiligten sind angewiesen, mit ihren Körpern in einer sozial erwartbaren Weise zu kommunizieren. Sie müssen die jeweiligen Regeln kennen bzw. »erhandeln«, die Symboliken des Gegenübers entziffern und »Techniken der Imagepflege « (Goffman 1996a: 10ff.) beherrschen, um die »Interaktionsordnung « aufrecht zu erhalten. Diese Ordnung ist insofern nicht starr, da sie jederzeit gefährdet und umkämpft ist und eben auch neu »ausgelotet « werden kann und muss.

Hier ergeben sich meines Erachtens Anschlussmöglichkeiten zwischen Goffmans Rahmenkonzept und der im Folgenden genauer zu diskutierenden Diskurstheorie, die sich auf Michel Foucault bezieht. Bei der Untersuchung von Körperpraktiken und der Frage nach ihrer Problematisierung werden die möglichen Rahmungen interessant, über die die Akteure, also die SchülerInnen und LehrerInnen, die AutorInnen in den Zeitschriften sowie die Forschenden in einer Situation verfügen (können). Sie bedienen sich des Rahmens als

12 Mit der Konversationsanalyse bzw. den Konversationsanalytikern hat sich Goffman allerdings immer wieder auseinander gesetzt und sie kritisiert (vgl. Bergmann 1991). In seinen späteren Arbeiten in "Forms of Talk" wendet er sich dann in Abgrenzung zur Konversationsanalyse mehr und mehr der sprachlichen Kommunikation, aber auch Formen des Selbstgesprächs zu. Einige dieser Aufsätze sind vor kurzem in deutscher Übersetzung erschienen (Goffman 2006).

13 Hiermit überspitze ich das bekannte Goffman-Zitat, in dem er verdeutlicht, worum es ihm in der Analyse von Interaktionen geht: »Es geht hier also nicht um Menschen und ihre Situationen, sondern eher um Situationen und ihre Menschen.« (Goffman 1996a: 9) 
mehr oder weniger komplexe Verstehensanweisung, die »einen Wirklichkeitsraum als Möglichkeitsraum [konstituiert], der in der Situation gleichsam schrittweise abzuarbeiten ist« (Willems 1997: 35). Begreift man, wie Willems weiter schreibt, Rahmen als »Sinntatsachen, die die Serialität des sozialen Lebens, [...] Verkettungen von Handlungen und Interaktionen ermöglichen und strukturieren« (ebd.), so lässt sich der Begriff der Rahmung mit dem der diskursiven Formationen und Beziehungen in Verbindung bringen, da die Möglichkeiten zu rahmen von Diskursen durchzogen sind. Eine Rahmung vorzunehmen kann in diesem Sinne als diskursive Praktik begriffen werden. Natürlich nehmen Goffman und Foucault verschiedene Gegenstandsebenen in den Blick: Goffman bettet seine mikrostrukturellen Analysen kaum historisch ein, während Foucault historisch diskursive Formationen zu speziellen (und doch allgegenwärtigen) Gebieten wie der Sexualität und des Wahnsinns rekonstruiert. So fokussieren denn auch die meisten aktuellen diskursanalytischen Untersuchungen vor allem auf öffentliche Äußerungen und Medien bzw. stark institutionalsierte Felder. Dabei scheint klar, dass sich »die Diskurse« in eben jenen Bereichen finden und sich grundsätzlich von »den Praktiken« unterscheiden, die verteilt und vereinzelt das Netz alltäglichen gesellschaftlichen Handelns durchziehen. Genau dieser Differenzierung möchte ich entgegenwirken. Goffmans Schriften bieten hier eine nötige Ergänzung und liefern Mittel der Beschreibung, um einerseits von Diskursen durchzogene »verstreute Alltagspraktiken in den Blick zu nehmen, und andererseits sich den Gegenständen an den Rändern der Diskurse zu nähern und die jeweiligen Beziehungen zwischen sprachlichen und nicht-sprachlichen Praktiken aufzuzeigen (vgl. Kap. ‘Grenzen der Diskurse`; Wrana/Langer 2007). ${ }^{14}$

Goffmans Analysen, Begriffe und metaphorischen Analogien sind für die Analyse und die ethnographische Beschreibung der Interaktionsprozesse und der darin eingebundenen Körperpraktiken von Bedeutung. Aber nicht nur dort. Da Goffmans Arbeiten vor allem durch eigene Feldforschungen sowie anhand vielfältiger Dokumente wie Zeitungsartikel, Filme, Comics etc. entstanden, er seine Theorien also an konkreten Gegenständen entwickelt hat, bleibt genau diese Nähe zum Gegenstand auch in seinen Schriften bestehen. Dies ermöglicht, Goffman bereits in der Feldforschung als eine Art »widerstreitende Begleitung« (vgl. Langer 2007a) zur detaillierten Beobachtung und

14 Die Idee, Goffman und Foucault zusammenzubringen, kann ich hier nur andeuten (vgl. auch Willems 1997: 288f., der die Verknüpfung beider Ansätze ebenfalls in Erwägung zieht). Eine fundierte Ausarbeitung, die die jeweiligen wissenschaftstheoretischen Kontexte einbezieht und die Anschlussfähigkeit der Begriffe genau überprüft und abwägt, steht noch aus. Sie wäre auch vor dem Hintergrund interessant, neuere Praxis-Theorien (Reckwitz 2003: 298; Hörning/ Reuter 2004) und Diskurstheorie zusammen zu diskutieren. 
der Reflexion der eigenen Rolle als Beobachterin zu nutzen, auch wenn er sein methodisches Arbeiten kaum expliziert hat. ${ }^{15}$ Sein »unkonventionelles« Vorgehen (Bergmann 1991: 306; Willems 1997: 290) enthält eine »kaum technisierbare $>$ Haltung « (Willems 1997: 293), die zur aktiven und reflektierten Auseinandersetzung mit dem Forschungsgegenstand auffordert und sich nicht einfach überstülpen oder als methodische Anleitung lesen lässt.

\section{Diskursive Praktiken}

In den zu analysierenden Texten erziehungswissenschaftlicher bzw. pädagogischer Fachliteratur werden Konzepte und didaktische Praktiken formuliert, die an bestimmte zeitgemäße und historisch gewordene Vorstellungen von Leib und Körper, Zeichenhaftigkeit von Körpern und notwendiger Körperdisziplinierung anknüpfen bzw. auf sie verweisen. Diese werden, wenn auch nicht unmittelbar, von PädagogInnen in konkrete Situationen im Rahmen der Institution Schule »hineingetragen«, erwartet und (re)produziert, ebenso wie in den Zeitschriftenartikeln von Praxiserfahrungen berichtet wird, womit diese in den Diskurs eingehen. Auch die SchülerInnen haben ein spezifisches Körperwissen und leibliche Erfahrungen. Um den Stellenwert des Körpers in Bildungs- und Subjektivierungsprozessen, seine Problematisierung in Bezug auf Schule sowie die Inkorporierung von Wissen und gesellschaftlichen Positionen herauszuarbeiten, ist es notwendig, das Vorgehen bzw. den Gegenstand der meisten Diskursanalysen zu erweitern. Sie beschäftigten sich meist mit im weitesten Sinne öffentlichen Diskursen oder Progammatiken. Ich untersuche dagegen nicht nur in Form von Texten vorliegende fachspezifische Materialien, sondern auch ethnographische Daten. ${ }^{16}$

15 Eine Ausnahme bildet ein interessantes kurzes Gespräch, in dem Goffman zur Feldforschung befragt wurde (Goffman 1996c), welches erst nach seinem Tod veröffentlicht wurde. Über das Reden über Feldforschung äußert er, »daß man bei jedem Versuch, Techniken auszuformulieren, Rationalitäten erzeugt - und wir befinden uns in der riskanten Lage, genau dies zu tun. Die einzige Rechtfertigung dafür, dieses Risiko einzugehen, besteht darin, dass die Leute für gewöhnlich ohne jedwede vorgängigen Überlegungen ins Feld hineingehen, so dass wir also nicht allzu viel Schaden anrichten können « (ebd.: 262).

16 Eine Verbindung von Diskursanalyse und Ethnographie wird bisher kaum praktiziert, auch wenn sie als möglicher Zugang im Zuge der Überlegungen zum Verhältnis von Diskursen und Subjekt aktuell immer wieder gefordert wird, z. B. von Stephan Moebius, wenn er schreibt, dass die poststrukturalistische Diskursanalyse »auch auf die 'Subjekte bzw. Akteure und ihre in der Iterabilität angelegten, ereignishaften und kontingenten Handlungspraktiken« (Moebius 2005: 143) ausgerichtet sei, oder Renn, welcher fordert die "Teilnehmerperspektive " einzubeziehen (vgl. Renn 2005: 123). Keller schlägt diesbezüglich vor, Ethnographie und Diskursanalyse zusammenzubringen (2005a: 255f.), empirische Untersuchungen und forschungspraktische Erfahrungen gibt es aber bisher kaum. 
Auf diese Weise geraten Praktiken auf verschiedenen Ebenen in den Blick:

- im Reden bzw. Schreiben über den Körper (Problematisierung des Körpers),

- im Erstellen von Unterrichtskonzepten (programmatische Texte),

- in beobachtbaren Interaktionen bzgl. des Körpers (Körperpraktiken).

Das heißt, ich sehe mir Körperpraktiken und Problematisierungen des Körpers in unterschiedlichen schulpädagogischen Bereichen an, aber immer mit dem gleichen Blick. Zur Bearbeitung und um die Nachvollziehbarkeit zu sichern, trenne ich die ethnographische Ebene und die Diskursebene zunächst analytisch und weitestgehend auch innerhalb der Darstellung. Letztlich fokussiere ich aber das gesamte Material von einer Perspektive aus, um die unbefriedigende Trennung in Diskurse einerseits und Handlung oder Wirkung andererseits zu überwinden. Trotzdem ist sehr wohl zu differenzieren zwischen unterschiedlichen Textgenres - beispielsweise präskriptiven, also Handlung anleitenden Texten (vgl. Wrana 2006: 55), philosophischen Texten oder Erfahrungsberichten - und jeweiligen Autorenpositionen sowie dem beobachtbaren Handeln in der Schule. Über Rituale im Unterricht zu schreiben, ist eine andere Praktik, als sie im Unterricht auszuüben, weshalb es auch unterschiedlicher Forschungsmethoden bedarf. Es sind jeweils spezifische Praktiken, die Relationen eingehen (oder eben auch nicht), aber nicht in einfachen Wirkungsverhältnissen stehen. ${ }^{17}$

Um das Vorgehen nachvollziehbar zu machen und reflektieren zu können sowie der diskursiv begriffenen Materialität von Körpern nachzugehen, ist es nötig, sich mit den Begriffen Diskurs bzw. diskursive Praktik zu beschäftigen, welche Grundlage meines methodischen Vorgehens und der vorgenommenen Analyse sind. Damit gebe ich zugleich einen Überblick über den derzeitigen Stand der Diskursforschung. ${ }^{18}$

17 Derzeit gibt es spraxistheoretische< Überlegungen (vor allem Reckwitz 2003), in denen die Materialität von Praktiken betont wird und somit Körper und Artefakte als Partizipanden sozialer Situationen besonders zur Geltung kommen. Wie sich in der Diskussion (Reckwitz 2003: 298; Hörning/Reuter 2004) zeigt, bestehen hier Anschlussmöglichkeiten für diskurstheoretische und -analytische $\mathrm{Zu}$ gänge. Ein solcher Anschluss würde eine entscheidende Lücke des Entwurfs des Praktikenbegriffs füllen, nämlich die, wie "praktisches Wissen", von welchem weitestgehend unbestimmt die Rede ist (vgl. die Kritik von Meier 2004: 59), mit diskursiven Praktiken verknüpft ist, in sie eingeht, aus ihnen hervorgeht etc. Es ginge genau um jene Relationen verschiedener Praktiken.

18 Den Begriff »Diskursforschung « nutze ich hier im Sinne eines sich entwickelnden Forschungsprogramms, womit sowohl diskurstheoretische Diskussionen als auch Diskursanalysen sowie darauf bezogene methodologische und methodische Fragen einhergehen. 


\section{Diskurstheoretische Annahmen}

Der Gegenstand sozialwissenschaftlicher Diskursanalysen ist »das Sprechen« als kommunikative und soziale Tätigkeit. ${ }^{19}$ Sprachliche Äußerungen werden auf die sozialen Praktiken ihrer Produktion hin interpretiert (vgl. Foucault 1981: 74). Mit Diskurs ist also kein alltagssprachlich gebrauchter, sich allgemein auf Diskussion oder Debatte beziehender Begriff gemeint, ${ }^{20}$ vielmehr sind die sprachliche Rede bzw. darüber hinaus auch nicht unmittelbar sprachliche Zeichen im Gebrauch und die darin eingeschlossene Machtförmigkeit von Interesse. Deshalb spreche ich von diskursiven Praktiken, deren Rekonstruktion, so schreibt Bublitz, »nicht der Aufdeckung eines geheimnisvollen Diskurses [dient], sondern [...] der genauen Beschreibung dessen, was gesagt und getan wird « (Bublitz 2003: 20f.).

In meiner Arbeit schließe ich (zunächst) an den Diskursbegriff von Foucault an, indem ich unter Diskursen Praktiken verstehe, die die Gegenstände, von denen sie sprechen, systematisch erzeugen (Foucault 1981: 74). Gegenstände erzeugen heißt, dass im Sprechen nicht nur Dinge bezeichnet werden und das Gesagte nicht einfach eine gegebene Welt von Sachverhalten abbildet, sondern ein bestimmtes Wissen produziert wird, welches wahr gesprochen wird. Die Welt als sinnhafte und intelligible und damit auch als ein Feld von Gegenständen und Themen wird im Sprechen erst hergestellt. Dies ist eine erste diskurstheoretische Annahme (Langer/Wrana 2009). Eine zweite ist, dass diskursive Praktiken im Kontext eines Verweisungszusammenhangs stattfinden, eines Netzes oder einer Formation anderer Äußerungen, die im Akt des Sprechens wiederholt, aufgegriffen, aktualisiert und modifiziert werden (Foucault 1981: 153). Jeder Akt des Sprechens wird deshalb als einer in

19 Systematische Rekonstruktionen des Diskursbegriffs mit verschiedenen Schwerpunkten finden sich bei Angermüller (2005a), Diaz-Bone (2002: 67-241), Bublitz (2003), Keller (2005a) und Wrana (2006: 93-162).

20 Das Wort Diskurs entstammt dem Lateinischen (discurrere: hin- und herlaufen) und hat in den romanischen Sprachen die Bedeutung von Gespräch, Rede, Diskussion, Vortrag, Monolog etc. angenommen, vgl. zur Geschichte des Begriffs: Keller (2005a: 97ff.), Wrana (2006: 113). Heute scheint der Begriff durch seinen vielfältigen eher unspezifischen Gebrauch im Alltag und der Wissenschaft »abgenutzt" (Schöttler 1997: 134) und unbestimmt, der damit verbundenen Polysemie entsprechen verschiedene Diskurstheorien. Michael Behnisch (2005: 109) stellt fest, dass der Begriff sowohl abstrakt genug sei, um an verschiedene Theorien anschlussfähig zu sein, als auch aufgrund dieser Unbestimmtheit allgemein kommunizierbar sei, so dass jeder ahne, was mit ihm gemeint sein könne. Andererseits gibt es eine spezifischere Bestimmung des Begriffs ausgehend von der französischen strukturalen Linguistik und im weiteren ihrer poststrukturalistischen Transformation, in deren Tradition auch die folgenden Bezüge auf Foucault stehen. Diesen Weg zeichnet Daniel Wrana (2006: 115-121) nach. 
einer Kette von Akten, als Wiederaufgreifen und Transformieren bereits vergangener Äußerungsakte begriffen. Die Genese von Bedeutung und Sinn im Sprechen ist demnach weder aus der sequentiellen Abfolge von Sprechhandlungen im Text- oder Gesprächsverlauf abzuleiten, noch kann sie lediglich von der einzelnen Sprechhandlung und den sie bestimmenden Intentionen her gedacht werden. Mit einer dritten Annahme wird davon ausgegangen, dass das Gesprochene nicht nur ein Ausdruck des sprechenden Subjekts ist, sondern dass das sprechende Subjekt im Akt des Sprechens zu dem wird, das diese Äußerung legitimerweise vollzieht und zugleich die hörenden und lesenden Subjekte dazu anruft, den gesprochenen Sinn anzuerkennen und sich diesem Sinn gemäß zu verhalten (vgl. Althusser 1977).

In der »Archäologie des Wissens « ${ }^{21}$ bezeichnet Foucault Diskurse »als eine Menge von Aussagen, die einem gleichen Formationssystem angehören « (Foucault 1981: 156), weshalb bei einer Diskursanalyse die »diskursiven Formationen«, die Regelmäßigkeiten, Verkettungen und Abspaltungen interessieren, mit denen diese verstreuten Aussagen zu eben jenem Wissen und $\mathrm{zu}$ Wissensordnungen werden. Es wird danach gefragt, wie diese wahr gesprochen werden und warum gerade diese Äußerung gemacht wurde. Foucault interessiert »jenes Denken, dass eine Praxis reflektiert, die aus irgendwelchen Gründen fragwürdig wird« (Schmid 1996: 8). Er unterscheidet vier Untersuchungsrichtungen bzw. Formationen, die in seinen Studien jeweils verschieden stark relevant und auf unterschiedlichen Ebenen angesiedelt sind: die Formation der Gegenstände (also deren systematische Erzeugung), die Äußerungsmodalitäten (also von welcher spezifischen Subjektposition eine Äußerung wie getätigt wird), die Begriffe und ihre Beziehungen, die hervorgebracht werden und die Strategien eines Diskurses nach Außen (vgl. Foucault 1981). ${ }^{22}$ Die Formationen bezeichnet Foucault als »Bündel von Beziehungen«, genauer als Bündel von Herstellungsfunktionen von Beziehungen (Foucault 1981: 70, 126). Das heißt, Diskurse »existieren« nach Foucault nicht ${ }^{23}$, sondern sie sind das, was Gegenstände als solche für uns produzieren, sie sind

21 Bei diesem Buch handelt es sich um eine methodologische Reflexion hinsichtlich der theoretischen Grundlagen der Arbeiten von Foucault. In der Rezeption Foucaults wird es meist als Abschluss der Phase der "Archäologie « betrachtet, dem die der »Genealogie« und der Analyse der Machtverhältnisse folgt (vgl. z. B. Koller/Lüders 2004). Für den hier zu entwickelnden diskurstheoretischen und -analytischen Zugang halte ich es für sinnvoll, beide sich ergänzenden und ineinander greifenden Perspektiven gemeinsam in die Überlegungen einzubeziehen.

22 Ein knappe erklärende Übersicht findet sich z. B. bei Koller/Lüders (2004: 59ff.) oder Keller (2005a: 132).

23 Sie sind also auch nicht einfach rekonstruierbar, sondern indem ich diskursive Praktiken sowie Beziehungen analysiere, konstruiere ich Diskurse. 
die Bedingung der Möglichkeit der Existenz von Objekten. Diese Möglichkeitsbedingung liegt nicht »in der Sprache«, sondern in den Praktiken des Sprechens: in diskursiven Praktiken. Nun ist damit nicht einfach »alles Diskurs« oder gar »alles Text«, die diskursiven Beziehungen setzen bei Foucault vielmehr das Sprachliche mit dem Nichtsprachlichen, die Institutionen und Subjekte mit dem Gesprochenen in Beziehung.

Diskursanalysen gehen somit über reine Sprach- bzw. Textanalysen hinaus, weil mit den diskursiven Praktiken zugleich ein spezifisches, gesellschaftlich hegemoniales Wissen untersucht wird (vgl. Angermüller 2001: 8). Die diskursive Aktivität lässt sich nicht auf Texte reduzieren. Ebenso wenig wie ein Text lediglich einem bestimmten Diskurs zugehörig ist, lässt sich ein Diskurs anhand eines Textes erfassen. Wir haben es mit verstreuten Äußerungen zu tun. Das können auch Bilder sein bzw. alles, was in der Lage ist, zu einem Zeichen zu werden. Gerade die Beziehungen von Text und Bild zueinander sind interessant, da Bilder aufgrund ihrer Indexikalität auf einen Blick komprimiert viele Symbole enthalten und die Betrachtenden auf eine beschleunigte Weise ansprechen. ${ }^{24}$ Die Annahme ist, dass diese ein Netz von Verweisen bilden. Die Texte implizieren Spuren aus anderen Texten und verweisen zugleich auf zukünftige Texte: »[...] any text is the absorption and transformation of another. The notion of intertextuality replaces that of intersubjectivity $[\ldots]$ « (Kristeva 1986: 37).

Texte oder auch Bilder sind nicht simple Informationsträger, sondern eine Praxis der Diskursproduktion, in der es um soziale Integration und Konsensfindung, Inklusion und Exklusion, Mobilisierung und kollektives Handeln geht (vgl. Hark 2005: 36). Alex Demirovic begreift Texte als Aktivität, »die interveniert und eine Konstellation und einen Kontext zu erzeugen sucht« (Demirovic 1999: 37). Ihre Bedeutung gewinnen sie nicht aus sich heraus, sondern als diskursive Ereignisse. Das heißt, sie beziehen sich auf und werden Teil verschiedener Diskurse, sie verweisen aufeinander und sind in spezifische Praktiken des Debattierens eingewoben.

Mit Foucaults machtanalytischen Arbeiten stehen somit nicht nur sprachliche Aspekte im Zentrum, sondern spezifische Macht/Wissen-Komplexe als strategische $>$ Kämpfe` oder `Spiele` der Wahrheit. Denn in, mit, um und gegen Diskurse wird gekämpft. Die diskursive Praxis ist immer mit anderen Praktiken (z. B. Selbst-, Macht-, Steuerungspraktiken) und Machtverhältnissen

24 In meiner Arbeit komme ich zum Teil auch auf Bilder zurück, allerdings nicht in dem Maße, wie es eigentlich möglich und sinnvoll wäre. Hierfür wäre es allerdings nötig, das gesamte Korpus hinsichtlich seiner Bilder zu betrachten und noch ein spezifisches Vorgehen für die Bildinterpretation im Rahmen der Diskursanalyse zu entwickeln, um deren spezifische Materialität zu berücksichtigen. Erste Ansätze dafür finden sich bei Maasen/Mayerhausen/Renggli (2006). 
verwoben. Sie ist als eine strategische und taktische Praxis zu verstehen, deren Kern das In-Beziehung-Setzen eines Feldes von Gegenständen, einer semantisch-semiotischen Organisation, einer Reihe von Subjektpositionen und Subjektivitäten sowie einer verbalen oder schriftlichen Materialität ist (Foucault 1981: 128ff.). ${ }^{25}$

\section{Zum Stand der Diskursforschung}

Diese zunächst für die Untersuchung von Diskursen geeigneten Anleihen an Foucault werden in den interdisziplinär geführten diskurstheoretischen Diskussionen fortgeführt. Die sozialwissenschaftliche Diskursforschung, die in den letzten Jahren als ein neuer Ansatz in der qualitativen Forschung entstanden ist, verbindet den poststrukturalistischen Diskursbegriff, wie er unter anderem von Foucault geprägt worden ist, mit verschiedenen Theorien und Methodologien des interpretativen Paradigmas. ${ }^{26} \mathrm{Zu}$ unterscheiden sind Diskurstheorie(n) ${ }^{27}$ (wie ich sie eben vorgestellt habe) und Diskursanalyse, d. h. die Methodologie und eine heterogene Vielfalt von Methoden, mit denen das Sprechen als soziale und kommunikative Tätigkeit untersucht wird. Die methodischen und methodologischen Diskussionen zur Diskursforschung (vgl. An-

25 Wrana hat diese vier Ebenen in seiner diskursanalytisch angelegten Untersuchung reflexiver Praktiken in sog. Lernjournalen, welche in Kursen der Erwachsenenbildung geführt wurden, im Anschluss an Foucault ausführlich dargelegt und methodologisch erweitert (Wrana 2006: 130-137).

26 Die Methodologie der »analyse du discours« entwickelte sich zunächst in den 1960er und 1970er Jahren unter dem Einfluss des Strukturalismus (vgl. Dosse 1999). Im deutschsprachigen Raum war die Diskursanalyse in den 1980er und 1990er Jahren vor allem eine Domäne der Text- und Sprachwissenschaften (Überblick in Bluhm/Deissler/Scharloth/Stukenbrock 2000), die genannte Verbindung mit der qualitativen Sozialforschung ist eine jüngere Entwicklung. Die neueren Debatten sind in einer Reihe von Sammelwerken und Handbüchern zu fïnden (Bublitz/Bührmann/Hanke/Seier 1999; Angermüller/Nonhoff/Bunzmann 2001; Keller/Hirseland/Schneider/Viehöver 2001, 2003, 2005). Auch in der Online-Zeitschrift »Forum Qualitative Sozialforschung finden sich vermehrt Diskussionen über diskursanalytische Verfahren (insbesondere 2/2007).

27 Abgegrenzt wird die momentan sich etablierende Diskursanalyse im Anschluss an Michel Foucault vor allem von anderen sprachanalytischen Verfahren, welche sich mit realen Kommunikationsprozessen in unterschiedlichen Kontexten beschäftigen, wie z. B. die ethnomethodologisch und/oder sprachwissenschaftlich begründete Konversationsanalyse. Diese Ansätze werden unter dem Sammelbegriff >discourse analysis gefasst, dem, so Keller, in der englischsprachigen Diskursliteratur am weitesten verbreiteten Diskursbegriff (Keller 2004: 20). Eine weitere Abgrenzung erfolgt gegenüber der » Theorie des kommunikativen Handelns « - der Diskursethik - von Jürgen Habermas (vgl. Amos 2004). Zudem nennen Keller et al. (2001) noch die kulturalistische Diskursforschung, zu denen sie auch einige Arbeiten Bourdieus zählen (vgl. auch Keller 2004: 34f.). 
germüller 2005a, Bublitz et al. 1999; Keller et al. 2001, 2003; Jäger 2004; Keller 2004) zeigen deutlich, dass nicht von der Diskursanalyse gesprochen werden kann. Es gibt sehr verschiedene Ansätze, die von unterschiedlichen Diskursbegriffen und -theorien ausgehen, in verschiedene disziplinäre Kontexte eingebettet sind und jeweils spezifische Gegenstände und Fragestellungen bearbeiten. ${ }^{28}$ Sie schließen an spezielle Forschungstraditionen und ein bestimmtes Methodenrepertoire an: an Verfahren qualitativer Forschung wie die Grounded Theory (z. B. Diaz-Bone 2002), die Inhaltsanalyse (Waldschmidt 2003; Kessl 2005; Walgenbach 2006), die Interaktionsforschung (Nolda 1996) oder sprachwissenschaftlich orientierte Textanalysen der französischen sanalyse du discours (z. B. Höhne/Kunz/Radtke 2005; Langer/Wrana 2005; Wrana 2006, Angermüller 2007). Anders als bei anderen Forschungsprogrammen lässt sich bei der Diskursforschung nicht auf ein mehr oder weniger standardisiertes methodisches Vorgehen zurückgreifen, sondern es erfordert einige Auseinandersetzung (mehr) mit der Methodologie und den Begriffen in Bezug auf den Forschungsgegenstand.

Auch innerhalb des Feldes der »Foucaultschen Diskursanalysen« werden Systematisierungsversuche unternommen. Johannes Angermüller (2005a) unterscheidet die verschiedenen Ansätze auf einer Linie von rekonstruktivistisch (wissenssoziologisch, verstehend-handlungstheoretisch orientiert) und dekonstruktivistisch (am Poststrukturalismus anknüpfend und zeichen- bzw. differenztheoretisch arbeitend). Ebenso wie hermeneutische und (post-)strukturalistische Ansätze in Verbindung gebracht und ihre möglichen Anschlüsse und Resonanzbildungen >in Angriff genommen werden ‘ (z. B. Keller 2005b, Renn 2005), werden die diesbezüglichen Differenzen und Unvereinbarkeiten (aus jeweils unterschiedlicher Perspektive) stark gemacht (z. B. Diaz-Bone 2003: 14; Angermüller 2005a). Daniel Wrana resümiert deshalb: »Betrachtet man diese Ansätze zusammen, steht der Begriff Diskurs nicht für einen konsensual bestimmten Gegenstand oder eine kollektive Methodologie, sondern für eine Problematik. Der Diskurs ist ebenso wie der Name Foucaults eine Art >Treffpunkt<, wie Dominique Maingueneau auf einer Tagung bemerkte.« (Wrana 2006: 111)

Während im deutschsprachigen Raum interdisziplinär mehr und mehr diskursanalytisch gearbeitet wird, entstehen auch in den Erziehungswissenschaf-

28 Langer und Wrana (2007) zeigen das in einem Vergleich vier verschiedener Diskursanalysen insbesondere bezogen auf die Erziehungswissenschaft. Deutlich wird dies außerdem in den interdisziplinären Sammelbänden bzw. Handbüchern (Angermüller et al. 2001; Keller et al. 2001, 2003; Jung 1997) wie auch in den Tagungsberichten zur Diskursforschung (Klemm/Glasze 2004; Viehöver 2004, Fegter/Langer 2008). 
ten Untersuchungen mit einer so ausgerichteten Forschungsperspektive. ${ }^{29}$ Der Diskursbegriff ist in den Erziehungswissenschaften aber keineswegs neu. Er wird bereits seit den späten 1970er Jahren rezipiert und gebraucht, allerdings nicht für empirische Diskursanalysen, sondern als philosophische, metaphysikkritische Diskurstheorie. Bildungstheoretisches Denken wurde mit der poststrukturalistischen Dezentrierung des Subjekts einer radikalen Kritik unterzogen und zugleich auf ein neues Reflexionsniveau gebracht, indem gesellschaftliche Macht- und Herrschaftsverhältnisse in den Blick genommen wurden (vgl. Koller/Lüders 2004: 57). Gegenwärtig wird diese Form bildungstheoretischer Reflexion und Kritik im Anschluss an Foucaults Konzept der Gouvernementalität wieder aufgegriffen (z. B. Maurer/Weber 2006).

Die hier angedeutete Heterogenität des Feldes wie auch die noch in der Entwicklung begriffene Etablierung der Diskursforschung ist nicht nur eine Herausforderung für eine diskursanalytisch angelegte Arbeit, sondern enthält auch ein besonderes Potenzial wissenschaftlichen Weiterdenkens, indem die Möglichkeit wechselseitiger Kontaktaufnahmen verschiedener theoretischer Konzepte besteht und damit eine methodologisch kontrollierte Öffnung, wie sich z. B. in der Auseinandersetzung und in den Versuchen der Annäherung von diskurstheoretischen und wissenssoziologischen Ansätzen (z. B. Keller et al. 2005) sowie der Verknüpfung von qualitativen und quantitativen Forschungsverfahren in verschiedenen Studien zeigt. Das jeweils konkrete Vorgehen innerhalb einer Untersuchung kann letztlich immer nur in Bezug auf den Gegenstand, die Fragestellung sowie die theoretischen und methodologischen Herangehensweisen entschieden werden.

\section{Subjekt, Macht und Diskurse - zur Performativität diskursiver Praktiken}

Als grundlegende Annahmen habe ich genannt, dass die Diskurstheorie unterstellt, jeder Äußerungsakt entfalte eine doppelte Performanz: bezüglich der Gegenstände, Sachverhalte und Themen einerseits und bezüglich der sprechenden und hörenden Subjekte andererseits. Diese Performanz kann ein Äußerungsakt aber nicht als einzelner und singulärer Akt herstellen, sie ist nur in einer diskursiven Praxis als Netz von Akten denkbar (vgl. Wrana 2006: 122).

29 z. B. Höhne 2003a, Höhne/Kunz/Radtke 2005; Kessl 2005; Kossack 2006; Langer/Wrana 2005; Langer/Ott/Wrana 2006; Reh 2003; Truschkat 2008; Wrana 2002, 2006 
Doch was heißt es, von Performanz bzw. Performativität ${ }^{30}$ diskursiver Praktiken zu sprechen? Der in der Diskursanalyse verwendete Performanzbegriff schließt an den Begründer der Sprechakttheorie John L. Austin an, der untersucht hat, inwiefern bestimmte Sprechakte Welt nicht einfach repräsentieren, sondern herstellen. Sätze wie »Die Sitzung ist eröffnet « oder »Ich taufe Dich auf den Namen $[\ldots]$ « sind Beispiele für solche performativen Sprechakte (Austin 1972: 27). Die poststrukturalistischen Theorien nehmen diese Argumentationen auf, weisen aber nicht nur bestimmten, sondern allen Sprechakten, auch scheinbar nur beschreibenden, einen herstellenden Charakter zu (vgl. Butler 1998: Derrida 2001). Sprache verliert damit ihren repräsentativen Status, wonach sie etwas bezeichnet, was ihr vorgängig ist. Um dies nachzuvollziehen, knüpfe ich an meine Ausführungen im Abschnitt »Diskursive Körper? « an und komme noch einmal auf Butlers Theorie des Performativen zurück.

Die Wirkung der Performativität beruht auf der zitatförmigen Wiederholung bereits kodierter Bedeutungen. Jacques Derrida betont die Iterabilität von Sprechakten: die Eigenschaft, eine Wiederholung zu sein und wiederholt werden zu können (Derrida 2001: 38). Diese Wiederholungen sind für die Fortschreibung von Macht unumgänglich, indem sie Konventionen zitieren. Sie sind allerdings nicht mit dem wiederholten Akt identisch, sondern durch den Bruch mit dem (semiotischen) Kontext jeweils anders und können als Effekt Neues produzieren. »Iter, nochmals, kommt von itara, anders in Sanskrit, und alles Folgende kann als Ausbeutung dieser Logik gelesen werden, die die Wiederholung mit der Andersheit verknüpft.« (Derrida 2001: 24) Das heißt, dass Sprechen nicht vollständig intentional in seinen Sinneffekten zu beherrschen ist, sondern die »spontane Individualität« innerhalb einer sozialen Praxis Effekt dieser Wiederholung ist (vgl. auch Wirth 2001: 18). Aufgrund der Iterabilität - des verändernden Wiederholens - kann innerhalb von Spielräumen mit dem »Zitierten« gebrochen und es können Verschiebungen vorgenommen werden. Butler (1998) spricht deshalb von »Erbschaften des Gebrauchs «, welche zu Sedimenten von Bedeutungen werden und weitet mit Be-

30 Um die Begriffe Performanz (als Darstellung) bzw. Performativität des Sprechaktes (als Modus der Konstitution) (vgl. Müller 2000: 94) - beide werden zum Teil synonym gebraucht - ist ein weites Bedeutungsfeld entstanden, zumal sie von verschiedenen Wissenschaftsdisziplinen gebraucht werden. So schreibt Uwe Wirth: "Performanz kann sich ebenso auf das ernsthafte Ausfïhren von Sprechakten, das inszenierende Aufführen von theatralen oder rituellen Handlungen, das materielle Verkörpern von Botschaften im 'Akt des Schreibens ( oder auf die Konstitution von Imaginationen im )Akt des Lesens beziehen. (Wirth 2002: 9, Herv. i. O.) Vgl. auch anschaulich genau jene Vielfalt von Begriffsnutzung im Sammelband von Wulf, Göhlich und Zirfas zu den »Grundlagen des Performativen« (2001). 
zug auf Derrida den performativen Charakter auf sämtliche Sprechakte aus. Der Äußerungsakt ist immer schon Teil einer Kette von Äußerungsakten, die er wiederholt und transformiert (Wrana 2006: 125). Auch wenn immer an etwas Vorausgehendes angeschlossen wird, da es sich nie um das gleiche »Ergebnis « handelt, nicht um ein identisches Duplikat, entsteht zugleich ein kreativer Moment sowie ein Überschuss an Bedeutung. »Damit ein Performativ funktionieren kann, muss es aus einem Satz sprachlicher Konventionen schöpfen, und diese Konventionen, die traditionell funktioniert haben, rezitieren, um eine gewisse Art von Effekten hervorzurufen. Die Kraft oder Effektivität eines Performativs hängt von der Möglichkeit ab, sich auf die Geschichtlichkeit dieser Konventionen in einer gegenwärtigen Handlung zu beziehen und sie neu zu kodieren. « (Butler 1993: 124) Damit verschleiert es aber auch die Historizität seiner Bezüge und es entstehen Naturalisierungseffekte.

Butler übernimmt von Derrida die Begriffe der Zitathaftigkeit und Iterabilität für ihre Konzeption des Performativen und entwickelt sie im Hinblick auf eine Theorie des Handlungsvermögens weiter. Performativität ist im Anschluss an die Ausführungen zu einem diskursiven Begriff von Körper auch auf Körperpraktiken zu beziehen. ${ }^{31}$ »Körpervorstellungen sind performativ in dem Sinne, dass sie die Individuen auffordern sich diesen entsprechend zu verstehen und zu erleben.« (Müller 2000: 100) In Butlers Konzept sind neben der Sprache oder besser dem Sprechen, der Körper und das Subjekt zentral. Performativität, die eben im Sprechen bzw. darüber hinausgehend im Praktizieren, herstellt, was vermeintlich vorher schon zu sein scheint (und im Anknüpfen an Vorheriges auch ist), ermöglicht Prozesse der Materialisierung. Diskursive Praktiken bilden eine eigenständige Materialität. »In ihnen verschränken sich Diskursives und Physisches, Semantisches und Sozio-Technisches ineinander.« (Bublitz 2003: 7) Performative Akte haben subjektivierende Effekte, das Subjekt und seine performativen Akte sind nicht voneinander zu trennen. Die so geformte Materie ist allerdings fragil, weshalb die Notwen-

31 Michael Göhlich (2001) überträgt den Begriff der Performativität auf nonverbale Praktiken als praktisches Vollziehen. Diese Erweiterung findet allerdings meines Erachtens - wie oben geschildert - bei Butler bereits statt, indem sie die sprachphilosophischen Konzepte mit »aktivistisch gefassten Ansätzen körperlicher Performanz (Tervooren 2006: 20) verknüpft. Die These ist, dass diskursive Praktiken als performative körperliche Gestalt annehmen (vgl. Kap. )Diskursive Körper? . Für empirische Forschungen mögen Göhlichs Überlegungen dennoch sinnvoll sein, da Butlers Theorie in empirischen Forschungen, die Interaktionen in den Blick nehmen, nicht einfach zu übertragen ist (vgl. auch Tervooren 2006: 20). Allerdings stellt Göhlich Sprechen als Sprache und Handeln als praktischen Vollzug gegenüber, eine Trennung die gerade in Butlers Konzept überwunden wird. 
digkeit der Wiederholung gegeben ist, wie Butler für die Herstellung von Geschlechtsidentität formuliert:

"Gleicht das >Annehmen eines Geschlechts einem Sprechakt? Oder ist es oder gleicht es einer zitatförmigen Strategie oder resignifizierenden Praxis? Im dem Maße wie das ,Ich von seiner sexuierten Position abgesichert wird, können dieses \Ich genommen werden, wodurch die )Annahme kein vereinzelter Akt oder vereinzeltes Ereignis ist, sondern vielmehr eine wiederholbare Praxis. Wenn eine sexuierte Position sanzunehmen heißt, auf eine gesetzgebende Norm zurückzugreifen [...], dann ist die `Annahme eine Angelegenheit des Wiederholens einer Norm, des Zitierens oder mimetischen Nachahmens der Norm« (Butler 1995: 149, Herv. i. O.).

Entscheidend ist, dass es sich nicht um einmalige Ereignisse handelt, sondern die »Aufführung« kontextuell immer wieder vollzogen wird, sich materialisiert. Zugleich wird sie in der Wiederholung verändert.

Foucault und seinen poststrukturalistischen RezipientInnen wurde und wird aufgrund der Skepsis gegenüber der Idee, dass das menschliche Subjekt Urheber und Schöpfer aller Dinge sei, oft vorgeworfen, das Subjekt gänzlich verabschieden zu wollen. Mit dem vorgestellten Konzept diskursiver Praktiken wird nun kein völlig von sozialen Strukturen determiniertes und unterworfenes Individuum angenommen, sondern deren Verhältnis betrachtet: die historischen Bedingungen ${ }^{32}$ und die in den Praktiken generierten Bedeutungen und Behandlungsweisen, also Prozesse der Subjektivierung. Das Konzept der Performativität verdeutlicht gerade, dass es keine vollständige Unterwerfung des Subjektes unter Diskurse gibt, vielmehr wird versucht, deren Verwobenheit theoretisch zu fassen.

Hierfür ist es des Weiteren nützlich, auf Louis Althussers Begriff der Anrufung (Althusser 1977) zurückzukommen. Louis Althusser interpretiert den Ruf des Polizisten »He, Sie da! « und die Reaktion, sich daraufhin umzudrehen, als Zusprechen eines Subjektstatus. Mit dieser Reaktion erkennt der Adressat an, dass dieser Ruf ihm gilt. Die Anrufung zitiert eine Konvention, eine gesellschaftliche Ordnung, die sich auch gegen den Willen des angerufenen Subjekts einschreibt. Während Foucault vor allem Subjektivierungspraktiken von Adressanten betrachtet hat, werden damit Mechanismen der Subjektkonstitution auf Seite der Adressaten einbezogen (vgl. Wrana 2006: 136). Es ist die herstellende Beziehung zwischen der Anrufung und der Anerkennung dieses Aktes, die das Subjekt konstituiert (Althusser 1977: 146). Im Sin-

32 Butler bezieht diese kaum in ihre Konzepte ein, weshalb KritikerInnen berechtigt fragen, inwiefern sie an dieser Stelle nicht hinter Foucaults Analysen zurückfalle (vgl. z. B. Landweer 1993; Becker-Schmidt/Knapp 2000). 
ne Althussers begreift auch Butler, die den Begriff der Anrufung auf die Sprechakttheorie bezogen hat, nicht als einseitigen Akt, sondern Anrufung ist auf die Annahme durch das Subjekt angewiesen. Aber auch diese Anerkennung ist nicht als einmaliges Ereignis zu begreifen, sondern die Subjektivierung funktioniert aufgrund von Wiederholungen. Dabei sind andere Effekte möglich, als die von den Anrufenden intendierten. Dies kommt auch dadurch zustande, dass die meisten (Unterwerfungs-)Situationen von komplexen Machtlinien durchzogen und deshalb überdeterminiert sind. Darauf machen besonders Ernesto Laclau und Chantal Mouffe in ihrer diskurstheoretischen Konzeption aufmerksam. Ebenfalls im Anschluss an Althusser, der sich wiederum auf Freuds Traumdeutung bezieht, verweisen sie darauf, dass »der symbolische, das heißt der überdeterminierte Charakter der gesellschaftlichen Verhältnisse impliziert [...], daß sie keine letzte Buchstäblichkeit besitzen, die sie auf zwangsläufige Momente eines immanenten Gesetzes reduzieren würde« (Laclau/Mouffe 1985: 145). Subjekte sind in jeder Situation vielen verschiedenen überlagernden, zum Teil widerstreitenden Diskursen und Konventionen ausgesetzt, denen entsprechend zu handeln, unmöglich ist. Subjektivierung ist also niemals nur auf eine einzelne Subjektivierungsstrategie zurückzuführen. Es werden aufgrund der Überdeterminierung Lücken produziert, ebenso wie darauf verweist Michel de Certeau mit seiner Untersuchung der »Gebrauchsweisen « $(1988)^{33}$ - eine Determination zu etwas anderem genutzt oder gar gegen sich selbst gewandt werden kann. Bezogen auf das Feld der Schule heißt das, dass SchülerInnen nicht nur dort als solche subjektiviert werden und andere Sozialisationsinstanzen dies einfach verdoppeln oder vereindeutigen, sondern gerade (etwas holzschnittartig) Jugend- und Schulkultur sich überlappen, widerstreiten, sich durchmischen.

Zusammenfassend lässt sich sagen, dass diskursive Praktiken gerade aufgrund der Verschiebung produktiv sind. Sie bringen etwas Neues hervor, jedoch nicht unabhängig vom Bestehenden, sondern innerhalb eines Rahmens des Denkbaren und Möglichen. Zugleich ist das Subjekt in jeder Situation mit einer Fülle von Diskursen, Regeln, Normen usw. konfrontiert, die durchaus widersprüchlich zueinander sein können, die nicht unabhängig von der jeweils eigenen sozialen Position, Geschichte, Erfahrung und dem historischen Moment zu verstehen sind.

33 Michel de Certeau interessiert die Art und Weise des Gebrauchs von Produkten, was Individuen damit anstellen. Ihm geht es um eine »andere Produktion, die als `Konsum bezeichnet wird: diese ist listenreich und verstreut, aber sie breitet sich überall aus, lautlos und fast unsichtbar, denn sie äußert sich nicht durch eigene Produkte, sondern in der Umgangsweise mit Produkten, die von einer herrschenden ökonomischen Ordnung aufgezwungen werden« (Certeau 1988:13). 
Ich möchte die Modelle der Anrufung und den performativen Charakter noch einmal präzisieren und zwar für die Situation, die vor allem bei der Analyse der Zeitschriften relevant ist. Bezieht man die Anrufung auf ein »Interaktionsbündnis $\ll^{34}$, das Lesende beim Lesen als Tätigkeit mit einem Text eingehen, so garantiert die materielle und textuelle Form noch nicht »den« Sinn. Unterschiedliche Interessen, Erwartungen, Lektürepraktiken, Lesekompetenzen, kulturelle Codierungen etc. verändern diesen (vgl. Sarasin 2001: 65). Je nach Form dieses Bündnisses entsteht so eine Lesweise und es gibt ebenso viele mögliche Lesweisen wie Interaktionsbündnisse. Doch sind Texte bezogen auf die möglichen Bündnisse und Lesweisen in der Regel nicht indifferent, sondern legen bestimmte Weisen nahe, fordern sie heraus. In diesem Sinne haben Texte Anrufungscharakter - eine Dimension ihrer Verflochtenheit in Machtverhältnisse.

Im Rahmen einer Theorie des Textverstehens hat Umberto Eco die Figur des Modell-Lesers (Eco 1990: 61-82) ausgearbeitet. Im Text enthaltene Leerstellen und Zwischenräume - das »Nicht-Gesagte« - müssen vom potenziellen Leser durch »kooperative Bewegungen« (ebd.: 62) angefüllt werden. Eco schlägt Analysepraktiken von Texten und Bildern vor, die in der Lage sind, diejenigen »kooperativen Bewegungen« herauszuarbeiten, die die Leerstellen des Textes in maximaler Weise »anfüllen«. Allerdings ist Ecos Theorem des Modell-Lesers nicht hinreichend, denn die kooperative Bewegung, die den Lesenden eines Textes nahe gelegt wird, ist mehr als ein bloß nachvollziehender Akt des Verstehens. Zahlreiche Textgenres fordern die AdressatInnen des Textes, also eine bestimmte Gruppe von LeserInnen, zu einer bestimmten Haltung und einer bestimmten Tätigkeit heraus. Ihre Funktion ist nicht nur, Wissen zu vermitteln, sondern zu einem Entschluss oder einem Tun zu motivieren (in der Analyse besonders deutlich in Kap. >Anrufungen durch ExpertInnen (). Sie sind also performativ, indem sie eine Bereitschaft in den Lesenden auslösen bzw. einen Effekt, der die Lesenden dazu bringt, eine bestimmte Subjektposition (Foucault 1981: 78ff) einzunehmen. Diese Performanz entfaltet ein Text aber nicht aus sich heraus, sondern indem er in ein Ensemble von anderen Texten und von Machtverhältnissen eingebunden ist. Es sind die gesellschaftlich anerkannten Diskurse, die eine bestimmte Lesweise positiv sanktionieren und eine bestimmte Subjektposition des Verstehens und des Einverständnisses herausfordern. Das heißt aber nicht, dass tatsächliche LeserInnen unausweichlich gezwungen wären, dieser Rhetorik zu folgen und der Text seine Performanz tatsächlich hat. Man kann mit einem Text immer auch ein anderes Interaktionsbündnis eingehen, allerdings nur, indem man die von

34 Den Begriff des Interaktions- bzw. Arbeitsbündnisses hat Christine Resch (1998) im Rahmen einer kritischen Methodologie ausgearbeitet. 
ihm nahe gelegten und geforderten Interaktionsbündnisse negiert (vgl. Langer/ Ott/Wrana 2006: 289). ${ }^{35}$

\section{Der Begriff der Problematisierung}

Ein Begriff, den ich in der Analyse immer wieder verwende, ist der der Problematisierung. Mit diesem Begriff fragt Foucault, was es heißt, dass bestimmte Dinge zum Problem werden, wieso beispielsweise bestimmte Verhaltensformen zu einem bestimmten historischen Zeitpunkt als »Wahnsinn « klassifiziert, während andere vernachlässigt wurden (Foucault 1996a: 178). Er geht davon aus, dass es zwischen einer problematisierten Sache und dem Prozess der Problematisierung eine Beziehung gibt (ebd.: 179).

»Problematisierung bedeutet nicht die Repräsentation eines präexistenten Objekts und auch nicht die diskursive Erschaffung eines nichtexistierenden Objekts. Es ist das Ensemble diskursiver und nicht-diskursiver Praktiken, das etwas ins Spiel des Wahren und Falschen eintreten läßt und es als Gegenstand für das Denken konstituiert (sei es in Form moralischer Reflexion, wissenschaftlicher Erkenntnis, politischer Analyse etc.).« (Foucault 1985: 15)

Damit negiert er nicht die Realität von Erscheinungen, sondern untersucht, wie sie Ziel sozialer Regulierung werden, welcher Zusammenhang zwischen Denken und Realität im Prozess der Problematisierung besteht. Denn die jeweilige Problematisierung ist eine von bestimmten Individuen von sozialen Positionen aus gegebene Antwort auf Situationen. »Wenn man über einen Diskurs berichtet, muß man [also] nicht nach der Wirklichkeit fragen, die diesen Diskurs wiedergibt, sondern nach der Wirklichkeit des Problems, weshalb man glaubt, darüber reden zu müssen.« (Foucault 1984: 97) Ergänzen ließe sich für meine Arbeit - soweit möglich -, Spuren dafür zu finden, weshalb nicht darüber geredet wird und in welchem Rahmen geredet und nicht geredet wird.

35 Höhne, Kunz und Radtke (2005) arbeiten in ihrer Studie zum »Migrantendiskurs« in Schulbüchern mit Ecos Konzept des Modell-Lesers. Sie konstruieren einen »Modell-Schüler" (ebd.: 56f.) und anhand der von Schulen verwendeten Lehrbücher dessen mögliche Lesebiographie. Der Modell-Schüler soll und kann bestimmte Dinge lesen und lernen. Dabei fungiert die Lehrerin als »Ko-Leserin", welche Interpretationshinweise gibt, indem sie Leerstellen im Text auf bestimmte Weise füllt und damit ebenfalls »Lesarten « vorgibt. Ergänzend herausgegebene Lehrerhandbücher sollen ihrerseits sicherstellen, dass auch sie in der gewünschten Weise liest und diese Lesweise weiter gibt. Erfasst werden mit dem so konstruierten Zugang der textliche Bedeutungskorridor der potenziellen LeserInnen und die Regulierung, die deren Interpretationsfreiheit vorstrukturiert (vgl. auch Langer/Wrana 2009). 
In der folgenden Analyse finden sich nun ein weit und ein eng gefasster Begriff von Problematisierung. Um einen weiten Begriff handelt es sich, wenn beispielsweise in den Fachzeitschriften der Körper problematisiert wird, indem problematisiert wird, dass er eben nicht problematisiert werde (insbesondere Mitte der 1990er Jahre). In Abgrenzung zum engen Problematisierungsbegriff spreche ich hier von »Thematisierung«. Ein enger Begriff liegt zugrunde, wenn der Körper als (pädagogisches) Problem konstruiert wird, welches es dann zu bearbeiten gilt. Daraus folgen pädagogische Interventionen oder zumindest Aufforderungen dazu. Deutlich wird durch die Anlage der Untersuchung als »diskursanalytische Ethnographie« aber noch eine weitere Dimension: nämlich, wenn etwas nicht thematisiert wird. Wenn also beispielsweise Körperpraktiken von SchülerInnen oder LehrerInnen beobachtet werden, die in den Zeitschriften überhaupt keine Rolle spielen oder nur einen geringen Stellenwert einnehmen. Damit lässt sich auch ein Verhältnis zwischen Tabuisierung und Problematisierung beschreiben.

\section{Grenzen der Diskurse}

Damit stellt sich diskurstheoretisch die Frage, was dieses Ungesagte sei. Ist es, indem es außerhalb des Gesagten ist, nicht-diskursiv? Die Unterscheidung von diskursiven und nicht-diskursiven Praktiken bleibt sowohl bei Foucault als auch in seiner Rezeption schwer greifbar (vgl. Wrana/Langer 2007). Es zeigen sich zwei Probleme. Zum einen stellt sich die Frage, außerhalb welcher diskursiven Formationen das Ungesagte steht, soll nicht »der« Diskurs zu etwas Ominösem, gewissermaßen Omnipotentem werden und als eine Einheit gedacht werden, die zu (re-)konstruieren unmöglich ist. Ist das Nicht-Diskursive das Außen von Diskursen oder sind es nicht vielmehr andere diskursive Praktiken, die die Grenze einer spezifischen Praktik bilden (vgl. Waldenfels 1991: 289ff.; Schneider/Hirseland 2005: 271)? Den Diskurs als Praxis zu analysieren, »der sich an ein bestimmtes Feld von Gegenständen wendet, der sich in den Händen einer gewissen Zahl von statuarisch bezeichneten Individuen befindet, der schließlich bestimmte Funktionen in der Gesellschaft zu erfüllen hat, sich über Praktiken artikuliert, die ihm äußerlich und selbst nicht-diskursiver Natur sind « (Foucault 1981: 234), bedeutet, die nicht-diskursiven Praktiken gerade nicht als dem Diskurs äußerlich zu verstehen. So konzipieren Hubert L. Dreyfus und Paul Rabinow in ihrer Foucault-Lektüre das Nicht-Diskursive weniger als »das Element oder de[n] Horizont [...], innerhalb dessen die Diskurspraktiken stattfinden, als vielmehr [als] Elemente, die die Diskurspraktiken aufnehmen und transformieren« (Dreyfus/Rabinow 1987: 103, Herv. i. O.). 
Ein zweites Problem ist mit einer weiteren Unterscheidung verbunden, die häufig mit der obigen gleichgesetzt wird: die Gegenüberstellung von sprachlichen Diskursen und nicht-sprachlichen Handlungsweisen. Die diskurstheoretische Unterscheidung von diskursiv und nicht-diskursiv überlagert sich mit der von Sprache und Handeln und bildet Interferenzen aus. Beispielsweise unterteilen Schneider und Hirseland »sprachliche (diskursive) oder nicht-sprachliche (nicht-diskursive) Handlungsmuster« (Schneider/Hirseland 2005: 253; vgl. auch Lorey 1999: 94; Keller: 2005: 230). Durch die Debatten zieht sich eine Konnotationskette, bei der auf der einen Seite Sprache, Diskurs, Symbolik und Geist stehen und als Gegenpol auf der anderen Handeln, Praktiken, Materialität und Körper. Hält man sich strikt an diese Unterscheidung, dann müsste man Diskursanalyse als Textanalyse begreifen. Die meisten DiskurstheoretikerInnen bzw. -analytikerInnen sind sich jedoch einig, dass dies nicht hinreichend ist. Da diskursanalytische Fragestellungen oft auf die Analyse von Machtverhältnissen hin ausgerichtet sind, gelte es »mehr« in den Blick zu nehmen (Lorey 1999: 94).

In der »Archäologie des Wissens« schreibt Foucault, was er unter diskursiven Beziehungen zwischen Institutionen, ökonomischen und gesellschaftlichen Prozessen, Normsystemen, Klassifizierungsweisen und Techniken etc. versteht:

"Sie befinden sich irgendwie an der Grenze des Diskurses: sie bieten ihm die Gegenstände, über die er reden kann, oder vielmehr (denn dieses Bild des Angebots setzt voraus, daß die Gegenstände auf der einen Seite gebildet werden und der Diskurs auf der anderen) sie bestimmen das Bündel von Beziehungen, die der Diskurs bewirken muß, um von diesen und jenen Gegenständen reden, sie behandeln, sie benennen, sie analysieren, sie klassifizieren, sie erklären zu können.« (Foucault 1981: 70)

Damit werden, wie auch schon im vorherigen Kapitel zur Problematisierung angeschnitten, besonders die Ränder von Diskursen interessant, um eben jene Beziehungen zu untersuchen. Zum Gegenstand wird genau der Moment der Verschränkung bzw. in welchem etwas Nicht-diskursives diskursiv wird, so dass die Unterscheidung zwar als analytische in bestimmten Momenten sinnvoll sein mag, mit den oben genannten Problemen jedoch meist zur theoretischen wird, die zu viel Gewicht erhält. Bei der »Suche« nach nicht-diskursiven Praktiken wird man immer wieder auf das Diskursive stoßen sowie es 
selbst produzieren, so dass die Unterscheidung von diskursiv und nicht-diskursiv problematisch wird. ${ }^{36}$

\section{Analytische Ebenen der Untersuchung diskursiver Praktiken}

Weil es nicht »den« Diskurs zu untersuchen gibt, er sich nicht als ein Objekt oder als eine semiotische Einheit definieren lässt, die an konkreten historischen Punkten beginnt und endet, ist es sinnvoll, verschiedene analytische Ebenen zu unterscheiden ${ }^{37}:$ »(1) die Texte, in denen sich eine diskursive Praxis materialisiert hat und die auf die eine oder andere Weise erhoben und zu einem Korpus zusammen gestellt worden sind; (2) die Äußerungen, Aussagen und Äußerungsakte, in denen der Diskurs produziert und reproduziert wird; (3) die >großflächige Ebene des diskursiven Raumes, der Formationen, der Archive und Wiederholungen, die gewöhnlich verkürzt als >der Diskurs zeichnet wird; (4) die Ebene der Subjektpositionen und der sozialen Akteure, die als AdressantInnen im Diskurs positioniert sind, ihn aufgreifen, stabilisieren, umarbeiten, für andere Zwecke gebrauchen; (5) und schließlich die diskursive Arena als Verweisungszusammenhang der Äußerungspositionen der Akteure und als Kräftefeld und institutioneller Rahmen«. (Langer/Wrana 2009; vgl. Wrana 2006f: 121f.) $)^{38}$

Die Ebene der Texte (1) ist wohl für jede Diskursanalyse von Bedeutung, sie hat es in der Regel mit solchen zu tun. Schon die Zusammenstellung des Korpus enthält analytische Dimensionen, da mit ihr bereits nach Spuren relevanter diskursiver Praktiken gesucht wird, ebenso wie Entscheidungen getroffen werden, welche Materialien systematisch und/oder forschungspragmatisch ausgeschlossen werden. Ich habe sie deshalb im Kapitel zum Materialkorpus

36 Eine ähnliche Position vertreten Laclau und Mouffe. Sie verwerfen die Unterscheidung von diskursiv « und nicht-diskursiv«. Ihr Argument ist, dass Bedeutungen notwendigerweise diskursiv hervorgebracht werden. Die materielle, Realität selbst unterliegt einem Konstitutionsprozess, womit sie das Materielle gegen die Annahme eines "geistigen Charakters« von Diskursen stark machen. »Nicht die Existenz von Gegenständen außerhalb unseres Denkens wird bestritten, sondern die ganz andere Behauptung, daß sie sich außerhalb jeder diskursiven Bedingung des Auftauchens als Gegenstände konstituieren könnten.« (Laclau/Mouffe 1985: 157ff.) Als eine wesentliche Konsequenz der Aufhebung der Dichotomie diskursiv/nicht-diskursiv sehen sie schlussfolgernd »die Preisgabe des Gegensatzes von Denken und Wirklichkeit« (ebd.: 161) an.

37 Die Ebenen verhalten sich zueinander nicht parallel, eher lassen sie sich als Schnitte durch eine rhizomatische Komplexität denken.

38 Diskurstheoretische Erörterungen zu den genannten Ebene finden sich unter anderem in der folgenden Literatur: Äußerungen, Äußerungsakt, Aussagen (Foucault 1981: 128ff., Benveniste 1974; Angermüller 2005b, Wrana 2006: 122-137); diskursiver Raum (Foucault 1981: 48ff.; Diaz-Bone 2002: 113-135); Subjektpositionen (z. B. Althusser 1977; Certeau 1988; Butler 2001). 
ausführlich dargestellt. Für meine Studie sind im Rahmen dieses Ebenenmodells außerdem die Ebenen 2 bis 4 interessant, auf die hin die Bilder, Texte bzw. Textfragmente zu untersuchen sind - allerdings nicht alle gleichermaßen. Das sind zum einen die Äußerungen (Ebene 2) von SchülerInnen und LehrerInnen in der Schule, in konkreten Situationen und Interaktionen - dem Unterricht, in der Pause, oder im Interview -, von AutorInnen verschiedener Textgenres in den Zeitschriften sowie den Forschenden in den Beobachtungsprotokollen. Zum anderen sind es die Subjektpositionen (Ebene 4), die beispielsweise konstruiert werden, wenn die Lehrenden über ihre SchülerInnen sprechen und damit einen spezifischen »Schülerkörper« entwerfen oder sich selbst als Professionelle konstituieren. Wenngleich ich weder eine historische Entwicklung, noch einen umfassenden »Körperdiskurs« in allen in Verbindung mit Schule möglichen Äußerungen rekonstruiere, sind doch bestimmte Knotenpunkte, an denen sich verschiedene Diskurse »kreuzen«, als Relationen zu untersuchen (Ebene 3). Häufig sind dies thematische Verknüpfungen, wie z. B. von Körperlichkeit und Hauptschule oder Leiblichkeit und Natürlichkeit. Hier zeichnen sich bestimmte diskursive Formationen oder Strategien $\mathrm{ab}$, die wiederholt und transformiert werden. Dabei lässt sich zeigen, was jeweils zum Problem wird und worauf damit "geantwortet« wird. Allerdings sind es immer nur Ausschnitte und kein Diskurs im Sinne einer Einheit (den herauszuarbeiten unmöglich ist). Mein Vorgehen lässt sich insofern als »Diskursanalytische Ethnographie« beschreiben, da ich eher mikroanalytisch vorgehe und den Anspruch einer Einheit des Diskurses relativiere. ${ }^{39}$ Im nächsten Kapitel soll dies weiter konkretisiert werden.

39 Die »Archäologie des Wissens « und ihre Rezeption suggerieren eine solche (autonome) Einheit zeitweise (Foucault 1981: 80; Dreyfus/Rabinow 1987: 91), ebenso wie die Rede von »dem« Diskurs (z. B. dem Migranten-Diskurs bei Höhne/Kunz/Radtke 2005). Foucaults Arbeiten z. B. zur Sexualität zeigen dagegen alles andere als eine solche Einheit. 


\section{Diskursanalytische Ethnographie - Forschungsprozess und Methoden}

Ausgehend von der These, dass Erziehung am Körper ansetzt, analysiere ich die Darstellung dieses Verhältnisses von Körper und Erziehung in pädagogischen Praktiken sowie die Art und Weise seiner Thematisierung und Problematisierung in schulpädagogischer Fachliteratur. Es gilt, das diskursive Feld zu systematisieren und Zusammenhänge von »körperorientierten « Themen und Erziehungs- und Bildungsdiskursen herauszuarbeiten. Dabei gehe ich über das Vorgehen der meisten Diskursanalysen hinaus, welche im weitesten Sinne öffentliche Diskurse oder Progammatiken untersuchen. Indem ich nicht nur in Form von Texten und Bildern vorliegende fachspezifische Materialien, sondern auch ethnographische Daten in die Analyse einbeziehe, nehme ich das Reden über Körper(lichkeit) sowie Körperpraktiken in Interaktionen im Unterricht in den Blick. Mittels diskursanalytischer Verfahren untersuche ich, ob es jenseits des »Körperbooms«, welcher vor allem den willentlich »markierten« Körper fokussiert, eine Thematisierung weniger an der Oberfläche der Texte, z. B. implizit in Form opaker Verweise auf den disziplinierten, gesellschaftsfähigen Körper gibt.

Ethnographische Feldforschung und insbesondere der am häufigsten damit verknüpfte methodische Zugang der teilnehmenden Beobachtung (vgl. Friebertshäuser 1997; Lüders 2000) eignen sich besonders, um Interaktionen und Körperpraktiken zu beobachten und »eine genaue Beschreibung sozialer Ordnungen « (Kelle 1997: 199) abzugeben. So ist Alltagshandeln zu beobachten, das zu einem großen Teil unbewusst und auf Nachfragen hin von den Beteiligten nicht sprachlich verfügbar ist, »weil sie es im Modus des Selbstverständlichen und der eingekörperten Routine haben« (Amann/Hirschauer 1997: 24). Und genau diese soll neben dem Reden über Körper(lichkeit) fokussiert werden. Ethnographische Feldforschung arbeitet mit einer Mischung aus 
»dichter Beschreibung « (Geertz 1983: 294)1 ${ }^{1}$, wissenschaftlicher Analyse, Interpretation und Reflexion, wobei die Sammlung und Auswertung der Daten weitgehend bzw. in bestimmten Phasen gleichzeitig stattfinden. Theoretische und empirische Prozesse sind also wechselseitig miteinander verwoben (vgl. Friebertshäuser 1997: 511); das umso mehr, als sich die Forschungsarbeit und auch die Art der Auswertung der Daten in diesem Fall an der Grounded Theory (Glaser/Strauss 1998) orientieren. So ist es möglich, sich verhältnismäßig offen zunächst auf die Praktiken und Regeln des Feldes einzulassen und diese zum Gegenstand der weiteren Forschung zu machen, von denen aus dann die Auseinandersetzung mit dem Zeitschriftenkorpus beginnen kann.

Die Verbindung von ethnographischer Forschung und Diskursanalyse ist ein Novum, weshalb ich im Verlauf der Arbeit etliche methodische und methodologische Fragen zu klären hatte. Da es bei diesem Vorgehen bisher wenig Erfahrungen gibt, kann die kritische Reflexion einer solchen »diskursanalytischen Ethnographie« für weitere ähnlich angelegte Untersuchungen sehr aufschlussreich sein. Ich sehe die Arbeit als einen ersten Schritt an, dem noch viele weitere methodologische und forschungspraktische Diskussionen folgen müssen. Um dies zu tun und das Vorgehen im Sinne formulierter Gütekriterien qualitativer Forschung transparent und nachvollziehbar zu machen (Steinke 2000: 324f.), rekonstruiere ich im folgenden Kapitel den Forschungsprozess und diskutiere damit einhergehende methodische Fragen.

\section{Körperpraktiken in schulischen Interaktionen - zum Prozess der ethnographischen Feldforschung}

Da sich meine Forschungsfragen innerhalb des ethnographisch arbeitenden Lehr-Forschungsprojekts zu »Körperinszenierungen im Jugendalter « im schulischen Rahmen entwickelten, beginne ich mit dem Einstieg in dieses Feld. Die gesamte Forschungsgruppe bestand aus 20 MitarbeiterInnen, davon waren 15 Studierende. Während sich die Beobachtungsgruppe vor Ort aus acht Personen zusammensetzte, die im Unterricht einer 7. Hauptschulklasse und in den Pausen beobachteten, waren in die Auswertung der dort entstandenen Materialien weitere MitarbeiterInnen involviert. Den Zugang zur Schulklasse ermöglichte eine pädagogische Mitarbeiterin der Universität. Die angefragten jungen, emanzipierten LehrerInnen waren sehr am Projekt interessiert sowie an einer Zusammenarbeit mit WissenschaftlerInnen, die ihnen eine besondere Art der Rückmeldung sowie Reflexion ermöglichen konnten, mit der sie bereits gute Erfahrungen gemacht hatten.

1 Eine kritische Auseinandersetzung mit dem Konzept von Clifford Geertz führt Amann (1997: 298ff.). 
Neben der teilnehmenden Beobachtung als wesentliche Erhebungsmethode haben wir Interviews mit Schülerinnen und Schülern geführt. Um der angenommenen Schwierigkeit entgegenzuwirken, dass besonders der (noch dazu sich gerade in diesem Alter stark verändernde) eigene Körper und die eigenen Körperpraktiken nur schwer sprachlich erfasst werden können, haben wir den Befragten Bilder vorgelegt, die als Erzählaufforderung dienten. Da in den Interviews von der Anlage der Interviews her ebenso wie von den Interviewten selbst kaum Bezüge zur Institution Schule hergestellt wurden, habe ich sie in meine Analyse nicht einbezogen. Einen größeren Stellenwert erhalten dagegen die Experteninterviews, die mit den Lehrerinnen geführt wurden. Die Lehrerinnen haben den Status von »Expertinnen ${ }^{2}$, weil sie als solche ein "Sonderwissen" haben und ihre Expertise sozial institutionalisiert ist. Sie interessierten als in den schulischen Kontext eingebundene Akteurinnen. Zugleich ist bei dieser Typisierung besondere Vorsicht geboten, denn ihr Expertenstatus kann eben auch nur im institutionellen Kontext interpretiert werden, d. h. ihr Wissen über »ihre« SchülerInnen muss daran rückgebunden werden, indem die spezifischen Hierarchien dieser Beziehung bei der Analyse des Interviews einbezogen werden. Es ist ein spezielles Handlungswissen, welches aber gerade für meine Fragestellungen interessant ist.

Die gesamte Feldphase erstreckte sich über ein halbes Jahr. Vier Monate lang haben wir an zwei Tagen der Woche die Klasse im Unterricht der beiden im Team arbeitenden Lehrerinnen sowie einer Fachlehrerin und eines Fachlehrers ${ }^{3}$ beobachtet. Dabei waren sowohl der Unterricht als auch die Pausen sowie Klassenfeste von Interesse. Letztere ermöglichten uns, mit den SchülerInnen in Kontakt zu kommen. Die Unterrichtsstrukturen ließen dies schließlich nicht ohne Weiteres zu. Während der Unterrichtsbeobachtungen fertigten wir in einem Feldtagebuch bereits Notizen an, die im Anschluss daran noch einmal systematisch protokolliert wurden. Von den meisten Beobachtungen stehen mehrere Protokolle für die Auswertung zur Verfügung, da in der Regel mindestens zwei Forschende vor Ort waren. Bei regelmäßigen Treffen haben wir den Forschungsprozess reflektiert, die Ergebnisse gingen dann wieder in das weitere Vorgehen ein.

2 Die Diskussion um diese Kategorie und ihre wissenschaftstheoretischen Hintergründe lassen sich bei Bogner/Menz (2002: 39ff.) und Meuser/Nagel (2002: 73f.) nachlesen.

3 In der folgenden Analyse stehen ausschließlich die Praktiken der Lehrerinnen im Fokus, da ich den Sportunterricht des Lehrers aus zwei Gründen unberücksichtigt lasse, auch wenn er in Bezug auf Körper und Schule eigentlich nahe läge: Zum einen, weil der Sportunterricht einen weiteren Bereich eröffnet, der aufgrund spezieller, für anderen Unterricht nicht typischer Raum-Körper-Regime gesonderte Betrachtung bedürfe (vgl. Klein 1984). Zum anderen, weil das Material für eine solche Auseinandersetzung zu begrenzt ist. 
Die (möglichst heterogene) Forschungsgruppe war von besonderer Bedeutung, um den Problemen zu begegnen, die Teil ethnographischen Forschens sind: das Verwobensein der Forschenden in der eigenen Kultur, deren selektive Beobachtung, der Rückgriff auf literarische Darstellungsformen im Schreiben und die Schwierigkeit, die Schlussfolgerungen nachzuprüfen. Bourdieu schlägt eine reflexive Anthropologie vor, die versucht, die Doxa und Bias der eigenen Deutung aufzuklären (Bourdieu/Wacquant 1996). In diesem Prozess spielt die Forschungsgruppe eine große Rolle. Die Arbeit im Forschungskolloquium, in der sowohl ein geteiltes Kontextwissen über die Situationen besteht, als auch Außenstehende mit einem fremden Blick mitwirken, ermöglicht durch »intersubjektive Nachvollziehbarkeit« (Steinke 1999: 207) eine »kommunikative Validierung« der Daten (vgl. auch Friebertshäuser 2001: 131).

\section{"Es riecht nach Schule» - erste Eindrücke im Forschungsfeld}

Nach diesem Überblick über die Rahmendaten der Feldforschung möchte ich mit der folgenden Passage, welche ich aus mehreren Beobachtungsprotokollen zusammengestellt habe, einen bzw. meinen ersten Eindruck vom Forschungsfeld vermitteln. Begeben wir uns also in die Schule...

Es ist Dienstagmorgen $8.30 \mathrm{Uhr}$ und ich befinde mich samt allerlei Grüppchen von SchülerInnen auf dem Schulhof einer Hauptschule. Einige ForschungskollegInnen sind schon da und ich geselle mich zu ihnen. Von den SchülerInnen werden wir neugierig beäugt. Als sich alle eingefunden haben - fünf Frauen und drei Männer - gehen wir gemeinsam in das Schulgebäude. Da die erste Schulstunde noch nicht zu Ende ist, warten wir auf dem Gang vor dem Klassenzimmer, bis es zur Pause läutet. Wie früher! Nur dass die Glocke nicht weithin zu hören ist, sondern eine Leuchte diesen - im Unterricht sitzend oft sehnlich erwarteten - Moment markiert. Erinnerungen an die eigene Schulzeit werden wach. Sogar der Geruch im Haus ist derselbe.

Von den zwei Lehrerinnen der Klasse, die im Teamteaching zumeist gemeinsam unterrichten, werden wir freundlich begrüßt, auch die ersten SchülerInnen nehmen mit Blicken Kontakt zu uns auf. Ein Junge nimmt mir bereitwillig einen Stuhl ab, den ich aus einem anderen Raum hole - denn so viele Sitzgelegenheiten gibt es hier gar nicht, um mit einer achtköpfigen Forschungsgruppe Platz zu finden. Dies soll auch nicht immer so sein, heute möchten wir uns aber der 7. Klasse gemeinsam vorstellen. Wir verteilen uns hinter den in U-Form aufgestellten Schulbänken im Raum. Auf der Fensterseite sitzen sämtliche Mädchen, die Jungen, die zwei Drittel der Klasse ausmachen, belegen die anderen Plätze. An den Wänden hängen jede Menge Werke aus dem Kunstunterricht - wie es scheint -, es gibt kaum noch freien Platz. Die Regale sind angefüllt mit Büchern und Spielen, auf den sonnenbestrahlten Fensterbänken stehen Grünpflanzen. In der hinteren Reihe an der Wand befinden sich einige Computer, sie wirken eher abgestellt, als dass sie den Eindruck eines nutzbaren 
Arbeitsplatzes vermitteln. An der Tafel stehen Hausaufgaben angeschrieben. Daneben hängen eine Pinnwand mit einem Klassenfoto und ein großer, von hinten gut einsehbarer Stundenplan.

Zu Beginn der Stunde stehen alle SchülerInnen auf. Ein Junge wird aufgefordert, seine Baseballkappe abzusetzen, woraufhin er antwortet: »Oh, hab ich vergessen! « - was mehr so klingt wie: `Man kann es ja mal probieren`. Es folgt ein mehr oder weniger zaghaftes »Guten Morgen«. Ohne lang zu überlegen, geradezu automatisch, erhebt sich auch die gesamte Forschungsgruppe und grüßt - ebenso verhalten.

Die Lehrerinnen erklären der Schulklasse unsere Anwesenheit. Sie stellen uns als die »neuen PraktikantInnen« vor, denn, so erläuterten sie uns an anderer Stelle, an diese seien die SchülerInnen gewöhnt. So sind die SchülerInnen bereits auf uns vorbereitet, allerdings doch ein wenig erstaunt, dass so viele »PraktikantInnen « gekommen sind. Als wir im Anschluss unser Forschungsvorhaben beschreiben, wird deutlich, wie schwer es ist, aus der »Wissenschaftssprache « auszusteigen und leicht verständlich zu erklären, was wir vorhaben und worum es uns geht. Unmittelbar im Anschluss an unsere Vorstellung schreiben die SchülerInnen einen Mathematiktest. Sie müssen sofort umschalten und sich konzentrieren. Räumlich markiert und hergestellt wird dieser Bruch, indem die Schulbänke auseinandergerückt werden. Wir können die Zeit nutzen, uns weiter umzusehen und unsere ersten Eindrücke zu notieren. Nachdem die SchülerInnen ihren Test geschrieben haben, können sie in die Pause gehen. Nach unserer ersten Schulstunde können auch wir uns endlich austauschen.

Im Laufe des Schultages machen wir so unsere Erfahrungen im Feld: Den Schlüssel für die Toiletten muss man im Sekretariat oder bei den Lehrenden erbitten - wir dürfen jedoch auch das WC des Lehrpersonals benutzen; die Stühle, die uns teilweise viel zu klein sind, sind hart und unbequem - wohl nicht nur uns, dem 1,80 Meter großen Schüler wahrscheinlich ebenso wie dem kleinsten in der Klasse, dessen Füße kaum den Boden erreichen; wir erfahren etwas über Verbformen, über Sinnesorgane - nein, das Herz gehöre nicht dazu - und die Römer; das Hoftor wird in der Pause abgeschlossen; wir erhalten Eintritt zur uns in unserer Schulzeit nie zugänglichen »Hinterbühne« (Goffman 1969) - dem Lehrerzimmer; wir werden sowohl von den SchülerInnen als auch den LehrerInnen neugierig oder »einsortierend « befragt, was wir denn in "ihrer « Schule wollten; wir werden distanziert betrachtet oder ignoriert; wir werden von einem Lehrer »aufgeklärt«, dass man den SchülerInnen bloß nicht alles glauben solle... Fünf Unterrichtsstunden am Stück zu beobachten ist sehr anstrengend, nach drei Stunden sind wir schon kaum noch aufnahmefähig. Zu Beginn ist es schwierig, nicht inhaltlich dem Unterrichtsgeschehen zu folgen, sondern auf die SchülerInnen sowie auf die stattfindenden Interaktionen zu achten. Was ist wichtig festzuhalten, was kann man überhaupt sehen? Viele unsortierte Eindrücke auf einmal. Die Jugendlichen finde ich alle sympathisch. In den anschlieBenden Gesprächen wird aber auch schnell deutlich, dass ich vor allem diejenigen in Erinnerung habe, die sich aktiv und auffallend in Szene gesetzt haben. Nun ist es 
erst einmal nötig zu sortieren, sich die Namen der einzelnen SchülerInnen zu merken und die Aufmerksamkeiten einigermaßen gleichmäßig zu verteilen.

Wir werden von der Klasse offen empfangen und für die SchülerInnen scheint es schnell zur Normalität zu gehören, dass sich »PraktikantInnen« für sie interessieren. Das erleichtert es, uns nicht wie Eindringlinge in eine »fremde Welt « vorzukommen. Die gegenseitige Annäherung erfolgt dennoch vorsichtig. Dass auch die Lehrerinnen unserem Vorhaben so offen, interessiert und unkompliziert gegenüberstehen, ermöglicht uns, neugierig zu sein und uns verhältnismäßig frei im Feld zu bewegen. (AL/AS/HA) ${ }^{4}$

\section{Forschungsbeziehungen}

Trotz der Beobachtung durch meist jeweils zwei ForscherInnen schien sich innerhalb der Klasse schnell normaler Schulalltag einzustellen. Von den SchülerInnen wurden wir sehr unterschiedlich aufgenommen bzw. behandelt: distanziert, neugierig, herausfordernd. Wir wurden ebenso in ihre Aktivitäten einbezogen wie uns deutlich gemacht wurde, dass wir genau da nichts zu suchen hätten. Die Lehrerinnen der Klasse hatten uns als »PraktikantInnen« bei den SchülerInnen eingeführt. Dieses Etikett ermöglichte uns, mittels einer Rolle, die innerhalb der Schule vorgesehen ist und der wir wahrscheinlich als HospitantInnen am nächsten kamen, einzusteigen. Denn, so wurde schnell offensichtlich, als ForscherInnen oder Leute von der Universität, ob Professorin oder Studentin, wären wir unfassbar und fremd geblieben. Vor allem für die SchülerInnen war es von großer Bedeutung, uns innerhalb der institutionellen Schulstrukturen, die sich auf die Rolle der Lehrerin, des Schülers, vielleicht noch der Sekretärin oder des Hausmeisters und eben der Praktikantin beschränken, einordnen zu können, da es für ihr Handeln und dessen, was sie sich »leisten« können, unmittelbare Folgen hat. Das zeigt sich z. B. in folgender Situation, welche sich in ähnlich versichernder Weise immer mal wieder abspielte:

Erhan fragte irgendwann, ob ich aufgeschrieben hätte und den Lehrerinnen sagen würde, dass Maris und er von einander abgeschrieben haben. (AL)

Der Auszug aus dem Feldtagebuch spiegelt die Unsicherheit wider, inwiefern uns vertraut werden kann. Welche Position innerhalb der in der Institution

4 Im Anschluss an die Ausschnitte aus den Beobachtungsprotokollen verweisen die Kürzel auf die jeweiligen AutorInnen. In diesem Fall habe ich drei verschiedene Protokolle zu einem »ethnographischen Quellentext « (Friebertshäuser 2001) zusammengeführt. Im Folgenden verwende ich jedoch meist die Originalauszüge. Des Weiteren sind die Namen der SchülerInnen und LehrerInnen verändert, um Anonymität zu gewährleisten. 
Schule möglichen nehmen wir ein? Wir sind zwar keine Lehrenden, uns sind als »Erwachsene« mit dem Lehrerzimmer und der Lehrertoilette aber Räume zugänglich, die eindeutig der Lehrerschaft zugeordnet und damit für die SchülerInnen tabu sind. Zugleich sind wir eindeutig »Nicht-SchülerInnen«. Unsere Erklärungen auf die Nachfragen, was Universität, Pädagogik und ein Semester seien, verstärkten die Unklarheit der Situation eher noch, da wir dabei, um der Verständlichkeit willen, immer wieder auf den Vergleich mit der Schule zurück kamen. Wie in dieser Auseinandersetzung deutlich wird, war aber auch für uns als (größtenteils studierende) Forschende nicht immer klar, von welcher Position aus wir agieren sollten. Auch dazu ein Beispiel:

Einer der Schüler hat irgendwelche Spendenüberweisungsträger mitgenommen, nun fliegen sie auf dem Schulhof herum, weil niemand sich mehr verantwortlich dafür fühlt, sie aufzuheben und wegzuschmeißen - das wäre entschieden uncool. Ich überlege, ob ich nicht sagen soll: »Nun hebt die Dinger mal auf, da ist ein Mülleimer«. Ich lasse es aber bleiben. Einerseits will ich nicht den Lehrer geben, andererseits will ich sehen, ob sie nicht doch noch von selbst drauf kommen (was nicht geschieht). (HA)

Im Laufe der Zeit hat sich diese Unsicherheit auf beiden Seiten gelegt. Wir wurden als (insbesondere junge) Frauen und Männer wahrgenommen, zu AnsprechpartnerInnen, Vorbildern, Respektpersonen, SpielgefährtInnen usw. Vereinzelt gab es SchülerInnen, die sich (offensichtlich jedenfalls) nach wie vor nicht um uns kümmerten. Die Beziehungen zu den einzelnen Jugendlichen waren von unterschiedlicher Intensität. In den Gesprächen, wie sie häufig nach Unterrichtsschluss, in den Pausen oder beim gemeinsamen Gang zur U-Bahn stattfanden, wurde auch deutlich, dass wir nicht nur als »Eindringlinge « im Feld wahrgenommen wurden, sondern wie wichtig wir für einige SchülerInnen wurden und welchen Einfluss wir mit unserer Anwesenheit auf das Feld ausübten.

Lorena fragt mich, wann wir wieder in die Klasse kämen, und als ich ihr sage, erst in einer Woche, guckt sie ganz betrübt. Ich frage sie, ob wir öfter kommen sollen. Das bejaht sie. Auf meine Frage, weshalb, stellt sie fest, dass es dann weniger stressig sei. Sie bezog das auf die gesamte Klasse, weniger auf die Lehrerinnen. Irgendwie würden sich alle mehr zusammenreißen. (AL)

Auch wenn dagegen die Lehrerinnen betonten, der Unterricht sei wie immer was nicht ausschließt, dass die eben zu Wort gekommene Schülerin das anders empfand -, interessierten diese sich ebenfalls für unsere Beobachtungen. Gerade in Bezug auf für sie schwierige Situationen war ihnen eine Rückmel- 
dung wichtig. Zum Teil versuchten sie auch, ihre Handlungen zu erklären bzw. zu legitimieren, wobei deutlich wurde, wie diffizil und konkurrierend das Verhältnis von >Wissenschaft $<$ und >Praxis $<$ ist bzw. als solches betrachtet wird. Als Vergleich zwischen dem Blick vom »Elfenbeinturm " und dem »wirklichen Schulalltag" wurde es immer wieder Gegenstand in den Gesprächen miteinander. Es wurde um Deutungshoheit gerungen, da gerade im Bereich der Schule alle Beteiligten persönliche Erfahrungen haben und zudem der wissenschaftliche Blick als der potenziell kritisierende wahrgenommen wird oder werden kann, jener aber doch dem "Alltagsgeschäft « enthoben scheint. Einen Vorteil in dieser manchmal konkurrierenden Situation hatten die Studierenden mit ihrer Position, die der von PraktikantInnen am nächsten kam. In der Interaktion mit Lehrenden konnten sie als noch Lernende begriffen werden, die mit ihrer eigenen Schulbiographie den SchülerInnen näher schienen als den Lehrenden.

\section{Den sKörper` in der Institution Schule erforschen}

Es wurde bereits deutlich, wie sehr der organisationelle Rahmen der Institution Schule die Möglichkeiten des forschenden Blicks vorstrukturiert (vgl. auch Weißköppel 2001: 68). Die Forschenden werden für eine gewiss Zeit und bis zu einem gewissen Grad Teil des Feldes, ihre Aufmerksamkeit wird von den vorhandenen Strukturen gelenkt. Vor allem, weil sie ihnen bereits ausgesprochen vertraut sind. Sie alle haben selbst viele Jahre Schule als SchülerIn »verinnerlicht $\ll$. Dementsprechend liegt es nahe, sich mit eben jenen zu identifizieren - was aber aus deren Sicht überhaupt nicht möglich ist. Wie schnell die »alten Muster« wieder greifen, wird in der folgenden Passage deutlich:

Der Unterricht an sich beherrscht stark meine Beobachtung. Es ist schwer, sich auf die Interaktionen der SchülerInnen zu konzentrieren und den Unterrichtsinhalt nicht weiter zu beachten. Eventuell ist das noch aus der eigenen Schulzeit im Unterbewusstsein: Konzentration auf das Wesentliche hieß immer Konzentration auf den Unterricht, nicht auf Mitschüler etc. (AS)

13 Jahre Schulsozialisation machen es schwer, auf einmal anders, jenseits dieser Rollenerwartungen zu agieren, die Erinnerungen der eigenen Schulzeit nicht zu übertragen. Die Aufmerksamkeit auf das Wesentliche wird quasi automatisch über das »Körpergedächtnis« (Hirschauer 1994: 674) hergestellt. Zugleich wurde bei den Beobachtungen deutlich, wie viel Selbstdisziplin nötig ist, um diese Aufmerksamkeit zu erreichen - sowohl bei den SchülerInnen, der Forschungsgruppe und manchmal auch den LehrerInnen. 
Das führt mich zum Thema dieses Abschnitts und meiner Arbeit insgesamt. Viele Fragen zum Umgang mit dem Körper in der Schule ergaben sich daraus, dass auch wir als ForscherInnen wieder mehrere Stunden am Stück in dieser Institution still sitzen mussten, auf den harten, von Minute zu Minute unbequemer werdenden, uns zum Teil viel zu kleinen Stühlen. Das eigene Körpergefühl und der Drang nach Bewegung öffneten den Blick für Umgangsformen mit dem Körper und seine Problematisierungen im Kontext schulischer Disziplinierung. So stehen sich beispielsweise zwei Wahrnehmungen während der Selbstbeobachtung der ForscherInnen gegenüber, die aufeinander verweisen:

In der Schulstunde: Während all dieser Beobachtungen merke ich, wie ich immer wieder auf dem Stuhl herumrutsche. Mal sitze ich ganz vorn am Rand, der Körper bildet fast eine gerade Linie, dann rutsche ich fast herunter, richte mich auf. Schlage mal das eine, mal das andere Bein über das jeweils andere. Die Knie schmerzen. Ich stelle meine Ellenbogen auf den Knien ab und beuge mich vor. Eine Weile später setze ich mich auf meinen einen Fuß. Sitze dann seitlich auf dem Stuhl, um meinen einen Arm auf der Rückenlehne abzulegen. (AL)

Beim Schreiben des Beobachtungsprotokolls: Während ich diese Szene beschreibe und mich zurückerinnere, sitze ich auf meinem bequemen und gepolsterten Bürostuhl und lehne mich zwischendrin gerne einmal weit zurück, denn bei meinem Stuhl ist das nicht nur gefahrlos möglich, sondern sogar vorgesehen. Der Rücken entspannt sich dabei für einen Augenblick, ich genieße diese Möglichkeit und spüre noch die Anspannung und Anstrengung des gestrigen Tages auf den harten Stühlen in der Schule. Warum müssen Kinder in der Schule auf derart unbequemen und harten Stühlen sitzen? (BF)

Forscherin 1 beobachtet nicht nur die SchülerInnen, wie sie es bewerkstelligen, 45 bzw. 90 Minuten am Stück auf den Schulstühlen zu sitzen, sondern sie bemerkt an sich selbst, wie schwierig es ist, dies in aufrechter, möglichst ordentlich geometrischer Anordnung der Gliedmaßen und Körperteile (vgl. Rumpf 1996b) zu tun. Forscherin 2 erinnert sich im Schreiben an ihre Versuche, während der Beobachtung still zu sitzen, und bemerkt die Vorzüge ihres eigenen »Arbeitsgeräts«, welches explizit Körperhaltungen vorsieht, wie das Zurücklehnen ähnlich dem Kippeln, die den SchülerInnen im Unterricht verboten sind (vgl. Kap. >Phänomene schulischer Sanktion<). Damit werden die Zumutungen dieses Körperregimes offensichtlich, die durch den Raum, das Mobiliar sowie die rhythmisierte Zeit entstehen. Als Forscherin wird man während der teilnehmenden Beobachtung mitsamt dem eigenen Körper (zwangsläufig) für eine gewisse Zeit Teil des Feldes. Die Forschungsfrage danach, wie der Körper in pädagogischen Praktiken zum Einsatz kommt, wie 
und mit welchen Implikationen über den Körper verhandelt wird und auf welche Körper-Konzepte dabei zurückgegriffen wird, entwickelte sich also gewissermaßen am eigenen Leibe. Klaus Amann und Stefan Hirschauer sprechen diesbezüglich von Ethnographien als »mimetische Formen empirischer Sozialforschung (1997: 20; Herv. i. O.). Die Partizipation im Forschungsfeld und die Subjektivität der Forschenden werden dabei nicht als Hindernis, sondern als Voraussetzung des Verstehens gewertet und genutzt. »Betrachtet man Distanz als eine reflexive Haltung (und nicht so sehr nur als Abstand oder Grenzziehung), so umfasst auch das Vertrautwerden mit dem Feld und vor allem mit sich im Feld einen Distanzierungsprozess. Dieser lässt sich als ein Oszillieren zwischen Nähe und Distanz zum Feld beschreiben.« (Langer 2006: 40) Durch die Irritation des Subjektiven, das Erleben der Regeln des Feldes, die reflexive Distanzierung und die Analyse und Reflexion des Arbeitsbündnisses ${ }^{5}$ zwischen Forschenden und Forschungsfeld lässt sich etwas über die Regeln des Feldes aussagen.

\section{Die Erweiterung des Materialkorpus}

Während der Feldforschung zeigte sich an immer wieder in ähnlicher Weise auftretenden Konflikten zwischen SchülerInnen und LehrerInnen, dass diese auch aufgrund unterschiedlicher individueller sowie institutioneller KörperKonzepte und des Aufeinandertreffens verschiedener, sich zum Teil ausschließender Rationalitäten und Programmatiken der Institution Schule und jugendkultureller oder medialer Inszenierungen entstanden. Sowohl PädagogInnen als auch SchülerInnen werden mit verschiedenen Lenkungsformen und Disziplinierungsweisen konfrontiert, die sie in ihr Handeln einbeziehen oder davon ausschließen bzw. mit sich und anderen verhandeln müssen. Dieses hier noch unspezifische Verhältnis näher beschreiben zu können, ist ein Ziel meiner Arbeit.

Um nun zu eruieren, welche Körperkonzepte über diese Schulklasse hinaus innerhalb der Schulpädagogik überhaupt bestehen, wie Körper und Leiblichkeit von PädagogInnen aus Wissenschaft und Praxis problematisiert werden, müssen andere Materialien hinzugezogen werden. Die Überlegungen und Entscheidungen dazu stelle ich im Folgenden ausführlich dar, denn die Materialaufbereitung enthält als »Basis und Herzstück « ${ }^{6}$ (Jäger 2001: 104) einer Diskursanalyse bereits Analyseanteile, indem erste Beobachtungen und Inter-

5 Ausführungen zum Begriff des Arbeitsbündnisses finden sich bei Resch (1998) sowie zur Analyse der Arbeitsbündnisse als interpretatives Verfahren bei Langer (2006).

6 Selbst in wissenschaftlichen Texten über Forschungsmethoden sind Körpermetaphern, wie ich sie später noch genauer untersuchen werde, präsent. 
pretationsansätze darin eingehen. Diese habe ich als Memos gesondert festgehalten bzw. gekennzeichnet. Die Erstellung des Materialkorpus ist ausführlich dokumentiert, da man über die Sichtung, Auswahl und Begründung möglicher Daten bereits zu ersten Ergebnissen hinsichtlich pädagogischer Körperdiskurse kommt, genauer gesagt, diese über die Auswahl zu einem gewissen Grad als solche mitkonstituiert werden. Denn, so Reiner Keller, »auch wenn die einzelnen Bestandteile von Diskursen als empirische Artefakte existieren, werden sie doch erst durch den beobachtenden Zugriff der Sozialwissenschaftler zum Diskurs« (Keller 2001: 137). Dies verdeutlicht, wie sehr die Forschenden in die Diskursanalyse involviert sind, dass sie ebenfalls nicht außerhalb diskursiver Praktiken und der Produktion von Diskursen stehen. Die eigene Position sowohl bezüglich des Selbstverständnisses dem Gegenstand gegenüber als auch bezüglich des theoretischen Blicks (was nicht unbedingt zu trennen ist) muss deshalb ebenso reflektiert werden, wie z. B. die Forschungsbeziehungen bei der teilnehmenden Beobachtung.

\section{Zur Auswahl der Medien}

In die Korpuszusammenstellung gingen verschiedene Überlegungen ein: Zunächst schien es so, als würde trotz des allgemeinen »Körperbooms« der Körper bzw. Leiblichkeit innerhalb der Erziehungswissenschaften, vor allem in Bezug auf pädagogische Prozesse und Institutionen, kaum thematisiert. Ein erster Überblick mittels Schlagwortabfragen im unmittelbaren semantischen Umkreis von >Körper/Leib` und `Pädagogik/Erziehung/Schule` in Bibliothekskatalogen schien das zu bestätigen. Thematisierungen fanden sich hauptsächlich in den markierten und marginalisierten Bereichen der Sonder- sowie der Theaterpädagogik. ${ }^{7}$ Doch muss die Thematisierung bzw. Problematisierung des menschlichen Körpers in Bildungs- und Erziehungsprozessen überhaupt immer explizit in Überschriften oder über Schlagwortkataloge ausgezeichnet sein? Könnte es nicht vielmehr sein, dass auf unterschiedliche Weisen - explizit oder implizit - Körperkonzepte in pädagogische Texte (samt ihrer Bebilderung) einfließen, auch wenn dies nicht ihr Hauptthema ist? Hier wird die Unterscheidung zwischen Text und Diskurs noch einmal evident. Eventuell sind für meine Fragestellung Textfragmente (Äußerungen) interessant, die eine Aussage innerhalb des nachzuzeichnenden Diskurses bilden, ohne dass von

7 Marginalisiert und markiert insofern, als sie beide auf etwas jenseits des als normal Angesehenen verweisen - die Behinderung, die über den Körper markiert ist, und das Schauspiel, in dem der Körper eingesetzt wird, um etwas vorzuspielen, welches somit nicht »echt « ist. 
den AutorInnen ${ }^{8}$ darauf hingewiesen wird, Teil des Körperdiskurses zu sein oder sein zu wollen. Es schien also angebracht, nicht lediglich die zum Thema Körper »einschlägige« Literatur bzw. das Wort »Körper« selbst als »Brille« zu benutzen, um den diskursiven Praktiken auf die Spur zu kommen, sondern Orte zu suchen, an denen diese aufzufinden sein könnte.

Welche Orte könnten dies sein? Um an den ethnographischen Teil meiner Arbeit anknüpfen zu können, kamen Dokumente mit programmatischem Charakter aus dem Bereich der »Schul- und Lehrer-Ratgeber « in Lehrerbildungsmaterialen und Handbüchern sowie pädagogischen/erziehungswissenschaftlichen Fachzeitschriften aus dem Bereich Schule in Frage. Diese verschiedenartigen Materialien unterschiedlicher Medien mussten nun begründet zu einem methodisch kontrolliert bearbeitbaren Korpus eingegrenzt werden. Das formal festgelegte Korpus steckt den nötigen Rahmen ab, der eine Übersicht über Problematisierungsweisen, thematische Zusammenschlüsse sowie Verweise auf Leerstellen, Tabuisierungen und Implizites gibt und letztlich die Validität durch Überprüf- und Vergleichbarkeit herstellt. Zugleich kann im Laufe des Forschungsprozesses, ohne dass alle möglichen Artikel, Textfragmente und Bilder einer genauen Analyse unterzogen werden, bereits eine qualitative Vollständigkeit diskursiver Formationen - quasi eine »Sättigung « eintreten (vgl. Keller 2004: 88).

Um einen Bereich abzustecken, in dem möglichst aktuelle Bezüge zu anderen diskursiven Ereignissen oder gesellschaftlichen Diskussionen hergestellt werden, habe ich drei auf Schule bezogene Fachzeitschriften ausgewählt. Das Medium Zeitschrift stellt ein Forum sowohl für systematische Grundfragen wissenschaftlicher Disziplinen als auch aktuell diskutierte Probleme dar. Es dient der Kommunikation, dem wissenschaftlichen bzw. fachöffentlichen Austausch, der eigenen Aufgabenzuschreibung und Selbstvergewisserung von Profession und Disziplin sowie damit verbunden der Schaffung von Zugehörigkeiten und Distinktionen. Die ausgewählten Zeitschriften begreife ich als Fachzeitschriften, die auf eine berufliche bzw. praktisch-pädagogische Verwendbarkeit ausgerichtet sind (vgl. Nafzger-Glöser 1994: 14). Als Material sind sie deshalb gut geeignet, weil sie periodisch mit bestimmten regelmäßigen Rubriken erscheinen und auf eine gewisse Kontinuität angelegt sind. Sie stellen einen Themenkanon, Forschungen und Problematiken in einer bestimmten historischen Situation dar. In der Regel stehen einzelne Zeitschriften für spezifische Positionen im Feld, auch wenn innerhalb der Zeitschrift kontrovers diskutiert werden kann (vgl. Langer/Wrana 2005: 2).

8 An dieser Stelle könnte auch die Verlegerin, die kategorisierende Person einer Bibliothek oder ein Rezensent stehen, also beteiligte DiskursproduzentInnen. 
Aus dem umfangreichen Angebot schulbezogener erziehungswissenschaftlicher bzw. pädagogischer Zeitschriften (vgl. Institut für Bildungsmedien 2004) habe ich folgende ausgewählt: die Zeitschriften >Pädagogik`, >Päd Forum` und \Schulmagazin 5 bis $10<$. Alle drei enthalten allgemeine sowie jeweils aktuelle pädagogische Fragen und nicht (nur) - wie die meisten Schulzeitschriften - spezielle Themen eines jeweils fächerbezogenen Unterrichts. Auch sind sie nicht auf eine bestimmte Schulart beschränkt. Die Eingrenzung auf die Schuljahre 5 bis 10 beim >Schulmagazin ist für mein Vorhaben insofern unerheblich, als wir es in Bezug auf den ethnographischen Teil mit einer siebten Klasse zu tun haben und insbesondere Themen in Bezug auf diese daran gekoppelte Altersgruppe interessant sein werden. Weitere Kriterien waren: eine möglichst weite Verbreitung bzw. hohe Auflage, unterschiedliche Positionierungen und Materialien bzw. Textgenres ${ }^{9}$ innerhalb einer Zeitschrift und nicht zuletzt die Praxisnähe, die sich bei der Leserschaft und in der Herkunft der AutorInnen widerspiegelt. Diese Kriterien sind in der folgenden Übersicht aufgeführt:

Tabelle 1: Übersicht über das Zeitschriftenkorpus

\begin{tabular}{|l|l|l|l|}
\hline & PÄDAGOGIK & PÄD Forum & $\begin{array}{l}\text { Schulmagazin } \\
\mathbf{5} \text { bis 10 }\end{array}$ \\
\hline $\begin{array}{l}\text { Kategori- } \\
\text { sierung }\end{array}$ & $\begin{array}{l}\text { Höchste Auflage } \\
\text { in Deutschland, } \\
\text { allgemeine The- } \\
\text { men, reformpäda- } \\
\text { gogisch ausge- } \\
\text { richtet }\end{array}$ & $\begin{array}{l}\text { Alternatives Spek- } \\
\text { trum, das auch über } \\
\text { Schule hinausgeht } \\
\text { (Reformpädagogik) }\end{array}$ & $\begin{array}{l}\text { Fächerübergreifend } \\
\text { und spezialisiert, } \\
\text { mit Unterrichtsma- } \\
\text { terialien, und allge- } \\
\text { meinen Themen }\end{array}$ \\
\hline Modus & $11 \mathrm{x}$ jährlich & $6 \mathrm{x}$ jährlich & $11 \mathrm{x}$ jährlich \\
\hline $\begin{array}{l}\text { Jahrgänge } \\
\text { bis 2005 }\end{array}$ & 57 & 33 & 73 \\
\hline Auflage & 12.000 & 1.000 & 6.400 \\
\hline
\end{tabular}

9 Es handelt sich um Tagungs-, Forschungs- und Erfahrungsberichte, wissenschaftliche Abhandlungen, didaktisch aufbereitetes Unterrichtsmaterial, philosophische Diskussionen.

10 Bis 1990 nannte sich die Zeitschrift »Hauptschulmagazin«, ihren spezifischen Fokus hat sie ab 1991 erweitert. 


\begin{tabular}{|l|l|l|l|}
\hline & PÄDAGOGIK & PÄD Forum & $\begin{array}{l}\text { Schulmagazin } \\
\mathbf{5} \text { bis 10 }\end{array}$ \\
\hline $\begin{array}{l}\text { Leserschaft } \\
\text { (Selbstbe- } \\
\text { schreibung } \\
\text { der Zeit- } \\
\text { schrift) }\end{array}$ & $\begin{array}{l}\text { (Wird nicht näher } \\
\text { eingegrenzt: vor } \\
\text { allem LehrerIn- } \\
\text { nen, aber auch } \\
\text { PädgogInnen an- } \\
\text { derer Bereiche) }\end{array}$ & $\begin{array}{l}\text { "Züren all jene, die an } \\
\text { sozialen Problemen, } \\
\text { pädagogischen Re- } \\
\text { formen und alterna- } \\
\text { tiven Entwürfen im } \\
\text { Umfeld von Schule, } \\
\text { Sozialpädagogik } \\
\text { und Erwachsenen- } \\
\text { darstufe I, die in } \\
\text { mehreren Fächern } \\
\text { unterrichten und an } \\
\text { Haupt-, Real-, Ge- } \\
\text { samt-, Regel-, Mit- } \\
\text { tel- und Sekundar- } \\
\text { schulen tätig } \\
\text { sind.« interessiert }\end{array}$ & $\begin{array}{l}\text { sind (Media-Info } \\
\text { Nr. 18, 2005) }\end{array}$ \\
\hline $\begin{array}{l}\text { AutorIn- } \\
\text { nen }{ }^{12}\end{array}$ & $\begin{array}{l}\text { Etwa zu gleichen } \\
\text { Teilen Praktike- } \\
\text { rInnen und Wis- } \\
\text { senschaftlerInnen, } \\
\text { variiert nach The- } \\
\text { menschwerpunk- } \\
\text { ten }\end{array}$ & $\begin{array}{l}\text { WissenschaftlerIn- } \\
\text { nen und PraktikerIn- } \\
\text { nen, wobei der An- } \\
\text { teil an Wissen- } \\
\text { schaftlern überwiegt }\end{array}$ & $\begin{array}{l}\text { Vorwiegend Prakti- } \\
\text { kerInnen, hin und } \\
\text { wieder auch Wissen- } \\
\text { schaftlerInnen }\end{array}$ \\
\hline
\end{tabular}

Aufgrund seiner geringeren Auflagenstärke fällt das >PÄD Forum Kriterienkatalog ein wenig heraus, die beiden anderen Zeitschriften sind sowohl die auflagenstärksten ihrer Art als auch ausgesprochen praxisnah. Wichtig erschien mir aber noch ein weiterer Punkt: Die drei Zeitschriften decken verschiedene Bereiche ab. Während die >Pädagogik « in reformpädagogischer Tradition stehend die Zeitschrift sowohl für LehrerInnen als auch PädagogInnen anderer Praxisfelder ist, ist das >Schulmagazin 5 bis $10<$ vor allem wegen seiner darin enthaltenen heraustrennbaren Unterrichtsmaterialien für LehrerInnen interessant. Das >PÄD Forum stellt gewissermaßen das Alternativprogramm dar. Hier werden vielfach wissenschaftliche Texte mit reformpädagogischen Anleihen veröffentlicht, jedoch auch Praxisnähe proklamiert. In welchem Ausmaß die Zeitschriften gelesen und rezipiert werden, wäre eine inter-

11 http://editor.aerit.net/Paedagogik/details.php?id intern=528 (12.01.2007)

12 Die AutorInnen kommen aus unterschiedlichen Wissenschaftsdisziplinen, wenn auch vorwiegend aus der Erziehungswissenschaft. Als PraktikerInnen bezeichne ich diejenigen, die entweder in der Schule als Lehrende tätig sind oder in beratenden, therapeutischen, sozialpädagogischen oder Erwachsenenbildungsbereichen. 
essante Größe, ist aber kaum nachzuvollziehen. Für meine Arbeit ist es insofern nicht von Bedeutung, da auch eine breite Rezeption sich nicht unbedingt im Handeln widerspiegeln muss. Sowohl die Artikelproduktion in den Zeitschriften als auch die beobachtbaren Körperpraktiken, Interaktionen und räumlichen Anordnungen sind Teil hier herauszuarbeitender pädagogischer bzw. gesellschaftlicher diskursiver Praktiken.

Die Recherche der Zeitschriften habe ich auf den Zeitraum von 1995 bis 2005 beschränkt. Mitte der 1990er Jahre ist in den Zeitschriften eine ausgesprochen starke Thematisierung des Körpers festzustellen, wie dies auch in anderen Bereichen zu verzeichnen ist (s. `Einleitung ‘), so dass ich dieses diskursive Ereignis als Beginn meiner Untersuchung markiere. Das erklärt sich auch daraus, dass das Korpus überhaupt bearbeitbar sein muss. Zudem geht es mir weniger darum, einen Geschichts- oder Diskursverlauf zu rekonstruieren, auch wenn sich bereits innerhalb dieses recht kurzen Zeitraums bestimmte Tendenzen erkennen lassen. Dafür müsste über dieses Korpus hinausgegangen werden.

\section{Alles Körper oder was? Von der ersten Sichtung des Materials zu einer thematischen Gliederung}

Innerhalb der ausgewählten Zeitschriften habe ich anhand der Titel in den Inhaltsverzeichnissen das Material weiter sondiert. Sich lediglich auf Ausgaben der Zeitschriften mit bestimmten Themenschwerpunkten, wie z. B. »Mit dem Körper lernen«, zu beschränken, griff zu kurz, da so die Rubriken jenseits dieser Abhandlung damit außen vor blieben. Doch unabhängig davon stellte sich die Frage, welche Themen einzubeziehen waren und welche nicht: zunächst diejenigen, in denen nach Auskunft des Titels explizit vom Körper die Rede ist. Das gestaltete sich (recht) einfach. Doch wo könnte bzw. müsste noch vom Körper geredet werden und wo nicht? Dass ein Essay zur Rechtschreibreform hier nicht interessant ist, möchte ich behaupten, doch was ist mit verschiedenen Berichten zu spezifischen Unterrichtsformen und -methoden? Sie beziehen sich auf bestimmte Didaktiken und Interaktionen zwischen LehrerInnen und SchülerInnen, da kann doch eigentlich deren Körper(lichkeit) nicht unerwähnt bleiben. In welchen sozialen Praxen lässt sich der Körper ausschließen? Andersherum gefragt: Was ist eigentlich alles «Körper<? Diese Fragen verweisen auf ein Problem, das ich während dieser Arbeit zu bewältigen hatte: dass der flüchtige Körper doch »irgendwie alles« und damit auch »nichts« ist, wenn man ihn nicht in bestimmten Relationen fokussiert. Sehr treffend formuliert das Carolyn Walker Bynum: »In gewissem Sinne ist es natürlich falsch, >den Körper`zum Thema zu machen. >Der Körper ist entweder über- 
haupt kein eigenes Thema, oder er umfaßt so gut wie alle Themen.« (Bynum 1996: 1)

Um dennoch für meine Fragestellung sinnvolle Eingrenzungen vorzunehmen, brachte mich einerseits die theoretische Auseinandersetzung mit den Körper- und Diskursbegriff sowie andererseits der Blick auf die Materialien und ersten Forschungsergebnisse aus der Feldforschung in der Schule weiter. Denn für meine Untersuchung spielen insbesondere die Themenbereiche eine Rolle, die auch dort relevant waren; sie sollten aufeinander bezogen werden können. Zudem sollten sie in allen drei Zeitschriften einigermaßen häufig vertreten sein. Auf diese Weise bin ich zu folgenden Themenkomplexen gelangt, die das Gerüst der Zeitschriftenanalyse bilden:

Tabelle 2: Themenkomplexe der analysierten Zeitschriftenartikel

\begin{tabular}{|l|c|}
\hline Themenkomplexe & Anzahl der Texte \\
\hline Körper (K) ${ }^{13}$ & 40 \\
\hline Jugend (J) & 11 \\
\hline Sexualität/Pubertät (SP) & 19 \\
\hline Gender (G) & 19 \\
\hline Disziplin/Unterrichtsordnung (D) & 42 \\
\hline LehrerInnen (LK) & 23 \\
\hline
\end{tabular}

Diese Komplexe habe ich ausgewählt, weil sie eine Schnittmenge bilden aus Kategorien, die sich aus dem Materialien der Feldforschung (Beobachtungsprotokolle, Interviews) eruieren ließen, sowie aus Kategorien innerhalb des Zeitschriftenkorpus, die neben anderen explizit oder implizit auf den Körper verwiesen. Diese gemeinsame Schnittmenge ermöglicht, die verschiedenen Materialien aufeinander zu beziehen. Aufeinander beziehen heißt nicht, die Materialien unreflektiert zusammenzuführen. Dies ist hier ebenso wenig möglich, wie bei anderen triangulativen Verfahren (vgl. Kelle 2001: 202). Die Auswahl schließt wiederum Bereiche aus, in denen Körperlichkeit ebenfalls thematisiert werden könnte. In den Zeitschriften sind es folgende: Unterrichtsund Erziehungskonzepte; Werte Kompetenz und Schlüsselqualifikationen das

13 Die Kürzel hinter den Themenkomplexen finden sich auch in den Kodierungen der Texte wieder, so dass meine Kategorisierung jeweils nachvollziehbar wird. Der Komplex >Disziplin umfasst weitere Subkategorien: Unterrichtsstörungen (17), Rituale (12), Strafen (7). Auf die Feinheiten, Gründe und Erklärungen verweise ich jeweils an entsprechender Stelle in der Analyse. 
Lernen lernen Drogen und Sucht Gewalt Soziales Lernen. Es sind zwar Themen, die durchaus im Zusammenhang mit Körper gedacht werden könnten bzw. müssten, sie kommen aber nicht in allen Zeitschriften und auch insgesamt nur verhältnismäßig selten vor. Nicht zuletzt wurden sie während der Feldforschung bzw. im Material nicht thematisiert.

In der Aufstellung der Themenkomplexe zeigen sich bereits verschiedene Ebenen der Problematisierung. Während der erste Bereich Texte enthält, deren Überschriften explizit das Thema Körper hervorheben, gibt es weiterhin Titel, die nach meiner Vorstellung >Körper(lichkeit)< im Text thematisieren müssten oder könnten, um damit latent oder implizit auf ihn zu verweisen. ${ }^{14}$ Die Unterscheidung dieser Ebenen habe ich als analytische für die weitere Systematisierung genutzt. Damit verknüpft waren folgende Fragen: Welche Körperkonzepte werden entworfen bzw. worauf wird wie rekurriert, wenn explizit das Thema Körper verhandelt wird? Inwiefern und in welcher Weise kommt der >Körperく innerhalb der anderen Themenkomplexe zum Einsatz? Geht man davon aus, dass mit der expliziten Thematisierung immer eine besondere Problematisierung einhergeht, so wird eventuell innerhalb der Kategorie »latent bzw. implizit« die Normalität im Sinne einer gängigen Thematisierung des Körpers besonders evident. Gibt es also unterschiedliche Problematisierungsstrategien?

Die aufgestellten Themenkomplexe bilden ein Netz von ebenfalls auf unterschiedlichen Ebenen angesiedelten Themen, welche sich teilweise überlappen, quer zueinander stehen, sich ergänzen, Ausschnitte bilden. Meine These ist, dass sich bestimmte Thematisierungsknoten herausarbeiten lassen, an denen sich verschiedene Diskurse überschneiden bzw. andersherum, der Körper innerhalb spezifischer Diskurse auf ähnliche Weise konstruiert wird. Der Begriff Thematisierungsknoten spezifiziert den Begriff Knotenpunkt von Laclau und Mouffe auf Themenbereiche hin. Sie prägen diesen Begriff, um zu verdeutlichen, dass es keine gänzlich und endgültig fixierten Diskurse, sondern nur partielle Fixierungen innerhalb einer diskursiven Praxis gibt. Die Punkte dieser partiellen Fixierung von Bedeutung nennen sie Knotenpunkte (Laclau/ Mouffe 1991: 164). Flottierende Elemente werden neu gebündelt und als Knotenpunkte konstituiert (vgl. auch Moebius 2006: 133). Da ich mich in meinem Vorgehen an Themenkomplexen im Sinne von material-gegenständlichen und potenziell-aktuellen Ordnungskategorien (Link 1999: 153) orientiere, nehme ich diese Spezifizierung vor. Gerade die Thematisierungsknoten

14 Die Bezeichnungen latent oder implizit sagen noch nichts darüber aus, ob >Körper(lichkeit)< im Text explizit oder implizit thematisiert wird, sie bezieht sich hier lediglich auf den Titel des Artikels. Ebenso gibt es einige Artikel, die zwar im Titel explizit auf den Körper verweisen (z. B. mittels einer KörperMetapher), im weiteren Text kommt `Körper` dann aber gar nicht vor. 
als Bereiche der Überschneidung verschiedener Diskurse könnten im Weiteren interessant sein.

\section{Forschungspraxis einer interpretativen Analytik ${ }^{15}$}

Die folgende Aufstellung verschafft noch einmal einen Überblick über die verschiedenen Materialien, die ich auf beschriebene Weise erhoben und in die die empirische Analyse einbezogen habe:

- 31 Beobachtungsprotokolle aus der Feldforschung (über je 2 bis 5 Unterrichtsstunden)

- 3 Interviews mit Expertinnen (Lehrerinnen)

- Weitere Dokumente (Schuldokumente, Fotografien, Gesetzestexte)

- 151 Artikel aus dem Korpus dreier Fachzeitschriften (Pädagogik, Päd Forum, Schulmagazin 5 bis 10; zum Teil mit Bildern; s. Tabelle 2)

Diese Menge an heterogenem Datenmaterial galt es nun theoriegeleitet detailliert zu analysieren. In den folgenden Abschnitten führe ich in mein methodisches Vorgehen bei der Auswertung der Daten ein und veranschauliche den weiteren Arbeitsprozess.

\section{Theoretical sampling}

Bereits im letzten Kapitel zeigte sich, wie sehr Datenaufbereitung und Oberflächenanalyse (vgl. Diaz-Bone 2005: 23) miteinander verknüpft sind. Dieses oszillierende Vorgehen hat Gemeinsamkeiten mit dem der Grounded Theory (Glaser/Strauss 1998). ${ }^{16}$ Das dort formulierte Prinzip des theoretical sampling lässt sich als zunehmend fokussierender Forschungsprozess beschreiben, bei dem »der Prozeß der Datenerhebung durch die sich entwickelnde Theorie kontrolliert« (Strauss 1994: 70; Herv. i. O.) wird. Ausgehend vom

15 Dreyfus und Rabinow (1987) haben Foucaults Position zwischen Strukturalismus und Hermeneutik mit diesem Begriff umschrieben, der auf das Verhältnis zwischen Analyse und Interpretation verweist. "Die Interpretation erwächst aus pragmatischen Anliegen und hat pragmatische Absichten.« (ebd.: 23), sie geht damit über das empirisch Abgesicherte hinaus. Keller betont mit diesem Begriff, dass bei einer Diskursanalyse nicht die Bedeutungseinheit des einzelnen Dokuments bzw. Textes im Vordergrund steht, sondern dass die durch analytische Gliederung und interpretierende Feinanalyse entstandenen Ergebnisse durchaus unterschiedlichen diskursiven Praktiken zugerechnet werden können (Keller 2005b: 68).

16 Weitere Darstellungen der Grounded Theory finden sich bei Strauss (1994), Strauss/Corbin (1996), Strübing 2004. Als Beispiel für einen Bezug zur Grounded Theory innerhalb einer Diskursanalyse sei hier außerdem die Untersuchung von Rainer Diaz-Bone (2002) genannt. 
bisher formal eingegrenzten Korpus findet eine »Identifizierung « von Daten für die Analyse statt. Diese erfordert bereits eine intensive Auseinandersetzung mit dem Feld, bei der die Forschenden unterschiedliche Distanzen zum Forschungsgegenstand einnehmen.

In ähnlicher Weise findet dieser Prozess auch bei der Auswertung der Protokolle aus der Schulbeobachtung statt. Die verschiedenen Materialsorten habe ich unter bestimmten situativ-ereignishaften wie auch thematischen Kriterien in »ethnographischen Quellentexten« (Friebertshäuser 2001: 127ff.) zusammengeführt, sie bilden gewissermaßen Ausgangspunkte für die weitere Analyse. Im Mittelpunkt der Sichtung standen dabei vor allem die Körperpraktiken, die in raum-zeitliche Strukturen eingebunden sind bzw. dieselben konstituieren, sowie das Reden über Körper(lichkeit). Das methodische Vorgehen geht zurück auf die von Helmut Apel et al. (1995) entwickelte Methode des »Wissenschaftlichen Quellentextes«, welche zwischen Grounded Theory und theoriegeleiteten Verfahren anzusiedeln ist. Bezeichnet wird damit »eine aufbereitete Zusammenstellung von primären und wissenschaftlich erzeugten Quellen unter analytischen Gesichtspunkten« (ebd.: 367f.). Das Verfahren dient dazu, die Materialien unterschiedlicher methodischer Herkunft (hier Beobachtungsprotokolle, Interviewtranskripte, Schuldokumente, Raumzeichnungen und Fotografien ${ }^{17}$ ) für die nachfolgende Interpretation zusammenzuführen. In einem mehrstufigen Prozess (ebd.: 371) werden die Materialien zunächst reflexiv anhand von Leitthemen und theoretischen Modellen, die den Gesamtrahmen abstecken, ausgewählt. Aus der Rekonstruktion des Geschehens und der empirienahen Kommentierung lassen sich so gegenstandsbezogene Theorien innerhalb des hier vorgestellten analytischen Rahmens formulieren. Dieser Prozess ist immer wieder zu reflektieren, insbesondere ist $\mathrm{zu}$ fragen, welche Interessen, Denk- und Bewertungsmuster darin einfließen.

Die Auswertung der Materialien fand in einem wechselseitigen Prozess statt, als eine Hin- und Herbewegung zwischen den Materialien der Feldforschung und den pädagogischen Zeitschriften als Medium des Redens über Unterricht und Schule. Diese Bewegung spiegelt sich auch in den einzelnen Kapiteln wider. In der Regel stellen die Beobachtungen einen Ausgangspunkt für die weitere Suchbewegung dar. Die Themenkomplexe, wie ich sie dargestellt habe, sind bereits ein erstes Ergebnis des Rekonstruierens von Schlüsseltexten und Kategorien im oben vorgestellten Sinne.

Ausgehend von einer interaktiven Praxis wurden für mich die jeweiligen Akteure als weitere ordnende Kategorie relevant, oder vielleicht besser die je-

17 Dafür hat die Forschungsgruppe ein eigenes Analyse-Instrumentarium entwickelt, welches das Foto in seiner Eigenrealität und den Kontext, in dem es entstanden ist, in die Interpretation einbezieht (vgl. Langer 2007b). 
weiligen Akteurspositionen: SchülerInnen und LehrerInnen. Anzunehmen war, dass Körperkonzepte nicht lediglich allgemein formuliert werden, sondern gerade in Bezug auf die jeweilige Position in der Schule. Verteilt man die »Rollen« auf die Themenkomplexe, ergibt sich dann folgendes Bild:

Tabelle 3: Themenkomplexe und Akteurspositionen

\begin{tabular}{|l|l|}
\hline Themenkomplex & Thematisierung des Körpers von... \\
\hline Körper & $\begin{array}{l}\text { allgemein (wenig spezifiziert auf SchülerInnen } \\
\text { oder LehrerInnen) }\end{array}$ \\
\hline Jugend & SchülerInnen \\
\hline Sexualität/Pubertät & SchülerInnen \\
\hline Gender & SchülerInnen und LehrerInnen \\
\hline Disziplin & LehrerInnen und SchülerInnen \\
\hline LehrerInnen & LehrerInnen \\
\hline
\end{tabular}

Diese Zuordnung ist bereits ein Ergebnis der Analyse. Wenn ich über das Verhältnis von Körper und Schule schreibe, schreibe ich zumeist über das Verhältnis von Schülerkörpern und/oder Lehrerkörpern zu Schule. Die jeweiligen Themenkomplexe stellen zugleich Teilkorpora dar, mit denen ich mich »dem« Schüler- oder Lehr(er)körper annähere. Ähnlich der Arbeit mit ethnographischen Quellentexten zeigte sich eine Verdichtung innerhalb dieser Komplexe. Das heißt aber nicht, dass die jeweiligen Texte immer nur in einem Komplex relevant wurden und in diesem Sinne konsistent wären oder konsistente Diskurse erzeugten. Zum Teil habe ich die Texte oder vielmehr Textfragmente unter anderem Blickwinkel erneut aufgenommen, da sich entweder dieselben diskursiven Praktiken rekonstruieren ließen oder sie bestimmte Formationen kontrastierten, wobei widersprüchlich und unvereinbar erscheinende Bedeutungsstrukturen durchaus diskursinhärent sein konnten.

Um solche diskursiven Praktiken herausarbeiten zu können, habe ich von den einzelnen Texten Protokolle angefertigt, in denen ich folgende Punkte festgehalten habe:

- die jeweiligen AutorInnen, die als DiskursproduzentInnen bestimmte legitimierte Sprecherpositionen einnehmen (z. B. die praktizierende Lehrerin als Expertin) 
- Subjektpositionen, also Positionierungen, die mittels diskursiver Praktiken erzeugt werden und sich auf spezifische AdressatInnen beziehen (z. B. Hauptschüler)

- das Interaktionsbündnis zwischen Text und LeserIn (z. B. Modus der Ansprache, Botschaften)

- Körperkonzepte (z. B. der Körper als von der Zivilisation umzingelter Leib)

- die Rolle der Pädagogik bzw. der Institution Schule und ggf. didaktische Praktiken (z. B. Schule als Instanz für Gesundheitsprävention oder Atemübungen)

- Organisation textueller Strukturen über Differenzen, Konnotationen, Argumentationen und Metaphern als diskursive Strategien (z. B. die bereits angesprochene Differenzierung zwischen Körper und Leib oder die Metapher des Raumes, wenn von »bewohnbarem Körper« die Rede ist)

- Memos zu weiteren Beobachtungen, Auffälligkeiten, Irritationen usw. (z. B. zur Kombination von Text und Bild)

Im Zuge des Schreibens und weiteren Verdichtens habe ich einige Texte bzw. Textfragmente als Schlüsselstellen herauskristallisiert. In ihnen vereinen sich diskursive Praktiken, die sich in anderen Texten fragmentarisch finden, da dort andere Schwerpunkte und Diskursfragmente überwiegen. Eine Schwierigkeit bestand zum Teil darin, dass es sich um unterschiedliche DiskursproduzentInnen und, häufig damit verknüpft, um unterschiedliche Textgenres bzw. widerstreitende Diskursarten (Lyotard 1989) handelt. Zwar können auch sie beispielsweise auf ein spezifisches Körperkonzept rekurrieren, dennoch ergeben sich aus unterschiedlichen Interessen und sozialen Sprecherpositionen schwer vergleichbare diskursive Strategien. Allerdings zeigen sich umgekehrt in dieser Schwierigkeit auch bestimmte Zuständigkeiten: Beispielsweise scheinen vor allem LehrerInnen als ExpertInnen der Praxis legitimiert, über Unterrichtsstörungen zu sprechen, während zum Thema Pubertät vor allem PsychologInnen oder SozialwissenschaftlerInnen eine Expertise zugestanden wird. Bevor ich jedoch über die Ergebnisse meiner Analyse berichte, möchte ich im nächsten Kapitel noch einmal näher auf konkrete Methoden der Text- bzw. Bildanalyse eingehen, die mir als »Werkzeug« dienen.

\section{Auswertungsmethoden für die Text- und Bildinterpretation}

Für die Feinanalyse der ausgewählten Texte waren vor allem sprachwissenschaftliche Perspektiven und Methoden nützlich, um die Textproduktion zu untersuchen. Ich habe sie in der Darstellung meines Protokollierens bereits erwähnt. Ausgangspunkt ist das in Kapitel >Subjekt, Macht und Diskurseく ein- 
geführte Interaktionsbündnis zwischen Text und LeserIn, welches die Performanz von Texten ermöglicht (zum Teil auch übertragbar auf das Arbeitsbündnis, welches im Interview von den Akteuren hergestellt wird). Diese Performanz entfaltet ein Text aber nicht aus sich heraus, sondern indem er auf andere Texte bzw. Diskurse verweist und indem ihm bestimmte diskursive Strategien eigen sind. Eine dieser Strategien ist die Setzung von Differenzen. Thomas Höhne zeigt unter anderem mit Hilfe des semiotischen Vierecks von Algirdas Julien Greimas (1971), wie sich im Migrationsdiskurs thematische Reihen durch Differenzsetzungen und Konnotationen herausarbeiten lassen (Höhne 2003a: 401ff.). Innerhalb meines Textkorpus ist es z. B. die Differenz gesund vs. krank, welche als basale Gegenüberstellung gesamte Texte organisiert. Durch die wiederholte Anwendung bestimmter Trennungen und Verknüpfungen, z. B. mit Leib vs. Körper, werden Konnotationsketten gebildet, die bestimmte Dinge, Eigenschaften, Personen usw. ein- oder auschließen sowie jeweils positiv oder negativ bewerten. Damit sind nicht nur die jeweiligen Differenzen selbst von Interesse, sondern vor allem auch ihre Verknüpfungen: die Gebrauchsweisen bzw. Praktiken des Differenzierens. Manche Differenzen werden so stark expliziert und markiert, dass sie den Text nicht nur basal strukturieren, sondern die Lesenden zu einer Entscheidung für die eine (positive) Seite der Differenz auffordern.

Gekoppelt mit dieser Strategie, aber auch unabhängig davon, wird in vielen Texten mit Metaphern operiert. Mit Metaphern werden komplexe oder abstrakte Phänomene »bildlich« in bekannte, einfache Zusammenhänge übertragen (Niehr/Böke 2003: 330). Sie veranschaulichen und plausibilisieren anhand von Assoziationen, die sie freisetzen. Häufig dienen sie einer Dramatisierung. "Metaphern fungieren nicht nur als stilistischer Schmuck, sondern als bildliche `Erläuterungen` mit kognitivem Mehrwert.« (ebd.) Das funktioniert, weil bestimmte Metapherntypen häufig innerhalb bestimmter Diskurse genutzt werden. Metaphern treten nicht vereinzelt auf, sondern bilden rekonstruierbare metaphorische Konzepte. Jürgen Link (1988: 286) spricht darüber hinaus von Kollektivsymbolik: Die Verwendung und Bevorzugung bestimmter Metaphern bzw. Topoi stehen nicht nur im Verwendungszusammenhang eines einzelnen Textes, vielmehr lassen sie Rückschlüsse auf individuelle, kollektive und epochenspezifische Denkweisen zu.

Diese verschiedenen methodischen Werkzeuge stellen Zwischenschritte dar, um diskursive Praktiken herausarbeiten zu können. Wesentlich ist dabei nicht die einzelne Figur, also z. B. eine spezifische Differenz, sondern die Art ihrer Verkettungen und Wiederholung (vgl. Höhne 2003a: 404ff., Langer/ Wrana 2005: 6-11; Wrana 2006: 144f.). Auf diese Weise untersuche ich nicht nur die Zeitschriftentexte, sondern auch die Experteninterviews, in denen über 
'Körper(lichkeit) gesprochen wird. Die Beobachtungsprotokolle könnten ebenso angeschaut werden (vgl. Ott 2008) - der Reflexivität halber habe ich das auch immer wieder getan -, um dem eigenen Selbstverständnis auf die Spur zu kommen. Dennoch setze ich sie hier anders ein: als Texte, welche beobachtete Situationen darstellen und in denen sich Körperpraktiken zeigen, über die auch oder eben gerade nicht geredet wird. Sie werden so zum Bezugsoder zum Kontrastpunkt des restlichen Materials und seiner Analysen.

Eine weitere Besonderheit sind die Bilder, die als wichtige diskursive Praktik eine spezifische Materialsorte darstellen. ${ }^{17}$ In allen drei Zeitschriften wird mit Bildern gearbeitet, allerdings mit sehr unterschiedlichen Bildsorten. Während in der Zeitschrift >Pädagogik` Schwarz-Weiß-Fotografien dominieren, die mit durchschnittlich ca. einem Drittel der Seiten viel Raum einnehmen, gehen die anderen beiden Zeitschriften mit solchem Bildmaterial und mit Bildern insgesamt sparsamer um. Sie enthalten vor allem Zeichnungen, im >Schulmagazin 5 bis $10<$ sind es meist comicartige Karrikaturen. Fotografien werden nur in geringem Umfang eingesetzt und sie haben eher (pädagogische) Situationen zum Sujet, während in der >Pädagogik` Großaufnahmen von SchülerInnen(-Körpern) besonders präsent sind. Eine systematische Analyse all dieser Bilder und ihre jeweiliger Wechselwirkungen mit den Texten wäre ein aufschlussreiches Unterfangen, das meine Untersuchung ergänzen und vervollständigen könnte. Da die Analyse von Bildern in ihrer Eigenrealität, die sie von geschriebenen Texten unterscheidet, sowie von komplexen TextBild-Graphik-Dokumenten sehr aufwändig ist und nicht nebenbei »miterledigt« werden kann, werde ich nur auf allgemeine, noch präziser zu fassende Beobachtungen und einzelne Bilder im Zuge besonders prägnanter Textstellen zurückkommen. Ich beziehe mich dabei auf Roland Barthes (1990) und Umberto Eco (1972) sowie verschiedene Verfahren der Fotoanalyse, wie sie in den letzten Jahren für die Erziehungs- und Sozialwissenschaften entwickelt wurden (Ehrenspeck/Schäffer 2003; Pilarczyk/Mietzner $2005^{18}$, Maasen/Mayerhausen/Renggli 2006).

17 Auf die ausführliche offene Diskussion, wie Bilder in Abgrenzung oder in Bezug auf Texte begriffen werden können, gehe ich hier nicht weiter ein (vgl. Barthes 1990: 21f., Friebertshäuser/Felden/Schäffer 2007). Ihre Spezifik, gewissermaßen eine andere Form von Textförmigkeit, wird in der Analyse an den entsprechenden Stellen deutlich werden.

18 Ulrike Pilarczyk und Ulrike Mietzner präsentieren in ihrem Band u. a. eine Analyse fotografischer Inszenierungen von Geschlecht in der Zeitschrift >Pädagogikı der Jahrgänge 1990 bis 2000 (Pilarczyk/Mietzner 2005: 205-213). 


\section{Reflexion des Forschungsprozesses}

Ähnlich wie sich das ethnographische Vorgehen und die »Daten«, die man dabei produziert, diskursanalytisch bearbeiten lassen, lässt sich die Analyse der verschiedenen Texte aus den Zeitschriften wie eine Feldforschung beschreiben und reflektieren. Zunächst gilt es ein Forschungsfeld abzustecken, einen möglichen Untersuchungsrahmen zu bilden. Die Korpusbildung stellt diesen ersten Rahmen dar. Sie ist alles andere als formal, auch wenn sie sich an bestimmten Kriterien wie Auflagenzahl, Leserschaft oder Praxisbezug zur Institution Schule orientiert. Ein solches Feld abzustecken findet über Entdeckungen statt. Nach und nach werden Möglichkeiten eröffnet, wieder beiseite gelegt, vorläufig in Erwägung gezogen. Ähnlich wie bei der teilnehmenden Beobachtung tastet man sich vor, »lernt« den Stil einer Zeitschrift, deren AutorInnen und die angenommene Leserschaft »kennen«.

Im Falle dieser Arbeit habe ich mich anhand von Themenkomplexen und Themenknoten fortbewegt, wodurch eine Art Netz entstanden ist. Diese Verknüpfung bildet den diskursiven Raum ab. Die Schwierigkeit besteht darin, dies auf einfach beschriebenen Seiten »abzubilden«. Um sich im Netz nicht selbst zu verheddern, musste ich immer wieder Begrenzungen einführen, stärkere Seile bzw. Verknotungen, die Orientierung bieten konnten. Eine Begrenzung ist beispielsweise die analytische Unterscheidung von Zeitschriftenartikeln in solche, die in ihrem Titel den Körper explizit ansprechen und solche, die aufgrund ihres thematischen Bereichs, z. B. Geschlecht, auch Körper(lichkeit) thematisieren könnten. Mit Texten in dieser Form zu arbeiten, ist ähnlich wie das Forschen im Feld, weil sich auch da Einstiegsmuster zeigen und das permanente Austarieren von Nähe und Distanz nötig ist. Es gibt Texte, die einem »sympathisch« sind, andere, die man sofort ablehnt. Damit stellen sich Fragen: Was ist da ein kritischer Blick, ist er schon gleichbedeutend mit Kritik? Wie lässt sich eine möglichst neutrale Haltung einnehmen? Innerhalb des Interaktionsbündnisses, welches ich mit den Texten einging, musste ich mich zu bestimmten Positionen verhalten, noch dazu Körper(lichkeit) auch immer etwas mit einem selbst zu tun hat. Vielfach sind es affirmative Texte, die einen einfangen, gegen deren Affirmativität man sich regelrecht zur Wehr setzen muss.

Diese Art des »Betroffenseins« hat viel mit dem Thema Körper zu tun und mit einer »leiblichen Textwahrnehmung«, die durch die Konzentration auf das Thema sensibilisiert wird. Ähnlich dem mimetischen Forschen bei der teilnehmenden Beobachtung lassen sich die Irritationen auch hier nutzen. Diskursanalyse ist eine Art und Weise mit Texten zu arbeiten, bei der es um ein Verstehen einer Logik geht und darum, eigene Arbeitsbündnisse mit dem 
Text aufzudecken. In dieser Beziehung ist die Situation der Forschenden ähnlich wie im Feld. Auch der Text wird fremd gemacht (vgl. Amann/Hirschauer 1997): durch »Protokolle« zu den Beobachtungen im Text. Diese Beobachtungen finden methodisch geleitet nach und nach immer fokussierter statt. Die Analyse geht damit über eine Bündelung von Themen oder einer Kategorisierung von Texten hinaus. Über die Themen und ihre Sortierungen gelangt man zu den Produktionsweisen von Texten, zu den Regelmäßigkeiten, wie Denkweisen konstituiert werden. Die Perspektive, zunächst mittels angenommener Thematisierungsknoten über >den Körper hinauszugehen, ermöglichte die Thematisierung bzw. Problematisierung von `Körper« dort herauszuarbeiten, wo es nicht vordergründig und allgemein um ihn geht. Durch die Ergänzung und Kontrastierung von Diskursanalyse und Ethnographie sollte es aber auch möglich sein, auf die »diskursiven Leerstellen« zu treffen, also auch das Nicht-gesagte, Unsagbare, Verschwiegene (welches sich allerdings auch andersherum in der ethnographischen Forschung als Problem darstellt; vgl. dazu Hirschauer 2001). Dabei bestand allerdings die Schwierigkeit, etwas zu finden und zu untersuchen, was gar nicht vorhanden ist, weil es nicht besprochen, nicht thematisiert wird. Hier wurde die Feldforschung in der Schule relevant, immer wieder war sie Ausgangs- und Rückkehrpunkt. Feldforschung und Zeitschriftenanalyse bilden einen Spannungsbogen, in dem jeweils Widersprüche zu Tage treten, sich neue Perspektiven auf Körper und Schule eröffnen sowie Erklärungen für Körperkonzepte und -praktiken geliefert werden. 



\section{Lernende und gelehrige Körper}

Das erste Kapitel des empirischen Teils der Arbeit führt von den SchülerInnen der 7. Klasse hin zu ersten Ergebnissen, wie über Körper- bzw. Leiblichkeit von SchülerInnen in den Zeitschriften diskutiert wird. Einen geeigneten Einstieg in die Klasse bietet der Klassenraum, der Ort, an dem sich die SchülerInnen die meiste Zeit ihres Schul(all)tages aufhalten und an dem auch der größte Teil der Beobachtungen stattfand. Räume organisieren soziales Mitund Nebeneinander, sie »beherbergen « Körper, geben Ordnungen vor, werden aber auch durch die Anordnung und Bewegungen von Körper organisiert (vgl. Löw 2001). »Schulische Räume sind durch ihre Institutionalisierung zumeist bereits (vor-)strukturiert, sie werden jedoch ständig neu hervorgebracht und bleiben über ein individuelles Handeln hinaus wirksam. Somit bilden sie quasi eine ‘Grenzregion zwischen kollektivem Handeln und eigener Konstituierung.«(Willems 2007: 223) Dies schien mir ein geeigneter Blickwinkel, um mich den SchülerInnen, präziser: dem SchülerInnen-Körper als Gegenstand der Untersuchung anzunähern. Im Vordergrund stehen also im Folgenden die SchülerInnen: als Lernende, deren Lernen gelehrige Körper bedingt und zugleich herstellt.

Körper in ihrem Verhältnis zum Raum zu betrachten, dient nicht nur als Einstieg ins Feld, sondern ist hilfreich, um die Flüchtigkeit von Körpern zu begrenzen und Bezugspunkte zu setzen, indem institutionelle Regeln jenseits individueller Handhabungen oder unmittelbarer Face-to-face-Interaktionen einbezogen werden. Im Zusammenhang damit zeichnete sich bei der Beobachtung frühzeitig eine zentrale Ordnungskategorie ab, die nahe liegend ist, wenn es um Körper geht: die Kategorie Geschlecht. Sie wird im Kontext von Körper(n) und Raum hervorgekehrt und als »Doing Gender« (West/Zimmermann 1991), also als fortlaufender Prozess von Attribuierungen und Wahrnehmungen in einer interaktiven Praxis, näher reflektiert. Da wir in einer 7. Klasse 
geforscht haben, wird auch die Inszenierung von Jugendlichkeit bzw. als Jugendliche eine wichtige Rolle spielen (vgl. Friebertshäuser/Langer/Richter 2008). Beide Kategorien - Geschlecht und Jugend - sind gewissermaßen Knotenpunkte, die relevant werden, beschäftigt man sich mit dem Körper von SchülerInnen in der Institution Schule. Im Anschluss an die allgemeinen Betrachtungen der Praktiken in der Schulklasse, welche deren Alltag im Sinne einer Ordnung ausmachen, »zoome« ich näher heran und fokussiere auf kleinste körperliche Haltungen, Gesten und Bewegungen eines einzelnen Schülers. Aufschlussreich ist dies, weil deutlich wird, wie viele Aktivitäten stattfinden und möglich sind, während ein Schüler »still sitzt«.

Der Frage, ob der einführend dargestellte, (mehr oder weniger) still sitzende Schüler und sein disziplinierter und gelehriger Körper als Bestandteil historischer Schultradition Gegenstand erziehungswissenschaftlicher bzw. pädagogischer Debatten ist, gehe ich am Ende des Kapitels nach, womit ich die Untersuchungsebene wechsele. Nicht mehr die Beobachtungen in der Schulklasse führen mich zu den lernenden und gelehrigen Körpern, sondern ich versuche diese bzw. dieses Verhältnis in den Zeitschriften zu eruieren. Die Suchbewegung, mit der ich meinen Forschungsprozess beschrieben habe, führt hier zunächst zu allgemeinen Körperkonzepten. Allgemein heißt, dass durchaus der Körper als historisch konstituierter und disziplinierter thematisiert bzw. problematisiert wird, allerdings kaum speziell im Verhältnis zur Schule. Doch zunächst werde ich den Klassenraum der 7. Klasse beschreiben, um einen Rahmen für mögliche Perspektiven auf diskursive Praktiken bezüglich des Verhältnisses von Körper und Schule abzustecken.

\section{Raumordnung als Sitzordnung}

Die Tische im Raum der 7. Klasse sind in Form eines »Hufeisens« angeordnet. Da hierbei nicht genügend Plätze für alle SchülerInnen vorhanden sind, stehen innerhalb des Us noch drei weitere Schulbänke, die zur Tafel hin ausgerichtet sind. So wird ein etwas geöffneter Kreis gebildet. Zwei etwas niedrigere Tische befinden sich direkt vor dem Lehrertisch - dort sitzen die kleinsten Jungen der Klasse. Sie wenden dem Rest der Klasse ihren Rücken zu. Ein weiterer Schüler sitzt am Rand innerhalb des Us, so dass sich ein Teil der Klasse hinter ihm befindet. Allen anderen ermöglicht die Anordnung, sich gegenseitig ins Gesicht zu schauen, nötigt aber auch dazu, sich im Blick zu haben. Der Tisch der Lehrerinnen schließt an die Schulbänke an und wird so in den Kreis integriert. Durch ihre Positionierung vor der Tafel, die Ausstattung mit einem größeren Tisch sowie drehbaren und gepolsterten Stühlen können sich die »Lehrkörper« dennoch von den Schülerkörpern abheben. 
Eine solche Anordnung vermittelt starre Positionen im Raum. Sie stellt neben der Frontalausrichtung von Schulbänken eine übliche Parzellierung einer Schulklasse dar, in der alle ihren zugeordneten Platz haben. Die Sitzordnung der Klasse ist mehr oder weniger festgelegt, die Lerngruppe mit ihren ungeordneten Körpern wird geordnet, um »ungewisse Verteilungen« oder »diffuses Herumschweifen « (Foucault 1998: 183) zu vermeiden und einen als für Lernen nutzbar begriffenen und institutionalisierten Raum zu erzeugen. Der Begriff der Sitzordnung ist fest im Schulvokabular verankert. Er verweist auf zwei wesentliche Dinge im Schulbetrieb: erstens auf die Tätigkeit des Sitzens und eine spezifische Körperhaltung, die die SchülerInnen während der meisten Zeit, die sie in der Schule verbringen, einnehmen und über die insbesondere während der letzten Jahrhundertwende viel diskutiert wurde, in welcher Art und Weise sie zu geschehen haben (vgl. Caruso 2003; Hnilica 2003; Rumpf 1981). Dass die Schule besuchen bzw. am Unterricht teilnehmen vorrangig sitzen bedeutet und zwar auf einem in bestimmter Weise klassifizierten Platz, darauf verweisen auch die Bezeichnungen »sitzen bleiben« bzw. »(nicht) versetzt werden«, wenn man eine Schulklasse aufsteigt oder eben nicht weiterkommt in der Bildungskarriere.

Eng verknüpft ist mit diesem Sitzen eine bestimmte Anordnung von Körpern im Raum, welche zueinander in Relationen stehen. Für die SchülerInnen heißt es, innerhalb dieser Ordnung platziert zu sein und nicht willkürlich einen beliebigen Platz einnehmen zu können. Zum einen, weil es der Raum und die Anordnung von Tischen und Stühlen so vorgeben, zum anderen, weil bestimmte Bedingungen auf bestimmte Plätze verweisen. Beispielsweise sitzen in dieser 7. Klasse diejenigen mit der geringeren Körpergröße ganz vorn, auch deshalb, weil sie als sog. IntegrationsschülerInnen gelten oder als diejenigen, die besonderer Unterstützung bedürfen, so dass unmittelbar vor dem Lehrertisch schnelles Erklären oder Einlenken der Lehrenden möglich sein soll. Oder ein Schüler sitzt ganz hinten, weil er so groß ist, dass alle, die hinter ihm sitzen würden, nichts mehr sehen könnten, weil er zumindest von der Körpergröße her zu denen gezählt wird, die den Überblick haben müssten. Eigentlich besteht auch hier Förderungsbedarf, die Lehrerinnen entscheiden allerdings zugunsten der Körpergröße des Jungen und des möglichst freien Blicks der MitschülerInnen. Weil in der Regel Frontalunterricht stattfindet, hängt die räumliche Nähe bzw. Distanz zur Lehrerin von der jeweiligen Sitzposition $a b$, da sie sich die meiste Zeit des Unterrichts im vorderen Bereich der Klasse befindet. Allerdings geht es nicht unbedingt um möglichst viel oder wenig Abstand, wie Breidenstein (2006: 44ff.) in seiner Untersuchung zeigt, sondern um prinzipielle räumliche Bedingungen für sehr unterschiedliche In- 
teraktionen, wofür sowohl gesteigerte Sicht- oder Hörbarkeit als auch weit möglichste Unsichtbarkeit vorteilhaft sein können.

Es geht also sowohl um Körperformung durch das Sitzen als auch um die Herstellung einer Körperordnung. Beides bildet zusammen ein für die Institution Schule spezifísches Körperregime, dessen machtvolle Praktiken sich bis in die kleinsten Bereiche des Körpers erstrecken. Wodurch sich diese Körperregime auszeichnen und inwiefern es sich um selbst und fremd vorgenommene Platzierungen als Platz einer Klassifizierung handelt, die als räumliche zugleich soziale sind (vgl. Bourdieu 1985), werde ich an Ausschnitten der Beobachtungen verschiedener Bereiche aufzeigen: an unterschiedlichen Geschlechterräumen sowie Regeln der Anordnung von Körpern und ihrer Aushandlung. Deutlich wird dabei, wie soziale Räume und Körper interaktiv und durch die Anordnung von Gegenständen hergestellt werden. In diesem Sinne verstehe ich in Anlehnung an Martina Löw (2001), die solche Praktiken als >Raum bildend beschreibt $^{1}$, diese in Präzisierung meines Gegenstands als >Körper bildendk.

Die Platzierung im Klassenraum innerhalb einer Sitzordnung lässt sich an folgendem Beispiel noch einmal verdeutlichen. Am achten Beobachtungstag notiert eine Beobachterin:

Es gibt einen neuen Sitzplan, dadurch verändert sich an der Kommunikation und der Atmosphäre in der Klasse einiges. Raik z. B. erscheint auf Erhans Platz inmitten der Klasse eher verunsichert, da er so viele Personen im Rücken hat. Er dreht sich immer wieder um, schaut in die Runde. Auf seinem früheren Platz habe ich ihn weniger hippelig erlebt. Oliver muss, nun aus der Lehrerinnen-Perspektive rechts vorn sitzend, nicht besonders laut durch die ganze Klasse rufen, um diese auf sich aufmerksam zu machen. Xenia auf Normans Platz ganz vorn links wirkt neben Mirco und Udo auf einmal viel größer. Maris und sie können nun aber doch wieder viel miteinander schwatzen. Die Jungen hinten sind zwar alle etwas auseinander gerissen, was wohl auch daran liegt, dass nicht alle anwesend sind. Aber das hält sie nicht davon ab, miteinander zu kommunizieren, sie müssen halt ein bisschen lauter werden. (AL)

In der geschilderten Beobachtungssituation zeichnet sich die Dynamik innerhalb des Schulraumes ebenso wie die Verwiesenheit auf einen bestimmten

1 Löw geht davon aus, »daß Räume sich aus der Anordnung der >Körper` ergeben« (Löw 2001: 67). Mit >Körper« ist hier nicht nur der menschliche Körper gemeint, sondern auch materielle, symbolische und soziale Güter (ebd.: 153). Und weiter: »Da die >Körper< bewegt sind, rückt das Raumwerden ebenso in den Vordergrund der Betrachtung wie das Anordnen als Handlungsvollzug. Dieser Prozeß wiederum kann [bzw. muss, A. L.] in Bezug gesetzt werden zu den Konstruktionen und Wahrnehmungen der >Betrachter`.« (ebd.: 67) 
Platz ab. Sie verdeutlicht mehrere, für das Verhältnis von SchülerInnen-Körper und Schulraum wichtige Punkte: Nicht nur, wie sehr die eigene Wahrnehmung von der jeweiligen Position im Raum abhängt, sondern wie sehr sie das gesamte körperliche und leibliche Sein bestimmt. Raik muss sich immer wieder umdrehen, um mitzubekommen, was hinter ihm passiert. Das, was Goffman als "persönlichen Raum« (1974: 56) bezeichnet, ist durch die Anordnung, durch die weitere Schüler hinter Raik sitzen, beschränkt. Er sitzt nicht mehr mit dem Rücken zur Wand und erfährt dadurch eine (ungefährliche) Begrenzung, sondern es passiert permanent etwas außerhalb seines Wahrnehmungsfeldes, würde er die auf den (Frontal-)Unterricht ausgerichtete Sitzhaltung einnehmen. ${ }^{2}$ Oliver dagegen muss nun nicht mehr so laut in die Klasse rufen, um von den Lehrerinnen drangenommen zu werden. Möglicherweise wird er von ihnen auch besser gesehen oder er kommt ihnen zumindest näher, indem er ihnen nahe gerückt ist bzw. wurde. Die Jungen in der hinteren Reihe haben jeder für sich einen eigenen Tisch. Sie können sich und ihre Arbeitsmaterialien ausbreiten und ihren, von anderen anzuerkennenden »Benutzungsraum« (Goffman 1974: 62) vergrößern. Da dies aber nicht nur eine Möglichkeit ist, sich auszubreiten, sondern sie zugleich die Aufforderung erhalten haben, zwischen sich und dem Nachbarn einen Platz frei zu halten, und damit an einem bestimmten Ort platziert wurden, sind ihre Körper für ihre gegenseitigen Kontakte und Interaktionen zu weit entfernt, so dass sie lauter miteinander reden als zuvor, um ihren gemeinsamen Raum herzustellen.

Die Orte, an denen die SchülerInnen jeweils sitzen, haben also für sie unterschiedliche Qualitäten. Aber nicht per se, sondern in Bezug auf bestimmte Dinge, Praktiken oder Personen. Georg Breidenstein (2006) unterscheidet für die Analyse räumlicher Ordnungen im Klassenzimmer visuelle, akustische und haptische Räume. Diese sind zwar letztlich miteinander gekoppelt bzw. überschneiden sich, doch wird mit der analytischen Unterscheidung deutlich, wie einerseits der institutionelle Rahmen die räumliche Struktur vorgibt und andererseits spezifische Praktiken von SchülerInnen (und auch LehrerInnen) diese aufgreifen, unterwandern oder festigen und sowohl Raum als auch Körper konstituieren.

\section{Geschlechter-Räume}

Der Eindruck beim erstmaligen Betreten des Raumes ist von einer rigiden Geschlechteraufteilung geprägt. Bei unseren ersten Besuchen sitzen alle sechs

2 Wären die Schulbänke alle nach vorn ausgerichtet, wäre das auch so, die Anordnung würde allerdings nicht dazu einladen, in der Lerngruppe miteinander zu kommunizieren, bzw. suggerieren, dass es um ein Miteinander gehen könnte. 
Mädchen in einer Reihe vor den Fenstern nebeneinander. Die anderen zwei Drittel der Klasse - die Jungen - sind auf den restlichen Plätzen verteilt, d. h. sie nehmen ca. drei Viertel des Raumes vor dem Lehrertisch ein. So entsteht ein Bild, als seien die Mädchen der Klasse Zuschauerinnen oder auch eine Art »Jury«, deren Blick sich auf das »Spektakel« der Jungen richtet. Jury und Spektakel deshalb, weil von jenen eine Menge visuelle, akustische und haptische Gesten und Signale ausgehen, während die Mädchen auf den ersten Blick vergleichsweise weniger aktiv wirken. Diese Wahrnehmung ist keine, die sich von jeder Stelle des Raumes aus derart aufdrängt. Besonders präsent ist der Eindruck beim Betreten des Klassenzimmers, dann steht man einer geschlossenen, wenig bewegten Mädchenreihe gleichsam wie einem Schutzwall gegenüber. Oder wenn man die Perspektive der Mädchen einnimmt: Ihr Blick ist, schauen sie ihrer Sitzhaltung entsprechend geradeaus, auf die gegenüber sitzenden Jungen ausgerichtet. Ihr Blickradius reicht allerdings weiter und ihre Aufmerksamkeit sollte aus Sicht der Lehrkraft sicherlich auf sie gerichtet sein, wird nicht gerade geschrieben oder gelesen. Die Lehrerinnen verbringen die meiste Zeit im Bereich vor der Tafel hinter ihrem Tisch. Betrachtet man die Klassenaufteilung aus der üblicherweise von ihnen eingenommenen Perspektive, also von vorn, so werden zwar die homogenen Geschlechtergruppen und der unterschiedlich große Raumumfang, den sie einnehmen, sehr deutlich, allerdings verschwindet der Jury-Charakter. Von hier wird die Reihe der Mädchen zu einer Randposition, die nicht stetig im Blickfeld der Lehrerinnen liegt und somit Gespräche und stille, vom Unterrichtsgeschehen unabhängige Handlungen zulässt.

Dass der Eindruck einer Geschlechtertrennung in allen Beobachtungsprotokollen als einer der ersten Punkte festgehalten wird, zeigt deutlich, wie sehr die Kategorie Geschlecht einerseits als »offensichtliche« auf den Körper bezogen ist und aus vielen Hinweisen wie Körperhaltung, Stimme, Gesichtszügen oder Kleidung resultiert, aber auch wie nahe liegend und unausweichlich sie als gesellschaftlich relevante für die Beobachtenden ist. Über sie erfolgt die erste Sortierung und Strukturierung in der für uns noch fremden Schulklasse. Gerade bei dem zunächst unüberschaubaren Geschehen erscheint Geschlecht als eine ordnende Kategorie, zumal das Wissen darüber routiniert zur Anwendung kommt (vgl. auch Breidenstein/Kelle 1998: 54f.).

Die von den SchülerInnen selbst hergestellte homogene Geschlechterordnung wurde im Verlauf unserer Beobachtungen zwar zeitweise, insbesondere von einem Mådchen sowie durch Eingriffe der Lehrerinnen minimal gestört oder irritiert, allerdings nicht so, dass grundsätzlich der »Mädchenraum« und der »Jungenraum« innerhalb der Klasse in Frage gestellt oder aufgelöst wurde. Dass Geschlecht eine zentrale Kategorie bei der Bildung von Sitzordnun- 
gen in der Schulklasse ist - und zwar ausgehend sowohl von SchülerInnen als auch LehrerInnen -, verdeutlichen die Untersuchungen von Faulstich-Wieland et al. (2004: 90ff.) und Willems (2007: 229ff.). In der tagtäglichen Wiederholung dieser allgegenwärtigen geschlechtshomogenen Anordnung, also dem performativen Charakter dieser Praktiken, wird Geschlechtszugehörigkeit immer wieder dargestellt und bestätigt. Im Rahmen der schulischen Ordnung wird dieses Arrangement institutionalisiert und über die Institutionalisierung normalisiert. ${ }^{3}$

Wie sehr die Kategorie Geschlecht und ihre räumliche Konstitution wirksam ist, zeigt sich auch, als SchülerInnen gemischte Gruppen bilden sollen:

Es sollen sich fünf Gruppen a vier Personen bilden mit mindestens einem Mädchen. Sie sollen diskutieren, ob die Tätigkeiten, die auf ihrem Arbeitsblatt notiert sind, ihrer Erfahrung nach eher Männer, Frauen oder beide vollziehen. Im Anschluss daran sollen sie sich auf ein Ergebnis einigen. Die folgende Gruppenbildung dauert ca. eine Viertelstunde:

Maris will unbedingt mit Xenia in eine Gruppe, greift sie am Arm, hält sie fest. Bekommt es aber von den Lehrerinnen untersagt. Recht schnell bildet sie dann mit Peter, Raik und Norwin Gruppe 1. Sie sitzen im Halbkreis; Sitzreihenfolge Peter, Maris, Raik, Norwin. Raik und Norwin haben untereinander viel Körperkontakt. Alle sind am Gespräch etwa gleich beteiligt.

Eine Weile später bildet sich Gruppe 2: Liv, Noel, Florenz, mit Abstand und verschränkten Armen Lorena. Liv bleibt auf ihrem Platz sitzen, die anderen stehen um sie herum. Später verlagert sich die Gruppe ans Fenster, wodurch Liv ihren Platz aufgeben muss. Am Gespräch sind alle etwa gleich beteiligt.

Die restlichen tun sich ungemein schwer, alle bleiben auf ihren Plätzen sitzen, keiner macht Anstalten sich zu bewegen und die Initiative zu ergreifen. Schließlich bildet sich Gruppe 3: Norman, Ahmed, Bent und Xenia. Die Jungen sind dicht aneinander gedrängt, Ahmed umarmt Bent immer wieder von hinten, Xenia steht mit einigem Abstand zu ihnen. Sie übernimmt das Vorlesen und muss oft gegen die drei Jungs diskutieren. Das tut sie auch lautstark.

Gruppe 4: Calha sitzt auf der einen Seite des Tisches, ihr gegenüber: Erhan, Mirco und Udo. Sie liest vor und fragt danach ihre Mitschüler der Reihe nach ab.

Die Gruppe 5 ist, obwohl (oder weil?) nun keine Wahl mehr besteht, fast nicht zusammenzubringen: Liza sitzt auf der einen Seite des Tisches, Leon, Tom und Oliver auf der anderen. Sie haben alle großen Abstand zu einander. Alle lesen mal vor, diskutiert wird kaum. Als sie als erste von allen Gruppen mit der Aufgabe fertig sind, setzen sie sich sofort wieder auseinander. (AL)

3 Das wäre nicht anders, würden z. B. jeweils ein Junge und ein Mädchen aus Disziplingründen nebeneinander gesetzt werden. 
Zunächst zeigt das Beispiel, wie schwierig es für die meisten SchülerInnen ist, zum einen eine Arbeitsgruppe zu bilden, in der eine bestimmte Geschlechterverteilung hergestellt und zum anderen die Geschlechterverteilung in der eigenen Familie und im eigenen Alltag thematisiert werden soll. Zweiergruppen oder aber auch größere Gruppen zu bilden, ist bei freier Auswahl der jeweiligen Teilnehmenden in der Klasse sonst kein größeres beobachtbares Problem. ${ }^{4}$ Auch in den vorgestellten Konstellationen sind befreundete SchülerInnen, die sonst sehr schnell zu einander finden. Dennoch scheint die Gruppenbildung besonders schwer zu sein. Die zuvor durch die Geschlechterhomogenität institutionalisierte Sicherheit wird erschüttert. Lediglich Gruppe 1 formiert sich schnell - aus Initiative des Mädchens, welches insbesondere mit einem der Jungen immer wieder zusammen sitzt. Beide kommunizieren häufig auf eine flirtende Art und Weise. Die drei Jungen dieser Gruppe bilden wiederum innerhalb der Schulklasse eine Clique. So scheint in diesem Fall klar, wer mit wem zusammenarbeiten wird. Deutlich wird hier, ebenso wie an der Konstellation der Gruppe 3, dass es den Jungen möglich ist, in ihren mehr oder weniger freundschaftlichen bzw. schulklassenspezifischen Beziehungen zusammenzubleiben, während die Mädchen diese aufbrechen müssen. In den jeweiligen körperlichen Bezugnahmen zeigt sich die Distanz: die Jungen der Gruppe 3, die sich gegenseitig sehr nahe sind und fast permanent Körperkontakt zueinander haben, während das Mädchen zu ihnen deutlich Abstand hält; die Gruppen 4 und 5, in denen ein Mädchen jeweils auf der anderen Tischseite den Jungen gegenüber sitzt. Über diese Platzierungen wird nun erneut hergestellt, was die räumliche Ordnung und damit den Alltag der Klasse auch sonst zentral bestimmt und bereits institutionalisiert ist: die Trennung der Geschlechter bzw. Mädchen- und Jungenräume. Barrie Thorne begreift diese Praktiken als »borderwork«. Darunter fasst sie »interaction across - yet interaction based on and even strengthening - gender boundaries« (Thorne 1993: 64). Wenn möglich werden geschlechtshomogene Räume hergestellt. Dennoch muss im geschilderten Fall ein gemeinsamer Arbeitsraum synthetisiert werden, indem die Mädchen als Einzelkämpferinnen dann sehr unterschiedlich agieren und sich zu den Mitschülern ins Verhältnis setzen - als »Lehrerin«, als »emanzipierte Frau«, als »Teilnehmerin wider Willen« oder »Opfer der Situation«. Sie müssen aber Einzelkämpferinnen bleiben, da auch das Thema >Männlich-Weiblich` die Trennung der zwei Geschlechter zum Gegenstand hat und die Zuordnungen eindeutig sind bzw. vereindeutigend sein

4 Ich spreche hier vom beobachtbaren Problem, da ich nichts darüber aussagen kann, wie die einzelne Person eine solche Zuordnungsprozedur erlebt und inwiefern diese für sie angenehm oder unangenehm oder gar problematisch ist. 
sollen. ${ }^{5}$ Weder Mädchen noch Jungen können sich qua zugewiesenem Geschlecht als solche ausnehmen, auch wenn sie vielleicht von unterschiedlichen Erfahrungen bezüglich der Zuständigkeiten von Frauen und Männern im Haushalt berichten können. Von den Lehrerinnen gibt es also die Auflage, die geschlechtshomogene Konstellation zu verlassen, weshalb sie in den einzelnen Gruppen erneut mittels des Körpers und seiner Relation zu den anderen hergestellt werden muss. Die Idee, Geschlechter-Räume (innerhalb der Schulklasse und der Familie) miteinander zu kontrastieren, reproduziert die bestehenden.

Gruppe 1 kontrastiert diese durch die Gegenüberstellung bzw. Distanz symbolisierte Geschlechtertrennung, insofern die Anordnung der Körper hier eher eine integrierende ist und Maris Rolle als Gruppenleiterin oder Gegendiskutantin nicht die gesamte Zeit aufrecht erhalten wird. Maris ist in der Klasse diejenige, die die räumliche Trennung immer wieder in Frage stellt, indem sie sich umsetzt bzw. darüber verhandelt - auch aus Interesse am andern Geschlecht. D. h. die Überwindung der Trennung erfolgt über ein Inszenieren des Begehrens, welches wiederum die Geschlechterdualität auf andere Art und Weise reproduziert. Interessant ist in diesem Zusammenhang, dass sich die Gruppe 1 als einzige auch bei einer anderen Gelegenheit, bei der die Zusammensetzung den SchülerInnen überlassen bleibt, als Arbeitsgruppe formiert. Dies geschieht in sehr ähnlicher Weise wie bereits beobachtet:

Bei der Gruppenaufteilung überrascht mich Maris, die ihre Gruppe völlig ohne Absprache mit den anderen festlegt. Lehrerin Matthes fragt Raik, Peter und Norwin, ob diese damit einverstanden wären, worauf sie wenig beteiligt zustimmen. Die Dominanz von Maris irritiert mich im Zusammenhang damit, dass es die drei Jungs ohne jegliche Überraschung, geschweige denn, Widerwehr hinnehmen. (AS)

Es gibt eine verhaltene Zustimmung der Jungen, die mit dieser Gruppenkonstellation bereits Erfahrung haben. Dass sie nicht in Begeisterung ausbrechen, kann viele Gründe haben, die nicht unbedingt etwas mit der Geschlechterverteilung zu tun haben müssen: schließlich geht es um die Bildung einer Arbeitsgruppe. Entscheidender ist, dass nicht das passiert, was sich in den anderen Gruppen in der zuvor geschilderten Situation beobachten ließ. Dort gab es genauso wenig offenen Protest wie es hier Zustimmung gibt. Die Abweisung wurde körperlich demonstriert - indem die SchülerInnen sich nicht von ihrem angestammten Platz bewegten, sich mit viel Abstand an den Tischen jeweils gegenüber setzten und die Tische damit eine Raumgrenze bildeten, sie sich

5 Unabhängig davon, ob bzw. dass die Lehrerinnen das Ansinnen haben, die Differenz gerade nicht so stark zu betonen. 
körperlich also nicht auf die Gruppe einließen und sie zu ihrem gemeinsamen Ensemble machten.

\section{Auf die Plätze - fertig - los? \\ Die Regel von der Ausnahme der Regel}

Kaum können wir alle Namen einigermaßen zuordnen, werden wir irritiert. Im Kunstunterricht sitzt ein Teil der SchülerInnen auf einmal auf anderen Plätzen. Wir erfahren, dass es in den beiden Kunststunden die Regel gibt, dass die SchülerInnen auswählen dürfen, mit und neben wem sie arbeiten möchten, und sich umsetzen dürfen. Voraussetzung ist dafür, dass Plätze frei sind bzw. dass sie sich untereinander einigen. Verhandlungen über einen eventuellen Plätzetausch verlaufen ruhig, zumal meist irgendjemand fehlt, so dass sich das Arrangement des Spiels »Reise nach Jerusalem«, bei der man um die knappen Plätze kämpfen muss, nicht ergibt. Außerdem sind es häufig dieselben SchülerInnen, die die Möglichkeit in Anspruch nehmen. Durch diese Regelung und indem sie gestatten, eine mitgebrachte Musik-CD oder Radio zu hören, heben die Lehrerinnen den Kunstunterricht von den anderen Fächern ab. Kreativität erlaubt bzw. soll andere Räume erzeugen, ebenso wie andere Raumanordnungen vielleicht Kreativität erzeugen sollen. Wer sich dabei zu wem setzt, gibt ähnlich wie die Bildung von Arbeitsgruppen Einblicke in das Beziehungsnetz der Schulklasse und in die Rangfolge von gegenwärtigen Beliebtheiten.

Beobachten konnten wir aber auch wirkliche Ausnahmen von der üblichen geregelten Sitzordnung, insbesondere befreundete SchülerInnen fragten bei den Lehrerinnen häufiger nach, ob sie zusammen sitzen dürften. Gingen die Lehrerinnen auf diesen Wunsch ein, war damit gleichzeitig die Aufforderung verknüpft, dass sie dann nicht miteinander »schwatzen«, sondern ruhig sein sollten. Die räumliche Trennung als Sanktion wäre und war ansonsten die Folge und so fand recht häufig ein Platzwechsel statt, der gerade für noch fremde Beobachtende die Orientierung erschwerte. ${ }^{6}$ Die Sitzordnung ist also häufig Grund von Ärgernissen sowohl für die Lehrerinnen als auch die SchülerInnen. Immer wieder kommt es zu Verhandlungen bzw. zu Versuchen von Verhandlungen seitens der SchülerInnen. Dazu ein Auszug aus einem Beobachtungsprotokoll:

Raik, Xenia und Maris beschweren sich, dass sie auseinander gesetzt wurden und die Jungs hinten, namentlich Oliver, Bent, Noel und Florenz noch immer zusammen sitzen dürften, obwohl diese viel mehr den Unterricht störten. Noel schiebt, als er

6 Hier zeigt sich noch einmal das minimale Aufbrechen der "Geschlechter-Fronten«. 
sich dazu äußern soll, alles auf Oliver (der ist nämlich heute nicht da). Bent verhält sich ruhig und zustimmend. Frau Matthes und Frau Timm weisen darauf hin, dass die Anwesenden auch ihren Teil zur Unruhe beitrügen und den BeschwerdeführerInnen gegenüber versichern sie, dass sie die Jungen im Auge hätten und auch überlegen würden, »was man da machen könnte«. Die beiden Mädchen haben zwar konkrete Vorschläge, wie sie sich eine zukünftige Sitzordnung vorstellen, aber die Lehrerinnen wiegeln ab und ermahnen die Jungen noch einmal. (HA)

Sitzordnungen stellen eine Grundlage für geordnetes Sitzen dar und werden sowohl von den Lehrerinnen als auch mit bestimmtem Interesse von den SchülerInnen als Steuerungsinstrument für »Disziplin« und eine ruhige Arbeitsatmosphäre angesehen. ${ }^{7}$ Es gilt, »die nützlichen Kommunikationskanäle zu installieren und die anderen zu unterbrechen « (Foucault 1998: 184). Die (An-)Ordnung wird von allen Beteiligten sehr genau beobachtet, die Entscheidungshoheit, was als Störung gilt, und die Möglichkeiten zur Durchsetzung für eventuelle Veränderungen liegen letztlich bei den LehrerInnen. So eingesetzt kann diese Ordnung auch als Sanktionsmittel fungieren, ohne dass das Ereignis, das sanktioniert wird, unmittelbar auf sie bezogen war. Mittels der Konstitution von Räumen werden zwischen Individualität und Konformität Machtverhältnisse ausgehandelt und sichtbar. In der Beobachtungssituation wird aber auch deutlich, dass es um so etwas wie Gerechtigkeit geht. Die SchülerInnen fordern ein, was andere in ihren Augen auch tun dürfen: neben ihren FreundInnen sitzen, ihnen körperlich nahe sein und damit für sich eine Art privaten Raum herzustellen, der innerhalb der potenziellen permanenten Sichtbarkeit in der Anordnung als U sonst kaum möglich ist. Die Sitzordnung bzw. die Verhandlung darüber entspricht (zum Teil) einer Art »SympathieOrdnung«, kann damit aber auch genutzt werden, um zu provozieren bzw. zu ärgern. Zum Beispiel, wenn Raik laut in die Klasse sagt, so dass es möglichst alle hören: »Ich will mich umsetzen«, womit er sich vor allem an seine Nachbarin Maris wendet, die er in dem Moment als »unerträglich« etikettiert. Über die Anordnung, ihre Transformation bzw. das Reden darüber sind symbolische Zuweisungen möglich, Beziehungen materialisieren sich.

Ein Sitzplatz in einer Schulklasse ist nicht einfach ein Sitzplatz. Indem sowohl LehrerInnen als auch SchülerInnen klassifizieren und Plätze markieren, sind damit Rangordnungen verbunden und das Positionieren wird zur machtrelevanten Ressource. Die an die Sitzordnung gekoppelte Disziplin »individualisiert die Körper durch eine Lokalisierung, die sie nicht verwurzelt, sondern in einem Netz von Relationen verteilt und zirkulieren läßt« (Foucault 1998: 187). Mit den Raumkonstruktionen werden Werte verkörpert und Nor-

7 Zumindest nutzen die SchülerInnen diese Gegebenheit als Argument. 
malität hergestellt, seien es die gegenseitige Aufmerksamkeit durch das Zugewendet-Sein innerhalb der Anordnung von Körpern, das Sitzen als Körperhaltung des Lernens, Beliebtheiten oder Geschlechterverhältnisse.

\section{UmOrdnungen}

Es gibt Gelegenheiten im Schulalltag, bei denen die gängige Sitzordnung aufgehoben wird, indem das Mobiliar umgestellt wird. Diese Momente weisen in der Regel auf eine besondere Situation hin, sie sind ritualisiert. Welche Situationen sind das, in denen jeweils ein spezifischer Raum konstituiert wird? Eine erste Situation erleben wir bereits an unserem ersten Schultag, an dem die SchülerInnen einen Mathematiktest zu schreiben haben:

Bevor der Test verteilt wird, sind die SchülerInnen angehalten, die Tische aus der üblichen Anordnung in eine verstreute Form zu bringen, um die Möglichkeit des Abschreibens einzudämmen. Sie sitzen sich dann jeweils an der Stirnseite der Tische gegenüber, zwischen ihnen befindet sich eine Sichtbarriere, gebaut aus Schultaschen, Rucksäcken, Büchern oder Kartons. Das »Tischerücken« geht schnell und reibungslos vonstatten. (AL)

Die SchülerInnen bereiten sich eine Arbeitsatmosphäre, die den Ernst der Situation spiegelt. Während bei der Vermittlung von Inhalten die Körper im Raum so angeordnet sind, dass über das Zugewandtsein gemeinschaftliche Bezüge entstehen und die einzelnen Möbel zu einem Gesamtmobiliar verschmelzen, werden beim Test separate »Zellen« hergestellt, die die SchülerInnen isolieren. Die sonst übliche Einheit von Mobiliar und Körpern wird zergliedert, was bereits darauf verweist, dass die Prüfung, der sie sich unterziehen müssen, selektiert. Die Raumordnung signalisiert den SchülerInnen, dass sie nun auf sich allein gestellt sind. Der individuelle Platz macht sowohl die Fremd- und Selbstkontrolle jedes Einzelnen als auch die gleichzeitige Arbeit aller möglich (vgl. Foucault 1998: 189). Indem die SchülerInnen selbst diese Raumordnung über bestimmte Bewegungen (Tische auseinander ziehen, hochheben, herumschieben, die Grenze ihrer »Zelle« mittels Gegenständen markieren) herstellen, wird äußerlich eine Situation geschaffen, die im Tun verinnerlicht werden kann, und gerade durch ihren rituellen Charakter bereits auf das Kommende vorbereitet. So wundert es nicht, dass entgegen den meisten anderen Situationen, in denen jede Gelegenheit genutzt wird, Kontakte zu MitschülerInnen aufzunehmen und jenseits von Unterricht mit ihnen zu kommunizieren, das Räumen hier sehr konzentriert vonstatten geht.

Ein anderes Ritual, in dem ein »neuer « Raum geschaffen wird, ist die Anordnung einer Festtafel. Dabei werden von einigen SchülerInnen, Lehrerinnen 
und Forschenden alle Schultische zu einer langen Tafel zusammengestellt. Beobachten konnten wir dies jeweils vor den Ferien, wenn der letzte Schultag feierlich begangen wurde. Verknüpft mit dem Räumlichen sind, wie auch schon im obigen Beispiel, zeitliche Komponenten: Es wird auf einen besonderen Zeitabschnitt verwiesen - hier auf das Ende eines Schulabschnitts. Die Festtafel steht dann quer im Klassenzimmer. Dieses Querstehen lässt sich durchaus metaphorisch interpretieren - Schulfeste finden zwar im Rahmen der Institution Schule statt, stehen jedoch in vielerlei Hinsicht quer zum normalen Schulalltag, da eben kein Unterricht stattfindet und auch andere Regeln gelockert sind (wie z. B. die Sitzordnung). Nachdem der Tisch gedeckt ist, gruppiert sich die gesamte Klasse, die Lehrerinnen und die Forschenden um die große Tafel und frühstücken. Auch in dieser Situation sitzen diejenigen, die freundschaftliche oder kollektive Verhältnisse ${ }^{8}$ pflegen, beisammen. Die beschriebene Geschlechtertrennung wird weitgehend eingehalten.

Eine letzte »umordnende« Situation ist der Stuhlkreis:

Die Lehrerinnen nutzen die erste Stunde für die Besprechung der aktuellen Klassensituation. Sie umschreiben diese mit »schlechtem Verhalten der Klasse«. Um eine intimere, persönlichere Atmosphäre zu haben, bilden alle einen Stuhlkreis. Frau Timm und Frau Matthes eröffnen das Gespräch, indem sie erklären, dass sie der Auffassung sind, dass die Klasse auf dem besten Weg sei, eine asoziale Klasse zu werden. Das Verhalten der Schüler wird kritisiert sowie der fehlende Zusammenhalt der Klasse. »Wir hauen uns nicht gegenseitig in die Pfanne!« ist ihr Appell. Es gab wohl in der Vergangenheit vier verschiedene Vorfälle, die nacheinander genannt werden und nun im Einzelnen besprochen werden sollen. (SR)

Ganz im Gegensatz zur individualisierenden Parzellierung in Beispiel 1 soll hier über den Stuhlkreis Gemeinschaft geschaffen werden. Der Kreis stellt ein Sinnbild für Harmonie dar, in dem die einzelnen Körper in etwa gleichem Abstand zum jeweiligen Nachbarn und zum Gegenüber angeordnet sind und das Gesamtbild keine Ecken und Kanten, sondern eine abgerundete Form hat. Damit bildet die Anordnung, ähnlich wie bei der Klassenarbeit, eine Art inhaltliche Vorbereitung. Hier ist es die harmonische Homologisierung einer Gruppe, in der alle füreinander stehen. Indem für den Schulraum typisches Mobiliar oder Artefakte, wie Tische, Schulmaterialien oder persönliche Gegenstände der SchülerInnen außerhalb des Kreises sind, können sie auch keine Barrieren

8 Breidenstein und Kelle weisen darauf hin, dass nicht alle Beziehungszeichen, die sich in der Schulöffentlichkeit beobachten lassen, Zeichen für Freundschaften sind. Angehörige einer Schulklasse sind notwendig durch eine kollektive Beziehungsgeschichte miteinander verbunden, die möglicherweise auf den Schulraum bzw. die Schulzeit begrenzt ist (vgl. Breidenstein/Kelle 1998: 122). 
bilden und »stören«, ebenso wenig bieten sie aber auch Sichtschutz oder Halt. Die SchülerInnen sind mit ihrem gesamten Körper, der sonst halb unter der Schulbank verschwindet, präsent bzw. der Beobachtung der Lehrerinnen und MitschülerInnen ausgesetzt. Diese Präsenz steht zum einen für die geforderte Auseinandersetzung - man kann sich dem Kreis nicht entziehen - und zum anderen dafür, dass innerhalb der Schulklasse alle (SchülerInnen und LehrerInnen $)^{9}$ füreinander da sein sollen. Es gibt ein kreisförmiges unsichtbares Band ohne Enden. Der Kreis symbolisiert das Soziale, den »runden Tisch «, an dem sich eben auch auseinander gesetzt wird und an dem nach Möglichkeit demokratisch Konsens geschaffen werden soll. Die räumliche Anordnung der Körper bildet so das Gegenstück zur Klassensituation, so wie sie die Lehrerinnen einschätzen. Auch die Rolle der Lehrerinnen ändert sich hier. Sie werden zum Bestandteil des Kreises, der Gemeinschaft, und verzichten auf ihre hervorgehobene Stellung, wie sie die übliche Sitzordnung vorbehält. Auch diese ist ein fast geschlossener Kreis, der Gleichheit und Gemeinsamkeit symbolisiert. Lediglich Sonderfälle werden - auch symbolisch - aus dieser Anordnung entfernt und bringen damit Ecken in den Kreis der Gemeinschaft. Die »Lehrkörper« heben sich durch ihre frontale Position außerhalb der Runde von den Schülerkörpern ab.

Beim schreibenden Ordnen dieser Situationen, die unter Hinzunahme oder Weglassen von Artefakten über bestimmte relationale Körperformationen Räume konstituieren, wird deutlich, dass die Konstitution von Gruppen auf andere Art und Weise vonstatten geht. Hier werden eben nicht über eine angeleitete bzw. ritualisierte Umordnung anhand von Gegenständen für alle ähnliche Gruppenräume geschaffen. Die SchülerInnen müssen ihren Körper von sich aus zum Einsatz bringen und drücken damit sehr deutlich ihre Beziehungen und Barrieren aus.

\section{Den Schultag begleiten und bekleiden}

Neben den Raumarrangements, die Raum und Körper wechselseitig konstituieren, indem sie auf bestimmte Positionen verweisen sowie Inszenierungen ermöglichen und nach sich ziehen, haben wir weitere Regeln und Rituale beobachtet. Es sind vor allem Rituale, die Übergänge markieren, z. B. von der Pause zur Schulstunde, und Regeln, die sich auf die Kleidung der SchülerInnen

9 Die Forschenden sitzen außerhalb des Kreises. Im Gegensatz zum Speisen an der Tafel, bei dem auch Gäste geladen werden können, gehören sie zu diesem "Wir« nicht dazu und bleiben außen vor. Deutlich wird dabei, dass sie, obwohl sie bei Klassenfesten partiell schon integriert sind, letztlich doch den Status des Fremden beibehalten bzw. zugewiesen bekommen. 
beziehen und sie gewissermaßen als SchülerInnen konstituieren. Beginnen möchte ich mit dem allmorgendlichen Begrüßungsritual.

\section{Zeitzeichen}

In der ersten Stunde haben wir unsere Plätze schräg hinter den SchülerInnen eingenommen. Die Lehrerinnen stehen beide hinter ihrem Tisch und die Klasse beginnt nach und nach, es den Lehrerinnen gleichzutun und aufzustehen. Irgendwann steht sie geschlossen da. Auch wir erheben uns, uns gegenseitig etwas verunsichert anblickend. Als alle stehen, begrüßen die Lehrerinnen die Klasse mit einem deutlichen "Guten Morgen«. Daraufhin erfolgt ein weniger vernehmbares »Guten Morgen« von uns genauso verhalten wie von den SchülerInnen - und der Unterricht beginnt. (AL)

Der Schultag beginnt mit einem Begrüßungsritual, bei dem sich alle Beteiligten erheben. Mit dem Einnehmen der aufrecht stehenden Haltung, bei der sich nach Möglichkeit die Blicke auf die Lehrerinnen richten und die sich deutlich vom üblichen Sitzen unterscheidet, wird der Beginn des Unterrichts signalisiert. Besser gesagt: des Schultages, denn dieses Ritual wird nicht vor jeder neuen Unterrichtsstunde wiederholt. Aufstehen und sich begrüßen orientieren sich an Höflichkeitsregeln, die die Aufmerksamkeit weg von der momentanen Tätigkeit hin zum Gegenüber lenken sollen: von Angesicht zu Angesicht und ohne mit anderen Dingen beschäftigt zu sein. Aufstehen und alles stehen und liegen lassen - eine Praktik, die den Beginn einer bestimmten zeitlichen Phase, den Arbeitstag in der Schule einleitet. Die SchülerInnen sind dabei mehr oder weniger bei der Sache. Nicht immer verläuft das Morgenritual so routiniert:

Der Unterricht beginnt sehr unruhig. Die Schüler betreten einzeln nacheinander die Klasse, Norwin kommt zu spät. Frau Matthes beginnt die Stunde allein, da Frau Timm wohl noch etwas zu erledigen hat, später dann jedoch hinzukommt. Die Schüler flachsen rum: »Die braucht bestimmt so lange, weil sie nicht einparken kann!« Es dauert ca. fünf Minuten, ehe die Schüler zur Begrüßung aufstehen und dann weniger einheitlich und kaum verständlich ein »Guten Morgen « hervorbringen. Frau Matthes gibt sich damit zufrieden und beginnt die Kunststunde, indem sie an das Thema der letzten Stunde anknüpft. (SR)

Die Routine wird hier gestört. Die Begrüßung ist in dieser Form ein Ritual, das Gleichzeitigkeit voraussetzt bzw. herstellen soll. Das ist schwer möglich, wenn noch gar nicht alle anwesend sind. Für Irritationen scheint dabei auch zu sorgen, dass Lehrerin Timm fehlt. Die SchülerInnen sind durchaus auf- 
merksam, sie nehmen ihr Fehlen wahr - die Klasse ist ohne sie noch nicht vollzählig. Es ist kein Automatismus, der da in Gang gesetzt wird, sondern der Vorgang des Grüßens ist tagtäglich erneut gefährdet. Mit dieser Form der Begrüßung geht eine Aktivierung des Körpers einher: sich einstellen auf den Unterricht und im Anschluss sich hineinversetzen in seine Inhalte. Symbolisch findet zudem eine Homogenisierung der heterogenen Schülerschaft statt, die nun im Laufe des Schultages mehr oder weniger einheitlich gemeinsam beschult werden kann. Das Signal sich einzulassen und dazuzugehören ist mit einer Höflichkeitsregel gekoppelt. Ihre Wirksamkeit zeigt sich an der Reaktion der BeobachterInnen, sie sind zwar ein wenig verunsichert, jedoch erscheint es in diesem Moment unmöglich, sich der Begrüßung zu entziehen, während sie vom anschließenden Unterrichtsgeschehen wie selbstverständlich ausgeschlossen sind.

Weitere derartige Rituale bzw. Rahmungen, abgesehen vom üblichen 45Minutentakt der Unterrichtsstunden, die mit einem Blinklicht ein- und ausgeleuchtet wurden, sowie den Pausen jeweils nach zwei solchen Stunden, haben wir nicht beobachtet. Eine Beobachterin ist irritiert, dass der Unterricht so wenig gerahmt wird. Es scheint aber Strukturen und Abläufe zu geben, die nicht (mehr) so offensichtlich durch Worte, bestimmte Körperpraktiken oder Umordnungen angezeigt werden (müssen). Routinen, die sicherlich ihre zeitlichen und räumlichen Markierungen haben, die aber so minimal sind, dass sie für die BeobachterInnen nicht ersichtlich waren. Das illustrieren die beiden folgenden Beispiele:

Für den Rest der Stunde ist scheinbar Stillarbeit angesagt. So still, dass ich nicht mitbekommen habe, wann diese angekündigt wurde und was der Gegenstand der Arbeit ist. Aber alle SchülerInnen haben scheinbar Arbeitsmappen ausgeteilt bekommen, die ansonsten vorn neben der Tafel gesammelt liegen. (HA)

Vor der vierten Stunde wird es plötzlich unruhig, einige laufen durch die Klasse. Noel steht auf, geht zum Waschbecken und trinkt Wasser. Es scheint eine Pause zu sein, die gewissermaßen fakultativ ist und über die nicht mehr verhandelt werden muss. (AL)

Die Forschenden sind irritiert, sie beobachten etwas, was sie nicht verstehen. Sie erwarten interpretierbare Zeichen von den LehrerInnen, die die SchülerInnen entweder nicht benötigen oder die sie, von den Beobachtenden unbemerkt, von den LehrerInnen empfangen haben. Verbale Aufforderungen gab es jedenfalls nicht, die nonverbalen haben die Beobachtenden jedoch »übersehen«, weil ihre Wahrnehmung darauf nicht »geschult« war und sie nicht in die Zeichenpraxis eingeführt waren. 


\section{Kappen ab und Jacken aus!}

Im Folgenden geht es um eine weitere Regel, die immer wieder Anlass zu Auseinandersetzungen und Aushandlungsprozessen gab.

Viele SchülerInnen kommen mit Mützen, Baseballcaps, kunstvoll zusammengebundenen Tüchern oder Stirnbändern zur Schule. Zu Unterrichtsbeginn bestehen die Lehrerinnen darauf, dass alle ihre Kopfbedeckungen abnehmen. Ausgenommen sind einfache Stirnbänder. Meist lassen die SchülerInnen sie unaufgefordert in ihren Taschen verschwinden, manchmal ist dafür eine Ermahnung erforderlich. Erhan hat bei der Begrüßung seine Kappe noch auf, er wird aufgefordert, sie abzusetzen, woraufhin er antwortet: »Oh, hab ich vergessen! « (Es klingt aber mehr nach: »Man kann es ja mal probieren ... «) Ein eindringlicher Blick der Lehrerin - und die Baseballkappe verschwindet. $\mathrm{Ab}$ und zu nimmt eine Lehrerin einem Schüler die Kappe sanft und wortlos vom Kopf. Einige Jungen versuchen immer wieder, die Regel zu unterlaufen, was dann zur allgemeinen Erheiterung der Klasse beiträgt. Teilweise ergeben sich aber auch »echte« Konflikte zwischen Lehrerinnen und SchülerInnen, in denen es um die Einhaltung der Kleiderordnung geht. Viele SchülerInnen behalten außerdem ihre Jacken im Unterricht an, obwohl es überhaupt nicht kalt ist. Dies thematisieren die Lehrerinnen allerdings nicht, fordern die SchülerInnen auch nicht auf, die Jacken auszuziehen, obwohl dies so erfahren wir später, auch eine Regel ist. (AL)

In der Schulklasse gibt es eine von den Lehrerinnen vorgegebene Kleiderordnung, die zwar nicht festlegt, was getragen werden soll ${ }^{10}$, jedoch was gerade nicht getragen werden darf. Welche Funktionen haben sowohl das Tragen dieser Kleidungsstücke als auch das Trageverbot? Jacke, Mütze, Hut - das alles sind Kleidungsstücke, die man in der Regel außerhalb von Innenräumen trägt und beim Betreten eines Raumes ablegt. Dies aber nicht nur pragmatischer Weise, weil die Temperaturen es verlangen, sondern als ein Element sozialer Umgangsformen und hier als ein Teil des schulischen Rahmens. Die Abnahme der Kopfbedeckung markiert den zeitlichen und räumlichen Übergang zwischen Freizeit und Unterricht, zwischen draußen und drinnen, welcher in ritualisierter Form stattfindet (vgl. Göhlich/Wagner-Willi 2001). Aus Sicht der Lehrenden wird es als etwas Vorläufiges interpretiert, begibt man sich in einen Raum, ohne sich seiner Jacke, Kappe oder Mütze zu entledigen - als wollten die SchülerInnen gleich wieder gehen, sich gar nicht erst festsetzen. Dagegen steht, dass die Anwesenheit im Unterricht verbindlich vorgeschrieben ist. Gleichzeitig können Kappe und Jacke den SchülerInnen dazu dienen,

10 Im Sinne einer Schuluniform, welche gerade in den letzten Jahren vor allem in den Medien immer wieder diskutiert wird und von manchen Schulen probeweise eingeführt wurde. 
etwas zu verhüllen, zu verbergen. Zudem ist es ihnen möglich, damit gegen eine Regel zu verstoßen und Aufmerksamkeit sowohl von der Klasse als auch von den LehrerInnen zu bekommen. Ob mit oder ohne Ermahnung seitens der Lehrkräfte lässt sich der Regelbruch demonstrieren. Die Konsequenzen einer Rüge sind verhältnismäßig harmlos, so dass das »Spiel« gern nach kürzerer Zeit wiederholt wird. Das Lachen unterstreicht den spielerischen Charakter.

Doch ist die Provokation nur ein Aspekt. Der Kopf eines Menschen gilt als der Körperteil, der am stärksten Identität verkörpert. Mit Mützen, Hüten, Tüchern oder Frisuren kann man diesen ohne viel Aufwand gestalten und verändern - und eben auch verdecken, beispielsweise mit einer Sonnenbrille, denn gerade der Blick in die Augen des Gegenübers wird für Interaktionen und die Kontrolle des zwischenmenschlichen Verhaltens als ganz wesentlich erachtet (vgl. Goffman 1971: 84ff.). Eine ähnliche Funktion kann dem Schirm eines Baseball-Caps zugesprochen werden. Er schafft Distanz, indem das Gegenüber je nach Tragetechnik und Blickwinkel weniger gut in die Augen und das Gesicht des Trägers blicken kann. Unter der Kappe kann man »sich« verbergen, sie bietet Schutz wie eine Maske. Im Unterricht nun hat man sich zu demaskieren, mittels der Kappe die Rolle des Jugendlichen abzulegen und Schüler zu sein. Es wird durch die schulische Regel dafür Sorge getragen, dass die SchülerInnen sich dem Blick der Lehrerinnen möglichst wenig entziehen können. Wie begründen das die Lehrerinnen im Interview? Ist es ein reflektiertes Verbot oder ein Überbleibsel alter Höflichkeitsformen, wenn Lehrerin Kilian sagt: »Und wir bestehen halt hier im Unterricht darauf, dass alles vom Kopf kommt, egal was! «?

Interviewerin: Ja, es gibt zum Beispiel viele Ritualisierungen, also dass der Unterricht beginnt und man aufsteht, sich begrüßt und die Kappen abgesetzt werden. Das finden ja manche der Schüler, die gerade auf dem Cool-Trip sind, ganz furchtbar, dass die jetzt irgendwie ihr ganzes Haar-Arrangement

Lehrerin Timm: Ja, aber es ist doch entscheidend, dass es auch äußerlich zum Ausdruck gebracht wird, wir befassen uns mit inhaltlichen Dingen.

Interviewerin: Das ist auch der Versuch dieses jugendkulturelle und diese Art von Lehrerin Timm: Nein, das ist der Versuch, deutlich zu machen, wir wechseln die Ebene und ihr lasst euch jetzt gefälligst darauf ein, ja? Und das ist ein äußerliches in Form dieses Rituals, ein Zeichen setzen, jetzt beginnt Unterricht und das ist für euch ein Signal wie: könnt ihr euch darauf einstellen, müsst, könnt, wollt, wie auch immer. Deswegen machen wir das.

Interviewerin: Und warum versuchen sie's immer wieder? Das ist auffällig, sie wissen's ganz genau.

Lehrerin Timm: Die Kappen aufzulassen? Das ist 'n Spiel. Warum haben wir versucht, heimlich das Schulgelände zu verlassen in unserer Schulzeit oder andere Din- 
ge zu tun? Ich denke, dass ist einfach das Ausprobieren wohl von Grenzen und vielleicht huscht man ja doch durch, ja? Und nimmt ein Stück seiner Persönlichkeit, die eigentlich im Unterricht nicht gelebt wird, auch mit rein, ja? Also ich kann das nur allzu gut nachvollziehen.

Während Frau Kilian die Regel lediglich setzt, aber nicht weiter erläutert, argumentiert Frau Timm für das Abnehmen der Kopfbedeckung als didaktische Praktik. Ähnlich wie ein spezifischer Raum markiert wird, wenn ein Test geschrieben wird, indem die Tische verschoben werden, soll durch das Ziehen der Kappe der Übergang zu »inhaltlichen Dingen« markiert werden. Die Markierung ist aber mehr als ein »äußerliches« Symbol, die SchülerInnen sollen sich laut Lehrerin Timm auf den Wechsel der Ebenen »einlassen«. Dieses Einlassen ist eine Körperpraktik, mit der der Schüler den Übergang vollzieht. Es ist die Herstellung des Schüler- bzw. Lernkörpers. Indem die SchülerInnen den Akt des Übergangs eben nicht vollziehen, signalisieren sie, dass sie sich nicht einlassen. Die Lehrerin bezeichnet das als »Spiel«. Die Metapher des Spiels eröffnet mehrere Dimensionen (vgl. Goffman1996b: 164ff.): einem Spiel liegen Regeln zugrunde, spielerisch steht für Leichtigkeit, dem Spiel steht der Ernst des Lebens bzw. die Realität gegenüber, meist gibt es MitspielerInnen, innerhalb bzw. trotz festgelegter Regeln wird viel ausgehandelt, es wird möglicherweise »geschummelt«. Im Spiel finde nach Frau Timm das »Ausprobieren von Grenzen« statt. Das Ausprobieren besteht aber nicht nur darin zu testen, wie weit man gehen kann, also wo die Grenze ist, sondern greift die Idee des Übergangs zum »Inhaltlichen« auf. Im »Spiel« wird genau jene Grenze, die der Übergang bildet, eben nicht überschritten. Das Spiel ist alles andere als beliebig, es ist durchaus ein »ernstes« Spiel, gerade weil es sich um die Kopfbedeckung handelt, um die »gespielt« wird. So lässt sich auch die Aussage der Lehrerin verstehen, dass »ein Stück seiner Persönlichkeit, die eigentlich im Unterricht nicht gelebt wird « auch mit hineingenommen wird. In ihrem Vergleich mit der eigenen Schulzeit stellt sie es als eine Normalität dieser Schülerpraktiken heraus - das machen SchülerInnen immer, das haben auch wir gemacht. Das Verlassen des Schulgebäudes ist insofern analog zu den hier diskutierten Praktiken zu betrachten, als auch da die Grenze zwischen drinnen und draußen sein - Schule und Nicht-Schule bzw. SchülerIn und Nicht-SchülerIn sein, Gegenstand des »Spiels« ist.

Der mögliche Ernst des Spiels zeigt sich in der folgenden Szene:

Liv hat sich zum Klassenfest besonders gestylt. Sie trägt ein pinkfarbenes Stirnband mit einem Schild, das ihren schulterlangen Haaren die »richtige« Form verleihen soll. Die Lippen hat sie sich in der gleichen Farbe mit Lipgloss geschminkt. Vor der Klasse wird sie von einer Lehrerin aufgefordert, »das Ding « vom Kopf zu nehmen. 
Für das Mädchen ist dies tragisch, denn damit wird ihre Frisur zerstört und die gesamte Inszenierung hinfällig. Sie protestiert, nimmt wütend und traurig ihren Kopfschmuck ab. Dann rennt sie zum Spiegel, ruft laut: »Das sieht ja Scheiße aus« und versucht, ihr ungeordnetes offenes Haar ein wenig zu ordnen. (AS)

Für die Schülerin geht es um mehr als das Tragen von einem beliebigen bzw. beliebten Kleidungsstück oder eine Möglichkeit zur recht risikolosen Regelverletzung. Kleidung, Körperschmuck, mehr oder weniger sichtbare Markierungen und damit einhergehende Praktiken können als Demonstration der eigenen Verfügung und der Selbstbestimmung über den Körper gedeutet werden. Die Selbstinszenierung dient der Herstellung von Individualität eines mehr oder weniger fragilen und verletzlichen Selbst. Als Abgrenzung von der Kindheit wird hier ein eigener jugendkultureller Raum konstituiert, der sich mit dem der Schulkultur und deren Grenzsetzungen arrangieren muss. Der individuelle Ausdruck, eine Kappe tragen zu wollen, der zwar ebenso konfektioniert ist wie der sonstige medial vermittelte Lifestyle, kollidiert mit den sozialen Regeln der Schule. Zugleich ist die Inszenierung des eigenen Körpers aber sehr wohl auf die Schule und ihre SchülerInnen bezogen, denn als Schülerin und Jugendliche verbringt das Mädchen einen Großteil ihrer Zeit, ihres Alltags, also auch »ihrer Jugend« in der Schule. Jugendliche zu werden und zu sein, sich als Jugendliche inszenieren ist keine Freizeitbeschäftigung, die in einer dualen Denkweise von Schule und Freizeit aufgeht. ${ }^{11}$ Für einige SchülerInnen stellt sich das Verhältnis in Bezug auf ein mögliches Publikum für die eigene Inszenierung vielleicht gerade andersherum dar. Ein Mädchen, deren »Freizeit« sich aus kulturellen oder sozialen Kontexten und mit zunehmender Verhäuslichung von Kindheit (Zeiher/Zeiher 1991) vor allem in der Familie abspielt, findet ihren Bezug zu Gleichaltrigen, der in den Theorien zur Adoleszenz eine besonders große Rolle spielt, eben gerade in der Schule. Die in den letzten Jahren durchgeführten ethnographischen Studien, in denen die interaktiven Prozesse der Geschlechtskonstitution von Jugendlichen in der Schule

11 Die Forschungsbereiche Jugend- und Schulforschung schließen meist aktiv aus. Heinz-Hermann Krüger et al. (2000: 13f.) konstatieren eingangs ihrer quantitativen Studie zum Verhältnis von jugendlichen Lebenswelten und Schulentwicklung nach wie vor ein Nebeneinander von Schul- und Jugendforschung. Die Schulforschung, so Werner Helsper (1993: 351), abstrahiere von den komplexen Weltbezügen und den separierten Lebenssphären der Jugendlichen. Andersherum blendet insbesondere die dominierende Subkultur- und Stilforschung der letzten Jahre die zentrale Bedeutung der Schule für Jugendliche aus. Ausnahmen bilden die zumeist in der expandierenden Kindheitsforschung angesiedelten ethnographischen Projekte, auf die ich bereits mehrfach hingewiesen habe. Übergänge zwischen >Schulkultur« und >Freizeitkultur« werden innerhalb der Ritualeforschung aufgegriffen (Göhlich/Wagner-Willi 2001; Wulf/Zirfas 2004a), ansonsten in der Jugendforschung aber nur selten gemeinsam untersucht. 
untersucht wurden (Faulstich-Wieland 2004; Güting 2004; Tervooren 2006), zeigen, dass Schule zwangsläufig einen Raum darstellt, in dem Körperstile eingeübt werden: sowohl als »weiblich« als auch als »männlich« geltende, aber auch jenseits der Kategorie Geschlecht »Jugend « verkörpernde Stile. Das Experiment der Schülerin, zum Klassenfest mit einem neuen Outfit zu erscheinen, ist offensichtlich nicht als Provokation oder Spiel gedacht. Sie hat sich für das Fest - welches eben kein Unterricht ist, sondern durchaus eine andere, eben festliche Rahmung nahe legt - schön gemacht, doch statt Komplimenten und sozialer Anerkennung als »junge Frau« erhält sie eine routinemäBige Zurechtweisung und wird aufgefordert, »das Ding « - etwas Undefinierbares und Überflüssiges - abzunehmen. Damit wird ihre gesamte Inszenierung hinfällig.

Eine weitere Situation, die dieser in vielen Punkten ähnelt:

Die SchülerInnen werden in der Hofpause für eine Arbeit im Kunstunterricht von ihrer Lehrerin mit dem Fotoapparat porträtiert. Norwin beginnt vor der Fotografin und dem anwesenden Publikum engagiert zu posieren - in lässiger »cooler K Körperhaltung, schräg angelegtem Kopf, Blick zur Kamera, nicht starr, sondern etwas in Bewegung. Die Lehrerin fordert ihn auf, sein Basecap für das Foto abzusetzen. Daraufhin protestiert er heftig. Laut ruft er immer wieder: »Nein - nein - nein, nicht ohne, das mach ich nicht! Nein! « Er fasst sich an seinen Kopf, an die Haare. Die Lehrerin spricht noch einmal leise mit ihm, woraufhin er die Kappe absetzt. Nun versucht er, ohne sie genauso >cook zu wirken, was sichtlich schwerer zu sein scheint. Seines Statussymbols beraubt, versucht er bestmöglich eine Körperhaltung einzunehmen, die seiner gewünschten Rolle gerecht wird. Er sieht sich das entstandene digitale Foto an und ssegnet< es sabc. Von der Anspannung gelöst, verlässt er nun die Situation, indem er wippend über den Schulhof geht und, ohne jemanden direkt anzusprechen, mehrmals fragt: »Wer will noch ein Autogramm? « (AS)

Der Schüler befindet sich auf dem Schulhof - einem Ort, an dem Kappen getragen werden dürfen, er davon also auch ausgehen kann. Er hat dieses Accessoire nach dem Unterricht vor dem Spiegel genauestens auf seinem Kopf »austariert«. Kappe und Körper gehen fast ineinander über. Das Basecap gehört ähnlich wie bei dem Mädchen im ersten Beispiel zu einem Gesamtarrangement, es soll seine Coolness unterstreichen. Sie abzunehmen, fällt ihm sichtlich schwer und erfordert einige Überredung durch die Lehrerin. Wie sehr Körper und Kleidungsstück miteinander verknüpft sind, wird in der Beschreibung deutlich: Norwin versucht nun, ohne das Accessoire mittels seines Körpers denselben von ihm gewünschten Eindruck zu erzeugen. Entweder, um die Situation zu retten, oder vielleicht auch mit einer gewissen Zufriedenheit, weil ihm seine Darstellung gelungen scheint, geht er dann jedoch, nicht 
wie Liv gebrochen und wütend aus ihr heraus, sondern er bezieht sie als ein bewältigtes Ereignis in seine Inszenierung ein.

Die SchülerInnen bewegen sich mit ihren Körperinszenierungen zwischen Konformität und Individualität. Dabei haben Körper- und Kleidungspraxis für sie eine hohe Bedeutung (vgl. Güting 2004: 128). Die Schule ist der Ort, in dem die jungen Menschen einen großen Teil ihrer Zeit verbringen, ein öffentlicher Ort mit interessiertem Publikum, an dem sie sich ausprobieren und experimentieren können. Als Bewertungsinstanz angemessener Ästhetiken und Körperpraktiken sind die FreundInnen, die Clique, die MitschülerInnen wichtig - für mimetische Angleichungen sowie Sanktionen unangebrachter Inszenierungen. »Das Einüben wird im Moment des Scheiterns diskursiv in der Gruppe verhandelt und bewertet. Auf diese Weise werden Distinktionskämpfe deutlich, welche die Mädchen [und Jungen, A. L.] führen, um sich von der eigenen, für sie unmittelbar zurückliegenden Vergangenheit zu distanzieren.« (Tervooren 2006: 101) Ihre spezielle Kleidung und insbesondere ihr Umgang damit ist eine Form von Subjektivierung und Selbstausdruck, die auch Macht gegenüber den LehrerInnen verkörpert. Die Reglementierungen können somit als ein Teil des nicht-offiziellen Lehrplans betrachtet werden, in dem es um die Anpassung an bestehende Regeln und Verhältnisse geht.

\section{„Körperportrait « eines Schülers}

Während in den bisherigen Ausführungen der Schülerkörper im Verhältnis zu Raum und Zeit und zum institutionellen Arrangement stand, möchte ich nun enger fokussieren (auch wenn die angesprochenen strukturierenden Elemente dabei nicht außen vor bleiben). Ich stelle eine Beobachtungssequenz vor, die die habituellen Aktivitäten des Körpers, das »Körpergehabe« (Rumpf 1996b: 26), die Bewegungen und Gesten eines Schülers ins Zentrum rücken, sie gewissermaßen in ihrer Abfolge als eine Momentaufnahme von Dingen, die vor sich gehen, einfrieren. Die fokussierte Beobachtung fand im Unterricht über ca. 35 Minuten statt. Die SchülerInnen bearbeiteten während dieser Zeit ihren sog. Wochenplan, einen mehr oder weniger individuell auf die jeweiligen SchülerInnen ausgerichteten Aufgabenplan, der sich aus unterschiedlichen Unterrichtsfächern zusammensetzen kann und in bestimmten Schulstunden nach eigenem Tempo bearbeitet wird.

Florenz ist ein 13 Jahre alter Junge, der uns weder als einer der ersten während der Beobachtungen auffällt, noch müssen wir uns ihn besonders in Erinnerung rufen, um ihn nicht aus den Augen zu verlieren. Er steht als Beispiel für einen in meiner Beobachtung »durchschnittlichen« Schüler, wie es viele gibt. Florenz trägt eine glänzende 
schwarze Nike-Jogginghose, ein Sweatshirt, Puma-Turnschuhe und hat vorn aufgestellte, leicht gegelte Haare.

Der Junge sitzt an der Stirnseite des Hufeisens und ist mit einer Geometrieaufgabe beschäftigt. Der Stuhl, auf dem er sitzt, passt zu seiner Körpergröße. Er hat die Beine breit auseinander gestellt, die Füße fallen auseinander. Kurz darauf stellt er die Füße auf den Zehenspitzen nach hinten unter den Stuhl. Da Noel, Florenz und Bent auseinander gesetzt wurden, so dass jeder einen Tisch für sich hat, müssen sie sich nun lauter unterhalten als bisher. Dafür gibt es so viel Platz, dass Florenz die Arme auf dem Tisch ausbreiten kann - er hat die Ellenbogen weit auseinander auf den Tisch gelegt. Während des Arbeitens ist der Kopf weit über den Tisch herunter gebeugt. Die Bewegung des Körpers während des »Stillsitzens« findet vor allem unter dem Tisch statt, d. h. alle paar Minuten mit den Beinen, wodurch sich die Sitzhaltung immer ein bisschen ändert. Jetzt streckt er die Beine nach vorn aus, das linke über das rechte geschlagen, dann rutscht er auf dem Stuhl nach hinten und stellt die Beine im rechten Winkel an. Seine Schultern sind dabei nach vorn eingerollt. Dann stellt er wieder ein Bein vor, das andere zurück. Zwischendurch legt er seine Arbeitspapiere ordentlich übereinander, so dass sie gerade abschließen. Er ist auf der Sitzfläche des Stuhls wieder nach vorn gerutscht, sitzt breitbeinig, so dass sein Körper fasst eine gerade Linie bildet.

Er dreht sich nach links zu Bent und zeigt ihm seine Arbeit. Die Beine fallen immer breiter auseinander, so dass er fast vom Stuhl unter den Tisch rutscht. Er schiebt sich wieder hoch, denn so lässt es sich mit dem Zirkel schlecht zeichnen. Nun sitzt er »im 90-Grad-Winkel«: Oberkörper, Oberschenkel, Schienbeine, Füße bilden jeweils einen solchen Winkel. Langsam wandern die Beine wieder auseinander, er führt die linke Hand an die Stirn, legt den Kopf darauf ab. Er steht auf, bleibt an seinem Platz stehen, um, den Hals reckend, aus dem Fenster zu sehen (es stürmt und gießt draußen - leichte Weltuntergangsstimmung). Bent und Noel machen es ihm nach. Dann setzt er sich wieder, kippelt mit dem Stuhl nach hinten. Kurz darauf steht er wieder auf, um nach vorn zu gehen. Nach ein paar Schritten hält er inne, sieht auf sein Blatt und geht wieder zurück zu seinem Platz. Er redet kurz mit Bent, blickt auf seinen Platz, setzt sich, schlägt die Beine übereinander und arbeitet weiter. Fünf Minuten später geht er zielstrebig mit großen Schritten vor zum Tisch der Lehrerinnen. Er stellt sich hinter die beiden Lehrerinnen, die auf ihren Stühlen sitzen. Sie blicken auf sein Blatt und fangen an, miteinander darüber zu diskutieren. Florenz steht unbeteiligt abwartend da, hält die Arme hinter den Rücken, schnalzt leicht mit den Lippen, blickt in die Klasse, lacht vorsichtig. Frau Matthes greift zu Ahmeds Arbeitsblatt, welcher vorn links sitzt und ohne Probleme im Sitzen zu erreichen ist, und zeigt beiden etwas auf dessen Blatt. Florenz beugt sich herunter, stützt die Arme durchgestreckt auf den Tisch und sieht ihr über die Schulter. Während Frau Matthes etwas auf Ahmeds Blatt für beide demonstriert, wiegt Florenz mit seinem Oberkörper hin und her.

Auf dem Weg zurück zu seinem Platz stoppt er bei Norman, »bohrt« ihm einen Finger von hinten in den Hals und pisackt ihn freundschaftlich mit den Armen und 
den Händen. Norman macht lächelnd mit. Dann stoppt er noch mal bei Bent und gemeinsam mit ihm und Norman macht er sich über Leon lustig (ich bekomme allerdings nicht mit, worum es geht). Nachdem sich Florenz wieder auf seinen Platz gesetzt hat, blickt er erst mal in Ruhe durch die ganze Runde. Er stellt die Beine v-förmig auseinander, zieht die linke Schulter etwas hoch, verbessert etwas auf seinem Blatt. Dann hält er es im Abstand seiner Armlänge vor sein Gesicht und betrachtet es »aus der Ferne «. Anschließend springt er auf, geht schnell vor zu Frau Matthes. Während er hinter ihr steht, sieht er zu Norman und Oliver. Frau Matthes kommentiert seine Verbesserungen mit einem anerkennenden "Ahaa". Oliver steht mittlerweile hinter Florenz und klatscht in die Hände. Florenz steht da, die Hände in die Seiten gestellt und sieht durch die Klasse. Dann lässt er die Arme hängen, streckt den Rücken gerade, neigt den Kopf nach vorn und hört Frau Matthes mit schnalzenden Lippen zu. Er geht in großen Schritten eilig zu seinem Platz zurück und arbeitet weiter. Er sieht sich sein Blatt erneut von der Ferne an, stellt dabei die Beine nach hinten, arbeitet konzentriert weiter, rutscht aber dabei fast unmerklich langsam wieder mit breiten Beinen nach vorn. Er bekommt einen Witz von Raik mit, lacht laut auf, arbeitet dabei aber trotzdem weiter und blickt nicht auf. Er kippelt mit dem Stuhl zurück und atmet laut durch. Dann arbeitet er noch bis in die Pause, obwohl es in der Klasse schon sehr unruhig wird. Bevor er seine Sachen wegpackt, ruft er Frau Matthes und fragt, ob es so richtig sei. (AL)

In vielen »Situationen « geschieht vieles parallel und vieles beginnt und endet $\mathrm{zu}$ verschiedenen Zeitpunkten - in Unterrichtssituationen allemal, wie diverse ethnographische Untersuchungen zeigen (z. B. Breidenstein 2006). Eine »gegenwärtige« Situation kann sich für die jeweilig Beteiligten also ganz unterschiedlich darstellen (Goffman 1996b: 17). In der geschilderten Sequenz wird diese Überlagerung von Situationen bezogen auf eine einzelne Person sehr deutlich. Ebenso gelangt an die Oberfläche, welche vielfältigen Körperaktivitäten und -praktiken bewusst, strategisch, nebenbei oder unbewusst »ablaufen« und von anderen Beteiligten beobachtet werden könnten. Die Sequenz lässt sich nun einerseits in ihrem Ablauf und hinsichtlich des darin zum Einsatz kommenden Körpers betrachten als auch auf weitere verschiedene Ebenen hin: der Bewegungen im Raum, des Verhältnisses zwischen der Konzentration auf eine Aufgabe und leiblichem Eingebundensein bzw. unwillkürlichen Regungen, des Betretens verschiedener »Räume« und Situationen. Dabei gehe ich - wie im Abschnitt zu den Kleidungsstilen - zum Teil über die Interpretation des Protokollierten hinaus, indem ich weitere Beobachtungen einbeziehe, um so ein Bild gängiger Körperpraktiken der SchülerInnen in Schule und Unterricht zu zeichnen. 


\section{Spiel(räume) der Bewegungen}

Während Florenz seine Aufgabe löst, sitzt er auf einem Stuhl und hat, so verlangt es die Regel der Institution, grundsätzlich auch dort sitzen zu bleiben. Dass Stuhl und Körper in ihrer Größe aufeinander abgestimmt wirken, ist deshalb hervorzuheben, weil dies nicht immer so ist. Hier zeigt sich eine Form der Heterogenität innerhalb der Schulklasse. Der eine Schüler reicht beim Sitzen kaum mit den Füßen auf den Boden. Er hat entweder Halt auf der Sitzfläche bzw. an der Rückenlehne und baumelt dann wie ein Kleinkind mit den Füßen. Oder er gelangt auf den Boden und rutscht dabei fasst vom Stuhl, verliert also noch mehr Halt. Ein anderer Schüler kann, weil er fast doppelt so groß ist, nur dann einigermaßen bequem sitzen, wenn er sich auf dem Stuhl lang macht. Sollen die Knie nicht an die Ohren stoßen, muss er mit seinem Körper eine Linie bilden und sich so mit der unteren Hälfte des Körpers unter den Tisch schieben. Dies entspricht - so ließe sich annehmen - seiner vorzugsweise angenommenen lässigen Haltung. Vielleicht kommt sie ihm deshalb entgegen, vielleicht aber trägt genau diese mehr oder weniger aufgezwungene Haltung auch dazu bei, dass sie als abweisende verstanden wird. Als »coole« Haltung suggeriert sie weder Aufmerksamkeit noch Anpassung an die schulischen Regeln.

Florenz dagegen scheint also auf seinen Stuhl zu »passen«. Dennoch kann von Stillsitzen keine Rede sein. Es lassen sich viele kleine Bewegungen beobachten, manchmal mit einzelnen Körperteilen, manchmal mit dem gesamten Körper. Die meisten Bewegungen finden unter dem Tisch statt, immer wieder wird den Füßen ein anderer Platz zugewiesen. Weil der restliche Körper der Bewegung folgt, verändert sich dadurch manchmal die gesamte Sitzhaltung. Einzig die weit auseinander gestellten Beine bleiben - eine Haltung, die bekanntermaßen als »männliche« gilt bzw. sich bei Männern häufig beobachten sowie manchmal (in öffentlichen Verkehrsmitteln beispielsweise) auch spüren lässt. Marianne Wex (1980) hat sie anhand von Fotografien anschaulich darstellt.

Florenz nimmt mit seinen Körperaktivitäten (manchmal gleichzeitig) verschiedene Räume ein. Mit dem Oberkörper bzw. den Ellenbogen oder, indem er seine Papiere als persönliche Habe sortiert und gerade auf dem Tisch ausrichtet, steckt er seinen persönlichen Raum ab. Diesen Raum beschreibt Goffman als eine »Kontur«, deren Überschreitung als Übergriff empfunden werde (1974: 56). Dies zeigt sich in einer Beobsehtung in der nachfolgenden Unterrichtsstunde, die an die, obige Sequenz aroschliebt: 
In Biologie liegt Florenz mit dem Oberkörper auf dem Tisch, als müsste er sich nun erst einmal ausruhen. Er zappelt dabei mit den Füßen. Weil Maris sich zwischen ihn und Noel gesetzt hat, rutscht er immer mehr von ihr weg zu Bent. (AL)

Maris tritt in seinen persönlichen Raum und ist dort nicht erwünscht. Florenz reagiert in zweifacher Weise darauf: Er versucht einerseits, mit seinen Armen den Platz zu behaupten, andererseits scheint er Nähe und Berührungen vermeiden zu wollen und schränkt seinen persönlichen Raum lieber ein, indem er sich seinem Nachbarn zur anderen Seite nähert. Da der persönliche Raum ein »temporäres, situationelles Reservat« (Goffman 1974: 57) darstellt, kann möglicherweise der gemeinsame Raum mit dem befreundeten Banknachbarn eher als persönlicher akzeptiert werden, als die undistanzierte Position zur Mitschülerin.

Aber nicht nur haptisch eignet sich Florenz Raum an oder gibt ihn wieder ab. Die drei befreundeten Schüler Bent, Florenz und Noel sitzen sonst näher beieinander, so dass sie sich weitestgehend flüsternd verständigen können. Nun hat zwar jeder für sich einen eigenen Tisch zur Verfügung, sie müssen diese Distanzen aber überbrücken, um ihre verbale Kommunikation aufrecht zu erhalten. Das tun sie, indem sie lauter sprechen als in den anderen Unterrichtsstunden und somit den Geräuschpegel der Klasse anheben. Florenz ist in seinen Aktionen kaum ohne seine beiden Nachbarn zu beobachten. Immer wieder treten sie in Interaktion, bleiben trotz räumlicher Entfernung mittels Blickkontakten zueinander in Verbindung. Es entsteht eine Dynamik zwischen ihnen, indem sie sich gegenseitig ihre Arbeiten zeigen, beim anderen nachschauen, aber auch, indem sie die Bewegungen des anderen aufgreifen. Als Florenz aufsteht und aus dem Fenster schaut, tun es ihm die beiden anderen Jungen nach. Sie signalisieren sich mit ihren jeweils den anderen spiegelnden Bewegungen gegenseitig ihre Bezogenheit aufeinander und bestärken ihre Beziehung untereinander. So vergewissern sie sich ihrer gemeinsamen Haltung gegenüber dem Unterricht und vor allem gegenüber den MitschülerInnen. Mit dem Blick aus dem Fenster konstituiert Florenz für sich aber auch noch einen weiteren visuellen Raum, der über das Klassenzimmer hinausgeht und den Blick in die Ferne ermöglicht. Zu einem späteren Zeitpunkt spielt er mit einem solchen Raum, indem er sein Arbeitspapier mit gestreckten Armen von sich hält und einen kritisch prüfenden Blick auf das Papier wirft.

In Abfolge des Geschehens kann das Aufstehen und aus dem Fenster sehen als erster Anlauf interpretiert werden, mit seinem Aufgabenblatt zu den Lehrerinnen zu gehen. Florenz setzt sich wieder, kippt mit dem Stuhl nach hinten und geht nicht weiter auf die Mitschüler ein. Es scheinen Bewegungsabläufe zu sein, die seine Gedankengänge begleiten und ihn innehalten lassen, bevor er einen erneuten Versuch unternimmt, nach vorn zu gehen. Auch die- 
sen bricht er im Gehen wieder ab. Wenn er auch nicht still sitzt, so ist er doch in seine Arbeit involviert und auf dem Weg zu einer Lösung des Problems. Dass sich Bewegung, Konzentration und Aufmerksamkeit nicht ausschließen, zeigt sich auch später, wenn Florenz an seiner Aufgabe weiterarbeitet und dabei immer wieder unwillkürlich wirkende Körperbewegungen stattfinden. Die Beine fallen mehrfach auseinander, er muss sich erneut aufrichten, um nicht von seinem Stuhl zu rutschen. Daneben finden parallel weitere Aufmerksamkeiten statt: Er lacht, ohne wirklich in die direkte Kommunikation mit dem Mitschüler einzusteigen, über dessen Witz oder ignoriert die Unruhe der begonnenen Pause. Goffman spricht von Engagement, von »gefangengenommen sein«: »Bei jeder Aktivität machen sich die Beteiligten gewöhnlich nicht nur ein Bild davon, was vor sich geht, sondern sie werden (bis zu einem gewissen Grade) auch spontan gefangen genommen, in Bann geschlagen.« (Goffman 1996a: 376) Zu bestimmten Rahmungen gehören normative Erwartungen, wie sehr Individuen in Vorgänge eingebunden sein sollen. Ein Schüler soll in erster Linie seine Aufmerksamkeit im Idealfall ganz auf die zu bewältigende Aufgabe richten. Die Beschreibung dessen, was passiert, zeigt, zu wie vielen Aufmerksamkeitsebenen sich Florenz - sichtbar, und zwar von einer bestimmten Beobachterposition aus - neben der Beschäftigung mit der Aufgabe und deren Lösung zu verhalten hat. Er ist in den Witz des Mitschülers involviert, lacht unwillkürlich, ohne aufzublicken. Und reagiert wie nebenbei auf eigene Körperbewegungen mit erneut aufnehmender Haltung.

\section{Bühnenwechsel}

Im dritten Anlauf geht Florenz sehr zielstrebig zum Tisch der Lehrerinnen. Er muss dazu den gesamten Raum durchqueren und hinter den Plätzen der anderen SchülerInnen entlang gehen. Als Interpretationsvariante bietet sich an, diese Szene mit Erving Goffmans Theatermodell (1969) zu betrachten. Goffman beschreibt anhand dieser Metapher, die die soziale Welt zur Bühne macht, auf der Ebene alltäglicher Interaktionen Strukturen sozialer Beziehungen. Er bedient sich der Theatersprache, um soziale Situationen und Regeln anhand von Begriffen wie Bühne, Darstellung oder Rolle zu analysieren, wobei der Inszenierung des Selbst große Bedeutung zukommt (Goffman 1969; 1996, S. 143-175). Sobald sich zwei oder mehr Menschen in Beziehung zueinander begeben, spielt das Bild, das sich die eine Person von der anderen macht, eine wesentliche Rolle. So bemüht sich jeder Mensch, sich in Gegenwart anderer in einer bestimmten Art und Weise darzustellen und einen bestimmten Eindruck bei ihnen zu erwecken (Goffman 1969: 10). Daraus ergibt sich die Notwendigkeit, diesen Eindruck zu kontrollieren und am individuel- 
len Image zu arbeiten, um eventuelle Schäden für die eigene Identität zu vermeiden. Dies wiederum führt zu dramaturgischen Prinzipien.

Die Interpretation des Beobachteten anhand dieser Metapher ist genauso naheliegend, wie auch Argumente dagegen sprechen können. Allzu häufig ist der vordere Teil des Schulraumes mit der Tafel und dem Bereich der Lehrkraft eine Bühne: für die Lehrenden im Frontalunterricht, bei einem Vortrag von LehrerInnen oder SchülerInnen, wenn ein Schüler an der Tafel etwas erklären soll oder im Klassenrat eine Schülerin die Leitung übernimmt (vgl. auch Breidenstein 2006: 111; Zinnecker 2001: 255). Goffman unterscheidet nun Vorder- und Hinterbühne ${ }^{12}$, so dass dieser Bereich mitsamt seinem Bühnenbild die Vorderbühne darstellen würde. Der Bereich, von dem aus die SchülerInnen den Unterricht verfolgen, wäre als Hinterbühne zu betrachten. Dass dies nicht die einzig mögliche Raumaufteilung ist, wurde schon in den vorherigen Kapiteln deutlich - beispielsweise bei der Aufteilung von Mädchen und Jungen innerhalb der Sitzordnung oder wenn man das Neben- und Durcheinander der vielfältigen sich überlagernden Situationen und Wahrnehmungsräume betrachtet. Wenn aber die Beteiligten in so viele Situationen gleichzeitig (mehr oder weniger) involviert sind, inwiefern lässt sich dann von solch einer Bühnenanordnung sprechen?

Um dies genauer zu betrachten, wende ich mich wieder den Aktivitäten von Florenz zu. Er betritt mit schnellen Schritten die Vorderbühne und stellt sich hinter die Lehrerinnen, während diese sein Arbeitsblatt (untereinander) besprechen. Florenz hat, so scheint es, auf der Bühne keinen ihm eindeutig zugewiesenen Platz. Während die Lehrerinnen sitzen, steht er vor der Klasse und ist damit für alle gut sichtbar. Aus dieser Position heraus stellen die MitschülerInnen ein Publikum dar, das seinen Auftritt verfolgen könnte, allerdings ein unkalkulierbares, da offen ist, wer von ihnen sich gerade als $\mathrm{Zu}$ schauerIn konstituiert oder, in die Arbeit (oder anderes) vertieft, gar nichts von Florenz Darstellung bemerkt. Der Schüler tritt selbst aus diesem Publikum heraus, er hat keine eindeutig präsentierende Rolle, da die Lehrerinnen und er die Handlung - das Besprechen der Aufgabe bzw. die Überprüfung ihrer Bewältigung - nicht öffentlich machen, indem sie es laut kommunizieren. Vielmehr sind es die körperlichen Gesten, die beobachtet werden können, die vom Publikum aber eventuell als Bestehen oder Versagen interpretiert werden. Wenn eine »Sprechstunde « besucht wird, deren Zweck ebenfalls in Überprüfungen, Stellungnahmen oder Inanspruchnahmen von Hilfe besteht,

12 Die Vorderbühne bezeichnet Goffman als »die Region, in der die Vorstellung stattfindet « (Goffman 1969: 100), die Hinterbühne definiert er »als eine hintere Region $[\ldots]$, de(n) zu einer Vorstellung zugehörige(n) Ort, an dem der durch die Darstellung hervorgerufene Eindruck bewußt und selbstverständlich widerlegt wird « (ebd.: 104). 
wird mit dem Besuch in der Regel ein baulich abgegrenzter Raum betreten. In dieser Offenheit scheint dagegen die Analogie näher zu liegen, dass in einem Bühnenstück ein Zuschauer unvermittelt aus dem Publikum ins Spiel der Darstellenden auf der Bühne einbezogen wird. Der einbezogene Schüler steht abwartend da, in Ungewissheit, was da jetzt wohl passieren wird. Seine Aufmerksamkeit gilt sowohl dem Geschehen auf der Bühne als auch dem Publikum, indem er in die Klasse blickt, so ihr Verhalten ihm gegenüber kontrolliert, und vorsichtig lächelt, ohne unmittelbar eine bestimmte Person dabei anzublicken. Goffman spricht von einem »Informationsspiel - eine[m] potenziell endlosen Kreislauf von Verheimlichung, Entdeckung, falscher Enthüllung und Wiederentdeckung « (Goffman 1969: 12), wobei die Kontrolle für den Einzelnen insofern gewinnbringend sei, da »die anderen im allgemeinen den scheinbar unkontrollierten Aspekten des Verhaltens verhältnismäßig unkritisch gegenüberstehen« (ebd.). So kann er Sicherungs- und Korrekturmaßnahmen treffen, um möglicherweise peinliche Situationen zu vermeiden oder diskreditierende Vorfälle auszugleichen. Das Lächeln könnte dementsprechend auch bedeuten, dass die Situation ins Lächerliche gezogen wird, um sich auf diese Weise von der eigenen Rolle zu distanzieren bzw. die Verbindung zwischen Person und Rolle zu lockern. Zugleich nimmt es das mögliche Lachen aus dem Publikum vorweg - wie Breidenstein schreibt, die vielleicht wichtigste und wirkungsvollste Form des Kommentierens von SchülerInnen im Unterricht (Breidenstein 2006: 116).

Indem Florenz dann aber anhand des Papiers eines anderen Schülers (aus dem Publikum) etwas gezeigt wird, wird er derart in das Handeln auf der Vorderbühne involviert, dass er sich engagieren muss. Sein Körper scheint dabei in eigenständiger gleichmäßiger Hin- und Herbewegung gefangen. Bei seinem »zweiten Auftritt« ein wenig später wiederholen sich die Darstellung und die Aktivitäten des Körpers in ähnlicher Weise.

Auch der Weg zurück zu seinem Platz lässt sich im Rahmen der Theatermetapher interpretieren, zumal dieser in besonderer Weise ritualisiert ist - zumindest bei den meisten Jungen der Klasse. Während Florenz an den SchülerInnen vorbei geht, stoppt er bei seinen Mitschülern und nimmt Kontakt zu ihnen auf. Dem einen bohrt er einen Finger in den Hals, boxt ihn leicht, worauf dieser lächelnd auf das Spiel eingeht. Mit den anderen lästert er über einen andern Schüler. Diese Art und Weise, die Vorderbühne zu verlassen, haben wir häufig beobachten können. Die Jungen streifen im Vorbeigehen einen Mitschüler, verteilen neckend kleine Hiebe oder Schläge in den Rücken oder auf den Kopf, manchmal auch schattenboxend ohne direkte Berührung, flachsen herum und nutzen den Weg, um soziale Kontakte verschiedener Art herzustellen, zu kommunizieren, sich zu solidarisieren. Mit Blick auf die Ausführun- 
gen zur Darstellung auf einer Bühne lassen sich diese Beobachtungen nicht nur als Nutzen einer Gelegenheit verstehen (bei der die Mädchen in der Regel ausgelassen werden, ebenso wie sich das Vorgehen bei ihnen kaum beobachten ließ), sondern als eine Art, das Ende der Darstellung und diese (wie auch immer) bestanden zu haben rituell zu begehen. Es ist eine ritualisierte Praktik, »durch deren symbolische Komponente der Handelnde zeigt, wie achtenswert er ist oder für wie achtenswert er die andern hält« (Goffman 1996b: 25). Mit ihr wird ein korrektiver Prozess in Gang gesetzt und die Anspannung aufgrund eines möglichen Imageverlustes auf der Vorderbühne kann sich in einer Ausgleichshandlung entladen. Im übertragenen Sinne kann sich der Darsteller von seinen Fans »bejubeln« lassen, sie »tragen« ihn zurück zu seinem Platz. Eine Variante dieses Ganges, die wir oft beobachtet haben, ist, in "gebrochener Manier« den Körper eingeknickt, träge schlurfend von einem Gespräch mit den Lehrerinnen zurückzukehren. Beendet wird in der beobachteten Sequenz die Ausgleichshandlung mit einem abschätzenden, ruhigen Rundumblick durch die Klasse - ein letzter Check, ob alles »gut« gegangen ist.

\section{Übung zwischen Spiel und Zwang}

Die beschriebene »Körperkommunikation« zwischen den Jungen möchte ich noch einmal aufgreifen und anhand eines weiteren Beispiels verdichten. In der folgenden Beobachtungssequenz üben zwei Schüler, Ahmed und Florenz, in einem sog. Partnerdiktat für den anstehenden Deutsch-Test.

Ahmed setzt sich rechts neben Florenz. Er wendet sich ihm zu, indem er sich seitlich auf den Stuhl setzt, nahe an ihn heran rückt und seine Beine zwischen die von Florenz schiebt. Dann steht er auf, schaut ihm über die Schulter, sie lachen gemeinsam über den Text. Ahmed setzt sich wieder. Florenz muss schreiben, guckt von einem Text ab, der am Fenster hängt für diejenigen, die eine andere Übungsweise bevorzugen. Ahmed bemerkt es, hält ihm die Hand vor die Augen. Florenz sitzt locker zurückgelehnt, breitbeinig auf seinem Stuhl, während er schreibt. Ahmed sieht ihm wieder über die Schulter, fasst ihm an den Nacken. Sie lachen. Das Diktat scheint nicht so wichtig, sie nutzen viel mehr die Gelegenheit, Spaß miteinander zu haben. Ahmed kippelt mit dem Stuhl, sitzt wieder seitlich, Florenz zugewandt. Sein Po rutscht hinten von der Sitzfläche runter. Das Diktieren klappt besser, nachdem sie getauscht haben, auch wenn Florenz Ahmed jedes Mal dazu anhalten muss, doch jetzt mal zu schreiben. Ahmed bekommt mit, dass Florenz den Text vom Fenster abliest. Er dreht sich um. Florenz hält ihn davon ab, indem er sein Gesicht zurückdreht. Frau Timm bekommt das mit, schreit Ahmed laut an, dass er in Rechtschreibung miserabel wäre und wie er das schaffen wolle. Dann fordert sie ihn auf, zu ihr zu kommen. Sie redet ruhig und eindringlich auf ihn ein. Auf dem Rückweg hält er bei den anderen Jungen an - schon kommt die nächste laute Ermahnung von Frau Timm. 
Am Platz angekommen nimmt er die gleiche Haltung wie vorher ein: setzt sich seitlich auf den Stuhl und kippelt. Die beiden Schüler werden allerdings ruhiger. Kurz darauf fordert Frau Timm Ahmed auf, doch das Laufdiktat ${ }^{13} \mathrm{zu}$ machen und einen Platz weiter (weg von Florenz) zu rutschen. Nach dem Lesen setzt er sich nur halb mit der rechten Körperhälfte auf den Stuhl. Er versucht, ohne aufzustehen den Text $\mathrm{zu}$ lesen. $\mathrm{Ab}$ und zu lässt er sich von Florenz ablenken. Wenn er aufsteht, nutzt er die Chance, um Florenz in den Nacken zu fassen, ihn zu knuffen oder anzurempeln. (AL)

Die beiden Schüler haben eine klare Arbeitsanweisung: Sie sollen sich gegenseitig einen Text diktieren. Es wird eine funktionale Arbeitsteilung nahegelegt: der eine liest abschnittweise vor, der andere schreibt, beide kontrollieren die Handlung und das Ergebnis des Schreibenden. Sie sollen nicht diskutieren oder eine Aufgabe gemeinsam lösen, sondern eine Übung durchführen. Die körperlichen Betätigungen wären damit Sprechen, Hören und Schreiben, während sie mit etwas Abstand nebeneinander auf ihren Plätzen sitzen. Die beiden Schüler machen diese Aufgabe zu einem Spiel, indem sie sie »bespielen«. Sie setzen sich nah zueinander, denn sie gelten im Partnerdiktat als Partner, d. h. sie gehen eine Beziehung ein, allerdings eine andere als die erwartete SenderEmpfänger-Beziehung. Den zu bearbeitenden Gegenstand nutzen sie für ihre eigene Ausgestaltung. Sie berühren sich an Beinen, Nacken, Kopf. Es sind körperliche Aktivitäten, mit denen die Jungen Nähe zueinander herstellen, und in die sie, zumindest teilweise, die Aufgabenstellung einbeziehen: Beispielsweise indem Ahmed Florenz die Augen zuhält oder Florenz Ahmed den Kopf zurückdreht, als er einen Blick auf den am Fenster aushängenden Text wirft. Beide verweisen damit auf geltende Regeln und Gebote von Unterricht und Prüfung: Du sollst nicht abschreiben. Allerdings stellen sie den Ernst der Situation in Frage (der hier auch nicht so ernst ist wie in einer Prüfung), indem sie durch einen Regelbruch auf die Regel - still zu sitzen und ruhig zu arbeiten - verweisen. Und wie soll Florenz schreiben, wenn Ahmed ihm die Augen zuhält? Die Schüler haben Spaß an diesem Miteinander, in dem das Diktat mehr oder weniger zur Nebensache wird. Allerdings nicht gänzlich: Mit ihm steht und fällt der Rahmen, der das körperbezogene Spiel innerhalb des Unterrichts so ausgiebig möglich macht. Um das Spiel aufrechterhalten zu können, muss das Paar sein Üben so weit in den Vordergrund rücken, dass das Lernen - was darüber stattfinden soll - sichtbar wird (und nicht nur sein Spiel). Sichtbar aufgrund der Sichtbarkeit ihrer Körper, also bestimmter Körperhaltungen, die das Ausführen der Übung anzeigen.

13 Laufdiktat heißt: Der Text ist im Raum bzw. am Fenster aufgehängt. Die SchülerInnen begeben sich dorthin, prägen sich einen Satz(teil) ein und schreiben ihn an ihrem Platz auf. Dann stehen sie erneut auf, schreiben usw. 
Genau dies findet nicht statt: Die Lehrerin interpretiert das Handeln der Schüler als Nichteinlösung der gestellten Aufgabe und begründet ihren Tadel mit der individuellen Leistung des Schülers und der Notwendigkeit zu üben und auf diese Weise zu lernen. Sie kann keinen gelehrigen Körper entdecken, der zugleich den Anschein erweckt ein lernender zu sein. In dieser Form spielend kann kein Diktat geschrieben werden. Lernen kann sich nicht mit anderen beiläufigen Tätigkeiten vermischen, ganz im Gegensatz zu neuen Lernkulturen, in denen eine Verbindung von Lernen und Unterhaltung gefordert wird. Ahmed wird aufgefordert, zu einer anderen Form der Übung überzugehen, die eine auf sich selbst bezogene Tätigkeit enthält. Im sog. Laufdiktat sollen Denken und Bewegung zusammen gebracht werden, so erklären die Lehrerinnen ihr Ansinnen den SchülerInnen. Die körperliche Bewegung, die den Jungen, da sie ständig miteinander in Bewegung sind, während des langen Sitzens zu fehlen scheint, hätte er beim Laufdiktat. Er soll die Bewegung zur Unterstützung des Lernens nutzen. Doch darum scheint es Ahmed nicht zu gehen, denn er versucht, den Text vom Platz aus zu lesen, und hintergeht damit die Idee der Übung. Vielmehr versucht er, sie pragmatisch hinter sich zu bringen, der Spaß am vorherigen Spiel scheint verschwunden.

Was lässt sich nun etwas losgelöst von den beobachteten Szenen und verallgemeinernd bezüglich des Verhältnisses von Körper und Institution Schule schlussfolgern? Ich habe das Kapitel mit der Überschrift »Lernende und gelehrige Körper« versehen. Sie enthält eine doppelte Lesweise: Lernende Schüler und deren gelehrige Körper sowie lernende Körper und gelehrige Körper. Besonders im letzten Beispiel wurde das Doppeldeutige und der Zusammenhang zwischen lernend und gelehrig sein deutlich. Im Vergleich zum Bild, das SchülerInnen in einer Unterrichtssituation mit ihrem Körper abgeben, mit dem Bild vom gelehrigen Körper eines »fiktiven Normschülers« (Pongratz 1989: 185) also wird »abgelesen«, ob diese lernen. Denn wie soll und kann sonst Lernen als Vorgang beobachtet werden (Scholz 2002: 134f.)? »Die Körperlichkeit ist der verhandelten Sache nicht äußerlich; sie zeigt die Teilnahme am Lehrstoff an. Es ist eben nicht die rechte $<$ innere Teilnahme am Lehrstoff « - und hier lässt sich das Zitat von Horst Rumpf nicht nur auf Lehrende, sondern auf SchülerInnen beziehen -, wenn die Schüler miteinander beschäftigt sind, sich berühren, knuffen, lachen. "Der Lehrstoff, jeder Lehrstoff offenbar, fordert strengste körperliche Selbstzucht.« (Rumpf 1981: 85; Herv. i. O.) Die Konzentration auf die Übung ohne das Spiel der Jungen hätte bestimmte mögliche Körperhaltungen zur Folge, die mittels ihrer alltäglichen Wiederholung eingeübt werden. Lernen in der Schule setzt gelehrige Körper voraus und erzeugt sie zugleich, aber nicht unbedingt in identischer Weise oder mit demselben Ergebnis. Der Körper erlernt in täglichen performativen 
Praktiken bestimmte Bewegungsrepertoires und Haltungen, die nicht nur in der Institution Schule gebraucht werden, sondern eine »verwaltete Gesellschaft« auszeichnen, also für eine bestimmte gesellschaftliche Ordnung stehen. Der »Lernkörper« stellt, so Rumpf, zugleich eine Schulung für den »Arbeits-, Verkehrs- oder Konsumkörper« dar (ebd.: 44). Viele soziale - ausgesprochene und unausgesprochene - Regeln lassen sich auf »die Welt« außerhalb von Schule übertragen. Ohne einen derart gelehrigen Körper, der einen bestimmten Zugang zur Welt erfahren und einstudiert hat, ist gesellschaftliches Überleben kaum möglich. Dazu gehört letztlich auch, als Schülerin eine Lernende zu verkörpern, zu lernen, welcher Körpereinsatz als Lernen gedeutet wird. Dabei steht vorwiegend der Körper als »Stativ« für das vor allem als kognitiv stattfindend verstandene Lernen. Ein Stativ hat die Funktion etwas unbeweglich zu machen, still zu halten, damit etwas anderes gut funktioniert und positive eindeutige Ergebnisse zum Vorschein kommen. Ein Stativ für den Kopf, der aktiv werden soll, während es, in der Metapher bleibend, experimentell erscheint, mit dem gesamten Körper zu lernen.

Die gelehrigen Körper gehen über das Lernen von vermittelten Inhalten weit hinaus. Einerseits weil sie von diesen zumeist distanziert werden, indem beispielsweise mit dem zu vermittelnden Wissen kaum an Empfindungen und körperlich-sinnliche Erfahrungen angeknüpft wird. Andererseits indem, wie zu Beginn des Kapitels geschildert, über die körperlich-räumliche Ordnung soziale Positionen und Geschlechterarrangements hergestellt werden und in ihrer alltäglich stattfindenden performativen Praxis verfestigt werden. Zugleich - und das zeigen die jeweiligen Beobachtungssequenzen ebenfalls kann die gegebene Ordnung »ausgereizt« werden und in der Wiederholung werden aufgrund der Iterabilität mögliche Grenzen verschoben.

\section{Körper(bewusstseins)schulung in pädagogischen Texten}

Mit diesen Überlegungen zum Verhältnis von gelehrigen und lernenden Körpern möchte ich nun die Aufmerksamkeit auf die untersuchten Zeitschriften richten. Wie wird dort Körper(lichkeit) von SchülerInnen und Schülern, der lernende und der gelehrige Körper thematisiert bzw. problematisiert? Ich werde erste Suchbewegungen vornehmen, die sich im Laufe der Arbeit verstetigen. Suchbewegungen deshalb, weil sich »der Schülerkörper« nicht einfach aus all dem Gesagten anhand der Titel der Zeitschriften oder ihrer Inhaltsverzeichnisse erschließt. ${ }^{14}$

14 Zugleich ist er aber zumindest in der >Pädagogik überaus präsent: in SchwarzWeiß-Fotografien, die mit ca. einem Drittel der Seiten viel Raum einnehmen. 
Für den Einstieg in das Material beginne ich mit dem Teil des Korpus, welcher Artikel enthält, die >Körper(lichkeit)< explizit thematisieren. Sie sind Zeitschriften mit entsprechendem Schwerpunkt entnommen oder es sind verstreute Texte mit Überschriften, die auf das Thema verweisen. So entstand ein Teilkorpus mit 87 Texten, innerhalb dessen ich 40 Artikel einer detaillierten Feinanalyse unterzog. Diese Reduzierung beruht nicht nur auf forschungspragmatischen Gründen. Vielfach finden sich Überschriften, die zwar Metaphern wie »Mit Kopf, Herz und Hand« enthalten, und Pestalozzis Maxime mit oder ohne Bezug auf ihn - als Motto eines »ganzheitlichen Unterricht« proklamieren. Im Text spielt Körper(lichkeit) jedoch dann gar keine Rolle. Letztlich fokussiere ich in diesem Kapitel die Thematisierung des Lern- bzw. Schüler(innen)körpers im Verhältnis zur Institution Schule, so dass ich vor allem auf jene Artikel zurückgreife, die auf dieses Verhältnis zu sprechen kommen (könnten). Zentral sind dabei vier Ausgaben zweier Zeitschriften, die Körper(lichkeit) zu ihrem Themenschwerpunkt erheben. ${ }^{15}$ Darüber hinaus werde ich zum Schluss des Kapitels vor allem auf Texte und Bilder zurückgreifen, die ich dem Bereich Gender und Pubertät zugeordnet habe. Um die Fokussierung auf das Verhältnis von Körper und Schule vornehmen zu können, ist allerdings erst einmal ein größerer Ausschnitt zu wählen, der den Rahmen der Thematisierung stellt. Es wird deshalb zunächst um allgemeine Körperkonzepte jenseits von Schule und von SchülerInnen gehen, die sich in den Zeitschriften finden.

\section{Körper als Problem:}

\section{Körperkonzepte zwischen Natur und Kultur}

Mitte der 1990er Jahre wurde in vielen Wissenschaftsdisziplinen und öffentlichen Medien verstärkt gefordert, sich mehr mit »dem Körper« zu beschäftigen. Er wurde gewissermaßen wieder entdeckt. Wieder entdeckt, weil vielfach bei diesem »Entdecken« von seinem diskursiven und - damit eng verknüpft - von seinem leiblich-spürbaren Verschwinden die Rede war. Auch in den pädagogischen Fachzeitschriften schlägt sich diese Entdeckung nieder. Sowohl das >Päd Forum « als auch die >Pädagogik « widmen sich zeitnah diesem Thema. Bereits die Titel der Zeitschriften »Mit dem Körper lernen« (Pädagogik) und »Körper - Körperbewußtsein« (Päd Forum) lenken die Aufmerksamkeit auf diese Situation. Der Titel der Ausgabe des >Päd Forums stellt Körper und Körperbewusstsein als unterschiedliche Dinge nebeneinander. Man hat

15 Es handelt sich um folgende Ausgaben: »Mit dem Körper lernen« (Pädagogik 6/1996), »Körper - Körperbewußtsein« (Päd Forum 5/1996), »LehrKÖRPER LernWELTEN« (Päd Forum 3/2004) sowie in den Artikeln auf Körper bezogen: »Ruherituale und Entspannung« (Päd Forum 1/1996). 
einen Körper, aber nicht unbedingt ein Bewusstsein dafür. Der Körper soll als etwas kaum Thematisiertes wahrgenommen werden, man soll sich seiner Vergesellschaftung bewusst werden. Für das Bewusstsein, welches Sinnlichkeit, Wahrnehmung, Kognitives und Körperkontrolle umfasst, sorgen die AutorInnen mit ihren Aufsätzen. Auch die Ausgabe der `Pädagogik« möchte dazu anregen, einer körperbewussten Lernkultur mehr Raum zu geben. »Mit dem Körper lernen" scheint nicht selbstverständlich zu sein. Womit lernt man sonst? Es scheint verschiedene Weisen zu lernen zu geben. Die körperliche ist davon eine, die wohl gesonderte Betrachtung verlangt. Der Tenor und die Botschaften der beiden Zeitschriften sind ähnlich, auch wenn es sich um verschiedene Textgenres und AdressatInnen handelt: Gesellschaftlich sei ein beherrscht funktionierender, disziplinierter Körper gefordert und in dieser langen Tradition stehe auch die Schule. Der Körper solle dem Geist gefügig gemacht werden, was zu einer Unterentwicklung körperbezogener, sinngebender Tätigkeiten in der Schule geführt habe. Aber - und das scheint zentral und an die »Körperdiskurse" Mitte der 1990er Jahre anzuknüpfen - es rege sich Widerstand im Zuge einer Technisierung, die den Körper scheinbar überflüssig werden lässt (PÄD K 05 96; PÄD K 06 96; PF K 09 96; PF K 12 96; PF K 15 96).

Diese Aussage konstituiert sich auf unterschiedliche Weise, abhängig davon, um welche Textgenres es sich handelt. Im >Päd Forum< finden sich vor allem anthropologische, philosophische oder soziologische Texte, deren AutorInnen vorwiegend Professoren aus der Erziehungswissenschaft, Philosophie, Medizin und Sportsoziologie sind. Die Texte der >Pädagogikı enthalten dagegen häufiger praktische Bezüge zu Schule und Unterricht, neben »wissenschaftlichen « Texten gibt es Erfahrungsberichte aus der Praxis. Im anthropologischen "wissenschaftlichen « Genre fallen vor allem Differenzierungspraktiken ins Auge, die hierfür typisch sind und mit denen andere Textgenres nicht arbeiten. Das heißt, es lassen sich grundlegende Differenzen dekonstruieren, die die Texte strukturieren und ein spezifisches Körperbild entstehen lassen: der vergangene vs. der gegenwärtige Körper, zum Teil ergänzt durch die Vorstellung eines zukünftigen Körpers, der gesunde vs. der kranke Körper und Körper vs. Leib. Diesen Differenzsetzungen kommt eine bedeutende Rolle zu, indem sie einerseits als zentrale Kategorien die Texte organisieren und andererseits als Differenzierungspraktik in einem Verhältnis zu den jeweiligen Differenzschemata anderer Texte innerhalb der selben Zeitschrift sowie darüber hinaus stehen. Sie stellen Verknüpfungen und Ausschlüsse her, so dass bei den Lesenden bestimmte Konnotationen aufgerufen und möglich werden. Im Arbeitsbündnis von Text und Leser haben sich die Lesenden zu diesen differenten Positionierungen zu verhalten, es wird eine Performanz im 
Leser hergestellt (vgl. Kap. >Subjekt, Macht und Diskurse $<$ ). Wie sieht nun diese Figur aus, von welchen Konnotationen spreche ich?

Ausgangspunkt in all diesen Texten ist eine momentane gesellschaftliche Situation, Diagnosen gesellschaftlicher Veränderungen bzw. die gegenwärtige Thematisierung von Körper, die von einer Vergangenheit und zum Teil einer möglichen Zukunft abgegrenzt wird. Diese Zeitabschnitte sind nicht überall gleich. Aber sie werden jeweils mit spezifischen Vorstellungen vom Körper gekoppelt. Zunächst ein Beispiel in tabellarischer Veranschaulichung:

Tabelle 4: Differenzen (PF K 09 96)

\begin{tabular}{|l|l|l|}
\hline Vergangenheit & Gegenwart & Zukunft \\
\hline Vergangener Körper & Gegenwärtiger Körper & Zukünftiger Körper \\
\hline Anders & Krank & Besser/Gesund \\
\hline
\end{tabular}

Hans Günther Homfeldt bezieht aus erziehungswissenschaftlicher Perspektive die Gegenwart auf die zurückliegenden zwanzig Jahre (PF K 09 96: 420). In anderen Texten beginnt dieser Zeitabschnitt bereits mit der Industrialisierung (PF K 13 96: 442) oder mit der Aufklärung (PF K 14 96: 462) oder sie wird zeitlich gar nicht konkretisiert (PF K 12 96). Diese unterschiedliche Datierung von Gegenwärtigem ist von besonderer Bedeutung, zumal sie jeweils nicht sofort ersichtlich ist: Gerade weil die Differenz von Vergangenheit und Gegenwart eine zentrale ist, wird sie intertextuell innerhalb des Themenheftes schnell eingängig als eine, die überall gleich zu sein scheint, immer auf denselben Zeitpunkt der Veränderung verweist und folglich im Weiteren auch immer dieselbe Veränderung meinen muss. Eine die - nicht immer genauso stringent, aber in der Tendenz - auf einen anderen, gesünderen, leiblicheren und implizit natürlicheren Körper hindeutet, während wir es in der momentanen Situation mit einem funktionalisierten und kranken Körper zu tun haben. Die Zeitachse wird demnach häufig mit der Differenz ‘gesund ‘ vs. ’krank` gekoppelt. Beispielsweise bei Thomas Loy: Er knüpft das >Gesunde` an das `Natürliche` und `Menschliche`. Für ihn gibt es einen natürlichen Körper, der den Menschen ausmacht, es herrschen die Gesetze der Anatomie. Was Leistungssportler treiben, sei dagegen widernatürlich und unmenschlich und - das ist das eigentliche Problem - es übertrage sich auch auf die allgemeine Bevölkerung. 
Tabelle 5: Differenzen (PF K 16 96)

\begin{tabular}{|l|l|}
\hline Vergangenheit & Gegenwart \\
\hline Menschen & Schlangenmenschen (Unmenschen) \\
\hline Gesetz der Autonomie & Als gehörten Körperteile nicht zu ihnen \\
\hline Biologische Gegebenheiten & Wider die Natur \\
\hline Freude an Bewegung & Sportlicher Fortschritt \\
\hline Gesunde Körperhaltung & Menschlicher Rückschritt \\
\hline (Natürliche Bewegungen) & Abstruse, unnatürliche Bewegungen \\
\hline
\end{tabular}

Eine derart explizite Naturalisierung, die identisch ist mit dem Mensch-Sein und einer Norm, findet sich in den anderen Texten nicht. Problematisch ist der gegenwärtige Körper jedoch allemal. Nach seinem »Verschwinden« aus dem Bereich des Diskursiven, womit interessanterweise, folgt man der Argumentation, auch der materielle Leib verkümmerte, kehrt nun ein materiell sichtbarer kranker Körper wieder. Krank ist er, weil er in Vergessenheit geraten war, einer permanenten Kontrolle ausgesetzt sei, ertüchtigt werde und nun streike, so beispielsweise Homfeldt (PF K 09 96: 421). Sportsoziologe Volker Rittner schreibt, die »rigide Körperdistanzierung« (PF K 12 96: 439), wie sie Elias herausgearbeitet habe, führe zur »Körperkatastrophe« (ebd.: 440). Immer mehr Menschen hätten mit ihrem Körper Probleme - und so werden der Körper und vor allem die Körperpraktiken zum Problem.

Die geforderte Aufmerksamkeit - das neue Körperbewusstsein - erfolgt nun in einigen Texten durch die ebenfalls an die Zeitachse gebundene Gegenüberstellung von Körper und Leib. Als Körper wird hier der vergesellschaftete Körper begriffen: der disziplinierte, instrumentalisierte, zivilisierte, objektivierte, tote, entfremdete. Der Leib, zu dem es aufgrund seiner Verkümmerung wieder zurückzukommen gelte, ist dagegen implizit der natürliche: der Empfindende, Lebendige, Unkontrollierbare, das »Subjekt«, das ein Eigenleben hat und Autonomie verspricht (PF K 15 96: 466-468; ähnlich PF K 09 96; PÄD K 06 96). Während der Körper »gute Kinder, Schüler, Bürger, Untertanen, Krieger, Patienten« zur Folge habe, so die Mediziner Milz und Ots, ermögliche der Leib »den selbständigen Menschen« (PF K 15 96: 471). Körperdisziplinierung und Leiberfahrung, im übertragenen Sinne sgelehrige Körper< und >lernende Körper`, werden einander gegenübergestellt. Das Leiberleben könne wieder »erwachen«, wenn es zu »Wiederbeleibungsversuchen « (ebd.: 472) käme, auch wenn dies, das sehen Milz und Ots durchaus, nicht außerhalb gesellschaftlicher Strukturen möglich sei. In der Idee der gesellschaftlichen Überformung des Leibes als Körper bleibt etwas ehemals oder ursprünglich Dagewesenes als diffuser Rest. 
Anhand dieser Differenzierungen entsteht ein Körperkonzept, welches den persönlichen Körper bzw. Leib dem sozialen, verobjektivierten Körper entgegenstellt. Häufig wird mit der Metapher des Raumes gearbeitet: der persönliche Körper als »Möglichkeitsraum ${ }^{16}{ }^{16}$, der auf die richtigen, geeigneten gesellschaftlichen Bedingungen treffen müsse (PF K 09 96), der Leib als Basis mit eigenem Potenzial (PF K 13 96; PF K 15 96), der in ein Wechselverhältnis zu seiner Umwelt tritt und bedroht ist durch die »zivilisatorische Umzingelung « (PF K 09 96: 421). Der Metapher des Raumes wird der des Kampfes hinzugefügt. ${ }^{17}$ Dabei bleibt eine Leerstelle: Wie kann dieses Verhältnis gestaltet werden, dass der Körper wieder zum Leib wird? Was bedeutet Körpersensibilisierung und welche mögliche Lebensqualität ist damit gemeint? Vor allem worauf wird rekurriert, wenn von einer »Wiederbeleibung« gesprochen wird? Natürlichkeit wie Leiblichkeit sind jeweils eine Art ursprünglicher Zustand, den es zu erreichen gilt. Ein Zustand, der diffus bleibt und an Vorstellungen eines aus sich heraus einzigartigen Subjekts gekoppelt ist. Wenn der gesellschaftliche Körper krank ist, bestimmte gesellschaftliche (disziplinierende) Praktiken den Körper krank machen, gibt »der Leib« eine Art Heilsversprechen $\mathrm{ab}$. Und wer hätte schon etwas gegen etwas mehr »Sinnlichkeit« einzuwenden - noch dazu in der disziplinierenden Schule? Denken wir an die oben rekonstruierten Differenzen, ist der Leib, den es zu erreichen gilt, allerdings nicht mit dem »vergangenen Leib« identisch. Die positiv besetzte Vergangenheit scheint aber nötig, um den derzeit »kranken Körper« davon abzuheben. Die »Re-Naturalisierung«, welche man auch als »Zurück in die Zukunft« formulieren kann, muss diskursiv hergestellt werden: Wir müssen darüber reden, damit wir etwas spüren und zu unseren Ursprüngen zurückkehren können. Insgesamt zeigt sich eine Tendenz, Körper in der Vergangenheit positiv zu besetzen und in der Gegenwart negativ, woraus sich Handlungsbedarf ableitet - nicht zuletzt für die Pädagogik. Jedoch ist hier von Schule kaum die Rede, lediglich bei Rumpf wird deutlich, dass sie am beschriebenen Prozess der Körperdistanzierung beteiligt ist (PF K 13 96).

16 Weitere Beispiele bei Milz und Ots sind: Leib als Versammlungsstätte, als Mittelpunkt, als Orientierungspunkt (PF K 15 96: 466), Körperräume (ebd.: 468), leibliche Heimat, belebter Raum, Leiblichkeit beherbergt Existenz (ebd.: 471).

17 Es ist die Rede vom »erbarmungslosen Ringen « um den Körper als Lebensinhalt sowie von »Streikbereitschaft des Körpers" (PF K 09 96: 420/421). Rumpf spricht vom »Großangriff auf den Menschenkörper « durch die Schulpflicht (PF K 13 96: 442). Das Verhältnis von Körper als Raum und wechselseitig Raum als Körper betrachtet Markus Schroer (2003). Erste Vorstellungen vom Körper als Raum finden sich bereits im 14. Jahrhundert, allerdings hat sich dieses Körperbild erst im Laufe von Rationalisierungsprozessen seit der Aufklärung durchgesetzt. Verbunden ist damit die Idee von außen drohender Gefahren, vor denen der Körper geschützt werden müsse (vgl. Schroer 2003: 80). 
Bedeutsam ist in diesem Zusammenhang eine weitere Tendenz, die sich in den folgenden Jahren in den Artikeln, die explizit zum Thema Körper geschrieben wurden, zeigt: Die Körperdisziplinierung scheint als historische Phase abgeschlossen, gewissermaßen überholt. Ein Beispiel dieser Verabschiedung, die eine Verschiebung von der Passivität hin zur Aktivität vermuten lässt, bietet Georg Hörmann mit dem Titel seines Aufsatzes: »Der Körper in der Schule. Vom dressierten und disziplinierten zum dekorierten und inszenierten Körper« (PF K 24 04). Auch die starke Verknüpfung zum Leiblichen und zur Sinnlichkeit wird nicht mehr betont. Wir haben es nun mit Fragen der aktiven, bewussten Inszenierung des Subjekts und vor allem der als damit einhergehend betrachteten Risiken sowie (nicht unpassend) der Gesundheitsprävention zu tun. Dabei kommt auch die Institution Schule verstärkt als Präventionsinstanz ins Spiel. In fünf der sechs Aufsätze des Themenheftes »LehrKÖRPER - LernWELTEN« (Päd Forum 3/2004) geht es im weitesten Sinne um Gesundheitserziehung, ob in Bezug auf Diagnosen wie »ein insgesamt problematischer Gesundheitszustand der jungen Generation« (PF K 24 04: 142) aufgrund von falscher Ernährung, Bewegungsmangel oder defizitärem Umgang mit Stress, ob in Bezug auf Praktiken des Piercings oder des Tätowierens (PF K 27 04) oder mit der Idee (oder besser: Ideologie?), in einem gesunden Körper wohne ein gesunder Geist (PF K 28 04). Eine solche thematische Ausrichtung lässt der Titel eigentlich nicht vermuten. Der Körper, der als real existierender jenseits philosophischer Fragen über dessen »Wesen« oder Materialität problematisiert wird, ist ein kranker bzw. potenziell krank (gemacht) werdender. Die individuellen Praktiken seiner Bearbeitung werden als risikoreich angesehen, ohne mit einem zehn Jahre zuvor angeprangerten Funktionalismus zu argumentieren. Diese Schwerpunktverschiebung lässt sich innerhalb derzeitiger Gesundheits-, Risiko- und Sicherheitsdiskurse verstehen, die potenzielle Risiken betonen und das Individuum aufrufen, sich abzusichern und ein Management der Unsicherheiten zu betreiben, indem sie ihm die Prävention überantworten. Das hat es aber auch zu leisten, da es damit Verantwortung für die Gemeinschaft übernähme und sonst eventuell selbst zum Risiko werde (vgl. Bröckling 2002; Lemke 2004b: 95ff.).

\section{Körper als Ziel: Körperbewusstes Lernen und Lehren}

Die Beziehung von Körper und Schule wird in den größtenteils praxisorientierten Texten der >Pädagogik hergestellt und präzisiert. Die Autoren sind zumeist PraktikerInnen, d. h. LehrerInnen, Therapeut(Inn)en usw. Lediglich der Einführungsartikel ist von einem Erziehungswissenschaftler geschrieben. Auch dort wird mit der beschriebenen Differenzierung in das Thema einge- 
führt: Nach Rumpf (PÄD K 06 96) gibt es einen Ist-Zustand des Körpers: Es ist der disziplinierte, der an gesellschaftliche, körperfeindliche Verhältnisse angepasst sei (Körper 1). Mit einem Alternativkörper (Körper 2), zu dem es zu gelangen gilt, könnten erste Schritte innerhalb und gegen die körperfeindliche Gesellschaft, wozu auch die Institution Schule gehört, unternommen werden. Dies wird folgendermaßen verbildlicht:

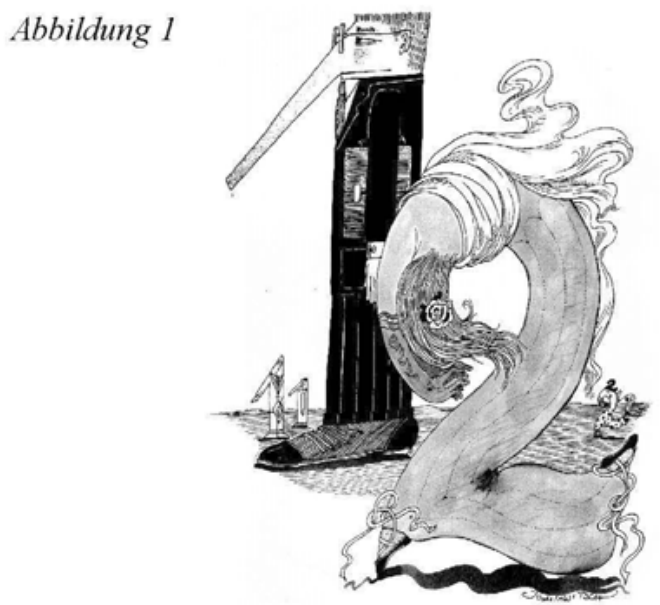

Rumpf überschreibt seinen Text mit der Überschrift »Über den zivilisierten Körper und sein Schulschicksal oder Körper 1/Körper 2«. Deren Ausprägung bekommen die Lesenden vor allem über die bildliche Darstellung veranschaulicht. Da die darauf folgenden Artikel in diesem Heft gewissermaßen die Überführung von $1 \mathrm{zu} 2$ darstellen, gehe ich auf das Bild, was Ausgangspunkt und Ziel des Weges präsentiert, ein. Körper 1 und 2 sind nicht nur zwei verschiedene Konzeptionen vom menschlichen Körper, sondern sie symbolisieren als Zahl jeweils eine eigene Körperform. Während die für zivilisierten Körper stehende 1 geradlinig, eckig sowie streng aussieht und Bürokratie und Männlichkeit verkörpert, erscheint die 2 geschwungen, rund, kreativ, künstlerisch, individuell. Sie ist mehr als funktional und statt in Bewegungslosigkeit zu verharren, rückt sie mit viel Dynamik ins Bild. In der gängigen Dichotomie von männlich und weiblich symbolisiert sie Weiblichkeit. Wenn Körper 1 der zivilisierte ist, so heißt das nicht, dass Körper 2 unzivilisiert oder undiszipliniert wäre. Jedoch wird dem gelehrigen, instrumentalisierten Körper der lernende gegenübergestellt. Darauf verweist der Titel des Zeitschriftenheftes. Körper 2 kann (und soll) in Eigenaktivität lernen. Die folgenden Artikel zeigen mögliche Wege zu einer »körperbewussten Lernkultur« (PÄD K 05 96: 
5). Um Zustand 1 zu überwinden, werden der körperfeindlichen Institution Schule körperbewusste LehrerInnen gegenüber gestellt. Hier lässt sich eine Parallele zum Themenheft »Körper-Körperbewusstsein« des »Päd Forums herstellen: Ziel ist, zu einem Körperbewusstsein zu gelangen. In der Ausgabe der >Pädagogik $<$ bezieht sich dies allerdings konkret auf Lernen (in der Schule), weshalb die Praktiken andere sind. Während im >Päd Forum< vorwiegend auf theoretischer Ebene zum Körper geschrieben wird und dabei vor allem um die Bewusstseins-Herstellung bei den Lesenden geht, sind es hier neben diesem Effekt, der sich aus der Interaktion zwischen Text und Lesenden ergibt, noch weitere Ebenen der Bewusstseins-Herstellung: Anleitungen zu Übungen insbesondere der eigenen Körperwahrnehmung für die Lesenden, also die Lehrenden (PÄD K 07 96), und Anleitungen, in der Regel als Erfahrung dargestellter didaktischer Praktiken, die sich dann auf eine Bewusstseins-Herstellung bei den SchülerInnen beziehen (PÄD K 08 96; PÄD K 09 96). ${ }^{18}$ Der Weg zu Körper 2 führt über das Bewusstsein der LehrerInnen zu den SchülerInnen: mittels konkreter didaktischer Praktiken, die unmittelbar das körperliche Erleben zum Gegenstand machen. Es geht somit weniger um Strukturänderungen, die die Institution Schule als solche körperfreundlicher gestalten, sondern um Praktiken innerhalb der Struktur, um die Arbeit am Individuum, damit es mit dieser arbeiten kann. Möglicherweise haben diese Praktiken Strukturänderungen zur Folge (z. B. wenn körperorientierte Arbeit Teil des Unterrichts wird und damit neue Räume geschaffen werden oder bezüglich der Geschlechterverhältnisse, wenn es zu anderem Umgang miteinander kommt), an der grundsätzlichen institutionellen Schullogik und deren Muster ändert das zunächst erst einmal nichts.

Der Befund verdeutlicht, dass - wie in vielen Texten beschrieben - der Körper sowohl in Bezug zum Selbst als auch in Interaktionen zu anderen steht. Der Ansatz, mit dem Körper zu lernen, scheint nur dann realisierbar, wenn die Lehrenden sich eben auch mit ihrem Körper darauf einlassen und es auch durch ihren Körper hindurchgeht. Es scheint also nicht möglich, sich lediglich »geistig« darauf einzulassen.

Zusammenfassend lässt sich sagen, dass eine körperbewusste Lernkultur in den meisten Texten zunächst am Körper der Lehrenden ansetzt (vgl. Kap. `Lehrende und gelehrige Körper $\iota)$. Doch was ist mit dem der SchülerInnen? SchülerInnen wie LehrerInnen sind damit befasst, so Rumpf, »zu sitzen, Bücher, Hefte, Stifte zu berühren und zu bewegen, sprachliche und mathematische Symbole über Mundbewegungen akustisch verlauten zu lassen« (PÄD K 06 96: 8). Die Schule unterschätze die leibgebundenen Weltberührungen und

18 Eine eingehende Analyse ist im Kapitel \Lehrkörper als Medium pädagogischer Praxis $<$ zu lesen. 
Tätigkeiten, die Sinnwelt werde nur zur Veranschaulichung abstrakter Lerninhalte herangezogen, ansonsten würden leibliche Regsamkeiten gezähmt, um sie kontrollierbar, vergleichbar und homogenisierbar zu machen (ebd.: 9). Für die SchülerInnen bedeute das Verlust. Körperliche Wahrnehmung und Bewegung werden als Voraussetzung für das Erlernen von Regeln und für soziale Beziehungen gewertet (PÄD K 06 96: 7; PÄD K 10 96: 27), ebenso wie Selbstbewusstsein beim eigenen Leib beginne (PÄD K 07 96: 12). Im >Päd Forum Kinder und Jugendlichen« werden konkrete Vorschläge unterbreitet, welche direkt am Lernkörper ansetzen. Ausgegangen wird dabei zum einen von der Diagnose, dass manchen Kindern »die natürliche Fähigkeit zur Ruhe und Besinnung verlorengegangen zu sein« scheint (PF K 06 96: 6). Zum anderen werden diese Kinder spezifiziert, indem spezifische Adressaten der Ruherituale ausgemacht werden: Kinder mit Verhaltensstörungen, Kinder in Kindergarten und Grundschule, SchülerInnen der Haupt- und Erziehungshilfeschule oder chronisch kranke Kinder. Nicht die Rede ist z. B. von GymnasialschülerInnen oder gar Erwachsenen. Die betroffenen Personen erscheinen auf diese Weise defizitär bzw. krank. Sie haben etwas verloren, was an sich natürlicherweise vorhanden sein müsste, so dass für einen Ausgleich gesorgt werden muss, den Ausgewachsene bzw. nicht weiter spezifizierte »Normale« in dieser Form nicht benötigen. Geht es also nicht um allgemeine soziologische, anthropologische oder philosophische Fragen zu Körper und Leiblichkeit, bei denen nur selten »Adressaten« genannt werden, sondern um konkrete pädagogische Praktiken, wird eine Gruppe von möglichen AdressatInnen nicht benannt und somit implizit zum Referenzpunkt für alle anderen: die GymnasiastInnen, die Erwachsenen, die, bei denen alles normal zu sein und zu funktionieren scheint. ${ }^{19}$ Dies ist nicht nur prekär, weil mit dieser diskursiven Praxis Etiketten und möglicherweise Stigmatisierungen verbunden sind. Es ist es auch deshalb, weil somit der Körper in Bezug auf Schule vor allem dann thematisiert wird, wenn er nicht ordnungsgemäß funktioniert oder defizitär erscheint. Damit wird genau das praktiziert, was kritisiert wird. Einer Reflexion über die alläglichen Bedingungen, die institutionellen Strukturen, die den Körper umgeben und durchziehen, oder alternativen Praktiken werden damit schnell Grenzen gesetzt.

19 Daran schließen sich wiederum bestimmte soziale Klassen und kulturelle Gruppen an. 


\section{Gelehrige und entspannte Körper: Übungen zur Geschlechtsidentität}

Körper(lichkeit) innerhalb didaktischer Praktiken wird in einem weiteren Bereich thematisiert, der innerhalb der Schule einen eher randständigen Status zugewiesen bekommt: in der Jungen- und Mädchenarbeit. Dort werden besondere Angebote für (zumeist außerunterrichtliche) körperliche Aktivitäten hervorgehoben. Die veranschlagten Themen sind vielfach auf das eigene Selbst und den Körper bezogen und werden didaktisch zum Teil in Form von »Körperarbeit« aufbereitet. Von dieser Beobachtung ausgehend betrachte ich, dieses Kapitel abschließend, die damit verbundenen Körperpolitiken.

Zunächst einige allgemeine Bemerkungen: Ins Auge fällt die besonders häufige Thematisierung und im engeren Sinne Problematisierung von Jungen (und Männern) innerhalb der Artikel, die ich dem Themenfeldern Gender zugeordnet habe. ${ }^{20}$ Allerdings relativiert sich diese Häufigkeit etwas, insofern es lediglich einen Einzelartikel innerhalb einer Ausgabe der >Pädagogik`mit dem Titel »Problemschüler« (10/2003) gibt, in dem danach gefragt wird, inwiefern Jungen im Allgemeinen zu einer besonderen Risikogruppe, "Problemfall« zu sein oder zu werden, gezählt werden könnten und besonderer Förderung bedürften. Zustande kommt die auffällige Menge der Texte durch zwei Ausgaben zu den Themen »Jungen und Männer in der Schule« (1999) und »Männerbildung oder Wie wird aus einem Jungen ein Mann..." (2002). Die Ausgabe von 1999 nimmt auf die Mitte der 1990er Jahre einsetzende Männerforschung Bezug, die wiederum auf die langjährigen Diskussionen zur Koedukation und der Benachteiligung und Diskriminierung von Mädchen und Frauen in Schule und Gesellschaft folgten. Mit der zweiten Ausgabe (2002) wird vor allem auf die zu dieser Zeit in den Printmedien geführten, vielfach dramatisierenden Debatten über die »armen Jungs « reagiert. ${ }^{21}$ Diese Relativierung wird nun wiederum dadurch relativiert, dass es im Untersuchungszeitraum von 1995-2005 zu Mädchen, Frauen und Mädchenarbeit keine solchen Schwerpunkt-Publikationen gab. Allerdings sind die Texte, in denen Mädchenarbeit bzw. Geschlechtergerechtigkeit thematisiert werden, im Korpus verstreuter, und so ließe sich schlussfolgern, selbstverständlicher.

20 Zur quantitativen Übersicht: Das Korpus enthält 15 Artikel zum Thema Jungen/ Männlichkeit/Jungenarbeit, zwei zur Mädchenarbeit, zwei zu Geschlechtergerechtigkeit, ohne bereits im Titel nach Mädchen und Jungen zu unterscheiden. In zwei der »Jungen-Artikel « wird explizit neben dem Blick auf die Jungen und einer spezifischen Arbeit mit ihnen eine Mädchenförderung gefordert.

21 Das Magazin »Focus« titelte im August 2002: »Das benachteiligte Geschlecht. Arme Jungs! (PF G 02 02: 267). Eine kritische Debatte über diesen in den letzten Jahren weitergeführten skandalisierenden Wettbewerb um das größere Opfer findet sich im Sammelband von Lotte Rose und Ulrike Schmauch (2005). 
Nach diesen allgemeinen und kontextualisierenden Beobachtungen sollen nun die Körperkonzepte und -praktiken im Vordergrund stehen. Nicht alle Artikel sind für die detaillierte Analyse interessant: Ein gutes Drittel der Texte kommt ohne die Thematisierung von Körper(lichkeit) aus und in den jeweiligen Texten ist der quantitative Stellenwert oft recht gering. Was heißt dies nun genau?

Als besondere Angebote mit viel Bewegung, die z. B. an speziellen Mädchen- und Jungentagen oder -stunden in einer Gesamtschule angeboten wurden, stellen Lehrerin Regina Malz-Teske und Erziehungswissenschaftlerin Katja Kansteiner-Schänzlin folgende vor: Maskenspiel, Akrobatik, Frisieren, Schminken, Skaten, Basketball, Klettern, Fußball, Theater, Yoga, Improvisationstanz für die Mädchengruppen (PF G 01 04: 83), Radtouren, Jonglieren, Trampolin, Klettern, Baseball, Karate, Tai Chi, Männertanz, Kanufahren, Schwimmen für Jungengruppen (ebd.: 84). Themen, die sich mit dem eigenen Selbst und dem Körper beschäftigen, werden vor allem für die Arbeit mit den Mädchen genannt. Da geht es um Frauen und Mode und es wird vielfach anhand von Körper-Bildern gearbeitet (PÄD G 01 95: 46). Oder es werden Themen wie »Ich und mein Körper «, »Schwanger, was nun? oder Prostitution (PF G 01 04: 83) angesprochen. Es sind Themen, die sich auf eine Körperidentität beziehen, in denen es um Vertrauen zu sich, das eigene Selbstbild, die Wahrnehmung des eigenen Körpers, um Gefühle, die eigene Stimme, Grenzen und deren Überschreitungen, Selbstverteidigung, Mut und Risiko geht (PÄD K 09 96: 21). Der Körper wird als zentraler Bestandteil der eigenen Identität angesehen (ebd.: 20), dabei werden weibliche und männliche Identitäten unterschieden. ${ }^{22}$ Die Lehrerinnen Hedwig Middendorf-Greife und Brigitte Lintzen gehen davon aus, dass Mädchen lernen, dass sie Jungen körperlich unterlegen seien, ihr Körper Defizite aufweise und so ein konflikthaftes Verhältnis zu ihrem Körper entstehe. Der Körper werde Medium sozialer und sexueller Attraktivität und es komme zu ästhetischen Stilisierungen nach Weiblichkeitsidealen. Jungen bewerteten ihren Körper dagegen nach funktionalen Gesichtspunkten. Diese Sicht findet sich auch in den Texten zur Pubertät, die anhand von empirischen Untersuchungen zu dem Ergebnis kommen, dass Mädchen häufig ein negatives Körperselbstbild haben, Jungen dagegen zufriedener mit ihrem Körper und den gesellschaftlichen Schönheitsidealen weniger ausgesetzt seien (SM SP 01 05: 6; PÄD SP 08 01: 10; PF K 26 04: 148f.). Die jeweilige Identität stelle sich durch den Umgang mit dem eigenen Körper und im Medium der Bewegung in selbstbestimmter Weise her, so die beiden Leh-

22 Inwiefern Heterosexualität und damit verbunden männliche und weibliche Identitäten im Diskurs über Pubertät als natürliche Normalität konstruiert werden, zeige ich in einer weiteren Analyse der Zeitschriften in Langer (2009). 
rerinnen (PÄD K 09 96: 21), was Körperarbeit mit Mädchen notwendig mache. Körperarbeit heißt, Übungen zu praktizieren, die vor allem die eigene Wahrnehmung ins Zentrum rücken, sie fördern - um Grenzen zu verdeutlichen und sie zu bearbeiten, um Aggressionen zu äußern, um zu entspannen.

Eine so ausführliche Begründung, weshalb Körperaktivitäten und körperbezogene Ansätze notwendig seien, findet sich in den Texten sonst kaum. Ich nehme allerdings an, dass die anderen AutorInnen ähnlich argumentieren würden. Der Zusammenhang von Körper und Identität bzw. der Körper, der als Identitätsträger genutzt wird (PF K 26 04: 149), ist eine Vorstellung, die sich insbesondere in den Texten explizit findet, die Körper(lichkeit) und Körperbewusstsein zum Gegenstand erheben (PF K 12 96; PF K 26 04).

Anders wird Körper und Körperlichkeit in der Jungenarbeit eingeführt. Es findet eine Problematisierung von Jungen (und nicht von Männlichkeit) statt: Jungen seien nicht so »schulkonform« wie Mädchen, deren Stärken Kommunikations-, Sprach- und Teamfähigkeit seien - etwas, so lässt sich schlussfolgern, was zur Institution Schule gehöre (PÄD G 03 99: 12). Jungen neigten körperlich und emotional zu »Panzerungen« (PÄD G 05 99: 23) und der Pädagoge müsse sich dementsprechend als »Panzerknacker« betätigen (ebd.: 24). »Jungen (und Männer) haben es schwer, sich selbst zu bewohnen.« (ebd.: 23) Jungen werden als »emotionale Analphabeten« (PF G 03 02: 269) bezeichnet, auch von einer »emotional defizitären Geschlechtsrollenübernahme« (PF G 02 02: 267) ist die Rede. ${ }^{23}$ Doch was haben all diese problematisierenden Jungenbilder mit Körper(lichkeit) zu tun? Die Panzerung lässt es erahnen: Die Rede ist von körperlicher und vor allem von emotionaler Distanzierung. Die Probleme, die Jungen machen und haben, werden vor allem als Folge von emotionalen Defiziten gesehen. Es tritt ein ambivalentes Verhältnis an die Oberfläche: Distanz einerseits und Distanzlosigkeit andererseits. An dieser Stelle kommt der Körper zum Einsatz: Als Raum, ihn und sein Selbst zu be-

23 Die beiden Zeitschriften, die Jungen und Männer fokussieren, unterscheiden sich grundsätzlich: (1) in ihrem Bezug auf Schule. Diesen kündigt die >Pädagogik im Titel an, im >Päd Forum k kommt sie nicht vor. (2) Als Schwerpunkt stellt die Zeitschrift `Pädagogik` die als exotisch betrachtete Jungenarbeit (PÄD G 04 99: 20) sowie ihre möglichen »Arbeiter« - die Lehrer bzw. Pädagogen - in den Mittelpunkt. Der Zusatz Pädagogen ist wichtig, da auffällt, dass die Autoren bis auf einen Lehrer aus dem außerschulischen Bereich kommen und als Experten Jungenarbeit betreiben bzw. sich dazu äußern. Dies bestätigt den konstatierten marginalen Status von Jungenarbeit an der Schule. Das >Päd Forum< stellt Ursachensuche und Erklärungen möglicher Benachteiligung und Defizite zur Diskussion. Daraus resultierend unterscheiden sich die beiden Magazine (3) in ihrem Praxisbezug, also auch in der Ausführung didaktischer Praktiken. Diese werden vor allem im Bereich der Schule - und damit im Weiteren - relevant. 
wohnen $^{24}$, gedacht, finde - vor allem aufgrund mangelnder Vorbilder einer $»$ vaterlosen Gesellschaft« (PF G 05 02: 276) - eine Distanzierung zu sich selbst statt und darüber eine Distanzlosigkeit zu anderen. »Jungenarbeiter« Holger Karl verwendet dafür eine weitere Raum- wie auch Gärtner-Metapher: die der »vergessenen Vorgärten(zäune)«, welche gepflegt werden sollten (PÄD G 05 99: 23). Keine Grenzen zu setzen, habe zur Folge »brutal« mit sich und anderen umzugehen: »Keine Grenzen zu kennen, heißt auch, vieles dicht an sich heranzulassen, unabgestuft, etwa der alltägliche körperliche Umgang, die `Zärtlichkeiten unter Jungen ‘ [...]. Jungen halten offenbar viel aus - und dann wird plötzlich und ohne Vorwarnung die letzte Grenze verteidigt.« (ebd.) Diese Arbeit mit und an Grenzen, die in dieser Metapher als »unsichtbare Grenze « außerhalb der Körperperipherie liegt, bedeutet in didaktischer Umsetzung Arbeit mit dem Körper. Immer wieder werden Massageübungen und Körperwahrnehmungsspiele (PÄD G 02 99: 9; PÄD G 04 99: 7; SM SP 03 99: 10) vorgeschlagen, Saunabesuche (SM SP 03 99: 10), Ringkämpfe nach Regeln (PÄD G 04 99: 17) oder theaterpädagogische Ansätze (SM SP 03 99: 11). Körperarbeit wird fast als selbstverständlicher Topos eingeführt, sie erscheint als Weg zu mehr Emotionalität. Durch Bewegungs-, Darstellungs- und mehr oder weniger reflektierende Körpererfahrung soll ein positives Körperbild vermittelt werden, das als Einstieg betrachtet wird, um weitere Probleme zu bearbeiten.

Der Stellenwert der Körperarbeit zeigt sich auch in den Bildern, die die Texte illustrieren. Knapp die Hälfte der Artikel stellt Körperarbeit mit Jungen und damit Jungen in ungewöhnlich körpernahen und ruhigen Posen dar. Körperkontakte zwischen Jungen werden sonst nur über Raufereien vermittelt, weil sie eng beieinander sitzen oder aufgrund von Raumgrößen etc., also aufgrund äußerer Gegebenheiten. Die Bilder bestärken den Topos >Arbeit mit dem Körper` als Zugang, Probleme mit Jungen zu lösen. Sie vermitteln zugleich enge pädagogische Beziehungen und eine Individualität, die in der Schule sonst kaum gegeben ist. ${ }^{25}$ Zudem stellt das Sujet >massierende Jungen eine Möglichkeit dar, Jungenarbeit zu verbildlichen. Ein weiteres solches Sujet ist das der miteinander `kämpfenden Jungen`. Der leicht kämpferische, boxende Umgang, den ich auch in Kapitel »»Körperportrait« eines Schülers« beschrieben habe, ist dabei der für Jungen als üblich dargestellte. Die anscheinend

24 Die pubertäre Entwicklung wird meist mit dem Bild einer »Metamorphose « beschrieben, indem ein »neuer Körper« »bewohnt « und verarbeitet werden müsse (z. B. PÄD SP 08 01: 8; vgl. Langer 2009).

25 Diese Vermittlung von Individualität ist für viele Fotos der Zeitschrift >Pädagogik ‘ typisch. Die über die Sichtbarkeit des Details hergestellte Nähe zur abgebildeten Person, die Darstellung von Emotionen mittels Großaufnahmen von Gesichtern suggeriert eine individuelle Pädagogik (vgl. Kap. ’Körperkontakt - eine Leerstelle im Diskurs?): 
unkoordinierten, Grenzen nicht wahrnehmenden Bewegungen und Berührungen sollen in zielgerichtete und reflektierte transformiert werden.
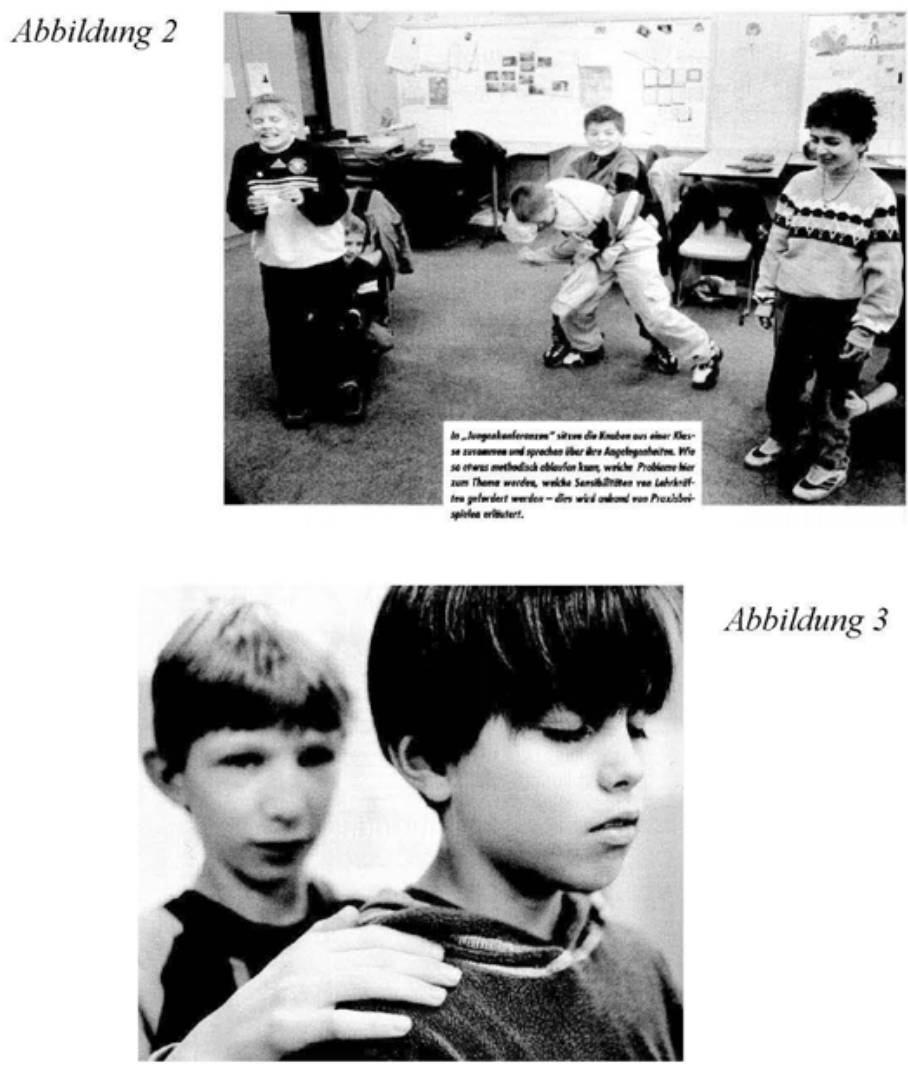

Abbildung 4

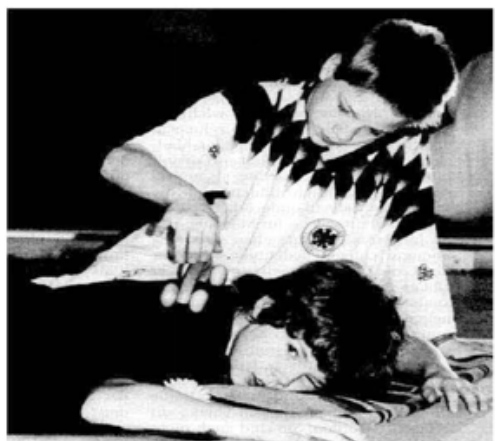


Solche Bilder, die ruhende körperliche Wahrnehmung als Übung von Sinnlichkeit darstellen, sind in den Zeitschriften sonst nur im Zusammenhang mit »Ruheritualen« zu finden, wenn Entspannungstechniken vorgestellt werden, um die üblichen Schulroutinen zu verlassen, für Bewegung, Ruhe und Entspannung zu sorgen, um SchülerInnen wieder fit für das Lernen zu machen (vor allem Päd Forum 6/1996). Allerdings sind dabei meist einzelne SchülerInnen bzw. keine körperlich aufeinander bezogenen Personen abgebildet. Bilder von Kämpfern wiederum gibt es sonst - wenn überhaupt - im Zusammenhang mit Gewalt oder Aggression bzw. Unterrichtsstörungen (Pädagogik 1/2000). Aufgrund dieses Überblicks wird das Bild der sich gegenseitig massierenden Jungen zum Symbol für geschlechtsspezifische und -identitäre Arbeit, für etwas Besonderes (wie schon der Sexualkundeunterricht) außerhalb der Normalität, obwohl gerade Normalität vermittelt werden soll. ${ }^{26}$ Körperwahrnehmung mittels Übungen erscheint in der Argumentation durchaus folgerichtig. Ich frage mich dennoch, inwiefern die besondere Betonung solcher Körperarbeit in dem Bereich zu einer »Besonderung« des Körpers führt. Sinnlicher, wie Horst Rumpf es fordert, wird die Schulpädagogik dadurch nicht, denn mit dem üblichen Schulalltag hat all das wenig zu tun. Das wird auch in einem Text deutlich, in dem Arbeitsmaterialien für Jungenarbeit in der Schule vorgestellt werden, wobei auch wieder auf körperorientiertes Arbeiten verwiesen wird. Dies aber nicht nur in gesonderten Jungenkonferenzen, sondern auch im Mathematikunterricht: Längen- und Winkelmaße, Massen, Geschwindigkeiten usw. ließen sich auch über Rennen, Hüpfen, Drehen und andere Bewegungen erfahren (PÄD G 08 99: 36). Eine solche Idee mag sich vielleicht in Fachzeitschriften zum Grundschulunterricht häufiger finden, im untersuchten Korpus ist sie eher die Ausnahme.

Bemerkenswert ist innerhalb der geschlechtsspezifischen Arbeit, dass insbesondere bei den Jungen an deren Körpers angesetzt wird: nicht nur, indem vielfältige sportliche Betätigung vorgeschlagen werden, sondern mit einer körperbezogenen Arbeit, die den Körper spürbar werden und die Körperwahrnehmung fördern soll. Es soll hier auf den Körper eingewirkt werden, um Normalität zu verändern. Körper und Identität sowie Körper und Emotionalität werden untrennbar miteinander verknüpft.

26 Einen ähnlichen symbolischen Wert erhält das Sujet der >miteinander kämpfenden Mädchen', welches ich allerdings aufgrund der geringeren Thematisierung nicht so häufig entdecken konnte. Es wäre - auch anhand weiterer Medien - zu prüfen, ob es, genauso wie das oben rekonstruierte, zum Symbol des »neuen« starken Mädchen (vgl. Fleißner 2002) bzw. Jungen wird. 


\section{SchülerInnen-Körper}

Der Titel »LehrKÖRPER - LernWELTEN« der Ausgabe des `Päd Forum«, das sich dem Körper widmet, irritierte mich zunächst durch die Hervorhebung der Wörter »Körper« und »Welten«. Mit den Ergebnissen der Analysen lässt sich nun sagen, dass diese Gegenüberstellung die Thematisierung von Lernkörper - die eben immer auch gelehrige Körper sind - widerspiegelt: dass es insgesamt wenig um »den Schülerkörper«, aber, wie sich noch zeigen wird, viel um den Lehr(erInnen)körper geht. Es gestaltete sich schwierig, die Thematisierungs- und Problematisierungsweisen des Lernkörpers bzw. des Körpers von SchülerInnen herauszuarbeiten. Das hat verschiedene Gründe: erstens eine breite Streuung der Äußerungen in sehr unterschiedlichen Zusammenhängen, zweitens jenseits der Texte die Heterogenität, bedingt durch die Vielzahl der SchülerInnen in einer Schulklasse, denen aber nur ein Lehrer oder eine Lehrerin gegenüber steht. Die Körper von SchülerInnen bzw. ihre Körper- bzw. Leiblichkeit beziehen sich zudem nur bedingt auf Schule. Drittens richten sich die Zeitschriften an LeserInnen, die als LehrerInnen arbeiten. Die Artikel sind für diesen Personenkreis geschrieben und Gegenstand ist dessen möglichst guter Unterricht. Damit geht es nur indirekt um SchülerInnen. Dies zeigt sich auch in der Studie von Rumpf (1981), der vor allem Material heranzieht, welches den »wahren« Lehrkörper, die Praktiken der Lehrkräfte sowie Schulaufgaben zum Gegenstand hat. Dies ist meines Erachtens nicht lediglich auf die subjektive Auswahl zurückzuführen, vielmehr ist der »blinde Fleck« den Schulmaterialien im weitesten Sinne selbst inhärent.

Er verdeutlicht die Notwendigkeit, ethnographische Beobachtungen zu Körperpraktiken von SchülerInnen einzubeziehen, auch wenn diese unterschiedlichen Materialien zunächst wie als nicht zusammenpassend oder -gehörend erscheinen mögen. In der Ethnographie typischer Körper-Raum-Regime wird das Verhältnis von disziplinierenden Arrangements, damit verbundenen Zumutungen wie auch die aktive Beteiligung der SchülerInnen an der Konstitution einer schulischen interaktiven Ordnung herausgestellt. Es zeigen sich überlagernde Dimensionen, die gleichzeitig stattfinden und je nach Perspektive fokussiert werden - beispielsweise auf die Herstellung der Zugehörigkeit von Geschlecht oder befreundeter Gruppen jenseits dieser Kategorie sowie Körperpraktiken und Aufmerksamkeitsebenen einzelner SchülerInnen. Die detaillierte Beschreibung zeigt die verschiedenen Facetten, die es unmöglich machen, eindimensional so etwas wie einen »Schülerkörper« auszuarbeiten.

Schule stellt für die SchülerInnen einen Ort dar, an dem sie sich selbst präsentieren. Während jedoch in den aufgegriffenen Körperdiskursen innerhalb der Zeitschriften die Inszenierung des Körpers losgelöst von Schule, im 
Allgemeinen hervorgehoben wird, wird das In-Szene-setzen der SchülerInnen sowohl in den beobachteten Situationen als auch in vielen Zeitschriftentexten im Rahmen einer gewünschten Situation der Disziplin als Störung begriffen. Im folgenden Kapitel werde ich mich genauer damit beschäftigen, was als Störung verstanden wird, inwiefern der Körper dabei eine Rolle spielt und welche Sanktionen - durchaus auch körperbezogen - dies zur Konsequenz hat. 


\section{Körper, Sanktion und Disziplin(-ierung?)}

Die Prügelstrafe bzw. das Recht von Lehrenden, SchülerInnen körperlich zu züchtigen, ist in der DDR 1949 und in Westdeutschland 1973 abgeschafft worden. Wieso schreibe ich dann 2007 in einem Kapitel von Körper und Sanktion? Ausgangspunkt sind aktuelle Phänomene schulischer Strafen ${ }^{1}$, deren verblüffte Beobachtung mich dazu angehalten hat zu hinterfragen, wie es eigentlich um das Verhältnis von Körper und Sanktion im Schulalltag steht, welches ja nicht immer »Züchtigung « bedeuten muss. Was lässt sich beobachten? Wie wird darüber gesprochen? Der Blick auf Körper(lichkeit) in der Institution Schule und sein Auftauchen oder Nicht-Erscheinen in den verschiedenen Diskursen macht darauf aufmerksam, dass wir es in Bezug auf Strafen im schulischen Bereich wie auch in der öffentlichen Erziehung mit einer Tabuisierung zu tun haben. Die Entkopplung von Sanktion und Körper im Zuge der Abschaffung der körperlichen Züchtigung führt innerhalb der diskursiven Praxen zu einem Verschwinden von Körper und Strafe. Das wiederum spiegelt sich unter anderem in einem Forschungsdesiderat wider.

Die weitere Beschäftigung mit dem Thema führt zu den Begriffen Disziplin und Disziplinierung, wie sie in der schulpädagogischen Diskussion gebraucht werden. Dabei zeigen sich Nähen, größtenteils jedoch Unterschiede zu jenem Begriff, wie ihn Foucault vertreten hat (vgl. Kap. >Disziplinierte Körper (). Disziplin stellt im Forschungsbereich einen Idealzustand dar, eine Situation der Disziplin, die kontrolliert werden muss. Im Reden über die Praxis der Disziplinierung jedoch, die den Prozess der Herstellung dieser Situation beschreiben müsste, wird eine »Blackbox « aufgemacht, indem dieser Prozess nicht benannt wird. Es besteht die Idee der Disziplin ohne Disziplinierung. Die Beobachtungen der Praktiken in der Schule wiederum füllen diese

1. Sanktion und Strafe benutze ich im Folgenden synonym. 
Leerstelle. Ein solcher hegemonialer Diskurs zwingt zudem die Lehrenden, die sehr wohl disziplinieren und sanktionieren, sich zu legitimieren. In den Zeitschriften wiederum lassen sich Transformationen dessen dekonstruieren, was Disziplinierung ist: An ihrer Stelle werden Rituale eingesetzt, die unter dem Vorzeichen der Prävention die Situation der Disziplin herstellen sollen. Dabei wird auch der Körper - der SchülerInnen und der LehrerInnen - wieder relevant. Das zeigt sich auch schon in den Beobachtungssequenzen in der 7. Klasse, die den Ausgangspunkt der Auseinandersetzung bilden.

\section{Phänomene schulischer Sanktion}

Die folgende Situation hat sich während der Schulbeobachtungen immer wieder in ähnlicher, wenn auch nicht immer genauso sichtbarer Weise abgespielt:

Beginn des neuen Schuljahres nach den Sommerferien, Geschichtsunterricht in der dritten Stunde. Die Lehrerin fragt nach den Römern und da dieses Thema bereits im letzten Schuljahr behandelt wurde, beteiligen sich recht viele SchülerInnen und tragen mit ihrem Wissen etwas zum Unterricht bei. Oliver ist eifrig dabei, meldet sich heftig. Er erinnert sich noch an recht viele Details und wird gelobt. Dann aber konzentriert sich die Lehrerin mehr auf die stillen SchülerInnen und fragt bei ihnen nach. Olivers heftiges Melden und Rufen »Ich weiß es! « wird nicht erhört. Unruhig kippelt er mit seinem Stuhl, was ihm gleich eine Rüge der Lehrerin einbringt »Oliver, du weißt, du sollst nicht mit dem Stuhl kippen! « - »Ja, ja, ich weiß« antwortet er und kippt zurück zum Tisch. Schon wenige Minuten später kippelt er erneut mit dem Stuhl und wird mit einem energischen »Oliver« von der Lehrerin ermahnt. Beim nächsten Kippeln wird die Lehrerin laut: »Oliver, wenn du jetzt noch einmal mit Deinem Stuhl kippst, dann stehst du bis zur 6. Stunde! Das ist kein Spaß! « Sie schaut ihn durchdringend und ernst an. »Jaaa antwortet Oliver genervt. Der Unterricht geht weiter. Die Frage nach einer Jahreszahl aus dem 2. Jahrhundert beantworten viele Schüler falsch. Oliver hat eine Antwort, meldet sich energisch, wird aber nicht drangenommen und ruft mehrfach »190« in den Klassenraum. Da aber die anderen SchülerInnen die Logik offensichtlich noch nicht verstanden haben, zeichnet die Lehrerin eine Achse mit Jahreszahlen an die Tafel und zeichnet die Jahrhunderte dazu ein. Oliver ist genervt und äußert stöhnend seine Ungeduld, kippt dabei wieder mit dem Stuhl nach hinten. Als sich die Lehrerin umdreht und ihn sieht, folgt die Konsequenz: »Oliver, du kippelst schon wieder, steh bitte auf? « »Ich will nicht! « entgegnet er verstockt und verschränkt dabei seine Arme vor der Brust. »Oliver, wir hatten eine Vereinbarung« erläutert die Lehrerin »du hast dich nicht daran gehalten und nun musst du die Folgen tragen, also steh jetzt auf.« "Nein, ich will nicht stehen « entgegnet Oliver noch einmal, »ich habe es ja nicht mit Absicht gemacht, ich kipple auch nicht mehr! « Oliver sitzt unbewegt. »Wenn du jetzt nicht aufstehst, verlässt du die Klasse, aber dann brauchst du heute nicht mehr zurückkommen, dann 
gehst du nach Hause!« bestimmt die Lehrerin. Oliver bleibt stumm sitzen. Es wird einen Augenblick ganz still in der Klasse. Die zweite Lehrerin greift ein: »Oliver, ihr hattet eine Vereinbarung und da du dich nicht daran gehalten hast, hat das Konsequenzen. Du kannst Dir jetzt überlegen, ob du aufstehen willst, ansonsten musst du die Klasse verlassen. Also überleg es Dir gut.« Der Unterricht geht für kurze Zeit weiter und wendet sich von ihm ab. Oliver sitzt auf seinem Platz und denkt nach, bewegt sich jedoch nicht. Dann geht nach einer Weile die zweite Lehrerin zu ihm, steht vor seinem Sitzplatz, redet flüsternd mit ihm und er packt daraufhin seine Sachen und verlässt stumm, mit leicht gesenktem Kopf den Raum, dabei wirkt er traurig. Es herrscht in der Klasse für einen Augenblick gespannte Stille. Dann geht der Unterricht weiter. Die zweite Lehrerin verlässt nun auch den Klassenraum und kommt erst nach einer Weile zurück. Oliver fehlt für den Rest des Unterrichts. (BF)

In der geschilderten Situation haben wir es mit einer Körperpraktik zu tun, die sanktioniert wird, indem andere Körperpraktiken dagegengestellt werden. Der Fall ist insofern »typisch«, als Oliver während unserer Beobachtungen immer wieder aufgrund dessen, dass er durch Kippeln, Reinrufen oder Beleidigen den Unterricht gestört habe, desselben verwiesen wird, und zugleich »extrem«, da er eine besondere Dramatik ${ }^{2}$ innehat, die in anderen Situationen nicht derart zu beobachten war. Es sind nun, fragt man nach den Einsätzen des Körpers, folgende Ebenen interessant: Welche Relevanz haben Körper und Körperlichkeit in dieser Situation? Inwiefern erfolgen Sanktionen aufgrund von Körperpraktiken sowie mittels Körperpraktiken? Welche Funktionen haben diese und was lässt sich daraus für das Verhältnis von Körper und Institution Schule schlussfolgern?

In der Unterrichtsituation werden der Klasse Fragen gestellt. ${ }^{3}$ Oliver meldet sich immer wieder, sein Wissen ist allerdings, nachdem er bereits einmal drangenommen wurde, nicht mehr gefragt. Während er die richtige Antwort weiß, verläuft das Frage-Antwort-Szenario schleppend, denn diejenigen, die gefragt werden, geben eben nicht die richtige Antwort. Oliver ist davon genervt, stöhnt darüber, wird unruhig. Er rutscht auf seinem Stuhl hin und her und bringt ihn durch Gewichtsverlagerung zum Kippen. Kippeln ist eine der wenigen Möglichkeiten, den gesamten Körper im Sitzen zu bewegen, es ermöglicht sowohl eine andere Sitzhaltung als auch einen Schaukelstuhleffekt. Letzterer kann insbesondere durch ein leichtes Wippen eine entspannende

2 Die Zuspitzung zeigt sich nicht nur auf Seiten des Schülers, welcher hier im Fokus steht. Innerhalb dieser machtdurchwobenen »Interaktionsspirale « müssen die Lehrerinnen die angedrohten Sanktionen durchsetzen, statt "Spaß« Ernst machen, wollen sie nicht ihre Autorität verlieren. Diese Dimension des Falls steht hier allerdings nicht im Vordergrund, ebenso wenig die Vorgeschichte, die uns aus der Sicht der Lehrerinnen im Anschluss an die Situation erzählt wurde.

3 Die Praxis der Lehrerfrage analysiert sehr anschaulich Rumpf (1981: 100-110). 
Wirkung haben, macht es jedoch auch zu einer Gleichgewichtsübung. Es besteht die Gefahr umzufallen, da es eine wackelige Angelegenheit ist. Kippeln ist in der Schule verboten - wahrscheinlich genau deshalb? Dies ist zumindest eine Erklärung, die rational erscheint. Erklärt wird das Verbot allerdings nicht. Oliver wird also ermahnt, er solle nicht mit dem Stuhl kippeln. Der Schüler weiß das, beginnt aber kurz darauf wieder damit. Seine Ungeduld ist auch eine körperliche Anspannung, er stöhnt und bewegt gleichzeitig sich und seinen Stuhl. Eigentlich müsste er still sitzen und ertragen, dass ein Teil der Klasse immer noch nicht begriffen hat, welches die richtige Antwort sei. Dies ist Bedingung und im Sinne Rumpfs eine »Grundqualifikation « für diese Form von Unterricht und Gesellschaft. »Die Grundqualifikation ist die Präsenz einer wirksamen inneren Zensur und Kontrolle. Zu lernen ist also in jedem Fall, die sinnlich manifest werdenden Medien der Äußerung (Körperbewegungen, animalische Körperfunktionen, Sprache) so in Gewalt zu bekommen, daß sie möglichst wenig von inneren Regungen, Reaktionen ausdrücken, sverraten ." (Rumpf 1981: 21) In Anlehnung an Elias verdeutlicht der Erziehungswissenschaftler, wie je nach Anforderungen der Situation der affektdurchdrungene Körper auf jeweils zweckmäßige Affektkontrolle sowie -durchlässigkeit eingestellt werden muss. Diese beim Schüler einer 7. Klasse vorausgesetzte Körperbeherrschung scheint hier nicht ganz wie gewünscht und als Normalität betrachtet zu funktionieren. Den Beobachtenden erscheint Olivers körperliche Unruhe wie ein Automatismus. Sie sind sich im Nachhinein darüber einig, dass ihm dass einfach so widerfahren sein muss, er es nicht gewollt bzw. absichtsvoll getan hat. Schwer zu sagen, weshalb sie sich da so sicher sind, seine Worte und seine Gesten der Verletztheit (Unbeweglichkeit, Stummheit, gesenkter Kopf) verleihen der Situation jedenfalls einen »authentischen « Eindruck. Dieser scheint für die Forschenden wichtig zu sein: Kippeln ist wohl etwas anderes, wenn es bewusst getan wird, als wenn es "so passiert«. Die Anwesenheit der Forschenden sorgt für eine weitere Öffentlichkeit, so dass für den Bestraften die Situation noch peinlicher und demütigender ist: Statt sich positiv mit seinem Wissen in Szene setzen zu können, wird er öffentlich gerügt und sanktioniert. Seine Ohnmacht wird in der Hilflosigkeit der Gegenwehr bzw. Verteidigung offenbar.

Die Strafe kommt dem Öffentlich an den Pranger Stellen gleich und ist ähnlich effektvoll. Der Vergleich zu einer vor Gericht verhandelten »Tat« ist durchaus nahe liegend. Denn sowohl das Stehen als auch der Platzverweis, den die Lehrerinnen bei weiteren Regelverstößen androhen, sind sanktionierende Praktiken. Wären sie es nicht, würde die Drohung gar nicht »funktionieren «. Das Stehen hat allerdings in diesem Zusammenhang verschiedene Dimensionen: Lange zu stehen ist, besonders wenn man es nicht gewohnt ist, 
anstrengender als lange zu sitzen. Wer steht, kann außerdem nicht mehr kippeln und diesbezüglich nicht gegen die Regel verstoßen. Insofern lässt sich eventuell zuspitzen: Still stehen ermöglicht noch weniger (auch minimale) Bewegungen und Ausführungsvarianten als still sitzen. Das Stehen wird gewissermaßen zur Fremdkontrolle und zwar im doppelten Sinne: als Übung zur Körperbeherrschung durch Ersatz einer Körperpraktik durch eine andere und als Kontrolle durch alle anderen Teilnehmenden. Denn Oliver müsste nicht nur bis zur 6. Stunde stehen, sondern er müsste vor der Klasse stehen. Das Stehen würde damit zur klassenöffentlich aufgeführten Strafe. Möglicherweise ist diese Schmach viel schlimmer, als gänzlich der Klasse verwiesen zu werden. Die körperliche Abwesenheit im letzteren Fall könnte den Schüler dagegen in Vergessenheit geraten lassen, da in diesem Fall die gesamte Person ausgeschlossen würde. Das Verhältnis von zu kontrollierenden Körperaktivitäten und sanktionierender Praktik ist hier ein anderes. Der Ausschluss aus der Klasse für eine bestimmte Zeit ist zwar notwendigerweise auch ein Ausschluss des Körpers, aber die Kontrollformen sind andere.

Angelehnt an Gerhard Hanak, Johannes Stehr und Heinz Steinert verstehe ich Sanktionen als »Skandalisierungen, in denen subkulturelle Normen und die sie stützende Öffentlichkeit angerufen werden. Das geschieht durchaus selektiv und als Mittel zur Verfolgung und Durchsetzung eigener Interessen. Diese Selektivität bezieht sich darauf, ob der normative Bezugsrahmen überhaupt mobilisiert wird und welcher Inhalt, was auch heißt: welche unterstützende Subkultur gewählt wird« (Hanak/Stehr/Steinert 1989: 95f.). Die Sanktion richtet sich also sowohl an die Person, deren Handeln sanktioniert werden soll (den Schüler), als auch an eine Öffentlichkeit (die Schulklasse) in doppelter Hinsicht: als Unterstützerin der Norm (also der Regel nicht zu kippeln) und der Ahndung des Regelbruchs sowie als angerufenes Publikum, welches die Konsequenzen des regelbrechenden Verhaltens innerhalb der Schulkultur vorgeführt bekommt. Die sanktionierende Instanz (die Lehrkraft) hat verschiedene Interessen: in Bezug auf den Schüler, sein Verhalten zu korrigieren, und die gesamte Klasse, möglichst störungsarm unterrichten zu können und als Autorität anerkannt zu werden. Letztlich heißt das: die Institution aufrecht zu erhalten.

Die Lehrerin spricht von einer gemeinsamen Vereinbarung mit Oliver, dass jener nicht mehr kippele. Ihre Weisung wird somit zu einem »Vertrag«. Um was für einen Vertrag handelt es sich? Seine Funktion ist, den Schüler zur Selbstdisziplinierung anzuhalten. Fremd- und Selbstkontrolle gehen hier Hand in Hand, letztlich ist jedoch das Ziel, dass der Schüler seine Körperbewegungen im Griff hat, oder allgemeiner formuliert: »das gesellschaftlich erforderliche Verhalten als vom Einzelnen selbst aus eigenem, innerem Antrieb so ge- 
wolltes Verhalten in Erscheinung zu treten lassen« (Elias 1997: 299). Da Oliver den Vertrag gebrochen habe, müsse er nun die Konsequenzen seines Handelns tragen. Die Strafe für etwas, was nicht sein soll aber getan wurde, wird zu einer Sanktion einer Handlung, die unterlassen wurde, indem der Vertrag nicht erfüllt wurde - ein für pädagogisches Handeln übliches Motiv. ${ }^{4}$ Dass auch Oliver bemüht ist, den Vertrag einzuhalten, zeigt sich wiederum in einer anderen Situation, als er, während sich die Lehrerinnen besprechen, in der Unterrichtsstunde aufsteht und seinen Stuhl gegen einen austauscht, der anders gebaut ist und mit dem sich nicht so leicht kippeln lässt. Über das Artefakt Stuhl, welches ganz wesentlich dazu beiträgt, welche Sitzhaltung man einnehmen kann ${ }^{5}$, und damit Körperhaltungen und -bewegungen entscheidend prägt, hält sich der Schüler an, sich selbst zu disziplinieren. Der Vertragscharakter verstärkt den Kontrolleffekt zusätzlich, indem eben auch die Lehrerinnen an ihn gebunden zu sein scheinen bzw. sind: Sie müssen sanktionieren, weil das ihr Teil des Vertrags ist, dessen Einhaltung die Schulklasse als Jury die aus dem Handeln der Lehrerinnen ebenso ihre Schlüsse ziehen könnte kontrolliert. Was Strafe zuallererst auszeichnet - die Vorführung und Ausübung von Herrschaft (vgl. Steinert 1993: 247f.) - erfährt eine Rationalisierung und Legitimierung zum Zwecke der Prävention. So verselbständigt sich die Praktik des Kippelns als ein zu verhandelnder Gegenstand jenseits von Weisungen und Verboten als etwas, was es für alle zu vermeiden gilt. Denn der Ausschluss erscheint hier als einer, der vom ausgeschlossenen Schüler selbst produziert wurde. Karin Amos schreibt zum schulischen Ausschluss, welcher als Folge persönlichen Versagens etikettiert wird, dass eine solche Sichtweise »in der Wahrnehmung der Beteiligten um so evidenter [wird A. L.], je mehr die sandere Seite`, nämlich die des Lehrers und der Schule plausibel machen kann, dass alles erdenkliche getan wurde, um den >Irregeleiteten oder `Fehlentschiedenen zu >retten « (Amos 2006: 80).

Wie sehr die Schulklasse am Geschehen beteiligt ist, wird auch deutlich, wenn sie Olivers Rauswurf (in einer anderen Situation) im Tonfall halb hoffnungslos, halb verärgert mit »schon wieder!« kommentiert. Andererseits finden die Verweise zum Teil so still und heimlich statt, dass die Forschenden aufgrund ihrer selektiven Beobachtung sie manchmal erst bemerken, wenn ein Schüler nicht mehr körperlich anwesend ist.

4 Im übertragenen Sinne wäre das die Bewegung vom Modell des Strafrechts hin zum Modell des Zivilrechts (Hanak/Stehr/Steinert 1989: 75).

5 Beispielsweise fordert ein Hocker oder auch ein Ball wesentlich mehr zum gerade sitzen auf als ein Stuhl mit Lehne. Zugleich ist es auf einem Ball nötig, permanent auszubalancieren, aber auch möglich zu wippen. Zur Besetzung von Stühlen wie auch ihrer Symbolik vgl. auch Kap. 'Spiel mit den Grenzen<. 
Was mir erst am Ende der Stunde auffällt, ist, dass Oliver nicht mehr da ist. Er kommt nach der Stunde und holt seine Sachen. Ich bemerkte es gar nicht, dass er herausgeschickt wurde und draußen vor der Klasse warten musste, bis die Stunde vorbei ist. (SR)

In dieser Situation können die Teilnehmenden, assoziativ anschließend an die bisher erlebten Verweise, nur noch davon ausgehen, dass Oliver wieder gestört haben müsse - denn warum verließ er sonst den Unterricht? Die nahe liegende Alltagsinterpretation auch für seine MitschülerInnen ist: Oliver ist ein Störer und wird deshalb mit Ausschluss bestraft, womit unter anderem aufgrund einer Körperpraktik - des Kippelns - ein Prozess in Gang gesetzt wird, der sich als Etikettierung beschreiben lässt (Keupp 1976; Steinert 1985; Peters 1996). Mit der Kategorisierung von Verhalten sind Sanktionen verbunden, denen bestimmte Behandlungsformen folgen. Durch diese Behandlung und/oder die Etikettierung, also nicht durch das Verhalten selbst, wird dann das Problem definiert. Der Behandlungsform, hier des Ausschlusses, folgt bisweilen schon eine Etikettierung, ohne auf ein bestimmtes beobachtetes Verhalten Bezug zu nehmen. Über den Ausschluss wird zugleich Normalität hergestellt: In der Klasse sitzen diejenigen, die ihre Affekte zügeln können, die zwischen Gefühl und Handlung dämpfende oder gar reflexive Filter einsetzen können (vgl. Rumpf 1981: 19). Vor der Tür dagegen steht die »Abweichung«: das im Rahmen der Schulklasse Unmögliche. Zur institutionell hergestellten Normalität wird aber nicht nur diese Unterscheidung, sondern auch der Ausschluss als solcher, welcher mit Disziplinierung in Zusammenhang gebracht wird. Helga Cremer-Schäfer und Heinz Steinert schreiben: »In der Vorstellung, Ordnung werde durch das Entfernen von >Störern` hergestellt, verbindet sich Ausschluss mit Disziplinierung.« (Cremer-Schäfer/Steinert 2000: 45) Der Ausschluss wird durch das Kippeln und die Etikette, Kippler zu sein, legitimiert und so zum legitimen Mittel innerhalb pädagogischer Ziele und bei der Herstellung von Ordnung.

Im Folgenden steht eine weitere sanktionierende pädagogische Maßnahme im Fokus, die wir immer wieder beobachten konnten bzw. die Gegenstand von Verhandlungen zwischen SchülerInnen und Lehrerinnen war: die Strafarbeit.

Es ist Klassenrat: Mirco und Noel haben ihre Hausaufgabe wiederholt nicht erledigt und sollten einen Satz 50 Mal aufschreiben. Auch das haben sie nicht getan. Sie werden auf die nicht erledigte Strafarbeit angesprochen. Noel wirkt still und betreten. Vor der ganzen Klasse werden sie nun gefragt, ob sie einen Vorschlag machen könnten, wie das jetzt zu lösen sei. Nachdem sie keine Ideen äußern, wird die ganze Klasse gefragt. Es kommen Vorschläge, wie in der Pause schreiben oder das Ganze $100 \mathrm{Mal}$. Die Lehrerinnen gehen darauf ein: in der Pause $50 \mathrm{Mal}$ schreiben und 
wenn sie es in der Zeit nicht schaffen, das Ganze bis Montag 100 Mal. Noel versucht noch zu verhandeln, scheitert aber. (AL)

Auch diese Situation lässt sich wieder mit verschiedenen Fragestellungen anschauen und interpretieren, es lässt sich über Sinn und Unsinn solcher Strafarbeiten sowie ihre Effekte diskutieren. Mit Blick auf die Frage nach den Einsätzen des Körpers setze ich den Fokus auf das Schreiben als eine performative Körperpraxis. Die SchülerInnen sollen, wenn sie etwas nicht dabei haben, also Hausaufgaben oder Unterrichtsmaterialien vergessen, verlegt oder verloren haben, ein und denselben Satz 50, 100 oder gar 300 Mal aufschreiben. Die Sätze, so bekommen wir später mit, haben folgende Wortlaute: »Ich muss an meine Hausaufgaben denken. «, »Ich darf mein Material nicht vergessen « oder in einem Fall die Androhung bei besonderer Unruhe in der Klasse: »Ich darf die Klasse nicht stören! «. In der Regel sind es Sätze, die eine Aussage darüber treffen, was diejenigen, die sie schreiben sollen, tun sollen bzw. nicht dürfen. Schreiben sollen sie diesen Satz in der Regel in ihrer Freizeit - also entweder in der Pause, im Anschluss an den Unterricht im Klassenraum oder zu Hause. Wenn sie die Strafarbeit in der Schule erledigen, spricht man meist von »nachsitzen«. Das Wort verweist einmal mehr auf die Haltung, die sie eben während des Unterrichts in der Regel einnehmen. Zunächst ist es eine stupide Arbeit, immer wieder denselben Satz zu schreiben, weshalb so mancher Schüler auch versucht, sich anderweitig zu helfen, auch wenn es da seitens der Lehrerinnen kein Pardon gibt:

Oliver hat seine $300 \mathrm{Mal}$ : »Ich darf mein Material nicht vergessen « mit Kohlepapier geschrieben und muss es nun in der Stunde noch einmal schreiben. Aber die Lehrerinnen amüsieren sich über seinen Trick. (JH)

Diese Art der Vervielfachung des Satzes zählt also nicht, auch wenn die Lösung des Schülers Anerkennung findet. Aber um alternative Problemlösungen geht es nicht, sondern darum, eine Strafarbeit abzuleisten und die Anweisungen genau zu befolgen. Deshalb (und betrachtet man diese Aufgabe nicht nur als eine Strafe, sondern greift deren Rationalisierung als Disziplinierung auf) ist zu fragen, was genau findet bei dieser Prozedur eigentlich statt? Schreiben ist eine Körperpraxis oder vielleicht noch treffender eine Körpertechnik. Mit diesem Begriff bezeichnet Marcel Mauss systematisch sozialisierte Körperhaltungen und -bewegungen, die Produkt spezifischer kultureller Bedingungen sind (Mauss 1978/1947: 202ff.). So ist Schreiben zunächst einmal eine 
spezifische Bewegung, die die Hand auf dem Papier vollzieht. ${ }^{6}$ Das hier geforderte Schreiben ist kein kreatives Schreiben, bei dem Gedankengänge vollzogen werden. Ebenso wenig ist es ein Schreiben in sog. Lerntagebücher zur Planung und Selbstkontrolle von Lernprozessen, worüber Reflexionen stattfinden (sollen) (vgl. Wrana 2006: 57-81). Stattdessen wiederholt sich immer wieder derselbe Satz, welcher nicht irgendeiner ist, sondern dessen Bedeutung die SchülerInnen verinnerlichen sollen. ${ }^{7}$ Sie sollen nicht einfach nur schreiben, dass sie ihr Material nicht vergessen, sondern sie sollen ihr Material nicht vergessen. In diesem Sinne findet hier mittels der Schreibbewegung als Körpertechnik eine Einschreibung in den Körper und ins Gedächtnis statt. Der Schreibvorgang soll zum Tun anhalten und die ständige Wiederholung diesen Prozess verstärken. ${ }^{s}$

\section{Ausschluss und Einschreibung aus der Perspektive der Lehrerinnen}

Der »Fall Oliver« veranlasste die Lehrerinnen, sich den Forschenden gegenüber zu ihren Praktiken zu äußern. Die Maßnahme, die die BeobachterInnen, wie sie in den Protokollen vermerken, »rabiat «, »krass «, »unangenehm zu beobachten « und »unangemessen « empfinden und bei der der Schüler ihnen leid tut, scheint unausgesprochen erklärungsbedürftig zu sein. Die Notwendigkeit sich zu äußern, zeigt an, dass es sich nicht um als selbstverständlich zu betrachtende Praktiken handelt bzw. um Praktiken, die selbstverständlich statt-

6 Ein irritierender Moment: Während ich vom Schreiben auf Papier schreibe und mir diese Handbewegung vorstelle, schreibe ich mit einer Computertastatur, was ganz andere Effekte hat und mich kurz ins Stocken geraten lässt, da Tippen und mit Füllfederhalter schreiben ganz unterschiedliche Bewegungsformen sind und deshalb schwer parallel zu denken. Diese Irritation zeigt jedoch sehr eindrücklich, inwiefern Schreiben jeweils eine spezifische Kulturtechnik ist, und bestätigt meines Erachtens die folgenden Ausführungen über das Einschreiben. Anzunehmen ist, dass Oliver nicht mit dem Computer schreiben darf (und den Satz 300 Mal kopieren).

7 Das erinnert an den Trailer der Comicserie "Simpsons«, der damit beginnt, dass Bart Simpson immer wieder den Satz: »Ich verschwende keine Kreide mehr« an die Tafel schreiben muss.

8 Auf die Spitze wird das in Harry Potter Bd. 5 (»Der Orden des Phönix «) getrieben. Auch Harry muss bei Professor Umbridge nachsitzen. Er muss den Satz "Ich soli nicht lügen!« mit einer verzauberten Feder auf seinen Arm schreiben. Der Satz brennt sich gewissermaßen wie ein Tattoo in seine Haut ein. Es schmerzt und das Geschriebene ist auch nach dem Schreiben noch zu sehen, womit eine Markierung stattgefunden hat. Das »Motiv« ließe sich literarisch noch weiter verfolgen und zuspitzen: Z. B. wird in Kafkas sIn der Strafkolonier ein Apparat beschrieben, der das Todesurteil solange mit spitzen Nadeln in die Haut des Verurteilten einritzt, bis der Tod eintritt (vgl. auch Richter 1987: 52). 
finden dürfen. Stattdessen müssen die Lehrerinnen sich und ihre Handlungen erklären. Dazu erläutern sie ihre Geschichte von und mit Oliver, welche sie als Ausgangspunkt ihres Handelns betrachten. Dabei wird uns Oliver als ein Schüler vorgestellt,

der an seinen bisherigen Schulen wegen Verhaltensauffälligkeiten im Unterricht gescheitert und als »schwer erziehbar«, »lernbehindert « und heute »verhaltensauffällig« eingestuft worden sei. Nachdem er zunächst eine Fördereinrichtung an einer Sonderschule besuchen sollte, kam er im 5. Schuljahr in die Klasse. Er habe sich im 6. Schuljahr so »stabilisiert", dass er jetzt in der 7. Klasse ist und gut integriert sei. Die Lehrerinnen hätten » sehr viel Arbeit in ihn investiert«, um ihn in der Klasse halten zu können. Lehrerin Timm: »Und deshalb verlangen wir auch etwas von ihm, er kennt die Regeln und muss auch lernen, sich zu integrieren. Wenn das zu Beginn des Schuljahres schon nicht klappt, dann wird es weiterhin schwierig. Deshalb konnte ich über dieses Verhalten nicht hinwegsehen. Er meinte ohnehin, sich vor Gästen inszenieren zu müssen, ohne ein Stopp hätte er auch noch richtig aufgedreht. « »Morgen kommt er wieder « ergänzt sie, »dann reden wir noch mal mit ihm darüber und dann ist es vergessen und funktioniert wieder. Hier muss man auch mal durchgreifen und klare Grenzen stecken, sonst läuft alles aus dem Ruder.« (BF)

Die Lehrerin erklärt ihr Handeln zum einen mit Olivers Geschichte und einer damit verbundenen Diagnose von Verhaltensauffälligkeit. Sie hätten nun die »Aufgabe« übernommen, den Schüler in ihre Klasse aufzunehmen und ihn zu fördern. Bedingung, dass dies weiterhin möglich sei, ist, dass Oliver eben nicht bzw. so wenig wie möglich »auffällt«. Was das konkret bedeutet, lässt sich beobachten: nicht auffallen durch sich still verhalten - verbal und körperlich, sich einer bestimmten Ordnung anpassen und die eigenen Praktiken kontrollieren. Dies wird mit »Integration« beschrieben. Der Terminus »verhaltensauffällig « muss im Reden darüber nicht erklärt werden, es wird davon ausgegangen, dass alle Beteiligten wissen, dass es sich um etwas handelt, was »unmöglich« ist, was einer Störung (von Situationen und der Person selbst) gleichkommt. Oliver, seine Praktiken bzw. die Interaktionen, in die er eingebunden ist, fallen uns tatsächlich auf - viel mehr als diejenigen in der Schulklasse, die still sitzen, nur leise mit dem Nachbarn schwatzen oder abschalten. Deren Praktiken der Unauffälligkeit fallen eben nicht dermaßen auf, man muss sich sehr bemühen, um sie überhaupt wahrzunehmen. Die Lehrerinnen argumentieren nun zum einen mit Integration und zum anderen mit ihrer Erfahrung. Es entspannt sich ein Bogen von Vergangenem (Oliver steht kurz vor der Sonderschule), über die Gegenwart (er ist halbwegs stabilisiert, steht aber auf der Kippe zwischen Integration und Ausschließung) zur Zukunft (mit den Weichenstellungen der Lehrerinnen könnte Integration möglich sein). Sie 
kennen wiederum den Prozess und die Symptome, sich nicht zu integrieren. "Sonst läuft alles aus dem Ruder « - wäre also, bei der Schiffsmetapher bleibend, nicht mehr steuerbar. Dem gilt es zu diesem Zeitpunkt Grenzen zu setzen, weshalb die Lehrerinnen nicht darüber hinwegsehen können, um steuerungsfähig bleiben zu können. Auch hier scheint die Vertragsmetapher durch: Sie tun etwas für Oliver, indem sie ihn in ihre Klasse aufnehmen, im Gegenzug muss nun Oliver lernen, sich den Regeln konform zu verhalten. So argumentiert, steht der Schüler in ihrer Schuld.

Die Disziplinierung des Körpers ist eine Anforderung gemäß dem »heimlichen Lehrplan« der Schule und zugleich Grundbedingung für Schul- bzw. Gesellschaftsfähigkeit. Das was Oliver an Wissen zum Unterricht beitragen könnte, spielt dabei eine untergeordnete Rolle. Es (und er) ist nur nützlich, wenn er es auf angemessene Art und Weise einbringt und auch körperlich die gewünschte Haltung einnimmt. Wo stünde Oliver möglicherweise mit genau diesem Unterrichtswissen, würde er seine Hausaufgaben regelmäßig machen, nicht kippeln und nicht laut in die Klasse rufen? Wer oder was hindert ihn am Lernen und vor allem an Lernen wovon? Ist der Körper nicht gelehrig genug? Die Form der einzustudierenden Körperbeherrschung geht mit einer technischadministrativen Entwicklung einher, die andere Körper und unangebrachte Gesten und Gewohnheiten nicht gebrauchen kann. In diesem Sinne hat der Schülerkörper zu funktionieren. Bei fehlender Selbstdisziplinierung droht der Ausschluss von schulischer Bildung. Der unbequeme Stuhl sowie sich nicht mit der Situation und ihrer Ordnung zu arrangieren wird zum weitreichenden Problem für den Einzelnen.

In den Interviews haben wir die Lehrerinnen zu ihren Strafpraktiken befragt. Ihre Äußerungen auf die direkte Nachfrage greife ich im Folgenden auf, um im Anschluss daran zur öffentlichen Rede über das Strafen und zur Problematisierung von Disziplin(ierung) in pädagogischen Zeitschriften überzuleiten.

Interviewerin: Wie ist das so mit Strafarbeiten oder so was? Oder mit Sanktionen, wenn dann irgendwas ist?

Lehrerin Matthes: Wobei, das hat weniger was mit Disziplin in der Gruppe zu tun, da geht es um Hausaufgaben und Material dabei haben. Und da haben wir zu Beginn, weil das so eingerissen ist am Ende der sechsten Klasse, wir müssen irgendwas tun. Und haben dann am Ende der Sechs beschlossen: okay, wir führen ein, also dreimal darf man in jedem Fach mal die Hausaufgaben vergessen in 'nem Halbjahr, das ist okay. Wer es mehr als dreimal vergisst, muss bei jedem nochmaligen Vergessen fünzigmal schreiben "Ich muss an meine Hausaufgaben denken«. Ach, ich kann sagen, so richtig erfolgreich ist das nicht. Also, es sind immer die gleichen, die schreiben und die schreiben es dann und vergessen es das nächste Mal wieder und 
machen es nicht. Wobei bei Materialien, habe ich schon den Eindruck, es bringt ne Menge. Bei einigen auch gar nicht, die sind resistent. Und da müssen wir uns auch irgendwas überlegen, was wir da machen, weil das ist ... Früher hatten wir: drei Striche machen und dann einen Brief an die Eltern. Das kannst du so in der Fünften machen und in der Sechsten vielleicht anfangs noch und dann nicht mehr. Und da schreibst du dir auch einen Wolf, ja. Also das ist auch noch mal so ein Ding, das hat ja auch noch so einen Ballon rundrum, ja. Also das sind auch eher so die Sachen. Und wenn wirklich heftige Vorfälle sind, an disziplinarischen Methoden, Mitteln, dann schließen wir von Ausflügen aus. Das kommt vor, oder wir schließen auch vom Unterricht aus.

Interviewerin: Wie ist das denn mit der Aufsichtspflicht dann?

Lehrerin Matthes: Vom Unterricht ausschließen? Laut Schulgesetz, wenn irgendwas vorgefallen ist, ist das eine pädagogische Maßnahme, oder schon 'ne Ordnungsmaßnahme, ich weiß gar nicht, ne, ne pädagogische. Und das muss halt vermerkt werden und das ist das mit der Aufsichtspflicht kein Ding mehr. Die Eltern müssen informiert werden, dass ihr Kind jetzt kommt, bzw. die Schule verlässt und dann ist es gut, das geht.

Die Lehrerin unterscheidet zunächst Disziplin in der Gruppe und Hausaufgaben bzw. Material dabeihaben als Bereiche, die für den Unterricht relevant und implizit störanfällig sind. Die Sanktion »Strafarbeit« bezieht sich auf den zweiten Bereich: wenn ein Schüler sein Arbeitsmaterial vergessen oder eine Schülerin ihre Hausaufgaben nicht erledigt hat. Die Strafarbeit erläutert sie als eine bewusst überlegte und eingesetzte Maßnahme gegen das Vergessen, das »eingerissen « sei, weshalb sich die Lehrerinnen zu einer Reaktion genötigt sahen. Die Praktiken der 5. Klasse (»früher«) erschienen ihnen für das momentane Alter ihrer SchülerInnen nicht mehr angemessen. Strafpraktiken werden damit, ähnlich dem geltenden staatlichen Strafrecht, zu altersabhängigen erklärt. Während bei den Kindern der 5. Klasse die Eltern als potenziell strafende Instanz eingeschaltet wurden oder als Drohung fungierten, sind die nun jugendlichen SchülerInnen jetzt direkt mit der Strafe konfrontiert. Den Umweg über die Eltern »kann man dann nicht mehr machen«. Weshalb dies so ist, bleibt unklar. Anzunehmen ist, dass die erhoffte Wirkung nicht eintrat, »und da schreibst du dir auch einen Wolf, ja«. Hier wäre am Ende nicht die Schülerin diejenige, die immer wieder denselben Satz schreibt, sondern die Lehrerin schreibt und schreibt, ohne für sie erkennbare Effekte. Inwiefern nun die neue Methode erfolgreich im Sinne der erwünschten Handlung ist, bleibt offen. Material werde daraufhin häufiger mitgebracht. Doch es seien immer wieder dieselben, die noch so oft schreiben können »ich muss an meine Hausaufgaben denken«, es aber dennoch nicht tun. Sie seien »resistent«. Greift man hier die Interpretation des performativen Schreibens auf, so bezeichnet die Lehre- 
rin diese Schüler als resistent gegen diese Einschreibung. Sie funktioniert, nimmt man die Beobachtungen hinzu, auch deshalb nicht, weil die Schüler die Strafarbeit ebenfalls »vergessen«.

In Abstufung zu den »heftigen Fällen« scheinen nicht erledigte Hausaufgaben oder vergessene Materialien aber weniger heftig zu sein. Denn diese hätten »disziplinarische Methoden, Mittel« wie Ausschlüsse von Unterricht oder Ausflügen zur Folge. Mit dieser Abgrenzung würden das Kippeln oder die Zwischenrufe von Oliver also zum »heftigen Fall.« Auf Nachfrage der Interviewerin, wie in diesem Fall die gesetzliche Regelung sei ${ }^{9}$, verweist die Lehrerin auf eine Unterscheidung zwischen pädagogischen und Ordnungsmaßnahmen. Dass sie sie nicht genau zuordnen kann, macht zum einen besonders auf die gesetzliche Unterscheidung aufmerksam, zum anderen zeigt es, dass eine mögliche Unterscheidung oder der Zusammenhang von Pädagogik und Ordnung für die Praktiken der Lehrerin nicht relevant ist, auch wenn eine Ordnungsmaßnahme - so vermittelt das Wörtchen »sogar« - über eine pädagogische hinauszugehen scheint und pädagogische Maßnahmen damit etwas anderes zum Ziel haben müssten als Ordnung herzustellen. Ebenso wenig relevant ist im Reden der Lehrerin die von mir hier eröffnete Dimension des Körperlichen. Um ihr Handeln zu legitimieren oder die Schwierigkeiten damit zu erläutern, ist das keine Ebene, die Problematisierung möglich oder nötig macht oder sich als anschlussfähig zeigt. Inwiefern die Idee des Einschreibens für die Lehrerin als solche zu lesen ist, bleibt offen.

Lehrerin Timm: In unserem Unterricht gibt's ja für Dummheiten keine Sanktionen, es gibt ja für Nichtmachen Sanktionen, also für Vergessen und für Nichtmachen. Das ist eine Form der Sanktionierung, die wir aus der Schule für Erziehungshilfe übernommen haben und die darauf fußt, dass es eine unmittelbare Sanktionierung, also nicht eine Sanktionierung in Form einer schlechten Note in drei, vier, fünf, sechs, sieben Monaten, sondern einer sofortigen Sanktionierung gibt. Und diese Sanktionierung ist natürlich stupide, weil sie schreiben müssen, aber diese Sanktionierung ist ganz wichtig, a) für mich, damit ich lerne konsequent zu sein (lacht). Nein es ist auch wirklich so, dass, wenn wir erzählen, ihr müsst das machen weil, wenn ihr mal 'n Beruf habt, dann könnt ihr auch nicht Sachen vergessen, das ist für die ja ganz weit weg. Und sie sollen lernen, Dinge zu machen, die ihnen auch, also ich meine mir wäre das auch zuwider, fünfzigmal, hundertmal, zweihundertmal zu schreiben, aber wir haben wirklich die Erfahrung im Laufe des Schuljahres, die Hausaufgaben werden regelmäßiger gemacht, die denken an ihre Sachen, weil sie

9 Den Verwaltungsvorschriften zufolge besteht für Lehrkräfte zwar uneingeschränkte Aufsichtspflicht, jedoch kann der Verweis aus dem Unterricht ausgesprochen werden, wenn keine andere Möglichkeit besteht, ordnungsgemäßen Unterricht durchführen zu können. Verbunden mit dem Verweis ist die ausdrückliche Aufforderung der SchülerInnen, ihr Verhalten zu ändern (Blaser et al. 2000: 4). 
einfach kein Bock haben, so was Stupides zu machen. Und das ist letztlich, das was wir erreichen wollen, ja? Und das geht nur unseres Erachtens über Sanktionen, wenn's noch was anderes gibt, ich bin für alles offen (lacht).

Interviewerin (lachend): Manchmal verhandeln sie ja drum.

Lehrerin Timm: Ja natürlich, das gehört zum Ritual dazu, natürlich, natürlich.

Davon abgesehen, dass diese Lehrerin die Effekte der Strafarbeiten optimistischer als ihre Kollegin sieht, spricht auch sie nicht explizit von einer auf den Körper bezogenen Sanktion. Sie bezeichnet die Maßnahme allerdings als eine stupide Tätigkeit, die gerade aus ihrer Stupidität ihre Wirkung bezieht. Strafe hat in Bezug auf ihre konkrete Form keinen anderen Sinn außer zu strafen. Implizit kommt damit der Körper ins Spiel: Schreiben wird zur stupiden körperlichen Arbeit, indem immer wieder derselbe Satz wiederholt und es jeglicher Kreativität enthoben wird. Um schreiben zu können, müssen die SchülerInnen das tun, was sie in der Schule zu tun haben: am Tisch still sitzen. Das Unmittelbare, welches die Lehrerin als bedeutsam für eine effektive Sanktionierung hervorhebt, ist in der Praxis ein dreifaches: in Abgrenzung zur Notengebung durch die relative zeitliche Nähe zur »Tat« (eigentlich zum NichtTun), als unmittelbare körperliche Praktik, die gewissermaßen zur leiblichen Erfahrung wird und eine für Schule grundlegende Körpertechnik darstellt, sowie durch die Aussage des zu schreibenden Satzes, der auf das erwünschte Handeln verweist. Zur legitimierenden Institution für diese Praxis wird die Schule für Erziehungshilfe, mit deren Nennung die eigenen Praktiken als professionelle ausgewiesen werden. Implizit bekommen die betreffenden SchülerInnen mit dieser Form der Strafarbeit und ihrer Legitimierung einen bestimmten Platz angewiesen: Sie werden zu (potenziellen) AdressatInnen dieser Einrichtung, indem die Praktik einerseits für sie als angebracht bzw. notwendig erscheint und andererseits zu fragen wäre, ob diese Form der Bestrafung auch gegenüber GymnasiastInnen angewandt würde. Dass die SchülerInnen im Falle einer Bestrafung versuchen zu verhandeln, liegt gerade - »natürlich« - wegen der gewollten Stupidität für die Lehrerin nahe. Die Reaktion einbeziehend begreift sie den Protest ob der Sinnlosigkeit außerhalb von Bestrafung zum Abschluss dieser Sequenz als Teil eines »Rituals«. Damit integriert sie die Widerständigkeit der Schüler, sie gehört zum Sanktionsritual dazu und verstärkt den strafenden unangenehmen Charakter der gestellten Aufgabe.

\section{Zur Tabuisierung von Disziplinieren und Strafen}

Das Phänomen zu strafen bereitete sowohl beim Schreiben der Protokolle und den (emotionalen) Bewertungen der Beobachtenden als auch im Reden der 
Lehrerinnen über die Situationen und ihre Strafpraxis Schwierigkeiten. Diese Feststellung aufgreifend untersuche ich nun, inwiefern Ähnliches oder auch Anderes in den Zeitschriftenartikeln artikuliert wird, die sich im Korpus zu den Themen Strafen, Disziplinieren, Unterrichtsstörungen und Rituale im Unterricht finden. Welche Problematisierungsstrategien - Muster oder Brüche gibt es? Weshalb glaubt man, worüber reden zu müssen? Bzw. wird überhaupt über die genannten Themen geredet? Im Fokus stehen auch hier nicht sämtliche diskursiven Praktiken, die in den Themenbereichen herauszuarbeiten wären, sondern der Körper im Gebrauch der Sprache und wie er innerhalb von in Erfahrungsberichten in beschriebenen didaktischen Praktiken zum Einsatz kommt. ${ }^{10}$

\section{Strafe(n) im Spannungsfeld von Legitimation und Tabu}

Im Anschluss an das vorherige Kapitel greife ich zunächst in knappen Umfang die Thematisierung von Strafen auf. Gefunden habe ich lediglich sieben Texte, von denen sich zwei innerhalb einer Gegenüberstellung knapper Pround Kontra-Statements mit sog. Sozialstrafen, wie der Säuberung des Schulhofs oder dem Streichen einer Wand beschäftigen. »Sozialstrafen« werden als sozial ausgezeichnet, da sie der Allgemeinheit innerhalb der Schule dienen sollen (PÄD D 05 02; PÄD D 06 02). Es wird diskutiert, ob sie sich von den oben beschriebenen Sanktionspraktiken im Sinn und in ihrer Form unterscheiden.

Mit der Fokussierung auf >Körper sind vor allem die anderen fünf Artikel relevant. Die Autoren dieser Texte ${ }^{11}$ problematisieren das, was im vorigen Kapitel durchschien - die Tabuisierung des Strafens. Bastian und Korte überschreiben ihre Texte mit den gleichen Worten: »Strafe muss sein?«. Die Unterscheidung liegt in der »Quotierung « dieser Frage: Korte stellt die Frage und erklärt sie zu einer pädagogischen, die verdrängt würde. Bastian setzt die

10 Zur Übersicht: Anhand der Überschriften der Texte habe ich im Zeitschriftenkorpus insgesamt 42 Artikel herausgesucht, davon sieben Artikel zum Thema Strafe(n), fünf Artikel zum Thema Disziplin(ierung), 17 Artikel zum Thema Unterrichtsstörungen und zwölf zum Thema Rituale.

11 Es handelt sich um die Erziehungswissenschaftler Johannes Bastian (1995), Walter Bärsch (1996), Fritz Osterwalder (2000), Jochen Korte (2002) und Hans Josef Tymister (2003). Der Text von Korte erscheint als wissenschaftlicher »Hintergrund « in der Rubrik »Thema« des `Schulmagazins‘; Bastian veröffentlicht eine überarbeitete Einführung in einen gleichnamigen, von ihm herausgegebenen Sammelband, daraus erscheint auch als Nachruf der Artikel von Bärsch. Der Text von Osterwalder erscheint innerhalb eines >Pädagogik -Themenheftes zu Unterrichtsstörungen, ebenso wie jener von Tymister zum Thema Disziplin. 
Worte in Anführungszeichen und das Fragezeichen dahinter. Er hinterfragt sie damit als Aussage. Beide Autoren zitieren damit eine Redewendung, die als »Volksweisheit« ohne Fragezeichen daherkommt und etwas zum quasinatürlichen Gegenstand macht: »Strafe muss sein!« Diese Redewendung steht gewissermaßen provokativ dem Tabu gegenüber, welches die Autoren in den Texten zum Gegenstand machen und worauf ich im Folgenden meinen Blick richten möchte. Schreibe man über Strafe, so begebe man sich auf »glattes Parkett « (SM D 04 02: 8), auf dem man also ausrutschen könnte - kein sicheres diskursives Terrain. Denn so Osterwalder: »Bis heute liegt über der schulischen Strafe ein Tabu, kaum jemand gibt ihr Berechtigung, alle aber praktizieren sie, auch wenn sie einen Schüler snur zu seinem eigenen Wohl beit nachschreiben lassen« (PÄD D 13 00: 25). Nachsitzen, Nacharbeiten, >vor die Tür setzen s seien, so Korte, strafähnliche Maßnahmen und »viele Lehrkräfte geben nur mit rotem Kopf zu, dass sie sich dieser Erziehungsmittel bedienen « (ebd.: 26). Osterwalder betrachtet die im 16. Jahrhundert beginnende Kontinuitätsgeschichte der Körperstrafe und der Kritik daran, um das Tabu zu erklären, während die beiden anderen Autoren die Gründe dafür in der nicht allzu fernen Vergangenheit, nämlich den »68ern« ausmachen. Gab es zuvor eine Strafpädagogik, so bedeutete die Abkehr von der Strafe zugleich ein Verschweigen der alltäglichen Praxis aufgrund ihres Widerspruchs zur normativ begründeten Aversion bzw. zu einem pädagogischen Anspruch (vgl. PÄD D 02 95). ${ }^{12}$ Man wüsste nun zwar, was falsch ist, aber nicht, was richtig (PÄD D 02 95: 40). Auf diskursiver Ebene zeigt sich dies daran, dass das Wort Strafe nicht gebraucht würde, so Bastian, stattdessen sei von Regelverstößen und ihren Folgen, Arbeitsdisziplin, logischen Konsequenzen, sozialen Grundfähigkeiten, Grenzsetzungen und -überschreitungen die Rede (ebd.: 38). Ähnlich wie das Wort Autorität sei Strafe ein Symbolbegriff einer repressiven Schule und verweise »ungeschminkt« auf die Disziplinarmacht Schule (ebd.: 39f.).

Die Beschäftigung mit dem Tabu steht nun in den Artikeln nicht für sich, sondern es sind Interessen und Forderungen damit gekoppelt: »[...] es ist an der Zeit, einen rationalen Diskurs über das Thema Strafe zu führen« (SM D 04 02: 8). Die gegenwärtige Zeit mit ihrer gesamtgesellschaftlichen Ausprägung wird zum "Auftraggeber « für einen rationalen Diskurs im Gegensatz zum bisher nicht-rationalen, von Geschmacksfragen und Meinungen geprägten Diskurs (= unvernünftig, emotional, falsch). Strafe »als gerechte Folge einer Regelverletzung« (ebd.: 9), die eben nicht immer natürlich gegeben sei,

12 Dieses Problem zeigt sich im Übrigen immer wieder in Seminaren an der Universität, welche Studierende zur Reflexion ihres Praktikums besuchen. Einerseits äußern sie als Reaktion auf Fälle, in denen gestraft wurde, moralische Entrüstung, andererseits fordern sie jedoch eindeutige Sanktionierungen. 
müsse zu einem Erziehungsmittel unter vielen werden, ein »wirksames Instrument zur Verhaltenssteuerung « (ebd.: 11). Auch für Bastian »ist die Zeit reif« (PÄD D 02 95: 37), dass über Strafe gesprochen werde, ohne zu neuer Strafpädagogik zu kommen und um zu verhindern, dass Strafe unreflektiert geschieht. Anhand von Locke und Durkheim argumentiert Osterwalder für eine andere Perspektive auf Strafe: als Lernprozess, um demokratische Regeln und ihr Funktionieren sowie den Umgang mit unpersönlicher Moral zu lernen (PÄD D 13 00: 27). Die Autoren problematisieren also weniger das Strafen selbst, sondern das Tabu, Strafen und strafende Erziehungsrealität zu thematisieren. Das lässt sich zum einen als Effekt des Tabus deuten - über Strafen wird nicht geredet, aber über das Tabu, darüber zu reden, durchaus - und zum anderen hinterlässt es eine Leerstelle: Auch wenn Strafen durchaus als Erziehungsrealität bemerkt werden, werden sie nicht näher expliziert. Ebenso wenig wird darüber gesprochen, an welche sanktionierenden Praktiken gedacht wird, wenn sie eingefordert werden. Ersteres wird zumindest bei Bastian klarer, der eine Studie zu Strafformen, welche Anfang der 1990er Jahre erstellt wurde, referiert. Einen Einblick gewährt auch der Text von Bärsch, der aus den hier rekonstruierten Formationen insofern herausfällt, als der Autor von seinen Erfahrungen als gestrafter Schüler und Sohn, strafender Lehrer und Vater sowie als »neutraler« Berater bei seiner Tätigkeit als Schulpsychologe erzählt. Sein Schreiben wird von der Redaktion der Zeitschrift in einem Nachruf als Rückschau auf sein Leben eingeführt (PÄD D 17 03: 38). In der Gesamtschau über die Texte gewinnt man den Eindruck, dass es lediglich aus dieser Perspektive des »alten weisen Mannes«, dessen Leben vor allem Rückblick bedeutet, angebracht ist, über das Thema Strafe(n) zu reden. Er spricht als einer, der mit allen möglichen Rollen innerhalb von Strafinteraktionen Erfahrungen gesammelt hat, und distanziert sich abschließend von Strafe als einem Erziehungsmittel (PÄD D 17 03: 41).

Relevant ist nun, inwiefern in den Texten Bezüge zum Körper hergestellt werden, inwiefern vom Körper (wessen?) bzw. von Körperstrafen gesprochen wird. Das geschieht auf sehr unterschiedliche Weisen: durch den Blick auf die historische Strafpraxis, die sich in erster Linie auf den Körper richtete (PÄD D 13 00: 24; PÄD D 17 03), durch den Blick auf die Gegenwart und ihre Strafformen (PÄD D 02 95: 37) sowie durch ein Verbot, welches ein Redeverbot enthält (SM D 04 02: 8). Für die Strafpädagogik ist der Körper des Schülers bzw. Zöglings zentrales Objekt, so dass eine Geschichte des Strafens nicht ohne ihn geschrieben werden kann (vgl. auch Rutschky 1977; Foucault 1988). Für Osterwalder steht er im Mittelpunkt seiner Ausführungen, verschwindet jedoch, je mehr er sich der Gegenwart nähert (PÄD D 13 00). Körperstrafen gehören der Vergangenheit an. Diese Tendenz findet sich auch bei 
Bärsch. Ebenso macht Bastian sie aus, indem er eine Studie zu Strafformen in familiären Kontexten, welche Anfang der 1990er Jahre von Bussman und Horn erstellt wurde, referiert. Danach nähme körperliche Gewalt als Strafform ab. Dennoch sei mit 80 Prozent der Strafmaßnahmen die Ohrfeige am weitesten verbreitet. Weitere Praktiken seien: deftige Ohrfeige, Prügel, Fernsehverbot, Kürzung von Taschengeld, Schweigen, Niederbrüllen - mehr oder weniger direkt eben doch auch Körperstrafen, ohne psychische Effekte, die damit einhergehen können, leugnen zu wollen.

In gänzlich anderer Weise thematisiert Korte den Körper: »Körperliche Züchtigung sollte immer ausgeschlossen bleiben! « (SM D 04 02: 10) und »Auf Arrest können wir gut verzichten! Über körperliche Züchtigung muss überhaupt gar kein Wort verloren werden. Sie hat in der Erziehung nichts zu suchen und in der Schule schon gar nichts« (PÄD D 02 95: 37). Sehr energisch, schon fast propagandistisch soll hier jeder Gedanke an Körperstrafen ausgeschlossen werden. Oder ist Züchtigung etwas anderes? Ist es die Züchtigung, die (auch aus dem Reden) ausgeschlossen werden soll? Das Propagandistische wird relativiert, indem Züchtigung nicht ausgeschlossen werden muss, sondern sollte. Nach Möglichkeit? Eine solche Assoziation wird verstärkt durch die Abstufung von Erziehung und Schule, in der körperliche Züchtigung als Steigerung von nichts »schon gar nichts« zu suchen habe. Also in der (familiären) Erziehung doch? Der Autor des Textes fordert geradewegs dazu auf, an dieser Stelle genau hinzusehen, indem er einfordert, dass, entgegen seiner Botschaft, über Strafe zu reden, über Körperstrafe »überhaupt gar kein Wort verloren werden « muss (darf?), dann aber doch darüber spricht.

Anhand dieser Texte lässt sich nun kein »Strafdiskurs« bezogen auf familiäre und institutionelle Erziehung ausmachen. Deshalb ist ein Blick in Lexika bzw. Handbücher der Pädagogik aufschlussreich. Bei der Suche nach dem Stichwort >Körper« bin ich immer wieder auf das Stichwort >Körperliche Züchtigungく bzw. \Körperstrafeく gestoßen (z. B. Schaub/Zenke 2000). Die darunter gefassten Praktiken, so die Aussagen, gehören der Vergangenheit an und sind historische Zeichen einer nicht mehr relevanten repressiven Pädagogik. Hier wird Fortschrittsgeschichte geschrieben. Darüber hinaus zeigt sich ein weiterer diskursiver Effekt: Mit dem bestraften Körper verschwindet der Körper bzw. Körper- oder Leiblichkeit überhaupt - in erster Linie aus den Lexika und Handbüchern der Schulpädagogik (z. B. Keck et al. 2004; Arnold et al. 2006). Wenn es keinen zu strafenden Körper »gibt«, so gibt es gar keinen mehr?

Die Ausführungen zum Strafen - die Beobachtungen, das Reden über die Beobachtungen, die Äußerungen in den Interviews und in den veröffentlichten Artikeln sowie die jeweilige Interpretation - zeigen, dass Strafe und Kör- 
per aufeinander bezogen werden und sind. Es lässt sich ein Verhältnis ausmachen, welches so weit geht, dass der Körper mit dem Reden über das Strafen aus der Rede verschwindet (und ebenso tabuisiert wird). Die konstatierte Tabuisierung, die mehr als das Strafen selbst Gegenstand der Autoren in den Zeitschriften ist, expliziert den »Erklärungsnotstand« der LehrerInnen, dass sie sich uns gegenüber genötigt sehen, sich und ihr Handeln in Bezug auf den Schüler Oliver zu legitimieren. Mit ihrer Thematisierung brechen sie zwar das Tabu - und in den Interviews zeigt sich, dass sie auch ohne »roten Kopf « über ihre Praktiken sprechen können -, doch können sie nicht außerhalb dieser diskursiven Praxis sprechen. Das bedeutet, sie müssen sich auf bestimmte Weise äußern, da ihre Praxis im historisch zu verstehenden Strafdiskurs verbrämt ist und moralisch und normativ nicht gerechtfertigt erscheint bzw. erscheinen könnte.

\section{Das Problem mit der Disziplin: Autorität und Störung}

Die interviewten Lehrerinnen beschreiben den strafenden Ausschluss als disziplinarische Methoden. Bastian spricht davon, dass statt von Strafen und Sanktionen von Arbeitsdisziplin oder Regelverstößen und ihren Folgen die Rede sei (PÄD D 02 95: 38). Disziplin und Strafe scheinen eng miteinander verknüpft zu werden, Sanktionen mit Disziplin einherzugehen. Mit Bezug auf Steinert vertrete ich dagegen die These, dass beide im Widerspruch zueinander stehen, da Strafe ihren Zweck prototypisch in sich trägt, während Disziplin auf nützliche Routinen ausgerichtet ist (Steinert 1993: 238ff.). Deshalb ist zu fragen, wovon hier eigentlich die Rede ist, wenn von Disziplin gesprochen wird und welchen Stellenwert Körperdisziplinierung dabei hat. Wird aufgrund der Tabuisierung von Strafe schlicht das eine durch das andere Vokabular ersetzt? Diesen Fragen gehe ich in einem ersten Schritt anhand der geführten Interviews und in einem zweiten Schritt anhand des Zeitschriftenmaterials nach.

In den Interviews haben wir die Lehrerinnen nach der Bedeutung von Disziplin in ihrer Arbeit und in Bezug auf die Schulklasse gefragt:

Interviewerin: Vielleicht eine Frage zum Thema Disziplin. Inwieweit ist dir das wichtig, im Unterricht zum Beispiel? Und was gibt es so für Regeln?

Lehrerin Matthes: Disziplin ist ein ganz großes Thema, ich denke mir, 'ne ganz große Grundlage ist, dass da auch so ein Respekt einfach da ist. Also, das was du auch vermittelst: »Hier, ich mag euch, aber es gibt klare Regeln und ich bin die Chefin. Wenn ich was sage, ist das einfach so.« Also ich finde, das ist so, das musst du als Person mitbringen. Und je mehr du das verkörpern kannst, desto weniger Probleme hast du auch mit Disziplin.

Interviewerin: $\mathrm{Mmh}$. 
Lehrerin Matthes: Disziplin ist insofern Thema, ja, was die Lautstärke angeht im Unterricht, klar. Das ist oftmals echt ein Kampf. Wobei ich sagen muss, die reden auch viel über unterrichtliche Themen. Dann kann ich gar nicht mehr so richtig sagen: Hier, ich reglementiere jetzt, ja. Aber das versuchen wir ihnen auch mitzuteilen, also zu sagen, wir sehen das, ja aber ihr müsst gucken, und das ist eine Regel, dass hier jeder in seinem Bereich auch lernen kann, das es einfach nicht überhand nimmt und zu laut ist. Also, wenn ich manchmal dahinten sitze und mitkriege, was so rundrum so alles an Gesprächen und Briefen und sonst was läuft, dann denk ich mir: "Boah, wie können die«. Also ich bewundere das, dass die dann trotzdem noch so viel mitkriegen vom Unterricht, ich würd' das nicht hinkriegen. Und so heftigere Disziplinverstöße, ne, gibt es eigentlich relativ wenig. Also es gibt so klare Regeln wie pünktlich kommen, Leute ausreden lassen, keine Beschimpfungen, das ist schwierig. ... Und so diese klassischen Sachen, wie rumlaufen im Unterricht, das hat sich gegeben. Also das hatten wir auch, dass Leute nicht sitzen bleiben konnten und permanent irgendwie rumlaufen mussten.

Wer welchen Begriff von Disziplin hat, lässt sich nicht getrennt von bzw. auBerhalb der Interaktion im Interview eruieren. Bereits die Interviewerin fragt innerhalb diskursiver Verweisungszusammenhänge. Sie beginnt damit, dass sie nun eine Frage zum Thema Disziplin stellen werde. Damit ermöglicht sie Assoziationen und weit gefasste Anschlussmöglichkeiten bei ihrer Gesprächspartnerin, wobei sie zugleich ankündigt, diese Assoziationen einzuschränken, indem sie dazu eine konkrete Frage stellt. Sie erklärt »Disziplin« zu einem besprechungswürdigen Thema, ohne selbst genauer zu erläutern, was sie darunter versteht. Es sind dann zwei Fragen: erstens nach der Wichtigkeit - der Bedeutung - von Disziplin, insbesondere für den Unterricht, womit Disziplin etwas mit Unterricht zu tun hat und innerhalb dessen vorkommt. Mit der zweiten Frage expliziert die Interviewerin ihren Begriff von Disziplin, in dem sie nach Regeln fragt. Disziplin hat also etwas mit Regeln zu tun, Regeln, die für den Unterricht gelten.

Mit der Antwort »Disziplin ist ein ganz großes Thema « bestätigt die interviewte Lehrerin, dass Disziplin einer Problematisierung unbedingt würdig ist, ohne genauer zu explizieren für wen. Da sie nach der Bedeutung für sie als Lehrerin gefragt wurde, ist es wahrscheinlich zunächst für sie ein »ganz großes Thema«, möglicherweise aber auch für andere. Jenseits ihrer Person scheint es für sich genommen ein eigenständiges Thema zu sein. Dessen Bedeutung wird durch die Formulierung »ganz groß« besonders hervorgehoben. Später expliziert die Interviewte, inwiefern Disziplin thematisch wird: »was die Lautstärke angeht im Unterricht, klar«. Es gibt einen akustischen Bereich, der steht für Disziplin, ein Bereich, der - so muss man als Leserin bzw. Gegenüber die Lücke füllen - der nicht so funktioniert, wie es wünschenswert 
ist. Das Wort »klar« verweist auf einen eindeutigen Missstand, aber auch, dass dieser schon fast selbstverständlich ist. Disziplin wird zu einem Thema, wenn etwas, was in ihren Bereich »gehört«, nicht funktioniert. Im Anschluss verwendet die Interviewte die Metapher des Kampfes. Es ist ein Missstand, gegen den gekämpft werden muss. Gegen was oder wen muss gekämpft werden: gegen die Nicht-Disziplin, die Lautstärke oder gegen die lauten SchülerInnen? Wer ist der Gegner in diesem Kampf? In einem Kampf stehen sich verschiedene Positionen gegenüber. Das Problem, das die Lehrerin nun formuliert, ist, dass die Positionen oft nicht eindeutig seien. Denn es werde auch laut, weil die SchülerInnen sich über Themen des Unterrichts unterhalten, (was als Lernen ja schlecht ausgeschlossen werden kann). »Dann kann ich gar nicht mehr so richtig sagen: Hier, ich reglementiere jetzt, ja.« Würden die SchülerInnen (und hier sind sie diejenigen, die der Lehrerin gegenüberstehen), sich nur über andere Dinge (laut) unterhalten, so wäre die mit der entscheidenden Macht ausgestattete Position klar, sie läge bei der Lehrerin. Das impliziert: Disziplin kann über eindeutige Regeln hergestellt werden. So wie Frau Matthes darüber spricht, haben innerhalb dieser aber auch die SchülerInnen selbst Verantwortung für die Einhaltung der Regeln zu übernehmen.

In diesem Sinne lässt sich auch die erste Antwort lesen: Grundlage von Disziplin ist, dass das Verhältnis zwischen Lehrerin als »Chefin« und SchülerInnen als Untergebene respektiert wird und dass sowohl dieses Verhältnis, als auch die Regeln, die die Lehrenden bzw. die Institution Schule vorgeben, klar - transparent, eindeutig - sind und anerkannt werden. Die Vorstellung von Respekt verläuft hier in eine Richtung: Die SchülerInnen haben Respekt gegenüber den LehrerInnen zu haben, nicht andersherum. Die Vermittlung dieser »Tatsache« liegt nun bei der Lehrenden. Disziplin kann und muss also vermittelt werden. Geschieht dies nicht, habe man Probleme mit ihr. Und hier bringt die Interviewte den Körper der Lehrenden ins Spiel: die Rolle der Chefin, die ihre Schüler mag, müssten sie »verkörpern«. Es reicht nicht, dass die Institution Schule zwei mehr oder weniger komplementäre Rollen Lehrer - Schüler vorgibt. Dass sie entsprechend ausgefüllt werden, ist Sache der Beteiligten. Je mehr die Lehrerin eine Chefin verkörpert, also ein nicht näher erläutertes Bild einer Chefin abgibt - welches dementsprechend auch die anderen an der Situation Teilnehmenden einigermaßen teilen müssen - desto weniger Probleme habe man mit Disziplin.

Dazu trage auch die körperliche Praxis der SchülerInnen bei: die Lautstärke, weil sie ihre Stimmen zu sehr einbringen, ebenso körperliche Aktivitäten wie »rumlaufen im Unterricht«, also »dass Leute nicht sitzen bleiben konnten und permanent irgendwie rumlaufen mussten«. Diese Praktiken bezeichnet die interviewte Lehrerin als »diese klassischen Sachen«. Damit werden sie zu et- 
was, was nicht nur in ihrer Schulklasse vorkäme, sondern was durchaus üblich ist für Unterrichtsgeschehen. Es ist nicht ihr eigenes Problem, sondern ein generelles, der Sache inhärentes. Nahe liegend ist dies, da gerade das Sitzen die Körpertechnik und einzunehmende Haltung ist, auf der mehr oder weniger der gesamte Unterricht basiert. Wird diese Grundhaltung nicht eingenommen, sind die Lernkörper nicht in der die Institution auszeichnenden Weise »disziplinierte - hier im Sinne Foucaults. Disziplin wird in den Äußerungen der befragten Lehrerin vordergründig zu einem Problem, welches sich auf körperliche Praktiken sowohl von Lehrenden als auch SchülerInnen bezieht. Es wird dann thematisch, wenn gegen die Regeln bzw. die Disziplin verstoßen wird. Disziplin selbst wird bei Interviewerin und Interviewter zur Einhaltung von Regeln.

Auch die beiden anderen befragten Lehrerinnen stellen den Körper der Lehrkraft sowie ihre »Persönlichkeit« in den Mittelpunkt ihrer Äußerungen zur Disziplin. Darauf werde ich im Kapitel zum »Lehrkörper« noch genauer eingehen, an dieser Stelle soll zunächst der Begriff von Disziplin im Vordergrund stehen. Darüber befragt, ob es schwieriger sei, in eine Hauptschulklasse Ruhe hineinzubringen als in einer Klasse anderer Schultypen, antwortet Lehrerin Kilian:

Ich denke aber, das hat auch ein bisschen was mit der mit der Lehrerpersönlichkeit einfach zu tun, also ich denk mal, wenn ich versuche, Disziplin in 'ne Klasse reinzubringen, ich kann auch mit 'ner gymnasialen Klasse [...] Probleme haben, wenn ich das denen nicht so rüberbringen kann, und genau so das ist für mich kein großer Unterschied. Ich find auch nicht, dass Hauptschüler schwerer zu disziplinieren [lacht] (sind), ja also sag ich mal dieses furchtbare Wort.

Ähnlich wie bei Lehrerin Matthes müsse Disziplin vermittelt und in eine Klasse hineingebracht werden. Es ist Aufgabe der Lehrenden, dies zu tun, was nicht unbedingt etwas mit ihrem jeweiligen Gegenüber, einer bestimmten »Sorte« SchülerIn zu tun hat. Damit grenzt sich Frau Kilian davon ab, dass HauptschülerInnen, so wie es auch die Interviewerin in diesem Moment unterstellt und was gerade die Problematisierung von Hauptschule in der medialen Öffentlichkeit suggeriert, prinzipiell schwierig seien. Sie erklärt damit die Gegenüberstellung von `schwierigen Hauptschülern` und seinfachen Gymnasiasten für nichtig. Da die Interviewte sich mit ihrer diskursiven Praktik, hier nicht derart zu differenzieren, positioniert, macht sie sich einerseits zur Expertin, die als Hauptschullehrerin und Lehrerin, welche auch schon an anderen Schulen unterrichtet hat, darüber sprechen kann (und darf). Andererseits konstituiert sie sich als Lehrerin, die ihren SchülerInnen nicht ohnmächtig gegenüber steht, sondern sie »disziplinieren« kann. Sie verwendet das Wort `diszi- 
plinieren und kommentiert es anschließend - zum einen durch ein (Unsicherheit oder Distanz ausdrückendes?) Lachen, zum anderen, indem sie das Wort zu einem »furchtbaren« erklärt. Damit wertet sie es und distanziert sich von ihm und seinem Gebrauch, sie setzt es nachträglich gewissermaßen in Anführungszeichen, als gehöre es nicht zu ihrem Vokabular. Ist >Disziplinieren< etwas anderes als $>$ Disziplin hineinbringen $\ll$ ? Jemanden disziplinieren setzt eine unmittelbare Person als Gegenüber voraus, Disziplin in eine Klasse hineinbringen setzt dagegen an der Situation in der Schulklasse an, die zwar aus Personen besteht, welche aber einen sozialen Raum bilden, an den Disziplin anknüpfen kann. In dieser Formulierung wird nicht eine Person »bearbeitet« und durch Fremdeinwirkung diszipliniert, sondern es wird ein disziplinierter sozialer Raum von der Lehrkraft hergestellt. Die Lehrerin wird so zur Gestalterin der Situation, in der, wie auch schon Lehrerin Matthes erklärt, die SchülerInnen Teil des Disziplinierens sind, sie selbst Verantwortung übernehmen sollen. Die SchülerInnen zzu disziplinieren<, scheint also nicht ohne Einschränkung sagbar zu sein, da diesem Vorgang etwas Repressives anhaftet, während `Disziplin hineinbringen positiv und produktiv besetzt wird. `Disziplinierung und `Disziplin` haben unterschiedliche Referenzräume. Während Disziplinierung mit äußerem Zwang gleichgesetzt wird, entsteht Disziplin durch die Befähigung zur Selbstführung mittels Situationen schaffender Führung durch die Lehrerin. Es ist ein Modus der Regierung, welcher weniger auf die direkte Steuerung von Handlungen der Akteure zielt, als auf die Art und Weise, wie diese ihr Verhalten selbst steuern (Foucault 1987: 25), der hier positiv besetzt wird.

Das repressive Moment kehrt Lehrerin Timm ironisch hervor, wenn sie sagt:

Disziplin, Disziplin dafür bring ich immer die Trillerpfeife mit [...].

Die Metapher der Trillerpfeife steht für Drill. Wer pfeift, gibt kurze und knappe Anweisungen, die befolgt werden müssen. Er braucht keine erklärenden Worte dazu. Die Signale sind in militärischem Stil eindeutig und nur mit mehr oder weniger vorbestimmten Gesten oder Haltungen zu beantworten. Gepfiffen wird in der Schule am ehesten noch von der Schiedsrichterin im Sport. Die Trillerpfeife gibt nonverbale Signale, auf die auch nur nonverbal geantwortet werden soll. Auch hier findet also eine Distanzierung vom Wort Disziplin statt, der Gebrauch scheint verpönt zu sein. Zugleich begreifen jedoch alle Interviewpartnerinnen Disziplin als etwas für Unterricht Grundlegendes. Worin genau dieses Grundlegende besteht, darüber muss scheinbar nicht geredet werden, es bleibt auch bei genauerem Hinsehen offen. Am ehesten tritt es 
dann in den Äußerungen in Erscheinung, wenn es nicht erfüllt ist und die Disziplin gestört wird. So Lehrerin Timm:

Strukturlosigkeit schafft Disziplinprobleme, nicht vorhandene Transparenz schafft Disziplinprobleme, Desinteresse an den Schülerinnen und Schülern oder am Unterrichtsgegenstand schafft Disziplinprobleme, mangelnde Konsequenz, ja? Also ich mein, manchmal bin ich auch disziplinlos und das überträgt sich auf die Klasse, ist klar.

Es gibt Probleme mit Disziplin, die im Sprechen darüber von den Lehrenden selbst geschaffen werden, ohne dass genau bestimmt wird, wie es aussieht, wenn alles funktioniert. Ablesen lässt sich dieser Zustand aber wohl bei den SchülerInnen bzw. der Schulklasse, so die Lehrerin weiter:

Aber ich denke es hängt auch damit zusammen, die wissen, sie können gewisse Dinge tun und sie können gewisse Dinge nicht tun und wenn sie gewisse Dinge, die sie nicht tun dürfen, tun, dann müssen sie mit Sanktionen rechnen.

Hier wird der Bogen hin zu den Sanktionen aufgenommen. Es geht um Regeln des Handlungsfeldes, diese bestimmen, was Disziplin ist, und wer sie nicht einhält, muss mit Sanktionen rechnen. Disziplin bezeichnet hier also ein Spannungsfeld zwischen den Regeln eines Feldes, ihrer Transparenz, der Einhaltung dieser Regeln und möglichen Sanktionen.

\section{Disziplin und Disziplinierung: Prävention, Normalisierung, Sanktion}

Begreift man den Akt des Sprechens und jede Äußerung innerhalb eines Verweisungszusammenhangs anderer Äußerungen, in dem wiederholt, aufgegriffen, aktualisierst und modifiziert wird, so ist es an dieser Stelle interessant, zu den ausgewählten Zeitschriften überzugehen und auch dort danach zu fragen, wer auf welche Weise und mit welcher Begründung Disziplin als Gegenstand konstituiert, der LehrerInnen als Lesende zu interessieren habe. Dabei zeigen sich Parallelen insbesondere bezüglich der vorgenommenen Unterscheidung zwischen Disziplin und Disziplinierung. Die Analyse basiert auf einer Auswahl von 41 Texten, welche ich den Themenschwerpunkten Disziplin, Unter- 
richtsstörungen und Rituale zugeordnet habe. ${ }^{13}$ Zunächst beziehe ich mich auf Texte zu Disziplin und Unterrichtsstörungen; welchen Platz Rituale innerhalb dieser beiden Bereiche einnehmen bzw. zugewiesen bekommen, zeige ich im Anschluss.

Lediglich in 14 Artikeln wird das Wort Disziplin verwendet. Was dann darunter verstanden wird, kann, da der Begriff als solcher nicht geklärt wird, nur über das semantische Feld, welches gewissermaßen um das Wort angesiedelt ist, erarbeitet werden. Worauf wird also verwiesen, wenn von Disziplin gesprochen wird? Es lassen sich drei Bereiche ausmachen, die einen Zustand beschreiben:

1) Herstellung einer Ordnung: Darunter lassen sich das Einhalten sozialer Regeln (PÄD D 17 03), eine innere und äußere Ordnung (PÄD D 16 03), Erziehen zu problem- und sachangemessenem Verhalten (PÄD D 18 03) sowie die Vorstellung von Disziplin als »Choreographie« fassen (PÄD D $1603)$.

2) Bezug auf ein Selbst: Dieser ist auszumachen in Selbstdisziplin (PÄD D 19 03), Selbstüberwindung, Härte gegen sich selbst, Selbstzwang (PÄD D 16 03), das Sollen zu wollen (PÄD D 19 03), Mitarbeit (SM D 0503 ). Verbunden werden diese beiden Bereiche durch etwas, was sich als

3) Atmosphäre benennen lässt: Arbeitsatmosphäre (PÄD D 10 00), hohe Konzentration, Stimmigkeit, Balance (PÄD D 1603 ), Stille (PÄD D 1903 ).

Häufiger findet sich eine Bestimmung von Disziplin, die sich auf alle drei genannten Bereiche bezieht und zugleich auf ihr Gegenteil aufmerksam macht: Disziplin ist vorhanden, wenn es keine Unterrichtsstörungen gibt (SM D 03 00; SM D 05 03; PF D 03 96). Sie wird also Unterrichtsstörungen bzw. Disziplinproblemen $^{14}$ gegenübergestellt. Disziplin als ein Zustand, der mit den oben genannten Merkmalen in Verbindung gesetzt wird, wird in den Texten durchgängig positiv besetzt, während Disziplinproblem und Unterrichtsstörung das negativ gewertete Gegenüber bilden. Es gibt weitere Konnotationen, die die positive Wertung von Disziplin verdeutlichen: Anstrengung und Leistung (SM D 06 02), Lernmotivation (PF D 03 96), Ernsthaftigkeit und Verant-

13 Es handelt sich um neun Artikel aus dem >Päd Forum`, 20 aus der `Pädagogik und 13 aus dem >Schulmagazin 5 bis 10<. Darunter befinden sich folgende Themenhefte: »Störfälle « (Päd Forum 03/1996), »Unterrichtsstörungen « (Pädagogik 01/2000), »Disziplin « (Pädagogik 12/2003) und im Bereich der Rituale: »Ruherituale und Entspannung mit Jugendlichen « (Päd Forum 1/1996), »Rituale in Schule und Unterricht « (Pädagogik 04/1999) sowie »Rituale in der Schule« (Schulmagazin 04/2002). Knapp zwei Drittel der AutorInnen arbeiten als LehrerInnen oder sind in der Weiterbildung für LehrerInnen tätig, ein Drittel kommt aus erziehungswissenschaftlichen Fachbereichen.

14 Vereinzelt wird auch vom Disziplinkonflikt gesprochen. 
wortungsbewusstsein, Energie, aber auch Sekundärtugenden wie Pünktlichkeit, Zuverlässigkeit, Vollständigkeit und Sauberkeit (PÄD D 19 03). Zum Problem wird nun Disziplin, wenn ein Mangel daran konstatiert wird, zum Beispiel von Thymister derart: »dass Anstrengung, Leistung und Disziplin im persönlichen wie im öffentlichen Leben und damit auch in der Erziehung nicht mehr >trendy « sind « (SM D 06 02: 6). Sie gehören damit in allen Bereichen der Gesellschaft der Vergangenheit an. Es mangele nicht nur an Disziplin, sondern auch an der »unverschleierten« Forderung danach bzw. einer angemessenen Sanktionierung, wenn sie ausbleibe. Der Mangel zeigt sich in Unterrichtsstörungen, die, so beispielsweise Erziehungswissenschaftlerin Heidrun Bründel und Lehrerin Erika Simon, zu den größten Problemen von LehrerInnen zählen, welche sich in Erfahrung von Machtlosigkeit niederschlügen (PÄD D 0304 : 40). Ebenso äußert sich Lehrerin Katrin Krause in einem Brief an die Herausgeber des >Päd Forum «: »Alle Kollegen kennen täglich Disziplinprobleme/Unterrichtsstörungen und sind am Ende der Woche ausgepumpt. « (PF D 03 96: 211) Im Editorial zum Themenheft >Disziplin< bezeichnet Johannes Bastian diese als »allgegenwärtiges Problem« und als »tägliche Herausforderung« (PÄD D 15 03: 3). Das erinnert an die Äußerung der Lehrerin im Interview, Disziplin sei ein ganz großes Thema. Seine Bedeutung für LehrerInnen lässt sich auch an der Nachfrage an Zeitschriften, die sich damit beschäftigen, ablesen: Die Themenhefte >Unterrichtsstörungen sowie >Disziplin< waren jeweils innerhalb von zwei Jahren vergriffen. ${ }^{15}$

Was als Unterrichtsstörung gilt, wird zum Teil ebenso näher erläutert und noch einmal in ihrer Gegenüberstellung zu >Disziplin` aufgeführt: Meist sei damit problematisches Schülerverhalten gemeint, wie schwatzen, dazwischen rufen oder andere Formen von »Unruhe«, welche aber auch durch Lehrkräfte gefördert werden könne (SM D 05 03: 53). Genannt werden außerdem Unkonzentriertheit und mangelnde Aufmerksamkeit (SM D 10 97: 47). Ursula Drews, Erziehungswissenschaftlerin, unterscheidet Unterrichtsstörungen nach ihren Wirkungen, welche a) Substanz und Persönlichkeit über den aktuellen Sachverhalt hinaus beschädigen, b) eine vermeidbare schlechte Unterrichtsorganisation und schulische Bedingungen anzeigen, c) heilsame Störungen sind, die ein Indiz für langweiligen Unterricht abgeben (PÄD D 08 00: 6f.). Insbesondere diejenigen Autoren, die Unterrichtsstörungen genauer präzisieren und unterscheiden, plädieren dafür, sie als Normalität zu betrachten, als Störung, die zur Kommuni-

15 So die Auskunft eines Mitarbeiters des Verlags. Lediglich zwei andere Titel der Zeitschrift waren im Zeitraum der Jahre von 2000 bis 2005 vergriffen. In ihnen wurden die Themen >Methodenvielfalt` und >Lempsychologie . diskutiert. Die (wenigen) vergriffenen Hefte der Jahre zuvor beziehen sich vorwiegend auf Unterrichtsmethoden sowie Ende der 1990er auf Schulprogrammarbeit (Stand 05/2005). 
kation bzw. zum Funktionieren dazu gehöre. Dieses Plädoyer, das sich in Überschriften wie »Unterrichtsstörungen - wie selbstverständlich sind sie? « (PÄD D 0800 ) oder »Unterrichtsstörungen - na und?« (PÄD D 09 00) abbildet, scheint für notwendig erachtet zu werden, eine diskursive Normalität innerhalb des Redens über Schule in derartigen Medien erst hergestellt werden zu müssen. Ich bezeichne diese diskursive Praktik deshalb als Normalisierungspraktik: Etwas wird als regelhaft, sinnhaft und rational im Verhältnis zur Situation erklärt (vgl. Cremer-Schäfer/Steinert 2000: 58). Im Konzept des flexiblen Normalismus Jürgen Links gedacht, werden die Störungen bzw. bestimmte Störungen, wie Unruhe, für normal erklärt und damit als solche integriert und integrierbar. Normalisierung bedeutet eben nicht die Sanktionierung des Normbruchs (Link 2006: 33). ${ }^{16}$ Durch die Integration der Störung als Teil der Unterrichtskommunikation und der störenden SchülerInnen in die Klasse werden andere Toleranzgrenzen und Bearbeitungspraktiken konstituiert.

Es lässt sich eine weitere Differenzierungspraktik rekonstruieren, wie sie bereits in den Interviews mit den Lehrerinnen ersichtlich wurde: Die AutorInnen arbeiten mit der Differenz zwischen Disziplin und Disziplinierung. Disziplin wird als positiver Zustand bzw. als Situation verstanden, in der sich die beteiligten (SchülerInnen) an die Regeln halten, indem sie sich auf die Aufgaben konzentrieren, aufmerksam mitarbeiten. Dies sollte nach Möglichkeit aus der Einsicht der SchülerInnen heraus geschehen, dass es gut für sie ist, was wiederum ihre Bereitschaft dazu steigern sollte. Disziplinierung, welche abgeleitet vom Wort Disziplin den Prozess beschreiben müsste, am Einzelnen ansetzend zu eben jener zu gelangen, wird dagegen nicht nur von den interviewten Lehrerinnen, sondern in allen hier ausgewählten Texten, die sie aufgreifen, negativ besetzt. Beschrieben wird Disziplinierung als Reglementierung und Sanktionierung (PF D 03 96), als Mechanismus von Regel - Verbot Kontrolle - Übertretung und Sanktion (PÄD D 10 00) sowie als Disziplinarmaßnahme mit Vorschriften, äußerem Zwang, Drill, Drohung und Strafe

16 Jürgen Link hat sich in seiner Untersuchung, die er »Versuch über den Normalismus« (2006) genannt hat, mit der Frage nach dem »Normalen«, nach der Herstellung von Normalität und den Verhältnissen zum Normativen eingehend auseinander gesetzt. Seine Normalismustheorie fasst das »Normale « als ein modernes Dispositiv auf, als eine »Klaviatur «, die eingesetzt werden kann, die sich vor allem in den letzten Jahrzehnten auf allen gesellschaftlichen Ebenen konsolidiert habe. Als Begriff sei das Normale erst im 18./19. Jahrhundert mit der Durchsetzung der Massenproduktion entstanden (ebd.: 20) und somit deutlich zu unterscheiden von Normativität. Der historisch ältere "Normativismus«, den Link in der christlichen Ethik und im demokratischen Humanismus verortet, konstituiert Werte, Normen und Paradigmen präskriptiv. Der Normalismus dagegen speist sich aus dem wissenschaftlichen Denken in Normalverteilungen, das Normale wird mittels Statistiken, Durschschnittsanalaysen und -abschätzungen etc. erst im Nachhinein aus einer Gesamtschau des betreffenden Feldes konstituiert. 
(PÄD D 16 03). Über Disziplinierung mag man nicht reden, erst recht nicht, sie praktizieren. Wird über sie gesprochen, dann als Reaktion auf ein bestehendes Disziplinproblem. Zentral für die Differenz Disziplin (+) vs. Disziplinierung (-) ist nicht nur bei letzterer die Konnotation mit Sanktionierung und Strafe, sondern die hier aufscheinende Differenz von Selbstdisziplin vs. Fremddisziplinierung bzw. innen vs. außen oder, fortgeführt ließe sich sagen, von produktiv vs. repressiv. Auch (Selbst-)Disziplin sei von Zwang gekennzeichnet - aber von positiv besetztem inneren Zwang. Erklärtes Ziel ist es demnach, zumindest von den in den Zeitschriften häufig vertretenen reformpädagogischen Positionen aus formuliert, »Disziplinanforderungen von außen eine Erziehung zu echter Selbstdisziplin werden zu lassen« (PÄD D 1903 : 28) oder noch deutlicher: "aus dem Müssen und Sollen ... ein Wollen und Können« zu lancieren (ebd.: 29, Herv. i. O.). An die Stelle einer äußeren Ordnung, so Annemarie von der Groeben, sollten gemeinsam akzeptierte Regeln und eine Disziplin, »die von der Sache ausgeht«, stehen (PÄD D 16 03: 7) die Spuren führen hier zurück bis zu Rousseau. Doch woher kommen die gemeinsam akzeptierten Regeln, wer stellt sie auf? Was ist die »Sache«? Und wie gelangt man zu (Selbst-)Disziplin, wenn nicht über Disziplinierung? Was steht an dieser Stelle?

Die Differenz zwischen Disziplin und Disziplinierung zieht sich durch die Texte hindurch, mit einer Ausnahme, in der sehr offensiv und explizit von Disziplinierung gesprochen wird. Es handelt sich um eine fortlaufende Reihe mit der Überschrift: »Klassenmanagement. Effektiver Umgang mit Unterrichtsstörungen - ein Trainingsprogramm«, welches Hubert Schmitt, der in der Weiterbildung arbeitet, in vier Teilausgaben des >Schulmagazins 10-13 97). Auch er normalisiert zunächst, indem er feststellt, dass 45 Prozent der Unterrichtszeit mit Disziplinieren von Unterrichtsstörungen verbracht würde. Dazu gehörten ein strenger Blick, Bestrafen, Ermahnen, Drohen, Schreien oder an sich unzulässiges Erteilen von Strafarbeiten. Disziplinieren versteht er als konkrete Handlung, eine Reaktion auf eine Störung bzw. in Vorwegnahme einer potenziellen Störung. Schmitt unterscheidet nun effektives und ineffektives Disziplinieren, wobei anzunehmen ist, das ersteres zu Disziplin führe, letzteres eben nicht. Die Reihe der Differenzen ließe sich nun fortsetzen: Während uneffektives Disziplinieren uneindeutig, falsch und unreflektiert sei und somit nicht funktioniere (aber häufig so stattfinde), sei effektives eindeutig, bewusst und reflektiert, implizit also richtig und - so das Versprechen - es funktioniere. Worauf Effektivität und Funktion ausgerichtet ist, bleibt dabei offen. Falsches Disziplinieren ist hier zwar ebenfalls negativ besetzt, Disziplinieren als solches aber nicht. Dies erfährt jedoch eine relativierende Wendung durch folgende Argumentation, die verdeutlicht, was sich in 
der herausgearbeiteten Negativbesetzung des Begriffs Disziplinierung verbirgt: Indem Disziplinierung oft als unreflektiertes Reiz-Reaktion-Schema erfolge, werde die Beziehung zwischen LehrerInnen und SchülerInnen als Macht erfahren und dadurch negativ beeinflusst, wodurch Disziplinprobleme häufig zunähmen (SM D 10 97: 47). Effektive Disziplinierung - impliziert dies werde demgegenüber nicht als machtvolle Praxis erfahren, was sich positiv auswirke. Offensichtliche Macht gilt es also zu vermeiden.

Der Blick auf das, was Michel Foucault als Disziplin bzw. Disziplinartechniken beschrieben hat, scheint hier nahe liegend und verdeutlicht das Analysierte noch einmal: Notwendigerweise von Macht durchzogene Disziplinartechniken ${ }^{17}$ sind immer zugleich repressiv und produktiv. Produktiv sind sie aufgrund ihrer Erzeugung von Nützlichkeit für gesellschaftliche bzw. institutionelle Ordnung und der Reibungslosigkeit von Abläufen. Indem hier die Macht als den Praktiken imanente nicht unbedingt als solche wahrgenommen wird, werden Widerstände gering gehalten. Nicht anders lässt es sich also verstehen, wenn in den oben vorgestellten Beispielen äußere Fremddisziplinierung in innere Selbstdisziplin(ierung) übergehen und das Subjekt sein Sollen als sein eigenes Wollen begreifen soll. Wovon dabei, insbesondere dort, wo Disziplinieren als repressive, sanktionierende Reglementierung verstanden wird, nicht gesprochen wird, ist die Machtdurchzogenheit der vorgeschlagenen alternativen Praktiken. Andererseits gibt es Positionen, die gerade eine Tabuisierung von Disziplinieren ${ }^{18}$ und Strafen beklagen, und auf die Durchsetzung ihrer machtvollen Position als Lehrer aufmerksam machen (PÄD D 09 00). Das schließt gewissermaßen an die Äußerung sErfahrung von Machtlosigkeit an, die mit Darstellung von Disziplinproblemen einhergeht, und verweist implizit auf einen Zusammenhang von Disziplin und Macht.

Das machtvolle Arrangement scheint an einer anderen Stelle als Kampf durch: Sowohl im Interview mit Lehrerin Matthes als auch in einigen Texten wird der Begriff des Kampfes gebraucht. »Es wird gegen Unterrichtsstörungen gekämpft« und es ist ein »Kampf gegen Windmühlenflügel« (PÄD D 08 00: 6) oder »der `Kampf mit Drachen« (PÄDD 16 03: 9), dabei ist man »Einzelkämpfer« (PÄD D 18 03: 20) in einem »dauerhafte[n] Machtkampf« (PÄD D 17 03: 15). ${ }^{19}$ Es dürfe nicht »um Bekämpfung von Krankheiten oder Störungsprozessen gehen, sondern um einen adäquaten Umgang mit ihnen: Der

17 Da Macht nie außerhalb sein kann (vgl. Kap. `Eine Analytik der Macht $/$ ).

18 Wobei der Begriff dann nicht benutzt wird und sich auch da - ähnlich wie beim Thema Strafen - Tabuisierungseffekte zeigen.

19 Ähnliche Assoziationen wecken auch die folgenden Metaphern, die im Zusammenhang mit der Bewältigung von Disziplinproblemen genannt werden: ") Brandherde< löschen « (PÄD D 19 03: 25) oder etwas zu tun gegen »beginnende ,Barbarisierung « (ebd.: 26) . 
provozierende Schüler benötigt keine Strafarbeit, wohl aber meine Bereitschaft, mich endlich auf ihn einzulassen... « (PF D 02 96: 210).

Im letzten Zitat wird dem Kampf das Einlassen auf den Konflikt gegenübergestellt. Abstrahiert auf der Ebene der Formationsregeln ist das die Gegenüberstellung von Sanktionierung und Normalisierung bzw., so ließe sich mit Blick auf das Folgende weiterführen, Prävention. Ein Teil der Artikel macht die Prävention von Disziplinproblemen bzw. Unterrichtsstörungen zum Thema. Ulrich Bröckling fasst Prävention folgendermaßen: »Prävention konstituiert eine Anthropologie im Gerundivum und bestimmt >den Menschen< als ein durch Techniken des Selbstmanagements auf der einen, durch eugenische, pädagogische, medizinische, rechtliche oder sozialpolitische Maßnahmen auf der anderen Seite zu entwerfendes und zu optimierendes Wesen. « (Bröckling 2002: 41) Die in den Zeitschriften darunter gefassten Praktiken liegen entweder vorwiegend bei den Lehrenden (1), betreffen die pädagogische Beziehung (2) oder stellen konkrete didaktische Praktiken dar (3):

(1) Die jeweils vorgeschlagenen Praktiken, die die Lehrenden unmittelbar betreffen, sind eine gute Unterrichtsorganisation (PÄD D 08 00: 7), alle SchülerInnen im Blick zu behalten (SM D 03 00), der Abbau von störendem Lehrerverhalten durch Überwachung der eigenen nonverbalen Steuerung des Unterrichtsflusses und hinsichtlich der Einhaltung von Regeln (SM D 05 03: 54). Vor allem körperliche Präsenz- und Stoppsignale hätten allergrößte Bedeutung und seien eine »echte Alternative zu endlosen Ermahnungen, Predigten, Bestrafungen« (ebd.: 55). Hier wird ein Bereich angesprochen, der gerade hinsichtlich der Frage, wie der Körper in der Schule zum Einsatz kommt (und kommen soll) relevant ist. Die meisten der aufgeführten Präventiv-Praktiken, die unmittelbar die Lehrenden betreffen, setzen am Lehrkörper an. Diesen Aspekt nehme ich später noch genauer in den Blick.

(2) Praktiken, die die pädagogische Beziehung betreffen, werden einmal auf der Lehr-Lern-Ebene in Bezug auf Tempo und die Vermeidung von Überoder Unterforderung gesehen, in der Aktivierung der SchülerInnen (SM D 05 03), welche dafür sorgen soll, die SchülerInnen »in keine passive Haltung fallen zu lassen«, jedoch »nicht zwangsläufig körperlich« sein müssen (SM D 03 00: 10). Ebenso zählt darunter die positive Verstärkung, die die Selbstbeobachtung und -erziehung der Lernenden in Gang bringen soll (PÄD D 09 00). Auf einer eher erzieherischen Ebene werden zum anderen möglichst wenig Verhaltensvorschriften, die unweigerlich Störungen zur Folge haben müssen (PÄD D 10 00: 15), das Einbeziehen von Interessen und Bedürfnissen der SchülerInnen z. B. durch Instrumente wie den Klassenrat (PÄD D 18 03: 22) sowie die Veränderung von Sitzordnungen (PÄD D 0900 12) genannt. 
(3) Die didaktischen Praktiken, die als präventiv in Bezug auf Disziplin relevaint srscheinen, beziehen sich vor allem auf einen angemessenen Wechsel von konzentriertem Lernen, Bewegung und Entspannung bzw. ausreichende Ruhe- und Pausenzeiten sowie -räume (SM D 01 96; SM D 02 96). Im >Päd Forumk mit dem Themenschwerpunkt »Ruherituale und Entspannung mit Kinder und Jugendlichen« (1/1996) werden konkrete Vorschläge unterbreitet, welche direkt am Lernkörper ansetzen.

\section{Rituale als präventive didaktische Praktiken}

Viele der oben dargestellten Präventiv-Praktiken finden sich in Texten wieder, die unter dem Stichwort Rituale gebündelt werden können. Von den ausgewählten Artikeln sind dies 15, also knapp ein weiteres Drittel. Das Thema Rituale schien mir insofern aufschlussreich, da es erstens auch in der Feldbeobachtung relevant wurde und zweitens Rituale als auf ein Kollektiv bezogene performative soziale Praktiken mit hohem symbolischem Gehalt eine sinnlich-körperliche Komponente haben (vgl. Friebertshäuser 2001: 503; Wulf/ Zirfas 2004b). Drittens lässt es sich aus den bisher zur Diskussion stehenden Texten ableiten. Dort finden sich einige Aussagen zu rituellen Praktiken, die zum Ziel haben, Disziplin herzustellen bzw. Unterrichtsstörungen zu vermeiden (PÄD D 16 03; PÄD D 18 03; PÄD D 19 03).

Es gibt im Textkorpus zwei Sparten, die unterschiedliche Arten von Ritualen zum Gegenstand machen: erstens Rituale, die auf den Unterricht, seine Strukturierung und die Vermeidung von Störungen ausgerichtet sind, also den Präventiv-Praktiken 1 und 3 entsprechen. Die zweite Kategorie Rituale lässt sich eher unter dem Begriff Zeremonien fassen. Dabei geht es um ritualisierte Ereignisse, die unter anderem Übergänge arrangieren und begleiten, Zugehörigkeit, Gemeinschaft sowie spezifische Subjektpositionen schaffen sollen und im Gegensatz zum Schulalltag eher etwas Besonderes darstellen - wie Einschulungen, Schulfeste oder Zeugnisausgaben. Für Fragen nach Körper und Unterricht ist vor allem die erste Kategorie interessant, zumal in diesem Zusammenhang immer auch Lehr- und/oder Lernkörper thematisiert werden. Es handelt sich um Praktiken der Rhythmisierung und Schaffung von Rahmungen des Unterrichtsgeschehens, die Orientierung bzw. eindeutige Hinweise geben, wie sich gerade jetzt in diesem Moment verhalten werden sollte. Sie sollen beispielsweise »der freiwilligen Selbstkontrolle in Bezug auf Lärm und Stille« (SM D 08 02: 9) dienen, der effektiven und produktiven Zeitnutzung durch Transparenz und Sicherheit für die SchülerInnen, die ihnen eine Konzentration auf Aufgaben erleichtert (PÄD D 0102 : 32). Statt vieler ungeschriebener Gesetze, die, werden sie nicht eingehalten, als Störung gewertet 
werden, gelte es, unausgesprochene Regeln transparent zu machen und eindeutige Zeichen zu setzen, womit SchülerInnen zum Mitmachen und zur Selbstbeteilung angehalten würden (ebd.). Unterricht sei von Ritualen geprägt, die zwar habitualisiert aber nicht unbedingt bewusst seien. Auf diese Weise lägen sie »im Rücken der Handelnden« (SM D 08 02: 8). Greift man diese Körpermetapher auf, müssten sie hervorgeholt werden, damit sie angeschaut werden können. Indem sie in den Blick geraten, könnten sie bewusst gemacht bzw. bewusst gestaltet werden.

In keinem der Texte wird von Disziplin (als Situation) oder Disziplinierung (als Prozess bzw. Praktiken gegenüber Einzelnen) gesprochen. Dabei oder vielleicht gerade deshalb - scheinen die beschriebenen rituellen Praktiken zu einem großen Teil die Leerstelle auszufüllen, die aus dem Problem entsteht, zu Disziplin zu gelangen, ohne disziplinieren zu wollen bzw. von Disziplinierung zu sprechen. Zur Veranschaulichung sollen hier einige Beispiele dienen, die in den Texten, die entweder als Einführung in ein Thema, als Erfahrungsbericht oder Lehrtext konzipiert sind, vorgestellt werden. Beispiel 1 ist die Schilderung einer Beobachtung in einer 1. Klasse: Die Lehrerin zeichnet einen Kreis an die Tafel. Daraufhin bilden die SchülerInnen einen Stuhlkreis. Wird der Kreis wieder abgewischt, gehen die Kinder wieder an ihre Plätze (PÄD D 01 02: 32). Beispiel 2 ist ebenso eine Beobachtung aus der Grundschule: »Ist es jemandem in der Klasse zu laut, dann kann sie bzw. er die linke Hand heben. Wer das sieht ist aufgefordert es nachzutun. An das Ruhezeichen ist als Bedingung geknüpft, alle anderen Aktivitäten einzustellen. (SM D 08 02: 9) Es sind vor allem nonverbale Zeichen, die hier in eine Handlung umgesetzt werden (sollen). Mit ihnen wird Zeit rhythmisiert, bestimmte räumliche und zeitliche Ordnungen werden geschaffen, eine Arbeitsatmosphäre hergestellt, Komplexität reduziert und die SchülerInnen zur Selbst- und Fremdbeobachtung angehalten. Es sind Praktiken, die Foucault als produktiv und nützlich machende Disziplinartechniken beschreibt.

Auffällt, dass die AdressatInnen dieser Unterricht strukturierenden Praktiken vorwiegend aus der Grundschule bzw. Sekundarstufe I stammen. Zum einen scheint es nicht angemessen, mit älteren SchülerInnen derart umzugehen, zum anderen aber auch nicht nötig, zumindest solange die gelehrigen Körper all jene strukturierenden und ordnenden Praktiken so eingeübt haben, dass sie ohne die gezielt eingesetzten performativen Zeichen funktionieren. Die körperliche Geste des Ruhezeichens wird als altersgemäß geltenden Gesten angepasst, aber beispielsweise in der 7. Klasse nicht aufgegeben - da es funktioniere, so etwa Achim Albrecht, welcher selbst als Lehrer tätig ist (PÄD LK 03 04: 10). Der Finger wird nun nicht mehr auf die Lippen gelegt, 
sondern nur noch die Hand erhoben. Die symbolische Geste kann reduziert werden, da ihr Gehalt selbstverständlich geworden ist.

In diesem Sinne nehmen die Beschreibungen ritualisierter Praktiken die Stelle einer produktiv gedachten Disziplinierung ein, die durch die negative Besetzung des Begriffs als sanktionierende Reglementierung so nicht angefült werden kann. Doch auch in (zumindest einigen) Artikeln, in denen über Rituale geschrieben wird, ist von »unhintergehbaren« (PÄD D 07 99: 7) Ambivalenzen oder von einem »pädagogisch schwierigem Begriff « (SM D 0902 : 51) die Rede. Mit Blick auf die Geschichte oder die »Schwarze Pädagogik« stelle sich die Frage nach dem guten oder schlechten Ritual, nach den Grenzen, nach ihren Kontexten. Auch hier werden ähnlich wie beim Thema Strafe die »68er« als Wendepunkt markiert, an dem mit »verkrusteten Ritualen« gebrochen werde (PÄD D 07 99: 7; SM D 09 02). Einer Herrschafts- und Unterwerfungspädagogik wird eine emanzipative gegenübergestellt, die Rituale neu diskutieren könne (PF D 01 97; PÄD D 07 99). Aufgegriffen wird die Rede über Ambivalenzen vor allem in den Texten, die allgemein von Ritualen und ihren Hintergründen handeln bzw. im Kontext zeremonialer Rituale. In Erfahrungsberichten, die zugleich handlungsanleitend als mögliche didaktische Praktiken gelesen werden können, und im Rahmen von alltäglichen Unterrichtsritualen, wie ich sie oben dargestellt habe, findet eine solche Problematisierung nicht statt.

Insbesondere bei den vorgeschlagenen (mehr oder weniger ritualisierten) präventiven Praktiken wird deutlich, wer für die Herstellung von Disziplin zuständig ist: die LehrerInnen. Wie ich bereits bei der Interpretation der Interviews festgestellt habe, verstehen die befragten Lehrerinnen es so, dass sie Disziplin in die Klasse hineintragen. D. h. aber, dass die gewünschte Selbstdisziplinierung der SchülerInnen immer über Fremddisziplinierung stattfindet, nur setzt sie nicht unmittelbar an den Personen an, sondern - und das ist im Rahmen der Fokussierung auf den Körper besonders interessant - zum einen an der Selbstdisziplinierung der Lehrenden und zum anderen an den Arrangements, in die sich die SchülerInnen (eben auch körperlich) hineinbegeben (sollen), die besonders in der Vorstellung von Unterrichtsritualen deutlich werden.

Die lesenden LehrerInnen werden auf unterschiedliche Weisen »angerufen«: als diejenigen, die Disziplin einzufordern haben (hier eher sanktionierend); als diejenigen, die die Botschaften der SchülerInnen, welche deren störendes Verhalten transportieren, entschlüsseln sollen (normalisierend) (PF D 06 96); als diejenigen, die ihr eigenes unterrichtsstörendes Verhalten verändern sollen (präventiv). Diese drei Formen der Anrufung entsprechen den drei diskursiven Formationen Sanktionierung, Normalisierung und Prävention, innerhalb derer über Disziplin und Disziplinierung geschrieben wird. Die Schü- 
lerInnen werden indirekt angerufen, wenn beispielsweise innerhalb der Prävention zur Selbstbeobachtung und Selbstkontrolle angeleitet werden soll (PÄD 09 00; SM D 08 02). ${ }^{20}$ Interessant ist, betrachtet man die Positionen, die SchülerInnen zugeschrieben werden, dass (auch da das Wort disziplinieren vermeidend) kaum vom undisziplinierten Schüler gesprochen wird, am ehesten vom »Störer«, vom »schwierigen Schüler«, vom »Problemschüler«, vom "Störfall«. Verallgemeinert man die Subjektpositionen, die in den Texten konzipiert werden, zieht sich durch viele eine Gegenüberstellung von der Figur des >störenden Schülers` und des >ohnmächtigen Lehrers` hindurch. Diese findet sich vor allem in narrativ geprägten Texten, in denen sich LehrerInnen im Rahmen von Fortbildungen äußern (PF D 04 96) oder Studierende über ihr früheres SchülerInnen-Dasein (PF D 05 96), ebenso in Erfahrungsberichten, die einen konkreten Fall konstruieren (PÄD D 11 00; PÄD D 17 03).

Fokussiere ich nun in den ausgewählten Artikeln zu Disziplin und Unterrichtsstörungen noch einmal auf den Körper bzw. die Körperlichkeit der SchülerInnen, lassen sich, auch wenn es wenig explizit darum geht, folgende Problematisierungsweisen extrahieren:

(1) Es sind vielfach Körperpraktiken von SchülerInnen, die stören - oder auch nicht stören, je nachdem, wie sie wahrgenommen und definiert werden. Das zeigen die Beobachtungen, die Ulrike Köhler und Doris Krammling-Jöhrens, zwei Lehrerinnen einer freien Schule, beschreiben. »Gleichzeitig schieben drei Jungen krachend die Tafel hinauf und herunter. Dabei reden sie ununterbrochen miteinander. Manchmal ertönt ein lautes `Bäng $\prec$ oder $>$ Baff $\varsigma$. Dann gibt es spielerische Zweikämpfe und wieder: Tafel rauf und runter. Zwischendurch geht es immer mal auf den Flur, dann kommen sie wieder hereingerannt.« (PÄD D 10 00: 15) In den Beobachtungsprotokollen finden sich viele Verben, die sich auf Körperpraktiken beziehen, die nicht per se eine Störung sind, sondern eher alltägliche Praktiken, die dann aber im Rahmen der Schule den Unterricht - also eine auf bestimmte Weise gerahmte Situation stören oder die Lehrerin als definierte Autoritätsperson beleidigen (vgl. auch SM D 01 96). Ebenso weist das Coverbild der Zeitschrift Pädagogik, in dem

20 In zwei Artikeln gibt es noch einen weiteren Umgang mit der Frage nach Disziplin und Unterrichtsstörungen, der mit den drei Formen der Anrufung bricht und in den analysierten Texten eher eine Ausnahme darstellt. Einmal indem deutlich gemacht wird, dass Störungen nur Störungen sind, wenn sie als solche definiert werden. Wenn es viele Vorschriften und Regeln gäbe, die festlegen, ob bestimmte Praktiken stören oder nicht, könne kaum noch situativ entschieden werden, ob diese tatsächlich gerade jemanden stören (PÄD D 10 00). Hier verweist die Autorin auf den Zusammenhang zwischen Struktur und Störung. Dieser wird auch in einem Erfahrungsbericht thematisiert, indem Schulentwicklung und die Änderung institutioneller Strukturen als Steuerungsinstrument für Disziplin eingesetzt werden (PÄD D 18 03). 
dieser Text zum Schwerpunkt Unterrichtsstörungen publiziert wurde, auf eine Körperpraktik.

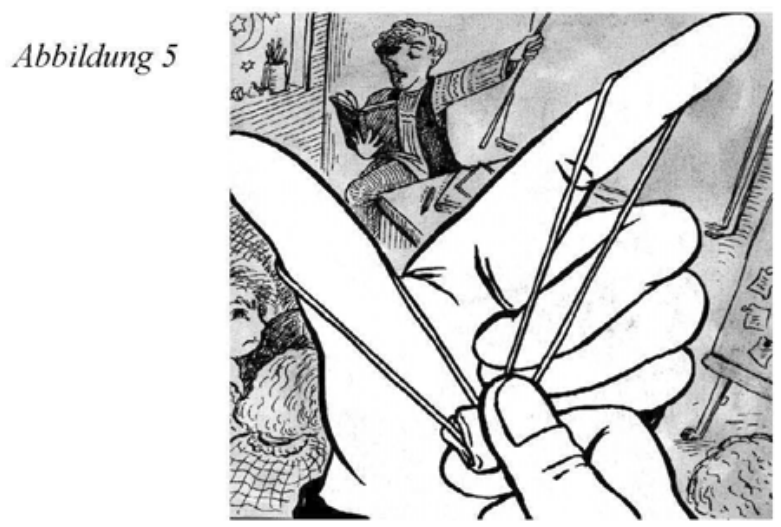

Im Vordergrund ist fast über das ganz Bild erstreckt eine Hand mit ausgestrecktem Daumen und Zeigefinger zu sehen, mit denen gerade eine Zwille gespannt wird. Das Wurfgeschoss (bzw. der Blick der Betrachterin) peilt in gerader Linie den im Hintergrund sitzenden, lesenden und gleichzeitig an die Tafel zeigenden Lehrer an, der damit derart beschäftigt zu sein scheint, dass er wenig Aufmerksamkeit auf die SchülerInnen richten kann. Die Hand ordnet man beim Betrachten des Bildes fast automatisch einem Schüler zu, denn in der Regel haben Schulklassen nur einen Lehrer, der eben jenen Platz vor der Tafel einnimmt. Sie ist überdimensional groß dargestellt, so dass sie ca. die Hälfte des Bildes ausmacht. Indem sie perspektivisch derart in der Vordergrund gerückt ist, wird man beim Betrachten in die Situation der Person versetzt, deren Hand gerade die Zwille auslöst, und kann die Wucht des Geschosses gewissermaßen empfinden. Eine solche Handlung passiert nicht aus Versehen, so die weitere Überlegung, sie kann nur gezielt sein. Es wird also gezielt und verletzend gestört. Die Betrachtenden befinden sich durch die Perspektivenübernahme im selben Hinterhalt wie der vermeintliche/n SchülerIn.

(2) Während Körperdisziplinierung der SchülerInnen nicht explizit zum Thema wird, wie es nach den Ausführungen über die negative Besetzung von Disziplinierungspraktiken nahe liegt, wird der Schülerkörper dann erwähnt, wenn die mit der Disziplinierung einhergehende Kontrolle nicht funktioniert, insbesondere wenn Gewalt als körperliche problematisiert wird (PF D 04 96; SM D 06 02) - und vielleicht würde auch die Handlung auf dem Bild so interpretiert. Relevant wird der Körper auch, wenn davon die Rede ist, dass die SchülerInnen aufgrund dessen, dass die Lehrkraft zu viel spricht, ermüden (SMD 0300 ). 
(3) Daran anschließend kommt der Schülerkörper als Seismograph für innere Zustände und Botschaften der SchülerInnen, die der Störung des Unterrichts oder Schulalltags inhärent seien, zum Einsatz. An der äußeren Erscheinung wird nicht nur Müdigkeit abgelesen, sondern z. B. die Rebellion einer jugendlichen Schülerin erkannt: »... alles ist jetzt ausgewählt schlampig. Ihr Styling signalisiert: Ich kiffe, ich nehme Drogen, nachts bin ich wach, ich lebe gefährlich! « (PÄD D 11 00: 16). Mit »Entzifferungsohr [und -auge, A. L.] « (PF D 06 96: 25) haben die PädagogInnen »die Signale der Schüler (verbale, gestische, mimische, lokomotorische u.a.m.)« (PF D 06 96: 227), die auf ihre Botschaften schließen lassen, wahrzunehmen und zu verstehen.

Abschließend komme ich auf Rituale zu sprechen, die im Besonderen am Körper ansetzen. Ein Teil der Literatur über Rituale bezieht sich auf Techniken der Entspannung, die zu Ruheritualen in der Schule werden (sollen oder können) oder für besondere sozialpädagogische Orte ergänzend zu Schule bzw. neben Unterricht gedacht sind (PF K 07 96: 44). Dabei wird von folgenden Prämissen ausgegangen: Es gibt eine natürliche Fähigkeit zur Ruhe, die bei vielen Kindern verloren gegangen sei (PF K 06 96: 6). Mit Übungen, wie autogenem Training, könne dem entgegengewirkt werden. Entspannung wird mit Ruhe, Konzentration auf sich (PF K 08 96: 62) und Körperwahrnehmung gleichgesetzt. Ulrike Petermann, Professorin für den Bereich Rehabilitation, sieht in solchen Ritualen, die Entspannung erzeugen, im Unterricht eingesetzt, »die Vorbedingung für die effektive Gestaltung von kognitivem und sozialem Lernen« (PF K 06 96: 6). Lernen - präziser: effektives, also an einem Ziel ausgerichtetes, irgendwie messbares Lernen - setzt demnach entspannte Körper voraus. Allerdings scheint ein Großteil der SchülerInnen (und Erwachsenen) schon entspannt genug, um zu lernen. Als AdressatInnen solcher Übungen, so habe ich bereits bemerkt, werden in allen Beiträgen, die sich mit derartigen Praktiken befassen, vorwiegend SchülerInnen der Grundschule, Hauptund Erziehungshilfeschule oder chronisch kranke Kinder bzw. solche, die Verhaltensauffälligkeiten diagnostiziert bekommen haben, begriffen. Es sind bestimmte SchülerInnen, denen ein Defizit zugeschrieben wird. Martin Freimann stellt fest, dass solche Verfahren heute »notwendige sonderpädagogische >Präventionsmaßnahmen«" seien, während sie früher im Rahmen von Religionsunterricht selbstverständliche Tradition gewesen seien (PF K 07 96: 39). Sie erfahren in dieser Sicht eine neue Normalität.

Für den Erfolg sei ein strukturiertes, gleich bleibendes Ritual nötig, was regelmäßig wiederholt werde. Bei der Auswahl wird wiederum auf Alter und Entwicklungsstand der Personen verwiesen. Hinsichtlich der Thematisierung von Körper ist interessant, sich eine solche Übung näher zu betrachten. Petermann stellt als ein Beispiel die Fortsetzungsgeschichte »Kapitän Nemo« vor. 
Fortsetzung heißt, die rahmenden Sequenzen bleiben als rituelle gleich, veränderlich ist die jeweilige Ausschmückung der Geschichte. Hier die Einstiegssequenz aus dem Text, den die Lehrkraft an die SchülerInnen richten soll:

"Stelle Dir vor, Du bist von Kapitän Nemo in sein Unterwasserboot Nautilus eingeladen. [...] Dazu hast Du einen speziellen Taucheranzug an. Er hat eine besondere Wirkung auf Dich. Du merkst schon beim Anziehen, daß Du vollkommen ruhig wirst. Zuerst steigst Du mit Deinem rechten Bein in den Taucheranzug. Du merkst und sagst zu Dir: Mein rechtes Bein ist ganz ruhig. Dann kommt das linke Bein dran. Auch das linke Bein wird ganz ruhig. Du sagst zu Dir: Mein linkes Bein ist ganz ruhig. [...] F Fortgesetzt wird dann mit einem Erlebnisbild: »Ihr schwimmt wieder an vielen bunten Fischen vorbei, und einige begleiten Euch [...] Die Tiere schwimmen ruhig, sicher und in Schwärmen um Euch herum. Du fühlst Dich ebenfalls vollkommen ruhig und sicher durch den Taucheranzug, sowie im Wasser auf besondere Art schwer und warm. Du sagst zu Dir: Mein rechter Arm ist auf besondere Art im Wasser schwer! Mein rechter Arm ist auf besondere Art im Wasser schwer! Du schaust zu Deinem linken Arm [...] « usw. (PF K 06 96: 7, Herv. i. O.)

In der Geschichte werden Elemente einer imaginierten Umgebung und mit Körperzuständen, die zu Leibesempfindungen führen können, verknüpft. Es werden jeweils spezifische Körperpraktiken wie liegen, spüren, hören mit metaphorischen Motiven, z. B. dem Wassermotiv gekoppelt. Die Vorstellung, im Meer zu schwimmen, kann Effekte für das leibliche Empfinden haben. Das bedeutet aber auch, dass die Beteiligten diese Erfahrung schon gemacht haben müssen. Oder inwiefern ist es möglich, sich vorzustellen, am Strand zu liegen, wenn man dies noch nie getan hat bzw. noch nie Sand angefasst hat oder noch nie geschwommen ist? Die Geschichte ist von regelmäßig wiederkehrenden Phrasen durchzogen: »Du sagst zu Dir: Mein rechter Arm ist auf besondere Art im Wasser schwer [...] «. In direkter Ansprache erfolgt die Anrufung hier doppelt (und damit wahrscheinlich besonders prägnant): einmal in der von der Lehrkraft kommenden Aufforderung »Du sagst zu Dir« und ein weiteres Mal im Vollzug, wenn ich es mir selbst sage. Ziel sind vor allem Wärme und Schwere - Zustände, die den Körper entspannen sollen. Vorausgesetzt wird bei einer solchen Übung, dass die Äußerungen performativ sind. Das Beispiel veranschaulicht, was mit Performativität im Butlerschen Sinne gemeint ist. Über die eindringliche Wiederholung innerhalb der Geschichte wie auch in der ritualisierten Anwendung können sich die Empfindungen einstellen. Das jeweilige Ziel der Entspannung ist auf den Körper (neuromuskoläre Aktivitäten, Herztätigkeit, Atmung) ausgerichtet (ebd.: 9), wobei in der Übung der Leib angesprochen werden soll. 


\section{Disziplin und Strafe}

Ausgangspunkt der Analyse waren Beobachtungen von Unterrichtssituationen und Schulalltag, in denen SchülerInnen aus dem Unterricht (Bildung als Ressource) und der Schulklasse (Gemeinschaft) ausgeschlossen bzw. Strafarbeiten auferlegt wurden. Im ersten Fall bestand der konkrete Auslöser in einer körperlichen Praktik, die nicht den Vorstellungen eines gelehrigen Körpers entspricht und auf die mit anderen ebenfalls unter anderem körperlich spürbaren Praktiken reagiert wurde. Auch die Strafarbeit ist ein körperlicher Akt, insofern es um das Schreiben eines Satzes mit der Hand geht, der immer und immer wieder geschrieben werden muss, woraus einprägende Effekte resultieren sollen. Zudem muss beim Schreiben die Körperhaltung eingenommen werden, die für den Unterricht üblich ist: das ruhige Sitzen. Sanktionen - so die Vorstellungen - sollen durch Entzug von Ressourcen oder Zuwendung sowie das Erteilen von Auflagen spürbar sein, sollen weh tun, indem Leid zugefügt wird. Korte formuliert das mit dem Verweis auf lerntheoretische Erkenntnisse als »Wesen« der Strafe, sie solle - bei ihm handlungsanleitend gedacht - »deutlich unangenehm und daher abschreckend wirken« (SM D 04 02: 10). Abschreckung funktioniert vor allem über Angst. Die Drohung mit dem Ausschluss ist als Anreiz gedacht, sich selbst zu disziplinieren, und wird zur »Generalprävention« (Cremer-Schäfer/Steinert 2000: 47).

Im Sprechen (und Nicht-Sprechen) über derartige Sanktionen wird sowohl in den Interviews mit den Lehrerinnen als auch in den pädagogischen Zeitschriften eine Tabuisierung des Themas offensichtlich. Die Lehrerinnen müssen sich äußern und die AutorInnen sprechen in ihren Artikeln vor allem über dieses Tabu. Ähnlich verhält es sich mit dem Begriff der Disziplinierung. Als repressiv verstandener wird er vor allem mit Zwängen und Sanktionen gleichgesetzt. Disziplin dagegen wird zu einem positiv besetzen Zustand, der die Basis jeglichen funktionierenden Unterrichts bildet und damit Grundlage für Produktivität. Die diskursive Leerstelle oder Blackbox, die entsteht, um zu diesem Zustand zu gelangen, wenn dies nicht über »repressive« Praktiken geschehen soll, nehmen vielfach Unterrichtsrituale ein, die zu einem großen Teil am Körper ansetzen, ihn mehr oder weniger direkt einbeziehen. Während Sanktionen gewissermaßen auf die Vergangenheit reagieren und die Zukunft mit Angst besetzen, dienen rituelle Praktiken gewissermaßen der Prävention. Damit rückt die Lehrkraft in den Vordergrund, an ihr ist es, die SchülerInnen zu eigener Selbstführung anzuleiten, zu der die ein oder andere Störung als Normalität gehört, auch wenn idealerweise und normativ der Unterricht jedoch möglichst frei davon sein sollte. Dies leitet über zum anschließenden Kapitel, in dem der Körper der Lehrenden bzw. der Lehrkörper im Vordergrund steht. 


\section{Lehrende und gelehrige Körper}

Was und wie erzählen ehemalige SchülerInnen, wenn sie sich an ihre früheren LehrerInnen erinnern? Folgende Bemerkungen habe ich den Zeitschriften entnehmen können, die den Körper von Lehrenden in der Schule ins Scheinwerferlicht stellen und einen Einstieg in das Kapitel ermöglichen:

„Frau Becker, ca. 55 Jahre, klein und faltig, betritt den Raum, keiner kümmert sich drum.« (PF D 05 96: 223)

"Das Problem des Herrn B. bestand darin, dass er sich absolut nicht durchsetzen konnte und zusätzlich noch zur Schusseligkeit neigte und immer riesige Schweißflecken unter den Armen hatte. « Wenn Herr B. merkte, dass sich die Klasse das Notenbuch »entliehen « hatte, »wurde er knallrot, Schweißperlen standen ihm auf der Stirn, und er zappelte unkontrolliert mit den Armen in der Luft herum. Wir hatten es mal wieder geschafft, [... ] Herrn B. aus der Fassung zu bringen. « (PF D 05 96: 220)

»Es war ein Lehrer, der kaum Respekt bei uns hatte. Er hatte keine Autorität, konnte sich nicht durchsetzen, war bei uns wegen seines Mundgeruchs verpönt. Die ersten Reihen blieben deswegen immer leer.« (PF D 05 96: 222)

Diese Äußerungen stammen nicht von SchülerInnen der 7. Klasse, sondern von Studierenden, die im Rückblick von Störfällen aus ihrer Schulzeit erzählen. Nachzulesen sind sie in einer Ausgabe des Päd Forum (3/1996), das den Titel »Störfälle - in und außerhalb von Schule« trägt. Sie sind die einzigen Texte dieser Art im gesamten Korpus. ${ }^{1}$ (Ehemalige) SchülerInnen kommen sonst kaum zu Wort. Hier werden den Studierenden vergleichsweise viele Seiten zugestanden. Als Störung begreifen sie sowohl ihre damaligen Praktiken als auch die der LehrerInnen. Sie stehen in einem Verhältnis. Diese Be-

1 Wie LehrerInnen mit ihrem Körper auf SchülerInnen wirken, demonstrieren in ähnlicher Weise Statements von Jugendlichen im >Schüler<-Jahresheft »Körper« (Becker et al. 2002: 114ff.). 
trachtung deutete sich bereits in den Ausführungen des vorhergehenden Kapitels an: Auch LehrerInnen können stören, bzw. das, was als Störung beschrieben wird, können oder sollen Lehrende insbesondere durch Einsatz ihres Körpers bewältigen, verhindern, kanalisieren.

Im Folgenden möchte ich den Fokus darauf setzen, wie und wofür der Körper von Lehrenden zum Einsatz kommt. In welcher Hinsicht wird er problematisiert, tritt er in Erscheinung, gilt ihm ein Interesse? Beginnen möchte ich wieder mit dem Blick in die Beobachtungsprotokolle. Daraus greife ich ein beobachtetes Phänomen heraus, das die Praktiken der Lehrerinnen verfremdet und zugleich auf den Punkt bringt: die Spiegelung des lehrenden Körpers durch die SchülerInnen. Nach der Analyse der Äußerungen, die die Lehrerinnen in den Interviews über ihren eigenen Körper in Schule und Unterricht machen, werde ich mir in den Zeitschriften ansehen, wie über professionelle Körperpraktiken und Bereiche, in denen der Körper von LehrerInnen zum Problem wird, gesprochen wird.

Eine Unterscheidung, die ich herausgearbeitet habe, möchte ich an dieser Stelle bereits vorwegnehmen, und zwar die zwischen Lehrkörper und Körper von LehrerInnen. Mit ihr werde ich weiter arbeiten, sie zieht sich durch das gesamte Kapitel. Ich differenziere beides aufgrund der verschiedenen Problematisierungsweisen, es sind verschiedene diskursive Formationen, mit denen der Körper beschrieben wird. Vom Lehrkörper spreche ich im Zusammenhang mit der Vermittlung durch Lehrende innerhalb einer pädagogischen Beziehung zu den SchülerInnen, wenn also Körperpraktiken aufgrund einer bestimmten Rolle interaktiv eingesetzt werden (sollen). Es geht hierbei um den in einer bestimmten Situation lehrenden Körper. Er wird als ein Medium bzw. Mittel innerhalb spezifischer Interaktionsgefüge konstruiert oder als Ziel, einen solchen Lehrkörper überhaupt erst herzustellen. Vom Körper der LehrerInnen spreche ich, wenn deren Körper als gesamter bzw. als Objekt problematisiert wird. So wird beispielsweise der kranke Körper zum Problem. Zum Objekt wird er, wenn LehrerInnen angehalten werden, ihn auf bestimmte Art und Weise zu bearbeiten.

\section{Spiel mit den Grenzen - spiegelnde Inszenierungen}

Die folgende Beobachtungssequenz gibt einen »Rollentausch« wieder. Beobachten konnten wir ihn während des sog. Klassenrats. Der Begriff stammt aus der Freinet-Pädagogik. Der Klassenrat ist kein Gremium, das die Interessen der Klasse »verwaltet«, sondern die gesamte Klasse nimmt an einer Besprechung teil, in der es um Fragen der Organisation, der Klassengemeinschaft, 
Einzelinteressen oder aktuelle Probleme geht. Zentrales Anliegen ist es, über diese Institution Demokratie zu lehren und zu lernen (vgl. Boer 2006).

In der dritten Stunde wird Klassenrat gehalten. Norman und Udo übernehmen den »Vorsitz«. Sie gehen nach vorn, nehmen auf den Stühlen der Lehrerinnen hinter deren Schreibtisch Platz. Udo reicht mit den Beinen gar nicht bis auf den Boden. Die beiden Lehrerinnen setzen sich auf die frei gewordenen Stühle. Xenia übernimmt es, Protokoll zu schreiben. Udo steht auf, nimmt sich ein Stück Kreide. Norman sitzt breitbeinig und selbstsicher mit einem zufriedenen Grinsen auf dem Drehstuhl einer Lehrerin und ruft diejenigen auf, die sich melden. Er nimmt ihre Wünsche für die Tagesordnung entgegen. Udo notiert die Stichworte, die genannt werden, auf der Tafel: Dienste, Pause, Ausflug, Sitzordnung und Verschiedenes. Während dessen lehnt sich Norman zurück und dreht den Stuhl leicht hin und her, guckt aufmerksam in die Runde. Udo setzt sich wieder, sein Blick schweift durch die Klasse. Es ist einen Augenblick still, wohl nicht ganz klar, wie es jetzt weitergehen soll. Maris fordert die beiden Jungen auf fortzufahren. Auch die Lehrerinnen signalisieren mit Blicken und Handzeichen, dass sie als Leitung an der Reihe sind. Udo guckt fragend, dann bittet er um Beiträge zu den einzelnen Punkten. Sie werden nach und nach durchgegangen. Die aufgrund ihres Vorsitzes Lehrenden »nehmen« die, die sich ordnungsgemäß melden, »dran«. Wer unaufgefordert in die Klasse spricht, wird ermahnt und aufgefordert, die Hand zu heben. Nur wer aufgefordert wird, darf reden. Auch die Lehrerinnen auf den Schülerplätzen melden sich, indem sie den Arm heben (und das ziemlich häufig). Udo steht immer wieder auf und hakt fein säuberlich und akkurat die Punkte ab, die erledigt sind. (AL)

Alles nur ein Platzwechsel? In der Beobachtung und ihrer Beschreibung deutet sich an, dass es mehr ist als das. Die beiden Lehrerinnen, die in der Siebten gemeinsam unterrichten, haben je nach Unterrichtsfach ihre Kompetenzen, und die jeweils andere hält sich mehr im Hintergrund. Ebenso haben sie jeweils eigene Körperstile, die eine bewegt sich meist schnell, ist hin und wieder recht laut, schreit auch mal durch die Klasse und passt sich gelegentlich der Sprache der SchülerInnen an; die andere wirkt ruhiger, bewegt sich langsam, greift mit aufmerksamen Blick auf, was die SchülerInnen sagen, spricht leise mit ihnen. In ihrer jeweiligen Expertise strahlen sie als Team zumeist eine sich gegenseitig ergänzende Gemeinsamkeit aus. In der oben beschriebenen Situation treten die beiden Lehrerinnen ohne spezialisierte Rollen auf. Sie versuchen, die Rolle der SchülerInnen einzunehmen, indem sie sich in die Klasse setzen und sich melden, wenn sie etwas sagen möchten. Verstärkt wird der Eindruck dadurch, dass sie auf den Stühlen von Udo und Norman mitten in der Klasse sitzen und nicht etwa hinten am Rand. Udo und Norman haben ihre Position eingenommen und müssen für den geordneten Verlauf sorgen. Die Lehrerinnen geben so die Verkörperung ihrer lehrenden und leitenden Po- 
sition auf, behalten aber zugleich den Überblick über die Klasse und geben die Leitung nur indirekt ab. Die Regeln für dieses »Spiel« scheinen ganz klar zu sein, sie müssen weder verhandelt noch erklärt werden, auch wenn der Fluss kurzzeitig ins Stocken gerät, weil die »jungen Lehrer« noch nicht so routiniert bei ihrer Arbeit sind. Norman und Udo genießen augenscheinlich ihr Amt, ebenso wie die doch wesentlich bequemeren Stühle, die dieses mit sich bringt. Faszinierend ist, wie sehr sie trotz oder gerade wegen der fehlenden Routine eine lehrerhafte Körperhaltung und den Gestus ihrer Lehrerinnen übernehmen. Sie ahmen Praktiken, Haltungen, Bewegungen, Gesten nach, die zum Handeln von LehrerInnen gehören, und verkörpern so die Lehrerrolle. Sei es der prüfende Blick, der durch die Klasse schweift, die Aufmerksamkeit der SchülerInnen bündelnde Praktik, einen Begriff an die Tafel zu schreiben und mit seiner Körperpräsenz darauf zu verweisen, »wo die Musik spielt«, oder die Ermahnung für diejenigen, die sich nicht an die Regeln halten - die moderierend lehrenden Schüler handeln mimetisch, wenn sie ihre Rolle ausfüllen. ${ }^{2}$ Sie orientieren sich an dem, was sie tagtäglich beobachten und erleben und spiegeln damit, was die Lehrerinnen tun. In ihrer Inszenierung überzeichnen sie deren Praktiken, so dass sie sie besonders hervorkehren. Diese besondere Betonung und die Zitathaftigkeit ihrer Körperpraktiken und Redeweisen stellt sie aber zugleich als Darstellende einer Aufführung bloß. ${ }^{3}$

Die Spiegelung ist eine mimetische Praktik aufgrund eines praktischen körpergebundenen Wissens. Sie ist keine bloße Imitation des beobachteten Handelns der Lehrerinnen. Die Aufführung hat eigene ästhetische Qualitäten und erzeugt etwas, was es so noch nicht gegeben hat. Sie ist nicht nur deshalb nicht identisch, weil es in der Klassenratperformance jeweils individuelle Aufführungen gibt oder die Rollen unterschiedlich gut beherrscht werden, sondern weil die Schüler immer noch Schüler sind und die Lehrerinnen währenddessen immer noch Lehrerinnen bleiben. Während man das Bemühen der Schüler erkennen kann, wie LehrerInnen zu agieren und zu »sein«, scheinen sich die Lehrerinnen zu bemühen, keine Leitungsrollen darzustellen. Für sie ist es leichter, in die Rolle der SchülerInnen zu schlüpfen, da sie diese selbst lang genug innehatten. Doch dürfen sie währenddessen ihre Aufgaben als Klassenleiterinnen nicht wirklich vergessen. Sie müssen in der SchülerInnen-

2 Wulf bezeichnet als mimetische soziale Handlungen jene, die sich im Nachvollziehen einer Bewegung auf andere Bewegungen beziehen, aber dennoch als eigenständige soziale Akte verstehbar sind (Wulf 2001b: 254).

3 Ähnlich beschreibt Hirschauer diesen Effekt bei einer möglichst »natürlichen « Inszenierung von Transsexuellen als das »jeweils andere « Geschlecht: »Eine um Perfektion bemühte Darstellung verweist wie eine Unschuldsbeteuerung auf sich selbst, anstatt von sich abzulenken, sie wird als eine Steuerung von Zuschreibungen und d. h. als Darstellung erkennbar.« (Hirschauer 1993: 43) 
rolle weiterhin professionell agieren und die Schulklasse im Blick behalten. Eine gewisse Erleichterung dabei könnte sein, dass es für sie nicht so relevant ist, überzeugend als Schülerinnen durchzugehen. Die Klassenratsvorsitzenden müssen dagegen alles tun, um als solche ernst genommen zu werden. So gesehen ist das Spiegeln für die beteiligten Akteure auch ein Agieren an Grenzen, die ausprobiert und austariert werden müssen. Zum Einsatz kommt dabei vor allem ihr Körper.

Die mimetische Übernahme des Lehrkörpers zeigt sich aber nicht nur in diesem institutionalisierten schulischen Ritual. Immer wieder beobachteten wir »informelle« Situationen, in denen SchülerInnen auf den Drehstühlen der Lehrenden Platz nahmen und sich mit ihnen zu einem »Lehrkörper« vereinten:

Der Lehrerstuhl nimmt eine zentrale Stellung in der Klasse ein. Er steht mittig vor der Tafel hinter einem Pult. Er ist von allen Seiten der Klasse aus gut zu sehen und hat somit eine zentrale Position im Klassenraum. Der Lehrerstuhl ist im Gegensatz zu den Schülerstühlen wesentlich bequemer. Er hat eine gepolsterte Sitzfläche und Rückenlehne. Gleichzeitig ist er ein Drehstuhl, so dass man entspannt seinen Körper hin und her drehen und dabei den gesamten Raum ins Blickfeld nehmen kann. Die SchülerInnen (vor allem die Schüler) nutzen jede Gelegenheit (Pausen, Feste, unachtsame Momente der Lehrerinnen, wenn sie sich durch die Klasse bewegen oder mit einzelnen SchülerInnen sprechen etc.), sich auf diesen Stuhl zu setzen, und verweilen dort so lange, bis sie aufgefordert werden, diesen zu verlassen. (AS/SR)

Die Drehstühle der LehrerInnen sind nicht nur deshalb interessant, weil sie um vieles bequemer sind als die Stühle der SchülerInnen und in ihnen ein entspannteres Sitzen möglich ist. Sich auf den Lehrerstuhl zu setzen, hat neben der bequemeren Sitzhaltung symbolische Bedeutung für die SchülerInnen. Mit ihm nehmen sie ein Statussymbol ein, das eine bestimmte »privilegierte« Position, Autorität und Macht symbolisiert. Im Moment des »Platz-nehmens« eignen sie sich einen Raum an, der ihnen eigentlich nicht zusteht und den sie sich nur »borgen « - in der Pause gewissermaßen unrechtmäßig und mit einem gewissen Risiko, des Platzes verwiesen zu werden, und im ersten Fall, um bestimmte Ämter wie den Vorsitz des Klassenrats zu bekleiden. Für einen kurzen Moment schlüpfen die SchülerInnen in eine andere Rolle, sie nehmen eine ganz neue Perspektive ein, lehnen sich entspannt zurück und beobachten das Geschehen, das sich vor ihnen auftut. Der Stuhl wird umkreist und erobert. Seine InhaberInnen werden umworben, womit an ihrem Status, also dem Status der Lehrperson, partizipiert wird. Es ist ein sich immer wiederholendes Spiel, welches bis zur Ermahnung ausgekostet wird, und so wird es zur Spiegelung und Grenzüberschreitung zugleich. 


\section{Über den eigenen Körper sprechen}

In den Interviews wurden die Lehrerinnen dazu befragt, inwiefern sie bewusst ihren eigenen Körper in die Schule einbringen, mit ihm agieren, ihn und sich mit ihm inszenieren und z. B. in der Schule eine bestimmte Arbeitskleidung tragen. Dass es nicht gerade einfach ist, über den eigenen Körper zu sprechen, zeigen sowohl die Fragen der Interviewerin als auch die Reaktion der Interviewten. Die Schwierigkeit besteht nicht nur darin, dass ein Schritt zur Reflexion unternommen werden muss und man sich im Reden über den eigenen Körper gewissermaßen von außen betrachtet, sondern dass es Widerstände gibt, die es unmöglich machen, z. B. leibliche Regungen in Worte zu fassen.

Interviewerin: Dann kommen wir jetzt mal so ein bisschen zu unserem Thema, und zwar: Welche Rolle der Körper spielt.

Lehrerin Matthes: Mmh.

Interviewerin: Also so im täglichen Umgang zum Beispiel? Du hast jetzt schon ein paar Sachen gesagt. Aber so der eigene Körper und der Schülerkörper zum Beispiel. Inwieweit ist das Thema, bewusst oder unbewusst?

Lehrerin Matthes: Eigener Körper? Mein eigener Körper?

Interviewerin: $\mathrm{Mmh}$.

Lehrerin Matthes: Mmh ... Puh... Schwierige Frage...

Interviewerin: Ja, es ist 'ne sehr schwierige Frage. Vielleicht, anzufangen wäre zum Beispiel so mit Körperkontakt. Wie sich das verändert hat, hast du jetzt schon so ein bisschen gesagt, aber inwieweit ist das wichtig, oder gibt es da Sachen, die du bewusst tust, oder?

Lehrerin Matthes: Ich denke, Körperkontakt...

Die Interviewerin führt zum Thema Körper, nachdem es im Interview zunächst um institutionelle Strukturen, die Klassengemeinschaft und die Beziehung zu den SchülerInnen ging. In Bezug auf Letzteres deutete sich bereits an, dass auch da eine körperliche Ebene relevant ist. Die Interviewte fragt nach: Worum soll es gehen - (etwa) den eigenen Körper? Einerseits muss sie fragen, weil auch die Körperlichkeit der SchülerInnen genannt war, andererseits auch, weil es doch ausgesprochen ungewöhnlich ist, nach dem eigenen Körper gefragt zu werden, befindet man sich nicht gerade beim Arzt - und dann steht in der Regel ein bestimmter Körperteil bzw. ein Problem im Fokus dessen, was es zu besprechen und zu untersuchen gilt. So gesehen könnte die Frage, wäre sie nicht mit dem Forschungsanliegen begründet, auch eine Grenzüberschreitung darstellen. Was geht andere mein Körper an? Die Frage ist also zum einen Nachfrage, zum anderen drückt sie Erstaunen aus. Eine Antwort ist nicht sofort parat. Es folgt ein Moment des Nachdenkens mit dem 
Kommentar: »Puh... Schwierige Frage... «. Das »Puh« unterstützt ihre Aussage, dass dies eine schwierige Frage sei, eine schwierige Frage in dem Sinne, dass es keine einfache Antwort gibt und sie sich bisher auch nicht selbstverständlich gestellt hat. Das Thema kann sich aus verschiedenen Gründen gegen eine Beschreibung sperren: aufgrund seiner Komplexität und Polyvalenz, weil es unaussprechlich ist, da »man « nicht darüber spricht und weil es sich um ein vorsprachliches körperliches Wissen handelt. Dessen Versprachlichung, so schreibt Hirschauer zu den Schwierigkeiten ethnograpischen Forschens und Schreibens, wäre »eminent unpraktisch [...]. Sie würde den Vollzug alltäglicher Aktivitäten behindern« (Hirschauer 2001: 443).

Die Interviewerin geht auf die Äußerung von Frau Matthes ein, indem sie bestätigt, dass die Frage sogar sehr schwierig sei. Sie ist sich dessen bewusst, traut der Lehrerin aber zu, darauf etwas antworten zu können. Sie hilft ihr auf die Sprünge, indem sie genauer fokussiert und ein Beispiel (Körperkontakte in der pädagogischen Beziehung) vorgibt, das sich auf das zuvor Gesagte bezieht, so dass die Interviewte anschließen kann. Daran knüpft Frau Matthes auch sofort an. Das Thema öffnet sich ein wenig, da hier auch wieder die Körper der SchülerInnen zur Debatte stehen, und über die scheint es (zumindest im Rahmen bestimmter Themen) einfacher zu reden zu sein. Sie bilden ähnlich wie Pubertät oder Gesundheitsfragen eine Art Vehikel, um Körper und Körperlichkeit - mehr oder weniger jenseits des eigenen - zur Sprache zu bringen.

\section{Kleider machen Leute}

Einigermaßen leicht fiel den interviewten Lehrerinnen, etwas zu ihrer »Arbeitskleidung« zu sagen. Wie sie diese auswählt, schildert Frau Matthes folgendermaßen:

Und ich glaube irgendwie, also ich wähle meine Kleidung für die Schule schon relativ bewusst aus, nämlich zweckmäßig, praktisch und ja, also ich bin noch nie, beispielsweise in 'nem Rock in die Schule gekommen. Weil ich das einfach fürchterlich unpraktisch finde. Also wenn ich, oder superschick. Klar, wenn man Verbeamtungsstunde hat, kommt man ein bisschen schicker, aber sonst, weil ich sau mich auch immer ein. Also ich bin auch so 'ne Wutz, wenn ich irgendwie mit Farben hantiere, dann bin ich eingesifft. Ja also, das ist so schon bewusste Auswahl, aber jetzt nicht irgendwie, dass ich mich dann style, das nicht. Aber das ist eine rein praktische Überlegung. Aber ich glaube so von Seiten der Schüler und Schülerinnen sind wir, also jetzt Frau Timm und ich, ich nehm uns jetzt mal beide zusammen, also a) sind wir vom Alter her ihnen noch relativ nah, im Vergleich zu anderen Kolleginnen und Kollegen, und ich glaube auch vom, vom Outfit her, irgendwo. Das verändert sich ja 
auch ständig, aber. Also mir fällt jetzt so 'ne Situation ein: Frau Timm hat, ach schon seit Jahrzehnten, irgendwie so Timberland-Schuhe, die sind jetzt superhip offensichtlich wieder. Und irgendwann ist das, ich glaub dem Norwin und dem Raik aufgefallen, und die haben gesagt: »Boah, wie cool«, ja. Aber das sind Schuhe, die sie irgendwie wohl schon seit, ich weiß nicht was, seit Anfang zwanzig trägt. Ja, aber das war plötzlich dann Thema. Mmh... und ansonsten mach' ich, also was so Körper angeht, ich beweg' mich auch gern und ich beweg' mich auch in der Klasse und agier' gerne.

Die Lehrerin spricht von einer »relativ bewussten« Wahl ihrer Kleidung. Das Wort »relativ« funktioniert als Absicherungsstrategie und schließt andere nicht ohne Weiteres zu reflektierende Gründe ein. Die Kleidung, die sie auswählt, sei »zweckmäßig« - also auf einen Zweck ausgerichtet - und »praktisch«. Was ist für eine Lehrerin praktisch? Wenn sie sich »bewegen « ${ }^{4}$ und »agieren« kann, beispielsweise im Fach Kunst mit Farben hantieren kann, ohne auf ihre Kleidung achten zu müssen. Dem gegenüber steht ein bestimmter Schick, wie zum Beispiel ein Rock, den die Lehrerin »fürchterlich unpraktisch« findet und deswegen auch noch nie getragen habe. Während sie das Tragen eines Rockes als eine Praktik empfindet, sich zu stylen, sei die pragmatische Auswahl der Kleidung als »rein praktische Überlegung « gerade kein Style. Bewusstes Wählen von Kleidungsstücken ist also nicht mit >sich stylen gleichzusetzen. Hier unterscheidet sie Pragmatik und Semantik. Zeichen müssten lediglich in außergewöhnlichen Situationen, wie der Verbeamtungsstunde, gesetzt werden, dort geben bestimmte AdressatInnen, die die Professionalität der Lehrerin prüfen, die Rahmung vor, auf die sie sich einzulassen hat. Bestimmten Außenstehenden vermittelt sie damit ein anderes Bild von sich als Lehrerin als den SchülerInnen im Alltag. Denen signalisiert sie zugleich die Besonderheit einer solchen Schulstunde. Womit allerdings deutlich wird, dass auch das pragmatische Kleiden als eine Art, den Körper zu besetzen, als Zeichen zu verstehen ist und dementsprechend wahrgenommen wird.

Zunächst erscheint es so, als seien im Schulalltag lediglich die »rein praktischen Überlegungen« - Zwecke und bestimmte Tätigkeiten - für die eigene Kleidungspraxis relevant, nicht dagegen die SchülerInnen als AdressatInnen einer Inszenierung. Das wird damit, sich eben gerade nicht zu stylen, ausgeschlossen. Der »Antistyle« ermöglicht, nicht besonders aufzufallen und eine Unverfänglichkeit, zum Beispiel durch die Vermeidung, mit dem in der Regel

4 Im Gegensatz zu den SchülerInnen ist es den Lehrenden im Unterricht möglich sich zu bewegen. Dies und, im beobachteten Fall, die wesentlich besser ausgestatteten Stühle machen eventuell wenig sensibel für die Leistung, die die SchülerInnen vollbringen, wenn sie sechs bis acht Schulstunden still sitzen bzw. andersherum, wenn sie eben nicht mehr still sitzen können. 
femininen Kleidungsstück Rock besonders »viel« Weiblichkeit zu demonstrieren. Im Wechsel der Perspektive hin zur Wahrnehmung durch die SchülerInnen wird deutlich, dass auch diese Art sich zu kleiden (ungewollt) zum Style wird. Zum einen, weil die SchülerInnen ihn kommentieren, zum anderen durch die damit einhergehende Distinktion. Ihren SchülerInnen seien sie vom Alter, aber auch »vom Outfit her « »noch relativ nah, im Vergleich zu anderen Kolleginnen und Kollegen«. Das Sportliche vermittelt Gleichgesinntheit und Ähnlichkeit. Die Nähe wird äußerlich erkennbar, was die jungen Lehrerinnen näher zu ihren SchülerInnen positioniert als zu ihren älteren KollegInnen. Damit kann die Art sich zu kleiden auch im Rahmen einer intensiven Beziehungsarbeit zu den SchülerInnen interpretiert werden, die die Lehrerinnen sowohl in den Interviews als auch in vielen Gesprächen während der Beobachtung immer wieder betonen. Sie suchen auf verschiedenen Ebenen verbaler und nonverbaler Kommunikation Nähe zu ihren SchülerInnen, um, auf dieser Beziehungsbasis aufbauend, Unterrichtsinhalte vermitteln zu können. Umgekehrt ist ihnen ihre Präsenz bei den SchülerInnen bewusst: Die Kommentierung durch die zwei Schüler, von der die Interviewte erzählt, transportiert zwar eine gewisse Zufälligkeit - die Schuhe trägt die Kollegin doch schon seit vielen Jahren -, als Beispiel, wie SchülerInnen ihre LehrerInnen genau in Augenschein nehmen, verweist es jedoch auf Alltagspraktiken, mit denen die LehrerInnen jederzeit rechnen müssen und die sie zur Kenntnis nehmen, wie auch der folgende Interviewausschnitt zeigt.

Interviewerin: Und zu deiner Kleidung, hast du da so Überlegungen, was du anziehst, oder spielt das gar keine Rolle?

Lehrerin Kilian: Na, was heißt, ich ziehe Sachen an, die mir gefallen und die ich bequem finde. Es kommen natürlich auch von den Schülern Kommentare, die sind sehr auf unsere Bekleidung fixiert und ...

Interviewerin: Mit irgendjemandem habe ich mich unterhalten. Wir haben früher immer gesagt, die hat heute das an, dann ist sie schlecht gelaunt, also so weit ging das.

Lehrerin Kilian: Also die Kleinen nicht, obwohl die machen auch schon manchmal Bemerkungen. Und bei den Großen ist es so, ich achte nicht drauf, ich habe eine Jeans-Star-Hose. Wirklich, wenn ich die anhabe, und ich denke da auch nicht immer dran, dann wird das wenigstens drei Mal an diesem Tag, ob das im Treppenhaus ist oder sonst irgendwo, weil das halt Hosen sind, die sie anziehen. Wenn wir Levis tragen, das ist für die, das ist wahrscheinlich was für alte Leute, ja. Das beeindruckt sie jetzt überhaupt nicht, aber das wird und auch die Größeren, meine 9. Klasse, die haben das also eigentlich fast täglich kommentiert.

Interviewerin: Wie denn?

Lehrerin Kilian: Ja, also meistens eher sowas Positives, dass das T-Shirt oder auch die Schuhe oder auch »Sie haben ja neue Schuhe « und »Die sind cool « oder sonst irgendwas in die Richtung, das machen sie aber auch untereinander. Ja, es ist einfach 
so. Ich kenne das auch noch aus meiner Schule, dass wir sehr genau registriert haben, was hat der Lehrer, die Lehrerin an. Dann gab es dann halt die Cordhosen- und Gelbe-Pulli-Fraktion, na ja und das oh Gott! Und das meistens gepaart mit ekligem Mundgeruch. Dann gab es natürlich die Englischlehrerin, die ein engelsgleiches Wesen war und auch immer soo schön angezogen war, es ist logisch, das wird zur Kenntnis genommen. Nur dass wir uns nicht getraut hätten, die Kleidung zu kommentieren, zu sagen, he, Sie haben heute eine tolle Hose an.

Auch für Lehrerin Kilian soll die Kleidung in der Schule in erster Linie bequem sein, sie trage das, was ihr gefalle. Kleiden für die Arbeit ist demnach ein selbstbestimmter Akt, der dazu dienen kann, sich wohlzufühlen. Sehr schnell leitet Frau Kilian nun zu ihren SchülerInnen über, die schließlich auch ihre Kleidung - und damit auch die Lehrerin als Person - kommentierten. Besonders die älteren SchülerInnen seien auf die Kleidung der Lehrenden fixiert. Sie wird als ein magisch anziehender Punkt, der täglich zur Debatte steht, zu einem wichtigen Element innerhalb des Verhältnisses von LehrerInnen und SchülerInnen. ${ }^{5}$ Aber nicht jedes Kleidungsstück ist der Rede würdig. Es sind vor allem jene Markenartikel, die auch - wie im obigen Beispiel - die SchülerInnen tragen (würden), die sie für »cool« befinden. Das Tragen einer solchen Hose oder solcher Schuhe macht auch die Lehrerin zu einer »coolen Lehrerin «. ${ }^{6}$ Von den Beweggründen, cool zu sein, grenzt sich die Interviewte jedoch ab, sie »achte nicht drauf«, die Marke interessiert sie nicht. Sie führt sie insofern dennoch ein, als sie feststellt, dass eine ehemals angesagte Marke wohl »überhaupt nicht beeindruckt«, nicht der Rede wert sei, sie sei »wahrscheinlich was für alte Leute«. Damit bringt sie die Kategorie Alter bzw. Generation ins Spiel, die auch für Lehrerin Matthes schon wichtig war. Je nach Kleidung rücken die LehrerInnen den SchülerInnen durch deren Praktiken altersmäßig näher oder geraten in Distanz zu ihnen. Gerade dadurch, dass die

5 Inwiefern es in dem, was die Lehrerinnen sagen, vor allem um Schüler und Lehrerinnen geht, also die Kategorie Geschlecht relevant wird, ist den Interviews nicht so recht zu entnehmen. Die Frage drängt sich auf, da es meist Jungen sind, die erwähnt werden, bzw. Frau Kilian in der Regel von Schülerinnen und Schülern spricht, wenn sie sie im Allgemeinen nennt. Dennoch ist dies nicht eindeutig und vielleicht auch eine sehr schnelle und viel zu nahe liegende Vermutung, die in dieser Art, Komplimente zu machen, ein geschlechtlich motiviertes Begehren sieht.

6 Hier ist anzunehmen, dass das allein nicht ausreicht, um »wirklich « als cool zu gelten, also lässig zu sein und Haltung zu bewahren angesichts von Bedrängnis (Lyman/Scott 1968: 93). Diese Coolness wird im Zusammenhang mit Artefakten als bestimmte Art von "Benehmen « inszeniert (Friebertshäuser/Langer/Richter 2004: 35; Friebertshäuser 2005: 132f., Tervooren 2006: 103f.). Die Karriere des mittlerweile inflationär für etwas »sehr Gutes«, "positiv Lässiges« stehenden Wortes "cool« und seine Verkörperungen als popkulturelles Phänomen zeichnet Ulf Poschardt (2002) in seinem gleichnamigen Buch nach. 
SchülerInnen auch untereinander kommentieren, was sie wie tragen, wird die Nähe verstärkt, die Lehrerin wird dadurch für einen Moment zu »einer von ihnen«. Das impliziert zugleich, wie auch im vorherigen Interviewausschnitt, eine Abgrenzung zu anderen KollegInnen, älteren oder vielleicht nicht so »gefragten« Lehrerfraktionen. Möglicherweise in Gang gesetzt durch die Äußerung der Interviewerin, dass auch sie sich früher über das Äußere von Lehrenden ausgetauscht hätten, erinnert sich Lehrerin Kilian an ihr ehemaliges Schülerinnen-Dasein und verweist im Reden darüber auf diese andere Kategorie LehrerIn. Aus dieser Perspektive wird das Handeln der SchülerInnen zudem verstehbar und »normal«. Schließlich sprechen alle SchülerInnen über das Äußere ihrer LehrerInnen. Nur bringt die Interviewte im Gegensatz zu den positiven Äußerungen ihrer SchülerInnen jetzt auch die negativen Beurteilungen an, die stark an die das Kapitel einführenden Zitate ehemaliger SchülerInnen erinnern.

Die Kommentare der SchülerInnen, von denen die Lehrerinnen erzählen und die wir teilweise in der Beobachtung registrierten, spiegeln indirekt eine Beziehung zwischen ihnen wieder. Zumindest signalisieren sie, wie sehr die SchülerInnen wahrnehmen, wie die Lehrenden sich kleiden, wie sie zum Unterricht erscheinen. Dass sie es kommentieren, wird von den Interviewten allerdings mehr oder weniger als Überschreitung einer Grenze begriffen, die sie früher nie überschritten hätten. Doch gewinnt man nicht den Eindruck, dass sie dies besonders schlimm findet. Letztlich werden vor allem positive Kommentare abgegeben, die Lehrerinnen gewürdigt, von den Jungen und Mädchen umworben und Anerkennung signalisiert.

\section{Autorität verkörpern}

Der Körper der Lehrerinnen kommt in weiteren Interviewpassagen zur Sprache. Auch dort geht es letztlich um das Verhältnis zu ihren SchülerInnen, um ihre machtvolle Position innerhalb dieses Verhältnisses und um Praktiken des Positionierens. Der Körper wird auf die Frage hin, welche Rolle Disziplin für ihren Unterricht spiele, thematisiert:

Interviewerin: Vielleicht eine Frage zum Thema Disziplin. Inwieweit ist dir das wichtig, im Unterricht zum Beispiel? Und, was gibt es so für Regeln?

Lehrerin Matthes: Disziplin ist ein ganz großes Thema, ich denke mir, 'ne ganz große Grundlage ist, dass da auch so ein Respekt einfach da ist. Also, das was du askly vermiñelst: Chefin. Wesn ish was sage, ist das einfach so. « Also ich finde, das ist so, das musst Gu als Person mitbringen. Und je mehr du das verkörpern kannst, desto weniger Probleme dist dut auch mit Disziplin. 
Grundlage für Disziplin sei Respekt, den Lehrende vermitteln müssten. Dieses Vermitteln kann nun auf verschiedenen Ebenen stattfinden, z. B. über Regeln innerhalb der Klasse oder darüber, dass Lehrende ihren SchülerInnen oder auch KollegInnen Respekt zollen, sie als Vorbilder wirken. Oder, wie hier hervorgehoben wird, dass sie Respektspersonen (ChefInnen) darstellen. Respekt und etwas, damit einem selbst Respekt gezollt wird, muss also, so Lehrerin Matthes, von der Lehrperson ausgehen, sie muss es verkörpern. D. h. allein qua Institution diese Position inne zu haben, ist nicht hinreichend, sondern die Rolle der »Chefin« muss nach außen hin sichtbar gemacht werden. Sie muss am Lehrkörper ablesbar sein, über den Körper zu räumlicher Präsenz kommen. Wie und auf welche Weise dies geschehen kann bzw. geschieht, bleibt allerdings offen.

Auch Lehrerin Timm spricht von etwas, was man als Lehrperson mitbringen muss, um Disziplin zu erreichen bzw. in diesem Beruf zu bestehen. Der Körper, den sie dabei explizit anspricht, entscheide aber gerade nicht darüber, ob dies gelingt.

Lehrerin Timm: Ihnen ist ja aufgefallen im Unterricht, ich werde dann mal lauter oder sag mal, jetzt reicht's und oft reicht auch schon ein Blick, ja? Aber das ist natürlich also Disziplin, Disziplin dafür bring ich immer die Trillerpfeife mit. Aber ich sag mal so 'n Auftreten und das Ausstrahlen einer, sehr abgenudeltes Wort, natürlichen Autorität, ist meines Erachtens nicht erlernbar und auch nicht an der Uni vermittelbar, sondern das ist 'ne Sache, die Disposition für diesen Beruf und das Auftreten, die hat man und an der kann man arbeiten und die kann man auch in gewisser Weise verfeinern und akzentuieren, aber ich glaube, es gibt eine gewisse Grunddisposition, die bringt man mit, oder man hat sie nicht und wenn man sie nicht hat, kriegt man Probleme. Und das hat dann auch nichts mit Alter zu tun und auch nichts mit Geschlecht und nicht mit Aussehen und mit Körpergröße und mit Stimmvolumen, sondern

Interviewerin: Sondern?

Lehrerin Timm: Ja, an nicht messbaren Parametern, es hängt an nicht messbaren Parametern. Also ich kann es für mich auch schlecht erklären, das hängt natürlich auch damit zusammen, man muss 'ne Leidenschaft für diesen Beruf mitbringen, man muss 'ne Offenheit mitbringen, man muss die Bereitschaft mitbringen zu scheitern und Niederlagen zu erleben und die zu reflektieren und man muss, ja die Bereitschaft mitbringen, sich auch auf Dinge, die man nicht kennt, einzulassen.

Auch hier werden ein spezifisches Auftreten und eine Ausstrahlung, die ohne den Körper unmöglich sind, als Kriterien vorangestellt. Darauf verweisen auch die Praktiken, welche die Interviewte als ihre nennt: mal lauter werden oder auf bestimmte nicht näher beschriebene Weise blicken. Mit dem Auftreten oder der Ausstrahlung verbindet sie aber mehr als derartige Körperprakti- 
ken: eine »natürliche Autorität«. Sie stelle eine Grunddisposition dar, mit der LehrerInnen ausgestattet sein müssten, um in ihrem Beruf bestehen zu können. Als natürliche Disposition könne sie nur gegeben sein - »die bringt man mit oder hat sie nicht « - sie könne deshalb auch nicht vermittel- und erlernbar sein. Zwar könne man sie »verfeinern« und »akzentuieren«, sie sich zulegen oder aneignen scheint jedoch in dieser Vorstellung unmöglich. Es bedarf demnach einer »geborenen Lehrerin«, nur sie kann in dieser Profession bestehen. Diese erfülle nicht einfach erklär- oder messbare Parameter, wie »Leidenschaft für den Beruf«, »Offenheit« für Fremdes, das Vermögen zu scheitern und dies zu reflektieren. Die Parameter stellen eine bestimmte Haltung dar, die Frau Timm explizit von sicht-, hör- und messbaren körperlichen Gegebenheiten, wie Alter, Geschlecht, Aussehen, Körpergröße und Stimmvolumen abgrenzt. Es ist nicht einfach ein körperliches Können, das gefragt sei. Diese Abgrenzung betont sie später noch einmal:

Also ich glaub', ich hab' relativ wenig Disziplinprobleme, ich könnt' jetzt nicht sagen, das ist, weil ich in der und der Stimmfrequenz rede oder weil ich so gucken kann, wie ich gucke oder - sehr schwierig.

Schlussfolgern lässt sich aus dem erneuten Aufgreifen der Unterscheidung und daraus, dass sie nur wenig Disziplinproblem habe, dass Frau Timm die Haltung, die sie für die Profession als notwendig erachtet, mitbringt. Sie stellt außerdem fest:

Also ich meine, manchmal bin ich auch disziplinlos, und das überträgt sich auf die Klasse, ist klar, ja.

Interessant wäre zu erfahren, wie dies zu erklären sei. Ist es die Haltung, die in diesem Moment abhanden kommt? Wie zeichnet sich Disziplinlosigkeit (nicht Undiszipliniertheit) bei einer Lehrerin aus? Es irritiert die starke Abgrenzung einer gewissermaßen natürlich gegebenen Disposition, die sich als Haltung gegen »messbare« bzw. zumindest teilweise veränderbare und somit erlernbare Parameter für gelungene Unterrichtsinteraktionen artikuliert. Nicht weil sie derart vorgenommen wird, sondern dass sie überhaupt vorgenommen wird. Warum ist es wichtig, sich davon abzugrenzen? Wovon genau grenzt sich die Lehrerin überhaupt ab?

Diese Fragen leiten zwar nicht zu Antworten über, die unmittelbar darauf zu geben bzw. zu beziehen wären. Sie verweisen aber auf jene diskursiven Praktiken, die im Folgenden Gegenstand der Analyse werden: die Problematisierung des Lehrkörpers innerhalb der ausgewählten Zeitschriftenartikel. 


\section{Körperpraktiken von LehrerInnen}

Bevor ich zur genauen Analyse der Texte übergehe, in denen auf verschiedene Art und Weise der Lehrkörper bzw. der Körper von LehrerInnen zum Gegenstand wird, gebe ich wieder einen Überblick über die Auswahl der Artikel. Insgesamt handelt es sich um 38 Texte, die aus den Themenbereichen Rituale/ Disziplin/Unterrichtsstörungen (15), Leitbild und Gesundheit von LehrerInnen (12), Präsentation (3) sowie Körper (6) ${ }^{7}$ und Körpersprache (2) stammen. Die zunächst heterogen erscheinenden Themenbereiche lassen erahnen, dass nicht nur der Körper unterschiedlich thematisiert wird, sondern dass es sich zudem um verschiedene Textgenres handelt. Über Erfahrungsberichte zu Ritualen im Unterricht schrieb ich bereits im vorigen Kapitel. Das zweite Textgenre lässt sich noch expliziter als Ratgeberliteratur definieren. Noch expliziter heißt, dass Elemente von Handlungsanleitungen meist auch in den Erfahrungsberichten zu finden sind (ebenso wie umgekehrt die Ratgeber oft auf Erfahrung aufbauen oder zumindest suggerieren, dass sie es tun). Ihnen gemeinsam ist, dass sie eine »good or best practice« formulieren, die Maßstäbe für guten Unterricht bzw. professionelles Lehrerhandeln setzen.

Beginnen möchte ich mit einer ausführlich protokollierten Unterrichtsstunde, die im Zeitschriftenkorpus in dieser Detailgenauigkeit eine Ausnahme darstellt. Ein Schulaufsichtsbeamter schreibt seine Beobachtungen einer von ihm als durchschnittlich benannten Schulstunde in einem Gymnasium nieder und veranschaulicht damit - zwangsläufig und nicht unbedingt vordergründig angestrebt - die körperlichen Aktivitäten des Lehrenden:

»Der Lehrer steht bereits im Klassenzimmer, blättert in seinen Vorbereitungen, macht Eintragungen ins Kursheft. [...] Der Lehrer blättert immer noch, die Schüler strömen. Sie sitzen im offenen Viereck, Hufeisenform, der Lehrer steht hinter seinem kleinen Tisch in der Öffnung. Jeder kann ihn sehen. [...] Es gongt. Sofort richtet sich der Lehrer auf, der im Kursheft geblättert hatte, und wendet sich der Gruppe zu: ,Wer trägt noch einmal vor [...]? Zögerlich meldet sich einer, dann noch einer. >Ja, bitte! « Er deutet auf einen der beiden. [...] Wendet sich nun, ein paar Schritte zurücktretend, an die ganze Gruppe. [...] Die Schüler senken die Köpfe über das Papier, der Lehrer geht zurück an den Tisch und setzt sich. [...] Es wird wieder still, gelegentlich hört man Flüstern, Papier knistert, der Lehrer geht durch den Raum und blickt den Schülern über die Schulter in die Aufzeichnungen. [...] 16 Minuten nach Beginn die-

7 Diese sechs Texte stammen aus zwei (der drei) Ausgaben explizit zum Thema Körper. In drei von sechs Artikeln des Päd Forum 3/2004 wird der Körper von LehrerInnen ganz kurz in Bezug auf Krankheiten erwähnt. In der Zeitschrift Pädagogik (6/1996) wird der Lehrkörper unter der Themenstellung »Mit dem Körper lernen« etwas ausführlicher thematisiert. 
ser Stillarbeitsphase [...] klopft der Lehrer auf seine Tischplatte und erhebt sich: `Ich glaube, ihr seid fertig ‘. [...] Der Lehrer bedenkt die kurzen Berichte am Ende jeweils mit winkenden, fast segnenden Handbewegungen. [...] Die Schüler hören gehorsam $\mathrm{zu}$, und schließlich meldet sich einer und fragt [...] Der Lehrer, sichtlich erfreut über die Frage [...] Die Schüler sitzen mit leeren Gesichtern da [...] Der Lehrer [...] schreibt an die Tafel [...] Dann dreht er sich um, schaut die Schüler an: `Und [...]? Ein Schüler murmelt etwas in die Klasse. Stille. `Bitte? Das Murmeln wiederholt sich. Der Lehrer tritt ein paar Schritte vor, bis er unmittelbar vor dem Schüler steht, und hält lauschend die rechte Handfläche hinter sein rechtes Ohr. [...] Die Schüler sitzen stumm, ihre Gesichter haben den Rest von höflichem Interesse verloren. [...] Der Lehrer schaut auf die Uhr [...] ich sehe ein leichtes Erschrecken auf seinem Gesicht. [...] Irgendwann schraubt er seine Stimme höher, unterstreicht quasi eine Aussage, die wohl eine Bilanz ist oder sein soll [...] Es kommen zögernd einsilbige Schüleraussagen [...] ich verstehe akustisch sehr wenig. Der Lehrer versteht es, da er von Schüler zu Schüler hüpft und quasi bei jedem sein Ohr anlegt. [...] Dann geht ihm endgültig die Puste aus. Nach einem heimlichen Seufzer hebt er den Kopf und schaut auf die Gruppe: ‘Gibt es noch Fragen? [ [...] die meisten sind schon aufgestanden. `Ach ja, die Hausaufgabe [...] Er spricht das ziemlich laut, um das einsetzende Gespräch der Schüler zu übertönen, die schon fast alle auf dem Weg zur Tür sind. Er schaut erleichtert zu mir, dann zur Tafel, geht hin und wischt die Ergebnisse der Stunde mit einem trockenen Lappen weg.« (PF LK 01 97: 10f.)

Ich habe die Beschreibung der Unterrichtsstunde auf die Stellen reduziert, in denen von Körperpraktiken, von bestimmter Gestik, Mimik, Tonfall oder Lautstärke der Stimme die Rede ist. Dadurch wird der Text verfremdet. Der Unterrichtsinhalt - es handelt sich um eine Geschichtsstunde - lässt sich meines Erachtens (mehr oder weniger) beliebig austauschen bzw. wie in diesem Fall weglassen. Der Eindruck des Geschehens, wie in etwa die Schulstunde abgelaufen ist, bleibt erhalten. ${ }^{8}$ Der Text zeigt, dass der Autor des Originals, der sich selbst als distanzierten Beobachter begreift (ebd.: 16), wesentlich auf die Beschreibung von Körperpraktiken zurückgreift, um den Verlauf der Stunde zu schildern. Es ist ein Schulaufsichtsbeamter, der hier eine Schulstunde mit einem spezifischen Blick und Interesse beobachtet sowie beschreibt und dies - wie alle Beobachtenden - selektiv tut. Ihm geht es nicht zuerst darum, wie genau dieser Lehrer seinen Körper einbringt, sondern er möchte, wie er sagt, eine durchschnittliche und »normale« Unterrichtsstunde auf ihre methodischen Mängel hin analysieren. Um dies zu tun, beschreibt er, besser gesagt: konstruiert er einen solchen Fall. Gerade weil dabei der Lehrer zwar be-

8 Das ist auch deshalb möglich, weil sich beim Lesen Erinnerungen an eigene Schulerfahrungen einstellen und diese Art Unterricht nicht fremd ist. Anders darstellen würde sich das wahrscheinlich bei LeserInnen, die noch nie eine Schule betreten und solchen Unterricht erlebt haben. 
sonders im »Scheinwerferlicht« steht, nicht aber in erster Linie sein Körpergehabe, ist dieser Text für meine Arbeit interessant. In die Konstruktion des Falls, der normalen durchschnittlichen Unterricht darstellen soll, gehen zu einem großen Teil Körperpraktiken des Lehrers ein. Die Beschreibung, wie der Lehrer sich vor der Klasse bewegt, auf die SchülerInnen zugeht, sich von ihnen entfernt, ihre Arbeit kontrolliert, sie zum Sprechen auffordert, körperlich einen Bezug herstellt zwischen dem, was sie sagen und was er an die Tafel schreibt, mit einer Geste signalisiert, dass er akustisch nicht recht verstehe und mit der impliziten Aufforderung, lauter zu sprechen, näher an sie heran tritt usw., verdeutlicht, wie sehr Unterricht durch eben jene Körperpraktiken von LehrerInnen (und SchülerInnen) bestimmt und in seinem Verlauf gestaltet wird. Die hier herausgefilterten Sequenzen nehmen mehr als ein Fünftel der Gesamtbeschreibung der Unterrichtsstunde ein. Sie bilden die Rahmung sowie Strukturierung des Geschehens und durchziehen damit die Unterrichtsinhalte. ${ }^{9}$ Wie Artefakte (Mobiliar, Unterrichtsmaterialien, Kleidung) sind die Körper von SchülerInnen und LehrerInnen Bestandteil von Praktiken. Sie sind »Partizipanden« (Hirschauer 2004: 74) und permanent in das Geschehen involviert - ein Geschehen, das sich durch eine Materialität auszeichnet.

Mit der verfremdeten Zitation verweise ich auf eine Relevanz von Körperpraktiken, die sich in ihrer Situiertheit beobachten lassen. Mich interessiert aber auch die Problematisierung von Körper(lichkeit), die mit diesem Schreiben in den Zeitschriften einhergeht. In den ausgewählten Auszügen wird zunächst beschrieben, wie Körperpraktiken Teil des Unterrichts sind, indem dies wohl zu einer Fallkonstruktion von Normalunterricht dazugehört. Doch welchen Stellenwert erhalten sie in der darauf folgenden Analyse der Unterrichtseinheit? Dieter Zeitz macht »Sieben Sünden«, also sieben häufig zu beobachtende unprofessionelle Verhaltensweisen von Lehrenden aus. ${ }^{10}$ Den Körpern als Partizipanden kommt dabei ebenfalls eine Sünde zu, betitelt mit »Die Frage der Stimmstärke« (PF LK 04 97: 178) - allerdings nicht die der Lehrenden, sondern die der SchülerInnen. Zeitz zitiert die Auszüge seines Textes, in denen die SchülerInnen leise Antworten geben, so dass sie kaum oder gar nicht zu verstehen sind, und erörtert dies als Problem. Ein Problem, das der Lehrer wiederum durch seine Körpersprache verstärke bzw. provoziere (ebd.: 179),

9 Da es sich in diesem Fall um ein Gymnasium und Frontalunterricht handelt, bringt das zwar möglicherweise spezifische Körperpraktiken mit sich, die bei anderen didaktischen Praktiken oder Schülergruppen noch einmal anders aussehen könnten, doch scheint mir eine grundlegende körperliche Rahmung unabhängig davon in jedem Fall gegeben zu sein.

10 In die Analyse der »Sieben Sünden« beziehe ich den Gesamttext als Serie ein, der in den drei aufeinander folgenden Ausgaben der Zeitschrift erschien (Päd Forum 1-3/1997). 
womit auch diese über den Umweg des Schülerkörpers als Problem generiert wird. Indem er auf die einzelnen zugeht und ihre leise Antwort mit einem Hörrohr - nämlich seiner Hand am $\mathrm{Ohr}$ - entgegen nimmt, verhindere er, dass die restliche Schulklasse irgendetwas davon erfahren kann. Die Kommunikation findet hier nur zwischen einem einzelnen Schüler und dem Lehrer statt, es sei denn, die MitschülerInnen bekommen ein Echo vom adressierten Lehrer. Damit komme ich zur ersten Weise der Problematisierung eines Lehrkörpers.

\section{Der Lehrkörper als Medium pädagogischer Praxis}

\section{Unterrichtseinstiege}

„Wie beginnen Sie eine Stunde? Betreten Sie den Raum pünktlich mit dem Klingelzeichen, ssammeln Sie vorher noch rasch einige Schülerinnen und Schüler ein (freundlich oder vorwurfsvoll?), [...] Lassen Sie energisch die Tür zuschlagen, damit akustisch wahrzunehmen ist: Die Pause ist zu Ende, jetzt hab ich hier wieder das Sagen? Werfen oder legen Sie Ihre Tasche auf den Tisch oder stellen Sie sie daneben? Holen Sie hektisch oder in aller Ruhe das Material für die Stunde heraus? Nehmen Sie währenddessen Kontakt zu einzelnen Kindern auf? « (SM D 08 02: 8)

Birte Friedrichs, selbst Lehrerin, verweist mit ihren Fragen an die lehrende LeserInnenschaft darauf, dass es sehr unterschiedliche Weisen gibt, einen Klassenraum zu betreten, dort anzukommen, Kontakt zu den SchülerInnen aufzunehmen und den Unterricht zu beginnen. Immer hinterlässt der Körper dabei bestimmte Eindrücke und ruft Reaktionen hervor. Mit seinem Erscheinen im Klassenraum strukturiere er bereits mittels seiner symbolischen Aussagekraft das Unterrichtsgeschehen. Die Autorin spricht von »Signalwirkung« für die Unterrichtsatmosphäre und von einem »habitualisierten Ritual« (ebd.). Als Alltagsroutine seien der Beginn der Stunde und seine Symbolik jedoch meist kaum bewusst. Die jeweiligen (Körper-)Praktiken mögen zwar individuell unterschiedlich sein, aber innerhalb der Schulstrukturen und einzelner Konzepte sind sie nicht beliebig. Deshalb ist es möglich, diese Fragen so detailgenau zu stellen und vor allem sich als LehrerIn unmittelbar angesprochen zu fühlen. Die Autorin bewertet die Praktiken nicht, dennoch kommt man als LeserIn, indem man als ebenfalls LehrerIn angesprochen wird, sofort ins Grübeln. Wie mache ich das eigentlich? Was hat das für Effekte? Ist das gut oder schlecht? Müsste ich etwas ändern?

Friedrichs geht davon aus, dass die Einstiegspraktiken vielfach unreflektierte sind. Bezieht man als LeserIn die Fragen, mit denen sie ihren Artikel beginnt, auf sich selbst, könnte sich die fehlende Reflexion eventuell bestäti- 
gen. Vielleicht ist es gar nicht so einfach, und es bedarf einiger Überlegung, um darauf zu antworten, denn man hat noch nie darüber nachgedacht. Friedrichs proklamiert den reflexiven und gezielten Einsatz nicht nur bestimmter Praktiken für den Unterrichtseinstieg, sondern von Ritualen, die den Unterricht strukturieren und rahmen. Die unbewusste und somit unreflektierte Art und Weise, als LehrerIn den eigenen Körper einzusetzen, könnte problematisch werden, denn das Ritual als »habitualisiertes « verberge sich damit »im Rücken der Handelnden « (ebd.) - also außer Sichtweite. Nimmt man die ritualisierten Praktiken nun in den Blick, legt sie offen und setzt sie vor allem gezielt und kontrolliert ein, werden sie, anstatt potenziell ein Problem darzustellen, zu einem Mittel gelungener Unterrichtspraxis. Abstrahiert ergibt sich aus dieser Argumentation folgende Gegenüberstellung, die einen Prozess des Hinsehens und der Reflexion impliziert, eine Bewegung vom `Unreflektiertierten hin zum $>$ Reflektierten :

$\begin{array}{lll}\text { unbewusst } & - & \text { bewusst } \\ \text { stören } & - & \text { gestalten } \\ \text { hinten } & - & \text { vorn } \\ \text { blind } & - & \text { sehend } \\ \text { misslungen } & - & \text { gelungen } \\ \text { ziellos } & - & \text { zielgerichtet } \\ \text { unreflektiert } & - & \text { reflektiert }\end{array}$

Diese diskursive Figur möchte ich anhand weiterer Beispiele explizieren, denn sie wird dort durch eine weitere Gegenüberstellung ergänzt. Ich komme dabei auf Texte zurück, die sich mit Klassenführung, Ritualen und der Prävention von Unterrichtsstörungen sowie der etwas allgemeineren Frage nach gutem und professionellem Unterricht befassen. Die Texte sind in den Zeitschriften `Pädagogik« und `Schulmagazin 5 bis 10< erschienen, zum Teil im Rahmen unterschiedlicher Themenschwerpunkte ${ }^{11}$, nie jedoch in ein und derselben Ausgabe einer Zeitschrift. Bei den AutorInnen handelt es ich um praxisnahe ExpertInnen, d. h. selbst um LehrerInnen, in der Aus- und Fortbildung Tätige wie auch um Professoren. Letztere stellen die Nähe im Text explizit her, indem sie betonen, dass sie einen Transfer zwischen Empirie bzw. theoretischer Modellbildung und Praxis schaffen möchten, der für die Praxis hilfreich sei. Diese Legitimation, über Unterrichtspraxis sprechen zu dürfen,

11 Es sind folgende: »Orientierung bieten « (PÄD D 01 02), »Frontalunterricht« (SM D 03 00), »Langeweile« (PÄD LK 01 97), »Erziehender Unterricht« (PÄD LK 03 04), »Beruf: Lehrer, Beruf: Lehrerin. Oder: Was wissen wir über den Lehrberuf? « (PÄD LK 11 97). 
scheint bei den anderen AutorInnen durch ihre jeweiligen Positionen, die mit Praxiserfahrungen einhergehen, nicht nötig zu sein.

\section{Effektivierungen}

Ausgangspunkt der jeweiligen Ausführungen ist eine mehr oder weniger übliche Unterrichtspraxis. Sie ist insbesondere gekennzeichnet durch Störungen ${ }^{12}$, die eben nicht nur durch SchülerInnen, sondern auch durch LehrerInnen ausgelöst bzw. gefördert werden. ${ }^{13}$ Letztere stehen hier im Fokus, die einzelnen Texte gehen aber meist darüber hinaus. Ziel ist in der Regel eine effektive(re) Klassenführung, die Vermeidung und Verringerung von Störungen und eine damit einhergehende Aktivierung sowie Selbstbeteiligung und -beobachtung der SchülerInnen. Als Probleme werden dabei angesehen, wenn Regeln nicht transparent sind (PÄD D 01 02), es undefinierte Zeiten gibt, die Uneindeutigkeiten produzieren, oder Störungen vor der gesamten Klasse bekämpft werden (SM D 05 03: 54). Im Frontalunterricht werde zu viel geredet und damit die SchülerInnen ermüdet, Gespräche untereinander könnten nur als Störung stattfinden (SM D 03 00: 10). Mittels Ermahnungen, Anschreien, Drohungen, strengen Blicken oder Bestrafungen werde in der Regel uneffektiv diszipliniert, aber fast die Hälfte der Unterrichtszeit verbracht (SMD 10 97: 47).

Um diese Missstände anzugehen und Unterricht bzw. Klassenführung effektiver zu gestalten, schlagen die AutorInnen verschiedene Maßnahmen vor. Sie betonen dabei die Bedeutung nonverbaler Zeichen und setzen jeweils unterschiedlich stark daran an, diese häufig intuitiv schon richtig genutzten Verweise gezielt einzusetzen. Das bei Friedrichs rekonstruierte Differenzschema wird so fortgeführt und um die Gegenüberstellung von uneffektiv vs. effektiv erweitert. Zum Teil gehen die Maßnahmen über die Erwähnung der besonderen Bedeutung nonverbaler Kommunikation nicht weit hinaus, beispielsweise in den »Zehn Merkmalen guten Unterrichts«, die Hilbert Meyer, Professor für Schulpädagogik, nennt (PÄD LK 02 03). Als Indikatoren eines strukturierten Lehr-Lernprozesses gelten für ihn unter anderem eine klare Körpersprache und Raumregie der Lehrkraft. Damit scheint der Lehrkörper ausreichend thematisiert zu sein. Wenn Britta Kohler, Erziehungswissenschaftlerin und ehemalige Lehrerin, für eine Verbesserung des Gesprächsverhaltens plädiert, unterscheidet sie zwischen verschiedenen Schulfächern: »Lehrkräfte, die Fremdsprachen unterrichten, sollten sich kaum um eine nonverbale Gesprächssteue-

12 Ich erinnere an die Funktion der Normalisierung (Kap. 'Disziplin und Disziplinierung(), die Forderung, Unterrichtsstörungen als zur Unterrichtsinteraktion dazugehörig zu betrachten, aber dennoch präventiv entgegenzuwirken.

13 Wobei die Störung nur dann zur Störung wird, wenn SchülerInnen darauf reagieren und diese Reaktion von der Lehrkraft als Störung angesehen wird. 
rung bemühen, und Lehrerinnen und Lehrer, die beispielsweise im Fach Geschichte ihre Schülerinnen und Schüler zu begeistern vermögen, sollten ihre Fähigkeit nutzen.« (SM D 03 00: 10) Damit stellt sie einen Bezug zwischen dem gesprochenen Inhalt und der körpersprachlichen bzw. stimmlichen Vermittlung her, der allerdings nicht in allen Schulfächern genauso relevant sei: EnglischlehrerInnen können sich zurücklehnen, das Pauken von Vokabeln gelingt auch ohne körperliche Unterstützung. Sprachunterricht bzw. Sprache scheint schon von sich aus lebendig zu sein, die (eben bereits vergangene) Geschichte muss erst zum Leben erweckt werden.

Was genau nonverbale Fähigkeiten sind und wie diese eingesetzt bzw. überhaupt herausgebildet, erlernt oder ausgebaut werden könnten, bleibt allerdings in den Texten, die recht knapp auf ihre Bedeutung hinweisen, offen. Die Thematisierung des Körpers als Lehrkörper, d. h. als einer, der in einer bestimmten Situation mit bestimmten TeilnehmerInnen, in auf bestimmte Art und Weise geordneten Räumen agiert und die Ordnung mit produziert, wird lediglich angedeutet. Körperpraxen bzw. »Körpersprache« werden erwähnt, als gehöre sich das der Vollständigkeit halber.

Um nun näher bestimmen zu können, inwiefern der Lehrkörper als ein Medium einer guten Unterrichtspraxis konstituiert wird, unterziehe ich die Texte, welche die unterstützenden Komponenten einer effektiven, störungsfreien Klassenführung und somit einer Professionalisierung der Lehrkräfte detailliert ausführen, einer genaueren Analyse. $\mathrm{Zu}$ unterscheiden sind dabei Praktiken mit zwei verschiedenen Ausrichtungen: (1) zum einen didaktische Praktiken, die sich auf die SchülerInnen und ein bestimmtes Lernziel beziehen; (2) zum anderen Praktiken, die auf die LehrerInnen selbst gerichtet sind.

\section{(1) Zur Performativität didaktischer Praktiken}

In der Vorstellung didaktischer Praktiken, d. h. im Sprechen über sie, »verschwindet« der Lehrkörper recht schnell wieder. Dies wird bei den beiden Beispielen deutlich, die ich im Kapitel >Disziplin und Disziplinierung < bereits angeführt habe. Beispiel 1 ist das Zeichnen eines Kreises an die Tafel, worauf die SchülerInnen einen Stuhlkreis bilden. Wird es gelöscht, lösen sie den Stuhlkreis wieder auf. Susanne Petersen schreibt dazu: »Jedes einzelne Kind kann dieses einfache Zeichen in Handlung übersetzen.« (PÄD D 0102 : 32) Ich würde präzisieren, das Zeichnen des Kreises wird in Handlung umgesetzt. Es ist die Praktik, zur Tafel zu gehen und den Kreis zu zeichnen bzw. ihn zu löschen, die performativ die Aufforderung enthält, darauf in bestimmter Weise zu reagieren. Das Zeichen selbst ist nicht performativ, sondern die Praktik enthält die Symbolik, die durch das Zeichen des Kreises verstärkt wird. Der Kreis präzisiert, wie sich die SchülerInnen im Raum anordnen sollen. 
Beispiel 2 ist das Ruhezeichen, das ich ebenfalls schon erwähnt habe. Es wird von einem weiteren Autor folgendermaßen beschrieben: »Der Zeigefinger der einen Hand wird auf die Lippen gelegt, die andere Hand wird erhoben bis vollständig Ruhe ist.« (PÄD LK 03 04: 10) Hier geht die Symbolik noch über das Heben der Hand als Zeichen dafür, dass es zu unruhig oder zu laut sei, hinaus. Der Finger auf den Lippen symbolisiert nicht nur »Sei still«, sondern das unmittelbare Nachahmen - die Körperpraktik als solche - hat den Effekt, dass zum einen der Mund mit dem Finger verschlossen wird und zum anderen die Hände nichts anderes mehr tun und folglich auch sie keine Unruhe mehr stiften können. D. h. es besteht nicht nur ein arbiträrer Zusammenhang zwischen Zeichen und Bedeutung, der als Konvention und gewohnheitsmäßige Verbindung eingeübt wird (Saussure 2001), sondern es ist eine suggestive Praktik. Der Finger auf dem Mund verhindert das Sprechen und erzeugt den angestrebten Effekt nicht nur symbolisch. Wenn es allerdings in der 7. Klasse, so weiter Achim Albrecht, nicht mehr nötig und angemessen erscheint, den Finger auf den Mund zu legen, wird der gewünschte Effekt ausschließlich über die Symbolik erzeugt, die Geste selbst wird Teil eines imaginären Handelns.

Albrecht schreibt in seinem Erfahrungsbericht, dass es vorwiegend die Lehrkräfte seien, die auf das Ritual zurückkämen, dass aber auch die SchülerInnen darauf zurückgreifen sollen und dies auch tun. Er begründet dies so: »Die Schülerinnen und Schüler sollen Verantwortung für die Arbeitsruhe übernehmen, die sie und die wir brauchen. « (PÄD LK 03 04: 10) Die Praktik, mit der die Lehrkraft also ihren Körper als Medium einsetzt, um Ruhe zu erreichen, soll an die SchülerInnen weitergegeben werden. Idealerweise sind sie es, von denen das Zeichen ausgeht. Auf diese Weise übergeben die LehrerInnen die Durchsetzung einer ruhigen Arbeitsatmosphäre auch an die SchülerInnen, womit sich zumindest potenziell auch Machtverhältnisse anders darstellen. ${ }^{14}$ Hier verschwindet der Lehrkörper also, indem diskursiv die SchülerInnen an seine Stelle rücken, während im ersten Beispiel der performative Effekt lediglich dem Zeichen als Symbol zugerechnet wird und nicht der Körperpraktik der Lehrenden. Unabhängig davon wird in der Analyse deutlich, wie der Lehrkörper - auch in Verbindung mit Artefakten oder anderen Symbolen - als pädagogisches Mittel zum Zwecke bestimmter Arrangements und ihres effektiven Zustandekommens fungiert.

14 Hier wäre eine genaue Beobachtung nötig, wie SchülerInnen mit dem Ruhezeichen umgehen, wofür sie es nutzen, wer es nutzt oder darauf verzichtet usw. 


\section{(2) Steuerung durch Selbstbezug}

Weiterhin werden Praktiken vorgeschlagen, die auf den Lehrkörper selbst zielen. Der folgende Artikel von Karl-Oswald Bauer, Erziehungswissenschaftler mit dem Schwerpunkt Schulentwicklungsforschung, wurde in der Zeitschrift >Pädagogik« mit dem Titel »Beruf: Lehrer. Beruf Lehrerin. Oder: Was wissen wir über den Lehrerberuf?« (9/1997) veröffentlicht. Von sechs darin enthaltenen Artikeln zum Thema ist er der einzige, in dem der Lehrkörper thematisiert wird. Unter der Überschrift »Pädagogische Professionalität und Lehrerarbeit« entwickelt er ein Modell mit fünf Dimensionen des Handlungsrepertoires, welches für die Bildung eines "professionellen Selbst ${ }^{15}$ und seiner Weiterentwicklung relevant sei. Der Lehrkörper bekommt einen zentralen Stellenwert, indem aus einer vom Autor durchgeführten Studie als erstes von mehreren Fallbeispielen die Lehrerin Hegel zum "professionellen Selbst« folgendermaßen zitiert wird: »)Meine eigene innere Haltung muß auch in der äuBeren Haltung seinen Niederschlag haben. [...] wie der Mensch seinen Geist auch eben selber verkörpert. Der Körper ist das Medium des Pädagogen.« (PÄD LK 11 97: 23) Der Autor wiederholt den letzten Satz: »Der Körper ist das Medium des Pädagogen. « Und fügt hinzu: »Auf die Haltung kommt es an." (ebd.) Indem er diese beiden Sätze als Aussagen von Frau Hegel wiederholt, sie als ihre Basisüberzeugung heraushebt und ihre Aussagen in ein eigenes Modell integriert, lässt er nicht nur Frau Hegel sprechen. Die Aussagen werden zu seiner eigenen Basisüberzeugung, da sie für pädagogisch professionelles Handeln brauchbar und wahr erscheinen. Bauer betrachtet den Körper als Medium, weil mit ihm eine innere Haltung - der »Geist « - verkörpert werde. PädagogInnen sollen diese innere Haltung vermitteln. Dazu bedarf es eines Mediums: ihres Körpers. Verknüpft ist damit die Idee, das "professionelle Selbst« als individuelles Entwicklungsprogramm zu verstehen. Bauer nimmt wieder Bezug auf das Beispiel Frau Hegel und schreibt: »Frau Hegel schiebt die Grenzen ihres Körperselbst immer weiter in die pädagogische Arbeit hinein, sie setzt ihren eigenen Körper, ihre Stimme, ihre Mimik und Gestik auf überraschende und riskante Weise ein und überschreitet dabei Grenzen, die sie sich bisher gezogen hat. «(PÄD LK 11 97: 23) Der Körper ist so nicht nur statisch Ausdruck eines Inneren und in diesem Sinne vermittelndes Medium, sondern er wird mit Mimik, Stimme und Gestik (in) einer Umgebung ein- und ausgesetzt. Ausgesetzt, weil es dabei auch um bewusste oder unkalkulierbare Grenzüberschreitungen geht, die das eigene »Körperselbst« betreffen. "Körperselbst« und "professionelles Selbst« erscheinen als verschiedene Teilmengen einer Person, wobei das "professionelle Selbst« nicht

15 Mit dem Begriff ersetzt der Autor die seiner Ansicht nach überholte Kategorie der »Lehrerpersönlichkeit« (PÄD LK 11 97: 23). 
ohne den körperlichen Einsatz zu denken ist. Denn: »Pädagogik ist Körperarbeit, Pädagogik heißt: Interagieren, Kommunizieren, Gestalten, soziale Strukturen bilden, Planen und Entwickeln« (ebd.: 26). So kehrt der Körper in zwei dieser fünf Dimensionen, die für Bauer das professionelle pädagogische Handlungsrepertoire ausmachen, wieder: im Interagieren und im Gestalten. ${ }^{16}$

Interagieren bedeutet hier professionell ausgerichtete Wahrnehmung seiner selbst und anderer (SchülerInnen und LehrerInnen), wobei das Medium der Wahrnehmung der Lehrkörper ist. Noch deutlicher wird bei der Dimension des Gestaltens auf den Lehrkörper verwiesen: »Gestaltung beginnt bei der eigenen Person, bei Stimme, Mimik, Gestik, Kleidung und Körperbewegungen im Raum. « Ebenso gehöre »das Markieren von Anfängen und Abschlüssen durch Rituale oder andere nonverbale Signale und Handlungen« (ebd.: 24) dazu. Diese Dimension wird in den meisten Artikeln, die den Lehrkörper als Medium oder Instrument in der pädagogischen Arbeit betrachten, problematisiert. Zum einen geht es um Rituale, die Unterricht strukturieren, zum anderen um Körpersprache, die alltäglich oder auch im Besonderen - beispielsweise bei einer Präsentation - stattfindet, als wenig bewusst angenommen wird und durch ihre Thematisierung sowie konkrete Übungen bewusst gemacht werden soll. Die Äußerung, dass Gestalten bei der eigenen Person beginnt, verweist auf etwas, was auch die meisten anderen Texte durchzieht: die »Körperarbeit« beginnt bei sich selbst. Und so spricht auch Bauer davon, dass die Handlungsrepertoires »eingeübt, trainiert werden« (ebd.: 26) und seine Ausführungen als Hilfestellung dafür begriffen werden können.

Ein weiterer Text, der explizit bei den Lehrenden ansetzt, ist in der Rubrik »Praxisforum« des Schulmagazins erschienen, das mit der Frage: »Praxistipps: Was tun, wenn...? überschrieben ist. Hans-Peter Nolting, tätig in der Pädagogischen Psychologie und Autor eines Buchs über Unterrichtsstörungen, beschäftigt sich hier mit Störungsprävention und Konfliktlösungen (SM D 05 03). Er geht davon aus, dass die komplexen Interaktionen im Klassenzimmer nicht leicht zu durchschauen sind, weil »das Verhalten der Schülerinnen und Schüler zum großen Teil nicht von auffälligen Handlungsweisen der Lehrkraft gesteuert wird, sondern von den stillen, unauffälligen« (SM D 05 03: 53). Zwar werde die Bedeutung von Regeln für den alltäglichen Unterrichtsablauf erkannt, die nonverbale Beeinflussung und die Aufrechterhaltung des Unterrichtsflusses jedoch weniger wahrgenommen. Dabei seien gerade diese Befunde eine »wahre Fundgrube« (ebd.), um Störungen zu verringern. Doch was sind auffällige und was sind unauffällige Verhaltensweisen? Kön-

16 Es fällt auf, dass der Körper in den Ausführungen zum »Kommunizieren« keine Rolle spielt. Bauer grenzt diese Kategorie vom Interagieren ab, indem er in diesem Bereich die Informationsübermittlung stark macht (PÄD LK 11 97: 24). 
nen nur die auffälligen auffallen, die anderen schlichtweg nicht wahrgenommen werden? Die Verkettung der Bereiche legt es nahe, dass auffällig solche sind, die mit Sprache und einer mehr oder weniger lauten Stimme einhergehen, vielleicht bewusst vorgenommen werden. Das Unauffällige ist dagegen still, nicht-sprachlich, körperlich, nicht bewusst - irgendwie heimlich, aber dafür umso wirksamer. Dass es von den Lehrenden nicht wahrgenommen werde, soll nicht heißen, dass die SchülerInnen es ebenfalls nicht tun. Gerade das Subtile scheint seine Effekte zu haben. Um nun zur »Fundgrube « zu werden, muss sich an der Wahrnehmung der LehrerInnen etwas ändern. Was sich dann finden (und verändern) lassen könnte, fasst Nolting in vier Aspekte des Verhaltens von Lehrenden: die Aktivierung der gesamten Klasse, die Vermeidung von Unterbrechungen des Unterrichts, klare Regeln sowie Präsenz- und Stoppsignale. Der letzte Aspekt ist hier von besonderem Interesse, da der Akzent dabei, so Nolting, »auf Überwachung und (größtenteils nonverbaler) Steuerung des Schülerverhaltens hinsichtlich der Einhaltung von Regeln« liege (SM D 05 03: 54).

Die Steuerung von Schülerverhalten, so die Aussage, finde vor allem nonverbal, das heißt anhand von Körperpraktiken und damit verknüpften Signalen des Lehrkörpers statt. Als Präsenz- und Stoppsignale bezeichnet Nolting minimale nonverbale Signale, die die Präsenz und die Aufmerksamkeit der Lehrkraft demonstrieren und einen auffordernden Charakter haben (meist etwas zu unterlassen). Das »bloße Anblicken oder die Bewegungen durch den Klassenraum « (ebd.: 55) sind Beispiele dafür. Als nicht-störende und effektive Signale seien sie »von allergrößter Bedeutung « und »eine echte Alternative zu endlosen Ermahnungen, Predigten und Bestrafungen. Man muss zeigen, dass man buchstäblich alles im Blick hat, dass man sogar >Augen im Hinterkopf« besitzt« (ebd.). Der störenden verbalen, lauten und zeitfressenden Praxis, Störungen entgegen zu wirken, werden nonverbale, leise, präventive bzw. den Ansatz einer Störung erfassende Praktiken entgegengesetzt. Dabei geht es um Führung, die gezielte und auch hier wieder effektive Beeinflussung durch körperliche Sichtbarkeit, insbesondere den (Rundum-)Blick, der alles sieht (oder zumindest potenziell alles sehen könnte). Breidenstein (2006: 46) weist in seiner ethnographischen Studie darauf hin, dass die kontrollierenden Blicke von LehrerInnen nicht im Sinne eines Panoptismus begriffen werden dürften, wie ihn Foucault in »Überwachen und Strafen« insbesondere anhand des Panopticons Benthams als Metapher für ein wesentliches Ordnungsprinzip westlich-liberaler Gesellschaft analysiert hat (Foucault 1977: 251, vgl. Kap. 'Eine Analytik der Macht $)$. Schließlich seien die beobachtenden Lehrkräfte in der Schule nicht gänzlich unsichtbar, und die Blicke der LehrerInnen ließen sich von den SchülerInnen ebenso kontrollieren. Das Blickregime, welches hier als 
professionelles vorgestellt wird, nämlich die Inszenierung dessen, dass man alles sehen könnte, kommt in ihrer Idealisierung der Idee des Panopticons allerdings recht nahe, ohne dass deshalb der Schulraum zum Gefängnis werden muss. Der Effekt, potenziell einer allgegenwärtigen Beobachtung ausgesetzt zu sein, ist hier zumindest angestrebt - und sollte er tatsächlich eintreten, auch mit visueller Gegenkontrolle nicht aufzuheben. Mit dem Rundum-Blick wird auch eine breite Aktivierung angestrebt. Für die Herstellung möglichst permanenter Aufmerksamkeit werden nicht nur interessant aufbereitete Inhalte, sondern auch die »breite Mobilisierung durch wandernde Blicke bei der Lehrerfrage " (SM D 05 03: 54) genannt. Der Blickkontakt dient dazu, möglichst viele SchülerInnen einzubeziehen, individuellen Kontakt herzustellen - sei es nur für eine Zehntelsekunde, so ließe sich ergänzen - und zwar auch dann, wenn letztlich eine andere Schülerin aufgefordert wird, die Frage zu beantworten. Über die Blicke (so sie denn erwidert werden) sollen Beziehungen zu den SchülerInnen immer wieder aufs Neue hergestellt und der Kontakt aufrecht erhalten werden.

\section{Lehrkörper im Einsatz}

Bündelt man all diese Einzelanalysen, so lässt sich explizieren, wie der Einsatz des Lehrkörpers als Mittel im Unterricht konstituiert wird. Es ergeben sich drei Problematisierungsweisen, die zugleich auf bestimmte Körperkonzepte hindeuten:

(1) Der Lehrkörper wird zum Medium, um Eindeutigkeiten innerhalb von Interaktion zu schaffen, eine Schulklasse und ihren Unterricht effektiv zu steuern und Aufmerksamkeiten zu bündeln. Umgekehrt gilt es, Uneindeutigkeiten wie zeitliche Leerstellen oder fehlende Transparenz und letztlich Unterrichtsstörungen zu vermeiden. Exemplarisch stehen dafür die vorgestellten didaktischen Praktiken wie auch der Text von Nolting (SM D 05 03), der die Steuerung der Lerngruppe durch unauffällige nonverbale Praktiken betont. Innerhalb der Feldforschung in der Schulklasse ließen sich ebenfalls solche steuernden Körperpraktiken beobachten.

(2) Der Lehrkörper wird zum Medium, um eine innere Haltung der Lehrkraft zu einer äußerlichen zu machen. Eine bestimmte Haltung soll verkörpert werden. Diese Vorstellung findet sich beispielsweise auch in den Interviews mit den Lehrerinnen: Autorität oder die Haltung »Ich bin Chefin « soll verkörpert werden. Zentral ist die Idee der Verkörperung einer Haltung im Modell des »professionellen Selbst« von Bauer (PÄD LK 11 97). Die Vorstellung basiert auf einem Körperkonzept, welches das, was hier häufig »Körpersprache« genannt wird, als Ausdruck einer inneren Bewegung begreift und damit eine 
spezifische Differenz zwischen `Innen und >Außen « konstituiert. Diese Differenz liegt vielen Texten zugrunde, die den Körper explizit thematisieren.

(3) Der Lehrkörper wird zum Medium, um Kontakte aufzunehmen und Beziehungen herzustellen bzw. zu pflegen. Es geht um die Art und Weise, wie Lehr-Lernprozesse auf der Beziehungsebene gestaltet werden könnten oder sollten. Diese Thematisierung zieht sich durch die meisten Texte explizit oder implizit hindurch, sie ist meist mit der Vorstellung einer körperlichen Steuerung verbunden. Im Text von Bauer findet sie sich vor allem unter dem Begriff des Interagierens wieder. Eine Verknüpfung von pädagogischer Beziehung durch körperliche Steuerung und Effektivität betont Schmitt, wenn er schreibt, es sei »effektiver sich so zu präsentieren, dass sich aktive und inaktive Schüler gleichermaßen beachtet (beobachtet) fühlen« (SM D 12 97: 68). Das entspricht der Inszenierung des "panoptischen Rundblicks « bei Nolting und bedeutet letztlich die Inszenierung einer Beziehung durch körperliche Signale. Die grundlegende Bedeutung körpersprachlichen Ausdrucks für zwischenmenschliche Kontakte wird vor allem auch in den Artikeln betont, die im nächsten Kapitel Gegenstand meiner Analyse sind. Wer bewusst mit dem eigenen Körper umgeht, so die Botschaft, schafft auch mehr Aufmerksamkeit für das Gegenüber.

Die den lehrenden LeserInnen gestellte Aufgabe, ihre nonverbalen Signale wahrzunehmen, zu verändern und bewusst als Mittel einzusetzen, erfordert, so Nolting, »Selbstdisziplin und Routine auf Seiten der jeweiligen Lehrkraft« (SM D 05 03: 55). Also eine permanente Arbeit an sich selbst, um auch mit den "Augen im Hinterkopf « sehen zu können, damit die Körperpraktiken in eine Körperroutine ein- und übergehen. Die Texte, die ich im Folgenden analysiere, machen diese Selbstdisziplinierung des Lehrkörpers zum Gegenstand. Damit der Lehrkörper als pädagogisches Medium in der Führung einer Schulklasse eingesetzt werden kann, muss er zunächst Ziel pädagogischer Selbstbearbeitung werden.

\section{Der Lehrkörper als Lernziel und Übungsobjekt}

Die Zeitschriftenartikel, die der folgenden Analyse zugrunde liegen, haben hinsichtlich ihrer Produktion mehr Gemeinsamkeiten als die bisherigen, die von verschiedenen Sprecherpositionen aus und zu unterschiedlichen Themen geschrieben wurden. In den bisherigen Texten wurde der Lehrkörper als Medium in der pädagogisch-didaktischen Arbeit konstruiert, und es gab erste Ansätze dafür, dass er Ziel einer Selbstbearbeitung und -kontrolle zu sein habe. Die folgenden Artikel präzisieren dieses Vorhaben, indem ihre AutorInnen vorschlagen, wie dies geschehen könnte oder sollte. Es sind zehn Texte inner- 
halb des Gesamtkorpus, die die »Körpersprache« von Lehrenden thematisieren. ${ }^{17}$

\section{Anrufungen durch Expertinnen}

Die AutorInnen agieren als ExpertInnen, sie arbeiten als Psychologe, SprecherzieherInnen oder Trainer. Als ExpertInnen wenden sie sich mit ihren Texten, welche als Ratgeber geschrieben sind, an LeserInnen, die in der Schule unterrichten. Eine Ausnahme bildet ein Text eines Lehrers, der als Erfahrungsbericht geschrieben ist; doch auch dieser enthält Sequenzen, die Anleihen eines Expertenhabitus und Ratgebers aufweisen. Woran lässt sich dies festmachen? Das Agieren als ExpertIn zeigt sich in den Texten auf verschiedenen Ebenen: zu allererst in der Ansprache der LeserInnen. Sie werden hier, wie auch schon in einigen Texten des vorherigen Kapitels, direkt angesprochen, z. B. folgendermaßen nach Reflexion fragend: »Wissen Sie eigentlich, wie Sie auf Schüler wirken, wenn Sie vorne stehen?« (PÄD LK 14 98: 28) oder als Handlungsanweisung »Halten Sie Blickkontakt mit dem Publikum« (SM LK 05 02: 7). Mit der Anrede »Sie« wird eine direkte kommunikative Beziehung zwischen den Schreibenden (bzw. dem Text) und den LeserInnen hergestellt. In der Performanz des Sprechakts wird den Lesenden die Position der »Betroffenen « zugewiesen und mittels der Anrufung werden die LeserInnen zu »TeilnehmerInnen« des Trainingsprogramms. Das jeweilige Interaktionsbündnis stellt sich allerdings unterschiedlich dar. Die Fragen, mit denen die Lesenden oft zu Beginn eines Artikels konfrontiert werden, fordern wie im Beispiel des Unterrichtseinstiegs von Friedrichs oder in der oben gestellten Frage auf, sich unmittelbar dazu zu verhalten. Sie greifen an und verunsichern eventuell. Möchte ich als Leserin mich weiter auf den Text einlassen, komme ich nicht umhin, mich gedanklich dazu zu äußern (einerlei, ob erstaunt, ärgerlich oder gelassen abwinkend). Die Handlungsanweisung fordert dagegen zu einem Tun auf, das nicht unmittelbar erfolgen muss, vielleicht auch nie erfolgt, jedoch in seiner Performanz und durch die Wiederholung ähnlicher prägnanter Aufforderungen Effekte für das eigenen Handeln haben kann, beispielsweise indem man sich, vor der Schulklasse stehend, kurz daran erinnert, dass es förderlich sei, Blickkontakt aufzunehmen, und seinen Blick bewusst durch die Runde schweifen lässt. Dass überhaupt Handlungsanweisungen in dieser Form gegeben werden, verweist ebenfalls auf die Einnahme

17 Sie finden sich in den Themenschwerpunkten »Präsentationstechniken « (Schulmagazin 11/2002), »Die gute Präsentation « (Pädagogik 03/2004), »Frontalunterricht - gut gemacht« (Pädagogik 05/1998), »Körpersprache und Stimme« (Schulmagazin 03/1996) und als Serie zum Thema »Klassenmanagement« in verschiedenen Ausgaben des Schulmagazins (1997). 
eines Expertenstatus. Wer wäre sonst berechtigt, solche Anweisungen zu geben, und von wem wäre man bereit, sie entgegen zu nehmen? Des Weiteren macht sich die Position der Schreibenden zumindest teilweise an einem spezifizierten Fachwissen fest. Als TrainerInnen sind die AutorInnen außerdem KennerInnen einer (Übungs-)Praxis, nicht unbedingt der Schul- bzw. Unterrichtspraxis, sondern ihrer eigenen Weiterbildungskurse.

So zeigt sich denn auch, dass in der Hälfte der Texte zwar minimale Bezüge zur Unterrichtspraxis hergestellt werden, dass sie aber letztlich eher allgemeine Ratgeber zu Präsentationstechniken darstellen, zu denen eben auch dem Publikum zugewandte Körperhaltungen sowie Blickkontakte gehören (SM LK 05 02; PÄD LK 15 02). Auch die AutorInnen, deren Bezugsrahmen der Frontalunterricht ist, gehen letztlich viel auf allgemeine Präsentationsstandards, jedoch wenig auf spezifische Situationen im schulischen Unterricht ein. Ich beziehe mich daher vor allem auf die Beispiele, die explizit Körper und Schule zusammenbringen.

\section{Zur Herstellung eines Lehrkörpers}

Ein solches explizit auf Schule bezogenes Beispiel ist die vierteilige Serie »Klassenmanagement. Effektiver Umgang mit Unterrichtsstörungen - ein Trainingsprogramm«. Sie ist unter der Rubrik »praxis compact« und unter dem Thema »Schulleben« erschienen. Der Autor und »Trainer $«{ }^{18}$ Hubert Schmitt bietet Fortbildungen in diesem Bereich an. Sein Training basiert zu einem großen Teil auf dem Konzept des Neurolinguistischen Programmierens (NLP). ${ }^{19}$ Ebenso wie bei Nolting sind es für ihn »überwiegend nonverbale Kommunikationsstrategien, mit denen Lehrer Störfaktoren effektiv begegnen können«, da ihr Anteil »zwischen 58\% und 80\% der Gesamtinformation (vgl. O'Connor/Seymour 1996, S. 123)« (SM D 10 97: 47) läge. Effizienz und nonverbale, also körperliche Zeichen gehen auch hier eine Verbindung ein. Uneffizienz entstehe durch Uneindeutigkeit, häufig seien die verbalen und die nonverbalen Informationen inkongruent. Damit werden nicht der Körper oder die Körperpraktiken ein Problem, sondern die Gefahr, dass verbale Äußerungen nicht mit nonverbalen Signalen übereinstimmen könnten. Diese Problematisierung zieht sich durch alle untersuchten Texte hindurch, die Körpersprache thematisieren. Das Training für die LehrerInnen richte sich deshalb auf deren Körpersprache, weil im Falle der Inkongruenz die Aufmerksamkeit »unwill-

18 Trainer in Anführungsstrichen, weil er im Interaktionsbündnis gegenüber den (lesenden und betroffenen) » TeilnehmerInnen « zum » Trainer « wird, unabhängig davon, dass er wahrscheinlich als solcher tätig ist.

19 Eine kritische Auseinandersetzung mit NLP nehmen Gustl Marlock und Michael May (2003) vor. 
kürlich« den nonverbalen Signalen gelte. Lehrende haben also erstens an ihrer Körpersprache zu arbeiten, um Inhalt und Ausdruck stimmig zu machen, und zweitens ihre Körperpraktiken zu kontrollieren, da SchülerInnen sonst unbewusst die unkontrollierten Körperpraktiken der LehrerInnen wahrnehmen und ebenso unkontrolliert darauf reagieren könnten. Das »Klassenmanagement«, worunter Schmitt »die Art des Umgehens, des Organisierens, Führens, Disziplinierens« (ebd.) versteht, also letztlich das Regieren einzelner SchülerInnen und der Gesamtgruppe, bedarf demnach zunächst des Selbstmanagements, des Trainings und der Selbstdisziplinierung der Lehrenden, insbesondere mittels spezifischer Körpertechniken und Übungen. Diese »Fertigkeiten ${ }^{20}-$ sicher beherrscht und sauber angewendet - können dann zur Selbstdisziplinierung der SchülerInnen anhalten. Zentral bei dieser Idee ist eine Trennung zwischen Unterrichten und Disziplinieren. ${ }^{21}$ Mit dem Training eines bestimmten körperlichen Ausdrucks sollen die LehrerInnen lernen, eine »Disziplinierungsrolle« einzunehmen. Diese zeichnet sich durch einen bestimmten »Disziplinierungsplatz«, also einen konkreten Ort, an dem diszipliniert wird, sowie eine bestimmte Disziplinierungsstimme und -körperhaltung aus. Für diese Rolle werden wie beim Theater Körperpraktiken eingeübt, die dann bei Bedarf auf einer dafür ausgewählten Bühne zur Aufführung kommen. Die Verknüpfung von Ort und Ritual soll den SchülerInnen ermöglichen, die Verhaltensweise der Lehrkraft eindeutig zuzuordnen (SM D 11 97: 50), weshalb dieselben Aktivitäten immer an ein und demselben Ort stattfinden müssten (SM D 10 97: 50). Um zu verdeutlichen, wie der Lehrkörper zum Ziel und der Körper der Lehrenden zum Objekt der Bearbeitung werden, um dann bei Beherrschung der anvisierten Körperpraktiken als Lehrkörper Medium im Disziplinierungsprozess zu sein, habe ich die Arbeitsanweisung zur Einübung der »Disziplinierungshaltung« ausgewählt.

»Die Disziplinierungshaltung

Üben Sie folgende Disziplinierungshaltung zunächst vor dem Spiegel und schärfen Sie konsequent die eigene Körperwahrnehmung:

$\rightarrow$ Stellen Sie sich mit parallel ausgerichteten Füßen in leicht gegrätschter Haltung fest auf den Boden.

20 Sie funktionieren, "wenn Sie es wollen« (SM D 10 97: 47) und daran glauben, so versichert der Autor in einem extra hervorgehobenen Kästchen. Einüben bedeutet mehr als Trainieren, es bedarf eines aktiven Willens dazu.

21 Schmitt und in einem weiteren Text Apel und Pfitzner (SM LK 02 04) sind die einzigen, die von »Disziplinieren« sprechen. Die Trennung dient auch dazu, dass die pädagogische Beziehung von SchülerInnen möglichst nicht als machtvolle wahrgenommen werde (SM D 10 97: 47; vgl. Kap. ‘Zur Tabuisierung von Disziplinieren und Strafen () . 
$\rightarrow$ Lassen Sie die Kraft, die die feste Verbundenheit mit dem Boden gibt, nach oben fließen (Atmen!).

$\rightarrow$ Richten Sie mithilfe dieser Kraft den Oberkörper so auf, dass sich der Brustkorb nach vorne wölbt.

$\rightarrow$ Schultern, Arme und Hände hängen seitlich locker und gerade nach unten (nicht nach vorne).

$\rightarrow$ Hals, Wirbelsäule und Kopf bilden eine Linie.

$\rightarrow$ Der Kopf sitzt dabei frei und locker auf der Wirbelsäule, das Kinn ist leicht nach hinten genommen.

$\rightarrow$ Der Blick ist fest und geradeaus gerichtet.

$\rightarrow$ Die Mimik signalisiert Ernsthaftigkeit.

$\rightarrow$ Sobald Sie diese Körperhaltung rasch einnehmen können, ergänzen Sie die Übung folgendermaßen:

$\rightarrow$ Eignen Sie sich eine eindeutig beschwichtigende Arm- und Handhaltung an (z.B. angewinkelte Arme - Handfläche nach unten - vgl. Abb.).

- Trainieren Sie, diese Haltung rasch einzunehmen und für einige Sekunden (mindestens fünf Sekunden) zu halten (seinfrieren`).

- Verbinden Sie die Haltung mit der entsprechenden verbalen Botschaft (Stimmführung vgl. Übung 6).

- Disziplinieren Sie in der Praxis dissoziiert am Disziplinierungsplatz, in Disziplinierungshaltung mit Disziplinierungsstimme.« (SM D 11 97: 37)

Dieser »Trainingsplan« ist zentraler Bestandteil des Übungsprogramms, weil er eine Grundstellung des Lehrkörpers aufbaut, die der Autor im Umgang mit Unterrichtsstörungen für geeignet hält. Sie wird in kleinen Schritten vorgestellt, damit sie möglichst problemlos nachvollzogen werden kann. Nachvollziehen heißt, nicht nur zu lesen, wie diese Haltung aussehen könnte, sondern die geschriebenen Sätze körperlich umzusetzen, sie auszuführen. Wie für eine Rolle im Theater oder eine Turnübung soll zunächst auf der Hinterbühne (vgl. Goffman 1969: 104) für sich geübt und geprobt werden, bevor dann bei ausreichendem Können die Vorderbühne, die Schulklasse, betreten werden kann. Als Voraussetzung bzw. Basis des gesamten Vorhabens gilt die Körperwahrnehmung, die, so Schmitt an anderer Stelle, »häufig verkümmert« (SM D 11 97: 37) sei. Verkümmert heißt, es gab sie - in der Vergangenheit der jeweiligen Person oder einer historischen, die diese Person gar nicht mehr erlebt hat. ${ }^{22}$ Indem nun Körperwahrnehmung und das Üben vor dem Spiegel in einem Satz genannt werden, erscheint es so, als sei die geforderte Wahrneh-

22 Oder beides, betrachtet man diese Interpretation mit der Geschichte des Körpers bei Elias und dessen Übertragung des Modells auf das Aufwachsen von Individuen, indem sich der historische Prozess ausgehend von einer körperlichen Unmittelbarkeit der Menschen im Mittelalter hin zum beherrschten Körper im individuellen Zivilisationsprozess » wiederholt« (vgl. Elias 1997a). 
mungsschulung vor allem über das visuell abgleichbare Spiegelbild möglich. Wahrnehmen bedeutet in diesem Sinne sehen zu können, das Sichtbare entdecken. Auf die Unterrichtssituation bezogen heißt es, das sehen zu können, was die SchülerInnen ebenfalls sehen könnten. Die einzunehmende Haltung wird präzisiert, indem die Position einzelner Körperteile beschrieben wird. Nicht ein Eindruck des Körpers in seinem gesamten Erscheinungsbild wird vermittelt, sondern es sind Einzelpraktiken auf einer Mikroebene. Das unterscheidet diese Übung von anderen körperbezogenen Übungen, bei denen vor allem die eigene körperliche Wahrnehmung im Mittelpunkt steht. Die Einzelkomponenten fügen sich dann zwar zu einem Gesamtbild (vor dem Spiegel) zusammen. Dennoch werden bestimmten Körperteilen bestimmte Ausdrucksmöglichkeiten zugeschrieben, beispielsweise der Arm- bzw. Handhaltung: Sie soll eindeutig beschwichtigend wirken. Die nachahmenden LeserInnen können sich hier am gegebenen Beispiel (angewinkelte Arme - Handfläche nach unten) orientieren, sich aber auch eine andere für sie eindeutige Geste aussuchen. Damit öffnet sich die handlungsanleitende Praktik und kann zu einer persönlichen (mit einer »persönlichen Note «) werden. Offen bleibt, trotz so genauer Vorgaben, was eine Mimik ist, die »Ernsthaftigkeit« signalisiert. Zunächst fällt mir ein: nicht zu lachen oder auch nur andeutungsweise zu lächeln. Doch ist das Gegenteil davon »Ernsthaftigkeit«? Wie könnte diese Mimik praktiziert werden - durch kritisches, angespanntes, drohendes, einschüchterndes, machtvolles Blicken? Hier ist wieder die Vorstellung der TeilnehmerInnen gefragt.

In der Zeitschrift gibt es insofern ein Gesamtbild, als neben dem Text eine Figur abgebildet ist, die die »Disziplinierungshaltung« einnimmt.

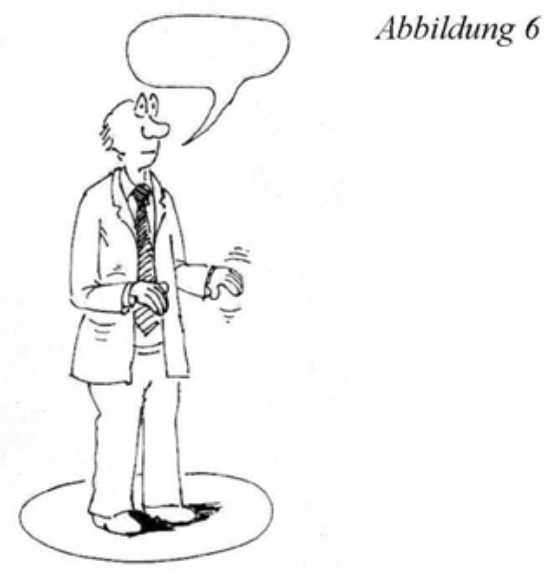


Diese Figur ist im Comic-Stil gezeichnet, was zur Folge hat, dass bei ihrer Betrachtung genau das Gegenteil dessen eintritt, was im Text gefordert wird: Die Eindeutigkeit und Ernsthaftigkeit der Haltung wird durch die Comiczeichnung konterkariert. Indem im Text aber auf sie verwiesen wird und die gemalte »Beschwichtigungsgeste $«$ Vorbildcharakter erhält, scheint es sich bei der Zeichnung weder um ein Comic noch um eine Karikatur zu handeln.

Die eingeübte Haltung muss nun trainiert werden, so dass sie möglichst rasch eingenommen werden kann und idealerweise in eine Körperroutine eingeht. Sie stellt lediglich einen Bestandteil in einem komplexen, aber innerhalb des Trainingsprogramms durchaus überschaubaren und bewältigbar wirkenden Interaktionsgefüge in der Schulklasse dar. Effektiv wird sie erst, so das Ende der Anleitung, indem sie mit einer bestimmten Stimme sowie an einem bestimmten, immer wieder einzunehmenden Ort eingenommen wird, d. h. ein spezifisches Körper-Raum-Gefüge hergestellt wird, das die SchülerInnen zur Disziplin anhält (vgl. das Spacing bei Löw 2001). Auch zu diesen »Teilaspekten« Ort und Stimme gibt es innerhalb des Trainingsprogramms Anleitungen, die der hier vorgestellten ähneln. Schritt für Schritt kann so gelernt werden, wie der disziplinierende Lehrkörper agiert. Der Körper der Lehrenden wird damit zum Objekt einer Selbstbearbeitung, der ohne viele (laute) Worte disziplinierende Lehrkörper zum Ziel dieser Selbstbearbeitung. Sie scheint dann erfolgreich, wenn das Ziel erreicht ist und der so hergestellte Lehrkörper das geeignete Medium zur Durchsetzung eines »Klassenmanagements« darstellt. Es wird suggeriert, dass mit dieser Haltung professionell gearbeitet sowie Professionalität inszeniert werden kann. Professionalität ist ein Thema, das zwar als solches kaum benannt wird, um das die Texte sich aber permanent drehen, ebenso die Interviews mit den Lehrerinnen. Sie müssen sich als Professionelle darstellen, sprachlich im Interview und körperlich vor der Klasse.

Inwieweit und inwiefern aber sind diese Übungen und die Form des Auftrags an lehrende LeserInnen, mit ihrem Körper zu arbeiten, im Zeitschriftenkorpus »üblich«? Es gibt zwei unterschiedliche Weisen, die sich vor allem auf den Ort, im Sinne der Vorder- oder Hinterbühne, verknüpft mit der Art der vorzunehmenden Körperpraktiken beziehen:

(1) Geht es um allgemeine Präsentationstechniken und -standards, finden sich solche ausgefeilten Körperübungen, die beispielsweise die Präsentation vorbereiten, eher selten. Die Handlungsanweisungen für Körperpraktiken beziehen sich vor allem auf eine generelle »good practice« jeweils bei der Präsentation bzw. beim Lehrvortrag. Dazu finden sich Äußerungen wie:

»Wenden Sie sich ihm [dem Publikum, A. L.] mit Körperhaltung, Blickkontakt und freundlicher Mimik ganz zu.« (SM LK 05 02: 5) 
»Wenn Sie verspannt sind und falsch atmen, sollten Sie zu Beginn einer Präsentation nicht noch einmal tief Luft holen, sondern zunächst ausatmen. Lassen Sie dabei die Schultern fallen und lächeln Sie die Zuhörer an. Dann klingt die Stimme auch gleich viel freundlicher und weniger angespannt. Nehmen Sie sich Zeit und machen Sie Pausen, damit sich die Atmung und ihr ganzer Körper beruhigt. (SM LK 0602 : 10)

Oder in indirekter Ansprache:

»Körpersprache (non-verbal): Blickkontakt zur Klasse intensivieren; Gestik und Mimik wirken lassen; Körperhaltung nicht zu locker einnehmen; Bewegung durch den Raum nicht ausufern lassen; Sprechweise (vokal): Deutlicher artikulieren; Lauter sprechen; Langsamer sprechen; Pausen gehäuft einsetzen; Betonung prägnant ausführen; Stimme am Aussageende absenken; Sprechweise im Vortrag variieren. (PÄD LK 13 98: 18)

Es fällt auf, dass der Körper in diesen Anweisungen tendenziell in seinem gesamten Erscheinungsbild angesprochen wird und nicht nur einzelne Körperteile thematisiert werden. Gesamtbild bzw. Situation und Körperelement sind meist miteinander verschränkt, so auch in den zitierten Äußerungen. So stellen die Schultern zwar einzelne Elemente dar, doch geht es um einen Gesamteindruck, der vor dem Publikum erzeugt werden soll. In der jeweiligen Verschränkung der Ebenen gibt es im Vergleich der Beispiele jeweils eine dominantere.

(2) Etwa die Hälfte der AutorInnen stellen Übungen vor, die jenseits des Auftretens vor einer Schulklasse stattfinden sollten, aufgrund der »Notwendigkeit eines rein physischen Trainings (Atmung, Körperhaltung, Bewegung)« (SM LK 07 96: 4; Herv. i. O.) oder um »handwerkliche Fertigkeiten« (PÄD LK 14 98: 28) zu erlernen. Die lehrenden LeserInnen werden aufgerufen, außerhalb der konkreten Unterrichtssituation an sich und mit ihrem Körper zu arbeiten und gefordert, ihn wahrzunehmen, beispielsweise indem Körpererfahrungen beim Balancieren gemacht werden, um das eigene »Sprechinstrument« zu spüren (SM LK 07 96: 5). Meist werden sie zudem an ExpertInnen und Weiterbildungsprogramme verwiesen. ${ }^{23}$ Hier besteht ein anderes Selbstverhältnis als bei der Einübung einer professionellen Haltung. Prinzipiell ist zuerst einmal offen, was bei den Übungen, die Körpererfahrung und Wahrnehmungschulungen zum Ziel haben, »herauskommt«. Sie sind nicht unmittelbar auf die Wirkung auf andere ausgerichtet, auch wenn diese

23 Eine erweiternde Ausnahme stellt der Artikel zu »Körpersprache und Stimme« von Christiane Schönherr dar, der nicht nur die Lehrenden im Visier hat, sondern auch die SchülerInnen (SM LK 07 96). 
sich durch die selbstsorgenden Praktiken verändern kann. In diesem Sinne sind es Übungen, die Reflexivität ermöglichen bzw. dazu anhalten. Die »Disziplinierungshaltung " bei Schmitt ist dagegen normativ und hat den gelehrigen Körper der Lehrenden zum Ziel und zum Ausgangspunkt eines Trainings.

\section{Lexikon einer (natürlichen) Körpersprache}

Einen deutlichen Bezug zwischen der körperbezogenen Arbeit der Lehrenden und der Situation in der Schule stellt Rudolf Heidemann, Professor für Psychologie, her, indem er die Übungen seines Trainingsprogramms direkt ins Klassenzimmer verlegt (PÄD LK 14 98) ${ }^{24}$ In dieser Art der Darstellung vermischen sich der Lehrkörper als Medium und der Lehrkörper als Ziel bzw. Objekt. Es werden Effekte von Körperpraktiken vorgeführt, womit der Lehrkörper als Instrument solcher möglichen Effekte eingesetzt wird. Zugleich werden die Lesenden aufgefordert, in ihrem Unterricht diesen Einsatz gezielt zu trainieren, allerdings nicht als »Trockenübung«, sondern unmittelbar »im Feld«. Das entspricht dem letzten Schritt der Abfolge für das Einnehmen einer »Disziplinierungshaltung«. Auch da findet das Üben letztlich im Klassenzimmer statt.

Bei den Texten, die den unmittelbaren Bezug zur Schulsituation herstellen, fällt auf, dass sie normativ festlegen, welche Gesten richtig und welche falsch sind. ${ }^{25}$ Die Eindeutigkeit, die immer wieder gefordert wird, bezieht sich dort nicht nur auf eine wie auch immer geartete Konsequenz und Transparenz bezüglich eigener Regeln und Anforderungen, die dann auch noch mit dem jeweiligen körpersprachlichen Ausdruck übereinstimmen sollen, sondern auf Gesten, die immer nur auf eine bestimmte Art und Weise verstanden würden. Bereits die Körperhaltungen und Gesten als solche erfahren eindeutige $\mathrm{Zu}-$ schreibungen, wie sich in den folgenden Beispielen zeigt:

"Das Stehen mit verschränkten Armen bedeutet Distanz und Ablehnung, das Anlehnen an die Tafel oder das Pult Unsicherheit [... ] (SM D 11 97: 37)

"Grundsätzlich gilt, daß Hände unterhalb der Gürtellinie eine negative Aussage, Hände zwischen der Gürtellinie eine neutrale Aussage und Hände auf Brusthöhe eine positive Aussage enthalten.« (PÄD LK 14 98: 31)

"Natürliche Gesten kommen aus dem Oberarm (Kugelgelenk).« (ebd.)

24 Heidemann hat eines der wenigen Bücher zum Thema herausgegeben. Mittlerweile ist es in der 7. Auflage erschienen ist.

25 Das ist trotz präziser Anleitungen, bestimmte Haltungen einzunehmen oder auszuprobieren, sonst nicht so. Wie der Blick oder die Haltung genau aussieht, was jeweils unter freundlicher Miene oder Zuwendung zum Publikum verstanden wird, erfährt einen großen Interpretationsspielraum. (Davon mal abgesehen, dass die Übersetzung in das eigene Tun noch einmal ganz anders aussehen kann.) 
Dass die Hände nicht unterhalb der Gürtellinie gesehen werden wollen, verweist auf eine Zweiteilung des Körpers in ein meist positiv besetztes »Oben« und ein negativ besetztes »Unten«, wobei die Mitte mit ihrer Neutralität eine Art »Nullmeridian« darstellt. Die Hände unterhalb der Gürtellinie könnten möglicherweise zu sehr auf die Genitalien verweisen. Auch die Differenz von hoch als positiv, dem offenen Himmel zugewandt, und tief als negativ, vom Boden begrenzt, ist eine kulturell und diskursiv hergestellte. Anlehnen wird als Schwäche verstanden, und worauf bezieht sich »die natürliche Geste« aus dem Oberarm? Die Aussagen oder Behauptungen werden im Artikel von Heidemann durch Fotografien verstärkt, in deren Unterschriften die gezeigte Haltung mit »RICHTIG! « oder »FALSCH! « kommentiert wird. Eine solche Kommentierung suggeriert, dass die jeweilige Körperhaltung immer eine sichtbare und eindeutige sei. Auf diese Weise wird der Körper zu einem, der als Anzeigeinstrument Wahrheiten ausdrückt (Willems 1998: 46). Es lässt sich in ihm lesen, allerdings benötigt man dafür ein Wissen, das die Decodierung einer Geste oder Mimik ermöglicht. Auch wenn ich nicht im Gegenzug behaupten möchte, dass es ein solches Körperwissen - reflexiv oder unbewusst als leibliches - nicht gäbe, so suggeriert diese Reduktion auf ein einfaches Übersetzungsverhältnis und kausale Gestaltungsmöglichkeiten, dass Interaktionen vorhersagbar und planbar seien. Die Situationsgebundenheit von Interaktionen, deren Bestandteil Körperpraktiken sind, wird weitestgehend ausgeblendet, womit auch die interpretativen Leistungen, die Situationsdefinitionen des Gegenübers, also der SchülerInnen, ignoriert werden und eben auch nicht in die eigene Interpretation und Reflexion einbezogen werden können. Statt dessen werden Standards kanonisiert und eine Art Lexikon erstellt, indem bestimmten Blicken, Gesten oder Mimiken eine eindeutige Bedeutung (und Wirkung) zugeschrieben wird und sie damit jeweils richtig und falsch sein können. Diese Ableitungen reichen dann bis in die Bestimmungen mikrodidaktischen Handelns.

In den auf den Fotografien im Text abgebildeten Körperhaltungen spiegelt sich diese Situiertheit ebenfalls kaum. Dafür wird deutlich, dass es sich bei den angenommenen Bedeutungen um kulturelle und soziale Konstruktionen handelt. Diese diskursiven Konstruktionen können zwar in bestimmten Momenten und möglicherweise recht häufig innerhalb der Definition einer Situation aufgrund einer gemeinsamen kulturellen Ordnung richtig erkannt werden (und werden es wahrscheinlich auch meistens). Ihre angenommene Eindeutigkeit kann jedoch schnell zu Fehlinterpretationen führen, sobald das Gegenüber die Situation anders rahmt (vgl. Goffman 1996b). Zum Teil widersprechen die Abbildungen den Aussagen im Text, ähnlich wie im Beispiel der »Disziplinierungshaltung « die Comiczeichnung nicht dem Text zu entspre- 
chen scheint. Beispielsweise signalisieren gekreuzte Beine zwar eigentlich nicht genügend Standfestigkeit, die Frau auf dem Foto allerdings hat ihre Beine gekreuzt. Sie trägt einen Rock, und wahrscheinlich gehört es sich für sie als Frau so, dass sie tugendhaft die Beine überschlägt. Die Bilder zeigen, zumindest bei Betrachtung mit dem geschulten Blick der Geschlechterforschung, wie viel jeweils außer der auf der Mikroebene fokussierten konkreten Geste mittransportiert wird. Die Ebene der Inszenierung von Geschlecht überlagert in diesem Fall die der Inszenierung der professionellen standhaften Lehrkraft, da sie für die kulturelle Ordnung von größerer Bedeutung ist. Ungewollt wird damit das vorgeführt, was durchaus angenommen wird, nämlich dass der Körper ein Eigenleben habe - ein Eigenleben, das sich aber weniger aus ihm selbst ergibt, sondern vor allem aus der Komplexität seiner Symboliken, bei der sich verschiedene Schichten überlagern können, die einerseits vom Blick der Betrachtenden abhängig sind und andererseits von deren Diskursivität.

Hier wird eine weitere Verknüpfung relevant, die genau jene Überdeterminierung von Diskursen ausblendet, in ihrer Argumentation aber auch nicht nötig erscheinen lässt. Auf einer als besonders authentisch gedachten Ebene von Kommunikation werden körperliche Gesten und Bewegungen als NichtSprachliche gewissermaßen zu Sprachlichen. D. h. es findet eine Analogisierung von Sprachlichem und Nicht-Sprachlichem statt. Diese Körpersprache wird im untersuchten Korpus regelmäßig als »natürliche Sprache« begriffen, ohne jegliche Historizität und Diskursivität. ${ }^{26}$ Körpersprache sei evolutionsgeschichtlich vor der verbalen Sprache anzusiedeln - damit also ursprünglicher. Dementsprechend könne "man [...] sich nicht nicht verhalten.« Und »im Zweifelsfall [sagt] das körpersprachliche Signal die Wahrheit« (PÄD LK 14 98: 28). Körpersprache wird, da sie affektiv sei, mit Ursprünglichkeit und Echtheit konnotiert. Daraus schlussfolgert der Autor, »dass sich das Entscheidende im Lehrerverhalten nicht trainingsmäßig erwerben läßt.« (ebd.) Es handle sich lediglich um eine Ergänzung der Persönlichkeit des Lehrers und seiner Kompetenzen. Dies betont Heidemann, da gerade PädagogInnen sich schwer tun würden, an sich zu arbeiten. Ihr Argument sei, die Kinder würden es doch sofort bemerken, wenn man nicht »echt" sei. Genau hier zeigt sich auch das Dilemma: Heidemann müsste dem eigentlich zustimmen, und doch ist da etwas, woran man arbeiten könne und müsse, sonst wäre sein Training unnütz. Aber nicht so viel, dass es zur Manipulation werde - dann wäre man nämlich

26 Ähnlich argumentiert auch eine Lehrerin im Interview. In der Analyse im Kapitel `Körperkontakt als pädagogisches Mittel« werden die Effekte einer solchen diskursiven Konstruktion bis hin zur Konturierung eines bestimmten Typus von Hauptschüler besonders deutlich. 
nicht mehr echt. Die Grenzen der Trainierbarkeit liegen hier in der Originalität des Einzelnen.

Die Lesenden werden immer wieder mit Ambivalenzen zwischen einem natürlichen Körperausdruck und einem künstlichen Hervorrufen von körperlichen Zeichen konfrontiert. Körpersprache wird als natürlich expliziert, um ihre »herausragende Bedeutung« vorzuführen. Wie steht diese Normativität der in Wort und Bild aufgeführten Körpergesten zu einer natürlichen Körpersprache? Angenommen, ein Lehrer würde alles falsch machen, ist seine Körpersprache dann unnatürlich? Oder wäre es unnatürlich, wenn er so trainieren würde, dass alles richtig wäre? Natürlichkeit wie Leiblichkeit sind hier eine Art Zustand, den es zu erreichen gilt und der aufgrund seiner Authentizität immer schon legitim erscheint. Sie geht mit bestimmten Normen sowie Subjektentwürfen einher, die nicht hinterfragt werden müssen.

\section{Der kranke Körper als Problem: Selbstsorge als Prävention, Heilung und Vorbild}

Es gibt eine weitere Form der Problematisierung des Körpers von LehrerInnen, die ich hier noch erwähnen möchte. In einer Reihe von Texten, insbesondere jenen, die sich mit Fragen der Gesundheit von Lehrenden sowie einer Arbeitsökonomie im Schulalltag beschäftigen, wird deren Körper in spezifischer Weise thematisiert: Infolge von Überlastung wird er als kranker Körper zu einem Problem. ${ }^{27}$ Die Belastung zeigt sich vor allem in einer hohen Krankheitsquote, dem sog. »Burn Out« und im frühzeitigen Ausstieg aus dem Beruf. ${ }^{28}$ Sie wird als Effekt permanenter Konzentration im Unterrichtsalltag (PÄD LK 07 02; PÄD LK 12 03), damit verbunden einer hohen Entscheidungsdichte (PÄD LK 12 03; SK LK 01 03), geringer zeitlicher und räumlicher Möglichkeiten für Ruhepausen (PÄD LK 12 03; PF K 24 04) sowie einer unrealistischen Einschätzung der eigenen Ansprüche und Erwartungen (PÄD

27 Es sind 15 Texte innerhalb des Gesamtkorpus, die den Körper in dieser Weise thematisieren. Fünf davon sind in einer Ausgabe der Pädagogik zum Thema »Belastung und Entlastung « (7-8/3002) erschienen, drei in einer den Körper explizit thematisierenden Ausgabe des Päd Forums mit dem Schwerpunkt: "Lehrkörper - Lernwelten « (03/2004) sowie weitere Einzelartikel. Bei den AutorInnen handelt es sich vor allem um WissenschaftlerInnen aus den Disziplinen Erziehungswissenschaft, Psychologie, Medizin und Arbeitswissenschaften, außerdem schreiben einige wenige LehrerInnen bzw. GesundheitspädagogInnen.

28 An dieser Stelle wird zumindest bei der Darstellung von Ergebnissen eigener empirischer Untersuchungen meist zwischen Männern und Frauen differenziert. Frauen seien insbesondere von psychischen und psychosomatischen Erkrankungen häufiger betroffen (PF K 29 04) bzw. wiesen ungünstigere Bewältigungsmuster auf (PÄD LK 07 02: 11). 
LK 07 02; PÄD LK 08 02) angesehen. Besonders verwiesen wird dabei auf die aktive Beteiligung der Lehrenden selbst; sie seien nicht lediglich Opfer der gegebenen institutionellen Strukturen und gesellschaftlicher Erwartungen. Dabei wird ein Spannungsfeld zwischen Verhalten und Verhältnissen entworfen, das zwar auf die Notwendigkeit hinweist, bildungspolitische Arrangements sowie Arbeitsbedingungen zu verändern. Entsprechende Forderungen, die über eine allgemeine Bemerkung hinausgehen, finden sich in den untersuchten Zeitschriften jedoch kaum. Stattdessen wird beim lehrenden Individuum und seiner Verantwortung für sich selbst angesetzt, um das Problem, dass es in diesem Beruf besonders häufig zu psychischen und physischen Krankheiten kommt, zu bearbeiten. ${ }^{29}$ Exemplarisch für diese Position steht die aus dem Gesamttext hervorgehobene Einführung im Artikel von Dagmar Rohnstock, einer Lehrerin und Mediationsbeauftragten: »Untersuchungen zur Belastung von Lehrern und Lehrerinnen und Statistiken über Frühpensionierungen sprechen eine deutliche Sprache [...] Dringend erforderlich sind persönlich wirksame Entlastungsstrategien, denn auf Erleichterung durch die Bildungspolitik kann man lange warten. (PÄD LK 05 01:39) Daran schließen dann »Anregungen und Übungen für ein lehrerspezifisches Selbstmanagement« (ebd.) an. In einem ähnlichen Tenor führt Landschulrat Peter Daschner in den Themenschwerpunkt »Belastung und Entlastung« ein:

"Aber sicherlich ist das Heil nicht allein von oben oder von außen zu erwarten. Die Lehrerinnen und Lehrer selbst und das jeweilige Kollegium sind nicht nur Betroffene, sondern auch Beteiligte an den Prozessen, die Schularbeit gelingen lassen, erschweren oder zum Scheitern bringen. Deshalb sind die Fragen und Antworten nach wirksamen Formen der Prävention und gesundheitlichen Vorsorge von größter Bedeutung.« (PÄD LK 06 02: 6)

Die Notwendigkeit, Krankheit und Gesundheit von LehrerInnen zu problematisieren, zeigt sich auch in Äußerungen wie diesen: " Verhaltensprävention als selbstverantwortliche und kollegiale Förderung der Leistungsfähigkeit und Gesundheit ist ein unverzichtbarer Schritt.« (PÄD LK 09 02: 22) Es wird ein Missstand konstatiert, dem zunehmend auch empirisch nachgegangen wird und dem dringend zu begegnen sei. Die Metapher des »Schritts « ist eine, die innerhalb der Texte häufiger verwandt wird. Sie assoziiert eine zielgerichtete (körperliche) Bewegung mit einem bestimmten Abstand innerhalb eines größeren Bewegungs- und Veränderungszusammenhangs, indem von »kleinschrit-

29 Der Beitrag zum Arbeitsschutzgesetz (PÄD LK 10 02) ist der einzige, der sich im Rahmen des Themenheftes »Belastung und Entlastung « tatsächlich mit Verhältnissen beschäftigt und nicht letztlich doch vor allem die LehrerInnen auffordert, ihre Einstellung zu ändern und an sich selbst zu arbeiten. 
tige(n) Ziele(n)« (PÄD LK $0501: 41)$ und vor allem von »Schritten in die richtige Richtung« (SM LK 01 03: 5) gesprochen wird. Diese Bewegung besteht nun in den meisten Texten aus Praktiken der Prävention, die sich die raktiv beteiligten Betroffenen zu eigen machen sollten. Die AdressatInnen der Maßnahmen sind hier nicht BildungspolitikerInnen, sondern die LeserInnen der Zeitschriften: also die LehrerInnen. Ihr individuelles präventives Zutun, mit dem sie sich die eigene Situation erleichtern können, ist gefragt. Vor allem auch deshalb, so formuliert es Carsten Bangert, weil zum einen die belastenden Bedingungen kaum verändert werden könnten (sie also nicht in Bewegung geraten), und zum anderen weil »Belastung stets eine subjektive Erfahrung « sei und »die individuelle Bewältigungsstrategie jedes Einzelnen« entscheide, »ob aus einer objektiven Belastung (Arbeitsbedingungen, belastende Erlebnisse) eine positive subjektive (der Lehrer fühlt sich herausgefordert und motiviert) oder eine negative Belastung (der Lehrer fühlt sich überfordert, wird krank) wird« (PF LK 03 02: 450). Indem jede objektive, also gesellschaftliche, politische, strukturelle Rahmung und die konkreten Situationen, in denen sich die Akteure befinden und in denen sie agieren, in eine individuelle Bewältigungsstrategie übersetzt und als individuelles Problem behandelt wird, bedarf es keiner »Bewegung « und keiner Kritik dieser objektiven Faktoren mehr. ${ }^{30}$

Aber nicht nur aufgrund von Ausfällen durch kranke LehrerInnen, die psychisch belastet sind und deren Körper versagt, bedarf es der präventiven Bearbeitung des konstatierten Problems. Mit ihm wird nämlich ein weiteres Problem verbunden, das im Anschluss an die von mir herausgearbeiteten Prämissen nahe liegt: Kranke und überforderte LehrerInnen sind kein Vorbild in einer Schule, deren Auftrag unter anderem auch in einer Gesundheitserziehung besteht (PÄD LK 10 02; PF LK 02 95; s. auch Hess. Schulgesetz §6(4)). Es werden also nicht nur der Schutz von Arbeitnehmenden in der Institution Schule, sondern auch professionelle Gründe angeführt: »Wenn Lehrkräfte ihren Schülerinnen und Schülern Gesundheit und Leistungsbereitschaft vermitteln wollen, müssen sie beides überzeugend vorleben.« (PÄD LK 09 02: 23) Mit dem »Bild eines professionellen Bergführers« gesprochen, dürfe der Pädagoge »anderen keinen Halt geben, wenn er selbst keinen hat, denn sonst stürzen beide in die Tiefe. Ebenso sind professionelle Pädagogen zu einem pfleglichen Umgang mit sich selbst verpflichtet.« (ebd.: 26) Angeführt wird hier das Beamtengesetz $§ 54$ BBG, womit, diesen Grundsatz verstärkend, nicht

30 Nicht alle Texte sind so konsequent individualisierend. Hin und wieder wird die Seite der "Verhältnisse « deutlicher in die Kritik genommen (PÄD LK 07 02; PÄD LK 10 02) oder zumindest darauf verwiesen, dass subjektive Stabilisierungspraktiken die »Empörung « über »gesellschaftliche Missstände und strukturelle Unzulänglichkeiten am Arbeitsplatz« nicht »betäuben oder abtöten« sollten (PÄD LK 08 02: 20). 
nur eine moralisch-professionelle, sondern auch eine rechtliche Kategorie ins diskursive Spiel gebracht wird. Ebenso betrachtet Daschner die "physische und psychische Stabilität der Lehrkräfte [als, A. L.] eine unabdingbare Voraussetzung für das Gelingen von Erziehungsprozessen« (PÄD LK 06 02: 7). Um das zu gewährleisten, bedarf es eines »sehr disziplinierte(n) Selbstmanagement(s)« (PÄD LK 08 02: 14). Dies zeigt sich besonders in den dazu vorgeschlagenen Maßnahmen und Übungen, die sich zu einem großen Teil wieder auf den Körper beziehen, womit er diskursiv (und im Falle der praktischen Umsetzung) zum Objekt einer Bearbeitung wird, um den kranken Körper als Problem zu bewältigen. Der Körper, welcher als kranker überwunden werden soll, ist also zugleich das Medium der Überwindung (vgl. Duttweiler 2003: 41). Was zeichnet nun die Praktiken aus, die den gesunden Körper zum Ziel haben? Inwiefern unterscheiden sie sich von denen, die für die bzw. in der Unterrichtsinteraktion eingesetzt werden sollen?

Um diese Fragen zu beantworten, betrachte ich zunächst wieder die Art von Interaktionsbündnis, das die LeserInnen mit den zur Debatte stehenden Texten eingehen können. Nicht alle Texte warten mit praktischen Übungen auf, um das oben genannte Ziel des »Selbstmanagements« oder der Prävention in Angriff nehmen zu können. Jedoch changieren viele Texte, auch wenn es sich nicht explizit um das Genre Ratgeber handelt, zwischen swissenschaftlichen Texten und Ratgeberanteilen hin und her. Das macht sie in besonderer Weise affirmativ. Sie operieren weniger mit der direkten Anrede, schaffen allerdings durch eine empirisch belegte Ausgangssituation, die sehr viele LehrerInnen betrifft - nämlich eine hohe Krankheitsquote, der frühzeitige Ausstieg aus dem Beruf und allgemein eine hohe Be- bzw. Überlastung - eine Gemeinsamkeit für die LeserInnen, die ihnen als potenziell ebenfalls Betroffene die nachfolgenden Reflexionsfragen, Tests und Übungen geradewegs auferlegt. Beispielsweise indem ein Absatz derart begonnen wird: »Über zwei Drittel der Lehrer leiden unter dem verbreitet ungünstigen Lehrerimage [...] und übergeht in »Um seine professionelle Selbstüberzeugung so stabil wie möglich zu halten, sollte jeder Lehrer gezielte und regelmäßige Maßnahmen des Selbstaufbaus praktizieren [...] (PÄD LK 05 01: 39; Herv. A. L.). Es wird eine umfangreiche »Leidensgemeinschaft« ausgemacht, deren Situation dazu auffordert, dass »jeder Lehrer«, auch der, der (noch) nicht zu dieser Gemeinschaft gehört, sich gezielt um präventive oder das Problem bearbeitende Maßnahmen bemüht.

Eine anderer Variante des Interaktionsbündnisses zwischen Text und Lesenden ist folgende: Indem sich die LeserInnen anhand von Statistiken über verschiedene Typen im Umgang mit Belastungen (PÄD LK 07 02) sowie anhand von typisierten und tabellarisch dargestellten Handlungsschemata (PÄD 
LK 08 02; PÄD LK 09 02; SM LK 01 03; SM D 02 96) selbst einzuschätzen wissen, können sie ihre subjektiven Empfindungen in generalisierte und objektivierte Kategorien einordnen und sich so in ein (vorstrukturiertes) Verhältnis zu anderen LehrerInnen setzen. Die Texte halten die Lesenden zu einer eigenen Positionierung in einem normativ gegliederten Feld an. Die Verortung bleibt jedoch insofern auf sich selbst bezogen, als dass, anders als bei Psychotests in Illustrierten, keine anschließende Punktezahl vergeben wird, die eine »eindeutige « Zuordnung des eruierten Handlungsmusters oder -typs innerhalb eines vorgegebenen Rasters nach sich zieht bzw. möglich macht.

Diese Tests setzen allerdings nicht in erster Linie am Körper an. Fokussierend auf die Thematisierung von Körper(lichkeit) sind es vor allem wieder Vorschläge für Übungen, die als »Maßnahmen des Selbstaufbaus« (PÄD LK 05 01: 39), »Verhaltensprävention « (PÄD LK 09 02: 22) oder »Entlastungsstrategien « (PÄD LK 05 01:39) gedacht werden. An zwei Beispielen möchte ich näher betrachten, wie der Körper in diesen programmatischen Übungen relevant und welcher Modus der Selbstbearbeitung dabei gegenständlich wird. Das erste Beispiel stammt aus einem Ratgebertext mit dem Titel: »Endlich wieder abschalten können! Anregungen und Übungen für ein lehrerspezifisches Selbstmanagement«:

„Verstärktes Anspannen - bewusstes Loslassen: Spannen Sie bewusst alle Muskeln Ihres Körpers an, halten Sie die Spannung und spüren Sie in das Gefühl der Anspannung hinein, aber atmen Sie normal weiter. Lassen Sie dann nach ca. 5-10 Sekunden plötzlich alle Muskeln locker und lassen Sie sich bewusst nach vorn sinken. Spüren Sie jetzt das Loslassen im ganzen Körper. […] (PÄD LK 09 02: 43; Herv. i. O.)

Das zweite Beispiel stammt aus einem Artikel, den unter dem Titel: »Der erfahrbare Atem. Ein Weg, sich im Leib wohlzufühlen« in einer der Zeitschriften erschienen ist, die den Körper zum Gegenstand ihres Schwerpunkts machen.

"Sie sitzen auf einem Hocker oder Stuhl mit gerader Sitzfläche und beschreiben um die Sitzhöcker, die beiden Knochen im Gesäß, einen Kreis mit dem Becken. Die Fußsohlen stehen auf dem Boden. Wechseln Sie nach einer Pause die Richtung. Die Atembewegung wird tiefer, der Atemrhythmus verlangsamt sich - Sie werden ruhiger.« (PÄD K 07 96: 11)

Beiden Texten ist gemeinsam, dass sie die Lesenden in direkter Anrede anhalten, eine Übung mit ihrem Körper durchzuführen, die entspannende Effekte mit sich bringen soll. Sie leiten mit genauen Anweisungen dazu an, welche Körperhaltung bzw. -bewegung mit welchen Hilfsmitteln oder wie lang einzu- 
nehmen bzw. durchzuführen ist. Das Spüren der Atmung und - in diesen Beispielen nicht erwähnt, aber sonst häufig ebenfalls Teil der Übungen - das Schließen der Augen sollen helfen, die Wahrnehmung des eigenen Körpers in Gang zu setzen. Die Wahrnehmung wird damit zu einer ausschließlich auf sich selbst gerichteten (anders als z. B. die Selbstbeobachtung im Spiegel). In beiden Übungen wird ein Wechsel von An- und Entspannung des Körpers zum Gegenstand. Analog dazu kann das in vielen Texten formulierte Ziel bzw. als didaktische Praktik vorgestellte Mittel, Anstrengung und Entspannung, Bewegung und Ruhe in der pädagogischen Arbeit zu rhythmisieren, verstanden werden. Rohnstock bezeichnet diese Rhythmitisierung als eine »Fähigkeit«, welche Voraussetzung für eine vernünftige gesunde Anspannung sei (PÄD LK 12 03: 19). Diese Fähigkeit nicht zu »besitzen«, kann die oben diagnostizierte Überlastung zur Folge haben. Sie kann allerdings erlernt werden: mit einer solchen Übung, die gänzlich auf den eigenen Körper und nicht auf eine Umwelt bezogen ist.

Ähnlich lässt sich auch das zweite Beispiel lesen. Mit der eingenommenen Haltung und der Bewegung verändert sich etwas unmittelbar. Diese Veränderung kann und soll gespürt werden. Sie wird in beiden Anleitungen vorweg genommen, das Gefühl bereits benannt: als ein »Loslassen « und »Ruhiger Werden«. Wie es sich dann bei der einzelnen Person, die die Übung durchführt, genau anfühlt, was sie tatsächlich wahrnimmt, bleibt zwar offen, bekommt jedoch eine Richtung, in die sich die Praktizierenden orientieren können, die sie in ihrer Wahrnehmung aufnehmen können. Der jeweils am Schluss formulierte Effekt bietet außerdem bereits beim Lesen Orientierung, ob und für welche Übungen ich als LeserIn mich entscheide, welchem Ziel ich selbst näher kommen möchte oder kommen sollte.

Der Atem und das Verhältnis vom angespannten und entspannten Körper nehmen in den Übungen im Allgemeinen und zumindest in diesen beiden Texten eine spezifische Rolle ein. Rohnstock thematisiert die Atmung »als grundlegende vegetative Funktion«, die »eine enge Verbindung zu Gefühlen, Gedanken und Körperprozessen hat (PÄD LK 04 01: 43). Indem sie beeinflusst wird, trage sie "gezielt zum inneren Abschalten und Beruhigen« (ebd.) bei. Körperhaltung, Atmung und innere Einstellung werden in ein Wechselverhältnis gebracht. Mit den Übungen sollen Spannung und Stress »weggeatmet« werden, indem zugleich die Vorstellungskraft eingesetzt wird, dass dies geschehe. Es sind nicht nur jeweils einzelne Praktiken oder Atemtechniken, um An- und Entspannung zu erzeugen, sondern beide Zustände sind mit Bedeutung überfrachtet. Um effektiv und gesund zu bleiben, sei es nötig »loszulassen« (PÄD LK 12 03: 20). Gesundheit und Effektivität werden hier miteinander verknüpft: Effektives Entspannen ist gefragt. Es geht nicht darum, ein- 
fach mal »nichts« zu tun, sondern darum, zielgerichtet und selbstverantwortlich mittels bestimmter Körperpraktiken und Übungen für sich selbst zu sorgen. Die Idee des »Loslassens« verspricht Heilung von der ausgemachten Überforderung. »Selbsterlösung durch Lösung von Ver- und Anspannungen« - so fasst es Stefanie Duttweiler in ihrer Analyse moderner Wellness-Diskurse zusammen (vgl. Duttweiler 2003: 39). Dort mache insbesondere das »Loslassen« mittels Entspannungstechniken ein zentrales Element aus, das suggeriert, sich selbstverantwortlich gegen Störungen nach Innen und Außen abschirmen zu können. Wenn das eigene Innenleben zur Richtschnur des Handelns wird, wird mit der persönlichen Verantwortungsübernahme dafür zugleich von äußeren Bedingungen und Möglichkeiten einer Entscheidung abstrahiert.

Auch Brigitte Wellner-Pricelius stellt eine Verbindung von Innen und Außen her: Der Atem verbinde Individuum und Umwelt. Die Atemübungen, die sie als »Atemarbeit« bezeichnet, begreift sie nicht als oberflächliche Körperbearbeitung, sondern als »persönlichkeitsbildende Leistung« (PÄD K 07 96: 13), die auch als Bewusstwerdungsprozess bewertet werden kann. Ein leiblich geschaffenes allgemeines »Wohlbefinden« diene ebenso der Gesundheitsherstellung und -vorsorge wie der Stärkung eines professionellen Selbst. Gerade weil die auf Disziplinierung der Körper ausgerichtete Institution Schule eine körperfeindliche Sozialisation für LehrerInnen und SchülerInnen begünstige und damit ein spezifisches Verhältnis von Körper und Selbst herstelle, seien wahrnehmungsfördernde Übungen mit dem eigenen Körper nötig und mit der von ihr vorgestellten Atemarbeit eine bewertungsfreie und konkurrenzlose Körperarbeit möglich. Anschließend an die Prämisse der Übertragbarkeit folgert die Autorin: »Je mehr ich selbst mich in meinem Leib wohlfühle, Disziplinierung und Entfremdung in mir auflöse, desto eher kann ich ein derartiges Lernen SchülerInnen ermöglichen.« (PÄD K 07 96: 13) Der Körperfeindlichkeit der Schule kann und soll also mit dem Körperbewusstsein von LehrerInnen begegnet werden, welches sich dann auch auf deren SchülerInnen übertrage.

Diese Übungen zur Selbstsorge gehen über das Einüben von Körpertechniken für die bzw. in der Interaktion mit SchülerInnen insofern hinaus, als sie einen deutlicheren Bezug zum Selbst eines Individuums fordern bzw. annehmen. Sie betonen Eigenverantwortlichkeit und Individualität der Lehrenden, die sich nicht nur auf deren Unterricht beschränken, sondern im Rahmen einer gesunden Lebensführung gesehen werden. Wohlfühlen und ein gesunder Rhythmus von Belastung und Entspannung, unterstützt durch verschiedene Formen von Körper- oder auch Selbstpraktiken, sollen Defizite beseitigen und Berufs- und Lebenszufriedenheit schaffen, womit ein enges, ineinander über- 
gehendes Verhältnis von Arbeit und Leben konstruiert wird (vgl. Langer/ Ott/Wrana 2006: 294). Sie gehen in den meisten Texten auch mit der Herstellung und Steigerung von Leistungsfähigkeit einher oder, wie z. B. Kretschmann das Ziel seines Trainingsprogramm formuliert, mit der »Steigerung individueller und kollektiver Bewältigungskompetenz« (PÄD LK 08 02; 15). Die Übungen, sowohl in der Art der oben vorgestellten direkt am Körper ansetzenden als auch die alltagspraktischen Veränderungen aufgrund einer bestimmten Selbsteinschätzung, sind Übungen zur Selbstführung und somit Subjektivierungspraktiken. Sie sind weniger an konkreten normierenden Zielen ausgerichtet, wie z. B. die »Disziplinierungshaltung«, die einen möglichst störungsfreien Unterricht schaffen soll, sondern versprechen Steigerung und Balance im Wechselspiel. Ziel ist eine Lebensweise, bei der Gesundheit zu einer möglichst selbstbestimmten Größe wird (PF LK 02 95: 24). Damit gehen sie über das Erlernen einer Körpertechnik hinaus, das analog der Handhabe eines Instruments gesehen werden könnte.

Einer solchen Führung seiner selbst werden Effekte zugeschrieben, die miteinander verbunden sind: Das gezielte Selbstmanagement, um stressfrei arbeiten zu können, stärkt die LehrerInnen in ihrer Gesundheit und ihrem professionellen Selbst. Das Managen betrifft aber nicht nur das Funktionieren als Arbeitskraft, sondern es ist das Potenzial der ganzen Person gefragt - wie es Bröckling für die Figur des »Unternehmers seiner selbst « herausgearbeitet hat (Bröckling 2000: 155). In dieser Gesamtheit wird es selbst zu einer vorbildlichen Führungspraktik, die nun den SchülerInnen vorgeführt werden kann. Über dieses Vorbild hinaus, dem nachgeeifert werden könnte, sollen und können die SchülerInnen innerhalb des Unterrichts bzw. in speziell geplanten Schulstunden oder -tagen ebenso in körperbezogene Übungen eingebunden werden. Die mit dem Selbstmanagement einhergehende verantwortungsvolle und effektivierende Haltung zu sich und seinem Körper bekommen sie einerseits vorgelebt, andererseits können sie diese auch selbst erfahren, durchführen und üben und letztlich so lernen, um sich selbst zu sorgen. Das Selbstmanagement der Lehrenden wird durch die Kopplung mit der Idee bzw. dem Auftrag verstärkt, als Person Vorbild zu sein.

\section{Körperpolitiken zwischen Professionalität und Selbst}

Ich habe aufgezeigt, wie der Lehrkörper als ein Medium konstituiert wird, um eindeutige Interaktionen in Unterrichtssituationen zu schaffen, eine bestimmte innere Haltung zu veräußerlichen sowie Kontakte und Beziehungen innerhalb pädagogischer Situationen herzustellen und aufrechtzuerhalten. Zum einen habe ich didaktische Praktiken herausgearbeitet, die spezifische Beziehungen 
zwischen Lehr- und Lernkörpern produzieren, zum anderen Körpertechniken, mit denen die Lehrenden an und mit ihrem Körper arbeiten (sollen) und die die Schaffung des professionellen Lehrkörpers selbst sowie Gesundheitsprävention zum Ziel haben. Welche Prämissen liegen diesen diskursiven Körperpraktiken zugrunde? Gibt es Ziele, die über die unmittelbare Unterrichtsinteraktion, »guten Unterricht« bzw. Arbeitsfähigkeit hinausgehen?

Eine erste Prämisse lässt sich mit den Begriffen Reziprozität oder Spiegelung umschreiben. Wenn in den Texten die nonverbale Kommunikation oder die Körpersprache der Lehrenden besonders betont wird, fußt dies auf der Annahme und der Erfahrung, dass die Gesamtwirkung einer Person und ihrer präsentierten Inhalte wesentlich vom Eindruck abhängt, den sie mit ihrem Körper, ihrer Stimme und Sprechweise erzeugt, und dass dieser Eindruck vom Publikum - also den SchülerInnen - körperlich und verbal gespiegelt wird. Die Aufmerksamkeit der SchülerInnen korrespondiert mit der Sprechweise der Lehrkraft: »Eine müde Stimme macht niemanden munter« oder »Wer andere in Atem halten will, darf selber nicht außer Atem kommen « (SM LK 07 96: 4). Diese Sätze lesen sich wie Volksweisheiten, sie sind dementsprechend eingängig, zumal man sie meist aus eigener Erfahrung bestätigen kann. Schlussfolgernd gilt es, Körperpraktiken zu vermeiden, die ungewollte (negative) Reaktionen hervorrufen könnten. Es ist die Idee einer wechselseitigen Übertragung, die dem zugrunde liegt.

Die Vorstellung einer reziproken Übertragung von Körperhaltungen und Stimmungen basiert häufig auf einer zweiten Prämisse, die sich metaphorisch mit verbaler Sprache als Teilmenge von körperlicher Sprache umschreiben ließe: Insbesondere in den zuletzt untersuchten Texten wird Körpersprache als "primäre« und als »ursprüngliche« Sprache thematisiert. Begründet wird dies zum einen evolutionsgeschichtlich, da die verbale Sprache erst später hinzugekommen sei, und zum anderen damit, dass das Nonverbale einen wesentlich höheren Anteil am Kommunikationsgeschehen habe als das Verbale und dem Sprachlichen in der Interaktion bereits immer vorausginge (PÄD LK 14 98; SM LK 06 02; SM LK 07 96). Das Körpersprachliche umkleidet hier gewissermaßen das Verbalsprachliche.

Ebenfalls anknüpfend an die Idee der Übertragung lässt sich die dritte Prämisse als körperlich-symbolische Steuerung formulieren. Diese Thematisierung des Lehrkörpers als Mittel in schulpädagogischen Interaktionsprozessen stellte ich ausführlich im Kapitel sDer Lehrkörper als Medium pädagogischer Praxis` dar. Hier wird auf die Performanz körperlicher Zeichen zum Teil im Zusammenwirken mit anderen Artefakten (meist Mobiliar des Schulraums oder Medien zur Unterrichtsgestaltung) verwiesen, mit der vor allem Rahmungen vorgenommen werden und Eindeutigkeiten geschaffen werden sol- 
len. Damit wird körperlichen Zeichen bzw. der Symbolik von Körperpraktiken im Zusammenhang mit transparenten Regeln eine hohe Präzision und Wirksamkeit zugeschrieben.

Zentral ist auch die vierte Prämisse: Der Lehrkörper bzw. allgemeiner die Lehrkraft gibt ein Vorbild für die SchülerInnen ab. Es gelte - nicht nur, aber wesentlich auch körperlich - ein Bild von sich zu präsentieren, das von den SchülerInnen als glaubwürdig empfunden werde. Die Qualifikation, die Lehrende beispielsweise bei einer Präsentation von ihren SchülerInnen erwarten, sollten sie auch selbst erfüllen (SM LK 06 02). In der Regel wird den LehrerInnen eine individuelle Zuständigkeit für ihre Vorbildwirkung zugeschrieben.

Auf diesen Prämissen beruhend lässt sich eine zentrale Aussage in den untersuchten Texten benennen: Selbstbearbeitung, Selbstdisziplinierung und Selbstsorge der Lehrenden, die zu einem großen Teil am Körper ansetzen, sind ausschlaggebend für eine aktivierende Fremd- und Selbstdisziplinierung der SchülerInnen. Diese macht sich auf zwei verschiedene Weisen fest. Einmal, indem für eine ruhige Unterrichtsatmosphäre Verantwortungsübertragung (SM D 02 96), Selbstbeobachtung (SM D 05 03) oder das Lernen einer freiwilligen Selbstkontrolle (SM D 08 02) im Zusammenhang mit den ritualisierten (Körper-)Praktiken von LehrerInnen als Ziel formuliert werden. Kohler zieht für die Art der Beobachtung und des Nachahmens durch SchülerInnen die traditionelle Handwerkslehre als Analogie heran (SM D 03 00: 11). Ziel ist letztlich aber nicht nur, dass die SchülerInnen aufmerksam sind, das richtige Verhalten an den Tag legen und motiviert den Unterricht verfolgen, sondern dass sie sich selbst beobachten, beispielsweise indem sie evaluieren, wer sich wie oft korrekt gemeldet hat (SM D 05 03: 56), und, führt man den Gedanken weiter, dass die Praktiken der Lehrkraft weniger stark zum Einsatz kommen müssen. Angedacht ist, dass es die SchülerInnen selbst sind, die Ruhe einfordern und deshalb das ritualisierte Zeichen einsetzen. ${ }^{31}$

Die Aussage, dass aus der Selbstdisziplinierung der LehrerInnen die der SchülerInnen folge, leitet sich zweitens daraus ab, dass die Methoden der Bearbeitung des Körpers selbst zum nachahmenswerten Vorbild werden. Es ist nicht nur das Erlernen von Körpertechniken (Mauss 1978), wie es exemplarisch das Einüben der »Disziplinierungshaltung « zeigt, das analog der Handhabe eines Instruments verstanden werden kann. Vielmehr wird »die Sorge um sich selbst [...] zur Arbeit an sich, und sie wird zur Sorge um Produkte

31 Die didaktischen Praktiken, die für Disziplin und eine ruhige Arbeitsatmosphäre sorgen sollen, werden häufig von LehrerInnen an sog. Freien Schulen mit reformpädagogischen Ansätzen vorgestellt, so dass der Schwerpunkt auf die Selbsttätigkeit der SchülerInnen auch bei der Strukturierung und Ritualisierung von Unterricht und nicht nur in Bezug auf Unterrichtsinhalte auch wegen dieses pädagogischen Hintergrunds besonders präsent sein könnte. 
dieser Arbeit an sich« so Stefan Rieger (2002: 82). Die Selbstsorge, die von den LehrerInnen gefordert wird, geht über das Üben von Körpertechniken hinaus, indem es um die Bildung eines "professionellen Selbst « (PÄD LK 11 97) geht, das sich in eben jenem reziproken Übertragungsgefüge befindet, oder Körper- und Stimmarbeit als »Persönlichkeitsbildung (SM LK 07 96: 11) bzw. »tiefgreifende persönlichkeitsbildende Leistung « (PÄD K 07 96: 13) angesehen wird. Sie geht auch darüber hinaus, wenn den Lehrenden Präventivpraktiken nahegelegt werden, um einerseits funktionstüchtig zu sein und andererseits ein positives Bild von Gesundheitsmanagement abzugeben und in ihrer Vermittlung an die SchülerInnen glaubwürdig zu sein.

Es fällt auf, dass die Forderung einer Problematisierung der Problematisierung des kranken Körpers bzw. einer präventiven Gegensteuerung erst seit fünf Jahren erhoben wird. ${ }^{32}$ Kein anderer Zusammenhang, in dessen Rahmen Körper(lichkeit) thematisiert wird, erfährt im untersuchten Zeitraum eine so offensichtliche Konjunktur. Sie geschieht innerhalb individualisierender Gesundheits- und Risikodiskurse, die in den letzten Jahren viele Bereiche - nicht nur medizinische - durchziehen (vgl. Lemke 2000, 2004: 7ff.). Die starke Verknüpfung von Körper- und Gesundheitsfragen zeigt sich auch bei den Texten, die explizit den Körper von LehrerInnen oder SchülerInnen thematisieren (Päd Forum 3/2004). Weshalb der Blick jedoch vor allem auf Gesundheit gerichtet wird, bleibt dort allerdings unklar und erscheint nicht zwingend notwendig. Oder doch? Müssen die lehrenden und lernenden Körper andere oder besonders produktiv sein? Es fällt jedenfalls auf, dass der Körper als kranker oder potenziell krankender als Problem entworfen wird, das nachträglich heilend oder präventiv bearbeitet werden muss. Im Sinne des knapp zehn Jahre zuvor entworfenen Bildes einer »Wiederbeleibung« (PF K 15 96: 472) in einer programmatischen Gegenüberstellung von Körper und Leib (vgl. Kap. `Körper als Problem () ließe sich das Erkranken ja auch als Widerstand bzw. Selbstschutz jenes unkontrollierbaren, mit einem Eigenleben versehenen Leibes interpretieren. Genau dies wird aber nicht getan. Vielmehr wird in einer so motivierten Selbstsorge die Durchdringung von äußeren Imperativen und eigenen Bedürfnissen plausibilisiert, die letztlich doch auf Funktionalität und Nützlichkeit ausgerichtet ist. Der sinnliche Körper - in der Schule übergangen - wird dann mittels Entspannungstechniken zur Reproduktion im mehr oder weniger Privaten zum Objekt. Dabei sind es nicht nur jeweils bestimmte Körperpraktiken, mit denen auch Normen und Werte inkorporiert

32 Ausgenommen der Artikel »Wie steht es um die Gesundheit der Gesundheitsförderer? Kritische Anmerkungen zu Konzepten schulischer Gesundheitsförderung " von Gisela Quentin (PF LK 02 95), in dem sie bereits 1995 einen mangelnde Gesundheitszustand von LehrerInnen und vor allem dessen fehlende Problematisierung konstatiert. 
werden, die sich langfristig habitualisieren, sondern es wird zugleich eine bestimmte Haltung zum Körper vermittelt, die sich selbst und dem eigenen Körper gegenüber eingenommen werden sollte.

Zusammenfassend verdeutlichen die Analysen, wie der Lehrkörper bzw. der Körper der Lehrenden sowohl in Bezug auf sich selbst als auch in Interaktion zu anderen problematisiert und als Medium, Ziel, Objekt oder Problem konstituiert wird. Eine körperbewusste Lernkultur setzt in den meisten Texten zunächst am Lehrerkörper an. Der Ansatz, »mit dem Körper zu lernen«, wie eine der Zeitschriften titelt (Pädagogik 6/1996), scheint demnach nur dann praktikabel zu werden, wenn die Lehrenden sich eben auch mit ihrem Körper darauf einlassen und Lehren und Lernen durch ihren Körper hindurch geschieht. 


\section{Körperliche Bezugnahme als Aspekt pädagogischer Beziehungsarbeit}

Während in den vorangegangenen Kapiteln der Fokus meist entweder den LehrerInnen oder den SchülerInnen galt, komme ich zum Abschluss der Analyse noch einmal verstärkt auf die Interaktionen zwischen beiden zu sprechen. Ausgangspunkt ist die verhältnismäßig häufige Beobachtung körperlicher Berührungen seitens der Lehrerinnen gegenüber den SchülerInnen. Bei näherem Hinsehen handelt es sich um Kontakte ganz unterschiedlicher Art, die je nach Gegenüber differenziert werden. Da die Beobachtungen für die Forschungsgruppe bemerkenswert schienen und so nicht erwartet wurden, möchte ich die Irritationen aufgreifen und der Frage nachgehen, welche Rolle körperliche Bezüge zwischen LehrerInnen und SchülerInnen sowie umgekehrt spielen und inwiefern dies auch zum Thema wird. Wie wird über körperliche Nähe und Berührungen geredet? Es zeigt sich, dass erneut Themen angesprochen werden, die bereits Gegenstand meiner Untersuchung waren (Gender, Pubertät) aber auch soziale und kulturelle Positionen - eine wichtige Dimension, die bisher unberücksichtigt blieb. Ebenso wird deutlich, wie wenig diese Ebene pädagogischer Beziehungen zur Sprache kommt.

\section{Körperkontakte im Unterricht: Beobachtungen}

Die beiden Lehrerinnen wirken sehr vertraut mit ihrer Schulklasse, die sie seit zwei Jahren unterrichten. Es fällt auf, wie sehr die beiden auch körperlich auf ihre SchülerInnen Bezug nehmen: dass sie sich zu ihnen hinunterbeugen, um auf eine Höhe zu kommen, dass sie sich nähern, um leiser sprechen zu können. Manchmal streichen sie einem der Jungen über den Rücken oder packen ihn freundschaftlich am Kragen. Auf den ersten Blick nehmen die Lehrerinnen jede(n) Einzelne(n) ernst. Dagegen 
wirkt die Fach-Lehrerin viel distanzierter. Wenn sie in der Klasse umher geht, bleibt sie aufrecht, beugt sich nicht zu den SchülerInnen herunter. (AL)

Den BeobachterInnen fallen die häufigen Körperkontakte zwischen den Lehrerinnen und den SchülerInnen besonders auf, ebenso wie die Unterschiede in dieser Bezugnahme. Immer wieder finden sich ähnliche Stellen in den Protokollen: Dem einen Jungen streicht eine Lehrerin beim Kontrollieren der Aufgaben während des Rundgangs durch die Klasse über den Kopf, dem anderen legt sie die Hand auf die Schulter. Da während des Unterrichts keine Kappen getragen werden sollen, werden sie den Schülern ab und zu mit einem eindringlich mahnenden Blick in die Augen sanft vom Kopf genommen. Die Lehrerinnen setzen sich neben die SchülerInnen auf den Tisch, beugen sich zu ihnen hinunter. Oder sie hocken sich vor oder neben sie, um mit ihnen auf Augenhöhe zu sein. Sie schauen ihnen in die Augen, lächeln sie an, vermitteln Nähe, Offenheit und Zuneigung. Eine Beobachterin schreibt dazu:

Die Nähe äußert sich verbal und körperlich. Verbal sind kleine Bemerkungen, Gespräche oder Fragen, die sich zwischen den Lehrerinnen und einzelnen SchülerInnen abspielen. Die Lehrerin geht dabei gezielt zu einem Schüler oder auch umgekehrt, und es werden flüsternd Dinge besprochen, die dem Rest der Klasse verborgen bleiben. Körperliche Nähe zeigt sich in kleinen Berührungen, Hieben, Stößen etc. zwischen Lehrerinnen und Schülern. Die körperliche Nähe kann ich jedoch nur zwischen den Jungen der Klasse und den Lehrerinnen beobachten. (SR)

In den Beschreibungen werden bestimmte körperliche Gesten der Lehrerinnen dargestellt, die im Unterricht häufig zu beobachten sind. Dabei handelt es sich um direkte und indirekte Körperkontakte. Als direkten Körperkontakt begreife ich z. B. einen Kniff in den Nacken oder das Legen der Hand auf die Schulter. Indirekte Körperkontakte sind beispielsweise ein eindringlicher Blick und das Annähern auf gleicher Augenhöhe. Hier unterscheide ich deshalb, da die zweite Variante eigentlich keinen Körperkontakt im engeren Sinne einer Berührung zweier Körper darstellt. Dennoch findet eine spezifische Kontaktaufnahme körperlicher Art, eine sinnliche Wahrnehmung statt. In beiden Fällen kann dieser Kontakt von Worten begleitet werden. Durch diese Art der Kontakte vermitteln sich eine von Vertrauen gekennzeichnete Beziehung sowie eine individuelle Bezugnahme auf den einzelnen Schüler bzw. die einzelne Schülerin innerhalb der Schulklasse. Deren Individualität wird innerhalb homogenisierender Schulstrukturen (vgl. Höhne 2003b: 221-223) durch eben jene Praxis der Lehrerinnen hergestellt. Es sind bestimmte Situationen, in denen solche Körperkontakte zu beobachten sind: nicht bei einer frontalunterrichtlich organisierten Abfrage von Wissen oder bei einem monologischen 
Vortrag an die gesamte Klasse, sondern meist dann, wenn die SchülerInnen mit Aufgaben beschäftigt sind und die Lehrerinnen durch das Klassenzimmer gehen, sie aufsuchen und sich ansehen, wie die Bearbeitung der Aufgaben voran geht. Dass diese körperliche Bezugnahme nicht immer so sein muss, wird in der Schilderung der Beobachtung der Fachlehrerin deutlich. Sie bleibt aufrecht und blickt von oben auf die Arbeiten der SchülerInnen herab. In einem weiteren Protokoll schreibt eine Beobachterin dazu:

Während die beiden Klassenlehrerinnen meist vor den SchülerInnen durch die Klasse gehen, sie dabei anschauen können, geht Frau Kilian hinter ihnen entlang. Sie schaut ihnen über die Schulter, so dass sie nicht sehen können, was sie gerade tut. (AL)

Hier zeigt sich nicht nur die Distanz, die über mehr körperlichen Abstand zueinander hergestellt wird, sondern dem Blick von oben folgt der von hinten. Für die SchülerInnen kann er als Anschleichen und als schwer einschätzbare Gefahr im Rücken interpretiert werden, denn eine Reaktion der kontrollierenden Lehrerin kann so von ihrem Gesicht nicht abgelesen werden. Zumindest nicht von der jeweils betreffenden Schülerin, von deren MitschülerInnen, die ihr in U-Form sitzend zugewandt sind, potenziell schon. Diese Gefahr kann als Unbehagen erlebt werden, zugleich aber auch als Herausforderung, beispielsweise unerlaubte Briefe oder andere Gegenstände, die im Unterricht nichts zu suchen haben, der Kontrolle vorzuenthalten. Für die Lehrerin ist eine solche Perspektive möglicherweise leichter, sie kann in den Heften der SchülerInnen lesen, ohne sie herumzudrehen (und sich bereits damit der Schülerin zuwenden zu müssen). Zudem hat sie so die gesamte Klasse im Blick. Aufmerksamkeit für ihre Anwesenheit stellt sie bei einem Hilfe- und Kontrollgang durch die Klasse in jedem Fall her, für die Gefahr im Rücken ebenso wie für das offensive und zugleich beobachtbare Zugehen von vorn.

Den Beobachtenden signalisieren die unterschiedlichen Weisen der Kontaktaufnahme verschieden starkes Interesse am einzelnen Schüler. Sie verstehen dies als Zuwendung und als ein Ernstnehmen ihrer Person. Ebenso könnten sie als besonders intensive Form der Kontrolle aufgefasst werden. ${ }^{1} \mathrm{Mit}$ den jeweiligen Gesten und der Art des Körpergehabes konstituieren sich die Lehrerinnen aber auch als Lehrerin eines bestimmten Schulfachs, das ihr Handlungsgebiet und ihre Zuständigkeit begrenzt, bzw. als Klassenlehrerin, die zugleich mehr ist als eine Wissensvermittlerin von bestimmten Unterrichtsinhalten. Das wird später auch noch einmal in den Interviews deutlich. Die Unter-

1 Die Art und Weise von Nähe und Distanz, die Dauer und Motive für die Herstellung von Nähe durch (Grundschul-)Lehrerinnen hat Werner Sacher (2000) untersucht. Als Motive nennt er 1. Unterstützung, 2. Attraktivität durch Leistung und Mitarbeit sowie 3. Disziplinierung und Stimulation (ebd.: 33f.). 
schiede im Bezug können so auch innerhalb eines jeweils spezifischen fachkulturellen Habitus erklärt werden, wie Willems (2007: 165ff.) anschaulich für die Lehrkräfte im Physik- bzw. Deutschunterricht an einem Gymnasium zeigt.

Neben den spezifischen Unterrichtssituationen, in denen sich Körperkontakte beobachten lassen, zeigt sich, dass es auch spezifische SchülerInnen sind, die in solche körperlich nahen Interaktionen einbezogen werden. Nicht nur diese eine Beobachterin stellt fest, dass die Lehrerinnen in der beschriebenen Weise vor allem auf Jungen zugehen. Dies ist zunächst einmal ein interessanter Beobachtungsbefund, der im Zusammenhang mit den Interviewaussagen der Lehrerinnen zu interpretieren ist. Sehr wohl unterscheiden sie da zwischen einzelnen SchülerInnen, dass sie nicht allen gleichermaßen nahe sind und nahe kommen und dass sich in diesen Verhältnissen mit der Zeit auch etwas verändert. Eine grundsätzliche geschlechtsspezifische Unterscheidung, wie sie beobachtet wurde, sehen sie allerdings nicht. Ihren eigenen, interessanterweise gleichgeschlechtlichen Ausschluss bemerken sie nicht.

Die Ausrichtung auf bestimmte Personen macht aber noch auf etwas anderes aufmerksam: Die SchülerInnen beobachten ebenfalls, wie sich die Lehrerinnen den anderen Klassenkameraden gegenüber verhalten. Das wird daran deutlich, dass sie viel damit beschäftigt sind, die Vorgänge in der gesamten Klasse zu verfolgen. ${ }^{2}$ Zudem zeigen es die Kommentare, die dazu abgegeben werden:

Lehrerin Matthes neckt Oliver, indem sie ihn humorvoll in den Nacken kneift. Raik ruft dazu lachend in die Klasse: „Fester!« (AL)

Das heißt, die SchülerInnen nehmen die jeweiligen Gesten und Handlungen und die damit signalisierten Beziehungen sehr wohl wahr. In diesem Fall solidarisiert sich der Schüler mit der Lehrerin und bestärkt sie. Das bedeutet aber auch, dass Ausschlüsse, die über solche Einschlüsse stattfinden, wahrgenommen werden. Eine allen gegenüber distanzierte Haltung (wie der Fachlehrerin) ermöglicht wiederum, diese Ausschlüsse gering zu halten.

\section{Körperkontakt als pädagogisches Mittel und die Figur des Hauptschülers}

Wie wichtig den Lehrerinnen der Körperkontakt ist, betonen sie im Interview. Körperlichkeit und Berührung werden als ein »Mittel« der pädagogischen Arbeit bezeichnet - ein Kommunikationsmittel, das strategisch eingesetzt und

2 Mit dieser Beobachtung setzt sich auch Breidenstein in der ethnographischen Studie seiner Forschungsgruppe auseinander (Breidenstein 2006: 110-118). 
zur pädagogischen Praktik wird, z. B. um Nähe herzustellen, um innerhalb der Schulklasse und während des Unterrichts leiser sprechen zu können, um zu ermahnen und eventuell auch zu sanktionieren. Wie begründen sie dies, und welche Dimensionen sind enthalten, wenn sie von Körperkontakt als pädagogischem Mittel sprechen? Auf die Frage der interviewenden Studentin, welche Rolle der Körper im täglichen Umgang mit den SchülerInnen spielt, antwortet Lehrerin Matthes:

Ich denke, Körperkontakt, da muss man vorsichtig sein, aber ich finde ihn wichtig. Sag ich jetzt einfach mal ungebremst raus, weil, du merkst es bei Schülern und auch bei Schülerinnen, letztendlich suchen die auch ganz stark Nähe. Also das ist nochmal so dieses Thema: Schule, Klasse, das ist auch so eine Heimat, so ein Nest, ja und es ist auch immer noch, jetzt auch in der Sieben so, dass sich auch oft welche bei uns ausheulen, ja, und sich anschmiegen, Kopf auf die Schulter und weinen sich mal aus. Aber ich denke, das ist immer, man muss gucken. Das kann natürlich auch gleich mal zu 'ner Grenzüberschreitung, oder es kann als Grenzüberschreitung gesehen werden. Also ich denke so, die Schüler und Schülerinnen signalisieren einem schon ziemlich deutlich, bis wohin es ihnen angenehm ist und wo nicht mehr.

Im Rahmen des Erzählens über die Beziehungen zu den SchülerInnen »ihrer« Klasse, kommt auch Lehrerin Timm im Interview mit einer Erziehungswissenschaftlerin auf das Thema Körperkontakt:

Lehrerin Timm: [...] Wobei man immer wieder auch sagen muss, Hauptschule bedeutet viel mehr Körperlichkeit und Berührung als an einem Gymnasium. Also das ist ein Mittel unserer Arbeit, das muss man so sagen, also die Hand mal auflegen oder auch selbst Jungs, wenn's denen nicht gut geht, auch mal in den Arm nehmen.

Interviewerin: Ja, das ist uns aufgefallen. Fanden wir bemerkenswert.

Lehrerin Timm: Das würde, das würde an 'nem Gymnasium nicht, das wär fehl am Platze, weil das 'ne andere Art und Weise des Umgehens ist, aber bei uns geht sehr viel auch über 'ne körperliche Ebene, und danach verlangen auch die Schülerinnen und Schüler.

Begründet werden die häufigen körperlichen Berührungen mit einem spezifischen Gegenüber in einer spezifischen Institution. In Abgrenzung zur Schulform des Gymnasiums wird körperliche Nähe als Teil der Arbeit an einer Hauptschule angesehen. HauptschülerInnen seien anders als GymnasiastInnen, der Ort und die Umgangsweisen bzw. Beziehungen zwischen LehrerInnen und SchülerInnen unterscheiden sich. Schule stelle für ihre SchülerInnen eine »Heimat« bzw. ein »Nest« dar - Metaphern, die für ein Zuhause stehen, einen Ort, der Schutz und Wärme verspricht, den man als den seinen betrachtet, mit dem man sich verbunden fühlt, der Rückzugsmöglichkeiten bietet. 
Dazu passt, dass die Lehrerinnen die Schulklasse als eine »Familie« beschreiben und sich selbst häufig in der Rolle von Mutter, Vater oder großer Schwester sehen und erleben. Im gemeinsamen Unterrichten könnten sie sich wechselseitig in diesen Rollen ergänzen. Der Analogisierung der Schulklasse als Familie kommen sie in dieser Ergänzung näher. ${ }^{3}$

Beide Interviewpartnerinnen betonen, dass es die SchülerInnen sind, die körperliche Nähe »suchen«, dass diese sie »verlangen«. Die Impulse gingen von den SchülerInnen selbst aus - womit die Lehrerinnen letztlich auf diese reagieren und ihnen auf diese Weise entgegenkommen, ihnen ein »Bedürfnis« erfüllen. Ihnen sei Körperkontakt wichtig, weil er auch für die SchülerInnen wichtig sei. Lehrerin Timm erläutert dies an einem Fall:

Oliver zum Beispiel, der braucht das, dass man ihn auch mal so anknufft oder mal so in den Arm nimmt, und es ist für den viel wichtiger, als wenn ich ihn zurechtweisen würde oder ihm versuchen würde, das mit Worten zu erklären, das ist 'ne Sprache, die er versteht.

Aufgrund seines Verhaltens interpretiert Lehrerin Timm, dass der Schüler Oliver die Vermittlung ihrer Botschaften über Körperpraktiken, wie in den Arm nehmen oder »anknuffen«, die eine eigene Form der Verständigung darstellten, besser verstehe als ihre verbalen Erklärungen. Offen und fraglich bleibt, woher sie weiß, dass Oliver das »braucht«, ob die körperliche Botschaft der verbalen entspricht und welche lang- oder kurzfristigen Ziele seitens der Lehrerin jeweils bestehen. Auf körperlicher Ebene zu agieren, bezeichnet die Interviewte als eine eigene Sprache. Es ist nicht ungewöhnlich, von Körpersprache zu reden, wenn es um nonverbale Kommunikation geht. Das zeigt sich auch in den untersuchten Zeitschriften.

So wie die Lehrerin im Interview körperliche Gesten als Sprache analogisiert, nimmt sie eine Differenzierung vor: von verbaler Sprache und nonverbaler körperlicher Sprache. Letztere verstehe Oliver besser als die übliche Verbalisierung, die man z. B. an einem Gymnasium einsetzen würde. Das impliziert aber auch, dass Oliver weniger in der Lage sei, verbale Sprache zu verstehen und noch allgemeiner: eine spezifische Vorstellung von der Figur des Hauptschülers. Körpersprache wird als eigene Sprache jenseits verbaler Sprache begriffen, die bestimmte SchülerInnen eben besser verstehen würden,

3 Historische Schriften zu pädagogischen Beziehungen zeigen, dass es sich bei der Selbstbeschreibung, gleichzeitig die Rolle von Vater und Mutter einzunehmen und sich als solche angenommen zu fühlen, um einen alten pädagogischen Topos handelt (bspw. Pestalozzi 1799/1980: 11f;; Wichern 1959: 253). Klaus Mollenhauer skizziert knapp die Durchsetzung der Thematik der Familie als pädagogische (vgl. Mollenhauer 1998: 608). 
womit sowohl über die beobachteten Körperpraktiken als auch im Reden innerhalb der Interviewsituation eine bestimmte Figur des Hauptschülers konstituiert bzw. konstruiert wird. An die differenzierenden Kategorisierungen >verbal-sprachlich` (sowie `sprach-fähig`) und `körper-sprachlich`werden soziale Positionen gekoppelt: hier der Gymnasiast, dort der Hauptschüler. Es werden Subjektpositionen (Foucault 1981: 78f.) entworfen und, erinnern wir uns an die Ausführungen zu Althusser (Kap. >Subjekt, Macht und Diskurse`), im verbalen und nonverbalen Handeln im Unterricht sind die SchülerInnen als sprachlich weniger befähigte HauptschülerInnen »angerufen«.

Jenes Sprechen der Lehrerinnen über die Körperpraktiken ist zugleich ein Sprechen über ein >Außen der eigenen sozialen Position. Denn die Position, von der aus das >Außen $<$ der (verbalen) Sprache identifiziert wird, ist eine bestimmte - hier eine bildungsbürgerliche - Position im sozialen Raum, darauf macht Bourdieu (1990) in seiner Auseinandersetzung mit der Praxis des Sprechens aufmerksam. Die auf einer körperlichen Ebene stattfindende Berührung ist mit sozialen Positionen sowie Zuschreibungen verbaler Fähigkeiten verknüpft. Zugleich stabilisiert nicht nur das legitimierende Reden über jene Körperpraktiken die soziale Ordnung, sondern dessen Performativität die Körperpraxis selbst (und damit wiederum die soziale Ordnung). Die Verknüpfung von bestimmten Körperpraktiken und sozialen und kulturellen Positionierungen wird in der Erklärung der Lehrerin Timm noch einmal verstärkt, indem sie die Herkunftsfamilien ihrer SchülerInnen einbezieht:

Ich denke, dass viele zu Hause auch diese unverfangene Form der Körperlichkeit gar nicht mehr, gar nicht kennen und das auch in der Schule ausagieren müssen.

D. h. zunächst, es gibt verschiedene Formen von Körperlichkeit. Unverfangen bedeutet in einer ersten Assoziation soviel wie »nicht in etwas verhakt, verwoben«, also »frei«. Diese eigentliche Form, so vermutet die Lehrerin, kennen die SchülerInnen von ihrem Elternhaus nicht (mehr?). Sie kennen also etwas anderes Reales. Implizit verweist die Interviewte auf eine unfreie - befangene - Körperlichkeit. Welche konkreten Körperpraktiken sich hinter diesen beiden Formen verbergen, bleibt in dieser Äußerung offen. Allerdings gibt es Hinweise, denn die SchülerInnen »müssen« etwas, was sie nicht kennen, was aber wohl »da« ist, »ausagieren«. Das lässt sich durch ihr Verlangen erklären und an ihrem Verhalten ablesen: Wenn sie sich bei den Lehrerinnen anlehnen und ausweinen oder sich (zumindest noch in der 5. Klasse) auf ihren Schoß setzten - etwas, was man in der Schule eigentlich nicht tut. Diese Art Körperlichkeit sei wohl zu Hause nicht möglich, weswegen es in der Schule passieren (dürfen) solle. Dieses »Irgendwie da sein« unverfangener Körperlichkeit entspricht der Ebene des Leibes in den Leib-Körper-Differenzierun- 
gen der untersuchten pädagogischen Fachzeitschriften (vor allem Päd Forum 5/1996; Pädagogik 6/1996). Etwas Eigentliches (die verschwundene Leiblichkeit) wird dort in bestimmten philosophischen bzw. bildungstheoretischen Texten einer Realität (dem historisch disziplinierten Körper) gegenübergestellt (vgl. Kap. ২Körper(bewusstseins)schulung $<$ ). Allerdings wird in den Zeitschriften jene (sinnliche) Leiblichkeit vermisst (vgl. auch Rumpf 1981), während es im Interview der im schulischen Sinne disziplinierte Körper ist, der nicht vorhanden sei. Denn die SchülerInnen agieren ja gerade in einer befremdenden, dem Leib eigenen Weise. Dieses Ausagieren reiche allerdings weiter - es sei nicht nur ein Leibliches oder dem Körper Inhärentes, was nun in der Schule herausplatze, sondern die Interviewte spricht von einer allgemeinen Distanzlosigkeit. Fest stellt sie eine

[...] manchmal befremdliche, völlig undistanzierte Art und Weise, und distanzlos, aber das entspringt natürlich auch ihrer sozialen Herkunft, ja? Also die stellen uns Fragen, die hätt' ich mich niemals gewagt, meiner Lehrerin zu stellen, und es hätte mich auch nicht interessiert. (Lehrerin Timm)

Soweit von einer »typischen« Hauptschulklasse gesprochen werden kann (vgl. Solga/Wagner 2004: 99, die vor allem die Unterschiede herausstellen), stellt diese 7. Klasse insofern eine solche dar, als die SchülerInnen vor allem aus bildungsfernen Bevölkerungsschichten kommen und häufig einen Migrationshintergrund haben. Im zitierten Ausschnitt spricht die Interviewte die familiären Hintergründe der SchülerInnen an und führt die beobachteten und erfahrenen, ihr an sich befremdlichen Umgangsweisen auf deren bestimmte, ihr ebenso fremde soziale Herkunft zurück. Diese Herkunft kann ebenso eine andere Erziehung enthalten wie auch die Vorstellung, es werde sich nicht genügend darum gekümmert, dass angemessene Distanz eingehalten und damit auch Respekt gezeigt werde. Die Lehrerin stellt diese Distanzlosigkeit als ein Passungsproblem ${ }^{4}$ unterschiedlicher Milieus dar. Im Zusammenhang mit der eingeforderten Distanziertheit, die der Lehrerin im Umgang mit ihr eigentlich angemessener erscheint, ist eine »unverfangene Körperlichkeit« eben keine mehr oder weniger »freie« und ursprüngliche Leiblichkeit, sondern eine distanzierte Körperlichkeit, die sie und ihr jeweiliges Gegenüber nicht in prekäre Situationen bringt, sie nicht darin »verfängt«. Eine Körperlichkeit, die nur am richtigen dafür vorgesehenen Ort, z. B. der Familie, ausagiert wird, bei der

4 In der erziehungswissenschaftlichen Diskussion problematisierten zunächst Klaus Hurrelmann und Hartmut K. Wolf (1986) Schulerfolg und -versagen als Passungsverhältnis zwischen biographischen, milieuspezifischen und schulischen Bereichen. Vgl. außerdem zu diesem Begriff Kramer (2002); Busse/Helsper (2004). 
man für sich selbst Unverfangenheit in Anspruch nimmt, dann aber in der Schule (und generell der Öffentlichkeit) dem Gegenüber und dem Publikum Unverfangenheit ermöglicht. Schlussfolgern ließe sich: Von zu Hause muss man den angemessenen körperlichen Umgang kennen, um an der Schule lernen zu können (und damit weiter zu kommen). Um diese Art Unverfangenheit zu ermöglichen, bedarf es wiederum der Verbalisierung, die z. B. aufgrund der verschiedenen Sprachen und daraus resultierenden Sprachbarrieren schwierig sein könnte. Dieser Zirkelschluss macht deutlich, dass die Gegenüberstellung von verbaler vs. nonverbaler Sprache eine weitreichende ist, werden an sie bestimmte Schüler- bzw. Bevölkerungsgruppen bzw. soziale Schichten gekoppelt. Sie schließt systematisch aus, wenn sie als binäre Klassifikation »nicht nur auf einen untergeordneten Platz innerhalb einer Gesellschaft verweis $[t]$, sondern den anderen den Status eines sminderen Menschen zuweis $[t]$, sie als ^Nicht-Zugehörige`zu Nation, Gesellschaft und Menschheit definier $[\mathrm{t}]$ « (Cremer-Schäfer 1995: 116).

Unthematisiert bleibt bei der Begründung, Körperkontakte seien wichtig, weil die SchülerInnen danach verlangten, inwiefern die Lehrerinnen dieses Verlangen bzw. eine solche Wahrnehmung mit produzieren. Indem die Lehrerinnen die körperliche Nähe, die vielleicht in der Grundschule als angemessen gilt, weiterhin zulassen, errichten auch sie von ihrer Seite keine Distanz. Betrachtet man dieses Verhältnis aus der Perspektive sozialer bzw. sozial hergestellter Ungleichheit, regrediert »der « Hauptschüler, indem er nicht die gleiche körperliche Distanziertheit kennenlernt und erfährt wie »der« sprachlich gewandte Gymnasiast, womit ihm eine bestimmte Art sozialen Kapitals vorenthalten wird. Hinsichtlich gesellschaftlicher Aufstiegschancen und damit verbundener Ressourcen, die vor allem AbsolventInnen mit Hauptschulabschluss durch besonders schlechte Chancen auf dem Arbeitsmarkt verwehrt sind (vgl. z. B. Hradil 2001: 174; Solga/Wagner 2004: 111), ließe sich mangelnde Sprachkompetenz nach Bourdieu als fehlendes kulturelles Kapital verstehen (vgl. Heinemann 2001: 124). ${ }^{5}$

Die Lehrerinnen begründen also den körperlichen Bezug einerseits mit der körperlichen Nähe, die von den SchülerInnen selbst ausginge, und daran anschließend als Mittel in der gerade in der Hauptschule als besonders wichtig

5 Auf organisationstheoretischer Ebene fanden Mechthild Gomolla und FrankOlaf Radtke (2002) in ihrer Studie zur direkten und indirekten institutionellen Diskriminierung heraus, dass in Bezug auf Migration nicht Nationalität, sondern Normalität vordergründige Kategorie der Ausschließung sei. Infolge homogener Lerngruppen würden vor allem MigrantInnen überproportional häufig nicht den Erwartungen entsprechen. Aufgrund von Sprachdefiziten werde der Übergang in die Sekundarstufe verhindert, so dass auch ansonsten lernstarke Kinder an Hauptschulen verweilten (Gomolla 2003: 104). 
hervorgehobenen Beziehungsarbeit, als eine Umsetzung von Beziehung. Diese sei die Basis jeglicher Wissensvermittlung und nähme sehr viel Raum und Zeit ein. D. h. es bedarf hier in besonderer Weise (im Vergleich zu anderen Schultypen) eines Antriebs auf der Beziehungsebene, um die SchülerInnen »bei der Stange zu halten«, ihrer Anwesenheit einen Sinn zu geben. Beziehungsarbeit ist präventiv, um die SchülerInnen »im Griff zu haben«, was eben auch körperlich zum Ausdruck gebracht wird. Zugleich wird die Nähe damit zum Eigenziel, um als Lehrerin akzeptiert zu werden und sich selbst wertgeschätzt zu fühlen, an Bedeutung zu gewinnen bzw. persönliche Befriedigung zu erlangen. Und so resümiert Lehrerin Timm:

[...] das ist für mich auch das Schöne an der Hauptschulklasse, dass solche Formen der Arbeit möglich sind und es nicht nur das Vermitteln von Inhalten ist.

\section{Grenzen und Grenzziehungen im Rahmen von Moralität, Professionalität und Geschlecht}

Körperkontakte zu den SchülerInnen sind für die befragten Lehrerinnen wichtig, sie sind pädagogisches Mittel. Aber man müsse auch »vorsichtig« sein, so Lehrerin Matthes. Wieso? In Bezug worauf bzw. auf wen? Die Vorsicht scheint hier eine doppelte zu sein:

- gegenüber den SchülerInnen, die bestimmte Berührungen als Grenzüberschreitung wahrnehmen könnten,

- aber auch gegenüber anderen BeobachterInnen, die Körperkontakte als Grenzüberschreitungen missbilligen könnten.

In der Äußerung, »das kann als Grenzüberschreitung angesehen werden«, sind beide Varianten als eine prinzipielle Möglichkeit enthalten, denn wer genau dies so sehen könnte, bleibt offen. Dass es nicht nur die betroffenen SchülerInnen sein könnten, die nachfolgend als durchaus kompetent dargestellt werden, ihre eigenen Grenzen signalisieren zu können und damit eine Überschreitung zu verhindern, macht auch der folgende nachgestellte Satz deutlich: »Ich denke, Körperkontakt, da muss man vorsichtig sein, aber ich finde ihn wichtig. Sag ich jetzt einfach mal ungebremst raus« Im Reden hat sich wohl eine Bremse gelöst, die eher gehalten werden sollte. Es scheint nicht selbstverständlich zu sein, dass eine Lehrerin sagen kann: >Ich finde Körperkontakte wichtig.< Um mit einer Körpermetapher zu sprechen: Möglich ist es nur mit vorgehaltener Hand, denn es scheint ein Tabuthema zu sein. Dass andere Personen etwas anderes wahrnehmen könnten als die beteiligten Akteure, ist an sich nicht das Problem. Verbunden mit der Wahrnehmung als Grenzüberschreitung sind jedoch zugleich gesellschaftliche Normen körperlicher 
Bezugnahmen und Distanzen und, was es hier noch einmal schwieriger macht, eine »moralische Grauzone«, die innerhalb der institutionellen Rahmung Fragen professionellen Handelns aufwirft. D. h. Moralität und Professionalität sind hier in nicht einfach aufzulösender Weise verschränkt. Insofern kann die Argumentation, die ich im vorigen Abschnitt interpretiert habe, auch als Legitimationsstrategie innerhalb dieses Verhältnisses von Moralităt und Professionalität angesehen werden. Die Lehrerinnen stellen sich als Professionelle dar, indem sie auf die Bedürfnisse der SchülerInnen eingehen und sie als sindividuelle Andere $<$ betrachten.

So muss denn auch der Satz: »Wobei ich natürlich gewisse Sachen, Berührungsgrenzen nicht überschreiten würde, das ist klar, ja? (Lehrerin Timm) der Interviewerin auf alle Fälle gesagt werden, um nicht in irgendeinen Verdacht zu geraten, übergriffig und in gewisser Weise Täterin zu sein. Zugleich sollen hier die eigenen persönlichen Grenzen nicht überschritten werden. Mittels der Worte »natürlich« sowie »das ist klar, ja?« wird die Aussage zu einem Selbstverständnis, zu einer Setzung, über die man nicht weiter sprechen muss. Was das für Sachen sind, um welche Grenzen es sich handelt, bleibt verborgen. Darüber redet man nicht und fragt im Interview auch nicht nach.

Die Verschränkung von Moralität und Professionalität wird in einem weiteren Auszug aus dem Interview mit Frau Timm deutlich, der sich ebenso auf eine körperliche Ebene bezieht:

[...] und für Außenstehende ist es, glaub ich auch manchmal, gar nicht nachzuvollziehen, manchmal verwischen ja auch die Grenzen zwischen Unterricht und und so 'ner Kumpelebene, da muß man halt immer wieder genau hingucken. Und da ist es auch wieder gut, jemanden im Team zu haben, der sagt: »Hör mal zu, was du jetzt gerade gemacht hast, das war unprofessionell «.

Es stellt sich im Handeln der Lehrerinnen nicht nur die Frage, ob sie mit einer Berührung die persönlichen Grenzen ihres Gegenübers oder ihre eigenen überschreiten, sondern ob diese Form der Bezugnahme professionell ist. Die Thematik Körperkontakt ausgehend von LehrerInnen zu ihren SchülerInnen ${ }^{6}$ ist einerseits Teil einer wohl für die pädagogische Arbeit typischen NäheDistanz-Problematik (vgl. Dörr/Müller 2006). Sie ist dieser Arbeit inhärent, da diese sich durch ein spezifisches Machtverhältnis zwischen Pädagogin und Educand auszeichnet, das nicht nur durch ein Spannungsverhältnis zwischen Hilfe und Kontrolle gekennzeichnet ist - wie es insbesondere für die soziale Arbeit beschrieben wird (vgl. Cremer-Schäfer/Steinert 1998: 60-62), aber auch für die dargestellten Situationen an der Hauptschule gilt -, sondern auch

6 Aber auch umgekehrt, wie ich noch zeigen werde. 
emotionale Abhängigkeiten aufweist. Nicht nur in Bezug auf (inter-)körperlicher Aspekte wird dieses pädagogische Verhältnis von Frau Matthes im Interview als "Gratwanderung « beschrieben. Diese Metapher steht für den nur schmalen begehbaren Bereich, der auszubalancieren ist. Die Gefahr, nach der einen Seite (zu viel Nähe) oder nach der anderen Seite (zu viel Distanz) abzugleiten, ist auf dem gesamten Weg immer wieder groß, und manche Stellen sind besonders schmal. Andererseits führt die Thematik in einen weiteren Bereich hinein: die Pubertät und damit verbunden Fragen nach Geschlecht und Sexualität. Im Interview äußert sich Lehrerin Matthes folgendermaßen:

Ich denk' mir jetzt auch, gerade in der siebten Klasse ist das auch so ein Umbruch. So Fünfte/Sechste, da war noch, ja, da war auch ganz viel Körperlichkeit bei denen noch, ja. Dass sie wirklich kamen und dass sie sich nicht bei dir auf den Schoß gesetzt haben, war noch gut. Also grad in der Fünf. Und so jetzt ist natürlich echt, also gerade so bei den Jungs, die distanzieren sich jetzt sehr. Ja, die werden jetzt cool, und da ist man mit Lehrerinnen vorsichtig. Aber du merkst es schon noch, also da sind so ein paar, die drücken ihre Zuneigung aus, aber müssen das auf eine etwas schroffe Art jetzt machen. Also früher war das noch so ein bisschen anders (lacht).

Hier taucht die »Vorsicht" wieder auf, aber aus einer anderen Perspektive. Die Lehrerin nimmt wahr, dass die Jungen ihr gegenüber zurückhaltender würden, dass die von ihnen ausgehende erlebte Körperlichkeit abnehme. Dass sie sich anders, weniger zutraulich oder, wie Frau Timm es nennt, weniger »anhänglich« verhielten, sich körperlich distanzierten. Diese Beobachtung erklärt Frau Matthes damit, dass die Jugendlichen jetzt »cool werden«, was ja bereits eine gewisse Distanziertheit impliziert (vgl. Poschardt 2002). Interessant ist, dass sie dies nicht als Abweisung ihrer Person oder ihrer Rolle als Lehrerin interpretiert, sondern lediglich als veränderte Art und Weise, Zuneigung auszudrücken, möglicherweise aufgrund einer »natürlichen Entwicklung«. Sie werden eben »schroffer«, weil man das in dieser Klassenstufe bzw. in diesem Alter so mache und weil Cool-sein eine Inszenierung von Schroffheit impliziere. An dieser Stelle zeigt sich, wie die Erfahrungen einer Lehrerin von der 7. Klasse mit gängigen Diskursen über Pubertät (vgl. Langer 2009) verknüpft bzw. verdichtet werden. Während sie zunächst mit dem Wort »die« konkret von den Jungen in ihrer Klasse spricht, wechselt sie dann zu einem unpersönlichen »da ist man mit Lehrerinnen vorsichtig«. Das Verhalten der Jungen wird innerhalb von Pubertäts- und Männlichkeits-Diskursen verstanden und somit zur Normalität erklärt. Coolness wird als Element eines männlichen Habitus (Bourdieu 1997; Poschardt 2002: 329) markiert, welcher mit einem bestimmten Alter und mit der Pubertät einhergeht. 
Auch Lehrerin Timm nimmt eine veränderte Körperlichkeit, d. h. einen anderen Umgang mit körperlichen Interaktionen wahr:

Also grade die Jungs, natürlich in der Pubertät distanzieren die sich, ja? Und haben auch ganz große Probleme mit Körperlichkeit, also wenn man sie mal berührt, da suchen sie auch schon 'ne körperliche Distanz, und man muss sich genau überlegen, ob das auch wohl dosiert ist. Wo bricht man es auf und wo darf man das aufbrechen, und wo bleibt man am besten ganz berührungsfrei.

Auch sie spricht von den sich seit dem letzten Schuljahr distanzierenden Jungen, welche in der 5 . Klasse am liebsten noch auf ihrem Schoss gesessen hätten. Im Unterschied zu Frau Matthes, die diese Veränderungen lediglich als andere, alterstypische Umgangsweisen einschätzt, spricht Frau Timm davon, dass die Jungen jetzt »ganz große Probleme mit Körperlichkeit« hätten. Die Lehrerin formuliert ein Problem, dass sie den Jungen zuschreibt. Offen bleibt, was genau eigentlich Körperlichkeit bedeutet. Mit wessen Körperlichkeit haben sie ein Problem? Ist das Problem, dass sie sich nun körperlich distanzieren, während sie dies bis dahin aus der Perspektive der Lehrerin zu wenig taten? Die Formulierung eines Problems schließt nicht aus, dass dies wie im anderen Interview die »übliche« Entwicklung darstellt, es muss deshalb keine problematische sein, sondern das Problem könnte als der pubertären Entwicklung inhärent angesehen werden. Dass es sich um solch eine Entwicklung handelt, macht der Vergleich deutlich, den die Lehrerin anbringt:

Bei dieser Klasse ist es jetzt sehr erstaunlich, dass die Pubertät, die ist bei denen sehr schleichend eingetreten und schon relativ früh, also das sechste Schuljahr hab' ich als wesentlich anstrengender empfunden als das siebte Schuljahr, hingegen meine andere Erfahrung aus vorangegangenen Klassen war eher, dass das siebte Schuljahr wirklich anstrengend ist und sich da die Pubertät ihre Bahn bricht. (Lehrerin Timm)

Auch diese Lehrerin greift auf Erfahrungen zurück, die sie bereits mit anderen Klassen gemacht hat. »Die Siebte - da geht es los« - eine Aussage, die immer wieder zu hören ist und die gewissermaßen einen Allgemeinplatz wohl nicht nur unter LehrerInnen darstellt. Es ist die Pubertät, die »ihre Bahn bricht« eine gewisse Kraft und Energie enthält, nicht aufzuhalten zu sein scheint, während etwas gebrochen wird. In dieser Formulierung sind die davon Betroffenen ihr völlig ausgesetzt, und es scheint nahe liegend, damit ein Problem zu haben, völlig überwältigt zu werden (allerdings nicht nur die Jungen, sondern die Lehrerinnen auch). Im Gegensatz dazu wird die als unausweichlich angesehene Entwicklung in dieser Klasse zwar als schleichende angesehen, aber nicht als weniger anstrengend. 
Als Lehrerin muss man nun mit dem Problem Körperlichkeit - das die Jungen haben - umgehen. Da es ein Problem ist, muss es auch behandelt werden und zwar »aufgebrochen« werden. Dem Durchbrechen der Pubertät ist ein anderes Aufbrechen entgegen zu setzen. Wichtig dabei sei, dies wohl dosiert zu tun - also wie im medizinischen Sinne die richtige Dosis zu finden. Eine Überdosis Körperlichkeit zu verabreichen, entspräche der bereits angesprochenen Grenzüberschreitung, denn es scheint Bereiche des »Dürfens« und des »Nicht-Dürfens« zu geben. Zu wenig hilft nicht genug, das Problem anzugehen. Deutlich wird hier wieder die Verknüpfung zur eigenen Professionalität. Professionell wäre, angemessen und ausgewogen zu dosieren. Für mich stellt sich bei dieser Dekonstruktion die Frage, worauf sich eine angemessene Dosierung eigentlich bezieht? Was ist das Ziel? Grenzüberschreitungen zu verhindern scheint nahe liegend, aber um etwas aufzubrechen, müssen Grenzen überschritten werden.

\section{Geschlechterdifferenzen}

Beim Lesen der letzten Kapitel wird wahrscheinlich aufgefallen sein, dass bisher lediglich von den Jungen der Schulklasse die Rede war. Die Unterscheidung zwischen Jungen und Mädchen bzw. Männlichkeit und Weiblichkeit scheint hier als grundsätzlich strukturierende zentral zu sein. Auf die Nachfrage, ob die Interviewte bei den beschriebenen Distanzierungen lediglich von den Jungen spricht, erklärt Frau Matthes:

Ja, bei den Jungs direkt jetzt, ja. Bei den Mädchen ist es ein bisschen anders. Also bei den Mädchen ist es eher so, dass man sich gegenseitig so ein bisschen angiftet, d. h. also sie mit uns und wir mit ihnen. Aber ich glaub', das ist auch sowas, wieder zum Thema Nähe, wir sind uns einfach auch sehr viel näher als Frauen, ja. Da sind einfach Anteile, die einem so vertraut sind und vielleicht auch so unterbewusst noch so ... weniger präsent sind, aber da sind, dass sie das ganze anders ansprechen, bzw. dass man da anders agiert.

Der Lehrerin scheint es leichter zu fallen, über das Verhältnis zu den Jungen zu reden, es erscheint klarer hinsichtlich nötiger Abgrenzungen. Möglicherweise setzen sich weibliche Lehrerinnen auch in Bezug auf das »andere « Geschlecht mehr damit auseinander. Inwiefern körperliche Nähe in diesem Verhältnis zu den Mädchen in der Pubertät eine Rolle spielt, wird nicht thematisiert. Trotzdem wird reflektiert, dass Distanz auf eine andere Weise hergestellt werde - und zwar von beiden Seiten: Von den Schülerinnen und den Lehrerinnen, die sich gegenseitig (verbal) »angiften«. Das Wort Angiften also ein Gift verbreiten - enthält etwas tendenziell Vernichtendes, zumindest 
aber etwas (Be-)Drohendes gegenüber der Person, die angegiftet wird. In einer Schulstunde, in der die Klasse nach Geschlechterstereotypen gefragt wurde, wurde prompt von Jungen und Mädchen gleichermaßen genannt, dass Mädchen giftig und zickig seien. Die Lehrerinnen scheinen diese Sicht in ihrer Beziehung zu den Mädchen zu bestätigen. Geht man davon aus, dass ein Konflikt zugrunde liegt, wenn man sich angiftet, so wird dieser in den Interviews nicht benannt. Zur Sprache kommt lediglich, dass dies die Form von Auseinandersetzung innerhalb eines spannungsgeladenen Verhältnisses sei, welches einerseits per se aufgrund einer gemeinsamen weiblichen Geschlechtsidentität vertraut oder verbunden sein müsse, andererseits aber durch (potenzielle) Konkurrenz untereinander zu einer Reibungsfläche werde, so dass Distanz geschaffen werden müsse. Auch gegenüber den Jungen achten die Lehrerinnen auf eine angemessene Distanz, und zwar indem sie deren Signale wahrnehmen und versuchen, sie in deren Sinne zu interpretieren. Den Mädchen gegenüber gibt es andere Kommunikationsmuster: Das gegenseitige Angiften scheint viel weniger reflektiert zu sein, was die Lehrerin selbst feststellt und mit ihrer prinzipiellen Nähe zum Weiblichen erklärt. Worin besteht diese Nähe? Zunächst einmal wird sie angenommen, um Ausgangspunkt für Beziehungen zu sein. Die Lehrerin spricht von »vertrauten Anteilen«. In der Differenz Mädchen - Jungen bedeutet dies: >vertraute Mädchen « - sfremde Jungen'; vielleicht auch ein Grund, warum gerade über die Ebene der Körperkontakte zu den Jungen etwas Vertrautes hergestellt wird bzw. werden muss, während das qua weiblichem Geschlecht angenommene Vertraute als "naturgemäß« Vorhandenes nicht erst aktiv erzeugt werden muss. Andererseits gibt es »unter Frauen« Anlass zu Auseinandersetzungen, zu einem Nicht-Verstehen. Die Mädchen verbindet zwar mit den Lehrerinnen das gemeinsame FrauSein, doch unterscheidet sich die Inszenierung dieses Frau-Seins und -Werdens stark von den Vorstellungen der feministisch aufgeklärten, emanzipierten jungen Lehrerinnen - eine Differenz, die beispielsweise Heike Fleißner (2002) auch in der sozialpädagogischen Mädchenarbeit häufig beobachtet. Und so sind sie sich doch trotz aller angenommenen Gemeinsamkeit - eben auch körperlich - fremd.

Interessant ist nun noch einmal die Beobachtung, dass Körperkontakte im Unterricht vor allem zwischen Lehrerinnen und Jungen stattfinden. Die zuletzt zitierte Aussage im Interview bestätigt dies in gewisser Weise. Ebenso wie Körperlichkeit und Berührungen zwischen Lehrerinnen und Mädchen nicht thematisiert werden, sind sie auch selten zu beobachten. In Interaktionsstudien im Rahmen der Koedukationsdebatte in den 1980er Jahren wurde die unterschiedliche Zuwendung von LehrerInnen zu Jungen und Mädchen immer 
wieder festgestellt. ${ }^{7}$ Uneinheitlich sind die Ergebnisse insofern, dass sowohl postuliert wurde, Jungen erlangten mehr Aufmerksamkeit unabhängig vom Zutun der SchülerInnen, als auch, dass bereits ihrerseits mehr Aufmerksamkeit eingefordert werde. Andrea Leitgeb (1991: 61) konstatiert nach Befragungen von LehrerInnen innerhalb eines Aktionsforschungsprojekts, dass nur wenige ein Bewusstsein für die Andersbehandlung von Mädchen und Jungen hätten. Außen vor bleibt in all diesen Studien genau jene körperliche Ebene der Bezugnahme. Und die scheint hier widersprüchlich: Gerade die Jungen werden als diejenigen vorgestellt, die auch körperlich besonders distanziert seien, und doch finden mit ihnen die meisten Körperkontakte statt. In der Selbstwahrnehmung der Lehrerin sieht das aber noch einmal anders aus:

Lehrerin Matthes: Also ich mein', wenn ich mal so 'rumgehe und schaue, was sie so machen, oder kontrolliere oder jemandem helfe. Also so eine Hand auf die Schulter legen, das mache ich eigentlich ziemlich häufig, sehr häufig. Aber mache ich auch nicht bei jedem. Nee, nee, nicht bei jedem. Also es gibt welche, wo ich es nicht mache. Ja.

Interviewerin: Sind es Unterschiede, die du machst von Schüler zu Schüler? Oder sind es Unterschiede zwischen Jungen und Mädchen?

Lehrerin Matthes: Ich bin grad am überlegen. Nee, es sind Unterschiede von Schüler zu Schüler, hat mit dem Geschlecht nichts zu tun. Also es gibt auch Mädchen, bei denen ich das nicht mache ... Und auch Jungs. Es sind wenige, aber das ist geschlechts-

Interviewerin: Wenige Jungs, oder?

Lehrerin Matthes: Wenige generell, aber es ist geschlechtsunspezifisch. Ja.

Interviewerin: Ist das dann gleich bleibend bei den Schülern und Schülerinnen, oder verändert sich das? Oder hast du welche, bei denen du prinzipiell sagst, da ist weniger da? Also, die berühr' ich einfach weniger?

Lehrerin Matthes: Es gibt prinzipiell welche, aber es verändert sich auch. Aber bei manchen ist es prinzipiell so, ja.

Ohne lange nachdenken zu müssen, erzählt die interviewte Lehrerin, dass sie Unterschiede im körperlichen Umgang mit den SchülerInnen macht, dass es Ausnahmen gibt: Schülerinnen und Schüler, die sie prinzipiell - aus welchen Gründen auch immer - nicht berührt. Das zeigt, dass das pädagogische Mittel Körperkontakt keines ist, was einfach so unüberlegt eingesetzt wird und werden kann. Es ist nicht vergleichbar mit anderen didaktischen Praktiken, die qua Unterrichtsplanung zur Anwendung kommen, denn es funktioniert nur individuell, und es wird individuell austariert. Auch wenn oder gerade weil

7 Vgl. z. B. Enders-Dragässer/Fuchs (1989); Horstkemper (1987). Eine kritische Auseinandersetzung mit den Studien führt Michaela Tzankoff (1995). 
Körperkontakt als strategisches Mittel genutzt wird, so gibt es viele Faktoren, die entscheidend sind, ob es eingesetzt wird: Vertrauen, Sympathie, Erfahrungen, die konkrete Situation und dabei Anwesende, persönliche Grenzen und Gewohnheiten aufgrund der eigenen Lebensgeschichte, Alter, Vorstellungen kulturspezifischer Umgangsweisen sowie nicht zuletzt das Geschlecht des Gegenübers, wenngleich die Befragten das selbst nicht so wahrnehmen. Wie von der Lehrerin angedeutet, sind gerade die Verzichtsgründe nicht unbedingt bewusst, ebenso wie sie nicht immer gleich sind. Verzicht auf Körperkontakt kann aber auch strategisches Nicht-Berühren sein.

Die Differenz, wie häufig Körperkontakte zu Mädchen und Jungen in der Klasse vorkommen, die wir beobachten konnten, ist für die Lehrerin auch nach längerem Nachdenken nicht präsent. Auch wenn mit in die Interpretation einzubeziehen ist, dass in der Klasse doppelt so viele Jungen wie Mädchen sind und schon allein deshalb mehr Kontakte zu den Jungen vorkommen, könnte die Differenz zwischen Selbst- und Fremdwahrnehmung auch damit zusammenhängen, dass die Vorstellung von einer prinzipiellen Nähe zum »Weiblichen « das Bewusstsein für die eigenen konkreten Handlungen ein wenig verstellt. Verstärkt wird diese These durch die im Interviewausschnitt hervorscheinenden normativen Vorstellungen in Bezug auf weibliches und männliches Geschlecht. Die Interviewte sagt, dass die Unterschiede im körperlichen Bezug nichts mit dem Geschlecht der SchülerInnen zu tun haben. Als nächstes führt sie als Erläuterung an: »Also es gibt auch Mädchen, bei denen ich das nicht mache« (Lehrerin Matthes) Dieses »auch« nimmt vorweg, dass man annimmt, dass es eher Jungen sind, die sie nicht berührt. Was impliziert: Jungen berührt man nicht - als Lehrerin nicht (im Verhältnis weibliche Lehrerin - männlicher Schüler), aber als Lehrer ebenso nicht, es könnte der Verdacht aufkommen, homosexuell oder pädophil zu sein. Und: Jungen lassen sich nicht berühren (auch wenn die Erfahrungen eigentlich andere sind), was aber in dem Kontext und mit all den Beobachtungen eher als der Versuch erscheint, zu legitimieren, dass man es eben nicht tut. Ähnlich liest sich, wenn Lehrerin Timm davon spricht, dass sie »selbst Jungs, wenn's denen mal nicht gut geht $\ll$, in den Arm nimmt. Auch das impliziert: Wir haben sogar Körperkontakte mit Jungen, obwohl das alles andere als »normal « ist. Hier zeichnen sich eigentümliche Widersprüche und Uneindeutigkeiten ab, ein Spannungsverhältnis zwischen beobachtbaren Körperpraktiken, Wahrnehmungen, Erklärungen und Legitimationen. Sie verweisen auf Körper-, Geschlechter-, Sexualitäts- und Professionalitätsdiskurse und Möglichkeitsräume des Sprechens.

Die Art der direkten, berührenden Körperkontakte zu den Jungen ist vielfältig. Neben der fürsorglich-kontrollierenden Hand auf der Schulter ließen sich neckende, kumpelhafte Berührungen beobachten, wie Anrempeln, ein Tritt ge- 
gen die Stuhllehne oder das Kneifen in den Nacken. Es sind kämpferische Gesten, die insbesondere im Mannschaftssport Formen von Kontaktaufnahmen darstellen, die einerseits einen Angriff des Gegners bedeuten können, zugleich aber auch Identifikation, Nähe und Gemeinschaft demonstrieren und als performative Praktiken diese auch herstellen. Indem die Lehrerinnen solche Gesten gebrauchen, nehmen sie auf Weisen körperlichen Kontakts Bezug, die den Jungen vertraut sind, und unterbreiten ihnen ein Angebot, mit dem diese sich mit ihnen, wenn auch nicht unmittelbar benannt, gegen andere verbünden.

Deutlich wird, dass die Lehrerinnen mit einem geschlechtlichen Schülerkörper umzugehen haben, auch wenn sie annehmen, dass die daraus folgenden Handlungskonsequenzen und Effekte weniger augenscheinlich sind. Die Geschlechterbinarität als »heterosexuelle Matrix" (Butler 1995: 21f.) nötigt zur Unterscheidung, sie zieht sich durch das Erleben und durch das Handeln durch. In diesem Rahmen muss letztlich auch die Frage nach den Grenzen körperlicher Bezugnahme und den möglichen Grenzüberschreitungen betrachtet werden. Es gibt unterschiedliche Grenzen, von denen sie sprechen: von persönlichen, von denen der SchülerInnen und von professionellen. Diese hängen miteinander zusammen. Die persönliche ist individuell vom Gegenüber abhängig, von der jeweiligen konkreten Interaktion, und sie ist geprägt von dem, was als professionell und was als unprofessionell gilt, wie es überhaupt gesellschaftlich möglich ist und nicht sanktioniert wird. Wesentlich prägend ist dabei die sexuelle Komponente, die besonders in dem Moment deutlich wird, wo Kinder »sexuell reifen«, wenn sie zu Männern und Frauen werden. Es wird ein Wissen darüber wirksam, das Foucault $(1985,1989)$ aus genealogisch historischer Perspektive als Sexualdispositiv beschreibt, welches in einem Konglomerat aus Gesetzen, Verboten, Empfehlungen, Anleitungen und eben Techniken des Selbst jene Spannungen und Diffusitäten erzeugen, die hier an die Oberfläche gelangen (vgl. Kap. >Disziplin, Macht und Selbstsorge $($ ). Die Brisanz des Themas explizieren die Lehrerinnen in den Interviews nicht. Implizit zeigt sie sich aber darin, dass die körperliche Nähe zu ihren Schülern einer Legitimierung bedarf. Diese besteht darin, dass es die Bedürfnisse der HauptschülerInnen sind, die ihr körpernahes Handeln als soziales notwendig machen. Für Lehrende wird damit nicht nur zur Gratwanderung, wie sie selbst auf Schüler oder Schülerinnen zugehen, inwiefern sie dabei als Professionelle die Signale der jeweiligen Schülerin wahrnehmen, erkennen und damit eben professionell umgehen, sondern wie sie auf körperliche Nähe reagieren, welche die SchülerInnen zu ihnen herstellen. 


\section{Grenzgänge, institutionelle Rahmung und Machtverhältnisse}

Bisher ging es um Körperkontakte, die von den Lehrerinnen ausgingen. Ich möchte nun eine weitere Perspektive hinzufügen, um einerseits Grenz-Situationen genauer zu betrachten und andererseits damit Machtverhältnisse und -praktiken in der Beziehung zwischen LehrerInnen und SchülerInnen zu fokussieren. Beobachtet haben wir auch Situationen, in denen solche Kontakte von SchülerInnen ausgingen, aber insgesamt sehr viel weniger. Vielleicht gibt es solche Situationen häufiger außerhalb des Unterrichts und sie sind uns entgangen, da wir in der Pause meist in Gespräche mit den SchülerInnen involviert waren bzw. die Pause als solche für uns selbst beanspruchten. Ich werde verschiedene Situationen vorstellen und sie kontrastierend analysieren.

Beim Klassenfest vor den Herbstferien, bei dem die Forschenden sowie einzelne Schüler in der Klasse fotografiert haben, war folgende Situation zu beobachten:

Eine der Lehrerinnen sitzt auf einem Stuhl in der Schulklasse und eine Fotografin steht mit der Kamera vor ihr. Sie ist im Begriff, die sitzende Lehrerin zu fotografieren. Maris bemerkt das, stürzt sich von hinten auf die Lehrerin, umarmt sie und schmiegt sich von hinten an sie. Liv tritt mit etwas Abstand zu dieser Szene dazu, um auch mit auf das Bild zu gelangen. Die Lehrerin wirkt erschrocken und irritiert, greift nach Maris Armen und lässt sich mit ihr fotografieren. (AL)

So ist ein Foto entstanden, auf dem sich eine Schülerin über die Schulter ihrer Lehrerin legt und sie dabei mit beiden Armen umschlingt. Sie berührt mit ihren Armen die Brust der Lehrerin, verschränkt sie davor, hält sie fest, engt sie ein. Mit ihrer Brust berührt sie zugleich den Rücken der Lehrerin. Außerdem schmiegt sie ihre Wange an die der Umarmten. Sie blickt direkt in die Kamera, und es zeigt sich ein wohlwollendes zufriedenes Lächeln auf ihrem Gesicht. Das Foto macht sichtbar, wie die umarmende Schülerin in der Situation triumphiert. Sie setzt ihren Körper ein und beansprucht die Lehrerin voll und ganz; zugleich demonstriert sie für die Anwesenden in diesem Moment und für die Betrachtenden des Fotos eine freundschaftliche Beziehung. Die Lehrerin wendet ihren Kopf etwas von der Schülerin ab, sie bewahrt Haltung und blickt freundlich mit leicht geöffnetem Mund, aber nicht lächelnd, in die Kamera. Sie hält den rechten Arm der Schülerin fest und legt ihre linke Hand auf die rechte Hand der Schülerin. Diese Haltung wirkt beschützend. Ihre Kopfhaltung und ihr Gesichtsausdruck passen aber nicht zu dieser Bestätigung der Umarmung. Der Moment, in dem die Schülerin einen für schulische Situationen ungewöhnlich engen Körperkontakt herstellt, der noch dazu von einer 
Forscherin mit einer Kamera festgehalten wird, scheint eine Hilflosigkeit bei der Lehrerin auszulösen; körperliche Geste und Mimik wirken widersprüchlich. In dieser Situation ist es der Lehrerin kaum möglich, die Schülerin zurückzuweisen, zumal eine weitere Schülerin ihrer Klasse - nicht in ihrem unmittelbaren Blickfeld, aber ebenfalls körperlich nahe, so dass sie spürbar wird - dazu tritt. Die Situation hat bei den Lehrerinnen auch im Nachhinein - im Team und in der Supervision - für Gesprächsstoff gesorgt, nicht nur, weil die Forschenden sie später darauf ansprachen (vgl. Hermann/Stötzer 2008).

Das Foto sowie die Situation, in der fotografiert wird, ist in einem besonderen Kontext entstanden: während einer Feier, bei der die Forschungsgruppe einen Fotoapparat ins Spiel bringt, zum Fotografieren und zur Inszenierung für das Foto auffordert. Die beschriebene Szene wird erst durch die Anwesenheit und das Handeln der Forschenden möglich. Sie eröffnen einen Interaktionsraum, der sonst nicht einfach gegeben ist, indem das Fotografieren in der Schulklasse zum Kommunikationsanlass wird. Wie Bourdieu in seinen Ausführungen über die »sozialen Gebrauchsweisen der Fotografie« (1981) herausgearbeitet hat, geht mit dem Einsatz der Kamera in bestimmter Weise die Aufforderung zur Inszenierung einher. Denn es gibt gesellschaftliche Definitionen, die bestimmen, wer was wann und wie fotografiert. Das heißt, Fotografieren und Fotos betrachten findet nach bestimmten Kategorien und Regeln traditioneller Weltdeutung und der Reproduktion von Wirklichkeit statt. Fotografieren ist ein Ritual. Diejenigen, die vor der Kamera stehen, nehmen eine Pose ein, von der sie annehmen, dass sie für sie vorteilhaft und ihrer würdig ist und dass sie von den anderen Anwesenden in dem Moment sowie von späteren Betrachtenden anerkannt wird. Sie wollen einen Moment festhalten, der damit später als genau so stattgefunden rekapituliert werden kann. So dient er als Beweis oder Trophäe. Dazu schreibt Bourdieu (1981: 92): »Wer posiert, wünscht in einer Haltung photographiert zu werden, die weder snatürlich ist noch dies sein will. Hinter einer `korrekten der Weigerung, sich bei einer alltäglichen Verrichtung überraschen zu lassen, steckt ein und dieselbe Absicht. Eine Pose einzunehmen bedeutet, sich selbst zu achten und von anderen Achtung zu erlangen.«

An dieser Stelle entsteht nun ein Problem. Im Rahmen des Rollenhandelns von LehrerInnen und SchülerInnen ist eine solche Umarmung eine eindeutige Grenzüberschreitung. Als Körperpraktik entspricht sie der Figur der intimen Mädchenfreundschaft - ein gängiges Foto-Motiv, das auch historisch verfolgt werden kann und für das die Metapher der »Busenfreundin« steht. Hier wird eine Intimität demonstriert, die es im Gegensatz dazu bei der Figur des »guten Kumpels« nicht gibt (und geben darf). Diese von dem Mädchen so inszenierte Freundschaft entspricht nicht der Beziehung, die für eine Lehrerin professio- 
nell wäre. Zugleich, so formuliert Frau Matthes später, wollte sie die Schülerin »nicht vor den Kopf stoßen«. Die Körpermetapher scheint hier angebracht, denn dies hätte in der Situation bedeutet, sie körperlich zurückzustoßen. Die Lehrerin wird körperlich überwältigt und vereinnahmt und muss in der Halböffentlichkeit der Schulklasse angemessen reagieren, d. h. auch die anderen Anwesenden - die SchülerInnen, ihre Kollegin und nicht zuletzt die Forschungsgruppe - in Sekundenschnelle einbeziehen. Insofern ist das entstandene Foto beispielhaft für tagtägliche Situationen in der Schule. Gedanklich lässt sich hier mit der Vorstellung spielen, die Schülerin durch einen Schüler zu ersetzen bzw. die Lehrerin durch einen Lehrer. Zu welchen Diskussionen würde dies führen, und letztendlich auf welche Diskurse würde dies verweisen?

Doch zu einer weiteren Beobachtung:

Nach der Unterrichtsstunde, als alle in die Pause gehen, haut Udo Frau Matthes im Vorbeigehen lachend und aufmunternd auf die Schulter. Er springt dabei hoch, denn er reicht aufgrund seiner geringen Körpergröße kaum an sie heran. (AL)

Diese kurze, der Beobachterin völlig willkürlich erscheinende Handlung, verläuft fast wie nebenbei und wird von den meisten in der Klasse wohl auch gar nicht wahrgenommen. Die Lehrerin reagiert darauf nicht sichtbar, vielleicht hat sie die Berührung gar nicht so recht bemerkt, oder sie ignoriert sie einfach. Eine für die Schule typische Geste eines Schülers ist es jedenfalls nicht, der Lehrerin auf die Schulter zu klopfen. Die Beobachterin interpretiert die Geste als Aufmunterung, also als eine gut gemeinte. Fragt sich, wie sie dazu kommt. Udo ist der kleinste Schüler der Klasse, auf dem Stuhl sitzend, reicht er mit den Füßen kaum auf den Boden. Als sog. Integrationsschüler gilt er als entwicklungsverzögert. Die Interpretation der Forscherin weist auf ihre Doxa (vgl. Bourdieu 1993: 80; Friebertshäuser 2006: 237), ihr Vorverständnis und ihre Klassifikationssysteme hin. Die Geste des Schülers begreift sie als nicht provokativ - was ja ebenfalls möglich wäre - einerseits, weil die Lehrerin nicht sichtbar reagiert, andererseits, weil sie den Jungen sowohl körperlich als auch in seiner Entwicklung als noch klein und kindlich betrachtet und ihm eine solche Geste (noch) zugesteht (ähnlich den Lehrerinnen im Interview). Aufgrund seiner Körpergröße kann er eben nicht von oben herab die Hand auf die Schulter legen (eine elterliche Geste, die das zuvor beschriebene Verhältnis umkehren würde und deshalb unangemessen und provokativ wäre), sondern muss hochspringen, um überhaupt die Schulter der Lehrerin zu erreichen. Dadurch kommt der Geste eine ganz andere Aussage zu, sie wirkt zwar neckend und annähernd fürsorglich, aber eben in keiner Weise paternalistisch und affirmativ. Es ist eine Geste, um auf sich aufmerksam zu machen, und des Sich-Mes- 
sens, obwohl dies als Schüler gegenüber der Lehrerin eigentlich aussichtslos erscheinen müsste.

Die kleine Szene macht auf etwas aufmerksam: Es ist zwar bemerkenswert, dass die Lehrerinnen der Klasse den SchülerInnen häufiger mal die Hand auf die Schulter legen, aber diese Geste irritiert nicht im gleichen Ausmaß, wie wenn ein Schüler die Schulter seiner Lehrerin berührt. In der Irritation zeigt sich die Asymmetrie dieses Verhältnisses: SchülerInnen können ihre LehrerInnen nicht ebenso in den Nacken zwicken, wie wir es umgekehrt beobachtet haben. Und sie können sie, wie in der zuvor geschilderten Szene, nicht einfach in den Arm nehmen, auch wenn es weniger »hinterhältig « als in der geschilderten Fotosituation vor sich geht. Es ist klar, wer wen berühren darf: Es ist eher eine einseitige, statusabhängige Initiative, denn LehrerInnen haben Berührungsprivilegien, welche die SchülerInnen nicht haben. Die Möglichkeit, körperlich Kontakt aufzunehmen, ist, soll sie nicht die übliche Distanz verletzen, für die SchülerInnen nur sehr begrenzt und am ehesten in eine Situation einzubinden wie die der Hilfeleistung im Sport. ${ }^{8}$ Die hier beobachteten Kontaktaufnahmen sind für die Schulklasse sonst eher unüblich. Interessant wäre hier ein Vergleich zu den Körperpraktiken in der 5. Klasse, auf die in den Interviews ja immer wieder verwiesen wird. Der damalige, von den SchülerInnen ausgehende Körperkontakt, von dem die Lehrerinnen berichten, erfolgt in einer spezifischen pädagogischen Rahmung bzw. in einer spezifischen Beziehung analog zu der von Eltern und Kind. Es ist der (mütterliche oder väterliche) Schoß, in dem die Kinder Schutz suchen und finden.

Interessant ist in diesem Zusammenhang, noch einmal genauer zu fragen, welche Körperteile eigentlich berührt werden. In den Protokollen ist von sin

8 Das ließ sich vor allem im Sportunterricht der Mädchen in verschiedenen Situationen im Umgang mit ihrem Sportlehrer beobachten:

(1) Silja ist gestürzt und spielt täuschend echt, dass es wirklich furchtbar wehtue, so dass sie tatsächlich die Aufmerksamkeit des Sportlehrers erhält und er ihr mit besorgtem Blick wieder aufhilft. Dann stellt sie sich sofort wieder zu den anderen Mädchen, und es scheint alles vergessen. (2) Xenia nimmt beim Balancieren mit einem Lächeln die angebotene Hand zur Hilfestellung entgegen. (3) Maris drängelt sich in die Gruppe von Schülerinnen und Lehrer und fordert den Lehrer während einer Übung, bei der die Mädchen miteinander kämpfen sollen, durch boxende Gesten zum Kampf auf. Der Lehrer lässt dies nicht zu. (AL)

Der Körperkontakt des Lehrers findet hier als Reaktion auf die Schülerinnen statt. Es sind zwei verschiedene Weisen, Körperkontakt mit dem Lehrer herzustellen: die betonte Inanspruchnahme einer unterrichtstypischen Hilfeleistung und die Aufforderung zum Kampf. Die Hilfestellung ist zwar Teil des Sportunterrichts, enthält aber von Seiten der Schülerinnen eine Flirt-Komponente bzw. etwas Provokatives, Austestendes. (Wett)kampf und Konkurrenz sind ebenso wesentliche Bestandteile des Sportunterrichts (vgl. Klein 1984; Schulz 1993). Die Situation ist durch eine andere Rahmung geprägt, in der die Berührung des Körpers zum Teil möglich oder gar unumgänglich ist (vgl. Goffman 1996b: 46-49). 
den Nacken kneifen und >freundschaftlich am Kragen packen die Rede, aber auch das Treten vor die Stuhllehne - der indirekte Tritt in den Rücken. Es wird über den Kopf und über die Schultern gestrichen bzw. an diesen Stellen die Hand aufgelegt. Es wird vor die Brust geboxt oder der Arm um die Schulter gelegt. Es ist also der Oberkörper Ort des Kontakts. Oft ist es gar nicht unmittelbar die Haut, sondern es ist die Kleidung, die berührt wird, womit der Körper weniger direkt ins Spiel kommt. Das Kneifen in den Nacken ist einer der wenigen direkten Kontakte. Aber auch hier kommen mir elterliche Assoziationen wie die Katze, die ihr Junges am Nacken packt und durch die Gegend trägt. Es sind freundschaftliche, zuneigende Gesten, die zugleich mit einer pädagogischen Botschaft gekoppelt sind: das Kneifen in den Nacken als Mahnung, als symbolische Grenze und Sanktion.

Das asymmetrische Verhältnis der pädagogischen Beziehung zeigt sich auch in einer weiteren Situation, in welcher der Kontakt wiederum von der Lehrerin ausgeht:

Frau Matthes bespricht mit Liv das Arbeitsblatt. Sie setzt sich neben sie auf den Tisch, beugt sich herunter. Liv liest stockend vor. Sie bekommt etwas erklärt. Dabei zwinkert sie viel mit den Augen, guckt über ihre Brille, aber Frau Matthes nicht an. (AL)

Hier findet gar kein direkter Körperkontakt statt. Dennoch beschleicht die Beobachterin etwas Unbehagen, versetzt man sich in die Schülerin. Eventuell wird die hier von der Lehrerin gut gemeinte Nähe als bereits zu nah empfunden. Zumindest stellt sich die Nähe nicht in gleicher Weise her; die Schülerin weicht mit dem Blick aus, es scheint ihr unangenehm zu sein. Verbunden ist die Situation eben nicht nur mit Sympathie oder Zuneigung (oder eben nicht), sondern die pädagogische Beziehung zeichnet mehr aus. Als Schülerin muss sie in diesem Moment eine Leistung erbringen, zeigen, was sie kann. Die Situation, in der ihr die Lehrerin nahe ist, wird zu einer Prüfung, zu einer unbequemen Nähe, die fürsorgliche Geste zur Machtpraktik.

Das führt zu einer Frage, die offen bleibt und weder von den Lehrerinnen noch von uns zu diesem Zeitpunkt gestellt worden ist: Wie empfinden eigentlich die SchülerInnen diese körperliche Nähe ihnen oder aber auch den anderen gegenüber? Was denken sie über die Nähe oder Distanz, die mit der demonstrierten Unterscheidung im jeweiligen Umgang zwischen ihnen und den anderen mittransportiert wird? Hier zeigt sich weiterer Forschungsbedarf.

Eine weitere schwierige Situation kann entstehen, wenn Kontaktaufnahmen dieser Art stattfinden, wie ich sie bereits beschrieben habe: 
Frau Timm kommt an Olivers Stuhl vorbei und tritt mit dem Fuß gegen die Lehne. (AL)

Der Tritt gegen die Stuhllehne, der aus einer Laune heraus zu geschehen scheint, ähnelt einer Praktik der Schüler, wie sie häufig im Unterricht zu beobachten ist. Wenn sie z. B. von einem Gespräch mit der Lehrerin zu ihrem Platz zurückkommen, rempeln sie einen Mitschüler, an dem sie gerade vorbeikommen, an oder pieksen ihn mit einem Finger in den Rücken. Damit wird Kontakt aufgenommen, geneckt, provoziert, Aufmerksamkeit erzeugt. Häufig reagieren die Schüler auf eine solche »Anmache« ebenso auf der körperlichen Ebene, boxen z. B. zurück (vgl. Kap. `»Körperportrait« eines Schülers $<$ ). Der Lehrerin gegenüber kann Oliver nun nicht in dieser Weise reagieren. Auch wenn sie lediglich »herumflachsen« möchte, bleibt ihm nur, verbal zu protestieren bzw. den Tritt hinzunehmen. Der im Treten gegen den Stuhl enthaltenen Kumpelhaftigkeit kann er nicht auf die gleiche Weise begegnen, wie er das seinen Mitschülern gegenüber täte. Die Lehrerin bleibt Lehrerin, der Respekt ihr gegenüber verbietet es, »kumpelig« zurückzutreten. Wenn also die Lehrerin eine andere Rolle als die der Lehrerin einnimmt - und dies körperlich vollzieht bzw. anzeigt - so kann der betreffende Schüler nicht ohne weiteres eine dazu komplementäre übernehmen.

Körperliche Bezugnahme als Aspekt der pädagogischen Beziehung schafft Individualität und bricht zumindest etwas den strengen schulischen Rahmen auf; zugleich können zuweilen Doublebind-Situationen entstehen, denn die Schüler können diese Beziehung nur innerhalb der Schulstrukturen interpretieren (also als strategische, wo es für sie darum geht, möglichst gut wegzukommen). Es wird aber auch von ihnen gefordert bzw. erwartet, dass sie diese Beziehung im Rahmen der Schule interpretieren, denn bestimmte Verhaltensweisen, wie z. B. auf dem Schoß zu sitzen, erscheinen doch irgendwie nicht angemessen. Es ergibt sich also für beide Beteiligten ein Dilemma, da sie mehr oder weniger auf die ihnen institutionell vorgegebenen Rollen verwiesen sind.

Deutlich wird in den Handlungen der SchülerInnen und den Erzählungen der Lehrerinnen, dass letztere nicht allein Wissensvermittlerinnen sind, sondern auch Vertraute, Bezugspersonen, Erzieherinnen. Dieses Vertrauen wird wiederum in den beobachteten Szenen sichtbar. Eine solche Nähe, die von den SchülerInnen zugelassen und eingefordert wird, ist nur auf einer Vertrauensbasis möglich. Körperlichkeit und Berührung begreifen die Lehrerinnen als professionelles Mittel und spezifische Form von Beziehungsarbeit, die in der Hauptschule besonders wichtig sei. Diese Beziehungsarbeit stehe ihrer Meinung nach dem Vermitteln von Inhalten gegenüber. Ebenso scheint sie Grundlage zu sein, um Wissensvermittlung bzw. Lernen zu ermöglichen. Diese Unterscheidung spielt besonders im Interview mit Frau Timm eine Rolle. 
Wichtig sei, dass die SchülerInnen (z. B. durch bestimmte Rituale oder eben auch durch nicht näher bestimmte körperliche Gesten) signalisiert bekämen, auf welcher Ebene gerade kommuniziert wird und dass sie dies verstehen. Das zu verstehen zu geben und als Lehrerin die Differenz selbst zu sehen begreift Frau Timm als Teil ihrer Professionalität, da viele SchülerInnen von allein nicht unterscheiden könnten, ob gerade auf der Beziehungs- oder der Inhaltsebene agiert werde. Die Frage, die sich aus der Gegenüberstellung ergibt, ist, ob sich die verschiedenen Ebenen, und damit verbunden die Rollen, welche die Lehrerinnen einnehmen, innerhalb der Schulstrukturen ausschließen oder ob es gerade dieses komplexe Verhältnis ist, das Doublebind-Situationen produzierend gerade das Typische am Schulalltag ist. Die verschiedenen Facetten des Körperlichen in pädagogischen Beziehungen, die ich aufzeigte, legen mit der Anlage meiner Studie die Frage nahe, inwiefern körperliche Bezugnahmen zwischen LehrerInnen und SchülerInnen im untersuchten Zeitschriftenkorpus thematisiert werden.

\section{Körperkontakt - eine Leerstelle im Diskurs?}

Mit diesen Analysen zum Körperkontakt innerhalb pädagogischer Beziehungen in der Schulklasse möchte ich ein letztes Mal zum Zeitschriftenkorpus übergehen. Die Überschrift deutet bereits an, dass sich die Tabuisierung, die sich in den Interviews zeigte, beispielsweise, wenn Frau Matthes davon spricht »ungebremst« über Körperkontakt zu ihren SchülerInnen zu reden, oder wenn Berührungen einer besonderen Legitimation bedürfen, in den untersuchten Zeitschriften fortsetzt. Während in den Interviews explizit nach körperlichen Bezugnahmen gefragt wurde, die Lehrerinnen diese reflektieren und mit Andeutungen oder Problematisierungen auf eine Tabuisierung verweisen, findet sich im Zeitschriftenkorpus quantitativ so gut wie nichts dazu. Körperkontakte kommen als Thema in den pädagogischen Texten schlichtweg nicht vor. Die Ausnahmen lassen sich einzeln aufführen. Ich greife sie hier auf, weil sie über das Tabu Aufschluss geben, indem dieses im Reden darüber gestreift wird. Nicht-Thematisiertes lässt sich schwerlich untersuchen, da nur die Positivität des Gesagten zum unmittelbaren Untersuchungsgegenstand werden kann, es aber keine Positivität der Unterlassung gibt (vgl. Hirschauer 1994: 678). So nutze ich die Ausnahmen des ansonsten Nicht-Gesagten, um dem Tabu bzw. zumindest einigen kritischen Punkten eventuell auf die Spur zu kommen.

In einem Artikel zu Unterrichtseinstiegen von Lehrenden, in dem verschiedene Beispiele des Beginns vorgestellt werden und deren Bedeutung für 
den Verlauf einer Schulstunde hervorgehoben wird, beschreibt Gudjons folgende Szene:

"Die [5. AL] Klasse arbeitet engagiert und konzentriert mit, - bis plötzlich und völlig unvermittelt Dicki laut anfängt seine unmittelbaren Nachbarn unflätig anzupöbeln und wüst zu beschimpfen. Was tut Frau L. [- die Lehrerin, A. L.]? Mit ruhigen Schritten geht sie auf Dicki zu, legt ihre Hand leicht auf seine Schulter und sagt: »Komm bitte einen Moment mit mir vor die Tür! « Dicki steht auf und geht schweigend mit Frau L. nach draußen.« (PÄD LK 04 99: 11)

Die zweite Ausnahme möchte ich gleich anschließen. Sie findet sich im Rahmen der bereits in Kapitel `Disziplin und Disziplinierung vorgestellten Serie »Klassenmanagement« von Trainer Hubert Schmitt (SM D 10-13 07), in der die Körpersprache der Lehrkraft als Disziplinierungsinstrument im Mittelpunkt steht. Unter dem Abschnitt »Fertigkeit 14: Die Aufmerksamkeit zurückgewinnen (〉Geisterhand $)$ « ist im Begleittext zu einer Übung für LehrerInnen, welche »Geisterhand « genannt wird, von der Praktik des Handauflegens auf die Schulter eines Schülers zu lesen. Das werde als Form der Beziehungsaufnahme ab und zu mit positiven Absichten getan, um Anerkennung oder Aufmunterung zu signalisieren. Allerdings, so Schmitt, würden solche Körperkontakte meist unbewusst und unreflektiert geschehen, so dass »sich die mit diesen Berührungen einhergehende beruhigende bzw. entspannende Wirkung auch nur eher zufällig ein[stellt]« (SM D 13 97: 52). Im Zusammenhang mit Disziplinierung wird den lesenden LehrerInnen nun erklärt, wie sie diese Wirkung, die zugleich Konzentration steigere, »durch ein bewusstes >Handauflegen« « (ebd.) gezielt erzeugen könnten.

In beiden Beispielen wird der körperliche Bezug als pädagogisches Mittel eingesetzt. Während im ersten Fall lediglich auf die Wichtigkeit nonverbaler Kommunikation im Unterricht und die Vermeidung dysfunktionaler Körpersprache hingewiesen und damit die Szene als good practice deklariert wird, wird dem von der Lehrkraft ausgehenden Körperkontakt im zweiten Textausschnitt eine eindeutige Wirkungsweise zugeschrieben, die mittels Übung in kleinen Schritten geprobt werden kann. Durch eine angenehme nachhaltende Wärme entstehe Beruhigung, Entspannung und Konzentration, so wird weiter erklärt. Allerdings kollidiert dies wohl mit einer Problematik, nämlich dass eine Berührung von manchen SchülerInnen trotz guter Beziehung zu ihnen nicht toleriert werde - und dann, so scheint es, sich auch der gewünschte Effekt nicht einstelle. Denn die Lehrenden würden dies an einer Verkrampfung der SchülerInnen merken. Die eindeutig zugeschriebene Wirkung erfährt hier gewissermaßen ihr Gegenteil: Ver- bzw. Anspannung statt Entspannung. Deshalb warnt Schmitt: »Diese Übung wird hier vorgestellt, obwohl gezielter 
Körperkontakt mit Schülern, vor allem mit älteren, nicht unproblematisch ist. Es wird deshalb darauf hingewiesen, dass Berührungen - die hier vorgestellten beschränken sich ausschließlich auf die Schulter - eine gute Beziehung zwischen Lehrer und Schüler voraussetzen.« (ebd.) Berührungen sind »nicht unproblematisch«, also problematisch. Weshalb, scheint nicht gesagt werden zu müssen oder zu dürfen. Andererseits kann wohl ein Konsens mit den LeserInnen nicht unbedingt vorausgesetzt werden, denn auf den Hinweis, dass Körperkontakte mit Vorsicht einzusetzen seien, kann zugleich nicht verzichtet werden. Auf Körperkontakte zu sprechen zu kommen, bedarf des Signals, dass sich der Autor möglicherweise heikler Situationen bewusst ist und Grenzen von SchülerInnen im Blick hat.

Heikel daran könnte das Alter der SchülerInnen sein. Mit zunehmendem Alter gestalte sich Berührung schwieriger, so Schmitt. Darauf verweist auch von der Groeben in einem Artikel über Rituale im Unterricht. In der Laborschule in Bielefeld könnten SchülerInnen im Morgenkreis in den Klassen 5 bis 7 auch mal auf dem Schoß der Lehrenden sitzen. Wenn aus Kindern allerdings Jugendliche geworden sind, käme es nicht mehr zu dieser Nähe, und die Atmosphäre werde sachlicher (PÄD D 07 99: 13). Annehmen ließe sich mit Elias, dass aufgrund des durchlaufenen Zivilisationsprozesses mit zunehmender Körperkontrolle, die auch erwartet wird, die Berührung, hier zugleich als emotionale verstanden, ihre Unschuld verliert. Berührung wird zur Grenzverletzung, so wie die Lehrerinnen es im Interview dargestellt haben. Zunehmendes Alter bedeutet zunehmender Abstand und Abstand Rationalität bzw. Sachlichkeit im Gegensatz zu Nähe, die zugleich Emotionalität konnotiert.

Jedoch ist das nicht alles, was problematisch sein könnte. Ebenso wichtig scheint es, hervorzuheben, dass die Berührung nur auf der Schulter erfolgen soll. Die Schulter wird zu einem harmlosen Körperteil, das sich in der Situation der Berührung nicht durch dieselbe Intimität wie das Halten der Hand (jenseits einer Begrüßung) auszeichnet. Gudjons schreibt, dass die Lehrerin »leicht« die Hand auf die Schulter des Jungen legt - vorsichtig, ohne Gewalt und so die Grenze nicht überschreitend. In der kleinschrittigen Arbeitsanleitung bei Schmitt, mit der diese »Fertigkeit« erlernt werden kann, wird die damit einhergehende Handhaltung spezifiziert und die Schritte, die vollzogen werden müssen, aufgelistet: »2. Legen Sie [...] Ihre Hand mit leicht gespreizten Fingern sanft auf die Schulter. 3. Verstärken Sie behutsam den Druck, aber achten Sie darauf, dass der Schüler sich noch völlig frei bewegen kann. Folgen Sie ggf. seinen Bewegungen.« (ebd.) Als Ziel wird die Nachhaltigkeit der Berührung genannt, die SchülerInnen sollen »das Gefühl der unmittelbaren Körpernähe des Lehrers auch dann noch empfinde[n], wenn dieser schon weg ist.« (ebd.) Damit erklärt sich die Bezeichnung »Geisterhand« - sie 
kommt nicht nur geisterhaft aus dem Jenseits, weil sie sich den SchülerInnen von hinten unbemerkt nähert, sondern sie bleibt als Geist der Lehrkraft erhalten, indem sie sich möglichst nach hinten, außerhalb des Blickfelds, verzieht. Ist ihr Geist es, der zur Konzentration anhält? Ist es dann nicht vielleicht doch eher die Anspannung, die den betreffenden Schüler die Haltung beibehalten lässt?

Die NLP-nahe Übung, die in der Logik der seriellen Schritte des »Klassenmanagements « steht, nachdem in diesem »Training « grundlegende Expertisen des (richtigen) Disziplinierens eingeführt wurden und die Ausführenden bereits Fortgeschrittene sind, ist im gesamten Korpus die einzige, die Berührung zum Gegenstand macht. Dabei zeigen sich ähnliche Legitimierungen und Problemandeutungen, wie sie die interviewten Lehrerinnen nennen. Jedoch wird die Funktionalisierung als disziplinierendes Mittel noch stärker herausgekehrt. Die individuelle Grenze der jeweiligen SchülerInnen wird zwar benannt, aber sie existiert immer nur als »Entweder-oder-Entscheidung«. Es gibt diejenigen, bei denen es so funktioniert, und diejenigen, deren Grenze bereits überschritten wird. Als eingesetzte Technik spielt weder die konkrete Situation noch eine Reflexion der Beziehung und der Statusungleichheit sowie der Machtpraktik als solcher eine Rolle. Die Altersgrenze und die Grenzüberschreitung entstehen aufgrund gesellschaftlicher Konventionen und damit verknüpfter Praktiken von Nähe und Distanz sowie innerhalb bestimmter Bilder von Professionalität - Gründe bzw. Reflexionen, die im letzten Beispiel jedoch außen vor bleiben.

Die individuelle Grenze von SchülerInnen gegenüber Personen in bestimmten Situationen und innerhalb der Institution Schule, in die die obigen gesellschaftlichen Diskurse eingehen und in denen kulturelle Aspekte üblicherweise ausgelassen werden, findet sich im Titel eines anderen Artikels. »Fassen Sie mich nicht an!«« - so lautet die Überschrift, die mit dem Untertitel »Der alltägliche Umgang eines Junglehrers mit schwierigen Schülern" (PÄD D 21 02: 20) näher spezifiziert wird. Das idealtypische Zitat vom "schwierigen Schülers« zeichnet jenen dadurch aus, dass er von der Lehrkraft nicht berührt werden möchte, dass er sich dagegen wehrt, angefasst zu werden, und sich ihr gegenüber distanziert. Die Situation, aus der dieses Zitat entnommen wird, ist die, dass der Lehrer den Jungen als »Störenfried« bereits der Klasse verwiesen hat und ihn am Oberarm aus der Klasse hinausführen möchte. Der Schüler ${ }^{9}$ zeigt nicht nur seine persönlichen Körpergrenzen, sondern weist den Lehrenden in seine Grenzen, was den Schüler erneut zum schwierigen Schüler macht. Die Verweigerung wird im Rahmen seiner Schwierigkeit interpretiert, indem einerseits der Lehrer den Jungen nur anfasst, weil der ihn bereits in

9 Könnte es auch eine Schülerin sein? 
eine schwierige Situation gebracht hat. Andererseits würden sich, so scheint es, »einfache« SchülerInnen auch nicht lautstark zur Wehr setzen oder hätten der körperlichen Berührung weniger entgegenzustellen. Hier wird eine Ambivalenz deutlich, die sich auch schon in den Interviews mit den Lehrerinnen zeigte, dass die Beherrschung eines altersgemäßen Körperhandelns zwar vorausgesetzt und erwartet wird, das Widerstreben gegenüber körperlicher Nähe aber zugleich als Schwierigkeit oder Defizit erachtet wird.

Zudem verweist die Bezeichnung »Junglehrer« darauf, dass davon ausgegangen wird, dass diese Szene erfahrenen LehrerInnen wohl nicht passiert wäre. Zugleich bleibt unreflektiert, das sich hier auch ein Konflikt »unter Männern« abspielen könnte - zumindest aus Sicht des Schülers, der Grenzüberschreitungen nicht duldet und damit die Autorität des Lehrers in Frage stellt. Auf diese Weise wird in einem solchen Konflikt mitverhandelt, wessen Deutung der Situation sich durchsetzen kann. Innerhalb der Schule sind die Möglichkeitsräume zwischen jungen Männern davon bestimmt, ob sie noch als Schüler oder schon als Mann bzw. Lehrer agieren. Außerhalb dieses gesellschaftlichen Rahmens würde man die Szene ganz anders interpretieren.

Die Auseinandersetzung und Interpretation der Einzelbeispiele lassen das, was ich eingangs mit »Leerstelle im Diskurs« betitelte, gar nicht mehr so »leer« erscheinen, da sie die diskursive Rahmung dessen, was nicht gesagt wird, hervorheben, indem sie auf andere Diskurse, wie z. B. Pubertät oder Individualität, verweisen. Um die Aussage der diskursiven Leerstelle noch einmal zu überprüfen, ist über die Ausnahmebeispiele hinaus ein Blick in die Literatur erforderlich, die sich mit Körpersprache im Unterricht beschäftigt. ${ }^{10}$ Inwiefern werden Körperkontakte zwischen LehrerInnen und SchülerInnen sowie umgekehrt thematisiert oder problematisiert? Insgesamt zeigt sich dort das gleiche Bild: Größtenteils findet körperliche Berührung innerhalb nonverbaler Unterrichtskommunikation gar keine Erwähnung (Heidemann 2003; ausgenommen ein Aufsatz von Rosenbusch/Schober 2004), oder es werden entsprechend den obigen Ausführungen knapp die zentralen Dimensionen aufgemacht: Fürsorglichkeit bei jungen SchülerInnen, Berührung der Schulter oder des Arms, Ablehnung bei Pubertierenden, vertrauensvolle Beziehung als

10 Die Bedeutung nonverbaler Kommunikation im Unterricht wird von den AutorInnen hoch eingeschätzt. Beispielsweise schreiben Heinz S. Rosenbusch und Otto Schober in ihrem Vorwort als ersten Satz: »Es dürfte wenige Berufe geben, bei denen Mechanismen nonverbaler Kommunikation eine größere Rolle spielen als im Lehrerberuf.« (ebd. 2004: V) In der Anzahl der Publikationen spiegelt sich dies auf den ersten Blick allerdings nicht wider: Es sind lediglich vier deutschsprachige (Lehr-)bücher. Allerdings existieren von allen jeweils mehrfache zum Teil überarbeitete Auflagen, was wiederum für die Nachfrage spricht. Zugleich scheint das, was geschrieben wird, nicht besonders diskussions- oder fragwürdig zu sein, wenn es keine Publikationen darüber hinaus gibt. 
Grundlage (Rosenbusch 2004: 149; Caswell/Neill 2003: 194-198). Einen längeren Abschnitt widmen Chris Caswell und Sean Neill in ihrem Buch, das aus dem Englischen übersetzt wurde, dem Thema Berührungen. Dabei beziehen sie auch eigene Studien ein, in denen SchülerInnen befragt wurden. Sie thematisieren die Problematik der Wahrnehmung von Grenzen, die für LehrerInnen vor allem in der Angst vor Missbrauch von Kindern bestünde wie auch davor, unprofessionell zu erscheinen. Hilbert Meyer und Liane Paradies bringen in ihrer Broschüre »Körpersprache im Unterricht« die beobachtete Tabuisierung auf den Punkt, indem sie diese auf eine bestimmte Weise selbst fortschreiben. Im Abschnitt »Körperkontakt« innerhalb der Benennung von Grundbegriffen zur Beschreibung von Körpersprache steht der einführende Satz: »Körperkontakt braucht nicht definiert werden; er stellt sozusagen den `Grenzwert< der Intimzone dar.« (Meyer/Paradies 2005: 22) Damit erklären und verfestigen sie gewissermaßen die Leerstelle im Diskurs. Wenn es etwas nicht geben darf bzw. nur in bestimmten Situationen - sie führen die Grundschule sowie bestimmte Unterrichtsfächer auf wie Sport, Musik oder Werken, die sie als traditionell ganzheitlich bezeichnen und in denen körperlich unterstützt werden muss -, dann muss dieses »Etwas« auch nicht näher definiert werden. Es bleibt unmittelbar auf die Sache bezogen außerhalb eines diskursiven Raumes; als Unsagbares gehört es nicht in den Möglichkeitsraum dessen, was gesagt werden kann (Schneider/Hirseland 2005: 270f.). Allerdings weisen darauf wiederum auch die beiden oben genannten AutorInnen selbst hin: Sie prangern die Tabuisierung an, die sie mit rigiden gesellschaftlichen Normen erklären, können aber nicht außerhalb eben jener diskursiven Praktiken argumentieren.

Wenn über Körperkontakte im engen Sinne nicht bzw. kaum gesprochen wird, werden sie vielleicht mittels nicht-textförmiger diskursiver Praktiken auf andere Weise zum Thema. Mit dieser Idee schaue ich abschließend auf das Bildmaterial des Zeitschriftenkorpus. Wie werden die Beziehungen von LehrerInnen und SchülerInnen dargestellt? Welche Rolle spielen körperliche Nähe und Berührungen dort? Die Betrachtung des Bildmaterials in den Zeitschriften, aus denen ich Artikel systematisch und detailliert analysierte, sowie stichprobenartig in weiteren Ausgaben, bestätigen das bisher Geschriebene. Körperkontakte sind generell kaum abgebildet, und zwischen Lehrenden und SchülerInnen schon gar nicht. Über dieses sehr eindeutige Ergebnis hinaus, dass über körperliche Beziehungsebenen nicht geredet wird, lassen sich jedoch wieder weitere aufschlussreiche Darstellungen beobachten bzw. vermissen.

Die drei Zeitschriften unterscheiden sich im Umfang ihrer Präsentation von Bildern sehr, jede hat ihr eigenes Bilder- bzw. Bebilderungskonzept, wozu sowohl das quantitative Verhältnis von Text und Bild als auch verschie- 
dene Bildgenres gehören (vgl. Kap. >Auswertungsmethoden`). ${ }^{11}$ In der >Pädagogik haben wir es vor allem mit Schwarz-Weiss-Fotografien, zum Teil auch mit Zeichnungen zu tun. Insgesamt wird das Heft großzügig bebildert. Fotografien vermitteln als besondere Sorte Bild so etwas wie Echtheit oder Authentizität. Beim Fotografieren wird ein Moment »als Schnitt durch die Zeit und den Raum« (Mietzner/Pilarczyk 2003: 23) festgehalten und in neue Beziehungen gesetzt, der tatsächlich in irgendeiner Weise stattfand. Fotos suggerieren so reale Situationen und reale Menschen - also gewissermaßen Objektivität. Das hat sich auch mit dem Wissen über Manipulierbarkeit durch digitale Fotografie kaum verändert. ${ }^{12}$

Fotografien gibt es im >Päd Forum`nur selten. Überhaupt gibt es nur sehr wenige Bilder, meist sind sie gezeichnet, vielfach karikaturistisch, oder es handelt sich um historische Bilder (Gemälde, Zeichnungen, Fotografien). Die gezeichneten Bilder abstrahieren von konkreten Personen und arbeiten zum Teil mit anderen Symbolen. Ebenso ist es im >Schulmagazin 5 bis 10<; dort sind es vielfach Zeichnungen mit karikativem Charakter, der insbesondere durch die Bildunterschriften entsteht. Hier ist allerdings zu unterscheiden zwischen Bildern, die sich an die LeserInnen der Zeitschrift richten, und Abbildungen, die darüber hinaus als Unterrichtsmaterialien für die SchülerInnen bestimmt sind. Letztere vermitteln mehr Eindeutigkeit, dieser Eindruck wäre allerdings noch genauer zu überprüfen.

Ich habe die verschiedenen Bildgenres deshalb so ausführlich beschrieben, weil sie im Zusammenhang damit stehen, was jeweils dargestellt wird bzw. werden kann. Was »abgebildet« wird, scheint vom Wie der Darstellung abhängig zu sein. So wurde bei der Recherche deutlich, dass in der Zeitschrift `Pädagogik`, die durch den Einsatz der Kamera eine ausgesprochene Nähe zum Schulalltag suggeriert und herstellt, nicht nur körperliche Berührungen nicht vorkommen. Auch pädagogische Beziehungen werden sehr selten dargestellt. Entweder sind vorwiegend SchülerInnen oder zu wesentlich geringerem Anteil LehrerInnen zu sehen. Beide jedoch gemeinsam auf einem Bild zu

11 Zum Konzept der Zeitschrift `Pädagogik` finden sich bei Pilarczyk und Mietzner (2005: 205) einige Informationen.

$12 \mathrm{Zu}$ den Veränderungen durch die Digitalisierung der Fotografie und deren Verhältnis zum tradierten gesellschaftlichen Umgang und der (Re)Produktion von Fotografien schreibt Bernd Stiegler: "Durch die Digitalisierung ist die Fotografie zwar zum Medium der technischen Manipulierbarkeit geworden, mit dem wir tagein tagaus zu tun haben, aber gleichzeitig haben die tradierten gesellschaftlichen und ästhetischen, diskursiven und lebensweltlichen Formen, die die Fotografiegeschichte hervorgebracht hat, keineswegs ihre Gültigkeit verloren. [...] Wir glauben nicht länger an die Objektivität der Fotografie, wohl aber daran, dass Fotografien in spezifischer Weise unsere Wirklichkeit sind." (Stiegler 2004: 32, Herv. i. O.) 
sehen, d. h. in einer Situation, gehört zu den Ausnahmen. Auch im >Päd Forum ist das so, allerdings geht diese Zeitschrift insgesamt mehr über den Bereich der Schule hinaus. Interessant ist, dass in den karikativen Zeichnungen im >Schulmagazin 5 bis 10 < dagegen häufig LehrerInnen und SchülerInnen dargestellt werden, doch auch hier ist Berührung ausgeschlossen.

Ich möchte hier auf eine besonders augenfällige Ausnahme in der Zeitschrift >Pädagogik` zurückkommen - auf eine Ausnahme, die in einem der Themenschwerpunkte dann doch zur Regel wird. Dieser trägt den Titel: »Beruf: Lehrer/Beruf: Lehrerin. Oder: Was wissen wir über den Lehrerberuf? (Pädagogik 4/1997). Die bildliche Berufsdarstellung besteht im Wesentlichen in der Darstellung von jeweils individuellen Bezügen zu SchülerInnen, d. h. von Gesprächen entweder mit einzelnen SchülerInnen oder mit einer kleinen Gruppe von SchülerInnen. Das ist insofern bemerkenswert, als sich zum einen solche Bilder sonst selten finden, obwohl pädagogische Professionalität übergreifendes Thema der Zeitschrift ist. Zum anderen stellen die Bilder ausschließlich individuelle Kommunikationssituationen dar; die Lehrkraft, die vor einer Schulklasse steht, gibt es dort nicht.

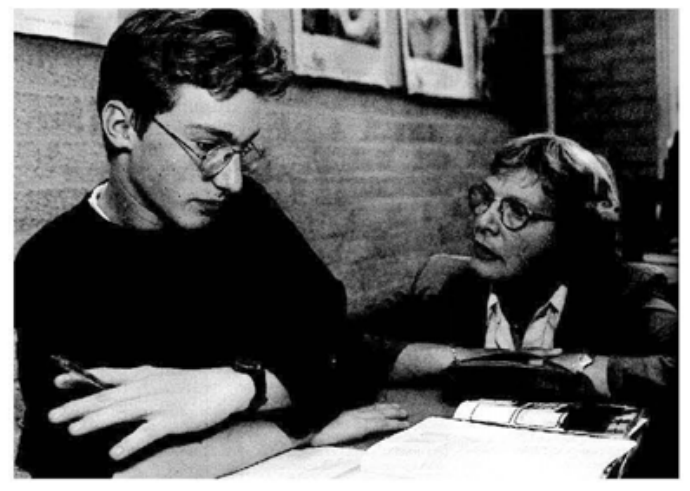

Abbildung 7

Abbildung 8

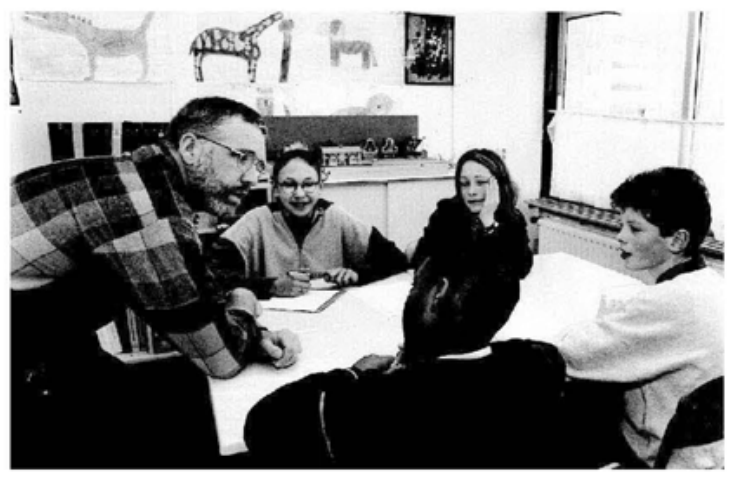




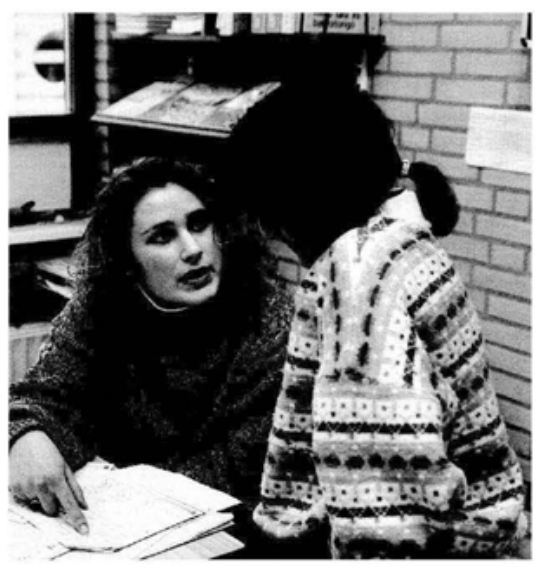

Abbildung 9

Deutlich wird in den Fotos die Präsentation der Lehrkraft auf Augenhöhe. Assoziieren lässt sich damit eine respektierende, gleichrangige, partnerschaftliche, individuelle Beziehung. Augenhöhe ist dabei eine relative Größe. Im Beispiel blickt die Lehrerin sogar ein wenig auf, was sie vor dem Schüler aber in Bezug auf ihre Position nicht kleiner erscheinen lässt. Dargestellt wird eine bestimmte pädagogische Gebärde, die verschieden gewichtete Aspekte vereint: individuelle Zuwendung, eine Erwartungshaltung sowie einen Zeigegestus, den das obige Bild nicht enthält, der aber häufig vorzufinden ist. Werden solche individuellen Zweiergespräche gezeigt, fällt auf, dass vor allem Lehrerinnen abgebildet werden, während Lehrer eher im Zusammenhang mit einer Gruppe dargestellt werden. In Weiblichkeit typisierender Weise ist es die Lehrerin, die Nähe zu den SchülerInnen herstellt. Dass gleiche Augenhöhe nicht unbedingt gegenseitiger Blickkontakt heißt, zeigt sich auch immer wieder.

Mit den Beobachtungen in dieser Zeitschriftenausgabe zum Berufsbild, die sich sicherlich noch ergänzen ließen, habe ich mir noch einmal die Zeitschriften angeschaut und festgestellt, dass die »klassische Frontalunterrichtssituation« als Bild kaum zu finden ist. Nun ließe sich einwenden, dass sich eine solche Situation im Ganzen nur schwer und mit hohem technischen Aufwand fotografisch einfangen ließe, da es bedeuten würde, den gesamten Raum aufzunehmen.13 Insofern liegt es doch nahe, entweder SchülerInnen oder LehrerInnen oder beide im Einzelgespräch abzulichten, ansonsten müsste die Lehrkraft den.?latz am frontal vor der Tafel stehenden Pult verlassen. Verein-

13 Solche Aufnahmen gibt es aber durchaus, beispielsweise in den Fotoanalysen von Pilarczyk und Mietzner, in denen sie pädagogische Gesten von LehrerInnen und Gesten von SchülerInnen in ihrer Historizität untersuchen (2005: 165; 190ff.). 
zelt gibt es solche Fotografien von Lerngruppen - hier sitzen die Lehrenden jedoch zumeist im Kreis der Schulklasse und die übliche Sitzordnung ist aufgehoben.

Ich habe auch von Ausnahmesituationen in der Zeitschrift >Pädagogikı geschrieben, in denen körperliche Berührungen zwischen LehrerIn und SchülerIn sichtbar werden. Sie lassen sich thematisch - d. h. in Bezug auf den Text, mit dem sie in Zusammenhang gebracht werden - genauer markieren: Ausnahmen zeigen sich, wenn es um integrative Pädagogik geht, um Suchtprävention oder Mädchen- und Jungenarbeit. Oder das Foto steht als metaphorisches Symbol, beispielsweise wenn ein Schüler von seiner Lehrerin seine Körpergröße vermessen bekommt, sie ihn dabei am Kopf berührt und der darunter stehende Text sich auf Maßnahmen aufgrund der PISA-Studien bezieht. Nicht nur das Foto stellt eine Ausnahme dar, sondern es sind Ausnahmesituationen im Schulalltag, die fotografiert werden. Entweder wird individuelle Förderung aufgrund eines Defizits demonstriert, oder als Ziel wird die Stärkung der Persönlichkeit der SchülerInnen genannt, in der auch besondere Nähe zum Körper zugelassen ist, ja sogar als körperbezogene Arbeit ein Teil didaktischer Praktiken ist (vgl. Kap. `Gelehrige und entspannte Körper $)$.

Wenn auch die >Pädagogik - auf die ich hier vor allem zurückkomme, weil sie eine Fülle von Bildmaterial bereitstellt - kaum pädagogische Beziehungen ins Bild rückt, so wird doch mit den Fotografien, die sie zeigt, etwas über die gewünschte pädagogische Beziehung ausgesagt. Und zwar in Bezug auf eine gute Unterrichtspraxis, wie sie in den Texten verhandelt wird. Diese bringt nämlich vorwiegend aufmerksame SchülerInnen hervor, so scheint es. Die vielen großformatigen Portraits stellen vor allem aufmerksam wirkende SchülerInnen ins Rampenlicht. Dies ist zwar zunächst ein subjektiver Eindruck, der jedoch diskursiv eingebettet wird, indem z. B. im Heft »Aufmerksamkeit« (1/2005) explizit vorgeführt wird, welche Gesten als Aufmerksamkeitsgesten verstanden werden, da dort die Texte unmittelbar auf die Bilder bezogen sind. Im Gegenzug finden wir im Themenheft »Langeweile« (9/1997) Gesten, die eben nicht Aufmerksamkeit bedeuten. Mit dem Prozess der medialen Vermittlung wird der Idealtyp einer Schülerin bzw. eines Schülers entworfen. ${ }^{14}$ Pilarczyk und Mietzner konstatieren bei ihrer Analyse von Unterrichtsfotografien: »Erst muss es eine pädagogische Idee des >guten Schülers geben, um diesen fotografieren zu können, und gleichzeitig wird solch ein Idealtyp durch das Foto überhaupt erst in Szene gesetzt.« (Pilarczyk/Mietzner

14 In der bereits genannten Analyse von Pilarczyk und Mietzner stellen die Autorinnen für den Zeitraum 1990 bis 2000 fest, dass zu Beginn der 1990er Jahre fast doppelt so viele Mädchen abgebildet wurden. Ihre These ist, dass Schülerinnen in ihrer Körperinszenierung diesem Idealtyp eher entsprechen und deshalb solche Fotografien dominieren (ebd.: 213). 
2005: 189) Dieser Typ wird gelegentlich konterkariert durch Gegendarstellungen (wie im Beispiel der Langeweile), doch stärkt diese Abweichung vom Ideal das Ideal dadurch, dass die Abweichung meist auch über den Text als solche näher bestimmt wird.

Der Exkurs auf das Bildmaterial bestätigt noch einmal, dass Körperkontakte zwischen LehrerInnen und SchülerInnen nicht thematisiert werden, sich also hier so etwas wie eine diskursive Leerstelle zeigt. Darüber hinaus lenkt er die Aufmerksamkeit darauf, dass zumindest in der Zeitschrift \Pädagogik` vor allem ein Idealtyp »aufmerksame/r SchülerIn« dargestellt wird, sich Schule in dieser »Bilderwelt« allerdings kaum durch institutionell geprägte pädagogische Beziehungen auszeichnet. Dieses Ergebnis müsste bzw. könnte nun weiter spezifiziert und hinsichtlich der Einbeziehung verschiedener Bildgenres und der Einbeziehung von Bild-Text-Komplexen differenziert werden.

\section{Körperlicher Bezug als Teil pädagogischer Beziehungsarbeit}

Ausgehend von den Beobachtungen in der Schulklasse, dass die Lehrerinnen die SchülerInnen an ihren Plätzen aufsuchen, sich auf gleiche Augenhöhe begeben, ihnen mal über den Rücken streichen, die Hand auf die Schulter legen oder auch gegen die Stuhllehne treten, rückte die Frage in den Fokus, inwiefern dies Instrument pädagogischer Kommunikation ist. Körperkontakte werden zum pädagogischen Mittel von einer bestimmten Machtposition aus. Als pädagogische Gesten finden sie in einem Spannungsfeld von Hilfe und Kontrolle statt, eine Dimension, die verloren geht, wenn ausschließlich individuelle Körpergrenzen darüber entscheiden, ob eine Schülerin berührt wird oder nicht. Die SchülerInnen können auf Berührungen immer nur aus ihrer Position heraus reagieren, die Möglichkeit, ebenfalls die Hand auf die Schulter der Lehrkraft zu legen, haben sie - von Ausnahmen, wie ich sie dargestellt habe, abgesehen - eigentlich nicht. Diese Ausnahmen werden von Lehrenden entweder als Grenzüberschreitung der SchülerInnen wahrgenommen oder aufgrund des Alters der SchülerInnen, ebenso wie ihres spezifischen Status als HauptschülerInnen, legitimiert.

Insgesamt wird bei der Betrachtung deutlich, dass eine bestimmte körperliche Nähe zwischen LehrerInnen und SchülerInnen Beziehungen herstellt, beeinflusst und verändert und eben mehr ist als eine losgelöste Geste. Es spannt sich ein Netz von Nähe und zum Teil auch Freundschaft sowie Distanz und Respekt, allerdings niemals losgelöst von den spezifischen Strukturen der Institution Schule. Beobachten lässt sich ein »Nähe-Distanz-Spiel«, welches sich für alle Beteiligten nicht nur auf das jeweilige Gegenüber, sondern vor allem auch auf den schulischen Rahmen als solchen bezieht: Was ist darin mög- 
lich - sowohl für die SchülerInnen (z. B. als Jugendliche oder Kinder) wie auch für die LehrerInnen (z. B. als Eltern oder FreundIn)? Ob Grenzen dabei überschritten werden und welche die zu überschreitenden Grenzen überhaupt sind, entscheidet sich in der Regel situativ. Die jeweils konkreten Grenzen werden innerhalb bestimmter Rahmungen und Diskurse ausgehandelt, bzw. es wird wie beim Beispiel des Fotos vom Klassenfest nachträglich von Professionellen geklärt, ob und inwiefern wer welche Grenzen verletzt hat und wie damit umzugehen ist.

Es bleibt die Schwierigkeit, über Körperliches zu sprechen, wie sich in den Interviews und in den Fachzeitschriften zeigt. Zum einen, weil Körperkontakte außerhalb des Privaten tabuisiert sind, zu einem großen Teil sexualisiert werden, und zum anderen, weil es nur begrenzt Worte für Körperliches gibt. So bleibt z. B. offen, anhand welcher Signale LehrerInnen erkennen, dass SchülerInnen Grenzen signalisieren. Wahrscheinlich funktionieren solche Grenzziehungen vor allem über leibliche Wahrnehmung, d. h. es kommunizieren die Körper miteinander, ohne dass dies reflexiv wird. Losgelöst von moralisch-professionellen Diskursen sind aber auch diese Wahrnehmungen und ihre Interpretationen nicht, auch wenn bzw. gerade weil sie nicht unmittelbar verbalisiert werden können. 


\section{Einsatz- und Gebrauchsweisen des Körpers in der Schule}

Die Arbeit begann mit der These, dass Erziehung stets auch am Körper ansetzt. Für die Institution Schule wurde dies als konsensfähige, jedoch kaum genauer betrachtete Ausgangssituation angenommen. Im Zuge der verstärkten Thematisierung des Körpers in unterschiedlichen wissenschaftlichen und öffentlichen Bereichen stellte sich die Frage, ob dabei auch das Verhältnis von Körper(lichkeit) und der Institution Schule in den Blick gerät, in der Heranwachsende einen Großteil ihrer Zeit und ihres Alltags verbringen. Inwiefern wird diese zentrale Sozialisationsinstanz als eine verstanden, die spezifische Körper hervorbringt? Welche Körper und Körperkonzepte setzt Schule voraus bzw. fördert sie?

Um diesen Fragen nachzugehen, nahm ich verschiedene Bereiche und Materialien in den Blick. Ausgangspunkt für den empirischen Teil der Arbeit waren die Beobachtungen vor Ort: In einer 7. Klasse einer großstädtischen Hauptschule, in der ich mit einer Forschungsgruppe über einen Zeitraum von vier Monaten am Unterricht teilnahm sowie Interviews mit Lehrerinnen und SchülerInnen führte. Auf der Ebene des Fachdiskurses analysierte ich zudem drei schulpädagogische Zeitschriften, die sich durch eine praxisnahe Konzeptionen auszeichnen: die Zeitschriften `Pädagogik«, >Päd Forum`sowie >Schulmagazin 5 bis $10<$. Ich rekonstruierte darüber die diskursive Konstitution des Verhältnisses von Körper und Schule in den Jahrgängen von 1995 bis 2005.

Damit wurden drei Ebenen in die Untersuchung einbezogen: erstens die gelebten Körperpraxen von SchülerInnen und Lehrerinnen, die im Unterricht beobachtet wurden und die die Interaktionen und die Konstitution der Körper in der Schule auszeichnen; zweitens Zeitschriften, in deren Texten ein Bild davon entworfen wird, wie PädagogInnen und AutorInnen benachbarter Disziplinen Körperlichkeit, Unterricht bzw. Schule verstehen und miteinander so- 
wie mit anderen Themen in Verbindung bringen. Deren Entwürfe, die andere Diskurse und diskursiv geprägte Erfahrungen aufgreifen, beeinflussen schulalltägliche Wirklichkeit, unter anderem indem sie eine Performanz in den LeserInnen der Texte und BetrachterInnen der Bilder bewirken. Die Diskursanalytische Auswertung dieser Materialien ermöglichte so differenzierende Interpretationen des Beobachteten. Umgekehrt ließen sich die Analysen der Zeitschriftentexte mit denen der Beobachtung kontrastieren. Auf einer dritten Ebene schließlich bildeten die Diskurse der Lehrerinnen in Gesprächen und den Interviews mit den Forschenden gewissermaßen das Bindeglied zwischen diesen beiden Bereichen der Untersuchung. Ihre Äußerungen lenkten die Aufmerksamkeit auf Gemeinsamkeiten diskursiver Praktiken ebenso wie auf Widersprüche gegenüber den Beobachtungen und den Darstellungen in den Zeitschriften.

Aufgrund spezifischer (thematischer) Verknüpfungen des >Körpers« mit Disziplin, Unterrichtsordnung, Gesundheit, Jugend, LehrerInnen und Geschlecht habe ich wesentliche Dimensionen dieses Verhältnisses aufgezeigt. Angesicht dieser Facetten, in der Körper(lichkeit) sowie Körperkonzepte relevant sind, kann nun noch einmal genauer gefragt werden: An wessen Körper setzt schulische Erziehung an? Oder mit einem Begriff formuliert, der die Studie als Metapher durchzieht: Wessen Körper kommen in der Schule sowie in den Konzeptionen funktionierender schulischer Praxis auf welche Weise und mit welchem Ziel zum Einsatz?

In den Zeitschriften analysierte ich zunächst Artikel, die sich explizit mit dem Thema Körper beschäftigen. Als Ergebnis zeigte sich, dass diese Thematisierung kaum im Zusammenhang mit Schule vorgenommen wird, so dass sich weder »SchülerInnen-Körper« noch »LehrerInnen-Körper« genauer konturieren ließen. Anknüpfend an die interdisziplinären Körperdiskurse der vergangenen 20 Jahre werden vielmehr allgemeine Körperkonzepte entworfen, die in einem Spannungsfeld zwischen einem problematisierten »Verschwinden« des Körpers und seiner »Wiederkehr« angesiedelt sind (vgl. Kap. 'Körper(bewusstseins)schulung in pädagogischen Texten $\triangleleft)$. Die Wiederkehr ${ }^{1}$ wird in dreifacher Hinsicht konstatiert: die verstärkte Thematisierung im Allgemeinen sowie eine Zunahme praktizierten Risikoverhaltens ebenso von

1 Der Begriff geht auf Dietmar Kamper und Christoph Wulf zurück, welche sich damit auf eine verlorene 'Einheit< von Körper und Geist und auf Rationalisierung im weitesten Sinne beziehen. Sie beschreiben mit der Metapher die "Distanzierung, Disziplinierung, Instrumentalisierung des Körperlichen als Grundlage historischen Fortschritts, die damit einhergehende Entfernung und Ersetzung des menschlichen Natur durch ein vermitteltes gesellschaftliches Konstrukt« (Kamper/Wulf 1982: 9). In der Rezeption des Begriffs bleibt allerdings häufig nur eine vielfältig und vage anfüllbare Metapher. 
Techniken der Selbstsorge, die auf den Körper ausgerichtet sind. Diese Bewegung vom Verschwinden zur Wiederkehr korrespondiert mit einer weiteren: Wird der verschwundene Körper in erster Linie als der disziplinierte begriffen, steht nun, vereinfacht gesagt, seine souveräne Inszenierung im Mittelpunkt. Etwas überspitzt formuliert, gehört somit der »disziplinierte Körper« der Geschichte an. Bezogen auf die Schule heißt das, dass wenn der Körperdisziplinerung in dieser Institution vor allem anhand historischer Quellen nachgegangen wird, sie selbst als historisch abgeschlossen erscheint.

Wenn sich auch nicht in allen Texten diese einfache Logik wiederfindet, so stellt sie doch eine grundlegende Figur dar, in der die Disziplinierung als Fremd-Disziplinierung und die Inszenierung als Selbst-Inszenierung begriffen wird, womit das Subjekt einen selbstbestimmten Status erhält. Wenig hinterfragt wird das Wechselverhältnis zwischen diesen beiden Polen, wenngleich Risiken in der Körperbearbeitung beispielsweise im Extremsport gesehen werden oder nach den Zwängen solcher Praktiken gefragt wird. Risiken oder eventueller Zwang zur Anpassung sind allerdings etwas anderes als Disziplinierungstechniken, die am Körper ansetzen. Diese gehen in der aktuellen Betrachtungsweise verloren.

Anhand ethnographischer Beschreibungen arbeitete ich das Verhältnis von disziplinierenden Arrangements, damit einhergehenden Zumutungen und aktiver Beteiligung von SchülerInnen bei der Herstellung schulischer Ordnung heraus. Innerhalb typischer Körper-Raum-Regime in der Schule haben die SchülerInnen zuallererst eines zu lernen: still zu sitzen. Das stille Sitzen auf dem Stuhl hinter einer Schulbank lässt sich mit Marcel Mauss (1978) als Körpertechnik verstehen, die eine kulturell systematisch hergestellte und funktionale Körperhaltung zur Folge hat. In der 7. Klasse wird davon ausgegangen, dass die SchülerInnen diese Basis-Haltung genügend eingeübt haben und sie ihnen förmlich in Fleisch und Blut übergangen ist. Als Basis lässt sie sich deshalb bezeichnen, da sie als selbstverständliche routiniert eingenommen und nicht hinterfragt wird. Gegenüber dem Wissen von SchülerInnen und ihrer Präsentation gelernter Unterrichtsinhalte erfährt sie sogar eine Höherbewertung. Das zeigt sich besonders bei den sanktionierenden Konsequenzen als Folge einer Abweichung von dieser normativen Erwartung, still zu sitzen (vgl. Kap. >Phänomene schulischer Sanktion`). Die richtige Antwort auf die Frage einer Lehrerin ist nur im richtigen Moment gefragt; der kippelnde Schüler wird, obwohl er durchaus etwas Produktives zum Unterricht beitragen könnte, des Raumes verwiesen.

Mit dem Sitzen in der Schulklasse sind weitere individualisierende Effekte verbunden, und es werden Distinktionen sowie Zugehörigkeiten erzeugt. Der zugewiesene und eingenommene Platz entspricht auch einer sozialen Po- 
sitionierung innerhalb der Schulklasse: Sie verweist beispielsweise die sog. IntegrationsschülerInnen, soweit es ihre Körpergröße zulässt und sie nicht den Blick versperren, gut sichtbar regelmäßig auf die vorderen Ränge. Aus Sicht der Lehrerinnen können sie so rasch intervenieren. Besonders deutlich wurde des Weiteren die Geschlechterordnung der Schulklasse. Die Mädchen der Klasse bilden eine geschlossene Front, die sie nur mit großen Widerständen aufgeben, wenn es die Lehrerinnen fordern (vgl. Kap. `Geschlechter-Räumer). Zeitweise wurde die selbst hergestellte homogene Ordnung zwar irritiert, allerdings nicht so, dass sie grundsätzlich in Frage gestellt oder aufgelöst wurde. Diese rigide räumliche Präsentation von Geschlechtszugehörigkeit wird in vielen ehtnographischen Untersuchungen beschrieben (z. B. Faulstich-Wieland et al. 2004: 90ff., Willems 2007: 229ff.). Im Rahmen der schulischen Ordnung und der alläglichen Wiederholung wird dieses Arrangement institutionalisiert und somit normalisiert.

Die detaillierten Beobachtungen einzelner bzw. benachbart sitzender SchülerInnen verdeutlichen aber auch, dass die raum-körperliche Ordnung umkämpft ist, z. B. wenn befreundete SchülerInnen nebeneinander sitzen möchten oder anderen eine solche Nähe verweigert wird. Ferner lassen sich eine Vielzahl von Taktiken beobachten, in denen die SchülerInnen ihre Körper gebrauchen: bei Kontaktaufnahmen durch Berührung anderer Schüler während des Rückwegs vom Pult der Lehrerin zu ihrem Platz; kleine Kappeleien, wenn im Unterricht Übergänge von einem Vorgang zum nächsten entstehen; das Tragen der Baseballkappe, solange es die Lehrperson nicht bemerkt. Die SchülerInnen gestalten also Situationen mitsamt ihrer Regeln. Es gibt Möglichkeitsräume, während sie im Unterricht auf einen bestimmten Platz sitzend festgelegt sind, die sie nutzen, um mit anderen zu kommunizieren, sich ihren eigenen Raum zu schaffen, Aufmerksamkeit und Anerkennung zu gewinnen, ihr Gesicht zu wahren. Dieser Gebrauch muss nicht unbedingt bewusst oder reflektiert sein, zumal der körperliche Leib sich des Gebrauchs auch entziehen bzw. widersetzen kann oder unkontrollierbare Reaktion zeigt.

In der jeweiligen Situation existiert für die SchülerInnen immer ein gewisses Risiko, nämlich dass ihr Tun seitens der Lehrenden als Störung begriffen wird. Unter Umständen zieht es auch Sanktionen nach sich. Werden in den Zeitschriften Unterrichtsstörungen problematisiert, sind es oft Körperpraktiken, die als solche kategorisiert werden. Im Kapitel `Kappen ab und Jacken aus! $<$ greife ich die Regel auf, dass im Unterricht der beobachteten 7. Klasse keine Kopfbedeckungen getragen werden dürfen. Hier zeigt sich einerseits ein Spiel der SchülerInnen »mit« dem Verbot - so begreifen es vor allem die Lehrerinnen im Interview - andererseits sind Tücher oder Baseball-Kappen Elemente, die die SchülerInnen in ihre körperliche Selbstinszenierungen ein- 
beziehen. Sie sind Teil eines Körperstils, der sie als Jugendliche, als junger Mann oder junge Frau auszeichnet und den sie einüben (vgl. Tervooren 2006). Diese Inszenierungen des eigenen Körpers gehen über ein austestendes Spiel durchaus hinaus. Schule stellt für die SchülerInnen auch einen Ort dar, an dem sie sich selbst präsentieren - inmitten ihres SchülerInnen-Daseins. Während jedoch in den aufgegriffenen Körperdiskursen innerhalb der Zeitschriften die Inszenierung des Körpers im Allgemeinen hervorgehoben wird, wird das In-Szene-setzen der SchülerInnen sowohl in den beobachteten Situationen als auch in vielen Zeitschriften im Rahmen von Disziplin als Störung begriffen.

Dieser Konflikt von Inszenierung als Störung kann als Teil eines widerspruchsvollen Nebeneinanders wie auch eines Verwobenseins von »Jugendkultur « und »Schulkultur « verstanden werden; Nebeneinander, da Jugendkulturelles häufig mit einem Bereich der Freizeit konnotiert wird und so der Selbst-Inszenierung in der obigen Unterscheidung zugeordnet wäre. Da aber gerade die Zeit in der Schule für viele Jugendliche eine ganz elementare Möglichkeit bietet, wichtige Bezugspersonen wie FreundInnen oder die Clique zu treffen, findet diese Trennung der Bereiche für die meisten SchülerInnen gar nicht statt. Die Peer-Group in der Schule wird zu einer wichtigen Instanz, die Körperpraktiken aushandelt und deren Bewertung in die Körperwahrnehmung und Auseinandersetzung mit dem eigenen Körper eingeht.

Zentral für das, was von Lehrenden als Unterrichtsstörung gewertet wird, sind deren Handlungserwartungen, die diskursiv geprägt sind. In den Interviews mit den Lehrerinnen sowie im Zeitschriftenkorpus sind es vielfach Körperpraktiken die als Störung begriffen werden. Wie ich gezeigt habe, wird darauf hin und wieder mit Strafen reagiert, die - wenn auch nicht physisch schmerzhaft - dennoch indirekt am Körper ansetzen. Im Reden darüber wird deutlich, wie tabuisiert dieses Thema ist (vgl. Kap. \Zur Tabuisierung von Disziplinieren und Strafen $\varsigma$ ): Die Anwesenheit der Forschenden zwingt die Lehrerinnen dazu, ihr Handeln ungefragt zu erklären und legitimierend zu kommentieren. In den wenigen Zeitschriftenartikeln zu diesem Thema wird vor allem die Tabuisierung des Strafens problematisiert. Mit der Abschaffung der körperlichen Züchtigung und im Zuge eher sanfter Kontrollpraktiken reformpädagogischer Ausprägung ist die Diskussion über Erziehung und Strafe im Bereich der Schule zwar nicht gänzlich eingestellt worden, sie wurde aber kaum geführt. In der diskursanalytischen Untersuchung zeigt sich ein Effekt, der damit einhergeht: Nicht nur über das Strafen wird nicht mehr geredet, sondern Körper(lichkeit) im Allgemeinen »verflüchtigt sich" damit als Thema. Ähnlich wie bei der Disziplinierung verhält es sich also auch bei der Strafe. Sie wird historisiert und erscheint damit, als Praxis der Vergangenheit, 
nicht mehr relevant oder - so stellt es sich meines Erachtens für die Disziplinierung dar - wird in ihren derzeitigen Techniken so selbstverständlich, dass sie nicht in Frage gestellt wird, und es offenbar keiner Thematisierung mehr bedarf.

Dass über Disziplinierung nicht gesprochen wird, hat einen weiteren Grund, der sich in das Bild der bisher aufgeführten diskursiven Praktiken fügt. Disziplinierung wird von den Lehrerinnen im Interview und den PädagogInnen in den Zeitschriften als repressive Herstellung funktionierender SchülerInnen verstanden, ähnlich einer Sanktion. Da solch ein Fremdzwang nicht gewollt ist, kommt es zu einer eigentümlichen Konstellation: Die Lehrenden sollen ohne Fremd-Disziplinierung zu einer Situation der Disziplin (als das Funktionierende) gelangen. Mit dieser Dethematisierung von Disziplinierung ist nun auch nicht mehr vom Körper die Rede. Dieser wird lediglich in den darauf bezogenen Beobachtungsprotokollen thematisiert sowie beim Aufgreifen ritueller Praktiken, die in den Erfahrungsberichten und Konzeptionen für guten Unterricht an die Stelle der Disziplinierung rücken. Explizite Vorschläge für eine körperorientierte Arbeit mit SchülerInnen werden dabei ausschließlich für SchülerInnen von Grund-, Haupt- und Förderschulen hervorgeracht. Ihre Funktion ist Ruhestiftung mittels Entspannung. Der Körper der SchülerInnen wird also dann thematisiert, wenn es darum geht, sie und ihren Körper »ruhig zu stellen« und in die als unabdingbar angesehene disziplinierte Grundhaltung zu überführen. Für das Gymnasium scheinen solche Praktiken nicht für notwendig erachtet zu werden (vgl. Kap. ২Körperkontakt als pädagogisches Mittel $)$.

Auf diese beschriebene Weise wird Fremddisziplinierung durch rituelle Arrangements sowie die disziplinierende Herstellung von "Gegebenheiten« wie Raum und Zeit zur Selbstdisziplinierung. ${ }^{2}$ Neben den möglichst »entspannten SchülerInnen« werden auch die »entspannten LehrerInnen« wichtig. Dem Körper der LehrerInnen und, wie ich gezeigt habe, der Herstellung eines professionellen »Lehrkörpers« werden im Zeitschriftendiskurs ebenso wie in den Interviews eine wesentliche Rolle in der Erzeugung einer Situation von Disziplin zugeschrieben. Sie treten neben den rituellen Praktiken oder innerhalb dieser an die Stelle der »Blackbox Disziplinierung". Der Lehrkörper wird als ein Mittel konstituiert, das so eingesetzt werden soll, dass in Unterrichtssituationen eindeutige Interaktionen geschaffen werden. Das bedeutet, Körperpraktiken zu vermeiden, die ungewollte, also negative Reaktionen, her-

2 Diese indirekte Steuerung konzipiert bereits Jean-Jacques Rousseau für die Erziehung der Figur Emile. Das Buch »Emile oder Über die Erziehung «, das als Gedankenexperiment die politischen Schriften Rousseaus miteinander verbindet, wird auch fast 250 Jahre nach seinem Erscheinen in den Erziehungswissenschaften als Erziehungsroman weitreichend rezipiert. 
vorrufen und so Unterrichtsstörungen provozieren könnten. Hier hinein spielt auch die Idee, körperlich eine bestimmte vorbildhafte innere Haltung zu veräußerlichen, die sich auf die SchülerInnen überträgt. Körperlichen Zeichen bzw. der Symbolik von Körperpraktiken wird, wenn sie thematisiert werden, im Zusammenhang mit transparenten Regeln eine hohe Präzision und Wirksamkeit zugeschrieben.

Dieser professionelle Einsatz des Körpers erfordert eine Selbstbearbeitung durch die Lehrenden, erst recht, wenn der kranke, häufig überarbeitete Körper zum Problem wird. Sein Funktionieren ist Bedingung für das Funktionieren von Unterricht. So erscheinen Selbstsorge und -disziplinierung als ausschlaggebend für eine aktivierende Fremd- und vor allem Selbstdisziplinierung der SchülerInnen. Nicht die Formung der SchülerInnen wird thematisiert, sondern die Frage bearbeitet, wie LehrerInnen an der Schule professionell »überleben« können. Auch deshalb ist die Figur des Schülers bzw. so etwas wie ein SchülerInnen-Körper so schwer zu bestimmen. In den Zeitschriften werden im Rahmen professionellen Handelns und einer »best practice« besonders die Körper von Lehrenden sowie der Lehrkörper expliziert. ${ }^{3}$ Dabei wird der SchülerInnen-Körper als das Andere, das Gegenüber, indirekt mitkonstruiert. Wenn die Lehrerinnen im Interview davon sprechen, dass sie Autorität verkörpern (müssen), dann ist diese Autorität an ein bestimmtes Gegenüber gerichtet. Die SchülerInnen werden in dieser Konstellation permanent mitgedacht, ihre Körper »spiegeln« den Lehrkörper.

Ausgeblendet in dieser vielfach affirmativen Anrufung der Lehrenden werden die institutionellen Strukturen und Zumutungen, die anderes Lehren und Lernen sowie einen anderen Umgang mit sich, den KollegInnen und den SchülerInnen schwer möglich machen. Für das Funktionieren und ihre Vorbildwirkung werden die einzelnen Lehrenden individuell als zuständig erachtet. Michael Behnisch kommt in seiner diskursanalytischen Untersuchung des Topos »Pädagogische Beziehung« zu dem Schluss, dass Forschungen dazu meist mit dem Ziel einer Optimierung verbunden seien. PädagogInnen werden "gleichsam in die Verantwortung des Optimalen gesetzt« (Behnisch 2005: 62). Sie haben an sich zu arbeiten und sich selbst und das zu erziehende Subjekt bzw. die SchülerInnen und die Situation ihrer Beziehung zu optimieren. Mit dieser Idee korrespondieren auch Konzepte für eine körperbewusste Lernkultur, wie sie vereinzelt in den Zeitschriften formuliert werden. Auch sie setzen unter Bezugnahme auf die Topoi Professionalität, Gesundheit und Sinnlichkeit zumeist am Körper und Körperbewusstsein der Lehrenden an. Ginge

3 Das stellt sich möglicherweise anders dar, wenn Themenkomplexe wie Gewalt, Gesundheitsprävention bei SchülerInnen oder Krankheitsbilder wie ADHS untersucht werden. 
es dagegen um die SchülerInnen-Körper, müsste es zwangsläufig um den disziplinierten Körper gehen, vor allem darum, ihn als solchen zu benennen. Letztlich hieße das auch, sich jenseits des individuellen Abbaus von Stress seitens der Lehrenden mit den Zumutungen der Institution Schule auseinanderzusetzen. Die disziplinierenden Aspekte von Entspannungsübungen, die die um sich sorgenden Lehrenden vollziehen (sollen), werden sonst leicht auBer Acht gelassen. Zur Aufrechterhaltung ihrer Funktionstüchtigkeit stellen diese Übungen und die mit ihnen verknüpfte, zu verinnerlichende Haltung ebenso disziplinierte Körper und Subjekte her, wie dies Ziel sog. Körperarbeit mit SchülerInnen ist.

Wie Körperlichkeit als Mittel im Unterricht und als Element zur Gestaltung pädagogischer Beziehungen und Situationen eingesetzt wird, illustriert noch einmal mehr das vorangegangene Kapitel. War bisher vom Lehrkörper die Rede, der durch die Lehrenden konstituiert wird und werden soll, zeichnete dieser sich durch räumliche Distanz zu den SchülerInnen aus. Vor der gesamten Schulklasse - auf der Vorderbühne - präsentiert sich die Lehrperson und dirigiert unter anderem mit ihrem Körper sämtliche anwesenden SchülerInnen. In der Beobachtung der 7. Klasse wurde eine Form der Bezugnahme offenbar, die durch körperliche Nähe und Berührung geprägt ist. Die Lehrerinnen erachten sie als bedeutsamen Einsatz, um individuelle Beziehungen auf Augenhöhe zu gestalten, Individualität herzustellen oder Störungen zu beseitigen. Körperliche Berührungen seitens der Lehrerinnen sind meist Teil von Hilfe- und Kontrollgängen durch die Klasse während der Bearbeitung einer Aufgabe. Möglich wird eine solche individuelle Begleitung auch, da die Lehrerinnen im Team arbeiten und die einzelne Lehrkraft während des Unterrichts nicht die gesamte Zeit für alle SchülerInnen zuständig sein muss.

Bei genauerer Auseinandersetzung zeigten sich verschiedene Effekte, die mit dieser Praktik einhergehen. Nicht alle SchülerInnen werden gleichermaßen in Körperkontakte involviert. Es zeigen sich geschlechtsspezifische Unterschiede: Körperkontakt seitens der Lehrerinnen wurde vor allem mit Jungen beobachtet. Umgekehrt haben die SchülerInnen kaum Möglichkeiten, derart auf die Lehrenden zuzugreifen; schnell wird dies als Grenzüberschreitung gewertet und möglicherweise in irgendeiner Form sanktioniert. Des Weiteren konstituiert die Praktik selbst und die Legitimation im Rahmen professionellen Handelns in besonderem Maße die Figur des Hauptschülers in Abgrenzung zu der des Gymnasiasten. Die Lehrerinnen im Interview ebenso wie die AutorInnen in den Zeitschriften schreiben den HauptschülerInnen ein ausgeprägtes Bedürfnis von Körperlichkeit bzw. körperlicher Nähe zu, das - an sich widersprüchlich erscheinend - zugleich mit einem Defizit an Körperlichkeit und Umgangsweisen mit dem Körper verknüpft wird. Körperbezogenes 
Arbeiten innerhalb der Schule führt hier zu einer »Besonderung« des Körpers ebenso wie der Personen, denen diese Form der Bearbeitung als »notwendige « zugeschrieben wird.

Diese Effekte verdeutlichen, dass körperliche Berührungen und der Einsatz des Körpers immer mehr als eine losgelöste Geste sind. Sie sind situativ gerahmt und in verschiedene Diskurse eingebunden. Im Reden über Körperkontakt in pädagogischem Handeln verschränken sich verschiedene Diskurse: Es geht um altersgemäßes Körperhandeln, gesellschaftliche Berührungsnormen in Bezug auf Sexualität, Geschlecht und Individualität innerhalb gesellschaftlicher Klassen bzw. Kultur sowie für die Lehrenden zentral um Professionalität. Trotz all dieser Schnittstellen findet sich aber vor allem eine Tabuisierung des Themas, die sich letztlich auch in den Legitimierungsweisen der Lehrerinnen im Interview widerspiegelt.

Anliegen dieser Studie war es, das Verhältnis von Körper und Schule genauer zu rekonstruieren. In der Arbeit habe ich verschiedene Dimensionen betrachtet, in denen Körperlichkeit in Unterrichtspraktiken und zum Teil darüber hinaus eine Rolle spielt bzw. als solche thematisiert wird. Die facettenreiche Darstellung von Körperpraktiken und -konzepten verdeutlicht, warum der Körper allgegenwärtig ist: Nicht nur, weil jegliches Handeln und Sein ein leibliches ist und Individuen sich nicht ihres Körpers entledigen können, sondern weil dieser materielle Körper, Körperpraktiken und Körperkonzepte eng ineinander verschränkt sind. Körperkonzepte sind mit bestimmten Funktionen verbunden, die über das körperliche Sein hinausgehen und, wie bei der Konstitution des Hauptschülers, über den Körper hinaus auf soziale und kulturelle Positionierungen verweisen. Sichtbar geworden ist außerdem, dass sich zwischen dem körperlichen Agieren und Reflektieren ein großes Feld des NichtSagbaren aufspannt. Körper sind zugleich individuell wie Teil kollektiver, institutionell und kulturell geprägter Inszenierungen. Sie werden geformt und in Erziehungsprozessen zu beeinflussen gesucht, wobei immer auch etwas Unzugängliches bleibt. 



\section{Dank}

Ethnographisches Entdecken, das Forschungsfeld zu durchdringen, sich mit dem Material und den eigenen Interpretationen auseinander zu setzen, gelingt nicht, wenn man sich in Konkurrenz befindet oder auf sich selbst gestellt ist. Deshalb möchte ich allen WeggefährtInnen danken für ihre solidarische Begleitung auf unerforschtem Terrain, auf Um- und Irrwegen und für die unschätzbare Unterstützung - ebenfalls im Bereich der Pole »Disziplinieren und Entspannen « - das Ziel im Auge zu behalten.

Vielen Dank an die SchülerInnen und LehrerInnen, die ihren Schulalltag mit uns geteilt und sich und ihr Wissen zur Verfügung gestellt haben.

An Barbara Friebertshäuser, die die Dissertation betreut und institutionell unterstützt hat. Sie hat mich durch ihr Vertrauen und ihre Offenheit bestärkt und motiviert: bei der Leitung des Forschungsprojekts ebenso wie im Prozess, etwas Eigenes daraus entstehen zu lassen.

Die Studierenden der Forschungsgruppe haben sich lange Zeit und immer wieder auf anstehende Aufgaben, Ungewissheiten und Irritationen eingelassen und zu andauernder Reflexion des Forschungsprozesses herausgefordert.

Bei der Suche nach Fragen und Antworten sowie am Schreibprozess waren viele »Produktionsgemeinschaften « beteiligt. In den verschiedenen Kolloquien gab es unzählige Diskussionen, Einwände, Ergänzungen und Ermutigungen, die zum Überdenken angeregt und die Arbeit vorangebracht haben.

Besonders danken möchte ich Marion Ott für ihre Bereitschaft, jederzeit ihre produktive Skepsis einzubringen, und für die freundschaftliche Selbstverständlichkeit, sehr genau hinzusehen und zu hinterfragen.

Mit Daniel Wrana habe ich viel Zeit insbesondere bei der Entwicklung der diskursanalytischen Methodologie verbracht. Ohne die gemeinsame Arbeit hätte es dieses theoretisch-methodische Fundament so nicht gegeben. 
In der $A G »$ Diskursanalyse und Gouvernementalität in der Erziehungswissenschaft « haben wir immer wieder auf's Neue nach angemessener Machtanalyse und Kritik sowie der möglichen methodischen Umsetzung gefragt.

Alex Ruhl hat mir mit seiner beruhigenden Zuverlässigkeit, dem Feilen am Text und beim Ertragen etwaigen Leides beständig zur Seite gestanden.

In die kritische Lektüre der Arbeit und wertvolle Diskussion einzelner Kapitel waren darüber hinaus vor allem Almut Stolte, Ellen Bareis, Christian Schütte-Bäumner, Cornelis Horlacher, Sohipa Richter und Birte Egloff involviert.

Mein Dank gilt auch Manfred Langer, Ulrikka Richter, Hanns-Christoph Ruhl und Heike Boller, die unermüdlich und sorgfältig lektoriert und für die orthographische Ordnung gesorgt haben.

Danke auch der Supervisionsgruppe, die hin und wieder den entscheidenden Ruck gab, sowie allen FreundInnen und KollegInnen, die neugierig waren, mich ermutigt und mit ihren Aufmerksamkeiten bedacht haben. 


\section{Literatur}

Alheit, Peter (Hg.) (1999): Biographie und Leib, Gießen: Psychosozial-Verlag. Alkemeyer, Thomas (2003): »Aufs Spiel gesetzte Körper: Eine Einführung in die Thematik». In: ders. et al. (Hg.), Aufs Spiel gesetzte Körper: Aufführungen des Sozialen in Sport und populärer Kultur, Konstanz: UVK, S. 7-15.

Althusser, Louis (1977): Ideologie und ideologische Staatsapparate, Hamburg: VSA.

Amann, Klaus (1997): »Ethnographie jenseits von Kulturdeutung. Über Geigespielen und Molekularbiologie«. In: Hirschauer, Stefan/Amann, Klaus (Hg.), Die Befremdung der eigenen Kultur. Zur ethnographischen Herausforderung soziologischer Empirie, Frankfurt/M.: Suhrkamp, S. 298-330.

Amann, Klaus/Hirschauer, Stefan (1997): »Die Befremdung der eigenen Kultur. Zur ethnographischen Herausforderung soziologischer Empirie. Ein Programm «. In: Hirschauer, Stefan/Amann, Klaus (Hg.), Die Befremdung der eigenen Kultur. Zur ethnographischen Herausforderung soziologischer Empirie, Frankfurt/M.: Suhrkamp, S. 7-52.

Amos, Karin (2004): »Diskurstheoretische Zugänge in der erziehungswissenschaftlichen Geschlechterforschung«. In: Glaser, Edith/Klika, Dorle/Prengel, Annedore (Hg.), Handbuch Gender und Erziehungswissenschaft, Bad Heilbrunn/Obb.: Klinkhardt, S. 76-90.

Amos, Karin (2006): »Zur Imagination der komplementären pädagogischen Praktiken des `Rettensı und `Jätensı. Überlegungen im Anschluss an Cultural Studies und Gouvernementalität«. In: Mecheril, Paul/Wirtsch, Monika (Hg.), Cultural Studies und Pädagogik. Kritische Artikulationen, Bielefeld: transcript. S. 77-110.

Angermüller, Johannes (2001): »Diskursanalyse: Strömungen, Tendenzen, Perspektiven. Eine Einführung«. In: Angermüller, Johannes/Bunzmann, 
Katharina/Nonhoff, Martin (Hg.), Diskursanalyse: Theorien, Methoden, Anwendungen, Hamburg: Argument, S. 7-22.

Angermüller, Johannes/Bunzmann, Katharina/Nonhoff, Martin (Hg.) (2001):

Diskursanalyse: Theorien, Methoden, Anwendungen, Hamburg: Argument.

Angermüller, Johannes (2005a): „Sozialwissenschaftliche Diskursanalyse in

Deutschland. Zwischen Rekonstruktion und Dekonstruktion«. In: Keller,

Reiner et al. (Hg.), Die diskursive Konstruktion von Wirklichkeit. Zum

Verhältnis von Wissenssoziologie und Diskursforschung, Konstanz:

UVK, S. 23-47.

Angermüller, Johannes (2005b): Claiming a different world - the enunciative dimension of »anti-globalization « discourse, Verfügbar über: http://www.johannes-angermueller.de/dateien/AngermuellerEnunciativeDim061005.pdf [24.02.2008]

Angermüller, Johannes (2007): Nach dem Strukturalismus. Theoriediskurs und intellektuelles Feld in Frankreich, Bielefeld: transcript.

Apel, Helmut et al. (1995): »Kulturanalyse und Ethnographie. Vergleichende

Feldforschung im studentischen Raum«. In: König, Eckard/Zedler, Peter (Hg.), Bilanz qualitativer Forschung, Bd. 2: Methoden, Weinheim: Dt. Studien-Verl., S. 343-375.

Austin, John (1972): Zur Theorie der Sprechakte, Stuttgart: Reclam.

Balzer, Nicole (2004): „Von den Schwierigkeiten, nicht oppositional zu denken. Linien der Foucault-Rezeption in der deutschsprachigen Erziehungswissenschaft«. In: Ricken, Norbert/Rieger-Ladich, Markus (Hg.), Michel Foucault: Pädagogische Lektüren, Wiesbaden: VS-Verl., S. 15-35.

Barthes, Roland (1990): Der entgegenkommende und der stumpfe Sinn, Frankfurt/M: : Suhrkamp.

Becker, Gerold et al. (Hg.) (2002): Friedrich-Jahresheft: ২Körper^.

Becker-Schmidt, Regina/Knapp, Gudrun-Axeli (2000): Feministische Theorien zur Einführung, Hamburg: Junius.

Behnisch, Michael (2005): Pädagogische Beziehung. Zur Funktion und Verwendungslogik eines Topos der Jugendhilfe, Würzburg: Ergon.

Beveniste, Émile (1974): »Die Ebenen der linguistischen Analyse». In: ders.: Probleme der allgemeinen Sprachwissenschaft, München: List, S. 135-150. Bergmann, Jörg A. (1991): „Goffmans Soziologie des Gesprächs und seine ambivalente Beziehung zur Konversationsanalyse«. In: Hettlage, Robert/ Lenz, Karl (Hg.), Erving Goffman ein soziologischer Klassiker der zweiten Generation, Bern, Stuttgart: UTB, S. 301-326. 
Bilstein, Johannes/Klein, Gabriele (2002): „Die Durchleuchtung des Körpers. Von Disziplinierung und Inszenierung«. In: Becker, Gerold et al. (Hg.), Friedrich-Jahresheft: >Körper`, S. 4-8.

Blaser, Elisabeth et al. (2000): Wie nehmen SchülerInnen und LehrerInnen den Rauswurf kognitiv und emotional wahr? Forschungsbericht zum Seminar: LehrerInnen und StudentInnen erforschen Schule und Unterricht, Oldenburg: Oldenburger VorDruck.

Bluhm, Claudia et al. (2000): »Linguistische Diskursanalyse: Überblick, Probleme, Perspektiven«. In: Sprache und Literatur (31), 2, S. 3-19.

Boer, Heike de (2006): Klassenrat als interaktive Praxis. Auseinandersetzung Kooperation - Imagepflege, Wiesbaden: VS-Verl.

Bogner, Alexander/Menz, Wolfgang (2002): »Das theoriegenerierende Experteninterview. Erkenntnisinteresse, Wissensformen, Interaktion «. In: Bogner, Alexander/Littig, Beate/Menz, Wolfgang (Hg.), Das Experteninterview. Theorie, Anwendung, Methode, Opladen: Leske und Budrich, S. 33-70.

Bourdieu, Pierre (1981): »Die gesellschaftliche Definition der Photographie«. In ders. et al. (Hg.), Eine illegitime Kunst. Die sozialen Gebrauchsweisen der Photographie, Frankfurt: Europäische Verlagsanstalt, S. 85-109.

Bourdieu, Pierre (1985): Sozialer Raum und »Klassen«. Leçon sur la leçon. Zwei Vorlesungen. Frankfurt/M: Suhrkamp.

Bourdieu, Pierre (1987): Sozialer Sinn. Kritik der theoretischen Vernunft, Frankfurt/M.: Suhrkamp.

Bourdieu, Pierre (1990): Was heißt sprechen? Wien: Braumüller.

Bourdieu, Pierre (1993): Soziologische Fragen, Frankfurt/Main: Suhrkamp.

Bourdieu, Pierre (1997): »Die männliche Herrschaft«. In: Dölling, Irene/ Krais, Beate (Hg.), Ein alltägliches Spiel. Geschlechterkonstruktion in der sozialen Praxis, Frankfurt/M.: Suhrkamp. S. 53-217.

Bourdieu, Pierre/Wacquant, Loïc J.D. (1996): Reflexive Anthropologie, Frankfurt/M.: Suhrkamp.

Breidenstein, Georg (2006): Teilnahme am Unterricht. Ethnographische Studien zum Schülerjob, Wiesbaden: VS-Verl.

Breidenstein, Georg/Helga Kelle (1998): Geschlechteralltag in der Schulklasse. Ethnographische Studien zur Gleichaltrigenkultur, Weinheim/München: Juventa.

Breitenbach, Eva (2005): »Vom Subjekt zur Kategorie. Veränderte Denkfiguren«. In: Casale, Rita et al. (Hg.), Geschlechterforschung in der Kritik. Jahrbuch Frauen- und Geschlechterforschung in der Erziehungswissenschaft. Opladen: Barbara Budrich Verlag, S. 73-86. 
Bröckling, Ulrich (2000): »Totale Mobilmachung. Menschenführung im Qualitäts- und Selbstmanagement «. In: Bröckling, Ulrich/Krasmann, Susanne/ Lemke, Thomas (Hg.), Gouvernementalität der Gegenwart. Studien zur Ökonomisierung des Sozialen, Frankfurt/M.: Suhrkamp, S. 131-167.

Bröckling, Ulrich (2002): »Die Macht der Vorbeugung. 16 Thesen zur Prävention «. In: Widersprüche (22), 86, S. 39-52.

Bublitz, Hannelore et al. (Hg.) (1999): Das Wuchern der Diskurse. Perspektiven der Diskursanalyse Foucaults, Frankfurt/M.: Campus.

Bublitz, Hannelore (2002): Judith Butler zur Einführung. Hamburg: Junius.

Bublitz, Hannelore (2003): Diskurs, Bielefeld: transcript.

Burkhart, Gunter (2003): »Der unzugängliche Leib. Probleme der Kulturwissenschaften mit der sozialen Natur des Körpers«. Sammelrezension in: ZBBS Schwerpunkt Körperdiskurse. 1/2003, Opladen: Leske und Budrich, S. 163-174.

Busse, Susann/Helsper, Werner (2004): "Schule und Familie». In: Helsper, Werner/Böhme, Jeanette (Hg.), Handbuch der Schulforschung, Wiesbaden: VS-Verl., S. 439-464.

Butler, Judith (1991): Das Unbehagen der Geschlechter, Frankfurt/M.: Suhrkamp.

Butler, Judith (1993): »Für ein sorgfältiges Lesen««. In: Benhabib, Seyla et al. (Hg.), Der Streit um Differenz. Feminismus und Postmoderne, Frankfurt/M.: Fischer, S. 122-132.

Butler, Judith (1995): Körper von Gewicht. Die diskursiven Grenzen des Geschlechts, Berlin: Berlin-Verl.

Butler, Judith (1998): Hass spricht. Zur Politik des Performativen, Berlin: Berlin-Verl.

Butler, Judith (2001): Psyche der Macht. Das Subjekt der Unterwerfung, Frankfurt/M.: Suhrkamp.

Bynum, Caroline (1996): »Warum das ganze Theater mit dem Körper? Die Sicht einer Mediävistin«. In: Historische Anthropologie (4), 1, S. 1-33.

Caruso, Marcelo (2003): Biopolitik im Klassenzimmer. Zur Ordnung der Führungspraktiken in den Bayerischen Volksschulen (1869 - 1918), Weinheim/ Basel/Berlin: Dt. Studien- Verl.

Certeau, Michel de (1988): Kunst des Handelns, Berlin: Merve.

Cremer-Schäfer, Helga (1995): „Einsortierung und Aussortieren. Zur Funktion der Strafe bei der Verwaltung sozialer Ausschließung «. In: Kriminologisches Journal (27), 2, S. 89-119.

Cremer-Schäfer, Helga/Steinert, Heinz (1998): Straflust und Repression. Zur Kritik der populistischen Kriminologie, Münster: Westfälisches Dampfboot. 
Demirovic, Alex (1999): Der nonkonformistische Intellektuelle. Die Entwicklung der kritischen Theorie zur Frankfurter Schule, Frankfurt/M.: Suhrkamp.

Derrida, Jacques (2001): Limited Inc., Wien: Passagen.

Diaz-Bone, Rainer (2002): Kulturwelt, Diskurs und Lebensstil. Eine diskurstheoretische Erweiterung der bourdieuschen Distinktionstheorie, Opladen: Leske und Budrich.

Diaz-Bone, Rainer (2003): »Entwicklungen im Feld der foucaultschen Diskursanalyse. Sammelbesprechung «. In: Forum Qualitative Sozialforschung/Forum: Qualitative Social Research [Online Journal], 4(3), Art. 1. Verfügbar: http://www.qualitative-research.net/fqs-texte/3-03/3-03review-diazboned.htm [24.02.2008].

Diaz-Bone, Rainer (2005): »Zur Methodologisierung der Foucaultschen Diskursanalyse«. In: Forum Qualitative Sozialforschung/Forum: Qualitative Social Reseach [Online Journal] 7(1), Art. 6. Verfügbar über: http://www. qualitative-research.net/fqs-texte/1-06/06-1-6-d.htm [24.02.2008].

Dörr, Margarete/Müller, Burkhard (Hg.) (2006): Nähe und Distanz. Ein Spannungsfeld pädagogischer Professionalität, Weinheim/München: Juventa.

Dosse, François (1999): Geschichte des Strukturalismus, Hamburg: Junius.

Dreyfus, Hubert L./Rabinow, Paul (1987): Michel Foucault. Jenseits von Strukturalismus und Hermeneutik, Weinheim: Beltz, Athenäum.

Duden, Barbara (1987): Geschichte unter der Haut. Ein Eisenacher Arzt und seine Patientinnen um 1730, Stuttgart: Klett-Cotta.

Duden, Barbara (1993): »Die Frau ohne Unterleib. Zu Judith Butlers Entkörperung. Ein Zeitdokument«. In: Feministische Studien (11), 2, S. 24-33.

Duttweiler, Stefanie (2003): »Body-Consciousness - Fitness - Wellness - Körpertechnologien als Technologien des Selbst«. In: Widersprüche (23), 87, S. 31-43.

Dzierzbicka, Agnieszka (2006): Vereinbaren statt anordnen. Neoliberale Gouvernementalität macht Schule, Wien: Löcker.

Eco, Umberto (1972) : Einführung in die Semiotik, München: Fink.

Eco, Umberto (1990): Lector in fabula. Die Mitarbeit der Interpretation in erzählenden Texten, München: DTV.

Ehrenspeck, Yvonne/Schäffer, Burkhard (Hg.) (2003): Film- und Fotoanalyse in der Erziehungswissenschaft. Ein Handbuch, Opladen: Leske und Budrich.

Elias, Norbert (1997a): Über den Prozess der Zivilisation. Soziogenetische und psychogenetische Untersuchungen, Bd. 1, Frankfurt/M.: Suhrkamp.

Elias, Norbert (1997b): Über den Prozess der Zivilisation. Soziogenetische und psychogenetische Untersuchungen, Bd. 2, Frankfurt/M.: Suhrkamp. 
Enders-Dragässer, Uta/Fuchs, Claudia (1989): Interaktionen der Geschlechter. Sexismusstrukturen in der Schule, Weinheim/München: Juventa.

Faustich-Wieland, Hannelore/Weber, Martina/Willems, Katharina (2004): Doing Gender im heutigen Schulalltag. Empirische Studien zur sozialen Konstruktion von Geschlecht in schulischen Interaktionen, Weinheim/ München: Juventa.

Fegter, Susann/Langer, Antje (2008). Diskursforschung im Prozess ihrer Etablierung. In: Forum Qualitative Sozialforschung/Forum: Qualitative Social Research, 9(2), Art. 18, Verfügbar über: http://www.qualitativeresearch.net/fqs-texte/2-08/08-2-18-d.htm [08.04.08]

Fischer-Lichte, Erika (Hg.) (2000): Körper-Inszenierungen. Präsenz und kultureller Wandel, Tübingen: Attempto.

Flaake, Karin (2001): Körper, Sexualität und Geschlecht. Studien zur Adoleszenz junger Frauen, Gießen: Psychosozial-Verl.

Fleißner, Heike (2002): »Mädchenpädagoginnen und ihre Mädchenbilder. Zwischen Wünschen und Widersprüchen«. In: ZFG/ZFS (Hg.), Körper und Geschlecht. Bremer-Oldenburger Vorlesungen zur Frauen- und Geschlechterforschung, Opladen: Leske und Budrich, S. 105-116.

Foucault, Michel (1978): Dispositive der Macht. Über Sexualität, Wissen und Wahrheit, Berlin: Merve.

Foucault, Michel (1981): Archäologie des Wissens, Frankfurt/M.: Suhrkamp.

Foucault, Michel (1984): „Geschichte und Homosexualität«. In: ders.: Von der Freundschaft als Lebensweise. Michel Foucault im Gespräch, Berlin: Merve, S. 95-110.

Foucault, Michel (1985): „Geschichte der Sexualität. Interview mit Michel Foucault«. In: Ästhetik und Kommunikation (15), 57/58, S. 157-164.

Foucault, Michel (1987): »Das Subjekt und die Macht«. In Dreyfus, Hubert L.: Rabinow, Paul (Hg.), Michel Foucault. Jenseits von Strukturalismus und Hermeneutik, Weinheim: Beltz, Athenäum, S. 243-264.

Foucault, Michel (1989): Der Gebrauch der Lüste. Sexualität und Wahrheit, Bd. 2, Frankfurt/M.: Suhrkamp.

Foucault, Michel (1993): »Technologien des Selbst«. In: ders. (Hg.), Technologien des Selbst, Frankfurt/M.: S. Fischer, S. 24-62.

Foucault, Michel (1996a): Diskurs und Wahrheit, Berlin: Merve.

Foucault, Michel (1996b): Der Mensch ist ein Erfahrungstier, Frankfurt/M. Suhrkamp.

Foucault, Michel (1998): Überwachen und Strafen. Die Geburt des Gefängnisses, Frankfurt/M.: Suhrkamp.

Foucault, Michel (1999): In Verteidigung der Gesellschaft, Frankfurt/M.: Suhrkamp. 
Foucault, Michel (2000): »Die `Gouvernementalität««. In: Bröckling, Ulrich/ Krasmann, Susanne/Lemke, Thomas (Hg.), Gouvernementalität der Gegenwart. Studien zur Ökonomisierung des Sozialen, Frankfurt/M.: Suhrkamp, S. 41-67.

Foucault, Michel (2004a): Geschichte der Gouvernementalität 1. Sicherheit, Territorium, Bevölkerung: Vorlesung am Collège de France 1977 - 1978, Frankfurt/M.: Suhrkamp.

Foucault, Michel (2004b): Geschichte der Gouvernementalität 2. Die Geburt der Biopolitik: Vorlesung am Collège de France 1978 - 1979, Frankfurt/M.: Suhrkamp.

Franz, Julia (2005): Die Regierung der Qualität. Eine Rekonstruktion neoliberaler Gouvernementalität am Beispiel von Qualitätsmanagement in der Erwachsenen- und Weiterbildung, Gießen: Diplomarbeit. Verfügbar über: http://blog.twoday.net/stories/745725/ [24.02.2008]

Frei Gerlach, Franziska et al. (Hg.) (2003): Körperkonzepte. Interdisziplinäre Studien zur Geschlechterforschung, Münster/New York: Waxmann.

Friebertshäuser, Barbara (1997): „Feldforschung und teilnehmende Beobachtung«. In: Friebertshäuser, Barbara/Prengel, Annedore (Hg.), Handbuch Qualitative Forschungsmethoden in der Erziehungswissenschaft, Weinheim/München: Juventa, S. 503-534.

Friebertshäuser, Barbara (2001): »Wege zur Ethnographie. Auswertungsstrategien für Feldforschungsdaten«. In: Panagiotopoulou, Argyro/Rohlfs, Carsten (Hg.), Lernbiografien im sozialen Kontext. Dokumentation und Auswertung einer internationalen Fachtagung in Siegen vom 6. bis 8. September 2000, Siegen: Universität Siegen, S. 117-134.

Friebertshäuser, Barbara (2002): Fremde Lebenswelten verstehen. Ethnographische Feldforschung und Kulturanalyse in der Erziehungswissenschaft, (unveröff. Habiltiationsschrift).

Friebertshäuser, Barbara/Langer, Antje/Richter, Sophia (2004): »Darstellen und Verstecken. Zur Inszenierung von Coolness im Jugendalter «. In: Forschung Frankfurt 2, S .33-36.

Friebertshäuser, Barbara (2005): »Statuspassage Erwachsenwerden und weitere Einflüsse auf die Bildungsprozesse von Schülerinnen und Schülern«. In: Schenk, Barbara (Hg.), Bausteine einer Bildungstheorie, Wiesbaden: VS-Verl., S. 127-144.

Friebertshäuser, Barbara (2006): „Verstehen als methodische Herausforderung für eine reflexive empirische Forschung «. In: Friebertshäuser, Barbara/Rieger-Ladich, Markus/Wigger, Lothar (Hg.), Reflexive Erziehungswissenschaft. Forschungsperspektiven im Anschluss an Pierre Bourdieu, Wiesbaden: VS-Verl., S. 231-251. 
Friebertshäuser, Barbara/Felden, Heide von/Burkhard Schäffer (Hg.) (2007): Bild und Text - Methoden und Methodologien visueller Sozialforschung in der Erziehungswissenschaft, Opladen: Barbara Budrich Verl.

Friebertshäuser, Barbara/Langer, Antje/Richter, Sophia (Hg.) (2008): (An)Passungen. Körperlichkeit und Beziehungen in der Schule - ethnographische Studien. Baltmannsweiler: Schneider-Verl. Hohengehren, i. E.

Friedrich, Malte (2002): »Inszenierte Blasierheit. Körpercode Coolness.« In: Becker, Gerold et al. (Hg.), Friedrich-Jahresheft: ’Körper«, S. 86-87.

Frömmer, Jörg/Löw, Martina/Rabe-Kleberg, Ursula (2003): „Körper und Leib als Gegenstand sozialwissenschaftlicher Analyse. Einführung in den Themenschwerpunkt«. In: ZBBS Schwerpunkt Körperdiskurse. 1/2003. Opladen: Leske und Budrich, S. 5-8.

Gaugele, Elke/Reiss, Kristina (Hg.) (2003): Jugend, Mode, Geschlecht. Die Inszenierung des Körpers in der Konsumkultur, Frankfurt/M.: Campus.

Geertz, Clifford (1983): Dichte Beschreibung. Beiträge zum Verstehen kultureller Systeme, Frankfurt/M.: Suhrkamp.

Glaser, Barney/Strauss, Anselm L. (1998): Grounded Theory. Strategien qualitativer Forschung, Bern/Göttingen/Toronto/Seattle: Huber.

Goffman, Erving (1969): Wir alle spielen Theater. Die Selbstdarstellung im Alltag, München: Piper.

Goffman, Erving (1971): Verhalten in sozialen Situationen. Strukturen und Regeln der Interaktion im öffentlichen Raum, Gütersloh: Bertelsmann.

Goffman, Erving (1974): Das Individuum im öffentlichen Austausch. Mikrostudien zur öffentlichen Ordnung, Frankfurt/M.: Suhrkamp.

Goffman, Erving (1994): »Die Interaktionsordnung». In: Knoblauch, Hubert A. (Hg.), Erving Goffman. Interaktion und Geschlecht, Frankfurt/New York: Campus, S. 50-104.

Goffman, Erving (1996a): Interaktionsrituale. Über Verhalten in direkter Kommunikation, Frankfurt/M.: Suhrkamp.

Goffman, Erving (1996b): Rahmen-Analyse. Ein Versuch über die Organisation von Alltagserfahrungen, Frankfurt/M.: Suhrkamp.

Goffman, Erving (1996c): „Über Feldforschung«. In: Knoblauch, Hubert A. (Hg.), Kommunikative Lebenswelten. Zur Ethnographie einer geschwätzigen Gesellschaft, Konstanz: UVK, S. 261-269.

Goffman, Erving (2006): Rede-Weisen, Konstanz: UVK.

Göhlich, Michael (2001): »Performative Äußerungen. John L. Austins Begriff als Instrument erziehungswissenschaftlicher Forschung «. In: Wulf, Christoph/Göhlich, Michael/Zirfas, Jörg (Hg.), Grundlagen des Performativen. Eine Einführung in die Zusammenhänge von Sprache, Macht und Handeln, Weinheim/München: Juventa, S. 25-46. 
Göhlich, Michael/Wagner-Willi, Monika (2001): »Rituelle Übergänge im Schulalltag - Zwischen Peergroup und Unterrichtsgemeinschaft «. In: Wulf, Christoph et al.: Das Soziale als Ritual. Zur performativen Bildung von Gemeinschaften, Opladen: Leske und Budrich, S. 119-204.

Gomolla, Mechthild (2003): »Fördern und Fordern allein genügt nicht! Mechanismen institutioneller Diskriminierung von Migrantenkindern und -jugendlichen im deutschen Schulsystem«. In: Auernheimer, Georg (Hg.), Schieflagen im Bildungssystem. Die Benachteiligung der Migrantenkinder, Opladen: Leske und Budrich, S. 97-112.

Gomolla, Mechtild/Radtke, Frank-Olaf (2002): Institutionelle Diskriminierung. Die Herstellung ethnischer Differenz in der Schule, Opladen: Leske und Budrich.

Greimas, Algirdas Julien (1971): Strukturale Semantik, Braunschweig: Vieweg.

Güting, Damaris (2004): Soziale Konstruktion von Geschlecht im Unterricht. Ethnographische Analysen alltäglicher Inszenierungspraktiken, Bad Heilbrunn/Obb.: Klinkhardt.

Gugutzer, Robert (2002): Leib, Körper und Identität. Eine phänomenologischsoziologische Untersuchung zur personalen Identität, Wiesbaden: Westdt. Verl.

Gugutzer, Robert (2004): Soziologie des Körpers, Bielefeld: transcript.

Hahn, Kornelia/Meuser, Michael (Hg.) (2002): Körperrepräsentationen. Die Ordnung des Sozialen und der Körper, Konstanz: UVK.

Hanak, Gerhard/Stehr, Johannes/Steinert, Heinz (1989): Ärgernisse und Lebenskatastrophen. Über den alltäglichen Umgang mit Kriminalität, Bielefeld: AJZ-Dr. u. Verl.

Hark, Sabine (2005): Dissidente Partizipation. Eine Diskursgeschichte des Feminismus, Frankfurt/M: : Suhrkamp.

Heinemann, Lars (2001): »Ethnizität und Geltung. Möglichkeiten und Grenzen konstruktivistischer Theorien bei der Erklärung ethnischer Vergemeinschaftung«. In: Rademacher, Claudia/Wiechens, Peter (Hg.), Geschlecht, Ethnizität, Klasse. Zur sozialen Konstruktion von Hierarchie und Differenz, Opladen: Leske und Budrich, S. 111-128.

Helfferich, Cornelia (1994): Jugend, Körper und Geschlecht. Die Suche nach sexueller Identität. Opladen: Leske und Budrich.

Helsper, Werner (1993): »Jugend und Schule«. In: Krüger, Heinz-Hermann (Hg.), Handbuch der Jugend-Forschung, Opladen: Leske und Budrich, S. 351-382.

Hengst, Heinz/Kelle, Helga (Hg.) (2003): Kinder - Körper - Identitäten. Theoretische und empirische Annäherungen an kulturelle Praxis und sozialen Wandel, Weinheim/München: Juventa. 
Hermann, Renate/Stötzer, Katja (2008): »Der Pädagogische Bezug im Bild«. In: Friebertshäuser, Barbara/Langer, Antje/Richter, Sophia (Hg.), (An)Passungen. Körperlichkeit und Beziehungen in der Schule - ethnographische Studien, Baltmannsweiler: Schneider-Verl. Hohengehren, i. E.

Hersey, George L. (1998): Verführung nach Maß. Ideal und Tyrannei des perfekten Körpers, Berlin: Siedler.

Herzog, Walter (1985): »Der Körper als Thema der Pädagogik «. In: Petzold, Hilarion (Hg.), Leiblichkeit. Phiolosophische, gesellschaftliche und therapeutische Perspektiven, Paderborn: Junfermann-Verl., S. 259-301.

Hessisches Schulgesetz (HSchG) in der Fassung vom 14. Juni 2005 (GVBl. I S. 442), zuletzt geändert durch Gesetz vom 13. Juli 2006 (GVB1. I S. 386) Hnilica, Sonja (2003): Disziplinierte Körper. Die Schulbank als Erziehungsapparat, Wien: Edition selene.

Hirschauer, Stefan (1993): Die soziale Konstruktion von Transsexualität, Frankfurt/M: Suhrkamp.

Hirschauer, Stefan (1994): »Die soziale Fortpflanzung der Zweigeschlechtigkeit«. In: Kölner Zeitschrift für Soziologie und Sozialpsychologie (46), 4, S. 668-692.

Hirschauer, Stefan (2001): »Ethnografisches Schreiben und die Schweigsamkeit des Sozialen. $\mathrm{Zu}$ einer Methodologie der Beschreibung «. In: Zeitschrift für Soziologie (30) 6, S. 429-451.

Hirschauer, Stefan (2004): »Praktiken und ihre Körper. Über materielle Partizipanden des Tuns«. In: Hörning, Karl H./Reuter, Julia (Hg.), Doing culture. Neue Positionen zum Verhältnis von Kultur und sozialer Praxis, Bielefeld: transcript, S. 73-91.

Höhne, Thomas (2003a): »Die Thematische Diskursanalyse - dargestellt am Beispiel von Schulbüchern«. In: Keller, Reiner et al. (Hg.), Handbuch Sozialwissenschaftliche Diskursanalyse, Bd. 2, Opladen: Leske und Budrich, S. 389-419.

Höhne, Thomas (2003b): Pädagogik der Wissensgesellschaft, Bielefeld: transcript.

Höhne, Thomas/Kunz, Thomas/Radtke, Frank-Olaf (2005): Bilder von Fremden. Was unsere Kinder aus Schulbüchern über Migranten lernen sollen, Frankfurt/M.: JWG-Universität.

Horlacher, Cornelis (2005): Regieren und/oder disziplinieren. Kritikansätze in der Auseinandersetzung mit Michel Foucaults Erbe, Frankfurt/M.: JWGUniversität. Unveröffentl. Diplomarbeit.

Horlacher, Cornelis (2007): »Wessen Kunst, wie nicht regiert zu werden? Vergleich einiger Rezeptionsweisen von Foucaults Begriff des Regierens in Texten zu Sozialer Arbeit«. In: Anhorn, Roland/Bettinger, Frank/Stehr, 
Johannes (Hg.), Foucaults Machtanalytik und Soziale Arbeit. Eine kritische Einführung und Bestandsaufnahme, Wiesbaden: VS-Verl.

Horn, Christoph (2001): »Ästhetik der Existenz und Selbstsorge«. In: Kleiner, Marcus S. (Hg.), Michel Foucault. Eine Einführung in sein Denken, Frankfurt/New York: Campus, S. 137-152.

Hörning Karl H./Reuter, Julia (Hg.) (2004): Doing culture. Neue Positionen zum Verhältnis von Kultur und sozialer Praxis, Bielefeld: transcript.

Horstkemper, Marianne (1987): Schule, Geschlecht und Selbstvertrauen, Weinheim/München: Juventa.

Hradil, Stefan (2001): Soziale Ungleichheit in Deutschland, Opladen: Leske und Budrich.

Hurrelmann, Klaus/Wolf, Hartmut K. (1986): Schulerfolg und Schulversagen im Jugendalter. Fallanalysen von Bildungslaufbahnen, Weinheim/München: Juventa.

Jäger, Siegfried (2001): Kritische Diskursanalyse. Eine Einführung, Duisburg: DISS.

Jäger, Ulle (2004): Der Körper, der Leib und die Soziologie. Entwurf einer Theorie der Inkorporierung, Köngistein/Ts.: Ulrike Helmer Verl.

Jung, Matthias (1997): Die Sprache des Migrationsdiskurses. Das Reden über »Ausländer« in Medien, Politik und Alltag, Opladen: Westdt. Verl.

Institut für Bildungsmedien e.V. (2004): Zeitschriften Kompass. Ein Führer durch das Angebot an Fachzeitschriften für das Bildungswesen, Frankfurt/M.: Eigenverlag.

Kamper, Dietmar/Wulf, Christoph (1982): „Die Parabel der Wiederkehr. Eine Einführung». In: dies. (Hg.), Die Wiederkehr des Körpers, Frankfurt/M.: Suhrkamp.

Kelle, Helga (1997): »Die Komplexität sozialer und kultureller Wirklichkeit als Problem qualitativer Forschung «. In: Friebertshäuser, Barbara/Prengel, Annedore (Hg.), Handbuch Qualitative Forschungsmethoden in der Erziehungswissenschaft, Weinheim/München: Juventa, S. 192-208.

Kelle Helga (2001): „Ethnographische Methodologie und Probleme der Triangulation. Am Beispiel der Peer Culture Forschung bei Kindern«. In: ZSE (21), 2, S. 192-208.

Keller, Reiner (2001): „Wissenssoziologische Diskursanalyse«. In: Keller, Reiner et al. (Hg.), Handbuch Sozialwissenschaftliche Diskursanalyse. Bd. 1, Opladen: Leske und Budrich, S. 113-143.

Keller, Reiner et al. (Hg.) (2001): Handbuch Sozialwissenschaftliche Diskursanalyse, Bd. 1, Opladen: Leske und Budrich.

Keller, Reiner et al. (Hg.) (2003): Handbuch Sozialwissenschaftliche Diskursanalyse, Bd. 2, Opladen: Leske und Budrich. 
Keller, Reiner (2004): Diskursforschung. Eine Einführung für SozialwissenschaftlerInnen, Opladen: Leske und Budrich.

Keller, Reiner (2005a): Wissenssoziologische Diskursanalyse. Grundlegung eines Forschungsprogramms, Wiesbaden: VS-Verl.

Keller, Reiner (2005b): „Wissenssoziologische Diskursanalyse als interpretative Analytik «. In: Keller, Reiner et al. (Hg.), Die diskursive Konstruktion von Wirklichkeit. Zum Verhältnis von Wissenssoziologie und Diskursforschung, Konstanz: UVK, S. 49-75.

Kessl, Fabian (2005): Der Gebrauch der eigenen Kräfte. Eine Gouvernementalität sozialer Arbeit, Weinheim/München: Juventa.

Keupp, Heinrich (1976): Abweichung und Alltagsroutine. Die Labeling-Perspektive in Theorie und Praxis, Hamburg: Hoffmann und Campe.

King, Vera/Flaake, Karin (Hg.) (2005): Männliche Adoleszenz. Sozialisation und Bildungsprozesse zwischen Kindheit und Erwachsensein, Frankfurt/M.: Campus.

Klein, Michael (Hg.) (1984): Sport und Körper, Reinbek bei Hamburg: Rowohlt.

Klemm, Jana/Glasze, Georg (2004): »Methodische Probleme Foucault-inspirierter Diskursanalysen in den Sozialwissenschaften. Tagungsbericht: `Praxisworkshop Diskursanalyse«" [64 Absätze]. In: Forum Qualitative Sozialforschung/Forum: Qualitative Social Reseach [Online Journal] 6(2), Art. 24. Verfügbar über: http://www.qualitative-research.net/fqs-texte/2-05/ 05-2-24-d.htm [24.02.2008].

Koppetsch, Cornelia (Hg.) (2000): Körper und Status. Zur Soziologie der Attraktivität, Konstanz: UVK.

Knoblauch, Hubert A. (1994): »Erving Goffmans Reich der Interaktion«. In: ders. (Hg.), Erving Goffman. Interaktion und Geschlecht, Frankfurt/New York: Campus, S. 7-49.

Koller, Hans-Christoph/Lüders, Jenny (2004): „Möglichkeiten und Grenzen der Foucaultschen Diskursanalyse«. In: Ricken, Norbert/Rieger-Ladich, Markus (Hg.), Michel Foucault: Pädagogische Lektüren, Wiesbaden: VSVerl., S. 57-76.

König, Eugen (1989): Körper - Wissen - Macht. Studien zur historischen Anthropologie des Körpers, Berlin: Reimer.

Kossack, Peter (2006): Lernen beraten. Eine dekonstruktive Analyse des Diskurses zur Weiterbildung, Bielefeld: transcript.

Kost, Franz (1985): Volksschule und Disziplin. Die Disziplinierung des innerund außerschulischen Lebens durch die Volksschule, am Beispiel der Zürcher Schulgeschichte zwischen 1830 und 1930, Zürich: Limmat-Verl. 
Kramer, Rolf-Torsten (2002): Schulkultur und Schülerbiographien. Rekonstruktionen zur Schulkultur II, Wiesbaden: VS-Verl.

Krappmann, Lothar/Oswald, Hans (1995): Alltag der Schulkinder. Beobachtungen und Analysen von Interaktionen und Sozialbeziehungen, Weinheim/München: Juventa.

Krüger, Heinz-Hermann et al. (2000): Jugendliche Lebenswelten und Schulentwicklung. Ergebnisse einer quantitativen Schüler- und Lehrerbefragung in Ostdeutschland, Opladen: Leske und Budrich.

Kristeva, Julia (1986): The Kristeva Reader. Edited by Toril Moi, Oxford: Blackwell.

Laclau, Ernesto/Mouffe, Chantal (1991): Hegemonie und radikale Demokratie. Zur Dekonstruktion des Marxismus, Wien: Passagen-Verl.

Landweer, Hilge (1993): »Kritik und Verteidigung der Kategorie Geschlecht». In: Feministische Studien (11), 2, S. 34-43.

Langer, Antje/Wrana, Daniel (2005): Diskursive Verstrickungen und diskursive Kämpfe: Erwachsenenbildung und Nationalsozialismus. Vortrag auf dem Workshop Diskursanalyse an der Universität Augsburg im Juli 2005, Gießen: wb.giessen Abrufbar unter: http://www.wb.uni-giessen.de/dokumente/langerwrana_verstrickungenkaempfe.pdf [10.01.2007]

Langer, Antje (2006): »Geglückte Forschungsbeziehungen«. In: Behr, Rafael/ Helga Cremer-Schäfer/Sebastian Scheerer (Hg.), Kriminalitäts-Geschichten. Ein Lesebuch über Geschäftigkeiten am Rande der Gesellschaft, Hamburg: LIT, S. 39-49.

Langer, Antje/Ott, Marion/Wrana, Daniel (2006): »Die Verknappung des Selbst. Stellenanzeigen und ihre Transformation in steuerungsrelevantes Wissen«. In: Maurer, Susanne/Weber, Susanne (Hg.), Gouvernementalität und Erziehungswissenschaft, Wiesbaden: VS-Verl., S. 281-300.

Langer, Antje (2007a): »Mit Goffman auf dem Drogenstrich. Rückblick auf eine >gelungene Forschungsbeziehung«». In: Österreichische Zeitschrift für Soziologie 2, S. 90-104.

Langer, Antje (2007b): »Fotografie in der ethnographischen Forschung - Soziale Gebrauchsweisen und Inszenierungen «. In: Friebertshäuser, Barbara/ Felden, Heide von/Schäffer, Burkhard (Hg.), Bild und Text - Methoden und Methodologien visueller Sozialforschung in der Erziehungswissenschaft, Opladen: Barbara Budrich Verl., S. 141-157.

Langer, Antje/Wrana, Daniel (2009): »Diskursanalyse: Gegenstände, Methodologie und Methoden«. In: Friebertshäuser, Barbara/Langer, Antje/Prengel, Annedore (Hg.), Handbuch Qualitative Forschungsmethoden in der Erziehungswissenschaft (Neuauflage), Weinheim/München: Juventa, i. E. 
Langer, Antje (2009): Pubertäts-Wissen. Vorstellungen von einer »normalen« pubertären Entwicklung und ihr Einfluss auf pädagogisches Handeln. In: Behnisch, Michael/Winkler, Michael (Hrsg.): Körperbilder, Kenndaten und Kausaleffekte. Wie naturwissenschaftliches Denken die soziale Arbeit verändert, München/Basel: Reinhardt-Verl., i. E.

Laqueur, Thomas (1992): Auf den Leib geschrieben. Die Inszenierung der Geschlechter von der Antike bis Freud, Frankfurt/New York: Campus.

Leitgeb, Andrea (1991): „Geschlechtsspezifisches Rollenverhalten in der Schule. Ein Bericht über ein Aktionsforschungsprojekt«: In: Birmily, Elisabeth et al. (Hg.), Die Schule ist männlich. Zur Situation von Schülerinnen und Lehrerinnen, Wien: Verl. für Gesellschaftskritik, S. 59-70.

Lemke, Thomas (2000): »Neoliberalismus, Staat und Selbsttechnologien. Ein kritischer Überblick über die governmentality studies«. Politische Vierteljahresschrift (41), 1, S. 31-47.

Lemke, Thomas (2004a): „Governance, Gouvenementaltität und die Dezentrierung der Ökonomie«. In: Reichert, Ramón (Hg.), Governmentality Studies. Analysen liberal-demokratischer Gesellschaften im Anschluss an Michel Foucault. Münster: LIT, S. 63-73.

Lemke, Thomas (2004b): »)Eine Kultur der Gefahr««. Dispositive der Unsicherheit im Neoliberalismus. In: Widerspruch (24), 46, S. 89-98.

Lemke, Thomas (2006): Die Polizei der Gene. Formen und Felder genetischer Diskriminierung, Frankfurt/New York: Campus.

Lenz, Karl 1991: „Erving Goffman - Werk und Rezeption«. In: Hettlage, Robert/Lenz, Karl (Hg.), Erving Goffman ein soziologischer Klassiker der zweiten Generation, Bern/Stuttgart: UTB, S. 25-93.

Link, Jürgen (1988): »Literaturanalyse als Interdiskursanalyse. Am Beispiel des Ursprungs literarischer Symbolik in der Kollektivsymbolik «. In: Fohrmann, Jürgen/Müller, Harro (Hg.), Diskurstheorien und Literaturwissenschaft, Frankfurt/M.: Suhrkamp, S. 284-307.

Link, Jürgen (1999): »Diskursive Ereignisse, Diskurse, Interdiskurse. Sieben Thesen zur Operativität der Diskursanalyse, am Beispiel des Normalismus«. In: Bublitz, Hannelore et al. (Hg.), Das Wuchern der Diskurse. Perspektiven der Diskursanalyse Foucaults, Frankfurt/New York: Campus, S. 148-161.

Link, Jürgen (2006): Versuch über den Normalismus. Wie Normalität produziert wird, Göttingen: Vandenhoeck \& Ruprecht.

Lorenz, Maren (2000): Leibhaftige Vergangenheit. Einführung in die Körpergeschichte, Tübingen: edition diskord. 
Lorey, Isabell (1995): »Immer Ärger mit dem Subjekt«. In: Haas, Erika (Hg.), Verwirrung der Geschlechter - Dekonstruktion und Feminismus. München: Profil.

Lorey, Isabell (1999): »Macht und Diskurs bei Foucault«. In: Bubitz, Hannelore et al. (Hg.), Das Wuchern der Diskurse. Perspektiven der Diskursanalyse Foucaults, Frankfurt/New York: Campus, S. 87-96.

Löw, Martina (2001): Raumsoziologie, Frankfurt/M.: Suhrkamp.

Ludewig, Karin (2002): Die Wiederkehr der Lust. Körperpolitik nach Foucault und Butler, Frankfurt/New York: Campus.

Lüders, Christian (2000): »Beobachten im Feld und Ethnographie«. In: Flick, Uwe/Kardorff, Ernst von/Steinke, Ines: Qualitative Forschung. Ein Handbuch, Reinbek bei Hamburg: Rowohlt, S. 384-401.

Lyman, Stanford M./Scott, Marvin B. (1968): „Coolness in Everyday Life«. In: Truzzi, Marcello (Hg.), Sociology and Everyday Life, Englewood Cliffs, NJ: Prentice-Hall, S. 92-101.

Lyotard, Jean-François (1989): Der Widerstreit, München: Fink.

Maasen, Sabine/Mayerhausen, Torsten/Renggli, Cornelia (Hg.) (2006): Bilder als Diskurse - Bilddiskurse, Weilerswist: Velbrück.

Macha, Hildegard (2003): »Die Natur des Menschen. Körper und Geschlecht». In: Liebau, Eckart/Peskoller, Helga/Wulf, Christoph (Hg.), Natur, Weinheim/Basel/Berlin: Dt. Studien-Verl., S. 180-196.

Macha, Hildegard/Fahrenwald, Claudia (2003): »Körper, Identität und Geschlecht zwischen Natur und Kultur«. In: dies. (Hg.), Körperbilder zwischen Natur und Kultur. Interdisziplinäre Beiträge zur Genderforschung, Opladen: Leske und Budrich, S. 15-41.

Maihofer, Andrea (1995): Geschlecht als Existenzweise. Macht, Moral, Recht und Geschlechterdifferenz, Frankfurt/M.: Ulrike Helmer Verl.

Marlock, Gustl/May, Michael (2003): »Von der Gestalttherapie zum NLP: Transformation von existentialistischem Selbstbezug in Selbsttechnologie«. In: Widersprüche (23), 87, S. 45-53.

Maurer, Susanne/Weber, Susanne (Hg.) (2006): Gouvernementalität und Erziehungswissenschaft. Wissen - Macht - Transformation, Wiesbaden: VS-Verl.

Mauss, Marcel (1978): Soziologie und Anthropologie, Bd. II, Frankfurt/Berlin/Wien: Ullstein.

Meier, Michael (2004): „Bourdieus Theorie der Praxis - eine >Theorie sozialer Praktiken`?« In: Hörning Karl H./Reuter, Julia (Hg.), Doing culture. Neue Positionen zum Verhältnis von Kultur und sozialer Praxis, Bielefeld: transcript, S. 55-69. 
Meuser, Michael/Nagel, Ulrike (2002): »Experteninterviews - vielfach erprobt, wenig bedacht. Ein Beitrag zur qualitativen Methodendiskussion«. In: Bogner, Alexander/Littig, Beate/Menz, Wolfgang (Hg.), Das Experteninterview. Theorie, Anwendung, Methode, Opladen: Leske und Budrich, S. 71-93.

Meyer-Drawe, Käte (1996): »Versuch einer Archäologie des pädagogischen Blicks«. In: Zeitschrift für Pädagogik (47) 5, S. 655-664.

Mietzner, Ulrike, Pilarczyk, Ulrike (2003): »Methoden der Fotografieanalyse«. In: Ehrenspeck, Yvonne/Schäffer, Burkhard (Hg.), Film- und Fotoanalyse in der Erziehungswissenschaft, Ein Handbuch. Opladen: Leske und Budrich, S. 19-36.

Mixa, Elisabeth (1996): Körper - Geschlecht - Geschichte. Historische und aktuelle Debatten in der Medizin, Innsbruck: Studienverlag.

Moebius, Stephan (2005): »Diskurs - Ereignis - Subjekt. Diskurs und Handlungstheorie im Ausgang einer poststrukturalistischen Sozialwissenschaft«. In: Keller, Reiner et al. (Hg.), Die diskursive Konstruktion von Wirklichkeit. Zum Verhältnis von Wissenssoziologie und Diskursforschung, Konstanz: UVK, S. 127-148.

Mollenhauer, Klaus (1998): „Familie - Familienerziehung«. In: Lenzen, Dieter (Hg.), Pädagogische Grundbegriffe Bd. 1, Reinbek bei Hamburg: Rowohlt, S. 603-613.

Müller, Birgit (2000): Körper, (De)Konstruktion, Praxen. Überlegungen zu neueren Diskursen, Berliner Arbeiten zur Erziehungs- und Kulturwissenschaft, Berlin: Logos.

Nafzger-Glöser, Jutta (1994): Vom >Turmhahn zum >Trojaner ‘. Die Erwachsenenbildung/Weiterbildung in der Bundesrepublik Deutschland von 1945 bis 1994 im Spiegel ihrer Zeitschriften, Frankfurt/M.: DIE.

Niehr, Thomas/Böke, Karin (2003): »Diskursanalyse unter linguistischen Gesichtspunkten - am Beispiel des Migrationsdiskurses«. In: Keller, Reiner et al. (Hg.), Handbuch Sozialwissenschaftliche Diskursanalyse, Bd. 2, Opladen: Leske und Budrich, S. 325-351.

Nolda, Sigrid (1996): Interaktion und Wissen. Eine qualitative Studie zum Lehr-Lernverhalten in Veranstaltungen der allgemeinen Erwachsenenbildung, Frankfurt/M.: DIE.

Ott, Marion (2008): „Zum reflexiven Umgang mit Jugendbildern bei der Forschung«. In: Friebertshäuser, Barbara/Langer, Antje/Richter, Sophia (Hg.), (An)Passungen. Körperlichkeit und Beziehungen in der Schule - ethnographische Studien, Baltmannsweiler: Schneider-Verl. Hohengehren, i. E. 
Pestalozzi, Johann Heinrich (1980): Pestalozzi über seine Anstalt in Stans (1799). Mit einer Interpretation von Wolfgang Klafki, Weinheim/Basel: Beltz.

Peters, Helge (1996): »Als Partisanenwissenschaft ausgedient, als Theorie aber nicht sterblich: der labeling approach«. Kriminologisches Journal (28) 2, S. 107-115.

Pilarczyk, Ulrike/Mietzner, Ulrike (2005): Das reflektierte Bild. Die seriellikonografische Fotoanalyse in den Erziehungs- und Sozialwissenschaften, Bad Heilbrunn: Klinkhardt.

Plessner, Helmuth (1975): Die Stufen des Organischen und der Mensch, Berlin: de Gruyter.

Pongratz, Ludwig A. (1989): Pädagogik im Prozess der Moderne. Studien zur Sozial- und Theoriegeschichte der Schule, Weinheim: Dt. Studien-Verl.

Pongratz, Ludwig A. (1990): »Schule als Dispositiv der Macht - pädagogische Reflexionen im Anschluß an Michel Foucault«. In: Vierteljahrschrift für wissenschaftliche Pädagogik (66) 3, S. 289-308.

Pongratz, Ludwig A. (1995): »Freiheit und Zwang. Pädagogische Strafformen im Wandel«. In: Die Deutsche Schule (87), 2, S. 183-195.

Pongratz, Ludwig A. (2004): »Freiwillige Selbstkontrolle. Schule zwischen Disziplinar- und Kontrollgesellschaft«. In: Ricken, Norbert/Rieger-Ladich, Markus (Hg.), Michel Foucault: Pädagogische Lektüren, Wiesbaden: VS, S. 243-259.

Poschardt, Ulf (2002): Cool, Reinbek bei Hamburg: Rowohlt.

Reckwitz, Andreas (2003): »Grundelemente einer Theorie sozialer Praktiken. Eine sozialtheoretische Perspektive«. In: Zeitschrift für Soziologie (32), 4, S. 282- 301.

Reh, Sabine (2003): Berufsbiographische Texte ostdeutscher Lehrer und Lehrerinnen als $>$ Bekenntnisse . Interpretationen und methodologische Überlegungen zur erziehungswissenschaftlichen Biographieforschung, Bad Heilbrunn/Obb.: Klinkhardt.

Reichert, Ramón (2004): „Einführung«. In: ders. (Hg.), Governementality Studies. Analysen liberal-demokratischer Gesellschaften im Anschluss an Michel Foucault, Münster: LIT, S. 11-32.

Renn, Joachim (2005): »Wie ist das Bewußtsein am Diskurs beteiligt? Handlungstheoretische Überlegungen zur performativen Beziehung zwischen Semantik und Intentionalität«. In: Keller, Reiner et al. (Hg.), Die diskursive Konstruktion von Wirklichkeit. Zum Verhältnis von Wissenssoziologie und Diskursforschung, Konstanz: UVK, S. 101-126.

Resch, Christine (1998): „Arbeitsbündnisse in der Sozialforschung». In: Steinert, Heinz (Hg.), Zur Kritik der empirischen Sozialforschung. Ein Me- 
thodengrundkurs, Frankfurt/M.: JWG-Universität. Studientexte zur Sozialwissenschaft, Bd. 14, S. 36-66.

Richter, Dieter (1987): Das fremde Kind. Zur Entstehung der Kindheitsbilder des bürgerlichen Zeitalters, Frankfurt/M.: S. Fischer.

Rieger, Stefan (2002): »Die Arbeit an sich. Dispositive der Selbstsorge in der Moderne«. In: Bröckling, Ulrich/Horn, Eva (Hg.), Anthropologie der Arbeit, Tübingen: Gunter Narr Verl., S. 79-96.

Rieger-Ladich, Markus (2004): »Unterwerfung und Überschreitung «: Michel Foucaults Theorie der Subjektivierung. In: Ricken, Norbert/Rieger-Ladich, Markus (Hg.), Michel Foucault: Pädagogische Lektüren. Wiesbaden: VS-Verl., S. 203-223.

Rohr, Elisabeth (Hg.) (2004): Körper und Identität. Gesellschaft auf den Leib geschrieben, Königstein/Ts.: Ulrike Helmer Verl.

Rose, Nikolas (2000): »Das Regieren unternehmerischer Individuen«. In: Kurswechsel (15), 2, S. 8-27.

Rose, Lotte (2002): »Sportlichkeit als Stil. Jugendliche Körperinszenierungen im Wandel«. In: Becker, Gerold et al. (Hg.), Friedrich-Jahresheft: ‘Körper<, S. 16-17.

Rose, Lotte/Ulrike Schmauch (Hg.) (2005): Jungen - die neuen Verlierer? Auf den Spuren eines öffentlichen Stimmungswechsels, Königstein/Ts.: Ulrike Helmer Verl.

Rumpf, Horst (1981): Die übergangene Sinnlichkeit. Drei Kapitel über die Schule, München: Juventa.

Rumpf, Horst (1996a): »Über den zivilisierten Körper und sein Schulschicksal oder Körper 1 - Körper 2 «. In: Pädagogik (48), 6, S. 7-9.

Rumpf, Horst (1996b): »Rechtwinklig - beherrscht geradlinig«. Über die Durchsetzung eines zivilisierten Körpergehabes. In: PÄD Forum (24/9), 5 , S. $442-447$.

Rumpf, Horst (1999): »Der Normalisierte Körper. Über pädagogische Begradigungen und Stillegungen«. In: Becker, Peter/Koch, Josef (Hg.), Was ist normal? Normalitätskonstruktionen in Jugendhilfe und Jugendphsychatrie, Weinheim/München: Juventa, S. 19-31.

Rutschky, Katharina (1977): Schwarze Pädagogik. Quellen zur Naturgeschichte der bürgerlichen Erziehung, Frankfurt/Berlin/Wien: Ullstein.

Sacher, Werner (2000): Proxemik im Klassenzimmer. Studien zu Nähe und Distanz im Schulalltag, Nürnberg: Schulpädagogische Untersuchungen.

Sarasin, Philipp (2001): »Diskurstheorie und Geschichtswissenschaft». In: Keller, Reiner et al. (Hg.), Handbuch Sozialwissenschaftliche Diskursanalyse, Bd. 1, Opladen: Leske und Budrich, S. 53-79. 
Saussure, Ferdinand de (2001): Grundfragen der allgemeinen Sprachwissenschaft, Berlin/New York: de Gruyter.

Schäfer, Alfred (2004): »»Die Seele. Gefängnis des Körpers««. In: Pongratz, Ludwig A. et al. (Hg.), Nach Foucault. Diskurs- und machtanalytische Perspektiven der Pädagogik, Wiesbaden: VS-Verl., S. 97-113.

Schaufler, Birgit (2002): ")Schöne Frauen - starke Männer«". Zur Konstruktion von Leib, Körper und Geschlecht, Opladen: Leske und Budrich.

Schmid, Wilhelm (1996): „Wer war Michel Foucault? « In: Foucault, Michel (Hg.), Der Mensch ist ein Erfahrungstier, Frankfurt/M.: Suhrkamp, S. $6-22$.

Schneider, Werner/Hirseland, Andreas (2005): »Macht - Wissen - Gesellchaftliche Praxis. Dispositivanalyse und Wissenssoziologie«. In: Keller, Reiner et al. (Hg.), Die diskursive Konstruktion von Wirklichkeit. Zum Verhältnis von Wissenssoziologie und Diskursforschung, Konstanz: UVK, S. 251-275.

Scholz, Gerold (2002): „Lernen als Kommunikation«. In: Gold, Andreas/ Scholz, Gerold: Lernen als Verhaltensänderung - Lernen als Kommunikation. Überlegungen zu einem erziehungswissenschaftlichen Lernbegriff, Frankfurt/M.: Eigendruck, S. 57-141.

Schöttler, Peter (1997): „Wer hat Angst vor dem slinguistic turn`? « In: Geschichte und Gesellschaft (23), S. 134-151.

Schroer, Markus (2003): »Raumköprer und Körperraum - zwischen Öffnung und Schließung«. In: Krämer-Badoni, Thomas/Kuhm, Klaus (Hg.), Die Gesellschaft und ihr Raum. Raum als Gegenstand der Soziologie, Opladen: Leske und Budrich, S. 73-90.

Schulz, Norbert (1993): »Neuere Erkenntnisse zum Körper als sozialer Kategorie. Konsequenzen für Schulsport und Sportlehrerausbildung«. In: Köppe, Günter (Hg.), Theoriegeleitete Praxis in der Sportlehrerausbildung, Sankt Augustin: Academia Verl., S. 101-124.

Seier, Andrea (2001): »Macht«. In: Kleiner, Marcus S. (Hg.), Michel Foucault. Eine Einführung in sein Denken, Frankfurt/New York: Campus, S. 90-107.

Solga, Heike/Wagner, Sandra J. (2004): »Die Bildungsexpansion und ihre Konsequenzen für das soziale Kapital der Hauptschule«. In: Engler, Steffani/Krais, Beate (Hg.), Das kulturelle Kapital und die Macht der Klassenstrukturen. Sozialstrukturelle Verschiebungen und Wandlungsprozesse des Habitus, Weinheim/München: Juventa, S. 97-114.

Steinert, Heinz (1985): »Zur Aktualität der Etikettierungstheorie». Kriminologisches Jorunal (17) 1, S. 29-43. 
Steinert, Heinz (1993): »Die Widersprüche von Disziplin und Strafe«. In: Frehsee, Detlev/Löschper, Gabi/Schumann, Karl F. (Hg.), Strafrecht, soziale Kontrolle, soziale Disziplinierung, Jahrbuch für Rechtssoziologie und Rechtstheorie Bd. XV, Opladen: Westdt. Verl., S. 238-256.

Steinke, Ines (1999): Kriterien qualitativer Sozialforschung. Ansätze zur Bewertung qualitativ-empirischer Sozialforschung, Weinheim/München: Juventa.

Steinke, Ines (2000): »Gütekriterien qualitativer Forschung «. In: Flick, Uwe/ Kardorff, Ernst von/Steinke, Ines (Hg.), Qualitative Forschung. Ein Handbuch, Reinbek bei Hamburg: Rowohlt, S. 319-331.

Stiegler, Bernd (2004): „Zur gesellschaftlichen Lage der Fotografie». In: WestEnd. Neue Zeitschrift für Sozialforschung (1), 1, S. 25-50.

Stockmeyer, Anne-Christin (2004): Identität und Körper in der (post)modernen Gesellschaft. Zum Stellenwert der Körper/Leib-Thematik in Identitätstheorien, Marburg: Tectum-Verl.

Strauss, Anselm L. (1994): Grundlagen qualitativer Sozialforschung. Datenanalyse und Theoriebildung in der empirischen soziologischen Forschung. München: UTB.

Strauss, Anselm L./Corbin, Juliet (1996): Grounded theory. Grundlagen qualitativer Sozialforschung, Weinheim: Beltz.

Strübing, Jörg (2004): Grounded Theory. Zur sozialtheoretischen und epistemologischen Fundierung des Verfahrens der empirisch begründeten Theoriebildung, Wiesbaden: VS-Verl.

Tervooren, Anja (2006): Im Spielraum von Geschlecht und Begehren. Ethnographie der ausgehenden Kindheit, Weinheim/München: Juventa.

Thorne, Barrie (1993): Gender Play. Girls and Boys in School, New Brunswick, New Jersey: Rutgers University Press.

Treiber, Hubert/Steinert, Heinz (2005): Die Fabrikation des zuverlässigen Menschen. Über die »Wahlverwandschaft « von Kloster- und Fabrikdisziplin, Münster: Westfälisches Dampfboot.

Truschkat, Inga (2008): Kompetenzdiskurs und Bewerbungsgespräche. Eine Dispositivanalyse (neuer) Rationalitäten sozialer Differenzierung. Wiesbaden: VS Verl.

Tuider, Elisabeth (2003): »Körpereventualitäten. Der Körper als kultureller Konstruktionsplatz«. In: Macha, Hildegart/Fahrenwald, Claudia (Hg.), Körperbilder zwischen Natur und Kultur. Interdisziplinäre Beiträge zur Genderforschung.,Opladen: Leske und Budrich, S. 43-67.

Tzankoff, Michaela (1995): Interaktionstheorie, Geschlecht und Schule, Opladen: Leske und Budrich. 
Viehöver, Willy (2004): »Tagungsbericht: Workshop »Diskurs - Wissen Kultur «/Praxis-Workshop 〉Diskursanalyse««. In: Forum Qualitative Sozialforschung/Forum Qualitative Social Research [On-line Journal], 5(3), Art. 38. Verfügbar über: http://www.qualitative-research.net/fqs-texte/3-04/ 04-3-38-d.htm [24.02.2008].

Waldenfels, Bernhard (1991): »Michel Foucault: Ordnung in Diskursen«. In: Ewald, François/Waldenfels, Bernhard (Hg.), Spiele der Wahrheit. Michel Foucaults Denken, Frankfurt/M.: Suhrkamp, S. 277-297.

Waldschmidt, Anne (2003): »Der Humangenetik-Diskurs der Experten: Erfahrungen mit dem Werkzeugkasten der Diskursanalyse«. In: Keller, Reiner et al. (Hg.), Handbuch sozialwissenschaftliche Diskursanalyse, Bd. 2, Opladen: Leske und Budrich, S. 147-169.

Walgenbach, Katharina (2006): Die weiße Frau als Trägerin deutscher Kultur, Frankfurt/New York: Campus.

Weißköppel, Cordula (2001): Ausländer und Kartoffeldeutsche. Identitätsperformanz im Alltag einer ethnisch gemischten Realschulklasse, Weinheim/ München: Juventa.

West, Candace/Zimmerman, Don H. (1991): »Doing Gender«. In: Lorber, Judith/Farell, Susan A. (Hg.), The social construciton of gender, Newbury Park/London/New Dehli: Sage, S. 13-37.

Wex, Marianne (1980): „Weibliche« und »männliche» Körpersprache als Folge patriarchalischer Machtverhältnisse, Frankfurt/M.: Frauenliteraturvertrieb Fees.

Wichern, Johann Hinrich (1959): Sämtliche Werke. Schriften zur Sozialpädagogik, Bd. 4/2, Berlin/Hamburg/Hannover: LVH.

Willems, Herbert (1997): Rahmen und Habitus. Zum theoretischen und methodischen Ansatz Erving Goffmans: Vergleiche, Anschlüsse und Anwendungen, Frankfurt/M.: Suhrkamp.

Willems, Herbert/Jurga, Martin (Hg.) (1998): Inszenierungsgesellschaft. Ein einführendes Handbuch, Opladen: Westdt. Verl.

Willems, Katharina (2007): Schulische Fachkulturen und Geschlecht. Physikund Deutsch - natürliche Gegenpole? Bielefeld: transcript.

Wirth, Uwe (2002): »Der Performanzbegriff im Spannungsfeld von Illokution, Iteration und Indexikalität. In: ders. (Hg.), Performanz. Zwischen Sprachphilosophie und Kulturwissenschaften, Frankfurt/M.: Suhrkamp, S. 9-60.

Wischermann, Clemens/Haas, Stefan (Hg.) (2000): Körper mit Geschichte. Der menschliche Körper als Ort der Selbst- und Weltdeutung, Stuttgart: Franz Steiner Verl. 
Wohne, Kerstin (2002): »Dünn und sexy. Wie Kinder und Jugendliche ihren Körper wollen«. In: Becker, Gerold et al. (Hg.), Friedrich-Jahresheft: `Körper<, S. 48-49.

Wrana, Daniel (2002): „Formen der Individualität. Eine Analyse diskursiver Praktiken der Gesellschaftsbeschreibung bei Kursleiter/-innen der Erwachsenenbildung «. In: Forneck, Herman J./Lippitz, Wilfried (Hg.), Literarität und Bildung, Marburg: Tectum, S. 115-176.

Wrana, Daniel (2006): Das Subjekt schreiben. Reflexive Praktiken und Subjektivierung in der Weiterbildung - eine Diskursanalyse, Baltmannsweiler: Schneider-Verl. Hohengehren.

Wrana, Daniel/Langer, Antje (2007): »An den Rändern der Diskurse. Jenseits der Unterscheidung diskursiver und nicht-diskursiver Praktiken«. Forum Qualitative Sozialforschung/Forum Qualitative Social Research, 8(2), Art. 20, http://www.qualitative-research.net/fqs-texte/2-07/07-2-20-d.htm [24.02.2008] Wulf, Christoph/Göhlich, Michael und Zirfas, Jörg (Hg.) (2001): Grundlagen des Performativen. Eine Einführung in die Zusammenhänge von Sprache, Macht und Handeln, Weinheim/München: Juventa.

Wulf, Christoph (2001a): Einführung in die Anthropologie der Erziehung, Weinheim/Basel: Beltz und Gelberg.

Wulf, Christoph (2001b): »Mimesis und Performatives Handeln. Gunter Gebauers und Christoph Wulfs Konzeption mimetischen Handelns in der sozialen Welt«. In: Wulf, Christoph/Göhlich, Michael und Zirfas, Jörg (Hg.), Grundlagen des Performativen. Eine Einführung in die Zusammenhänge von Sprache, Macht und Handeln, Weinheim/München: Juventa, S. 253-272.

Wulf, Christoph (2003): „Auf der Suche nach der Natur. Der Körper als Bezugspunkt der Anthropologie«. In Liebau, Eckart/Peskoller, Helga/Wulf, Christoph (Hg.), Natur. Pädagogisch-anthropologische Perspektiven, Weinheim/Basel/Berlin: Dt. Studien Verl., S. 205-215.

Wulf, Christoph/Zirfas, Jörg (Hg.) (2004a): Innovation und Ritual. Jugend, Geschlecht, Schule. Zeitschrift für Erziehungswissenschaften - Sonderheft Bd. 2, Wiesbaden: VS-Verl.

Wulf, Christoph/Zirfas, Jörg (2004b): »Performative Welten. Einführung in die historischen, systematischen und methodischen Dimensionen des Rituals«. In: dies.(Hg.), Die Kultur des Rituals. Inszenierungen. Praktiken. Symbole, München: Fink, S. 7-45.

Zeiher, Helga/Zeiher, Hartmut J. (1991): „Wie Kinderalltage zustande kommen«. In: Berg, Christa (Hg.), Kinderwelten, Frankfurt/M.: Suhrkamp, S. 243-269.

Zinnecker, Jürgen (2001): Stadtkids. Kinderleben zwischen Straße und Schule, Weinheim/München: Juventa. 


\section{Zitierte Artikel aus dem Materialkorpus}

\section{Codierung Artikel}

PÄD D 0102 Petersen, Susanne (2002): »Regeln und Rituale. Orientierung bieten in Schulstunden «. Pädagogik (54) 4, S. 30-33.

PÄD D 0295 Bastian, Johannes (1995): »)Strafe muss sein<? Einführende Gedanken zum Strafproblem in der Erziehung«. Pädagogik (47) 5, S. 36-41.

PÄD D 0402 Schulz, Ursula (2002): »Kleine Selbstverständlichkeiten - und doch so wichtig! Rituale in der Schule«. Pädagogik (54) 12, S. 12-13.

PÄD D 0502 Höhmann, Katrin (2002): »Sozialstrafen in der Schule - Pro«. Pädagogik (54) 12, S. 50.

PÄD D 0602 Gudjons, Herbert (2002): »Sozialstrafen in der Schule - Contra«. Pädagogik (54) 12, S. 51.

PÄD D 0799 Groeben, Annemarie von der (1999): »Was sind und wozu brauchen Schulen >gute` Rituale? « Pädagogik (51) 4, S. 6-9.

PÄD D 0800 Drews, Ursula (2000): »Unterrichtsstörungen - wie selbstverständlich sind sie? « Pädagogik (52) 1, S. 6-7.

PÄD D 0900 Hensel, Horst (2000): »Unterrichtsstörungen - na und? Man kann sich darauf einstellen und gelassen damit umgehen«. Pädagogik (52) 1, S. 8-12.

PÄD D 1000 Köhler, Ulrike/Kramming-Jöhrens, Doris (2000): »Wird in freien Schulen anders gestört? Erfahrungen aus der GlockseeSchule«. Pädagogik (52) 1, S. 13-15.

PÄD D 1100 Bonorden, Heinz et al. (2000): "Sarah spielt nicht mehr mit. Einladung zum Gespräch über einen Störfall«. Pädagogik, (52) 1, S. 16-20. 


\section{Codierung Artikel}

PÄD D 1300 Osterwalder, Fritz (2000): »Rute oder Schande - Therapie oder öffentliches Lernen? Zur Geschichte des Umgangs der Schule mit Störungen und Strafe«. Pädagogik (52) 1, S. 24-27.

PÄD D 1503 Bastian, Johannes (2003): »Disziplin«. Pädagogik (55) 12, S. 3.

PÄD D 1603 Groeben, Annemarie von der (2003): „Die Sache als Lehrmeister. Ein Plädoyer für Lernen ohne >Disziplinarmaßnahmen« «. Pädagogik (55) 12, S. 6-9.

PÄD D 1700 Tymister, Hans Josef (2003): »Disziplin durch Strafe? Wie Lehrer und Schüler Arbeitsdisziplin und Störungsfreiheit lernen können«. Pädagogik (55) 12, S. 15-17.

PÄD D 1803 Wagner, Gerd (2003): „Wir haben unsere Schule verändert. Zum Zusammenhang zwischen Schulentwicklung und Disziplin«. Pädagogik (55) 12, S. 19-23.

PÄD D 1903 Seydel, Otto (2003): »Sekundärtugenden in der Schule. Höflichkeit und Hefte-TÜV «. Pädagogik (55) 12, S. 25-29.

PÄD D 2102 Kleinknecht, Marc (2002): »)Fassen Sie mich nicht an! «. Der allägliche Umgang eines Junglehrers mit schwierigen Schülern«. Pädagogik (54) 2, S. 20-21.

PF D 0197 Grunder, Hans Uwe (1997): »Initiation und Institution. Die Schule und ihre Rolle im Kulturtransfer«. PÄD Forum (25/10) 2, S. 29-40.

PF D 0296 Benikowski, Bernd/Winkel, Rainer (1996): »Einführung in den Themenschwerpunkt. Störungen - in und außerhalb von Schule«. PÄD Forum (24/9) 3, S. 210.

PF D 0396 Krause, Katrin (1996): »)Hilfe, Schule!««. PÄD Forum (24/9) 3, S. 211.

PF D 0496 Verschieden AutorInnen o. A. (1996): »Störende Schüler Verstörte Lehrer. Fälle, Szenen, Eindrücke aus einem Lehrerfortbildungsseminar «. PÄD Forum (24/9) 3, S. 214-215.

PF D 0596 Verschiedene AutorInnen o. A. (1996): »Erinnerungen an die Schulzeit heutiger Studenten. Als der Unterricht einmal gestört wurde«. PÄD Forum (24/9) 3, S. 219-224.

PF D 0696 Winkel, Rainer (1996): »Wenn Schüler stören, wollen sie uns etwas sagen. Die Frage ist nur: Was? Warum? Und: Wozu? « PÄD Forum (24/9) 3, S. 225-228.

SM D 0196 Brutscher, Barbara (1996): »Sich in der Schule wohlfühlen was denken Kinder und Jugendliche? « Schulmagazin 5-10 (64) 11, S. 8-11. 


\section{Codierung}

SM D 0296

SM D 0300

SM D 0402

SM D 0503

SM D 0602

SM D 0702

SM D 0802

SM D 0902

SM D 1097

SM D 1197

SM D 1297 Schmitt, Hubert (1997): »Klassenmanagement. Effektiver Umgang mit Unterrichtsstörungen - ein Trainingsprogramm (Teil III)«. Schulmagazin 5-10 (65) 4, S. 65-68.

SM D 1397 Schmitt, Hubert (1997): »Klassenmanagement. Effektiver Umgang mit Unterrichtsstörungen - ein Trainingsprogramm (Teil IV)«. Schulmagazin 5-10 (65) 4, S. 51-54.

PÄD G 0195 Böttger, Gudrun (1995): »Mädchenarbeit. Ein Tag zum Thema Selbst- und Fremdbild«. Pädagogik (47) 11, S. 44-47. 


\section{Codierung Artikel}

PÄD G 0299 Zieske, Andreas (1999): »>Jungenarbeit< an der Schule. Ziele, Probleme, Praxisansätze«. Pädagogik (51) 5, S. 6-9.

PÄD G 0399 Preuss-Lausitz, Ulf (1999): »Die Schule benachteiligt die Jungen? « Pädagogik (51) 5, S. 11-14.

PÄD G 0499 Biermann, Christine/Boldt, Uli (1999): »)Die Jungen packen eben eher bei Männern aus`. Ein Praxisbericht über Jungenkonferenzen«. Pädagogik (51) 5, S. 16-21.

PÄD G 0599 Karl, Holger (1999): »Vergessene Vorgärten. Grenzfragen in der Jungenarbeit«. Pädagogik (51) 5, S. 22-24.

PÄD G 0899 Klewin, Gabriele (1999): »»Mann kann auch einfach mal miteinander reden`. Materialien zur Jungenarbeit in der Schule«. Pädagogik (51) 5, S. 34-36.

PF G 0104 Malz-Teske, Regina/Kansteiner-Schänzlin, Katja (2004): "Schulprofil: geschlechtergerechte Schule. Das Beispiel einer Hamburger Gesamtschule «. PÄD Forum: unterrichten + erziehen $(32 / 22)$ 2, S. 81-85.

PF G 0202 Redaktion (2002): „Männerbildung (Wie wird aus einem Jungen ein Mann...). Einleitung«. PÄD Forum (30/15) 4, S. 267.

PF G 0302 Arnold, Rolf (2002): „)Wann ist ein Mann ein Mann?<Die doppelt gebrochene emotionale Identität des Mannes«. PÄD Forum (30/15) 4, S. 269-271.

PF G 0502 Bach, Thomas (2002): »Bin ich ein Mann? Fragen und Antworten an das System Familie«. PÄD Forum (30/15) 4, S. 276-278.

PÄD K 0596 Bastian, Johannes (1996): »Mit dem Körper lernen«. Pädagogik, (48) 6, S. 5 .

PÄD K 0696 Rumpf, Horst (1996): »Über den zivilisierten Körper und sein Schulschicksal. Oder: Körper 1/Körper 2. Pädagogik « (48) 6, S. 6-9.

PÄD K 0796 Wellner-Pricelius, Brigitte (1996): »Der erfahrbare Atem Ein Weg sich im Leib wohlzufühlen«. Pädagogik, (48) 6, S. 10-13.

PÄD K 0896 Müller, Renate (1996): »Körper und Musik in Jugendkulturen«. Pädagogik (48) 6, S. 14-18.

PÄD K 0996 Middendorf-Greife, Hedwig/Lintzen, Brigitte (1996): »Die Frau im Körper. Körperorientierte Mädchenarbeit während der Pubertät«. Pädagogik (48) 6, S. 20-24. 


\section{Codierung}

PF K 0696

PF K 0796

PK K 0896

PF K 0996

PF K 1296

PF K 1396

PF K 1496

PF K 1596

PF K 1696

PF K 22 01P

PF K 2404 Hörmann, Georg (2004): »Der Körper in der Schule. Vom dressierten und disziplinierten zum dekorierten und inszenierten Körper«. PÄD Forum: unterrichten und erziehen $(32 / 23)$ 3, S. 141-144.

PF K 2604 Raithel, Jürgen (2004): „Risikoverhalten, Körperkonzepte und Geschlechtsidentitätsentwicklung im Jugendalter«. PÄD Forum: unterrichten erziehen (32/23) 3, S. 148-150. 


\section{Codierung Artikel}

PF K 2704 Bleuel, Heike-Solweig (2004): „Piercing und Tattoo im Schulunterricht«. PÄD Forum: unterrichten erziehen $(32 / 23)$ 3, S. 151-154.

PF K 2804 Meier, Marion (2004): »Was Odysseus mit dem Körper in der Schule zu tun hat. Die MediPäds - Lehrer und Ärzte im Team, Schulische Gesundheitsförderung durch lebendiges Gesundheitslernen«. PÄD Forum: unterrichten erziehen (32/23) 3, S. 155-158.

PF K 2904 Weber, Andreas/Weltle, Dieter/Lederer, Peter (2004): »Krankheitsbedingter vorzeitiger Berufsausstieg bei Lehrkräften. Die Public Health Perspektive«. PÄD Forum: unterrichten erziehen $(32 / 23) 3$, S. 167-173.

PÄD LK 0197 krates (1997): »Sieben Tips für die Erzeugung von Langeweile im Unterricht». Pädagogik (49) 9, S. 30.

PÄD LK 0203 Meyer, Hilbert (2003): »Zehn Merkmale guten Unterrichts. Empirische Befunde und didaktische Ratschläge«. Pädagogik (55) 10, S. 36-43.

PÄD LK 0304 Albrecht, Achim ( 2004): »Lehrerverhalten im Erziehenden Unterricht. Was bedeuten Haltung, Konsequenz und VorbildSein in der Praxis? «Pädagogik (56) 9, S. 10-13.

PÄD LK 0499 Gudjons, Herbert (1999): »Der Einstieg ist nicht der Anfang. Szenen aus der Praxis«. Pädagogik (51) 3, S. 8-13.

PÄD LK 0501 Rohnstock, Dagmar (2001): »Endlich wieder abschalten können! Anregungen und Übungen für ein lehrerspezifisches Selbstmanagement «. Pädagogik (53) 1, S. 39-43.

PÄD LK 0602 Daschner, Peter (2002): »Ein schön-schwerer Beruf. Zur Einführung in den Themenschwerpunkt«. Pädagogik (54) 7-8, S. 6-7.

PÄD LK 0702 Schaarschmidt, Uwe (2002): „Die Belastungssituation von Lehrerinnen und Lehrern. Ergebnisse und Schlussfolgerungen aus der Potsdamer Lehrerstudie «. Pädagogik (54) 7-8, S. $8-13$

PÄD LK 0802 Kretschmann, Rudolf (2002): »Wie man vorbeugt, wie man sich schützt. Stressmanagement für Lehrerinnen und Lehrer«. Pädagogik (54) 7-8, S. 14-20.

PÄD LK 0902 Sieland, Bernhard (2002): »Verhaltensprävention - ein unverzichtbarer Schritt «. Pädagogik (54) 7-8, S. 22-28. 


\section{Codierung Artikel}

PÄD LK 1002 Rudow, Bernd (2002): »Das Arbeitsschutzgesetz gilt auf für Lehrkräfte. Verhältnisprävention im Schulbereich«. Pädagogik (54) 7-8, S. 36-41.

PÄD LK 1197 Bauer, Karl-Oswald (1997): »Pädagogische Professionalität und Lehrerarbeit«. Pädagogik (49) 4, S. 22-26.

PÄD LK 1203 Rohnstock, Dagmar (2003): »Unbelastete Freiräume schaffen. Arbeit und Erholung rhythmisieren«. Pädagogik (55) 11, S. $19-22$.

PÄD LK 1398 Langhammer, Ralf (1998): »Lehrvortrag - >gut< gemacht. Einige kommunikative und rhetorische Hilfen«. Pädagogik (50) 5, S. 17-22.

PÄD LK 1498 Heidemann, Rolf (1998): »Die Körpersprache des Lehrers im Frontalunterricht. Aufrechte Strenge oder lockeres Entertainment? « Pädagogik (50) 5, S. 28-32.

PÄD LK 1504 Hartmann, Martin/Jacobs-Strack, Doris (2004): »Die gute Darbietung. Lehrkräfte lernen präsentieren«. Pädagogik (56) 3, S. 30-34.

PF LK 0197 Zeitz, Dieter (1997): »Sieben Sünden im Unterricht (1)«. PÄD Forum (25/10) 1, S. 8-16.

PF LK 0295 Quentin, Gisela (1995): »Wie steht es um die Gesundheit der Gesundheitsförderer? Kritische Anmerkungen zu Konzepten schulischer Gesundheitsförderung«. PÄD EXTRA (23) 6, S. 23-25.

PF LK 0302 Bangert, Carsten (2002): „Zwölf Impulse für mehr Zufriedenheit und Gesundheit im Lehrerberuf«. PÄD Forum (30/15) 6, S. 450-455.

PF LK 0497 Zeitz, Dieter (1997): »Sieben Sünden im Unterricht (2)«. PÄD Forum (25/10) 2, S. 175-181.

SM LK 0103 Kretschmann, Rudolf (2003): »Stress überwinden - Freiräume schaffen. Einige Schritte in die richtige Richtung «. Schulmagazin 5-10 (71) 9, S. 5-8.

SM LK 0204 Apel, Hans Jürgen/Pfitzner, Michael (2004): »Pädagogische Führung. Klassen erfolgreich unterrichten und Eltern beteiligen«. Schulmagazin 5-10 (72) 10, S. 53-56.

SM LK 0502 Hartmann, Martin/Schwarz, Thomas (2002): »Präsentieren im Schulalltag. Möglichkeiten zur zielgerichteten und adressatenorientierten Präsentation«. Schulmagazin 5-10 (70) 11, S. 4-8. 


\section{Codierung Artikel}

SM LK 0602 Pabst-Weinschenk, Marita (2002): »Worauf soll man beim Vortrag achten? Sprech-rhetorische Grundqualifikationen zur Verbesserung der Präsentationsleistung«. Schulmagazin 5-10 (70) 11, S. 9-11.

SMLK 0796 Schönherr, Christine (1996): »Körpersprache und Stimme. Körpersprache und Stimme im Unterricht«. Schulmagazin 5-10 (64) 3, S. 4-11.

PÄD SP 0801 Gudjons, Herbert (2001): »)Ich will halt anders sein wie die anderen!««. Neue Befunde zur Pubertät. Pädagogik (53) 7-8, S. 6-11.

SM SP 0105 Oerter, Rolf (2005): »Pubertät. Veränderungen und mögliche Folgen «. Schulmagazin 5 bis 10 (73) 6, S. 5-8.

SM SP 0399 Biermann, Christine (1999): „Liebe, Freundschaft, Sexualität. Ein fächerübergreifendes Projekt für Mädchen und Jungen auf dem Weg zum Schulprogramm«. Schulmagazin 5 bis 10 (67) 5, S. 9-12.

Arnold, Karl-Heinz (Hg.) (2006): Handbuch Unterricht, Bad Heilbrunn/Obb.: Klinkhardt, 1. Aufl.

Caswell, Chris/Neill, Sean (2003): Körpersprache im Unterricht. Techniken nonverbaler Kommunikation in Schule und Weiterbildung, Münster: Daedalusverl., 2. Aufl. [engl. Orig. 1993].

Heidemann, Rudolf (2003): Körpersprache im Unterricht. Ein Ratgeber für Lehrende, Wiebelsheim: Quelle und Meyer, 7. Aufl.

Keck, Rudolf W. et al. (Hg.) (2004): Wörterbuch Schulpädagogik. Ein Nachschlagewerk für Studium und Schulpraxis, Bad Heilbrunn/Obb.: Klinkhardt, 2. Aufl.

Meyer, Hilbert/Paradies, Liane (2005): Körpersprache im Unterricht, Oldenburg: Oldenburger Vor-Drucke 193, 10. Aufl.

Rosenbusch, Heinz S. (2004): »Nonverbale Kommunikation im Unterricht. Die stille Sprache im Klassenzimmer«. In: Rosenbusch, Heinz S./Schober, Otto (Hg.), Körpersprache und Pädagogik. Das Handbuch, Baltmannsweiler: Schneider-Verlag Hohengehren, S. S. 138-176.

Rosenbusch, Heinz S./Schober, Otto (Hg.) (2004): Körpersprache und Pädagogik. Das Handbuch, Baltmannsweiler: Schneider Verlag Hohengehren, 4. Aufl. 


\section{Abbildungsverzeichnis}

Abbildung 1, S. 134: Pädagogik (48) 6/1996, S. 6 (PÄD K 06 96)

Abbildung 2, S. 141: Pädagogik (51) 5/1999, S. 16 (PÄD G 04 99)

Abbildung 3, S. 141: Pädagogik (51) 5/1999, S. 20 (PÄD G 04 99)

Abbildung 4, S. 141: Schulmagazin 5 bis 10 (67) 5/1999, S. 9 (SM SP 03 99)

Abbildung 5, S. 179: Pädagogik (52) 5/2000, Cover

Abbildung 6, S. 213: Schulmagazin 5 bis 10 (65) 5/1997, S. 37 (SM D 11 97)

Abbildung 7, S. 262: Pädagogik (49) 4/1997, S. 22 (PÄD LK 11 97)

Abbildung 8, S. 262: Pädagogik (49) 4/1997, S. 13

Abbildung 9, S. 263: Pädagogik (49) 4/1997, S. 28 


\section{Pädagogik}

Antje Langer

\section{Disziplinieren und} entspannen

Körper in der Schule eine diskursanalytische Ethnographie

Mai 2008, 310 Seiten,

kart., $29,80 €$,

ISBN : $978-3-89942-932-9$

Christian Schütte-Bäumner

Que(e)r durch die

Soziale Arbeit

Professionelle Praxis in den

AIDS-Hilfen

2007, 304 Seiten,

kart., $29,80 €$,

ISBN : $978-3-89942-717-2$

Johannes Giesinger

\section{Autonomie und}

Verletzlichkeit

Der moralische Status von

Kindern und die Rechtfertigung von Erziehung

2007, 218 Seiten,

kart., $23.80 €$,

ISBN : $978-3-89942-795-0$

Felicitas Lowinski

Bewegung im Dazwischen

Ein körperorientierter Ansatz

für kulturpädagogische Projekte

mit benachteiligten

Jugendlichen

2007, 242 Seiten,

kart., $25,80 €$,

ISBN : $978-3-89942-726-4$

Kathrin Audehm

Erziehung bei Tisch

Zur sozialen Magie eines

Familienrituals

2007, 226 Seiten,

kart., $24,80 €$,

ISBN : $978-3-89942-617-5$
Fabian Lamp

Soziale Arbeit zwischen

Umverteilung und

Anerkennung

Der Umgang mit Differenz in der sozialpädagogischen

Theorie und Praxis

2007, 258 Seiten,

kart., $25,80 €$.

ISBN: $978-3-89942-662-5$

Paul Mecheril,

Monika Witsch (Hg.)

Cultural Studies und

Pädagogik

Kritische Artikulationen

2006, 322 Seiten,

kart., $28,80 €$.

ISBN: $978-3-89942-366-2$

Peter Kossack

\section{Lernen Beraten}

Eine dekonstruktive Analyse des Diskurses zur

Weiterbildung

2006, 218 Seiten,

kart., $25,80 €$,

ISBN: $978-3-89942-294^{-8}$

Andrea Liesner,

Olaf Sanders (Hg.)

Bildung der Universität

Beiträge zum Reformdiskurs

2005, 164 Seiten.

kart., $18,80 €$,

ISBN: $978-3-89942-316-7$

Werner Friedrichs,

Olaf Sanders (Hg.)

Bildung / Transformation

Kulturelle und gesellschaftliche

Umbrüche aus bildungs-

theoretischer Perspektive

2002, 252 Seiten,

kart., $24,80 €$,

ISBN: $978-3-933127-94-5$

Leseproben und weitere Informationen finden Sie unter: www.transcript-verlag.de 